\title{
LA PSICOTERAPIA SISTÉMICA Y EL ARTE: ESTUDIO DE CASO DE UNA FAMILIA EN EL MARCO DEL CONFLICTO ARMADO COLOMBIANO.
}

\author{
Por: \\ Nidia Gabriela Caro Zamudio \\ Alejandra Joelly Durán Guarín \\ Johana Andrea Niño Cañas
}

Director:

Alexandra Gutiérrez Velasco

Universidad Santo Tomás

Departamento de Ciencias de la Salud

Facultad de Psicología

Maestría en Psicología Clínica y de la Familia

Bogotá, D.C.

2018 
Queremos darles un especial agradecimiento a nuestras familias, al apoyo incondicional, escucha constante y palabras de aliento de nuestros padres y madres, así como de nuestros hermanos y parejas durante el desarrollo de este trabajo de grado; demostrándonos su inmenso amor en cada etapa de este hermoso proyecto que decidimos emprender. Así mismo, a las familias y profesionales que han vivenciado el Conflicto Armado Colombiano con las que pudimos conversar y quienes desde el confiar en nosotras y contar sus historias nos permitieron comprender desde otra perspectiva este fenómeno y como es vivenciado de manera individual, familiar y social. Finalmente, agradecemos a Jenifer quien desde su carisma y desde su trabajo en el Centro de Proyección Social de Usme posibilito acercarnos desde lecturas contextuales y conversaciones reflexivas a esta realidad, así como a la familia que participo en este estudio de caso y nos permitió ingresar a sus vidas y transformarse junto a nosotras desde el tocar nuestros corazones durante un proceso ético y estético. 


\section{Contenido}

RESUMEN

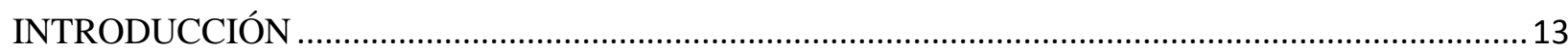

Objetivos de la investigación / intervención ................................................................................... 18

Hipótesis de Investigación - Intervención ............................................................................... 18

Pregunta de investigación- intervención ....................................................................................... 19

ESTADO DEL ARTE

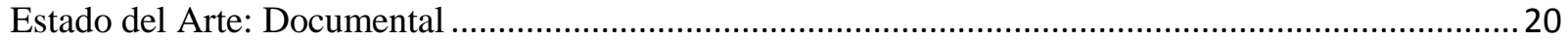

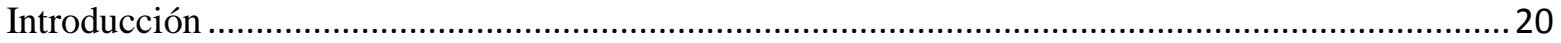

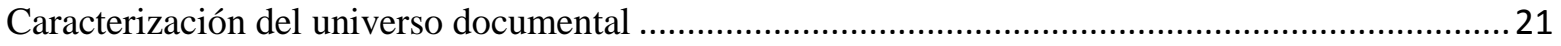

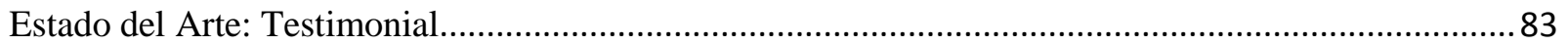

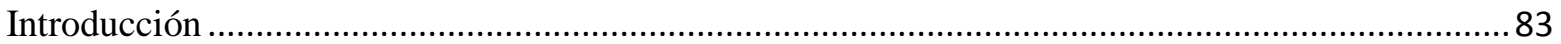

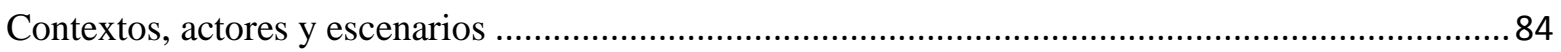

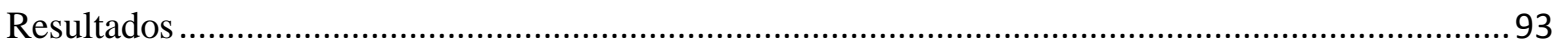

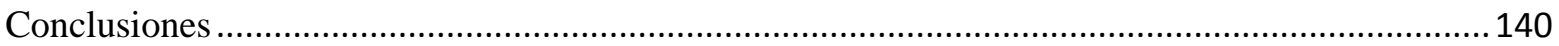

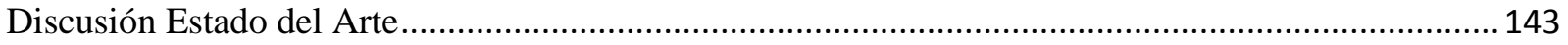

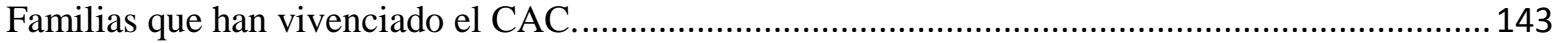

Salud mental y reconfiguración de la experiencia. ....................................................................... 147

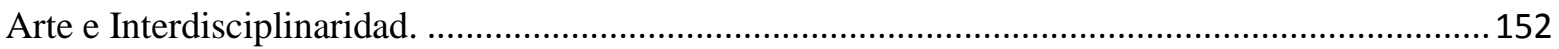

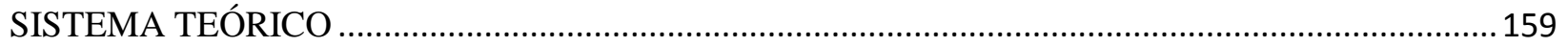

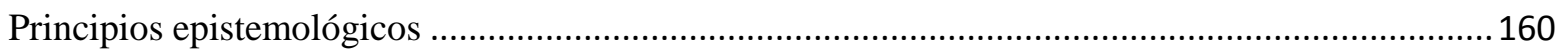

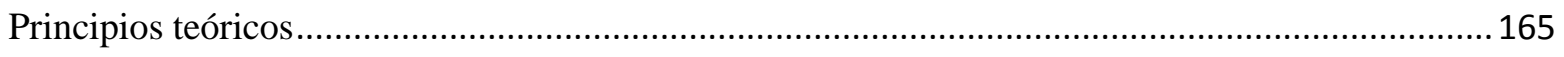

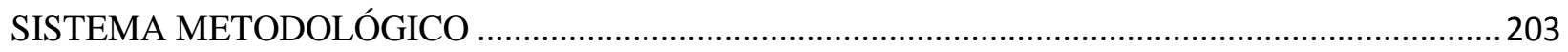

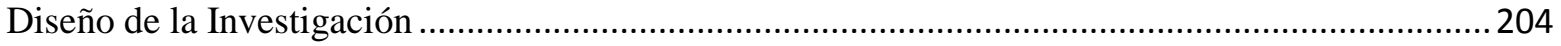

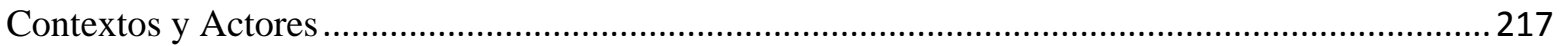

Descripción de los prediseños, diseños y neodiseños de investigación-intervención ........................218

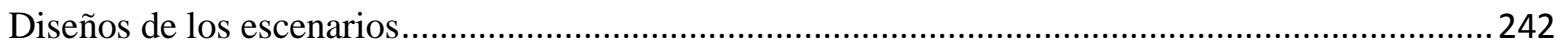

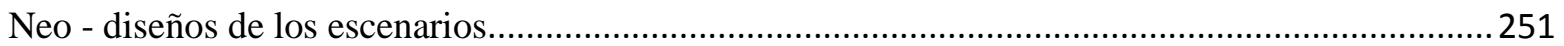

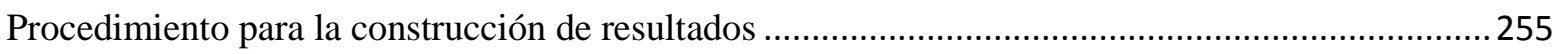

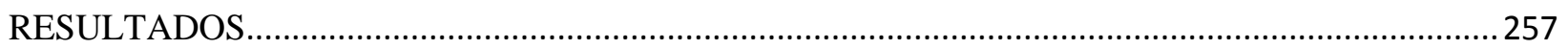

Cambios en el funcionamiento familiar al vivenciar acontecimiento del CAC ...................................260

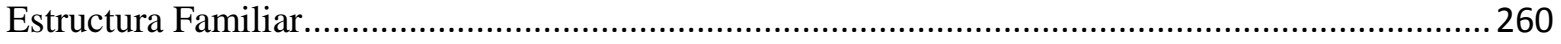

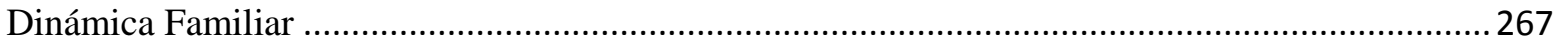




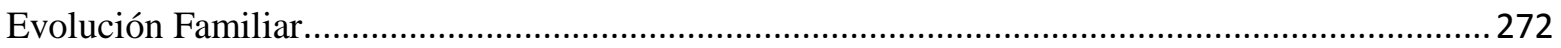

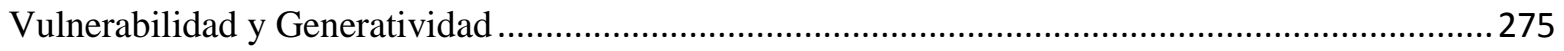

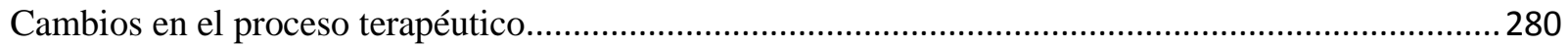

No quiero ser como mi madre, pero estoy condenada a serlo.........................................................282

Yo quiero un padre amoroso, pero prefiero al hombre de corbata............................................... 300

No quiero un padre para mis hijos, ni un esposo como mi padrastro, pero le exijo ser como él .......310

Mis hijos pueden escoger lo que quieran ser, pero deben ser profesionales .................................... 325

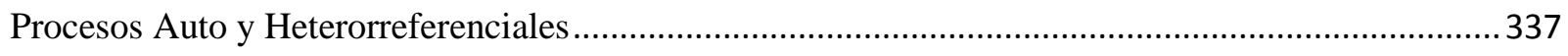

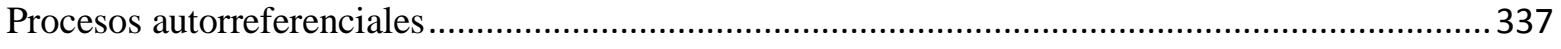

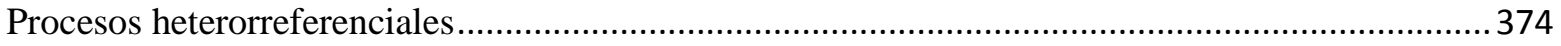

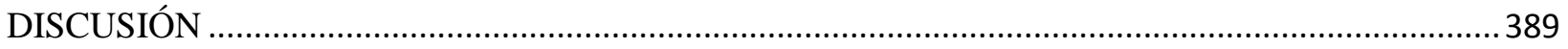

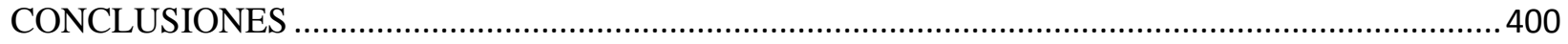

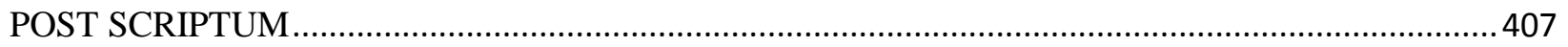

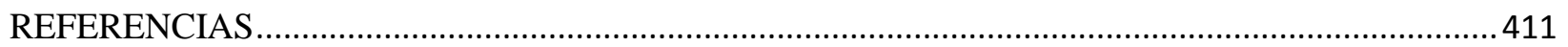

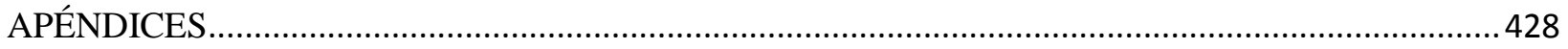




\section{Tabla de Graficas}

Gráfico 1 - Tendencia por tipo de documento. Fuente Autoras ........................................... 22

Gráfico 2 - Tendencia por disciplinas. Fuente Autoras ....................................................... 22

Gráfico 3 - Tendencia cronológica. Fuente Autoras ......................................................... 25

Gráfico 4 - Tendencia por ciudad. Fuente Autoras.............................................................. 26

Gráfico 5- Tendencia por tipo de investigación. Fuente Autoras.......................................... 28

Gráfico 6 - Tendencia de Población. Fuente Autoras ........................................................... 28

Gráfico 7 - Tendencia por Categoría emergente. Fuente Autoras ......................................... 30

Gráfico 8 - Tendencia de Técnicas de Investigación usadas. Fuente Autoras........................ 39

Gráfico 9 - Tendencia de Instrumentos de Investigación usados. Fuente Autoras ................. 40

Gráfico 10 - Tendencia cronológica. Fuente Autoras .............................................................. 42

Gráfico 11 - Tendencia por tipo de documento. Fuente Autoras........................................... 43

Gráfico 12 - Tendencia por ciudad. Fuente Autoras.............................................................. 43

Gráfico 13 - Tendencia por metodología de investigación. Fuente Autoras ........................... 46

Gráfico 14 - Técnicas de investigación. Fuente Autoras......................................................... 47

Gráfico 15 - Instrumentos de investigación. Fuente Autoras ................................................ 48

Gráfico 16 - Estrategias de investigación. Fuente Autoras...................................................... 49

Gráfico 17 - Tendencia de Población. Fuente Autoras ............................................................ 50

Gráfico 18 - Tendencia por Categoría emergente. Fuente Autora.......................................... 54

Gráfico 19 - Tendencia por Disciplina. Fuente Autoras ....................................................... 59

Gráfico 20 - Tendencia por tipo de documento. Fuente Autoras............................................ 64

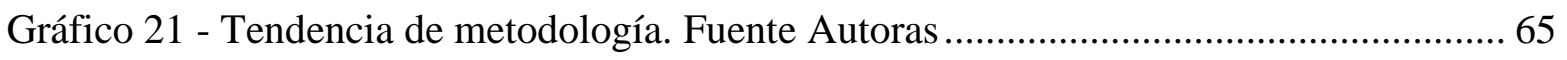

Gráfico 22 - Tendencia en el tiempo. Fuente Autoras .................................................................... 65

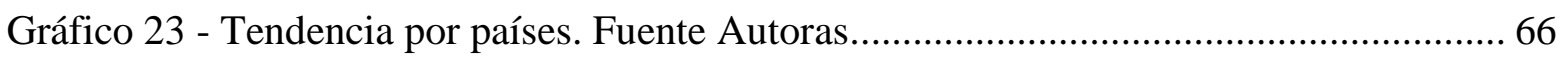

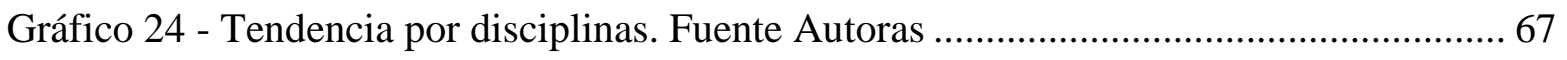

Gráfico 25 - Tendencia por población. Fuente autoras.......................................................... 69

Gráfico 26 - Tendencia de técnica. Fuente Autoras............................................................... 69

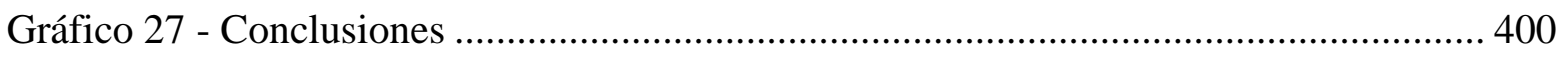




\section{LA PSICOTERAPIA SISTÉMICA Y EL ARTE: ESTUDIO DE CASO DE UNA FAMILIA EN EL MARCO DEL CONFLICTO ARMADO COLOMBIANO.}

\section{RESUMEN}

La presente investigación-intervención hace parte del Macroproyecto de "Historias y narrativas familiares en diversidad de contextos" y pertenece a la línea Psicología, Familia y Sistemas Humanos y al grupo Psicología, Familia y Redes del programa de Maestría en Psicología Clínica y de la Familia de la Universidad Santo Tomás la cual se orientó hacia la comprensión de los cambios en el funcionamiento de una familia que ha vivenciado acontecimientos del conflicto armado colombiano como parte de su proceso de adaptación vital, utilizando el arte como mediador entre la experiencia vivida y la experiencia narrada, desde las estrategias artístico terapéuticas con enfoque sistémico en un estudio de caso a través de una investigación de corte cualitativo. El desarrollo del proceso terapéutico se realizó en ocho (8) encuentros seis (6) escenarios, con una familia en condición de desplazamiento forzado; el diseño que fue construido por cada encuentro para ejecutarse en cuatro escenas; se contó además con un guion de intervención, matriz de observación para el equipo terapéutico que estaba como espectador en la intervención y una matriz de análisis de cada producto artístico. Comprendiendo como variaciones respecto a las pautas de comunicación y la emergencia de relatos novedosos a partir de las comprensiones del sistema frente a las diversas vicisitudes del transcurrir de la vida, 
dan cuenta del surgimiento de capacidades a nivel individual, familiar y comunitario que les permitieron afrontar las diferentes situaciones movilizando a la familia hacia la evolución y autoorganización, mientras las estrategias artístico terapéuticas sistémicas emergieron como un plan determinado para la intervención terapéutica potenciándose unas de ellas entre sí para aperturar cambios en primer y segundo orden, en tanto posibilitan la re significación de la experiencia vivida a partir de la co-construcción de nuevos relatos.

Palabras claves: Arte, Conflicto Armado, Psicoterapia, Familia.

\section{Summary}

The present investigation-intervention is part of the research line of the Macroproject of "Family histories and narratives in diversity of contexts" of the Master's program in Clinical and Family Psychology of Santo Tomas University in which the changes in the functioning of a family that has experienced events of the Colombian armed conflict as part of its process of life adaptation, where art was the mediator between the experience lived and the experience narrated, building changes in family functioning from the artistic therapeutic strategies with a focus systemic in a case study through qualitative research. From the development of a therapeutic

process of six (6) scenarios in eight (8) meetings, with a family in forced displacement condition; design that was built for each encounter to be executed in four scenes; There was also an intervention script, observation matrix for the therapeutic team that was as a spectator in the intervention and a matrix of analysis of each artistic product. Understanding as variations with respect to communication patterns and the emergence of novel stories based on the understanding of the system in the face of the different vicissitudes of the passing of life, they 
account for the emergence of capacities at the individual, family and community level that enabled them to face the different situations mobilizing the family towards the evolution and self-organization, while the systemic artistic therapeutic strategies emerged as a determined plan for the therapeutic intervention, strengthening one of them to open up changes in the first and second order, as they make possible the re signification of the experience lived from the coconstruction of new stories.

Keywords: Art, Armed Conflict, Psychotherapy, Family. 


\section{PRESENTACIÓN}

Esta investigación-intervención hace parte del Macroproyecto de "Historias y narrativas familiares en diversidad de contextos" y pertenece a la línea Psicología, Familia y Sistemas Humanos y al grupo Psicología, Familia y Redes del programa de Maestría en Psicología Clínica y de la Familia de la Universidad Santo Tomás. El problema de investigación reconoce la complejidad del Conflicto Armado Colombiano en el que se entretejen diversas dimensiones de la vida de las personas y de sus familias, se evidencio la singularidad de aquellas familias que vivenciaron acontecimientos del CAC y como los estresores psicosociales generaron reajustes en su funcionamiento coadyuvando con los procesos de adaptación vital y la propia historia, aperturando la emergencia del malestar (Palacio y Madariaga, 2006; citado por Amar-Amar y Otros 2011), comprendiendo la salud mental en la interacción con los contextos amplios y no meramente en el miembro que es considerado el portador del síntoma (Lozano y Gómez, 2004; Campo-Arias, Oviedo y Herazo, 2014); al concebir que las crisis propias de los ciclos vitales familiares, es decir la dimensión histórica evolutiva, se potencia por las mismas condiciones contextuales, económicas, políticas y sociales de las realidades a las que se enfrentan estas familias al experimentar el proceso de desplazamiento forzado.

Por lo que al considerarse que es reconfigurada e incorporada la violencia en el cuerpo de quienes la vivencian (Chaves, 2011), se plantea la necesidad de generar acciones terapéuticas en donde se profundice en los estresores psicosociales por los que la familia atraviesa y en la situación de desplazamiento forzado incluyéndolos en el trabajo corporal, el arte y las experiencias personales (Rodríguez, 2015), puesto que en las críticas a las investigaciones 
revisadas en el estado del arte documental se cuestiona el enfoque medicalizador y psicologizador de las personas en situación de desplazamiento forzado (Rodríguez, 2015; Campo-Arias, Oviedo y Herazo, 2014; Sinisterra \& otros, 2012; Jiménez, 2009; Castro \& Mina, 2008; Puertas y otros, 2006) al encontrarse intervenciones estandarizadas e institucionalizadas que les urge un enfoque diferencial, que involucre y garantice la permanencia de niños, niñas y jóvenes (Andrade, Parra y Torres, 2011). Siendo importante a fomentar el manejo de la relación entre la violencia vivida y la reproducción de la misma, mediante el arte como estrategia de cambio y la conversación metafórica de las personas y la familia, en aras de develar el simbolismo y las especificidades de sus historias de vida y su ciclo vital, para reconfigurar el sentido de sus experiencias, posibilitar aspectos generativos en las diversas crisis emergentes y transformarse como seres humanos capaces de solventar sus propias adversidades.

Durante el desarrollo de esta investigación-intervención se recibió el apoyo del Centro de Proyección Social de la Universidad Santo Tomás ubicado en la localidad de Usme de Bogotá, D.C. Siendo esta investigación pertinente para el campo de la psicología clínica en tanto se busca proponer una nueva manera de intervenir a la familia respecto al fenómeno del Conflicto Armado Colombiano, en donde desde lo sistémico, la complejidad, el constructivismo y el construccionismo como principios epistemológicos se comprende el fenómeno de interés desde una complejidad integrada, tal como lo es el ser humano; entendiendo que las relaciones sociales son construcciones en nuestra realidad a partir de la interacción del lenguaje con nuestras percepciones individuales retomando los postulados de Maldonado \& Gómez (2011), Rodríguez \& Serna (2015), Estupiñán, 2003), Agudelo \& Estrada (2012), Feixas \& Villegas (2000). Así mismo, se retoman conceptos teóricos que ahondan en este fenómeno social respecto al funcionamiento familiar, en relación a la teoría de los sistemas y a la teoría ecológica de 
Bronfenbrenner, entendiendo que se gestan procesos vinculares desde la memoria y las narraciones familiares e individuales que promueven la vida en tanto se comprende un continuo entre salud/enfermedad, vulnerabilidad/generatividad, en relación a procesos de cambio; es decir desde una visión circular y de los recursos y capacidades propios de la comunidad, de la familia y de sus miembros; para ello se retoman los siguientes autores: Monzón (2004), Estupiñán (2003, 2007), Hernández (2009), (Minuchin, 2004), Olson \& Otros (1989), Hernández \& Bravo (2006), Rodríguez \& Serna (2015), Marxen (2011).

Es así que se desarrolló como un proceso psicoterapéutico de seis (6) escenarios en ocho (8) encuentros, con una familia en condición de desplazamiento forzado. Como diseño, cada encuentro contó con cuatro escenas en donde en la primera se explicó el escenario y se conversó sobre las percepciones del encuentro anterior, la segunda fue la actividad propuesta del escenario, la tercera la intercesión que decidió la intervención del equipo reflexivo o la transmisión de un mensaje por medio de una investigadora-interventora, y la última escena la conversación de la familia con la terapeuta y los acuerdos para el siguiente encuentro; Así mismo, se contó con el guion de intervención, la matriz de observación para el equipo terapéutico que estaba como espectador de la misma y se diligenció por cada encuentro la matriz de análisis de cada producto artístico.

Desde el analizar las siguientes seis (6) unidades de observación; estructura familiar (límites/fronteras, jerarquías, roles y composición familiar), dinámica familiar (pautas de relación sintomática, relación afectiva, alianzas/coaliciones, comunicación, toma de decisiones, resolución de conflictos), evolución (funciones de cada miembro, indicadores de ajuste adaptabilidad y ciclo vital), vulnerabilidad/generatividad (red vincular, dinámica relacional, filiación, socio cultural, vulnerabilidad social, histórico evolutivo, jurídico), cambio y reflexiones 
sobre la estrategia artística. Desde el análisis de la información por medio de la micro codificación (atlas ti) emerge la categoría "no quiero ser como mi madre, pero estoy condenada a serlo", posteriormente se desarrolla codificación axial, y matriz de análisis de la información.

Por lo que a partir del análisis desarrollado se identificó que si bien la familia vivencio acontecimientos del conflicto armado colombiano no se generaron grandes transformaciones en el funcionamiento familiar, sino que se exacerban las dificultades a nivel relacional entre los subsistemas. Al vivenciar estos acontecimientos propios del conflicto armado, la familia experimenta situaciones traumáticas difíciles de externalizar, por lo que las estrategias artístico terapéutico sistémicas movilizan durante el proceso terapéutico la posibilidad de resignificar la experiencia vivida a partir de la co-construcción de nuevos relatos, potenciando sus recursos adaptativos a nivel familiar e individual, lo cual promueve un cambio en el funcionamiento familiar que apertura un mayor bienestar en su proceso de adaptación vital. 


\section{INTRODUCCIÓN}

Durante la revisión bibliográfica se pudo identificar que Colombia es uno de los países con el índice de desplazamiento forzado más alto en el mundo, inclusive después de otros países, debido al desarrollo del conflicto armado interno (Fontecha, Moreno y Medina, 2010); en el que convergen diversos grupos unos al margen de la ley, así como el narcotráfico, la población civil, políticos y otros; y aunque este conflicto armado se exacerbó a mediados de los 80 , durante los últimos diez años comenzó a presentarse un descenso ligado a diversas situaciones en el país como nuevas ofensivas militares, la firma del proceso de paz, la reglamentación de atención y reparación de víctimas y la justicia para la paz, que sin embargo no menguan el surgimiento de secuelas en la vida de la población civil colombiana (Fontecha y Moreno, 2010).

Encontrándose dicho conflicto entretejido a las dinámicas propias de los procesos de transición sociopolíticos del país, surge recientemente preocupación por las dificultades que los individuos y sus familias vivencian llevando a algunas investigaciones a reconocer los vacíos que existen al desarrollarse procesos de atención terapéuticos (Rodríguez, 2015; Sinisterra \& otros, 2012; Jiménez, 2009; Castro \& Mina, 2008; Puertas y otros, 2006), en tanto se ha prestado mayor interés en este tema durante los últimos años, se encuentra en el estado del arte documental un porcentaje de investigaciones que supera el $40 \%$ de tipo reflexivo de orden descriptivo y exploratorio, centradas críticamente en la manera como se han abordado los procesos interventivos con la población que ha vivenciado acontecimientos del CAC por encima del planteamiento específico de propuestas interventivas.

En este sentido, al reconocerse dichas falencias a nivel interventivo se hace evidente cómo las familias que han vivenciado dicho conflicto bélico se encuentran desprovistas de una óptima 
intervención en la que se tenga en cuenta su situación y los estresores psicosociales por los que se han visto obligados a atravesar. Constituyendo el desplazamiento forzado uno de los fenómenos en los que se evidencia la prevalencia de síntomas emocionales relacionados a los estresores psicosociales tales como ansiedad, estrés postraumático y depresión (Campo-Arias, Oviedo y Herazo, 2014), puesto que su posición social y económica al verse impactada por dicho fenómeno afecta de manera notable su salud mental, en tanto se alteran las funciones de cada miembro y se generan nuevas dinámicas a nivel de pareja y/o parentofiliales (Beiser 1988, citado en Rousseau y Nadeau, 2003).

Prevaleciendo dichos impactos socio económicos durante varios años posteriores a la vivencia del proceso de desplazamiento, lo cual es identificado durante el desarrollo del estado del arte testimonial y el trabajo de campo en los que se reconoce como las familias que se encuentran en la capital bajo dicha caracterización, a pesar de ya haber pasado varios años del suceso presentan actualmente dilemas propios de sus ciclos vitales e historias familiares particulares, potenciados por los diferentes estresores psicosociales a los que se han enfrentado durante todo su proceso de desplazamiento forzado, así como de adaptación a su nuevo contexto y sus actuales condiciones sociales, culturales, políticas, económicas y jurídicas (Campo-Arias, Oviedo y Herazo, 2014).

$\mathrm{Al}$ reconocerse las afectaciones que emergen en las familias en condición de desplazamiento al verse enfrentados a estresores psicosociales, surge la preocupación por comprender los cambios que se presentan en el funcionamiento de las familias que han vivenciado el CAC en relación a la experiencia vivida y los procesos adaptativos en el nuevo contexto, pretendiendo promover la emergencia de nuevas comprensiones en las que se posibiliten intervenciones terapéuticas novedosas abordando los dilemas humanos desde una comprensión contextual e 
interaccional, en tanto se comprende la salud mental como un proceso de aprendizaje que relaciona las dimensiones biológica, psicológica y sociocultural, y la capacidad de las personas por desarrollar y manejar sus potencialidades psicológicas, cognitivas, afectivas y relacionales (Hernández \& Morales, 2003); por lo que desde la búsqueda de una mirada más holística esta investigación - intervención se enmarca en el macroproyecto de historias y narrativas familiares en diversidad de contextos acorde con los principios del enfoque sistémico y ecológico desde una perspectiva compleja, constructivista y construccionista.

Esta comprensión holística del fenómeno posibilita reconocer las particularidades psicosociales de estas familias, quienes provienen de otra cultura, de otros niveles educativos y contextuales, brindando así fuerza a la pertinencia de promover el desarrollo de estrategias interventivas, principalmente del arte, en las que se posibilite la expresión de la experiencia vivida en pro a la emergencia de otras narrativas que permitan la reconfiguración de la experiencia previa a través del aprendizaje y de la interacción con otras personas y contextos en los que se encuentran inmersos (Fontecha y Moreno, 2010); ubicándose la familia y sus miembros hacia un proceso de aprendizaje para afrontar y transformar la vida, bajo la adaptación al nuevo momento desde una visión ecológica, de procesos de co-aprendizaje, co-evolución y por ende de cambio que les permitan adaptarse a su nueva realidad bajo el tiempo propio del sistema y de los integrantes del mismo, desde la apuesta por las capacidades y de sus posibilidades auto-organizadoras.

En este sentido, se comprende que el Conflicto Armado Colombiano es un fenómeno complejo, que surge bajo "ámbitos en donde suceden imprecisiones, vacíos, incertidumbres, nolinealidades, sorpresas, fluctuaciones y cascadas de fallas" (Maldonado \& Gómez, 2011, p. 14); en tanto, se entreteje en diversas dimensiones de la vida de las personas y de familias que han 
vivenciado estos hechos violentos y son influenciados por estresores psicosociales en la misma medida que el proceso de reajuste que este hecho trae consigo en el funcionamiento familiar, $\mathrm{y}$ también de los cambios que se presentan en las familias como parte de los procesos de adaptación vital y la propia historia, aperturando la emergencia del malestar (Palacio y Madariaga, 2006; citado por Amar-Amar y Otros 2011), siendo así necesario enmarcar la salud mental en la interacción con los contextos amplios y no exclusivamente en el miembro que es considerado el portador del síntoma (Lozano y Gómez, 2004; Campo-Arias, Oviedo y Herazo, 2014); al comprenderse que diversos eventos no normativos propios de las condiciones contextuales, económicas, políticas y sociales al generarse el proceso de desplazamiento aperturan las crisis propias de los ciclos vitales familiares, es decir la dimensión histórica evolutiva, y generan afectaciones a nivel de los sistemas amplios en los que estas familias se relacionan.

Es así que el malestar que la familia en condición de desplazamiento vivencia se ha visto enmarcado bajo las diferentes dimensiones de la familia y de los miembros que la componen, como de una historia en donde se ha incorporado la violencia en el cuerpo de quienes la han experimentado (Chaves, 2011), aunado esto a las condiciones particulares académicas y culturales de estas familias se invita a generar acciones terapéuticas en donde se ahonde en los estresores psicosociales por los que la familia atraviesa desde un trabajo más corporal, artístico y de experiencias personales (Rodríguez, 2015), en tanto las críticas a las investigaciones revisadas en el estado del arte documental se cuestiona el enfoque medicalizador y psicologizador de las personas en situación de desplazamiento forzado (Rodríguez, 2015; Campo-Arias, Oviedo y Herazo, 2014; Sinisterra \& otros, 2012; Jiménez, 2009; Castro \& Mina, 2008; Puertas y otros, 2006) al evidenciarse intervenciones estandarizadas e institucionalizadas 
que carecen de un enfoque diferencial, que permitan involucrar y garantizar la permanencia de niños, niñas y jóvenes (Andrade, Parra y Torres, 2011). Dándose importancia a promover el manejo de la relación entre la violencia vivida y la reproducción de la misma, a través del arte como estrategia de cambio y la conversación metafórica de las personas y la familia, en tanto es entendido como un medio de comunicación y de resignificación de la experiencia (Alyami, 2015), en aras de develar el simbolismo y las especificidades de sus historias de vida y su ciclo vital, que permitan reconfigurar el sentido de sus experiencias, posibilitar aspectos generativos en las diversas crisis emergentes y transformarse como seres humanos capaces de solventar sus propias adversidades al construir nuevas posibilidades (Bustos, 2013), en tanto el arte posibilita la expresión de las emociones con diversidad de poblaciones (Farokhi, 2011).

A partir de la mediación del arte en los procesos de intervención, se posibilitan comprensiones en torno a cómo se desarrollan las circunstancias en el proceso de adaptabilidad vital, en las que las familias se direccionan hacia condiciones y circunstancias dirigidas a la vulnerabilidad (contextos psicopatológicos), en donde se comienzan a identificar síntomas interaccionales que se han construido en el contexto familiar, en el marco de las condiciones y experiencias psicosociales propias del conflicto bélico (Nieto y Ravelo, 2012). Puesto que las familias con sus historias, aprendizajes y experiencias vitales con el CAC, han cristalizado dichos hechos violentos en sus narrativas de sí mismos y de vinculación afectiva, produciendo así un malestar que obstaculiza sus procesos de aprendizaje, adaptación, desarrollo de relaciones familiares y potencialización de nuevas redes sociales (Andrade, Parra y Torres, 2011).

Por lo anterior se describen a continuación los objetivos (general y específicos), la hipótesis y la pregunta orientadora de la investigación - intervención: 


\section{Objetivos de la investigación / intervención}

\section{$\underline{\text { Objetivo general }}$}

Comprender los procesos de cambio de una familia que vivenció acontecimientos del Conflicto Armado Colombiano y ha realizado una demanda de ayuda psicológica como parte de su proceso de adaptación vital, construyendo así una estrategia terapéutica sistémica que utilice el arte como mediador entre la experiencia vivida y la experiencia narrada.

$\underline{\text { Objetivos específicos de investigación: }}$

Comprender los procesos de cambio que se entretejen en la recursión entre la vulnerabilidad - generatividad de una familia, que ha vivenciado acontecimientos del Conflicto Armado Colombiano.

Objetivos específicos de intervención:

Promover estrategias artístico terapéuticas con enfoque sistémico que favorezcan la emergencia de capacidades individuales y familiares dentro de su proceso adaptativo.

\section{Hipótesis de Investigación - Intervención}

El funcionamiento de las familias que han vivenciado acontecimientos del Conflicto Armado Colombiano presenta cambios en su adaptación vital, los cuales se potencian al verse enfrentados a conflictos psicosociales, económicos y políticos propios de dicho fenómeno, entretejiéndose pautas sintomáticas que se expresan en el funcionamiento y la recursión entre 
la vulnerabilidad - generatividad familiar, al cristalizarse la narrativa de la experiencia vivida, facilitando la emergencia del malestar al interior de la familia y su relación con el entorno; por lo que, al usar las estrategias artístico - terapéuticas sistémicas se dinamizan las capacidades individuales y familiares y se da el cambio en la experiencia narrada del bienestar deseado.

En tanto, en el estado del arte documental Lacárcel (2003) propone el arte como un lenguaje universal promotor de nuevas realidades, encontrándose de acuerdo con autores como Bustos (2013) y González (2008), quienes argumentan que éste posibilita la expresión del sentir y generan un proceso de liberación tanto afectiva como intelectual. De igual manera, Van Lith, (2016) identifica que la creación de dichos ambientes, objetos y experiencias artísticas aperturan la comunicación con otros, puesto que al participar en los procesos interventivos las personas que han vivenciado eventos traumáticos se aperturan a procesos de externalización y resignificación de la experiencia narrada y de su prospectiva vital.

\section{Pregunta de investigación- intervención}

¿Cómo posibilitar que las estrategias artístico - terapéuticas con enfoque sistémico sean promotoras del proceso de cambio en el funcionamiento de una familia que haya vivenciado acontecimientos del Conflicto Armado Colombiano y que ha realizado una demanda de ayuda psicológica? 


\section{ESTADO DEL ARTE}

\section{Estado del Arte: Documental}

\section{Introducción}

El objetivo de este estado del arte es reconocer cómo ha sido estudiado el fenómeno del conflicto armado por las ciencias sociales (antropología, trabajo social, psicología y sociología) y de la salud, en el transcurso de 15 años (2000 - 2017), con el fin de identificar las categorías de análisis, hipótesis, metodologías de abordaje, los resultados de las diferentes investigaciones consultadas y las experiencias de intervención en salud mental y de la familia, leídos a la luz del paradigma sistémico constructivista construccionista complejo. Ésta búsqueda se delimitó por una parte en las investigaciones referentes a la paz - Conflicto Armado en Colombia, con el fin de reconocer las diferentes perspectivas de las ciencias sociales frente a la comprensión del contexto, siguiendo las palabras claves de: conflicto armado, post conflicto, desplazamiento forzado y desmovilización. Esta información fue consultada en artículos de reflexión, e informes de resultados de investigación en idioma español e inglés en revistas indexadas en bases de datos como Scielo, Redalyc.org, Elsevier y Sciencie direct, información que fue consultada a nivel de latinoamérica, países asiáticos, europeos y de norte américa.

En este entendido, se evidencia la necesidad de reconocer las afectaciones de salud mental de las personas y familias, buscando así resaltar la relación entre la salud mental en el contexto del CAC, de las personas o familias en condición de desplazamiento forzado y/o en proceso de desmovilización. Lo cual, nos lleva a reconocer la necesidad de identificar cómo se han generado 
los procesos interventivos a través del arte con personas y familias impactadas por el CAC, filtrando la búsqueda a investigaciones enfocados a procesos interventivos que promuevan la salud mental en el contexto del conflicto armado y del CAC. Esto nos permitió llevar a cabo una revisión de diecinueve (19) publicaciones para la primera categoría, identificando aspectos en común como son: la manifestación del conflicto y postconflicto, las intervenciones psicosociales, los abordajes de la salud mental con enfoque sistémico y la noción de paz, en consulta de autores como Plata \& Guerra (2005), Chávez (2011), López \& Rodríguez (2012), Peñas \& Felizzola \& Otros (2015).

En relación a la categoría de salud mental se consultaron veinte (20) publicaciones encontrando en común: las acciones psicosociales y de salud mental, la relación de salud mental y conflicto armado en Colombia, con autores como Amar - Amar \& Otros (2011); Nieto \& Rabelo (2012); Villa (2013); Campo Arias \& otros (2014); Rodríguez (2015); Ardón \& otros (2015); y por último, en la categoría del arte como estrategia de cambio se consultaron dieciocho (18) publicaciones que permitieron identificar la psicología y la terapia ocupacional, como las disciplinas que usan con mayor frecuencia el arte como herramienta interventiva; así mismo se estableció que las manifestaciones artísticas más utilizadas en el proceso terapéutico son la música en seis (6) publicaciones y el arte como la pintura, teatro y títeres para doce (12) investigaciones, en consulta de autores como Pérez (2014); Michel y Luzzi (2010).

\section{Caracterización del universo documental}

\section{Paz - Conflicto Armado en Colombia (CAC)}

El universo documental revisado para esta categoría incluye diecinueve (19) artículos de 
publicaciones seriadas, ensayos, textos reflexivos e informes de resultados de investigaciones de tesis o trabajos de grado.

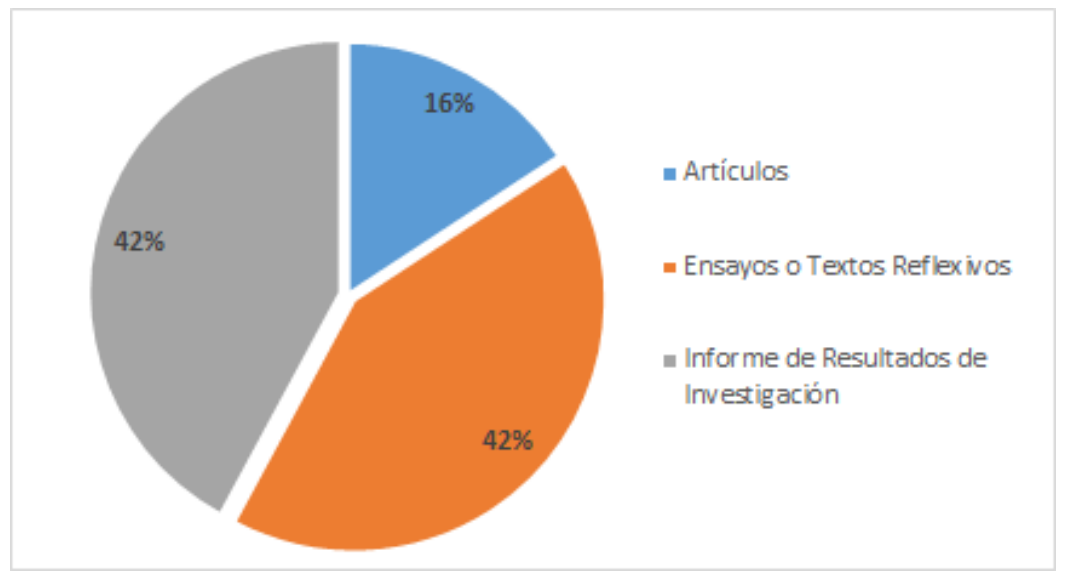

Gráfico 1 - Tendencia por tipo de documento. Fuente Autoras

Lo anterior, y para la muestra documental tomada se observa una gran producción de textos de orden reflexivo en igualdad de número para informes de resultados de investigación, lo que da cuenta de que la reflexión como producción final de procesos de investigación es predominante en comparación con los artículos científicos que sean asequibles para la comunidad, en tanto se tienden a quedar las investigaciones en un orden más local y académico.

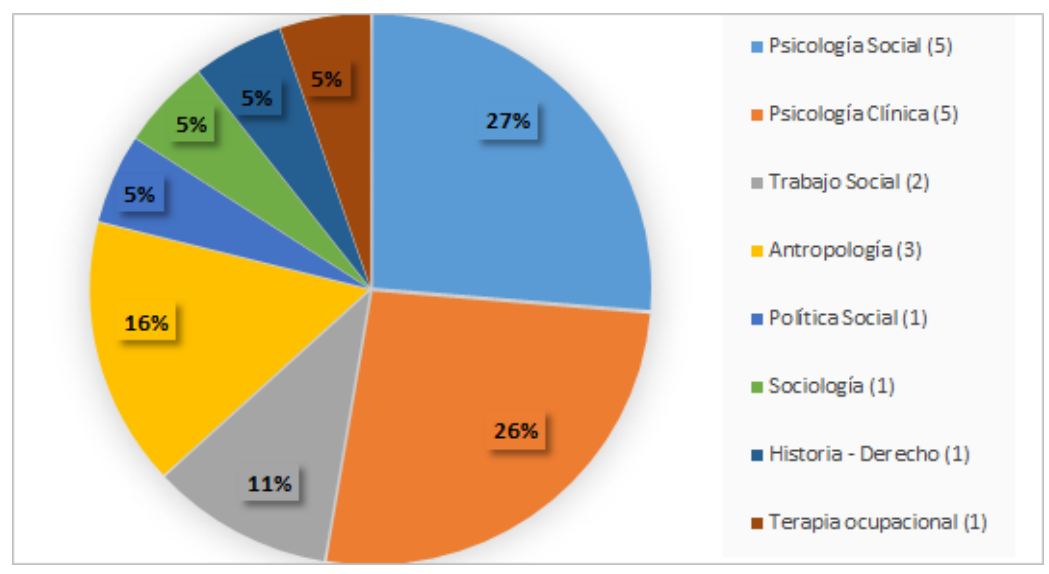

Gráfico 2 - Tendencia por disciplinas. Fuente Autoras 
De otra parte, con relación a las disciplinas que han abordado el estudio de estas categorías encontramos que con un 27\% la Psicología Clínica y la Psicología Social son las que muestran más interés por el tema, seguidas de la Antropología con un 16\% y luego del Trabajo Social con un $11 \%$. De igual forma, otras disciplinas como Política Social, Sociología, Historia, Derecho y Terapia Ocupacional con un 5\% han mostrado preocupación por abordar este fenómeno, pero desde lo humano, para ligar sus objetos de estudio a las causas e impacto que genera el CAC.

De esta forma, la psicología en su enfoque tanto clínico como social (27 y $26 \%$ respectivamente) es la disciplina que ha generado más productos de investigación y análisis en los últimos 11 años de acuerdo con los documentos rastreados, posiblemente buscando comprender el fenómeno del conflicto armado colombiano, en aras de aportar interventivamente, en tanto existen significativos atrasos en estas comprensiones en un país con índices de conflicto y desplazamiento altos.

En tanto, para la Psicología es perentoria la necesidad de reconocer que el trauma no es lo único existente desde lo puntuado por la medicina, sino que es ineludible propiciar una intervención con las personas que han vivenciado los hechos violentos, con sus familias y además con sus redes de apoyo, en tanto su objetivo es impactar la cotidianidad de su vida y de las mismas instituciones involucradas en los procesos de restablecimiento de derechos y garantes de la protección social estatal; debido a que el fenómeno del desplazamiento forzado, los devenires familiares y los integrantes del sistema que reconstruyen el proyecto de su vida, así como la forma de vincularse en la que predomina el maltrato entre personas y entre sus generaciones, debido a las diversas formas de violencia, obligan a la psicología a generar comprensiones sobre la condición humana inmersa en el conflicto armado colombiano. Puesto 
que se cuestiona la atención e intervención institucional que afectan los mismos procesos socializantes entre las partes (Plata \& Guerra, 2005).

De otra parte, la Antropología busca demostrar cómo en las diversas situaciones de violencia el cuerpo del ser humano muestra una tendencia a la transición entre convertirse en objeto de esa violencia y la forma de incorporarla. De esta forma, un actor o actores del CAC que fueron violentados en sus cuerpos o a través de los cuerpos de otros, incorporan esos actos violentos y posteriormente reflejan en sus interacciones sociales estos hechos; siendo esto el fundamento para abordar los cambios de orden político, cultural, social y económico que se producen luego de esta incorporación o de las estrategias de resistencia a estas situaciones de forma individual o colectiva (Chávez, 2011).

Así mismo, desde el Trabajo Social se ha indagado en las particularidades denominadas como capacidades, que facilitan tanto al individuo como al colectivo, descubrir, incrementar y fortalecer las competencias de orden cognitivo y técnico en aras de reconfigurar y transformar sus propios conflictos y gestionarlos de forma pacífica, lo que les permite visualizar más oportunidades para tener acceso a la política y para la construcción de una línea enfocada en la consecución de objetivos para su crecimiento; todo mediante una metodología que identifica la situación de las comunidades en relación a las capacidades y las condiciones de sus integrantes enfocadas a la construcción de paz (Katz, 2011).

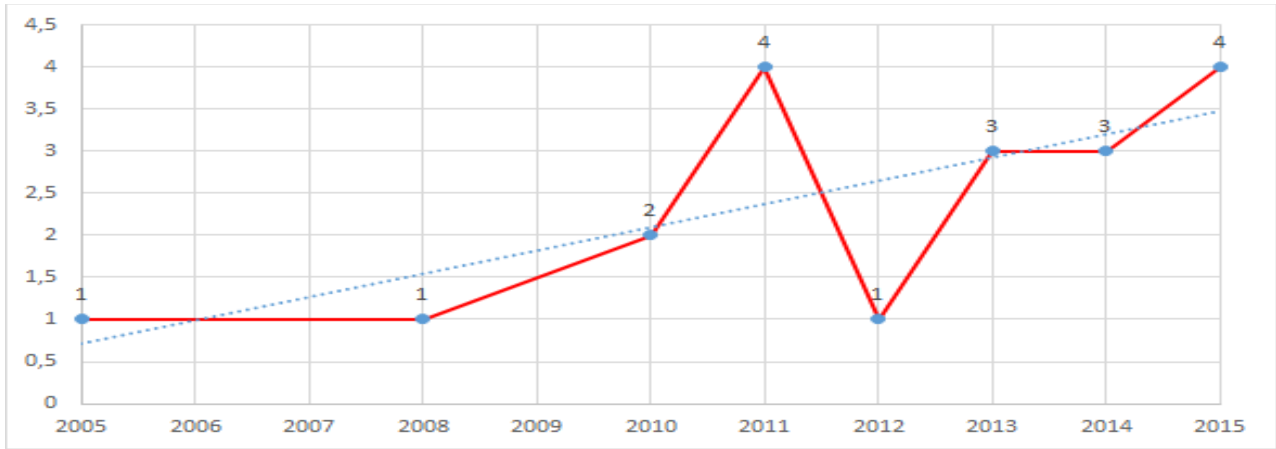




\section{Gráfico 3 - Tendencia cronológica. Fuente Autoras}

Así mismo, la organización cronológica de la información recogida en este estudio permite identificar y comprender cómo este tema se ha venido trabajando de forma constante y la misma organización temática corresponde a las tendencias que emergen acorde con las necesidades de investigación en Colombia, en el ámbito latinoamericano, y otros países.

En este entendido, en el análisis de tendencias cronológico se observa un leve aumento de la producción documental para el año 2010, aumentando significativamente para los años 2011, 2013 - 2015. Periodo en el cual se presentan hechos significativos como son: En el año 2010 se produce relevo presidencial en Colombia y en 2011 se sanciona por el nuevo presidente la Ley 1448 del 10 de junio, por medio de la cual se dictan medidas de atención, asistencia, y reparación integral de víctimas del conflicto armado interno y se dictan otras disposiciones; sin desconocer que fue un proyecto presentado por el congreso al Gobierno anterior, sin alcanzar en su momento aprobación debido al no reconocimiento de la existencia de un conflicto armado interno en el país por parte de ese gobierno; siendo esto un hecho significativo en el reconocimiento de las víctimas, en su retorno a sus territorios a través de la recuperación de las tierras de las cuales fueron despojados como consecuencia del conflicto. Este hecho ha generado reconocimiento del país tanto a nivel nacional como internacional debido a los aportes relevantes en torno a un proceso de reconciliación en Colombia.

Además, de que en el numeral 4 artículo 145 del capítulo IX se indica: "Fomentar a través de los programas y entidades existentes, la investigación histórica sobre el conflicto armado en Colombia y contribuir a la difusión de sus resultados", lo que sin duda ha generado este incremento significativo en la necesidad de investigar en todo lo concerniente a víctimas. No menos importante, en este mismo capítulo se ordena la creación del Centro Nacional de Memoria Histórica -CNMH-, el cual a través de sus investigaciones y especialmente a través del 
documento denominado ¡Basta Ya! (2013), nos introduce a numeral 1.4.6 en las causas del desplazamiento forzado en Colombia y a numeral 4.2.3 los impactos y daños generados por el conflicto armado en Colombia, en especial en los relacionado al desplazamiento forzado.

Actualmente, y sin que se hayan desinteresado por el objetivo anterior, las investigaciones vienen dando una gran relevancia al estudio de fenómenos como el conflicto y el posconflicto, cómo estos fenómenos se relacionan con los procesos de paz adelantados tanto en Colombia, como en el mundo, y cómo se afectan algunos de los actores del CAC en especial las personas en situaciones de desplazamiento, hecho que muestra un pico de disminución importante de las investigaciones sobre conflicto armado para el año 2012, posiblemente debido a que se da inicio a los diálogos de paz en la Habana para ese año.

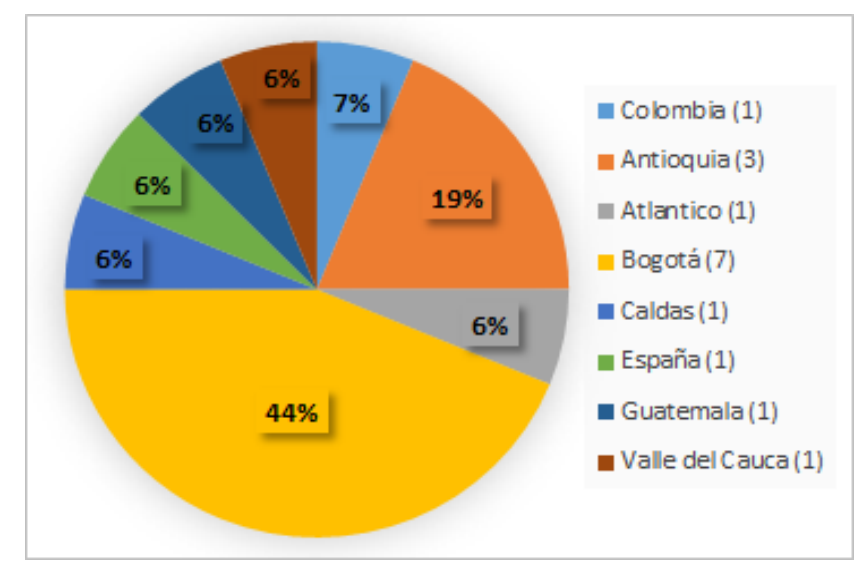

Gráfico 4 - Tendencia por ciudad. Fuente Autoras

Sin embargo, en lo relacionado a la distribución de los documentos consultados se encuentra que predominan en ciudades principales como Bogotá y Medellín en nuestro país, así como en Barcelona y ciudad de Guatemala; pero congruentemente, estudios de este fenómeno en ciudades pequeñas no son representativos, no son muy evidentes o no tienen la difusión 
adecuada. De igual forma, se observó que una gran parte de las investigaciones sobre estos fenómenos que se han realizado en nuestro país, se publican o se ubican en los repositorios directamente en las universidades, limitando el acceso a dicha información.

Es así que, para las familias desplazadas el arribo a Bogotá se convierte en otro factor de estrés, aunado a los eventos traumáticos y de tortura en muchos casos (Meier \& Celis, 2006), al ser un escenario que permite a esta población distanciarse tanto física como emocionalmente de las situaciones puntuadas como estresantes e iniciar una nueva vida alterna. Sin embargo, ante estas dificultades que se presentan en la ciudad para prestar atención oportuna a las diversas necesidades de la población desplazada, relacionadas con la carencia de una conciencia y de una sensibilidad de parte de varios sectores de esta ciudad.

Además, se observa, la manifestación sobre la existencia de una gran limitación en lo referente a acceder a zonas específicas, por el mismo contexto cultural y social, en donde predomina: la violencia, el poder retomado por grupos al margen de la ley, escasez de recursos para la investigación, entre otros, que dificultan el proceso de observación, abordaje y análisis de este fenómeno.

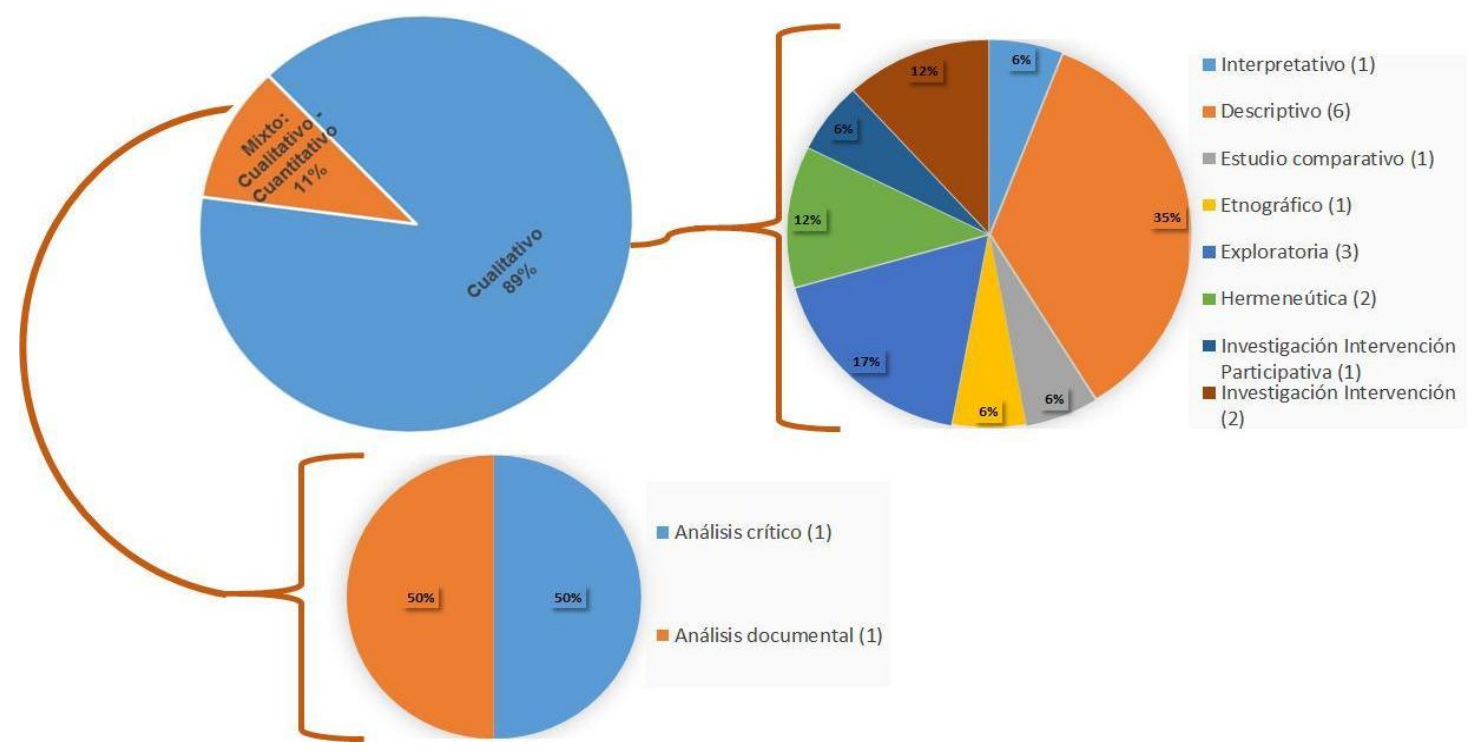


Gráfico 5- Tendencia por tipo de investigación. Fuente Autoras.

Así mismo, una gran parte de las investigaciones consultadas que fueron realizadas en Colombia sobre esta categoría son de tipo cualitativo en las que se realizan en su mayoría escritos de orden descriptivo o exploratorias por sobre el orden interventivo. Además, son escasas las investigaciones de orden comparativo tanto entre tipos de poblaciones, de conflicto, de violencias y de impactos, y entre lugares de perpetraciones de hechos de conflicto etc. Así como la investigación de tipo mixto (cualitativo - cuantitativo) se fundamenta en análisis de índole crítico y documental.

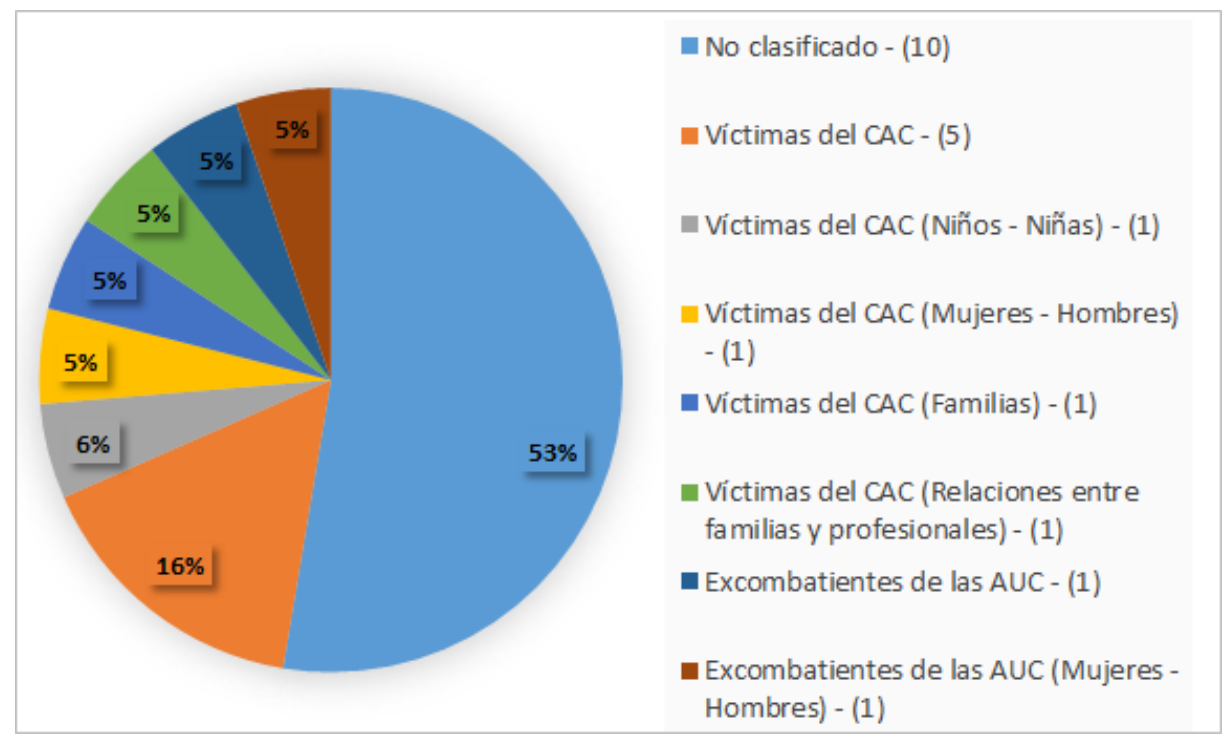

Gráfico 6 - Tendencia de Población. Fuente Autoras

De otra parte, con relación a la población se encuentra -teniendo en cuenta que son significativos en número los artículos de orden reflexivo o descriptivo consultados- un porcentaje del $53 \%$ equivalente a la no clasificación de la población, en donde se realizan análisis sobre las causas, evolución y consecuencias del CAC, mientras que un 16\% refleja investigaciones inherentes a víctimas del CAC sin desagregar el grupo etario objeto de análisis. 
De otra parte, en una proporción del $5 \%$ se identifica a la población como niños y niñas, mujeres, hombres, familias y las relaciones entre familia y profesionales. En algunas de estas investigaciones se identifican con claridad el número de hombres y mujeres, mientras que en otros sólo enuncia el grupo al que pertenece la población bien sea víctimas o excombatientes del CAC. En este entendido, es relevante identificar que en las investigaciones que enuncian la población como víctimas del CAC y excombatientes, se observa un 37\% para víctimas y un $10 \%$ para excombatientes. De igual forma, es importante mencionar que las investigaciones que identifican la población objeto de estudio se encuentran ubicada en zonas veredales y urbanas.

De igual forma, las intervenciones psicosociales se documentan para los diferentes grupos etarios, exceptuando población adulto mayor para la cual no se encontraron reportes específicos. Las alteraciones emocionales o de las conductas provocadas por el fenómeno del desplazamiento forzado, el riesgo de presentar afectaciones psicosociales, ruptura de redes sociales, no realización de duelos, alteración de hábitos y rutinas, y necesidad de formar en valores para la convivencia y la paz, son problemáticas descritas en las experiencias consultadas. Llama la atención las intervenciones sobre riesgos psicosociales, dirigidas a funcionarios que trabajan con víctimas del conflicto e integrantes de fuerzas armadas (PeñasFelizzola, Gómez-Galindo \& Parra-Esquivel, 2015).

El desplazamiento producto del fenómeno del CAC y el posconflicto han sido fenómenos estudiados en Colombia, aunque el primero presenta un mayor abordaje que el segundo. Sin embargo, la Psicología ha presentado un gran interés en el estudio de estos fenómenos y varios investigadores se han dedicado a estudiarlos en lo referente a sus causas, dinámica y algunos efectos sobre la salud y la salud mental, tanto desde lo individual como desde lo colectivo, y algunos de los modos de intervención que existen; aunque no se evidencian procesos 
interventivos que muestren resultados relacionados con la re-significación o transformación de las experiencia vivida durante los eventos traumáticos de exposición por el CAC.

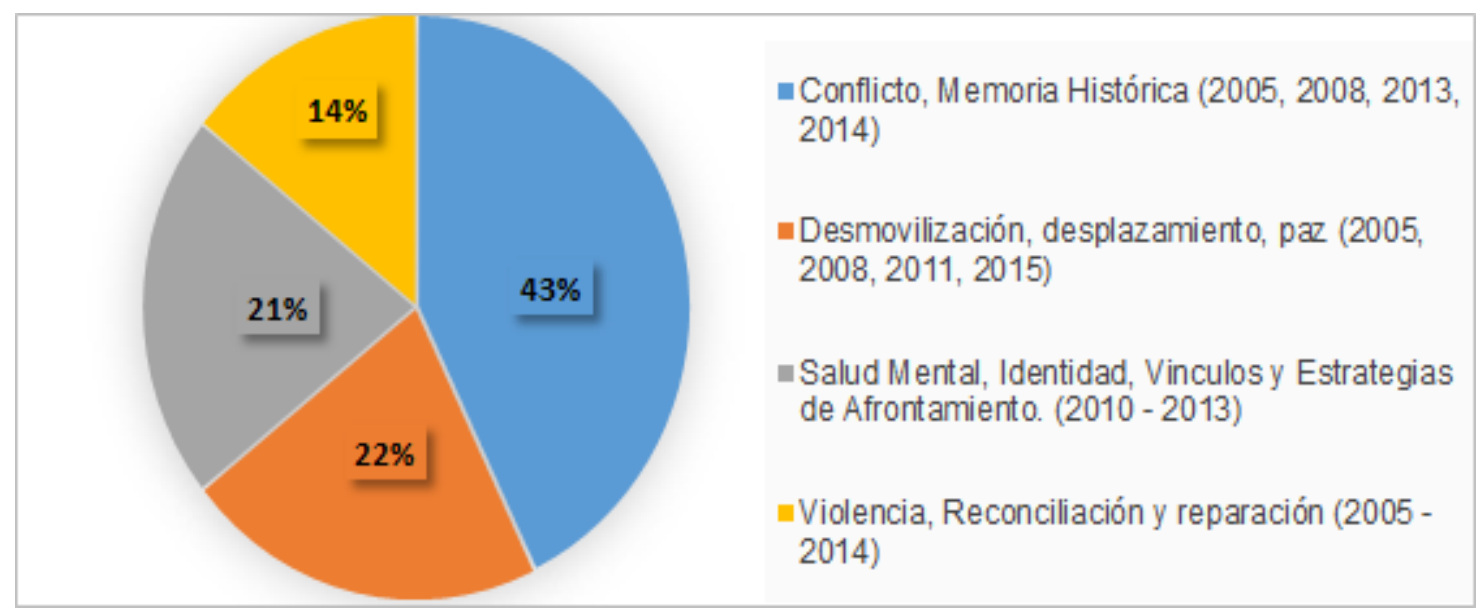

Gráfico 7 - Tendencia por Categoría emergente. Fuente Autoras

De igual forma, las hipótesis y preguntas de investigación abordadas en las investigaciones le apuntaban a conocer cómo se relaciona el conocimiento social y las políticas sociales, cómo se logra una interacción y comunicación entre los investigadores y quienes tienen poder de decisión para poder colocar en disposición y en práctica el conocimiento generado en la investigación de orden social en pro del mejoramiento de la sociedad, siendo de gran relevancia como el pensamiento sistémico puede ayudar a que la transformación de los conflictos se vuelva mucho más eficiente.

Algunos de los resultados arrojan información importante para la comprensión de este fenómeno en relación con la autopercepción esperada de calidad de vida de los evaluados (desplazados) considerada como más complicada a la que tenían antes de ser expulsados. En este entendido, la percepción de lo esperado por las personas en condición de desplazamiento se observa menoscabada y además desvirtuada cuando se enfrentan a la situación de adaptación obligada a la que son sometidos. Sin embargo, es menester indagar cómo se resignifican esas 
vivencias en las personas en condición de desplazamiento para contribuir en un proceso de reparación emocional en las víctimas del CAC (Amar-Amar, Abello-Llanos \& Otros, 2011; Andrade, Parra \& Torres, 2011 y Llanos \& Otros, 2009). En donde la misma des-legitimidad de las instituciones del Estado, la pérdida de esperanza de la transformación de esa situación, la revictimización permanente y la ausencia de mecanismos de atención en salud física y psicosocial, mantienen y agudizan los efectos físicos y psicosociales que generan los hechos de violencia (Campo-Arias, A y otros (2014); a pesar de que los actos públicos de memoria y la construcción de la memoria colectiva en la que trabaja arduamente el CNMH, tratan de hacer la construcción de una perspectiva posibilitadora en la ciudadanía en contra de esa impunidad y reclamó efectivo de derechos de la verdad, justicia y reparación esperada (Basta ya, 2013).

Todo lo anterior, aunado a un papel de solidaridad y escucha de una sociedad que es indiferente al sufrimiento de las víctimas del CAC de la mano de políticas que mantienen y perpetúan los discursos de guerra y en una descompensación conceptual y epistemológica en el que prima la violencia por sobre la paz; surge de las condiciones estructurales sobre las cuales se construyó este país y a la herencia política que las organiza.

De otra parte, el incremento del conflicto armado en Colombia, las intenciones de la firma de un acuerdo de paz, así como la gran afectación en cuanto a salud mental, es producto de la interacción de los actores en este ámbito, que han despertado el interés de investigar estos fenómenos para comprender esta complejidad desde diferentes concepciones teóricas.

De todo lo mencionado anteriormente surgieron las siguientes categorías: Conflicto memoria histórica, desmovilización, desplazamiento y paz, salud mental, identidad, Vínculos, Estrategias de Afrontamiento, y Violencia, Reconciliación y Reparación, las cuales se desagregan a continuación: 
En cuanto a la categoría de Conflicto - Memoria Histórica prevalente en un 41\%, debido a que Colombia desde hace varios años vive un conflicto armado interno que ya alcanza dimensiones internacionales en razón de factores como el narcotráfico, que articula tanto la economía como organizaciones criminales en el mundo, el impacto que se genera en los países vecinos en tanto en las zonas fronterizas es visible este flagelo, y el fenómeno de la globalización que facilita la interrelación de los sucesos internos con la internacionalización. Igualmente, en este conflicto confluyen distintos grupos tanto legales como ilegales como son guerrilla, ejército, paramilitarismo, narcotráfico, políticos, personas con altos recursos económicos y dueños de grandes extensiones de terreno en el país, y otros que han coadyuvado a masificar el número y el incremento de actos violentos con la sociedad civil colombiana (Fontecha, Moreno \& Medina, 2010). Además, que para mediados de los años 80 el conflicto en Colombia entró en un período de asentamiento que se ha perpetuado durante varios años, y que durante aproximadamente los últimos diez años ha mostrado descensos notorios debido a la ofensiva instaurada de las fuerzas militares colombianas; sin embargo, esta guerra ha conseguido mantenerse en la vida de varias generaciones de este país.

Es por ello, que se determina éste conflicto armado Colombiano como una compleja problemática que ha logrado atravesar la historia de éste país produciendo una variedad de fenómenos y de situaciones que intervienen tanto de forma directa como indirecta en la calidad de la vida y del bienestar de todos los ciudadanos, impactando directamente todas las dinámicas y las estructuras de éstas familias colombianas sin percatarse de su precaria condición socioeconómica, coadyuvada por cientos de realidades referidas por Cifuentes (2005) como aquellas pérdidas de diversas naturalezas que permean la composición y su propia estructura de relación, que han sido producidas por las constantes pérdidas de los miembros del sistema a 
causa de asesinato, la desaparición, la vinculación a grupos armados, la huida; la misma pérdida de sus pertenencias, por el desarraigo, la inevitable pérdida de sus activos y además por la incesante transformación del nicho tanto afectivo como cultural en razón a los permanentes procesos de desplazamiento que se generan (Torres, 2013).

De esta forma, la dinámica de éste conflicto prolongado ha generado cifras importantes e impactantes señaladas en último reporte por la ACNUR (2009), mostrando que tres (3) de los trece (13) millones de personas desarraigadas de forma interna a las que facilitó la atención durante el 2008 en el mundo se trata de colombianos, equivalente esta cifra al $23 \%$ de todo el total y en un promedio de familias de 700 mil, colocando a nuestro país con el primer lugar en el número de desplazados asistidos por la ONU. Así mismo, la Amnistía Internacional en el año 2008 indica que, en 20 años atrás, entre unos tres y hasta cuatro millones de compatriotas han sido obligados(as) a dejar su hogar; en razón a esta cifra magnificada se coloca a Colombia con el índice de desplazamiento forzado más alto en el mundo, inclusive después del país de Sudán (Fontecha, Moreno \& Medina, 2010).

Cobrando fuerza de esta forma, la necesidad de esclarecer la verdad a acerca de muchos hechos ocurridos en todas esas situaciones de guerra, masacre, desplazamientos, asesinatos, secuestros y otros tantos delitos de lesa humanidad, a partir de un proceso de reconstrucción del pasado vivido y que ha sido experimentado por actores del conflicto armado colombiano,

para ello el CNMH pretende visibilizar la voz de las víctimas del CAC, basándose en la reconstrucción de ese pasado como fundamento esencial de la construcción de una memoria histórica para este país, para permitirle a la sociedad tener conocimiento de sí misma, de su propia historia y sus propias representaciones en razón a que, aunque la historia continua el pasado permanece latente en los actores de este conflicto. 
En este entendido, esta memoria histórica se convierte en un proceso colectivo del propio lenguaje y significado que le atribuyen de forma igual los miembros de una sociedad, que cuando vuelven al pasado a través de sus relatos van siendo conscientes de su coparticipación y como esto permea la construcción de su propia identidad. De esta forma, para lograr esta construcción de la memoria histórica se hace de gran utilidad la experiencia vivida por cada uno de los actores del CAC, y que como afirmara Heinz Von Foerster (1996) casi siempre las ciencias duras se encargan de la mayor parte de los acontecimientos blandos, y a su vez es menester de los blandos ocuparse de aquellos puntuados como problemas duros. Así que para discernir lo que es la experiencia vivida es necesario que se narre y que una gran parte de lo que la investigación social persigue se pueda narrar a través de las divergencias del devenir tanto individual, de los colectivos humanos y como nación (Plata \& Guerra, 2005).

De otra parte, en relación con el surgimiento de la categoría de Desmovilización - Paz con un $22 \%$ se determina que para el año 2005, entra en vigencia la Ley 975 denominada Ley de Justicia y Paz, que pretendía generar un espacio de transición hacia la paz en Colombia y que involucraba a todos los grupos armados organizados al margen de la ley, a someterse a ella, sin desconocer a las víctimas, sus necesidades y derechos en tanto es necesaria que la verdad, justicia y reparación se hagan efectivos.

Dándose de esta forma un gran auge político, en ese entonces por el acuerdo de paz liderado por el presidente de la época, que da fuerte prioridad a la visibilización de lo que estaba pasando en Colombia en razón al conflicto armado y los errores productos de este flagelo, por lo que comienzan a surgir los informes de control y monitoreo como de investigación que daban cuenta de los procesos de desmovilización de grupos paramilitares que dejaron las armas de manera colectiva, planteando preguntas sobre cómo sistematizar los modelos de conflictos 
mentales y las narrativas de las partes implicadas de modo que puedan relacionarse de forma más adecuada, en tanto para el año 2006 mediante decreto 3043 se crea la Alta Consejería para la Reintegración Social y Económica de Personas y Grupos Alzados en Armas.

Así mismo desde el año 2007 se da una importante visibilización sobre niños y niñas combatientes integrantes de los grupos al margen de la ley, prioritariamente relacionada con el reclutamiento ilegal o vinculación directa de menores a estas estructuras de los grupos armados, siendo de gran interés académico la investigación de estos hechos principalmente por la desmovilización de menores, inclusive desde los años 90 aproximadamente cobrando especial auge entre los años 2009 y 2011, siendo relevante la participación de ICBF con apoyo de la ONU a través del programa para la protección y la reintegración de los niños separados de los grupos armados no estatales.

De igual forma, a partir del año 2011 se hacen relevantes lo estudios sobre la organización de procesos de paz y capacidades para la construcción de paz que datan sobre los últimos años. En donde la participación y deliberante de individuos, organizaciones, comunidades y autoridades del territorio en todos los procesos de desarrollo y construcción de paz se hace vital como condición para la apropiación y asunción de responsabilidades. El promover la participación debe acompañarse ineludiblemente con el empoderamiento de los individuos y de las mismas organizaciones a nivel económico, político y cultural, lo cual indica proveer todas las condiciones para que estos y ellas apropien mayores niveles de identidad, autonomía y capacidades (Katz, 2011). En tanto, los individuos y las comunidades amplíen sus competencias tanto humanas, como cognitivas y técnicas para actuar en el propósito de transformar sus propios conflictos y tramitarlos por la vía pacífica.

De otra parte, en relación al surgimiento de la categoría de salud mental, identidad, 
vínculos y estrategias de afrontamiento en un $21 \%$ se hace evidente que en consonancia con las consecuencias acaecidas por el CAC los procesos terapéuticos deben contribuir a la coconstrucción de un sin número de historias de orden esperanzador en la cual estos actores logren reconocer y valorar el sin número de aprendizajes adquiridos desde de las diversas experiencias violentas desde la sociopolítica, siendo la memoria de gran ayuda, al realizar el sentido de lo que es la convivencia y la misma solidaridad dada a partir de su dinámica relacional con el entorno. De igual forma, estas historias relacionadas con ese deseo de apoyar y ayudar a otros generan fortalecimiento en el mismo sentido humanitario en todos ellos, respondiendo a esa sensación protectora que experimentaron todos los actores, en especial las víctimas de este conflicto armado colombiano (Fontecha, Moreno \& Medina, 2011).

Siendo de esta forma, de gran análisis en la familia el impacto secundario con todas esas repercusiones y los sufrimientos que originan vulnerabilidad, derechos a esa libertad, a lo que se conoce como debido proceso, a la misma integridad, y a la construcción identitaria de los integrantes, una conveniente vinculación entre ellos, al derecho de no padecer tratos de crueldad y a hacer parte de lo que es una familia. En tanto, ésta se transforma directamente en víctima de este fenómeno del desaparecimiento, porque si bien es cierto es sobre ese desaparecido que recae de forma directa el hecho, es en este sistema en quien públicamente aparece y quien hace que se visibilicen esos derechos de quien desapareció (López \& Rodríguez, 2012). Sin embargo, este aparte de esta investigación desconoce que independiente del reconocimiento de derechos de quien desaparece, también se vuelven relevantes las condiciones en las que la familia se ve inmersa, en una gran mayoría a la situación de desplazamiento a la que es evocada en aras de salvaguardar la vida de los miembros restantes.

De esa forma, en las capacidades de las diferentes personas se debe ir focalizando y 
recreando de manera complementaria la configuración identitaria de esas víctimas, la de los mismos sobrevivientes, y de esos procesos psicosociales que a través de su atención fortalecen la recursividad tanto de las personas, de las familias y de las mismas comunidades, en aras de ampliar los límites de sus propias narrativas descriptivas identitarias, no sólo desde lo puntuado como déficit sino a partir de todas las posibilidades para lograr la reconstrucción de sus vidas (Arévalo, 2010). .

Es así, que la asesoría familiar desde el enfoque de la resiliencia, abarca las realidades de los sistemas familiares desde una perspectiva tanto histórica como en relación a lo que es la comprensión, búsqueda y transformación de diversas formas de construcción de su particular vida al enfrentar los complejos problemas, asociados con diferentes pérdidas que generan impacto en la estructura relacional y en su propia composición fruto de todas esas pérdidas de sus integrantes a causa de la huida, la desaparición forzada, el asesinato, su pertenencia a grupos armados al margen de la ley y también del desplazamiento forzado (Cifuentes, 2005. Citado por Torres, 2013), p. 33).

Según Baruch, Bush y Folberg (1996), citados por Estupiñán y González (2006), se reconoce en la asesoría bajo un enfoque de resiliencia la oportunidad de abarcar el conflicto de una forma que genera afrontamiento, revalorización, negociación, reconocimiento entre los actores para:

construir desde allí el cambio a partir de la movilización de recursos emocionales, acciones y cogniciones, y de acuerdo con las exigencias de contexto el fortalecimiento de vínculos entre sus miembros y el contexto (p. 116-, Citado por Torres, 2013, p. 3940).

Además, en relación a la categoría emergente de violencia, reconciliación y reparación con 
un $14 \%$ se hace relevante el estudio de la violencia en sus diversas manifestaciones, siendo que la violencia compromete diversas condiciones de orden político económico y social que reconstituyen humanitariamente a las personas mostrando novedosamente una nueva ética y moral que disponen la forma de cómo vivir, cómo los actos violentos se humanizan, mediante una incorporación exitosa tanto en lo cotidiano como en los procesos reconciliatorios y reparadores, en que los investigadores se han concentrado en examinar cómo éste conflicto y desplazamiento se interpone en el conocimiento y política social (Plata \& Guerra; 2005), reflexionando sobre las concreciones o diferencias estilísticas de la cotidianidad de la experiencia sobre el conflicto armado colombiano y las proposiciones del estado para reparar y reconciliar, siendo esa confianza una oportunidad para investigar.

Aunque, la forma de relacionarse de todos los actores inmersos en la reparación se convierte en conminatorio del Estado para que se reconstruya el acercamiento con las víctimas, en tanto reparar será posible cuando esos seres humanos sean reconocidos como sujetos de derecho por el Estado, reconocidos como aquellos ciudadanos a los que se les vulneró sus derechos, y para los cuales el estado hace hasta lo imposible para reparar las consecuencias de ese daño (Arévalo, 2010). En tanto, fortalecer los significados construidos sobre ese proceso reparatorio, y los mismos sentidos contenidos para la reedificación de las historias y los proyectos de su propia vida, permiten conocer qué se convierte en útil y qué no en ese proceso, así se sostengan fundamentales orientaciones y principios encaminados a ese desarrollo de medidas reparatorias, no se podría desconocer lo particular y necesario para cada una de las personas, las familias y las mismas comunidades (Arévalo, 2010), en tanto:

"Particularmente, entendimos la reparación como un modo de dinamizar la configuración de identidad mediante la construcción de historias con mejores formas (Sluzki 
2006), que inciden en el posicionamiento como ciudadano, miembro de una comunidad y una familia, en un momento histórico que dispone los recursos de afrontamiento con los cuales víctimas y familias han lidiado con el sufrimiento, las maneras en que se han resistido y han construido sentidos de la experiencia (incluidos elementos de tipo político, cultural, material y espiritual)” (Estrada, Ripoll \& Rodríguez, 2010, p. 109).

Así mismo, el proceso transicional que está presente en Colombia se considera uno de los procesos más íntegros en materia de justicia transicional, en tanto víctimas y victimarios son considerados actores partícipes del CAC. Es por ello por lo que la Ley 1448 del 10 de junio de 2011, contempla los derechos de verdad, justicia y reparación, convirtiéndose esto en un gran adelanto en el proceso de reivindicar las víctimas en el marco de éste CAC e inclusive a la sociedad en general.

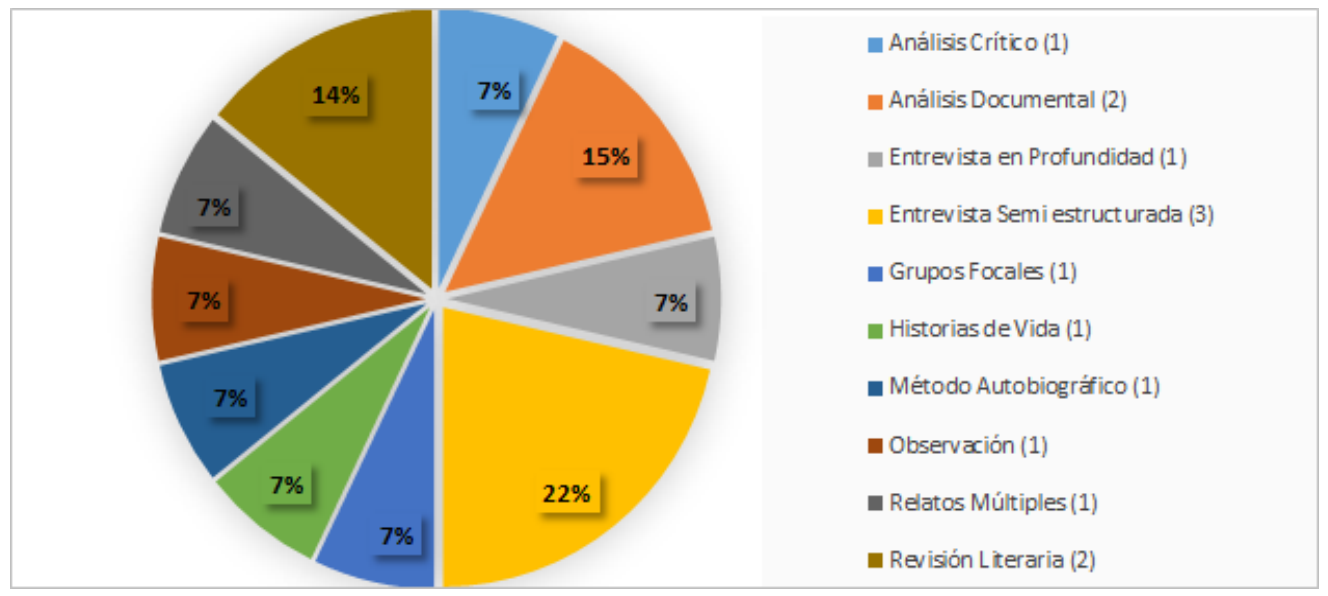

Gráfico 8 - Tendencia de Técnicas de Investigación usadas. Fuente Autoras

Por otro lado, se encuentra que para el proceso investigativo predomina el uso de técnicas como: Entrevistas semiestructuradas en un 40\%, seguidas del análisis documental y revisión literaria cada una con un 15\% y 14\%, estas dos últimas con relación al significativo número de artículos de orden descriptivo. De igual forma, son usadas técnicas como análisis crítico, grupos 
focales, historias de vida, autobiografías, observación directa e indirecta, relatos y entrevista en profundidad. Encaminados estas técnicas a recopilar datos y caracterización de la población para analizar y describir los fenómenos clínicos abordados:

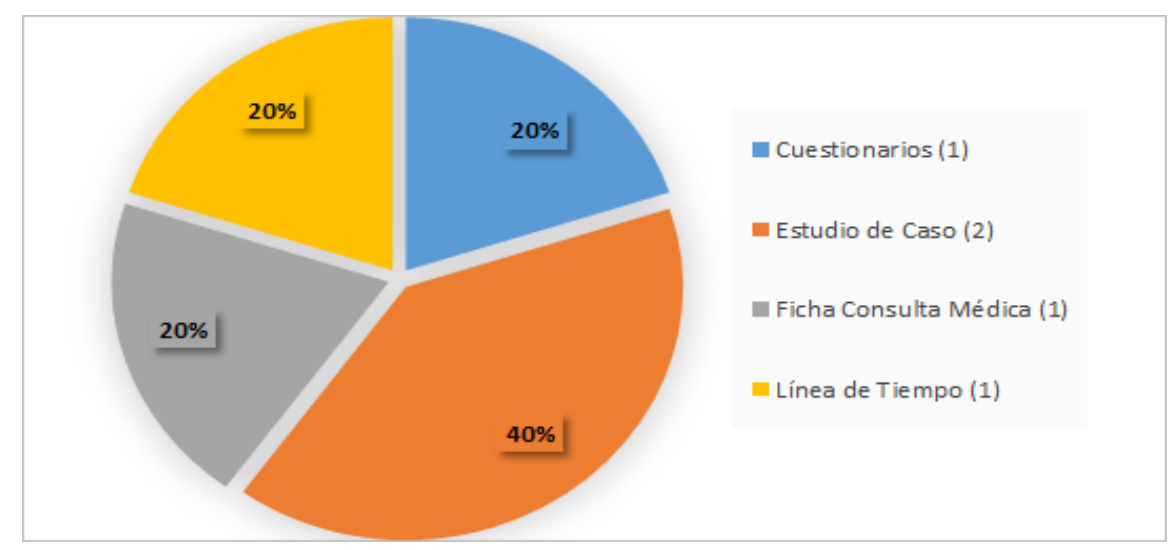

Gráfico 9 - Tendencia de Instrumentos de Investigación usados. Fuente Autoras

Con relación a los instrumentos se identifica como predominante el uso de estudios de caso con un $40 \%$, seguido en igual proporción del $20 \%$ los cuestionarios, líneas de tiempo y fichas médicas. Siendo de gran relevancia el uso de estudios de caso, en el entendido que se facilita la comprensión del fenómeno desde un ámbito clínico a través de procesos conversacionales y construcciones de historias de vida y relatos múltiples.

De igual forma, y a su vez, es relevante el uso de estrategias utilizadas en el área psicosocial enfocadas a las actividades terapéuticas tanto individual como grupal encaminadas a fortalecer la socio afectividad (referidas a las manifestaciones literarias, musicales, corporales, dramáticas y plásticas); con intervención directa en las instituciones o en espacios naturales, y de forma indirecta con los sistemas familiares en modalidad terapéutica educativa y domiciliario; además de tareas de juego que involucran el tiempo libre, y la exploración y el desarrollo ocupacional de intereses (en tareas de arte y orientación espiritual), y además para el manejo del estrés (Peñas-Felizzola, Gómez-Galindo, \& Parra-Esquivel, 2015). 
Por lo que, es pertinente reflexionar sobre las diversas formas de orden cultural y social para reconocer ese escenario o práctica del desplazamiento colombiano, en tanto no se trata de una ausencia de algo, sino que está dada por la complejidad del fenómeno a través de las reconfiguraciones de la violencia en sus distintas formas, siendo que los hechos se integran mostrándose en las prácticas corporales de las sociedades (Chaves, 2011).

En este entendido, es importante promover investigaciones que permitan aclarar la fenomenología del post trauma en relación con las diversas variables que determinan la condición del desplazado, investigaciones sobre la aplicabilidad y validez de instrumentos diagnósticos e investigaciones que permitan dimensionar las diversas problemáticas de salud mental vinculadas con la violencia en Colombia (Alejo, 2005). Además, de visibilizar la forma cómo se reconfiguran las vivencias de las familias que han sido impactadas por el CAC a través del desplazamiento, y la forma como se pueden transformar y lograr cambios en esa vivencia actual de los actores.

\section{Salud Mental}

Frente al desarrollo de este núcleo de investigación se realiza un rastreo documental de 13 años, entre el 2002 y 2015, encontrándose la siguiente tendencia cronológica:

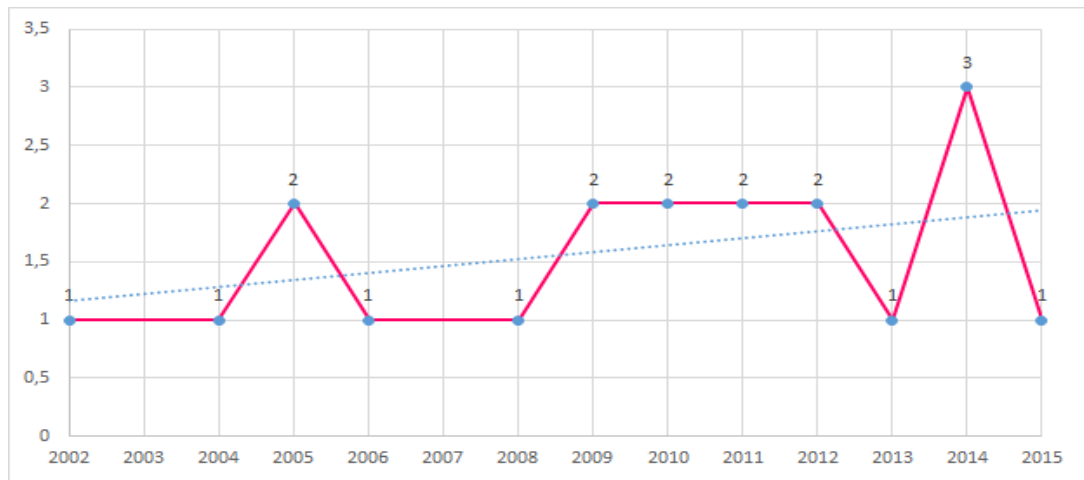




\section{Gráfico 10 - Tendencia cronológica. Fuente Autoras}

En el anterior gráfico se evidencia un pico en los artículos realizados en el 2014, año en el cual es reelegido el presidente Juan Manuel Santos, y en el que ha transcurrido un año del proceso de paz en la Habana. Mientras que en los demás años se recopilaron 1 o 2 artículos. Siendo evidente en varias de las investigaciones una urgente sugerencia de prestar mayor atención a la salud mental de las familias desplazadas, en tanto el sistema de salud colombiano no contempla esta área como prioridad de atención, pues esta población se encuentra en una condición que trasciende lo social y lo físico (Nieto y Ravelo, 2012).

En este sentido, Rodríguez, de la Torre y Miranda (2002) plantean la importancia de la atención primaria de la salud mental en la situación de urgencia, es decir atender en el momento en que se presenta la situación del desplazamiento o atender lo más pronto posible. Los mismos autores reconocieron que dentro de los inconvenientes de brindar esta atención de urgencias los profesionales no están preparados para trabajar con el impacto de este fenómeno, la lejanía de los entes hospitalarios respecto al lugar donde las personas se trasladan y la tradición de generar diagnósticos tradicionales eternos y estáticos sin tener en cuenta la situación coyuntural y posibles cambios que las personas sufren a través del tiempo.

Es así que la revisión documental ha evidenciado cierta preocupación por parte de la comunidad científica por comprender cómo el CAC ha repercutido en la salud mental de los que han estado inmersos en él, y de esta manera poder buscar estrategias que permitan replantear los procesos de atención de salud (Rodríguez, de la Torre \& Miranda, 2002; Alejo, 2005; Puertas, Ríos, Del Valle, 2006); para este análisis se han revisado diecinueve (19) artículos de publicaciones seriadas; distribuidos así: cuatro (4) textos reflexivos, trece (13) informes de resultados de investigaciones, y dos (2) tesis o trabajos de grado, los cuales se distribuyen de la 
siguiente manera:

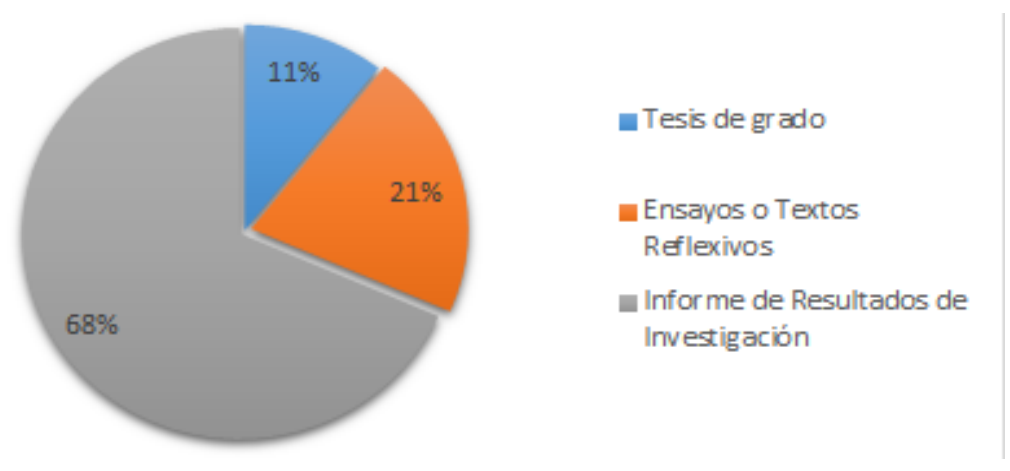

Gráfico 11 - Tendencia por tipo de documento. Fuente Autoras

Destacándose un alto porcentaje (68\%) en resultados de investigación, en tanto el conflicto armado en Colombia se ha convertido en problema de salud mental, al llevar más de 5 décadas vigente, dejando un gran impacto desde diversas formas de violencia sociopolítica tales como; desaparición forzada, masacres, torturas, violencia sexual y desplazamiento forzado (Campo Arias Oviedo \& Herazo, 2014).

Siendo así necesario reconocer los lugares de publicación en las cuales estas investigaciones se han llevado a cabo, encontrándose la siguiente tendencia:
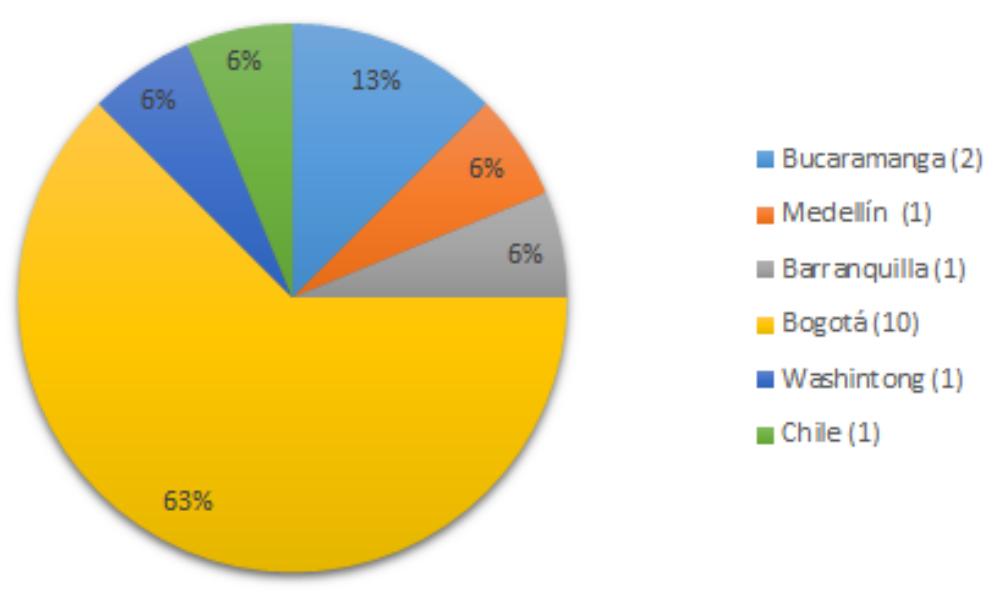

Gráfico 12 - Tendencia por ciudad. Fuente Autoras 
Cabe resaltar, que, si bien estas representan las ciudades de publicación, no son los mismos lugares de ejecución de las mismas. Por lo que, se puede señalar que la mayor parte de los textos son publicaciones nacionales, dieciséis (16) para ser exactos, específicamente diez (10) son publicados en Bogotá: siete (7) son investigación sobre dicha ciudad, una (1) se realiza en Barranquilla, otra (1) hace referencia al contexto latinoamericano y del caribe y una (1) última a nivel nacional; dos (2) se publican en Bucaramanga, una (1) en Medellín, la cual realizó su investigación en el Quindío; otra (1) publicada en Barranquilla, la cual llevó a cabo su investigación en Bogotá, y por último, dos (2) mencionan a Colombia como lugar de publicación, en donde una (1) investigación se desarrolló en el Caquetá y la última (1) en el suroriente de Colombia (Caquetá, Nariño, Putumayo y Cauca).

Además, se identifican tres (3) publicaciones a nivel internacional; una (1) en Washington, la cual realizó su investigación en Sincelejo - Sucre, una (1) de Chile, que realizó su investigación en zonas rurales del Norte de Colombia, y una (1) en España, que basó en su investigación a nivel Colombia. Esto nos muestra un alto índice de investigaciones en aquellas zonas en donde la violencia y la fuerte presencia de la guerrilla han impactado a un gran número de personas, dejándolas en condición de desplazamiento por la violencia; constituyendo por su parte a Bogotá como un gran centro al que las personas pueden migrar con la ilusión de encontrar nuevas oportunidades, en tanto es la capital, posicionándose en un primer lugar respecto al mayor número de investigaciones (63\%).

Así mismo, Bucaramanga con 13\% se convierte en la segunda ciudad con mayor número de publicaciones, en tanto recoge a un gran número de desplazados debido a la presencia de la guerrilla en la zona nororiental del país. Siendo pertinente destacar que si bien existen otros sectores del país que son fuertemente impactados por la violencia, estos no cuentan con un 
potencial desarrollo a nivel formativo que les permita generar un mayor número de investigaciones reconocidas a nivel nacional.

Se evidencia que esta temática representa un tema de impacto internacional en tanto todos los procesos de migración a nivel local generan graves dificultades para la sociedad colombiana, al encontrarse inmersa en una problemática no solo a nivel social y jurídica tal como lo afirma Lozano y Gómez (2004), sino también, a nivel de salud mental en donde existe relación entre la violencia y cómo las personas la afrontan. Por lo que se reconoce una fuerte preocupación por parte de la comunidad científica respecto a cómo abordar las dificultades por las que estas personas se encuentran inmersas; en tanto existe la necesidad de generar estrategias que les posibiliten transformaciones favorables en su condición de vulnerabilidad, la cual queda doblemente victimizada por el hecho acaecido, por los prejuicios y estigmas que recaen cuando llegan a las ciudades (Médicos sin fronteras, 2010; Nieto y Ravelo, 2012).

Por lo que es pertinente reconocer los procesos metodológicos que en su conjunto las investigaciones rastreadas han desarrollado para profundizar sobre el núcleo de investigación de salud mental y el CAC, de esta manera: 


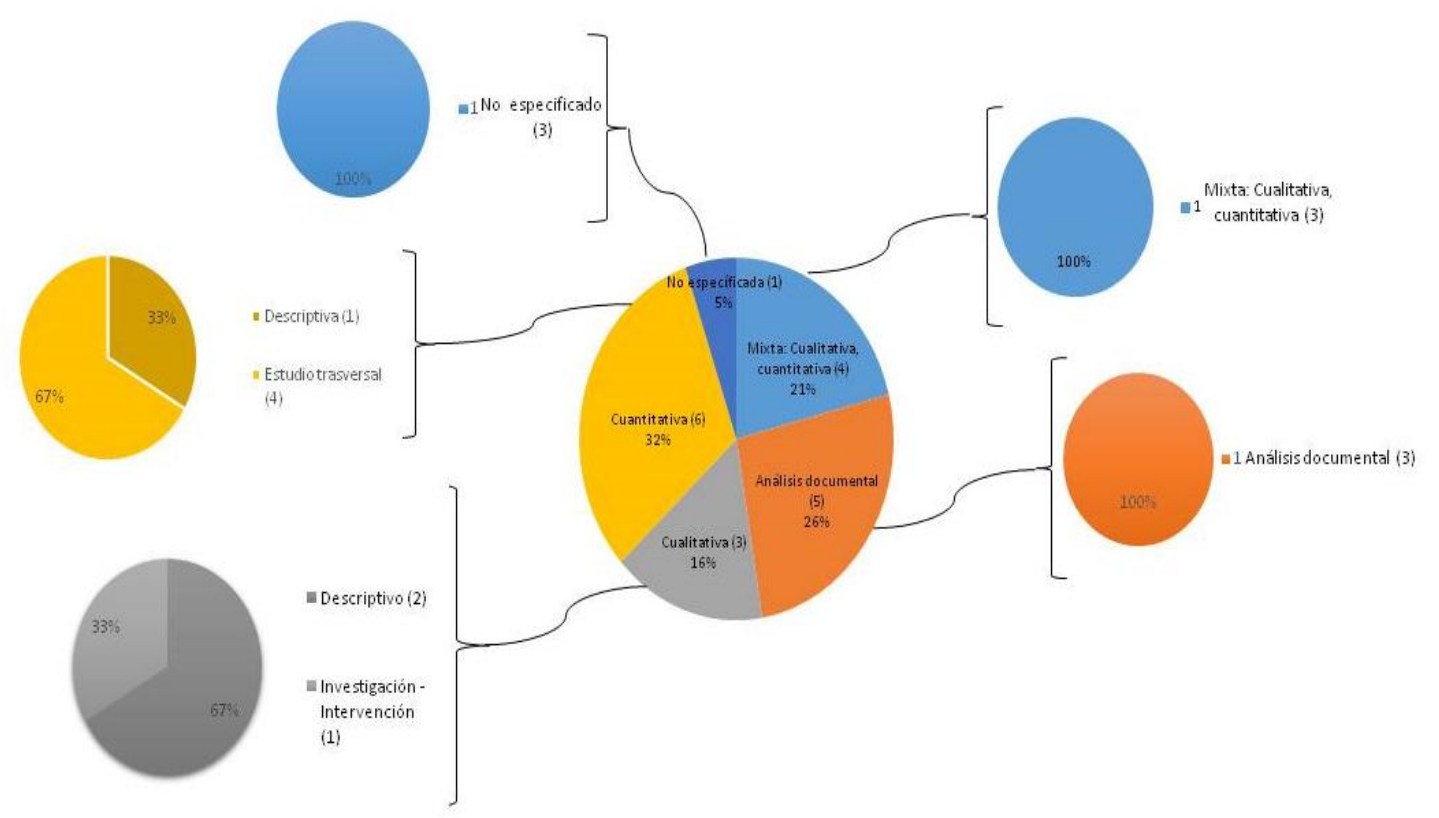

Gráfico 13 - Tendencia por metodología de investigación. Fuente Autoras

Se puede evidenciar que la mayoría de las investigaciones, es decir el $32 \%$, son de corte cuantitativo, en tanto se pretende buscar los posibles diagnósticos de salud mental, reconociendo los factores que en estos se encuentran inmersos, en un $33 \%$ son descriptivas y en un $67 \%$ estudios transversales. Sin embargo, es de denotar que se presenta fortaleza en el análisis documental pues existe una fuerte preocupación por la comunidad científica por reconocer las investigaciones que permitan mostrar cómo el fenómeno del CAC ha generado impacto en la salud mental de los colombianos, para comprender cómo ha transcurrido la evolución de su comprensión y sus falencias.

Por otra parte, se evidencia un $23 \%$ de investigaciones mixtas: es decir de corte cualitativo y cuantitativo, al ser también pertinente profundizar acerca de los relatos y las comprensiones de las personas que han sido afectadas por el CAC, y a su vez evidenciar los porcentajes de los síntomas y posibles trastornos que los aquejan. Existe un $16 \%$ de investigaciones que se 
enfocan en la metodología cualitativa, que bien pueden ser descriptivas (67\%), de investigación - participación (33\%), y en un 5\% se evidencia una investigación no especificada, al constituirse más como un texto reflexivo.

En coherencia con los procesos metodológicos mencionados y el buscar evidenciar los factores de salud mental, se reconoce el uso de las siguientes técnicas de investigación en los artículos rastreados:

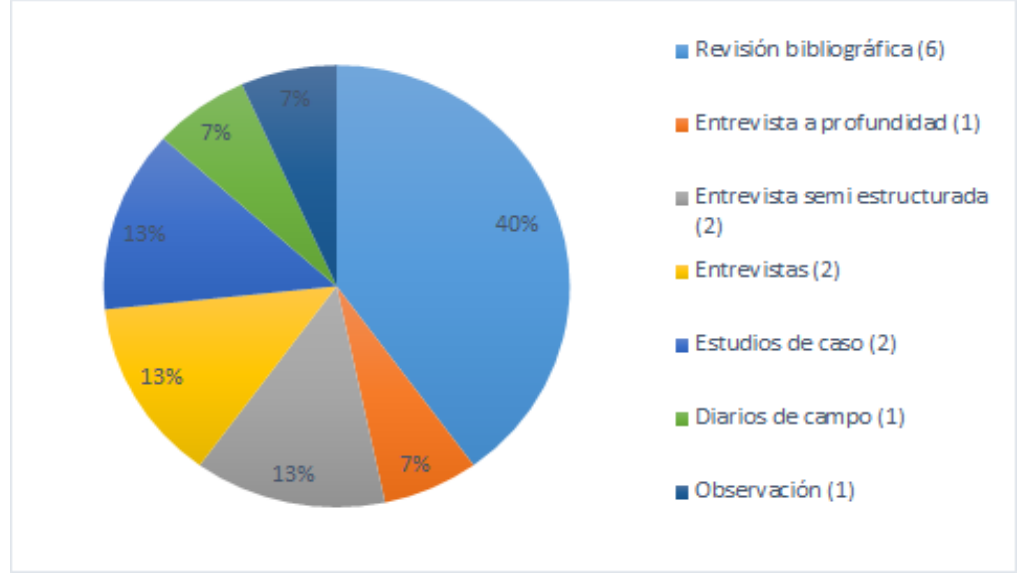

Gráfico 14 - Técnicas de investigación. Fuente Autoras.

La técnica más utilizada es la revisión bibliográfica (40\%) en cuanto se reconoce que algunos estudios pretendían correlacionar datos de investigaciones referentes a salud mental en personas en condición de desplazamiento forzado debido al CAC, o reflexiones frente a este tema. Sin embargo, los demás artículos en la necesidad de generar comprensiones y nuevos hallazgos del fenómeno emplearon en un $13 \%$ las técnicas de entrevistas semiestructuradas, estudio de caso, y con un $7 \%$ respectivamente, aplicaron las técnicas de entrevista a profundidad, diarios de campo y observación.

Por lo que para recolectar la información pertinente se identifica que estos artículos encontrados utilizaron los siguientes instrumentos de investigación: 


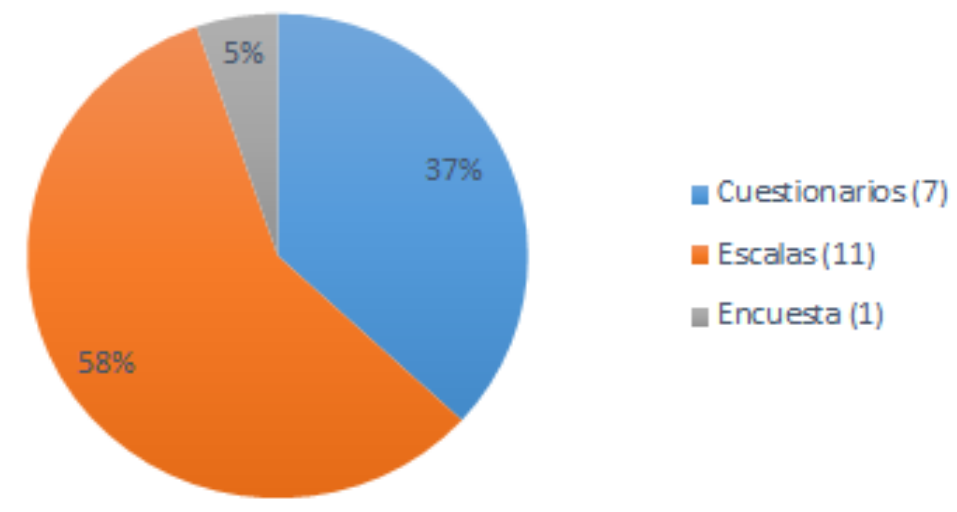

Gráfico 15 - Instrumentos de investigación. Fuente Autoras

En un $58 \%$ se aplican cuestionarios que hacen referencia a datos sociodemográficos, datos estresantes, de salud tales como SF-36 y ASSIS, de 90 y que hace referencia a síntomas SCL-90R. Las escalas de medición representan el segundo instrumento más aplicado con un 37\%, referente a estrategias y estilos de afrontamiento, tanto para adultos como para adolescentes, de declaraciones de síntomas, de trastornos de la personalidad, del bienestar subjetivo, de satisfacción personal, de cognición postraumática, de fatalismo y de afecto. Mientras la encuesta es el instrumento menos utilizada (5\%); encuesta domiciliaria.

Para generar el proceso de análisis de la información recolectada por dichos instrumentos se identifica que fueron utilizadas las siguientes estrategias de análisis: 


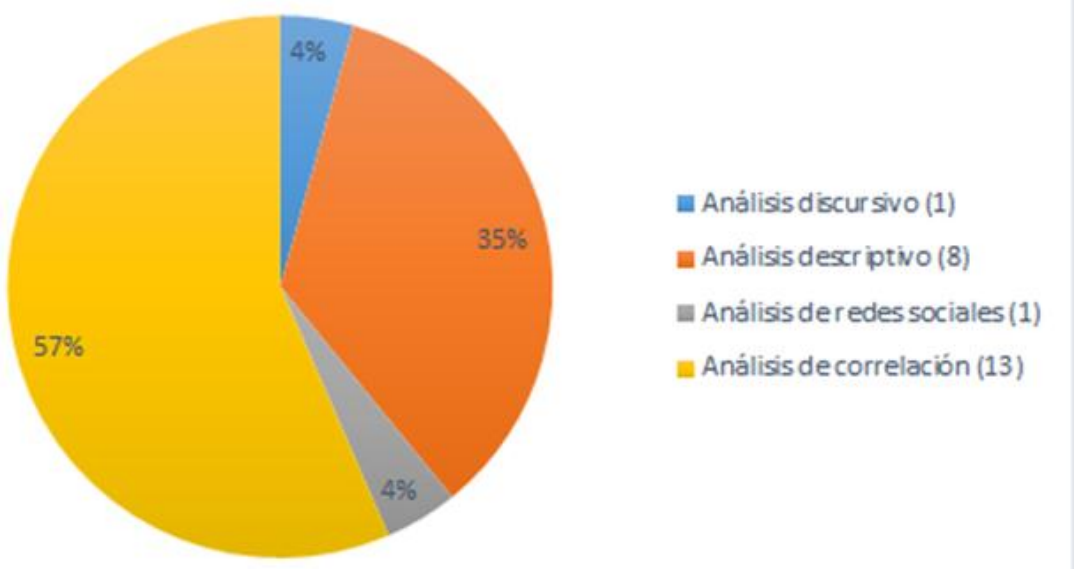

Gráfico 16- Estrategias de investigación. Fuente Autoras

En un 57\% se aplicó un análisis correlacional, para relacionar los resultados obtenidos respecto a los diferentes factores que influyen en la salud mental. En un $35 \%$ un análisis descriptivo, en el que se pretendía no solo brindar datos correlacionales sino también describirlos. Constituyendo el análisis del discurso (4\%) y de redes sociales (4\%), los tipos de análisis menos utilizados.

Siendo también pertinente analizar la muestra bajo la cual se aplicaron las técnicas de recolección de datos e instrumentos, encontrándose la siguiente tendencia poblacional:

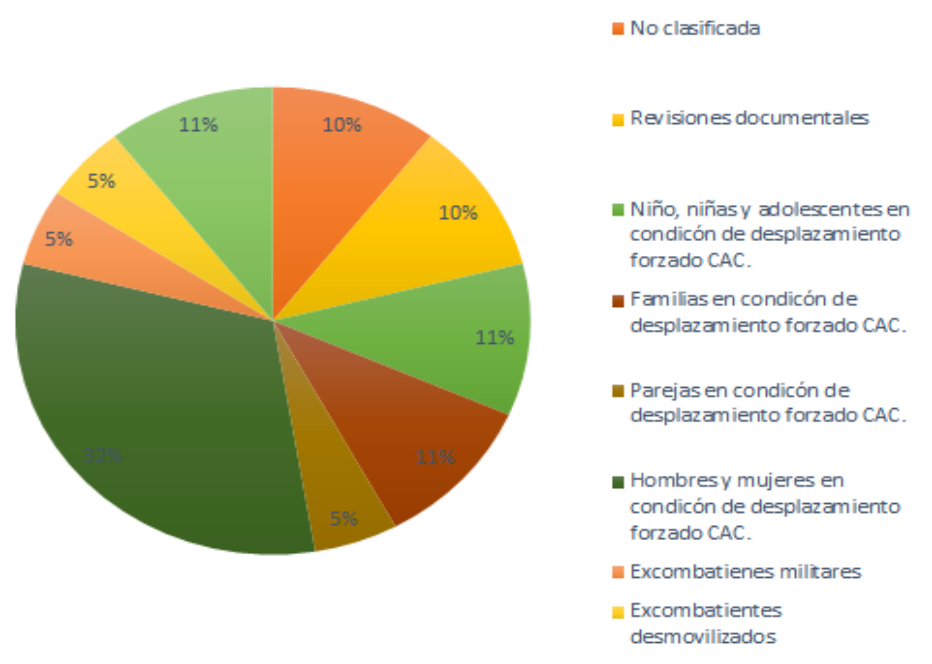




\section{Gráfico 17 - Tendencia de Población. Fuente Autoras}

Se evidencia, que en un $32 \%$ se ha estudiado en su mayoría tanto a hombres (entre los 1-19 años, y 20 -83 años), como a mujeres (1 - 6 años, y 19 - 83 años) en condición de desplazamiento forzado del CAC, teniendo mayor representación las mujeres en un $50 \%$ de las investigaciones, de otra parte se evidencian estudios exclusivos para las mujeres entre los $18 \mathrm{y}$ 79 años y los 2 y 28 años, situación que no se presenta con los hombres en tanto la mayor parte de la población en condición de desplazamiento son mujeres y menores de edad, pues en su mayoría son los hombres los que reciben una mayor carga (Estudio nacional de salud mental, 2003; Sinisterra \& otros, 2010), al ser por ejemplo los más asesinados o desaparecidos. Sin embargo, a pesar de que los niños, niñas y adolescentes constituyen el grupo etario más golpeado por la violencia, solo se recolectó un $11 \%$ de investigaciones en los que fueran tomados en cuenta de manera individual.

Un porcentaje del $5 \%$ es el referente a parejas desplazadas por el CAC, ex combatientes militares y ex combatientes desmovilizados mayores de 18 años. Es así, que dentro de los actores del conflicto armado en Colombia se evidencia como no solo los desplazados presentan repercusiones a nivel de salud mental, sino también como los militares y desmovilizados comienzan a ser parte del gran abanico de posibilidades de víctimas que el conflicto bélico deja en su camino. Según Amar-Amar, Abello-Llanos \& Otros (2011), la mayoría de estos actores del CAC terminan migrando a nuevos espacios urbanos, en los que se ponen a prueba de manera constante al llegar a un nuevo territorio. Generando dicha situación afectaciones en los niveles de su calidad de vida, en la obtención de recursos que les permitan afrontar su situación de manera adecuada y por ende una inestabilidad emocional.

Se hace necesario generar un trabajo en lo que respecta a sus redes, ya que se buscan algunas 
mejoras en los mecanismos de supervivencia y de conservación de la salud, por medio de la generación de redes más complejas, con la probabilidad de obtener mayores recursos de supervivencia; transformando así la noción asistencialista en una dinámica relacionada a la gestión continua socio-comunitaria (Amar-Amar, Abello-Llanos \& Otros, 2011).

Siendo evidente para Jiménez (2009) que los ex combatientes son otro actor importante del conflicto bélico, en tanto son parte primordial dentro la salud mental, al considerarse como posibles agentes de la reconstrucción social, aunque no son reconocidos desde la perspectiva de víctimas sino de victimarios. Se hace hincapié en la importancia de la creación de un sistema de evaluación y control en los procedimientos de asistencia humanitaria y apoyo comunitario, y de mecanismos de vigilancia sobre posibles factores que afectan reincidencia de actos violentos, tal como ya ha ocurrido de varias ocasiones en Colombia.

De otro lado, existe una preocupación por las familias (11\%), en tanto se han logrado reconocer el gran impacto que este núcleo primario comienza a vivenciar afectando la salud mental de sus miembros. Por lo que es, de resaltar la necesidad de que, a nivel social, psicológico y cultural, se abordan las dificultades y los conflictos que viven las familias, para no ver a los actores del conflicto como el problema que hay que eliminar, sino como la situación vital que hay que aprovechar como motor del cambio. Ya que desde una postura sistémica según López (2014), los problemas psicológicos se refieren a la co-construcción de las dificultades en el lenguaje en las relaciones con los demás, en donde el problema psicológico y compartido en un contexto social no debe ser visto como una situación individual. Por lo que, en un pensamiento más complejo el contexto interaccional juega un papel importante en la comprensión de lo psicopatológico.

Es entonces que la familia juega un papel importante en la vida de todo aquel que ha sido 
afectado por el CAC, en tanto su dinámica también se ve impactada por los eventos estresantes relacionados a amenazas que producen: pánico, temor, incertidumbre y miedo, ya que termina influyendo en el bienestar del individuo y por ende en las relaciones intrafamiliares, ya que así mismo de acuerdo al evento vivido, y si los miembros deben separarse o alguno fallece, se termina en un nuevo contexto reestructurando también los roles familiares, y las relaciones y manifestaciones afectivas (Lozano \& Gómez, 2004). Lo cual es reafirmado por Andrade, Parra \& Torres (2011) años más tarde, adicionando que las familias que llegan juntas a nuevo lugar de reasentamiento muestran una dinámica relacional difusa, ya que se generan cambios en los roles familiares y mientras algunos miembros de la familia acallan su origen, otros rápidamente logran expresar lo sucedido y construyen redes de apoyo.

Se identifica en un $10 \%$ que la muestra poblacional no es clara, porque uno de los textos es reflexivo y el otro tiene en cuenta la población desplazada en general, sin generar ningún tipo de especificaciones a nivel etario, etnia y ciclo vital. Se presentaron dos (2) artículos que hicieron referencia a la recopilación de documentos legislativos referentes al desplazamiento forzado debido al CAC, y por otra parte revisiones narrativas de personas en condición de desplazamiento del CAC.

Continuando el rastreo, sólo una investigación cuenta con la tipificación de su muestra en términos de etnia, en donde son reconocidos mestizos, afrodescendientes e indígenas, denotando el poco reconocimiento de la multi, pluri e interculturalidad en los estudios desarrollados con las personas en condición de desplazamiento y ex combatientes, factor que de ser tomado en cuenta permitiría ampliar las posibilidades de acción e intervención con los mismos.

Es así como es de destacar que los autores de las investigaciones rastreadas esperan 
describir las afectaciones que ha acaecido el conflicto armado en aquellas personas que se encuentran en condiciones de desplazamiento forzado por el conflicto armado en Latinoamérica, pero especialmente en Colombia, y en un poco porcentaje a los excombatientes. Sin embargo, se evidencia un mayor número de objetivos en dichas investigaciones, que la especificación de hipótesis.

Hacia el 2002 se busca la comprensión del impacto en la salud mental del conflicto armado en Latinoamérica, mientras que en los años posteriores del 2005 al 2008 se reconoce una fuerte preocupación especial por los diagnósticos y la prevalencia de trastornos mentales en las personas en condición de desplazamiento.

En medio de una época en la que se presta gran importancia a las consecuencias del CAC y se comienza a prever la posibilidad de dar fin al conflicto, es que se evidencia como hacía el periodo 2009-2011 se da la apertura al término calidad de vida en referencia no solo al impacto de las personas en condición de desplazamiento forzado, sino también de los ex combatientes de las fuerzas militares colombianas, y de los que han pertenecido a diferentes grupos al margen de la ley; y es en este último año que se genera una investigación que permita reconocer la relación y la prevalencia de tendencias psicopatológicas del conflicto en el periodo 2005 a 2011.

Es así que si bien hacia el 2004, se genera una investigación que buscaba identificar los aspectos psicológicos, sociales y jurídicos luego que existe un impacto por el CAC, ocho años después ya en el 2012 bajo un marco del reconocimiento de las normas se busca analizar la evolución de la misma tanto a nivel nacional como internacional, para así comenzar a hablar desde el 2013 de la necesidad de trabajar sobre las políticas públicas referentes a la salud mental y en el 2015 de los desafíos del posconflicto en el sector salud, sin antes no haber dado respuesta en el año anterior 2014 a la necesidad de realizar una revisión de síntomas y de casos de 
trastornos mentales entre 1999 y 2013, así como reconocer los distintos niveles de discriminación por los cuales las personas impactadas por el CAC han tenido que atravesar.

Con base en lo anterior, la tendencia evidenciada de las hipótesis y objetivos de los artículos revisados se pueden reconocer cuatro (4) grandes categorías emergentes distribuidas de la siguiente forma:

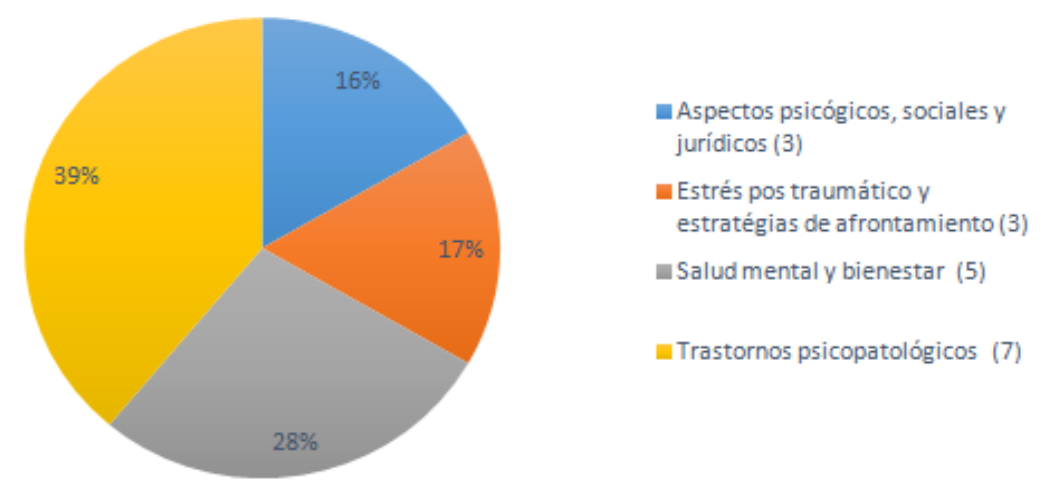

Gráfico 18 - Tendencia por Categoría emergente. Fuente Autora

La primera categoría emergente hace referencia a los aspectos psicológicos, sociales y jurídicos, en las investigaciones de los años 2004, 2012 y 2013, en donde se retoman temas referentes a las implicaciones del contexto y las condiciones jurídicas en la salud mental de las personas en condición de desplazamiento (Lozano \& Gómez, 2004), y se reconocen las políticas referentes a la salud mental en Colombia (Ardón- Centeno \& Cubillos-Novella, 2012; Médicos sin fronteras, 2013). Lo cual nos invitaría a reflexionar que si bien se reconoce hacia el 2004 los aspectos sociales y jurídicos que comprende el desplazamiento forzado, se retoma este tema hacía los años 2012 y 2013 en esa búsqueda de una comprensión de la situación desde un enfoque más integral.

Ya que, al ser impactados por el CAC, se presentan repercusiones profundas en la cultura y la sociedad colombiana, al ser un problema social y político que genera graves consecuencias en 
el bienestar emocional, en la forma en que se relaciona con los otros y el mundo. Siendo necesario analizar el conflicto no como ausencia de violencia, sino la forma como las personas reconfiguran e incorporan la violencia en su cuerpo y vida, y el cómo se construyen cambios éticos, morales y a su vez identitarios, naturalizando la violencia (Chaves, 2011).

Por lo que se recalca la pertinencia de estudios referentes a temas de salud mental en personas impactadas por el conflicto en tanto se ha generado un trabajo más desde lo psicosocial y jurídico, sin desconocer la importancia de un trabajo holístico (Campo-Arias, Oviedo \& Herazo, 2014). Que permita buscar un mayor diálogo entre las diferentes disciplinas y actores del conflicto, así como lograr procesos exitosos de reparación en las que se trascienda el lenguaje técnico y exista una mayor interconexión con las diferentes voces implicadas (Estrada, Ripoll \& Rodríguez, 2010).

Desde hace varios años son evidentes las dificultades de los procesos de justicia, verdad y reparación, en donde las víctimas se han visto doblemente victimizadas. Convirtiéndose la reivindicación de sus voces en el pilar mediante el cual se generarían reales cambios a nivel emocional, tal como sucede en los procesos psicosociales que hacen énfasis en una memoria colectiva. Así mismo, permitiría vislumbrar un claro campo jurídico que obstaculiza la reivindicación de los derechos de las personas impactadas y su estabilidad emocional y espacios en los que se permita una construcción lingüística del dolor, en donde la persona pueda potenciar sus capacidades de afrontamiento y de resiliencia (Villa, 2013; Villa, 2014). Evidenciándose que los trastornos mentales se convierten en una cuestión no solo del individuo, sino que se entreteje con los otros (Baró, 1984, citado por (Andrade, Parra \& Torres, 2011)). Teniendo en cuenta que la problemática del desplazamiento forzado no solo hace referencia a las dificultades que el país presenta desde un orden jurídico y/o político, sino que también incluye temáticas relacionadas a 
la interacción violencia - salud mental (Lozano y Gómez, 2004; Rodríguez, 2015).

La segunda categoría emergente, se denomina Estrés postraumático y estrategias de afrontamiento, principalmente en las investigaciones del 2005, 2008, 2010, donde se hace explícito el trastorno de estrés los traumático (Rodríguez \& Otros, 2005; Castro \& Mina, 2008; Mosquera, \& Otros, 2010) y se hace hincapié en las estrategias de afrontamiento de las personas en esta condición de desplazamiento (Rodríguez \& Otros, 2005; Castro \& Mina, D, 2008). Con lo que se pensaría que entre el 2005 y 2010 existe una especial inquietud por el generar perfiles cognitivos desde una postura positivista, que permitan una adecuada interpretación de las afectaciones en la salud mental de las personas en condición de desplazamiento, en donde el trastorno de estrés postraumático constituye un cuadro diagnóstico posible.

Desde hace ya un tiempo se venía trabajando el hecho que la persona al no tener claridad acerca de lo que se encuentra vivenciando y al encontrarse sin una evidente explicación que le permita sobrepasar lo sucedido, comienza a producirse una ideación ideo-afectiva, el cual genera en la persona parálisis, al existir un deterioro de la autoestima y de la desconfianza (Castaño, 1994, García, 1990, citado por Lozano \& Gómez, 2004).

Se comienza entonces a reconocer como las amenazas de reclutamiento y en contra de la vida, así como los homicidios y las torturas directas o indirectas se constituyen en eventos de mayor riesgo, comienzan a generar afectaciones en la vida de estas personas en condición de desplazamiento, generando la creación de una variabilidad de estrategias de afrontamiento que se encuentran atravesadas por el choque cultural, y la sintomatología del estrés post traumático (Rodríguez \& Otros, 2005; Alejo, 2005). Se recomienda de esta manera en una investigación posterior el trabajar sobre esos factores psicológicos que se asocian a la condición de desplazamiento para resignificar la condición de víctima, al considerarse que estos pueden 
determinar la presencia de trastornos mentales (Castro \& Mina, 2008).

La tercera se denomina Trastornos psicopatológicos, en las investigaciones de 2002, 2006, 2010, 2011, 2014, en las que se retoman las diversas afectaciones de esta condición en la salud mental (Rodríguez \& otros, 2002; Puertas, Ríos \& del Valle, 2006; Médicos sin fronteras, 2010; (Andrade, Parra \& Torres, 2011) \& Campo -Arias, Oviedo \& Herazo, 2014). Invitando a reconocer como la preocupación por los procesos de salud mental de las personas en condición de desplazamiento se encuentran mediadas por el constante interés de evidenciar y comprender el papel que juegan los trastornos de salud mental en dicha población.

Es así que en lo revisado se puede evidenciar una alta frecuencia de síntomas de ansiedad, depresión, psicosomáticos, intentos de suicidio, esquemas mal adaptativos y de estrés post traumático, resultados que concuerdan con los estudios que señalan alta prevalencia en síntomas emocionales en personas que afrontan estresores psicosociales (Campo-Arias, Oviedo, \& Herazo, 2014; Médicos Sin Fronteras, 2013 (Andrade, Parra \& Torres, 2011); Castro \& Mina, 2008; Puertas, Ríos \& Valle (2006); Alejo, 2005; Rodríguez \& Otros, 2005).

La última de las categorías es la de Salud mental y bienestar, en las investigaciones del 2009, 2011, 2012, 2014, 2015, en las que se identifican las condiciones de calidad de vida de las personas luego de participar en la guerra, no solo en aquellas en condiciones de desplazamiento forzado (Llanos \& Otros, 2009), sino también de militares (Jiménez, 2009) y de los grupos al margen de la ley (Amar-Amar, 2011). Siendo de destacar que hacía el año 2012 se comienzan a reconocer investigaciones que retoman la perspectiva de narrativas, de patrones de interacción y dificultades de adaptación, tomándose concepciones más sistémicas y no tan tradicionalistas desde un enfoque más positivista, para reconocer a la población en condición de desplazamiento (Nieto y Ravelo, 2012), y los combatientes desmovilizados de los grupos armados al margen de 
la ley (López, 2014).

De igual manera, se resaltan las dificultades en términos del estigma social que las personas en condición de desplazamiento forzado vivencian (Campo-Arias \& Herazo, 2014). Es finalmente pertinente mostrar el que se haga hincapié en el posconflicto, luego de vivirse un proceso de desmovilización a nivel nacional por los ex combatientes entre los años 2003 y 2006, y el encontrarse a portas de un segundo proceso; concepto que sin embargo es cuestionado por varios autores al considerar que Colombia aún continúa en un inminente conflicto (Jiménez, 2009 \& Rodríguez, 2015).

Destacándose que a pesar de las dificultades de las personas bajo esta condición logran continuar con sus vidas, superar la adversidad y evaluar de manera positiva sus logros, a pesar de que dicha condición de desplazamiento y de dificultades económicas generan mayor preocupación por el sobrevivir al perder ese interés por desarrollar sus potencialidades (Llanos \& Otros, 2009).

Se reconocen las grandes dificultades a la hora de generar trabajos terapéuticos con las personas afectadas por el conflicto bélico, y constantemente en las investigaciones que han sido rastreadas en relación a salud mental y conflicto armado, han demostrado una fuerte necesidad de trabajar sobre una nueva concepción de las acciones psicosociales y de salud mental, que se encuentren relacionadas con las diferentes dimensiones del ser humano, para poder generar desde allí la apertura a nuevos conocimientos (Rodríguez, 2015; Sinisterra \& otros, 2012; Jiménez, 2009; Castro \& Mina, 2008; Puertas \& otros, 2006).

En las investigaciones consultadas, se pudo identificar las siguientes disciplinas que trabajaron la relación entre la salud mental y el CAC: 


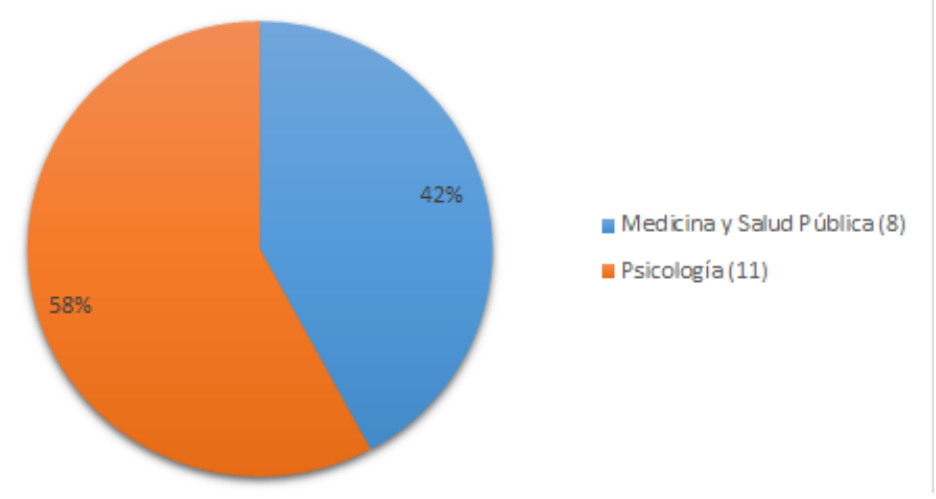

Gráfico 19 - Tendencia por Disciplina. Fuente Autoras

La psicología en un $58 \%$ es la disciplina que más productos de investigación y análisis ha generado en los últimos 13 años de acuerdo con lo consultado, probablemente en esa búsqueda de comprensión del fenómeno para así permitirse generar aportes a nivel interventivo, al reconocer los grandes atrasos que existían en su momento a pesar de que el país lleva un largo periodo de tiempo inmerso en un conflicto interno. Siguiendo esta escala se encuentra la medicina y salud pública con un $42 \%$.

La psicología encuentra que los eventos que acompañan el desplazamiento forzado representan un mayor riesgo en las personas impactadas por este hecho, ya que estas pueden desarrollar desórdenes en su salud mental, de acuerdo a la intensidad y severidad del evento de la amenaza vivenciada; es decir un malestar clínicamente significativo que puede repercutir en todas las dimensiones de la vida de estas personas y sus esferas vitales, en donde por ejemplo; las pérdidas que implican un duelo, los desórdenes en los estado de ánimo, los proceso de adaptación cultural y las presiones de adaptación son comórbidos al TEPT ((Andrade, Parra \& Torres, 2011); Castro \& Mina, 2008; Rodríguez \& otros, 2005, Alejo,2005; Lozano \& Gómez, 2004).

Este trauma vivenciado por las personas en condición de desplazamiento se encuentra ligado 
a sus cualidades personales (Llanos \& otros, 2009; Lozano \& Gómez, 2004), en algunos casos desde una percepción negativa, ya que, al perder interés por desarrollar sus potencialidades, disminuyen su autoaceptación, al sentirse culpables por no haber actuado en su momento. Sin embargo, en otros casos aumenta su propósito de vida, incrementando la satisfacción con la vida, lo cual les permite una evaluación positiva de lo que han logrado (Llanos \& otros, 2009).

Es así como las historias permanentes de violencia desintegran el sistema de creencias de las personas impactadas por el CAC, imposibilitando el establecimiento de relaciones en las nuevas comunidades a las cuales migran (Llanos \& Otros, 2009). Así mismo, vivencian procesos de discriminación, que promueven expresiones poco ajustadas del pasado traumático, que buscan adaptarse a las nuevas exigencias del medio citadino y sus demandas (Andrade, Parra \& Torres, 2011).

De otro lado, los cambios en las dimensiones de salud mental afectan el sistema familiar en su totalidad, en tanto la migración implica una ruptura del marco externo interiorizado por cada miembro, teniendo que dejar el pasado para adaptarse a un presente. Generando esto una dinámica difusa de las familias, al existir cambios de roles (Andrade, Parra y Torres, 2011; Nieto y Ravelo, 2012).

Se comprende que por medio de las narrativas se pueden resignificar historias, en las que se pueden transformar emociones y percepciones de la realidad, que antes eran estáticas e inmóviles (Campo-Arias \& Herazo, 2014), y se propone así trabajar sobre los factores psicológicos del desplazamiento para re significar su condición de víctima, es decir comenzar a generar un abordaje de intervención integral que esté más allá del asistencialismo, en el cual se perfeccionen estrategias de evaluación y diagnóstico (Sinisterra \& Otros, 2010; Castro \& Mina, 2008).

De otro lado, con relación a los excombatientes se propone generar un sistema de evaluación 
y control que genere mecanismos de vigilancia de los posibles factores que afecten su salud mental en pro al mejoramiento de su calidad de vida, pues se evidencia la presencia de vínculos familiares deficientes, especialmente en los desmovilizados (Jiménez, 2009; Amar-Amar \& Otros, 2011)

Finalmente, en algunos de los artículos rastreados de esta área señalan por un lado la importancia de tener en cuenta a la hora de aplicar un instrumento la población, como sus niveles de escolarización, para así disminuir el margen de error en la interpretación de resultados ((Andrade, Parra \& Torres, 2011)), y de otra parte generar un análisis del desarrollo afectivo de los niños y niñas para construir estrategias dirigidas al manejo de la relación entre la violencia vivida, la reproducción de la misma y su manejo (Alejo, 2005).

Desde la medicina y salud mental se identifica que la violencia constituye un gran problema para la sociedad Colombiana en términos de mortalidad, morbilidad y deterioro de las condiciones de vida de las personas, generando altos costos para la sociedad en general y al sector salud (Médicos sin fronteras, 2013), lo que reafirma la necesidad de atender la salud mental como emergencia, y como factor primario, en donde se genere un desarrollo social inclusivo que garantice el goce al derecho de salud; en tanto el abandono de la instituciones genera un mayor estigma y silencio por parte de la sociedad, es decir un mayor impacto en el sufrimiento psicológico de esas personas impactadas por el CAC. Siendo evidente que, de acuerdo con la estratificación, las localidades en las que se asientan y empresas sociales del estado, las personas pueden o no acceder a servicios públicos de salud de calidad (Rodríguez, de la Torre \& Miranda, 2002; Puertos, Ríos \& Del Valle, 2006; Médicos sin fronteras, 2010; ArdónCenteno \& Cubillos-Novella, 2012; Campo-Arias \& Herazo, 2014).

A pesar que se han generado varias iniciativas por mejorar el panorama de salud mental en 
Colombia y que desde la perspectiva de los profesionales de salud se ha logrado un posicionamiento progresivo referente a la atención sanitaria en salud mental y de su esfuerzo por ser éticos y brindar un servicio de calidad, según los estudios encontrados, se identifican aún deficiencias en recursos humanos y en la organización sanitaria de salud mental y la necesidad de generar nuevas herramientas que permitan un trabajo más integral con las personas en esta condición (Ardón-Centeno \& Cubillos-Novella, 2012; Puertas, Ríos \& Valle, 2006; Rodríguez, de la Torre \& Miranda, 2002). En tanto se hace necesario un impacto económico en las políticas públicas colombianas al existir un alto porcentaje de enfermedades mentales (Estudio nacional de salud mental, 2015).

Siendo evidente que las exposiciones a la violencia aumentan el riesgo de desarrollar síntomas de ansiedad, depresión, o de un posible cuadro postraumático, se propone un abordaje terapéutico en el cual se relacionan factores vitales, externos y devastadores (Médicos sin fronteras, 2010 \& 2013). Así como que se integren también aspectos referentes a la verdad, justicia y reparación, al evidenciarse la fuerte necesidad de que las acciones psicosociales y de salud mental promuevan una memoria social y cultural, en donde se garantice la no repetición y la restitución de tierras que le permitan a su vez una re-territorialización del cuerpo en pro a espacios de convivencia comunitaria que permitan la participación activa (Rodríguez, 2015).

Por lo que una atención integral a las víctimas implica también replantear los estudios realizados referentes a salud mental, en donde por un lado los psiquiatras pueden generar procesos de evaluación clínicos más rigurosos que minimicen una posibilidad de diagnóstico errado, es decir que realmente cumpla con todos los criterios expuestos, y que se utilicen por ejemplo entrevistas clínicas estructuradas en la evaluación diagnóstica, las cuales permitan también analizar el papel de la estigmatización en relación a la condición de desplazamiento 
forzado y el bienestar emocional de los mismos (López, 2014; Campo-Arias \& Herazo, 2014).

Es así que, la necesidad de replantear los procesos interventivos más integrales, constituye un factor común en los aportes evidenciados por las disciplinas de la psicología y la medicina. Por lo cual, se puede afirmar que desde la psicología se ha vislumbrado la dificultad de la familia y en general de los actores del conflicto bélico de exponer lo sucedido a profesionales de la salud, ya que consideran implica una situación muy dolorosa, obstaculizando que los sujetos reciban apoyo en la situación por la cual se encuentran atravesando. Identificando la importancia de promover la reconfiguración de la experiencia, en el que se les brinde la posibilidad a las personas de expresar lo vivenciado de una manera metafórica y como se ha reconfigurado su identidad y sus comprensiones (Nieto y Ravelo, 2012).

De igual manera desde la disciplina de la medicina se considera necesario integrar a la atención primaria en salud bajo un modelo basado en la comunidad, en donde se genere una adecuada distribución del recurso humano, y la apertura a nuevos saberes como el arte, el trabajo corporal y los recursos sanadores de las mismas personas al ser reconocidos como los únicos expertos de su propia vida y lo vivenciado (Rodríguez, 2015).

Es así, que se reconoce como el arte se convierte en un promotor de un proceso de resignificación de los procesos de cambio en el área de salud mental, de manera individual, social e histórica del sufrimiento humano, tal como se evidenció en varias de las investigaciones rastreadas, y de las cuales se hará referencia en el siguiente apartado. Ya que una intervención busca la resignificación de las experiencias vividas durante la guerra mediante el uso del arte, permitiendo a las personas expresar sus más dolorosas vivencias, para así convertirlas en motores que les permiten salir adelante (Marín, 2013). 


\section{El arte como proceso de cambio}

El análisis documental realizado para este núcleo de investigación incluye dieciocho (18) artículos, distribuidos en textos reflexivos, informes de resultados, propuesta de investigación, ensayos, artículos exploratorios y experimentales, relacionados así:

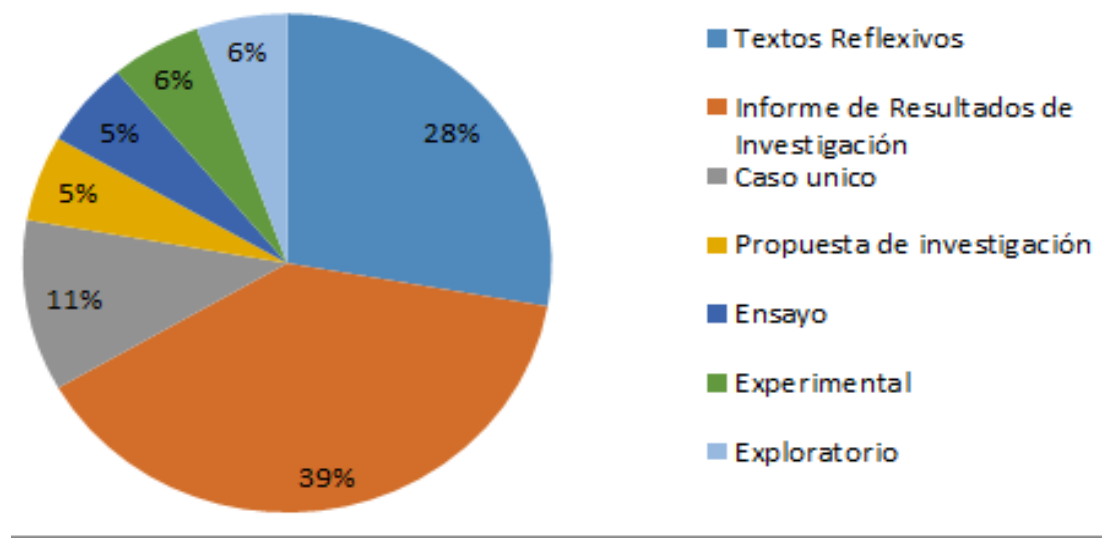

Gráfico 20 - Tendencia por tipo de documento. Fuente Autoras

Esta gráfica, nos permitió identificar una alta producción de textos reflexivos e informes de resultados de investigación, lo que da cuenta de una creación significativa de conocimiento; aunque la mayoría de las investigaciones constituyen resultados de investigación, identificamos que en mayor porcentaje corresponde a la revisión o análisis documental, siguiendo las investigaciones de tipo cualitativo. Es interesante ver que las conclusiones de esta tendencia metodológica respaldan lo anteriormente planteado, aunque las rutas de análisis metodológica, población y experimentación eran diferentes; estas investigaciones logran plantear en común que el arte (desde cualquiera de sus manifestaciones) puede ser utilizado en un proceso terapéutico con personas que hayan sufrido cualquier tipo de trauma (con o sin un diagnóstico), que hayan sido víctimas de cualquier tipo de violencia, pero que les genere un malestar, pues esta herramienta permite la reconfiguración de lo vivido a nivel de la salud mental brindando una 
sensación de bienestar.

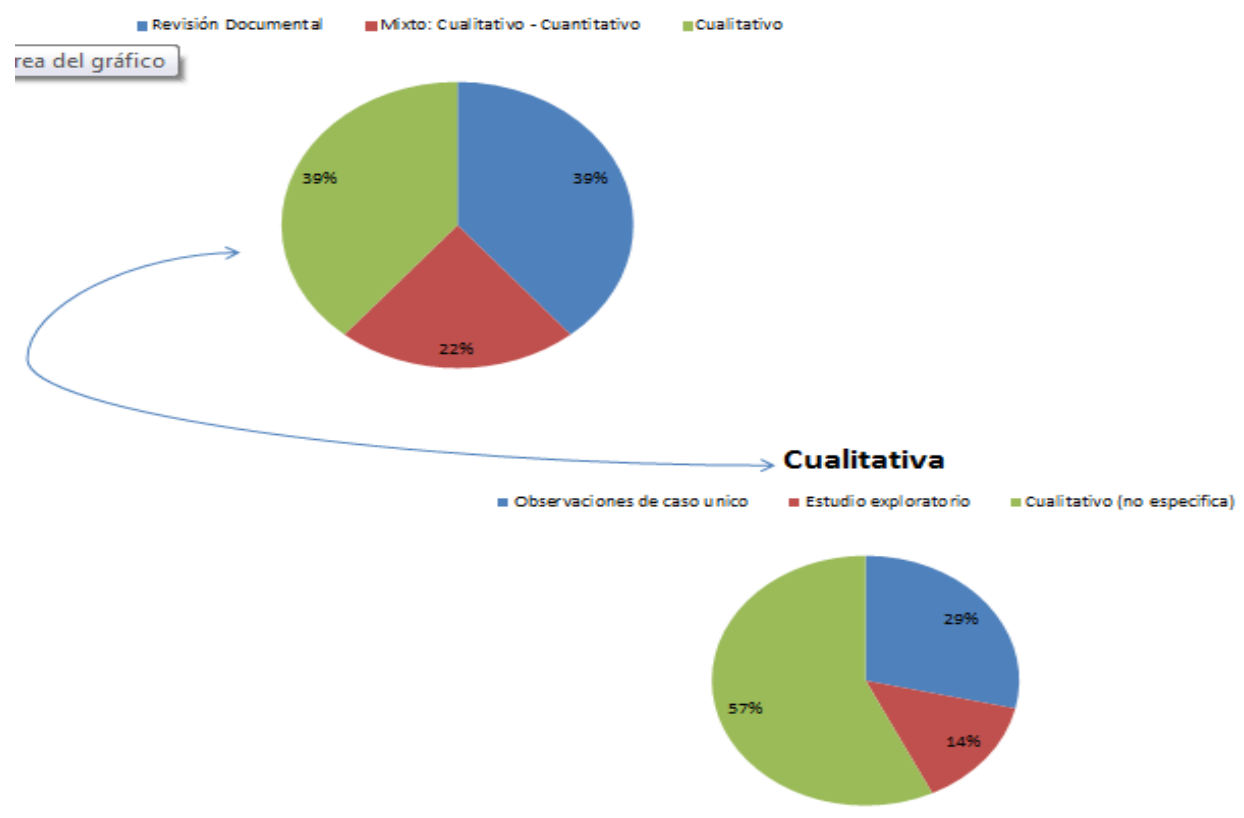

Gráfico 21 - Tendencia de metodología. Fuente Autoras

A su vez, la información recogida en esta categoría fue organizada cronológicamente de la siguiente manera, permitiendo identificar las tendencias que emergieron a nivel latinoamericano y de otros países:

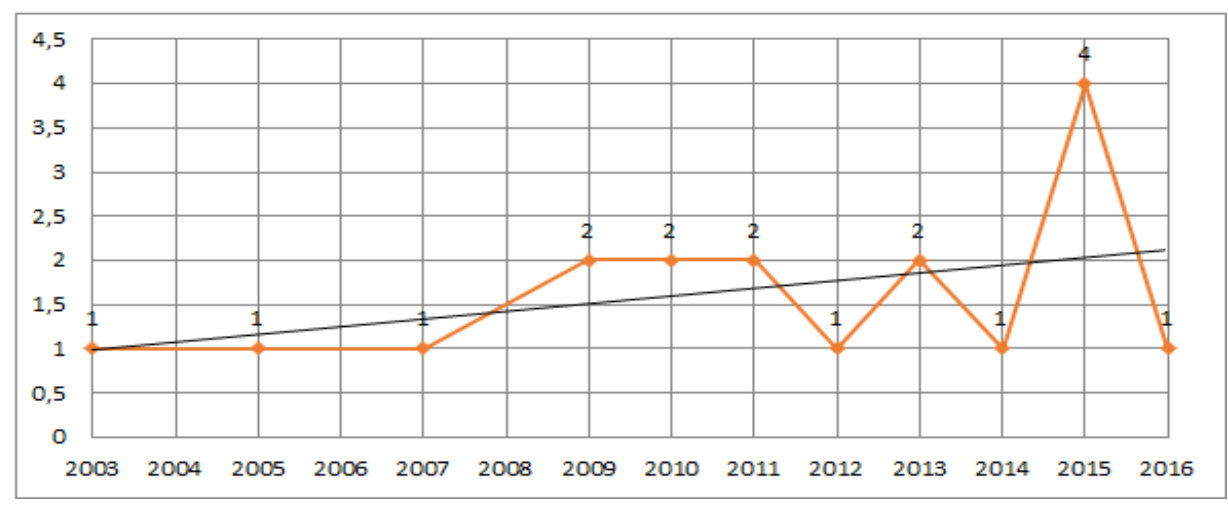

Gráfico 22 - Tendencia en el tiempo. Fuente Autoras 

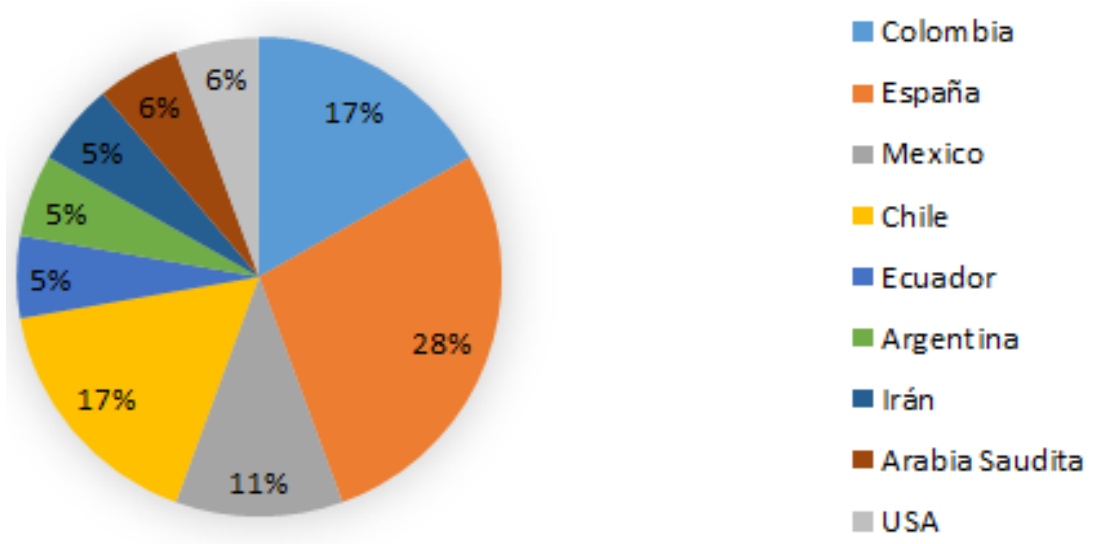

Gráfico 23 - Tendencia por países. Fuente Autoras.

Como podemos observar en la gráfica del tiempo, del año 2003 al 2007, la producción documental es bastante constante, pues solo tenemos un artículo por año recuperado, mientras que encontramos un leve aumento (2 por año) del 2009 al 2011. Si miramos la categoría anterior -CAC- en ese momento Colombia se encontraba en un cambio presidencial en el 2010 y en el 2011, se sancionó la Ley 1448 que se refiere a la atención a víctimas del Conflicto interno; pero como veremos en la gráfica de la "tendencia por países", otros países latinoamericanos han sido quienes realizaron más investigaciones -respecto al arte- durante este periodo de tiempo.

Durante el 2012 y el 2014, identificamos un retroceso en las investigaciones -se retoma nuevamente un artículo por año- siendo España el país con más investigaciones durante este periodo. En el año 2015, se presenta un aumento significativo en las investigaciones (4 artículos) a nivel mundial liderado por España. Y ya en el 2016, aunque hay una disminución (1 articulo) es contextual primero porque es publicado en enero, segundo, al momento de realizar la búsqueda de artículos hasta ahora se estaba comenzando el año como para tener más publicaciones, lo cual podría impactar negativamente para este año. 

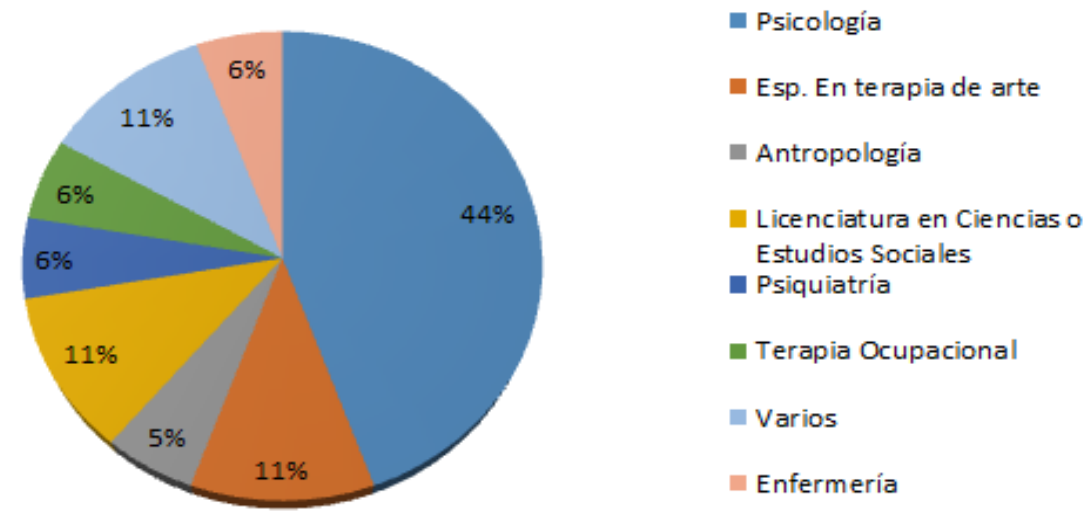

Gráfico 24 - Tendencia por disciplinas. Fuente Autoras

La disciplina que más ha estudiado el uso del arte como una herramienta interventiva ha sido la Psicología, principalmente desde el psicoanálisis y un estudio desde la psicología sistémica; aunque se encuentran diferentes aportes desde Vygotsky y Winnicot, entre otras corrientes teóricas, en donde ha sido utilizado el arte como un medio de comunicación y re-significación de las experiencias de las personas, siendo un instrumento que permite, mediante la conversación sobre el objeto construido, realizar reflexiones e interiorizaciones (Alyami, 2015).

De igual manera, se tiene en cuenta la importancia del contexto local en el cual las personas se han desarrollado y crecido, para desde ahí poder generar movilizaciones. La antropología, por ejemplo, propone trabajos artísticos desde el colectivo, ya que utilizan la Comunidad imaginada (como herramienta de análisis para la reflexión), proponen que "la comunidad se erige por intermedio de prácticas que les permiten "imaginarse" haciendo parte de un colectivo que es tan amplio que nunca podrían conocerse todos con todos, debido a esto es imaginada" (Blanco, 2009, p. 111). Así pues, buscan -no desde el espacio terapéutico- ayudar a las personas, desde ese colectivo o grupo con que comparten experiencias, superar el hecho sufrido o vivenciado a partir de la resignificación de la experiencia y así poder salir adelante. Es necesario fortalecer las redes interinstitucionales para lograr atender a esta población, incrementando procesos 
formativos, encaminados en especial hacia la ciudadanía para que superen los prejuicios y no sean más ajenas a las situaciones de maltrato, desplazamiento, ejecuciones extrajudiciales, desvinculación laboral, acoso laboral, que dificulten procesos de reincorporación de las personas afectadas (Marín, 2015).

A continuación, referimos la gráfica referente a ese tipo de población en la cual estas disciplinas buscaron generar un impacto, y por lo tanto utilizaron las manifestaciones artísticas como herramientas de intervención. En algunas situaciones se buscaba resignificar el evento traumático y en otros casos buscaron que fuera una salida o evitar que los participantes no siguieran siendo parte de estas situaciones violentas que les generaban malestar en la salud mental.

En la gráfica se puede identificar cuatro grandes grupos en los que puede organizarse la población en general según el porcentaje obtenido por cada grupo participante. En primer lugar, está el $17 \%$ compuesto por los estudios en los que no especificaron la población, adolescentes y pacientes con enfermedad mental, en segundo lugar, está el $11 \%$ caracterizado por mujeres violentadas y mayores de 40 años. En tercer lugar, está el 6\% correspondiente a las investigaciones realizadas en colegios de Medellín y con hombres mayores de 18 años. Y el cuarto y último grupo, corresponde al 5\% realizadas en la costa colombiana, en las favelas de Río de Janeiro y niños con retardo mental. 


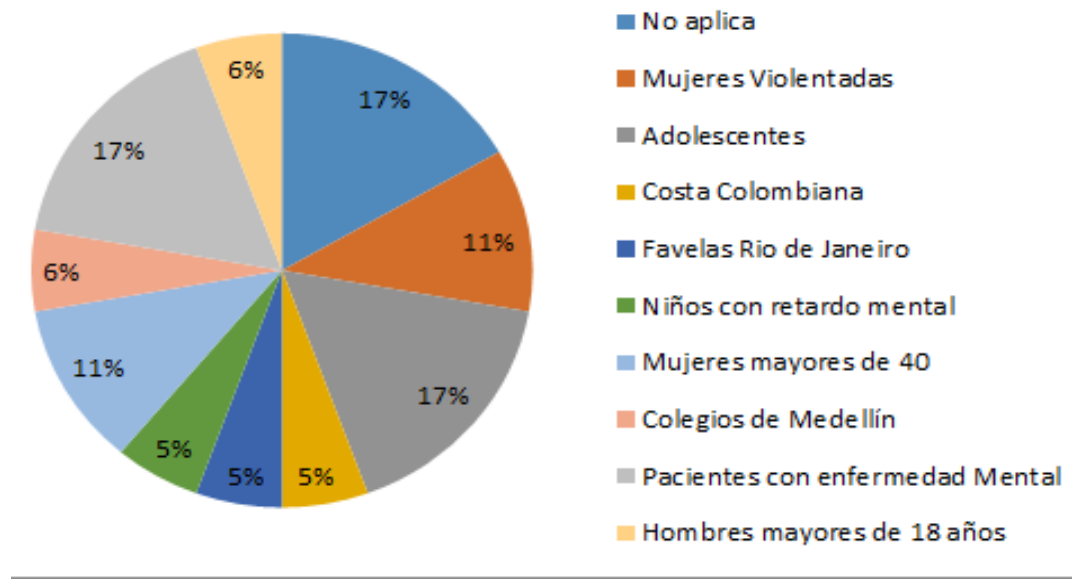

Gráfico 25 - Tendencia por población. Fuente autoras

Cuando se realizó el análisis de la información, encontramos que la frecuencia de uso de la música es menor respecto al arte, como los títeres, la pintura, el teatro y demás consideraciones, aunque ambas técnicas parten de la premisa de que el arte puede ser utilizado para la expresión de una gran variedad de emociones, y es práctico para toda la diversidad de población: individuos, parejas, familias, grupos (Farokhi, 2011) incluido el terapeuta.

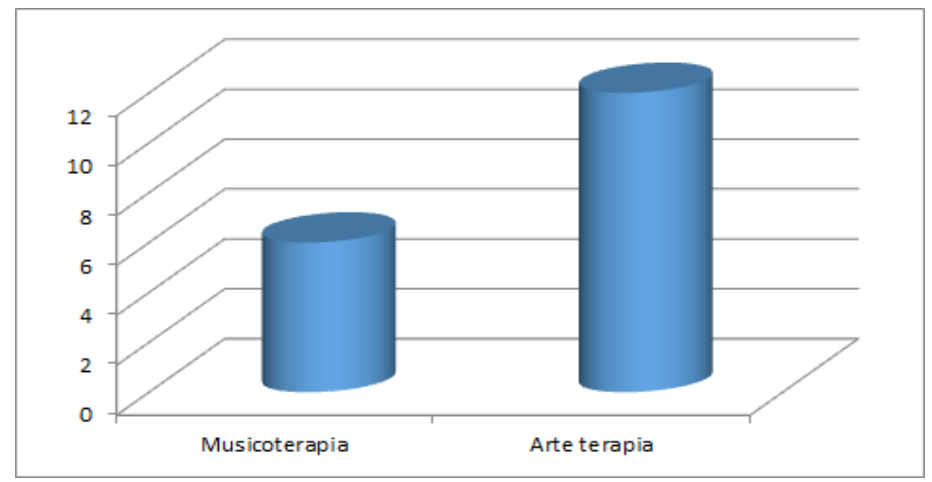

Gráfico 26 - Tendencia de técnica. Fuente Autoras.

Al hacer uso del arte - en cualquiera de sus manifestaciones- como herramienta de cambio, diferentes preguntas o interrogantes suelen surgir al imaginarse cómo podría usarse el arte en un proceso de intervención, y aún más desde la psicología sistémica compleja en un proceso de 
investigación-intervención. Este segundo proceso genera controversia porque cambia la posición del investigador, la ruta de la investigación, el proceso de la intervención y por ende los posibles cambios que se puedan presentar.

El arte es definido por la RAE como "la manifestación de la actividad humana mediante la cual se expresa una visión personal y desinteresada que interpreta lo real o imaginado con recursos, plásticos, lingüísticos o sonoros” (Pérez, 2014, p. 160).

Durante la revisión, nos encontramos con que el arte abarca diferentes corrientes o manifestaciones, como la música, la pintura, el teatro, los títeres, etc. que permiten reconocer en él "el carácter generador, productivo de la psique humana, la cual es capaz de producir nuevas realidades, de anticiparse a elementos que no existen en la realidad y que son la base de su acción” (Bustos, 2013, p. 8; González Rey, 2008).

En relación con Bustos (2013), Lacárcel (2003) plantea que la música entendida como arte, ciencia y lenguaje universal, es un medio de expresión que llega a lo personal (o íntimo) de cada sujeto, pues esta puede transmitir estados de ánimo y emociones por medio de "símbolos e imágenes aurales, que libera la función auditiva tanto emocional como afectiva e intelectual" (p. 221) pero, como hemos mencionado, este tipo de expresiones no solo se logra con la música, esta es solo una de las tantas manifestaciones artísticas que permiten esa resignificación de experiencias vividas a partir de la expresión de las emociones, que no siempre pueden ser evocadas de forma oral.

Así mismo, se reconoce como estas técnicas o manifestaciones del arte pueden ser utilizados como parte del proceso terapéutico con personas que hayan sufrido algún tipo de trauma o que hayan sido actores de la violencia, generando una reconfiguración de lo vivido a nivel de salud mental y de su sensación de bienestar. Teniendo en cuenta que el arte hace referencia al uso de 
las habilidades y la imaginación en la creación de objetos, ambientes o experiencias, los cuales pueden ser compartidos con los demás (Van Lith, 2016). Podemos afirmar que, según las investigaciones encontradas, mediante el arte las personas que hayan experimentado algún tipo de trauma pueden beneficiarse de la expresión creativa, y diversos terapeutas han incorporado técnicas propias del arte terapia a su propio modelo intervención (Farokhi, 2011).

Después de ver los beneficios del arte en la intervención, encontramos la transición del uso del arte en los procesos terapéuticos, por ejemplo, en el 2003 se proponía la relación entre la psicología y la música, al punto de llegar al entablar un vínculo entre la inteligencia emocional y la conducta musical. En el 2005 identificamos que hay una propuesta que profundiza en esa relación, y es a partir del uso de la música como alternativa terapéutica para incrementar la autoestima en mujeres que han sido violentadas. Para el 2007 hay un cambio en la técnica de intervención, es decir que ya no se centra en la música como herramienta sino en el arte para la expresión de la emoción, manteniéndose esta como eje en donde esta vez su centro son los conflictos con la autoridad.

En el 2009 hay una caracterización de una población respecto al tipo de música que la define y así se establecen sus relaciones y su forma de resolver los conflictos, proponiendo que la identidad musical permite disminuir la violencia. En el 2010 empiezan los estudios a proponer el uso del arte en cualquier situación de la vida que genere malestar o sufrimiento a las personas y no necesariamente estar atadas a un diagnóstico o situaciones de violencia. En el 2011 se retoman los ejes temáticos de intervención propuestos en el 2005 pero continúa con la humanización del trabajo terapéutico, es decir la no necesidad de una patología para trabajar con el arte.

Los siguientes tres años (2012 - 2014) tienen como intereses de investigación la salud 
mental y la violencia. Empiezan a proponer una salud mental colectiva, mencionando que el arte terapia permite la resignificación de hechos violentos o cuando no se puede manifestar con palabras las situaciones vividas y/o como forma de interacción cuando hay conflictos. El 2015 al ser el año que más investigaciones presenta, retoma ejes temáticos del 2005 y 2007 sin olvidar los aportes recibidos del 2011, es decir, la relación de la Salud mental con el arte sin la necesidad de tener un diagnóstico para el uso de la técnica en un proceso terapéutico y a su vez, en personas impactadas por diferentes situaciones de violencia.

En el 2016 se presenta el mismo aporte que el año anterior, pero se presenta una disminución significativa en la cantidad de artículos, permitiendo concluir este apartado que no han habido muchos cambios desde el primer hasta el último artículo analizado, pues en todos se ha reconocido que con el uso de cualquiera de las manifestaciones artísticas los sujetos pueden resignificar la experiencia vivida, sea traumática o no, pero que en el momento de la terapia están generando malestar alguno; además esta herramienta puede ser usada en otro tipo de contextos ya que permite la expresión de sentimientos y emociones que no siempre pueden ser comunicados de forma oral y así enfrentar las nuevas situaciones que la vida presenta. Es importante recalcar que en los diferentes artículos analizados no fue evidenciado el uso del arte como estrategia de cambio, no es explícito el proceso o el cómo llegaron al cambio, simplemente se reconoce y se le utiliza como técnica o herramienta de respaldo de un proceso interventivo.

\section{Conclusiones}

Realizando el análisis de los diferentes artículos revisados para la elaboración de este escrito, se pudo identificar la emergencia de varios ejes temáticos basados en las categorías que estructuraron la búsqueda de los documentos. Estas fueron para Conflicto Armado Colombiano: 
Conflicto y Memoria Histórica, Desmovilización, Desplazamiento y paz, Salud mental, identidad, vínculos y estrategias de afrontamiento, Violencia, reconciliación y reparación; y para Salud Mental nacieron: Aspectos psicológicos, sociales y jurídicos, Estrés postraumático y estrategias de afrontamiento, Salud mental y bienestar, Trastornos psicopatológicos; mientras la categoría de arte como estrategia de cambio no presentó modificaciones.

Reconociendo los tipos de investigación, en esta revisión se pudo identificar que el 89\% de los artículos rastreados corresponde a investigaciones de tipo cualitativo, y el $42 \%$ de los artículos explorados refieren textos reflexivos en estudios descriptivos y exploratorios por sobre el orden interventivo, comprendidos estos estudios cualitativos más que la forma de registrar patrones del hombre en la vida social como una perspectiva de mostrar nuevos y diversos modos de acción hacia la transformación en tanto se potencian las voces de los participantes. De esta forma, para la psicología y especialmente el paradigma sistémico, del cual se basan algunos artículos rastreados, la investigación de tipo cualitativo se convierte en un punto de referencia comprensivo de la realidad, entendiendo el conocimiento como una creación desde la construcción y la interpretación, siendo interactivo y que deviene del pensamiento crítico; en donde las relaciones entre investigador e investigado cobran significado desde la metacognición del propio investigador en donde la cibernética de segundo orden muestra la necesidad de incorporarse como observador en lo observado desde una postura reflexiva. (Gergen, 1996; González y Ávila, 2002; Maturana citado por Packman, 1996; Packman, 1996, citados por Fontecha y Moreno, 2010); de esta forma y en tanto el CAC se produce en el entramado social mostrando sus dinámicas a través de los cambios transicionales y sociopolíticos del país, algunas investigaciones reconocen grandes dificultades a la hora de generar trabajos terapéuticos con las personas afectadas por el conflicto bélico (Rodríguez, 2015; Sinisterra \& otros, 2012; Jiménez, 
2009; Castro \& Mina, 2008; Puertas y otros, 2006). Proponiendo así la necesidad desde el enfoque sistémico de promover el reconocimiento de las diferentes narrativas y perspectivas como parte esencial de cualquier conflicto (Ropers, R., 2008).

Teniendo en cuenta estas categorías se evidencia que algunos autores como Guerra y Sánchez (2015), Guerra y Plata (2015) reconocen la importancia de relacionar el Conflicto Armado Colombiano con acciones pedagógicas que posibiliten procesos de reconciliación, en los que se potencien los vínculos y se resignifiquen las experiencias; puesto que para López y Rodríguez (2012) no solo con éste se obstaculiza el perpetuar las dinámicas de violencia, sino también desde el potenciarse procesos de emancipación en especial del propio sufrimiento, es decir se presenta una preocupación por la salud mental y el bienestar de las personas y familias que han vivenciado acontecimientos del conflicto armado colombiano.

Es así que se plantea desde un enfoque complejo la necesidad de comprender de manera integral el conflicto; la paz en la violencia y la violencia en hechos pacíficos (HernándezHerreíra y López, 2014). Afirmando Torres, (2013) como el reconocimiento de la memoria histórica a su vez posibilita comprender a la población que ha sido afectada por la violencia y su relación con su vinculación a los nuevos contextos a los que deben desplazarse, lo cual promueve la comprensión de algunas investigaciones de Villa, (2014); Villa, (2013), en donde se evidencia la necesidad de buscar la participación en grupos de las personas que han sido afectadas por la violencia con el fin de que el sufrimiento se nombre de manera compartida y desde un discurso colectivo se potencie la memoria colectiva.

Lo anterior, teniendo en cuenta que Colombia es uno de los países con el índice de desplazamiento forzado más alto en el mundo, inclusive después del país de Sudán, debido al desarrollo del conflicto armado interno (Fontecha, Moreno y Medina, 2010); en donde 
convergen diversos grupos al margen de la ley como los paramilitares, las guerrillas, el narcotráfico, población civil, políticos y otros; y aunque este conflicto se exacerbó desde mediados de los 80 , durante los últimos diez años se ha presentado un descenso ligado a cambios sociopolíticos en el país como nuevas ofensivas militares, la firma del proceso de paz y reglamentación de atención y reparación de víctimas y de la justicia para la paz, que sin embargo no menguan la permanencia de las consecuencias en la vida de la población civil colombiana (Fontecha y Moreno, 2010); coadyuvando esto en el incremento de investigaciones descriptivas y reflexivas que en un 53\% no clasifican la población objeto de estudio, y en un porcentaje más bajo refieren víctimas del CAC sin desagregar el grupo etario, aunque un 5\% se identifican niños y niñas, mujeres, hombres, familias y las relaciones entre familia y profesionales. Además, en pocas de estas investigaciones se identifican a los participantes por género, aunque predominan las mujeres debido a que el asesinado o desaparecido frecuentemente es el hombre mientras que en pocos estudios se encontraron niños, niñas y adolescentes (Peñas-Felizzola, Gómez-Galindo \& Parra-Esquivel, 2015). Así mismo, las investigaciones que describen la población las ubican en zonas veredales y urbanas, siendo las primeras las que incrementan los índices de desplazamiento en la ciudad.

Además sólo una investigación cuenta con la tipificación de su muestra en términos de etnia, en donde son reconocidos mestizos, afrodescendientes e indígenas, denotando el poco reconocimiento de la multi, pluri e interculturalidad en los estudios desarrollados con las personas en condición de desplazamiento y ex combatientes, factor que de ser tomado en cuenta permitiría ampliar las posibilidades de acción e intervención con los mismos; en tanto es necesario analizar el conflicto no como ausencia de violencia, sino como la forma en que las personas la reconfiguran e incorporan en su cuerpo y vida, y el cómo se construyen cambios 
éticos, morales y a su vez identitarios, naturalizando la violencia (Chaves, 2011), y siendo parte de un nuevo contexto con una cultura particular a la cual estas personas y familias deben incorporarse.

Es así que, Amar-Amar, Abello-Llanos y Otros (2011) Andrade, Parra y Torres (2011) y Llanos \& Otros (2009), exponen cómo estos actores del CAC migran a nuevos espacios urbanos, en los que se enfrentan a afectaciones en los niveles de su calidad de vida, en la obtención de recursos que les permitan afrontar su situación de manera adecuada y por ende a una inestabilidad emocional; realidades referidas por Cifuentes (2005) y Nieto y Ravelo (2012) como aquellas pérdidas de diversas naturalezas que permean la composición, su propia estructura de relación, y a su vez el funcionamiento de las familias que se han encontrado inmersas en dicho conflicto. Exponiendo así Plata y Guerra (2005) las dificultades institucionales por intervenir dichos procesos socializantes, con relación a los pocos trabajos que generan un nuevo conocimiento aunado a la rigurosidad de indagación sobre la realidad de las familias inmersas en estos contextos.

Lo anterior debido a que la participación de las familias en procesos de investigación era incipiente, sin embargo, aproximadamente desde hace unos cuatro años se comienza a reconocer en estas el gran impacto que este núcleo primario genera en la salud mental de sus integrantes, al influir en el bienestar del individuo y en las relaciones intrafamiliares de acuerdo al evento vivido y a la separación o fallecimiento de miembros, hasta reestructurar los roles familiares, y las relaciones y manifestaciones afectivas en el nuevo contexto (Lozano y Gómez, 2004). En tanto el enfoque sistémico parte del principio que la familia es un sistema que ésta en relación con otros sistemas, y se debe enfatizar en la indagación y aprehensión de las dinámicas relacionales en las que sus integrantes están involucrados, siendo esto vital para el 
discernimiento sobre cómo se comprenden sus formas de comportarse y encauzar los procesos terapéuticos (Andolfi, 1984; Feixas, et al, 2012, citados por López, 2014).

En este sentido, algunos autores como Llanos y otros, 2009; Lozano y Gómez, 2004, exponen a su vez cómo estas dificultades vivenciadas se relacionan con las cualidades personales y la manera cómo se afrontan dichas adversidades. Por lo que la psicología reconoce que el proceso del desplazamiento forzado promueve el desarrollo de diversos desórdenes de salud mental afirmando que, según lo planteado por Andrade, Parra \& Torres (2011); Rodríguez y otros (2011); Castro y Mina (2008); Rodríguez y otros (2005), Alejo (2005); Lozano y Gómez (2004), dependiendo de la intensidad y severidad de los eventos vivenciados se generan repercusiones en los estados de ánimo, procesos adaptativos y el TEPT. Identificando CampoArias, Oviedo y Herazo (2014) que la prevalencia de síntomas emocionales relacionados a los estresores psicosociales, se reflejan en síntomas de ansiedad, depresión y estrés postraumático.

Reconociendo que el contexto influye en la Salud Mental, autores como Campo-Arias, Oviedo \& Herazo (2014) exponen que este fenómeno del desplazamiento forzado se ve atravesado por una situación psicosocial y jurídica; así como, Estrada, Ripoll \& Rodríguez (2010) identifican la pertinencia de generar un diálogo entre las diferentes disciplinas y actores del conflicto trascendiendo el lenguaje técnico. Tal es el caso de la Antropología, con estudios sobre la violencia del cuerpo, y el abordar los cambios de orden político, cultural, social y económico que se producen luego de esta incorporación o de las estrategias de resistencia a estas situaciones de forma individual o colectiva (Chávez, 2011), mientras en Trabajo Social se propone una metodología en la que se enfoque según Katz (2011) las comunidades en relación a las capacidades y las condiciones de sus integrantes enfocadas a la construcción de paz. Y por su parte, la sociología reconoce que el apoyo económico brindado por el estado es visto como 
un proceso de estigmatización para obtener la ayuda o de auto exclusión teniendo en cuenta la importancia del ser proveedor y del estatus que esto brinda en nuestra cultura. Por lo anterior, al identificarse como cada disciplina se enfoca en un eje de acción se reafirma la necesidad de generar procesos de atención psicosocial integral y a su vez potenciar el desarrollo de herramientas que permitan trascender el trauma y un apoyo emocional en el que se incluya el trabajo con la familia, la comunidad y redes cercanas (Jiménez, 2009).

En este sentido, la medicina identifica que es vital comenzar a atender la salud mental como un factor primario, ya que el abandono de las instituciones genera mayor estigma y silencio por parte de la sociedad (Rodríguez, 2015; Nieto y Hernán, 2012; Campo-Arias; Oviedo y Herazo, 2014). Siendo evidente que existe una marcada inequidad en el acceso a servicios de la salud, falencias en el recurso humano, y el desarrollo de herramientas que permitan un trabajo integral, visualizando la necesidad de que se evidencie un gran impacto económico en las políticas públicas (Rodríguez, 2015), puesto que, como afirman Campo-Arias, Oviedo y Herazo (2014), los estudios referentes a salud mental presentan una relación de 1 por año dificultando las comprensiones respecto a cómo se relacionan con la violencia sociopolítica y el fenómeno del desplazamiento forzado interno, presentándose por el contrario una alta tendencia a psicologizar y medicalizar las dificultades propias del conflicto armado colombiano.

En tanto, la posición social y económica se convierte en una situación que impacta notablemente la salud mental de las personas en situación de desplazamiento; puesto que al perderse la ubicación económica y social de los desplazados se propende por la alteración en la ejecución de las funciones que cada miembro de la familia desempeña, en especial en la dinámica relacional de la pareja o en la parento filial (Beiser 1988, citado en Rousseau y Nadeau, 2003), lo anterior debido a la dificultad para acceder a las prestación de servicios de 
salud que garanticen atención adecuada. Es así, que se propone un trabajo que integre acciones psicosociales y de salud mental que promuevan una memoria social y cultural enmarcadas en la justicia, verdad y reparación, y se generen procesos de evaluación más rigurosos en donde según Rodríguez (2015) en la evaluación diagnóstica se utilice entrevistas clínicas estructuradas.

En este entendido, las técnicas de recolección de información que fueron utilizadas en los artículos revisados permiten la descripción y generalización de los mismos para así construir reflexiones y comprensiones macro desde sus hallazgos en conversación con su disciplina y/u otras ciencias. Por ejemplo, se identifica con mayor frecuencia el uso de entrevistas semiestructuradas, análisis documental, revisión literaria, así como el análisis crítico, grupos focales, historias de vida, autobiografías, observación directa e indirecta, relatos, entrevista en profundidad, entrevistas semiestructuradas, estudio de caso y diarios de campo. Siendo los estudios de caso predominantes en un $40 \%$ en esta revisión documental, y comprendidos como la estrategia investigativa conducida a la comprensión en contextos particulares de las formas de interacción que se presentan, y que permiten además comprender el fenómeno desde diversas miradas, desde el compendio de información sobre una persona, grupo o institución en particular. Siendo estos clasificados de dos formas: 1) generar conclusiones universales desde una cantidad de casos limitada; 2) precisar conclusiones desde un solo caso. Por lo que esta investigación se orienta al segundo tipo en donde a partir de la unidad de observación "familia" con único caso se busca precisar conclusiones sobre las estrategias artísticas como mediadoras de cambio (Eisenhardt, 1989, Martínez, 2006, citados por Fontecha y Moreno, 2010), desde una postura vivencial, contextual y particular desde la innovación en la intervención con las estrategias hasta la particularidad de quién y cómo vivencia la situación del CAC en relación 
con su cotidianidad (Martínez, 2006), encontrando divergencias y convergencias en las narrativas que facilitan la comprensión compleja del fenómeno desde un ámbito clínico a través de procesos conversacionales y construcciones de historias de vida y relatos múltiples.

De acuerdo a lo anterior, comienza a hacerse evidente cómo las narrativas se convierten en la manera en que se legitiman algunos discursos psicopatológicos e individualizantes propios de una visión exclusivamente biológica, al identificarse un mayor porcentaje en la aplicación de instrumentos en los que se referencian datos sociodemográficos, escalas de trastornos psicológicos o síntomas, así como estrategias de afrontamiento, se hace pertinente reconocer procesos de atención que se realizan a las personas que han vivenciado el conflicto armado en los que se reconozcan los niveles de escolarización y ciclos vitales, en tanto no se tienen en cuenta en el momento de aplicar instrumentos y desarrollar intervenciones, según Andrade, Parra y Torres (2011); lo que a su vez, según Alejo (2005), permite dimensionar las diversas problemáticas de salud mental vinculadas con la violencia en Colombia. Proponiendo en este sentido Campo-Arias y Herazo (2014) el buscar resignificar historias, en las que se transformen emociones y percepciones de la realidad, desde según Sinisterra y Otros (2010); Castro y Mina (2008) procesos de atención integral en los que las afectaciones en las diferentes áreas sean reconocidas con relación a la familia y sus miembros en condición de desplazamiento. Así como, se recuerda que la entrevista semiestructurada es la técnica más confiable de recolección de información en temas referentes al diagnóstico de cualquier trastorno mental según CampoArias, Oviedo, y Herazo (2014). Proponiendo a su vez Sinisterra y otros (2010) el perfeccionar las estrategias de evaluación y diagnóstico psicosocial, la pertinencia de desarrollar intervenciones integrales con las personas en condición de desplazamiento.

De esta manera, una de las investigaciones menciona la importancia de intervenir desde 
estrategias encaminadas a permitirle a los miembros de las familias la construcción de significados recreativos de su propia realidad a partir de su imaginación e idealización para manifestar su sentir y pensar, compartir con otras personas y aperturar otros espacios de bienestar (Fontecha y Moreno, 2010), en tanto se comprende dificultad para expresar los acontecimientos vivenciados producto del desplazamiento forzado al implicar la narración de la experiencia vivida dolor que obstaculiza los procesos de externalización durante la atención prestada por profesionales de la salud (Nieto y Ravelo, 2012).

Por lo que desde esta comprensión se identifican investigaciones que proponen procesos terapéuticos grupales con las instituciones que promuevan el trabajo en el componente socioafectivo desde el uso de actividades artísticas tales como el juego, el dibujo y los títeres que permiten expresar emociones de tristeza, dolor y rabia, y se identifica la importancia de reconocer los recursos tanto individuales como familiares en los procesos de agenciamiento (Peñas y Gómez-Galindo, 2015; Fontecha, Moreno y Álvarez, 2011). Es así que autores como Henao (2013) y Rodríguez (2015) afirman que es necesario introducir novedad e innovación en los procesos de intervención en pro a generar un mayor impacto a nivel de salud mental, para así fortalecer los procesos identitarios, así como también el contemplarse otras apuestas novedosas y centradas en los sujetos, tales como; arte, Gestalt y el trabajo corporal, unidos a los trabajos de justicia y reparación como intervenciones integrales.

Siendo aquí importante mencionar que uno de los artículos indagados refiere el equipo reflexivo como un artefacto que promueve reflexividad en el contexto terapéutico, al escuchar y comprender la observación externa de los investigadores-interventores de lo acontecido en la sesión, como un aporte al análisis e interpretación del caso y ajuste de la misma intervención. Además de ser promotor de la reflexión en los integrantes de las familias en pro de la apertura al 
cambio y resignificación de problemas. (Fontecha \& Moreno, 2010). Por lo que, Baruch, Bush y Folberg (1996), citados por Estupiñán y González (2006), proponen que desde un enfoque de resiliencia se abarque el conflicto de una forma que genere afrontamiento, revalorización, negociación; reafirmando la apuesta de Villa (2013 - 2014) desde el potenciar las capacidades de afrontamiento y de resiliencia.

Esto lleva a indagar por nuevos métodos de intervención, entre los que se evidencia una especial atención por el arte, el cual se constituye como medio de comunicación y resignificación de las experiencias de las personas y sus familias, siendo un instrumento que permite, mediante la conversación sobre el objeto construido, realizar reflexiones e interiorizaciones (Alyami, 2015), al constituir una herramienta para la reflexión y para la expresión de una gran variedad de emociones, y siendo práctico para toda la diversidad de población: individuos, parejas, familias, grupos (Farokhi, 2011; Bustos, 2013; González Rey, 2008) e incluido el terapeuta; posibilitando el narrarlos con el fin de evitar conflictos en la construcción de relaciones, en la salud mental y/o física (Arévalo, 2010). Evidenciándose el uso del arte no como una estrategia de cambio, sino como técnica o herramienta de respaldo de un proceso interventivo, tal como se comprende en aportes significativos en este campo por parte de la psicología, desde la postura psicoanalítica, aportes de Vygotsky y Winnicot y un estudio desde la psicología sistémica, que ratifican la utilización del arte como un medio, como una técnica, sin explicar el proceso que posibilita el cambio en o con las personas con las que se trabaja (Alyami, 2015); siendo así, importante y pertinente comprenderlo como una estrategia de cambio, puesto que se comienza a identificar que aunque el proceso terapéutico no coloca fin al conflicto, si posibilita la reducción de las manifestaciones de la violencia, al poder trasformar a los sujetos partícipes mediante la expresión de la singularidad humana, la identificación de herramientas, 
fortalezas y/o capacidades que propicien la creación de posibles soluciones a dichos eventos (Durston, 2009); al ser desafiadas las percepciones establecidas y se obliga a trabajar con las diferentes etnias, perspectivas y culturas (Fariña \& Otros 2010).

Sumado a lo anterior, emerge el interrogante sobre cómo el arte puede brindar estos cambios, ya que en los escritos es descrito como una técnica anexa al proceso terapéutico/interventivo/social y no explica la manera como se llega a este cambio; situación que nos permite plantear en este estudio de caso el arte como una estrategia de cambio y no una técnica; entendiendo la estrategia como lo describe la RAE (2018), como "un conjunto de reglas [no fijas pero si como guía] que aseguran una decisión óptima en cada momento”, lo que permite orientarse durante el proceso terapéutico y así tomar decisiones que permiten la creación de nuevos mundos posibles en pro del bienestar o el cambio deseado por sí mismo y así mejorar la auto percepción de la salud mental individual y familiar.

\section{Estado del Arte: Testimonial}

\section{Introducción}

El estado del arte testimonial o contextual como se conoce en la Maestría en Psicología Clínica y de la Familia, busca "levantar textos narrativos escritos a partir de escuchar las voces de las instituciones, organizaciones, equipos, familias y demás actores sociales de dicho campo, en torno a las explicaciones y visiones de los "problemas" y fenómenos investigados, así como reconocer las posibles prácticas sociales y modos relacionales (p.e. patrones interactivos) que organizan los contextos pragmáticos de relación de interés” (Estupiñán \& González, 2008, p. 1). En este orden de ideas y en relación con la problemática escogida para la investigación, los 
actores convocados para realizar este documento fueron las familias que han vivenciado el Conflicto Armado en Colombia (CAC) para el primer escenario y para el segundo, los interventores que trabajan con la población inmersa en el CAC.

Al manejar dos escenarios se plantearon los objetivos correspondientes para cada uno, pero manteniendo la relación con el interés de la presente investigación. Para el primer escenario el objetivo era comprender en la experiencia narrada los cambios y transformaciones que se han presentado en las familias que han vivenciado el conflicto armado en Colombia (CAC), y para el segundo, construir desde el relato testimonial los criterios que los profesionales utilizan para comprender los cambios que las familias han vivenciado durante el proceso de atención psicosocial.

\section{Contextos, actores y escenarios}

El primer escenario fue realizado con dos (2) familias que residen en diferentes sectores de la ciudad de Bogotá, que a pesar de que geográficamente se encuentran distantes, hoy en día comparten situaciones muy similares. La primera familia reside al suroccidente de la ciudad, en la localidad de Bosa, y se encuentra conformada por cinco (5) miembros (Padre, Madre y tres hijos); en ellos el segundo hijo es definido como problema al tener dificultades a nivel académico en el área de la escritura. Respecto a la segunda familia se encuentra ubicada en el centro de la misma, cerca del antiguo cartucho, y se conforma por cuatro miembros, aunque en este momento residen madre, padre e hija, puesto que el hijo ya vive con su familia nuclear. Así mismo, en la segunda familia la segunda hija es descrita como problema al presentar alteraciones en su salud mental después de haber padecido meningitis en su primera infancia.

Ambas familias, vivenciaron acontecimientos del CAC desde la definición dada por el estado como de víctimas y se encuentran en condición de desplazamiento forzado, desde cada 
caso particular encarcelamiento y amenazas que impulsaron al asentamiento de éstas en zonas peligrosas y aisladas de la ciudad, pero que se han ajustados a las condiciones económicas y contextuales para cada una de ellas.

Como fue planteado inicialmente en el primer escenario, se esperaba conversar con familias descritas como "víctimas y victimarios" pero no fue posible por razones administrativas, en tanto por situaciones de seguridad y del cuidado que las organizaciones tienen con la población de reinsertados, más específicamente, se presentaron varios filtros burocráticos requeridos para poder conversar con esta población y para las instituciones no es tan claro por qué se lleva a cabo un estado del arte testimonial antes de presentar el diseño del proyecto. De igual manera, los profesionales que tienen contacto con familias de reinsertados afirman la importancia de generar un vínculo mediante la Agencia Colombiana para la Reintegración (ACR), ya que se requiere cumplir con estrictos protocolos de seguridad no solo para las familias sino para nosotras como investigadoras - interventoras.

En segunda instancia, se logró realizar tres (3) escenarios conversacionales con profesionales que trabajaron con la población de reinsertados, desplazados y víctimas de estado en instituciones como interventores psicosociales. Durante el escrito no se mencionan las instituciones con las cuales ellos han trabajado por cuestión de reserva a solicitud de ellos mismos y como fue mencionado anteriormente, ellos hablaron no en representación de las mismas sino como profesionales.

Así mismo, uno de estos profesionales es trabajador social, actualmente desempeña un cargo directivo universitario y llevó a cabo trabajo psicosocial en Medellín con las bandas de los mondongueros y del carrusel, en las comunas 5, 6, y 7, por un periodo de aproximadamente 2 a 3 años, y en un programa contra los cultivos ilícitos denominado guardia golfo en el Urabá 
antioqueño y chocoano con desmovilizados del bloque Elmer Cárdenas de las AUC, por 3 años. La otra profesional es una psicóloga egresada de la Universidad Católica de Pereira, que actualmente trabaja en el área de investigación con reinsertados, y lleva 9 años en el desempeño profesional con temas referentes a los psicosocial, salud mental y de acompañamiento psicosocial con actores del conflicto armado en Colombia. El tercer profesional es Psicólogo de la UPTC con aproximadamente ocho años de experiencia en atención de víctimas de estado, usando el arte y la medicina tradicional como formas de externalización y resignificación de la experiencia vivida.

Teniendo en cuenta la anterior caracterización, a continuación, se adjuntan las tablas de los escenarios, las cuales describen el procedimiento ejecutado con las familias y los profesionales, más las preguntas guía que orientan la aproximación. Respecto a la primera tabla, no se presentaron modificaciones en las escenas por lo que el escenario se desarrolló en su totalidad y normalidad; mientras que el segundo escenario, sufrió cambios en la última escena, pues por cuestiones de tiempo por parte de las personas entrevistadas no se alcanzó a trabajar la parte del compartir acerca de las sensaciones e ideas entre los actores; además que, el tiempo fue muy limitado e hizo que se tuviera que trabajar lo más concreto posible. Así mismo, en el segundo escenario surgieron nuevas preguntas enfocadas a cómo los profesionales perciben el trabajo inter, transdisciplinario, y sus comprensiones referentes a la temática de salud mental.

\section{Escenario 1: Hablando con las Familias}

Actores Convocados:

Familias que han vivenciado acontecimientos del conflicto armado colombiano. 
cambios y transformaciones que se han presentado en las familias que han vivenciado el conflicto armado en Colombia (CAC).

\begin{tabular}{|c|c|}
\hline \multirow[t]{5}{*}{ Focos: } & Resignificación de los procesos de adaptación \\
\hline & de la familia que ha vivenciado \\
\hline & acontecimientos del CAC. \\
\hline & Transformaciones en la salud mental frente a \\
\hline & la adaptación al nuevo contexto. \\
\hline \multirow[t]{7}{*}{ Preguntas orientadoras: } & ¿Cuáles son los cambios en el \\
\hline & funcionamiento luego de que la familia haya \\
\hline & vivenciado acontecimientos del CAC? \\
\hline & ¿Cómo se ha posibilitado la reconfiguración \\
\hline & de los relatos de la familia y la emergencia de \\
\hline & nuevos significados en la experiencia vivida \\
\hline & después de vivenciar el CAC? \\
\hline \multirow[t]{8}{*}{ Guion Conversacional: } & ¿Cómo era su familia antes de haber \\
\hline & vivenciado acontecimientos del CAC? \\
\hline & ¿Cómo ha cambiado su familia luego de \\
\hline & vivenciar el acontecimiento del CAC? \\
\hline & ¿Qué diferencias encuentran respecto a las \\
\hline & dificultades que viven vs. a las que pudieran \\
\hline & vivenciar encontrándose en su lugar de \\
\hline & origen? \\
\hline
\end{tabular}


¿Cuáles son las experiencias que han tenido

en su familia en cuanto a la atención en salud mental recibida?

¿Cómo esta atención les ha permitido hacer resignificaciones en torno a esa experiencia vivida?

¿Cómo les gustaría que fueran esos procesos de atención?

¿Si en algún momento les ofrecen un proceso terapéutico a partir de estrategias artísticas, estarían motivados a participar?

¿Qué les llamaría la atención de este proceso, que no?

¿En las actuales circunstancias, estarían interesados en un proceso terapéutico?

Escena 1: Se realizará la presentación de los investigadores y la familia.

Socialización del propósito de la investigación y del encuentro.

Escena 2:

Ejecución del proceso conversacional con entrevista semiestructurada desde un enfoque sistémico encaminada a identificar cómo resignifican los actores del CAC su 
experiencia, y como se ha dado la transformación de la salud mental después de los procesos de adaptación al nuevo contexto. Escena 3: Discusión entre las familias e investigadores frente a las comprensiones emergentes durante el encuentro.

Fuente: Autoras. Tabla \#1 Escenario. Encuentro Testimonial Familias

\section{Escenario 2: Hablando con los profesionales}

Actores Convocados:

Objetivo del Escenario:
Profesionales que hayan trabajado con familias vinculadas al conflicto armado en Colombia.

Construir desde el relato testimonial los criterios que los profesionales utilizan para comprender los cambios y transformaciones que las familias han vivenciado durante el proceso de atención psicosocial.

Relatos sobre la dinámica familiar donde se ha reforzado o mantenido el conflicto armado durante los procesos de psicoterapia.

Comprensiones acerca de la intervención prestada por parte de los diferentes profesionales en relación con el conflicto 
armado en Colombia.

Comprensiones acerca de la intervención ¿Cree que las víctimas del conflicto armado prestada por parte de los diferentes deben compartir sus historias de vida durante profesionales en relación con el conflicto los procesos terapéuticos?, o ¿con quién y para armado en Colombia. qué hacerlo?

¿Las experiencias de los actores del conflicto armado se ven reflejadas en la memoria colectiva del país y se tienen en cuenta durante los procesos terapéuticos?

¿Cuáles considera que serían las versiones enunciadas por la familia con integrantes actores del conflicto armado que presentan dificultades con otros actores del conflicto del mismo?

¿Cómo considera que las familias comprenden el conflicto armado en Colombia?

¿Usted ha intervenido otras personas fuera del actor de conflicto armado, como por ejemplo miembros de la familia para intentar resolver el conflicto y qué ha pasado? en las familias de los actores del conflicto armado cuando se presentan conflictos que la 
familia no soluciona por sí solas?

¿Cuáles cree que serían las formas adecuadas de resolver los conflictos y la misma violencia entre los actores del conflicto armado y en sus familias?

¿Cómo considera que la familia comprende las funciones que presta la institución con relación a la atención de actores del conflicto armado? ¿Qué estrategias ha utilizado para la atención e intervención de familias vinculadas al conflicto armado?

¿Cómo ha evaluado el proceso interventivo llevado a cabo con dichas familias?

¿Cuál es su opinión respecto a la evaluación de procesos interventivos a partir de actividades artísticas?

¿Las experiencias de los actores del Presentación de los investigadores y los conflicto armado se ven reflejadas en la profesionales que han realizado procesos memoria colectiva del país y se tienen en interventivos con familias vinculadas al cuenta durante los procesos terapéuticos? conflicto armado en Colombia. Socialización del propósito de la investigación. Se trabajarán sesiones individuales con los profesionales.

¿Cuáles considera que serían las versiones Desarrollo del proceso conversacional con 


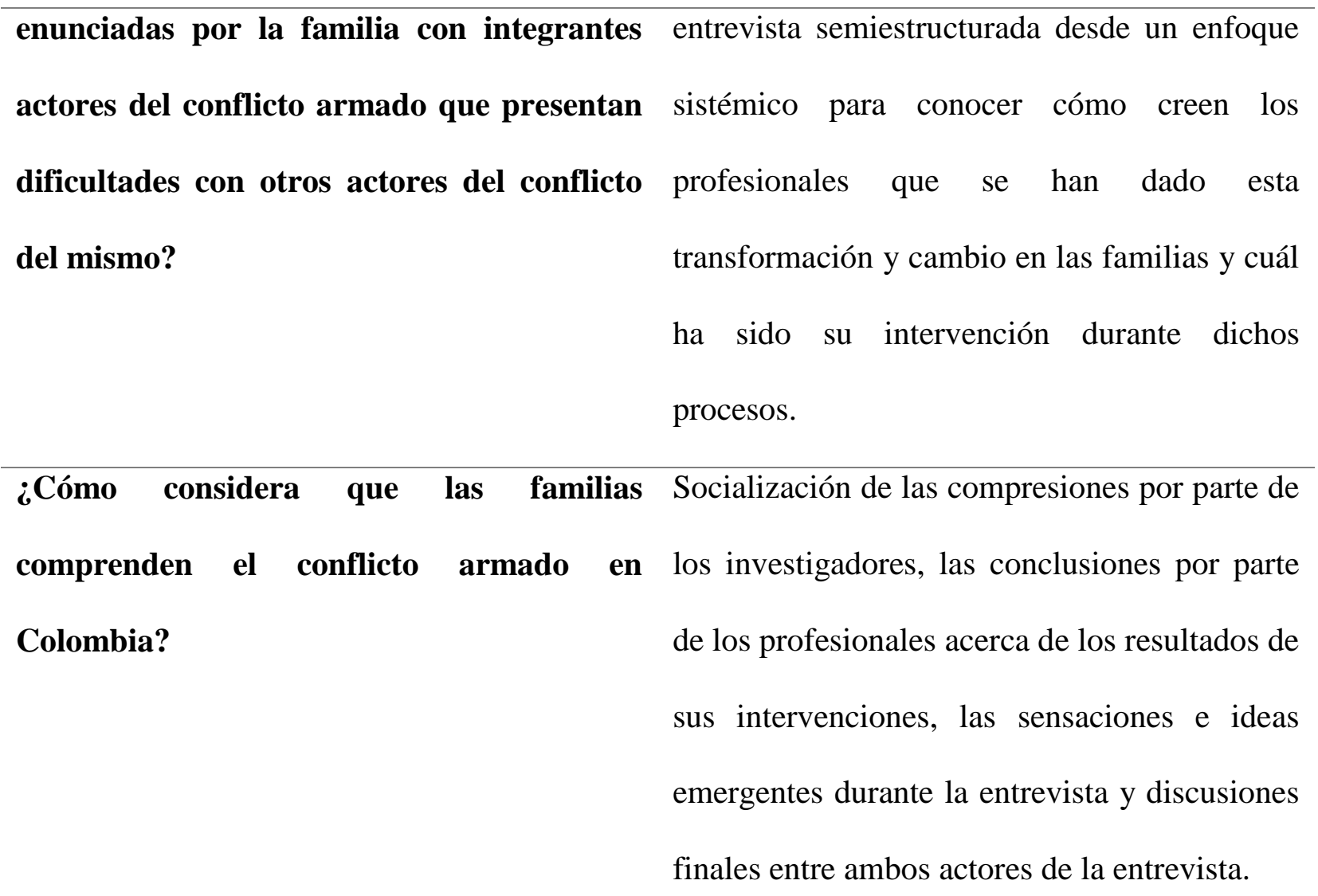

\section{Fuente: Autoras. Tabla \#2 Escenario Encuentro Testimonial Profesionales}

Durante el desarrollo de este escrito identificamos que las categorías planteadas para el desarrollo del estado del arte documental -Conflicto Armado en Colombia (CAC), Salud Mental y el arte como proceso de cambio y transformación- se transformaron en tres nuevas categorías, así:

- Familias impactadas por el CAC.

- Proceso de atención psicosocial e interdisciplinaridad.

- Reconfiguración de la experiencia 


\section{Resultados}

\section{Escenario 1. Familias.}

\section{Familias impactadas por el conflicto Armado en Colombia (CAC)}

Entendiendo que la familia es la unidad de observación de esta investigación, se hace necesario convocar las voces de aquellos miembros que han vivenciado el CAC, pero no desde las posturas tradicionales vistas en el Estado del Arte documental, como lo son el individuo y/o grupos sociales amplios -sociedades-, sino desde los cambios que este hecho produce al interior del grupo social más pequeño, al escuchar su experiencia no solo como individuos sino como familias, permitiéndonos realizar nuevas comprensiones sobre este fenómeno y las intervenciones que se realizan.

Lo anterior posibilita la transformación de la categoría Paz - Conflicto Armado en Colombia (CAC) por familias impactadas por el conflicto armado en Colombia, y se reconocerá los diferentes dominios que ayudarán a ampliar la comprensión sobre esta problemática contextual colombiana.

\section{Dominio paradigmático}

La vivencia del CAC en estas familias entrevistadas produjo ciertas transformaciones en la cotidianidad de las mismas, no solamente por el desplazamiento vivido sino también, tal como sucede con la familia de Bosa (Bogotá, Colombia), privaciones de la libertad por la participación política de uno de los miembros, pues como lo menciona el padre

"la cuestión de:: de los paramilitares que se metieron a esa zona I y prácticamente a todos los que pensábamos diferente I a:: a un partido liberal y conservador que éramos de:: de:: de avanzada no, (...), nosotros éramos 5 concejales del mismo grupo político I los dos:: los 
dos que nos salimos estamos vivos, los tres que quedaron los mataron I y inicie, pues yo me fui hacia la cordillera (...), a mí me detuvieron en Neiva I Mmmm huyendo mi señora tuvo a este:: (...) cuando a mí me detuvieron en Neiva, simplemente por estar viviendo en un:: en un municipio guerrillero, hay que decirlo así, me acusaron:: me montaron lo que llaman lo falsos positivos de testigos, (...), este pelado estaba de 6-7 mesecitos tenía él, duro:: I eh:: I estuve 2 años y medio detenido, sali absuelto, o sea I no hubieron pruebas" (Padre, FB, L6), y es así como se producen modificaciones al interior de este sistema familiar, principalmente en la estructura potenciando la nutrición emocional en el subsistema fraternal.

Es de destacar que, si bien las familias migran a la capital como un tema de subsistencia, al asentarse en este nuevo contexto con toda su familia se pone de presente que los procesos adaptativos son diferentes según la edad y el ciclo vital de cada uno de los miembros de la familia, reconociendo que para los padres ha sido más compleja dicha adaptación mientras que para los hijos, quienes han crecido en este nuevo contexto de ciudad no desean retornar a su lugar de origen

"Sí:: yo soy más:: la más dada a ese tema, ya estoy aburrida como del tema de la ciudad y todo, pero entonces ahora hay un eslabón que son lo hijos que no I que no se quieren ir, como nunca han salido de acá de Bogotá, prácticamente aquí se criaron y todo como que ya ellos no quieren saber qué es eso, que es un pueblo que es.: no nada de eso"(Madre, FB, L73).

Mientras que para la madre de la familia del Centro el proceso de adaptación se torna difícil justificándose en el bienestar de la hija, quien cuenta con una condición especial de salud al sufrir de meningitis en su infancia, versus la situación de inseguridad de Bogotá especialmente del sector donde residen, lo que argumenta mejoraría al retornar a su lugar de origen debido a las 
condiciones diversas y diferentes a la capital.

"Pues estaría ya más contenta, sin un peligro para ella aquí, porque uno acá tiene que estar en un peligro, porque tiene que estar tras de ella, quien llegó a la casa y quien no llegó, porque usted sabe que por ahí la gente :: la niña ya tiene su edad, en cambio allá en la finca estaba ella, ya más relajada por la edad que tiene, está en otro aire, en cambio el aire de aquí de Bogotá no es bueno I no::" (Madre, FC, L75).

A pesar de que este proceso adaptativo ha sido descrito por los hijos de la familia de Bosa como más natural, se empiezan a presentar dificultades a nivel de aprendizaje en el segundo de estos, la cual es relacionada por los padres como producto del desplazamiento

"Pues yo que digo, yo no sé, yo no soy psicóloga ni esto, nunca lo he hecho [jajaja] pero yo creo que a él de cierta forma si le afecto el tema del desplazamiento I porque él nació como en medio de ese conflicto, si me entiende, digamos el nació digamos de tiempo completo pero fue más por un susto que por otras cosa, y fue como muy mal atendido el parto, bueno ese tipo de cosas, entonces no sabemos qué pasó ahí, bueno, en el lapso de tiempo que digamos él estuvo detenido y esto, a ellos, me tocó dejarlos a los dos, durante tres meses en bienestar familiar, bajo protección" (Madre, FB, L145).

Situación que conduce a que la familia, principalmente la madre, reafirme dicha condición al haberse presentado diferentes pérdidas por este estresor no normativo vivenciado por la familia "Pues porque yo quede, mejor dicho, con la vida llevada, llevada en ese momento, que quede sin casa, con él detenido, que sin trabajo" (Madre, FB, L147).

En este sentido, se indaga un poco más sobre la creencia construida por la madre sobre la relación entre lo vivenciado por el conflicto y por lo que presenta uno de los hijos, buscando crear aperturas en las compresiones realizadas en torno a esta construcción familiar, ante ello la 
madre responde que "no, yo bien, yo le echo la culpa un poco a eso, a ese tipo de cosas, o no sé si" (Madre, FB, L181). Creencia que comienzan a construirse y establecerse cuando este hijo empieza crecer y a formar parte del sistema escolar, “...el tiempo corrió, y cuando él ya entró a estudiar y eso, empezamos como a detectar eso y ese tipo de cosas, y pues no sé si él quiera hablar del tema pero yo a él si lo siento así, yo siento que hay algo F que, que él debe de:: cómo hablarlo, como:: no se ahí como sería tratarlo con él” (Madre, FB, L183). Contexto que permite identificar la construcción de la creencia a partir de reconocer que la dificultad proviene de un posible trauma por la vivencia del desplazamiento, dejando de lado que probablemente este proceso obstaculizo su ingreso oportuno al sistema de educación, lo cual lo deja en desventaja con sus otros compañeros.

Siendo explicada una situación similar por la madre de la familia del centro al relacionar su vivencia de situaciones del desplazamiento como la causa de la enfermedad de su hija, al describirse a sí misma como una mujer nerviosa. "Sí, porque uno era: y a mí siempre yo toda la vida eh sido muy nerviosa, entonces ahí fue donde Paola pudo haber cogido todo eso, que uno le daba miedo y yo miraba, será que viene por uno, o que pasaría, pero no ellos no, pasaban todo:: todas las noches mantenían por ahi en una finca” (Madre, FC, L57).

De otra parte, la familia de Bosa comienza a exponer cómo el estado no cumple con aportar con las condiciones básicas para que las familias en condición de desplazamiento sobrevivan de una manera digna, situación que los conduce a cambiar sus dinámicas para garantizarse su propia protección

"Y:: y entonces yo les escuchaba eso a ellos y a mí me habían dicho que habían unas casas I eh:: del distrito, en ese entonces el alcalde era Lucho Garzón (...) y le mandamos de ahí desde la organización se le mandaron como unas cuatro cartas, solicitándole una 
audiencia para hablar del tema de vivienda de los desplazados, no, (...) y (...), nunca tuvimos respuesta, entonces nos dijeron de unas casas, que eran, que las estaba construyendo FAVIDI (...), y estaba por ahí en Patio Bonito, en un sector que se llama Riveras de occidente I (...), hacía como cinco años que estaban abandonadas, (...), por alrededor había una gente viviendo pero esas casas, y lotes vacíos para construir otro resto, entonces una vez nos reunimos con FAVIDI y le planteamos eso, y dijeron que no, que eso era imposible (...) entonces dijo metamos a $G$ entonces para que nos ayude a organizar esa toma y nos metimos con otro muchacho que venía del Tolima también de Soacha (...)” (Padre, FB, L26).

En este sentido, resaltan que el contexto citadino al cual tuvieron que enfrentarse empieza a tornarse hostil, vivenciando procesos de discriminación en algunos colegios, exponiéndose a que "a veces tocaba ir hasta a pelear con ellos mismos para que le abrieran los cupos a los muchachos, no eran dados a abrirle cupos a los pelados desplazados ...” (Padre, FB, L233)" “...él el que me ponía al tanto, me decía mire mami que allá les dan comida, a todos los niños les dan carne, les dan no sé qué y a nosotros no nos dan carne no nos dan o sea a ellos siempre como que los discriminaban -..." (Madre, FB, L241).

Es así como este nuevo contexto puede considerarse a su vez hostil, e incluso similar del que se desplazaron, en tanto se enfrentan a un sinnúmero de adversidades que son difíciles de controlar en este nuevo espacio, tal como le sucedió a la familia del centro:

"Que les iba a decir, cuando yo llegué la primera vez aquí que nos desplazaron, adivinen a donde llegué II al propio cartucho (...) y uno viendo:: que la guerrilla o los paracos asesinan, y uno venir y cuando uno pasa, pasar uno así y llegar a ver cuándo mataban la gente y todo eso, es mucho el trauma que uno tiene encima, viendo:: que uno que pasa y 
que no tenía uno pa donde más trabajar, porque nosotros trabajamos con tinto, llegamos y eso fue lo que:: a trabajar con tinto, (...) que eso es lo que a uno más dolor le da de llegar uno y ver:: ver antes peor por aqui, en ese tiempo” (Madre, FC, L213).

Condiciones que a algunas familias las conduce a que su sistema familiar empiece a reconocer espacios de apoyo para las familias establecidas o definidas, por el Estado y/o asociaciones, como "víctimas"; diferentes personas buscan la forma o crean situaciones que les permitan mantener este estatus, estado o caracterización a través de la repetición de los hechos para así mantener o sostener los beneficios, aun cuando el Estado intente crear nuevas condiciones sociales

"él fue a ese refugio temporal que se lo ofreció ahí la organización a España, a Asturias, en España, y estuvo allá y regreso y ya dejó contactos y todo eso, y vino y vino el otro y nosotros dijimos, vino y se hizo amenazar otra vez (Risa de A) porque vino y se hizo amenazar [jajaja] se hizo amenazar porque no creo que lo hagan amenazado (Risa de A) (Padre, FB, L400) ... [jajaja] El trabajo de él es trabajar la madera y esa cuestión, entonces dijo, ah sí un carpintero amenazado [jajaja] Bueno, pero dejo su contacto y ahorita está viviendo en Francia, allá está viviendo con la mujer y los hijos (Padre, FB, L404).

\section{Dominio técnico/interventivo}

Durante la vivencia de CAC, surge un evento no normativo que altera la dinámica familiar sobrecargando a la madre ante la ausencia de la figura paterna "Pues porque yo quede, mejor dicho, con la vida llevada, llevada en ese momento, que quede sin casa, con él detenido, que sin trabajo" (Madre, FB, L147). Situación que se transforma al retornar el padre a la casa luego de encontrarse privado de la libertad, equilibrando así las cargas del hogar; en donde el padre asume un rol de proveedor y la madre se dedica a las tareas o quehaceres del hogar: "anteriormente le 
tocaba a ella sola y prácticamente buscar (...) quien le cuidara los niños, pero después de que yo salí pues prácticamente yo salí a trabajar o salía a mis reuniones y ella se quedaba en la casa (...)” (Padre, FB, L24).

Pero, en contraposición a lo esperado en una separación abrupta al interior de un sistema familiar a causa de la vivencia del CAC, afectando la estructura y composición, se logra conocer que la Madre pretende mantener la figura del padre bastante presente, aunque no fuera presencial, reconociendo que

“bien, pues, o sea, eh:: esos tres meses fueron:: iniciales ¿no? o sea cuando él recién callo y esto, pero ya:: pues yo después logré como estabilizar eso, ya busque quien los:: quien los cuidara, eh bueno toda esta cuestión, entonces pues:: cuando él salió como que todo seguía normal, si o sea no, de pronto el tiempo más difícil, por así decirlo, claro que lo digo yo, ellos estaban pequeños en ese momento, de haber estado separados de los dos fue en ese tiempo, pero ya después no, o sea nosotros no nos hemos vuelto a separar ni nada, todo ha seguido normal” (Padre, FB, L177).

Mientras que en su relato la madre de la familia del Centro refiere cambios en la estructura de su familia de origen durante la vivencia de los acontecimientos del CAC, así como es su familia nuclear

"Mi esposo ya estaba aquí, yo estaba en embarazo de:: de Yesica, él estaba ya aquí viviendo con la tía, yo estaba era con mi mamá, la prima le hizo a mi mamá una casa, y ellos pensaron que nosotros éramos de:: (...) entonces ya empezaron a jodernos a todos y todos se desplazaron para:: mi mamá está en Pereira I mi hermana está en el Choco II y ahí comenzaron a tirarle las ventanas (M contiene el llanto), las ventanas -..- se metían a la casa y a molestarlo a uno (M llora), y nosotros esa noche éramos -..- y sin poder hacer 
nada” (Madre, FC, L8).

\section{Dominio ideológico}

Al momento de vivenciar diferentes situaciones los seres humanos atribuyen emociones y/o construyen creencias en torno a las diferentes situaciones que permiten realizar reflexiones en pro del cambio o estancamientos, haciendo que se construya una demanda de ayuda para transformar aquellas interiorizaciones que producen malestar.

Estas familias no son la excepción ante la creación de formas de protección ante la situación vivida, lo que hace necesario indagar sobre aquellas atribuciones que las familias y sus miembros realizaron para proteger y salvaguardar al sistema; en este sentido la madre reconoce que

"No, no, yo siento que no, yo siento que pues o sea, de todas formas aunque fue mal hecho lo que hice, lo hice por el bien de ellos, no llevo nada en la conciencia que haya sido por culpa mía o nada de eso, cosas del destino que en ese momento pasaron así, entonces pues:: pero de todas formas no deja de:: de doler, pues porque era algo que ellos no sabían hasta el momento (La voz se le quebranta)" (Madre, FB, L153).

Situación que tiende a ser resignificada por el padre como una forma de protección y cuidado, puesto que pensaron en el bienestar de los menores por encima de la unión como familia en la crisis que estaban viviendo "Porque simplemente fue como una cuestión de madre sustituta donde ella iba cierto tiempito a visitarlos y todo eso, y fue un lapso de tres meses no más” (Padre, FB, L160).

El salvaguardar a los hijos tiende a ser prioridad en estas familias, aunque la necesidad, la seguridad y/o el poder solicitar ayuda al estado, sea pospuesta por mantener la cohesión familiar, "yo me demore como dos meses pa ir, que yo decía no:: yo que voy a ir, y él me dijo vaya a 
la -..- allá la ayudan, yo le decía no:: yo que voy a ir por allá a que me quiten la niña, porque uno, así sea chiquita pero enferma pero uno la quería mucho, yo dije no:: pa' que me quiten la niña, yo no voy por allá, yo prefiero aguantar y sufrir, pero no que me quiten a P” (Madre, FC, L320) "Porque como hoy en día el bienestar familiar eso que quitan lo hijos y todo eso, entonces a mí se me metió eso, y dije yo no:: y mi niña especial, no que me la quiten, no yo no voy por allá, y una vez se me enfermo tanto la niña, que ahí si me toco ir a contar mi historia (...)" (Madre, FC, L322).

Cabe reconocer que, aunque la situación fue una forma de aliviar la preocupación del bienestar físico y emocional de los hijos, si se convirtió en un factor estresante y tensionante para la madre puesto que aumentaron los niveles de preocupación por perder a sus hijos, esto no le permitía estar tranquila de continuar dejándolos bajo protección, siendo así el último recurso que volvería a tomar para salvaguardar la vida de estos

"Después me dijeron, no si usted quiere volverlos a dejar, nosotros la seguimos, pero no, todo:: todo estuvo bien y pues o sea cuando quiera puede volverlos a dejar [jajaja] pero no:: yo algo que:: [jajaja] definitivamente no, y más en el lapso de tiempo que ellos estuvieron allá, ver yo que dieron dos niños en adopción, porque no los veían, porque no está-..- yo no:: eso es algo que no, para mí no, no tenía ninguna:: I razón de ser, si:: (Madre, FB, L173).

Situación que plantea la necesidad de realizar un comparativo entre la vida en el contexto municipal y el contexto capital, bajo la creencia de estar mejor allá que en la ciudad, luego del desplazamiento, siempre anhelando retomar lo dejado atrás,

"Si, somos nosotros. Mi vida anteriormente I antes del desplazamiento, era dirigente político, eh:: del municipio donde vivía, fui concejal I tres periodos consecutivos I allá, iba 
rumbo a la alcaldía que pedía:: era lo otro que tenía campo, tenía buenas posibilidades de llegar a:: a ser alcalde del municipio, claro que todavía no se me han quitado las ganas ac ¿no?, ahorita con el proceso de paz y de todo eso tengo ganas de volver ac / [jajaja]” (Padre, FB, LA).

En este sentido, estos estresores no normativos (como parte del proceso de desplazamiento), potenciaron cambios en el desarrollo académico del segundo hijo, teniendo la idea los padres que al no haber podido participar en todos los niveles de formación, se ha dificultado su proceso de aprendizaje

"y yo, yo considero que a él le hizo falta una cuestión vital que le hace falta a casi todos los niños, -... - que es la cuestión de estar como en un jardín ¿no? como estar en la formación de un jardín, de:: de pasar al preescolar que llaman, a él como que le hizo mucha falta ese proceso de aprendizaje ¿no?” (Padre, FB, L185). “Cuando llegamos acá no estuvo si no como un mes o dos meses ya antes de:: digamos de salir para:: pal colegio, entonces no tuvo como ese proceso de jardín mientras que él sí y él sí, entonces pues o sea, no sé qué pasó ahi” (Madre, FB, L188).

Sumado esto a la discriminación que vivenciaron por parte de los profesores ubicados en el norte de la ciudad con respecto a las personas en situación de desplazamiento "Inclusive fue hasta bien complejo, porque mira que los profesores y es un análisis que yo hago, los profesores prácticamente del norte tiene como una cierta a:: apatía al desplazado” (Madre, FB, L229).

Por lo que, se hace necesario exponer a la profesora el proceso de desplazamiento por el cual han tenido que atravesar al considerarse que el desplazamiento genera grandes repercusiones en el proceso de aprendizaje del hijo y con el fin de conseguir ajustes razonables en el proceso de escolarización del joven "Como con una barrera hacia él, qué él no hace nada, qué él no sirve, 
que no sé qué, que si se cuándo, (...) entonces me puse a explicarle yo a ella, y mire profesora a nosotros nos ha tocado esto, (...), yo creo que el viene de ese proceso y eso es lo que en partes le ha afectado a él, y ¿Cómo? ¿Y porque ustedes no habían dicho antes eso?, (...)” (Padre, FB, L282).

\section{Proceso de Atención Psicosocial e interdisciplinariedad.}

Así como se presentaron transformaciones en el apartado anterior, en esta categoría se comienza a presentar aperturas no solamente en los procesos de atención psicológica sino también en diferentes estrategias que estas familias han utilizado para afrontar y sobrellevar los diferentes acontecimientos luego de haber vivenciado el CAC-y en las cotidianidades del nuevo contexto. Por ello, al indagar acerca de las experiencias en procesos de atención psicosocial e interdisciplinariedad de las familias que vivenciaron acontecimientos del CAC se encontraron las siguientes comprensiones:

\section{Dominio paradigmático}

En relación a los procesos de atención psicosocial, la familia que reside en el Centro de Bogotá (Colombia), los explica como una utilidad para el abordaje de problemas individuales y/o al interior de los subsistemas del sistema, como lo es la discapacidad y las alteraciones en la dinámica familiar producto de la situación de desplazamiento, "pa' la niña y pa que me quiten todo:: todo este estrés:: toda esta cosa que yo cargo encima de la edad debido a lo que me paso, porque el esposo usted si es repelente, usted si es mala clase [jajaja]" (Madre, FC, L170); haciendo énfasis en un posible objetivo terapéutico en donde se direcciona la atención 
inicialmente hacia la hija y luego se incluye la madre, al mencionar que "por calmarla uno y si por:: porque dicen que el psicólogo eh:: pues como ustedes le van ayudando a uno a:: a calmar tanta cosa, eso es lo que a mí me gustaría” (Madre, FC, L176).

Así mismo, con la actividad del equipo reflexivo realizado durante la entrevista, esta madre logra distanciarse un poco del malestar que vivenciaba en silencio, "como le digo yo a usted, como cuando está el señor o ángeles, que lo:: lo:: le van quitando como todo ese estrés:: yo no sé:: mejor dicho, yo me siento como relajada, como que este cuerpito no fuera el mío [jajaja]" (Madre, FC, L273). Esto en tanto se reconoce que, en situaciones de dolor, las palabras no logran ser expresadas, "no se preocupe, importante es que usted nos: como comprender cómo usted se siente, y lo que nos ha explicado claro, a veces uno no logra entender exactamente con palabras que fue, pero usted::” (Interventoras, FC, 280).

Por otro lado, en relación con procesos interdisciplinarios se explica cómo algunos de los apoyos que el estado ofrece a personas en condición de desplazamiento son destinados a bonos para alimentación, en donde esta familia desde un nivel reflexivo determina que al contar con la necesidad de alimentación satisfecha prefieren que otros reciban este beneficio

“(...) hay veces tenemos un bono, (...) y él consiguió trabajito en esos días, y él se retiró del bono, dijo ese bocado que me llega a mí, eso le puede llegar a otra persona que lo necesita" (Madre, FC, L217), "y él dice que (...) piensa volver a ir a hacerlo otra vez, pero si mi Dios me da otra oportunidad, porque ese bono es comida para otro que lo necesita, y eso sí tenemos nosotros” (Madre, FC, L219).

\section{Dominio técnico/interventivo}

El proceso de desplazamiento enfrentó a estas familias a diversas dificultades en las cuales 
tuvieron que realizar movilizaciones destinadas a cubrir necesidades básicas, en especial la de vivienda y educación ante la ausencia o el poco apoyo que el estado puede hacer para garantizar sus derechos. Contexto que, produce que, en algunos momentos, los procesos de atención psicosocial tiendan a venir acompañados de un subsidio o indemnización que permita sobrellevar las exigencias que el medio al que se incorporan las familias sea, no más fácil, pero sí más sencillo de transitar, evitando así, enfrentar los problemas "mentales" al verse solventados en algo los económicos. Por ejemplo, la familia del centro menciona que "sí, pelee por eso para yo poder poner algo un negocio a donde yo pueda trabajar ahí mismo en el negocio y cuidar a mi niña, porque eso sí puede uno hacer, pero uno a veces sin plata, nada más lo que haga ese pobre hombre, porque el hijo ya con hijos que pa los pañales, que la leche que ropa, que por ahí mami tenga estos 3.000, mami tenga estos 4.000 [jajaja] “ (Madre, FC, L 326).

Situación similar se presenta en la familia de Bosa (Bogotá, Colombia), en la cual estas crisis presentadas por el nuevo contexto suscitan problemas con uno de los hijos, quien ha debido participar de varios procesos de atención encaminados a su nivelación escolar " $y$ : y a nivel de estudios lo más difícil ha sido con este pelado, porque con él si se estuvo en un proceso ¿no?” (Padre, FB, L30). La participación en procesos de atención psicológica y de terapias dan cuenta del cambio que ha venido mostrando este hijo en el contexto escolar. Aunque la voz dominante de la madre coloca de presente el malestar mostrado por el hijo para convocar el contexto terapéutico

“(...) cuando estaba pequeño como unos 5 - 6 años más o menos, eh:: él en el colegio no rendía I entonces le mandaron a terapia con el psicólogo, con terapia de lenguaje, (...) ¿ocupacional? (...) hubo un lapso de tiempo donde el perdió digamos tercero, (...) y ahorita digamos, pues ya está en (...) noveno y este año ha tenido como:: como esos desniveles otra 
vez y esto, y pues ahí está mirando a ver cómo se le sacan citas otra vez, a ver qué pasa” (Madre, FB, L134).

Estas intervenciones han facilitado la identificación del problema y el inicio de la intervención del contexto salud

“(...) pues como no duró mucho, digamos que allá no le detectaron como esa situación, llegamos (...) aquí a Bosa, y el ingresó digamos a continuar el año, pues eh:: así pequeñito no escribía muy bien, (...) ya como en segundo fue que comenzaron el proceso los profesores, (...) Y:: comencé a llevarlo así, (...) con los especialistas que lo mandaban y eso, eh:: la psicóloga y eso dijeron que:: que él tenía un problema de ¿disgrafía?” (Madre, FB, L251).

Al respecto se realizaron gestiones y se aplicaron pruebas para validar el diagnóstico, aunque la familia no continuó con el proceso dejando de lado el apoyo que debía recibir su hijo exacerbando el problema

“de disgrafí, (...) le hicieron el coeficiente intelectual (...) me dijeron no su hijo está bien o sea tiene un coeficiente buenísimo\entonces uno dice, no pues todo está bien tan, yo cogí el:: el papelito todo lo que me entregaron debajo de la cama, yo nunca lo lleve al colegio, (...), y él siguió, normal con su problema (...) pero no:. / no daba pie con bola el chino [jajaja] entonces perdió tercero” (Madre, FB, L253).

Lo anterior, reactiva la necesidad de atención psicológica del hijo, aunque las dificultades con el sistema de salud no facilitan la accesibilidad para los servicios que se requieren para apoyar a este hijo, lo que genera insatisfacción, "sí, pues ahí nos mandan otra vez que a psicólogo, que a:: bueno traiga esa vaina” (Madre, FB, L239). "Eso es muy engorroso muy mala la salud aquí, huy no” (Madre, FB, L302, “pedirle citas para eso, pero usted sabe que es 
pedirle cita a una EPS para eso" (Padre, FB, L285). De otra parte, algunos miembros del sistema familiar participaron en procesos de atención a nivel grupal e individual, sin conocer a mayor precisión su participación sobre estos, "tenemos unas cuestiones con una vaina que se llamaba incolde ¿No? Pero eran unas reuniones asi:: muy informales entre todos ¿No?” (Madre, FB, L334).

Así mismo, un evento no normativo como es el encarcelamiento del padre -de la familia de Bosa- suceso desencadenado por el desplazamiento, lleva a la madre a buscar apoyo del estado, acudiendo así al ICBF, dejando a sus hijos en un hogar de protección y participando de un proceso terapéutico,

"yo si tuve ayuda psicológica, eh:: durante tres meses cuando:: pues todo el proceso ¿No? que él estuvo detenido, que me tocó entregarlos a ellos, el mismo centro zonal digamos donde los deje a ellos, me brindaron esa ayuda psicológica, porque o si no hubiera terminado loca [jajaja] entonces yo si tuve, digamos de pronto esa ayuda en ese momento, pero hacia acá, o sea después de eso no mucho, no:: nos ha tocado solos, el llegar acá a Bogotá, (...) (Madre, FB, L 337).

Apoyo que la madre expone como beneficioso desde un sentido terapéutico, en tanto al haber participado comprende la dinámica relacional de su familia de una manera diferente realizando distinciones sobre sus propios procesos de crianza

“sí, porque yo digo que si yo no hubiera tenido ese proceso tampoco tendríamos la familia que tenemos, porque yo no hubiera tenido la paciencia para sacarlos adelante a ellos dos, por lo mismo que a mí me criaron así, ¿Sí? Como tan mal, como tan a los golpes, (...), entonces eso me enseñó a aprender, a quererlos a ellos, y a cuidarlos, (...)” (Madre, FB, L351). 
Este proceso terapéutico facilita además a la madre identificar una metáfora que le permite comprender la necesidad de "romper cadenas", logrando realizar distinciones entre la relación parental y la fraternal. “...como un lazo, como una cadena, así mismo habría sido con ellos, entonces como que me enseñaron a:: a no, no debo digamos descargar la rabia con ellos, no tienen la culpa ellos, lo que a mí me paso ya paso, bueno como a separar las cosas" (Madre, FB, L 355).

En pro de indagar sobre las técnicas utilizadas en el proceso terapéutico del cual participó la madre de Bosa, se conoce que se desarrollan metodologías prácticas "Mmmm me acuerdo que me puso a:: [jajaja] me puso a pegarle a mi abuela [jajaja] es algo loco, como:: como hacer una almohada y pegarle y descargar toda la:: la rabia, como todo lo que quería decirle a esa persona, como si fuera algo así, es como lo que más me acuerdo, no más” (Madre, FB, L 361). Mostrándose un especial énfasis en procesos conversacionales "Si:: todo era como hablado, como:: cómo contarle mis problemas a ella, como:: ese tipo de cosas” (Madre, FB, L366).

Se expone la reserva para socializar sus vivencias producto del desplazamiento, seleccionando historias poco importantes para ellos o más fáciles de contarle a otros, “no, yo no, prácticamente ni le prestaba atención a eso, la verdad yo me parecía que no:: no, no, no, yo ni recuerdo de que hablábamos, yo simplemente se contábamos así, historias y cuestiones asi"” (Padre, FB, L384).

En este sentido, se conoce que esta familia también desarrolla procesos terapéuticos en una organización religiosa al llegar a Bogotá, pero tampoco logran reconocer el apoyo o la importancia de esta participación en sus vidas, "ahh no, fue recién llegamos aquí a la:: a:: Bogotá, en una cuestión que se llamaba, una organización que se llamaba MEDICOL, (...) como a una especie de terapias que (...) como una iglesia minoritaria que habia” (Padre, FB, L376). 
Sin embargo, en contraposición a la familia de Bosa, la familia del Centro no logra acceder a un proceso terapéutico y relaciona éste con la ayuda económica, generando esto malestar en el proceso operativo de la búsqueda del subsidio, "y que uno a madrugar y con esa muchacha, hay veces que me tocaba hasta dejarla y llegar a las diez u once de la mañana y la niña toda emparamada, pa un bono tan:: cada año un bono, porque cada año le llega a uno el bono, y yo ya hace como pa dos o tres años que yo no recibo nada" (Madre, FC, L160). Considerando que quien logra expresar mejor, logra mejores resultados en estos trámites de apoyos, quitándole la oportunidad a las personas que no cuentan con recursos o los apoyos, y realmente los necesitan “todos van, y como dicen, todos van al mismo tiempo, pero el que tiene más lengua y el que sabe más expresarse las cosas, ese es el que va y le quita lo poquito a los que sí necesitan" (Madre, FC, L164).

Las dificultades que el proceso de desplazamiento genera en las familias ha permeado las dinámicas relacionales de diferentes formas, pero también, han conducido a que las situaciones de la cotidianidad -del hoy en día- sean afrontados manteniendo la unidad y se busque el apoyo entre los miembros del sistema, a pesar de que las condiciones contextuales los permee y busque nuevas formas de adaptación,

“(...) yo no sé, por allá me mandaron pa 'un hospital, [tos] 8 días me dejaron con ella allá, con $P$, ardida en fiebre, bueno, a mí se me olvido esa carta, viendo a $P$ tan mal, me fui por indigente, [jajaja] y la metí al hospital, donde me dijeron L espere, yo cuando miro una vez, me pongo a rebuscar lo papeles, yo este es que, carta de desplazado, yo oigan pues, y me fui y volví y la metí donde el médico, y desde eso yo, que a rogarle a ese gobierno, no, [tos] mi dios como pueda nos saca adelante, ahorita si le puse fue a E, que le dije yo a E, E pelee por eso, porque yo necesito verdad, él me dice que, una casa, yo casa no quiero, porque yo 
pa que casa, sin un local a donde yo pueda poner algo:: y en el local ya va uno comenzando porque uno va progresando, por el negocito uno va progresando y pone:: su casita, pero yo pa que una casa, con que voy a pagar luz, con que voy a pagar agua, como le digo a Nando, el gobierno sí, le da a uno una casa, pero si usted me falta yo que hago, yo con que voy a mantener la casa, ¿sí o no? y que las casas se están rajando y todo, eso es lo que está dando el gobierno, entonces le dije E, pele por eso y::" (Madre, FC, L326) “pero si, eso sí le dije yo a E, póngase pila E pa' que me ayude pa' un negocio, y que me quede algo, pa yo meterme en una casita aunque sea por acá fuera de Bogotá (...) (Madre, FC, L328).

\section{Dominio ideológico}

Durante el desarrollo de estos encuentros, se empieza a conocer que desde el momento en que la familia de Bosa llega a la ciudad, se acerca al contexto religioso como una red de apoyo pero no terapéutico, pues comienza a ser visto con precaución, limitando la forma en cómo dan a conocer su experiencia del desplazamiento, apoyados en la creencia arraigada de cuidar lo privado "menobonita, algo así, yo fui unas veces, con ella también fuimos, y entonces nos reunimos varias familias, y contábamos así muy someramente lo que:: desplazados, de donde veníamos, sí:: pero no contábamos en sí a fondo" (Padre, FB, L378). Percibiendo el soporte ofrecido por esta red de apoyo más a nivel económico que psicológico a pesar de recibir orientación para convocar procesos de externalización,

“sí, (...), por aquí uno casi ni conoce los vecinos, saben ellos de que uno llegó como familia desplazada pero no:: uno nunca se sienta a contar como, cuando, que le paso, nada, nada, nada de eso, porque uno eso lo tiene como conservado, y así pasaba allá en esa iglesia, y simplemente nos daban un apoyo por ahí que uno mercaditos, que esto que lo otro, pero 
unas vainas como le digo, de contar y de hablar y había una persona que nos explicaba la cuestión psicológica, eso fue lo que tuvimos, pero así muy pasajero, recién llegamos, de resto no" (Padre, FB, L382).

Esta dificultad de aperturarse a la externalización de las vivencias propias del desplazamiento disminuye la posibilidad, sobre todo para el padre, de participar de un proceso terapéutico, en tanto se exacerba la creencia de poder solucionar por sí mismo situaciones adversas,

“no:: no, yo considero que no, yo considero que la ayuda mía siempre la he tenido como de mi interior, como de mi fuerza, de mi cuestión, de mí:: que siempre trato de buscar las, las cuestiones yo mismo, entonces no:: porque a pesar de lo que me paso, yo he tenido mucha resistencia en ese aspecto, porque lo que me pasó era para irse quién sabe uno, pero no.:” (Padre, FB, L386).

En este sentido, se comienza a identificar cierto inconveniente por parte de la familia del centro para reconocer la dificultad que genera el poder externalizar las emociones y pensamientos que se relacionan con los acontecimientos del CAC, "yo siempre soy muy olvidada [jajaja] es lo único que les digo, yo:: como que estoy sufriendo algo:: porque yo las oigo hablar, por eso le decía yo, pero como espere, me gusto lo que ella hablo (mira y señala a T1), lo que:: pero se me olvido” (Madre, FC, L224).

Situación que comienza a plantear contradicciones al observar que, la familia de Bosa descalifica sus creencias y se refiere a los psicólogos como quienes tienen un mayor conocimiento reconociendo una posibilidad de ayuda, "Sí como:: bueno [jajaja] ustedes saben más del tema, si como a:: a:: a valorarlos I mucho más, como a ser pasiva, como a ser tolerante, como todo ese tipo de cosas" (Madre, FB, L347). 
De igual manera, la familia del centro se descalifica a sí misma respecto a las decisiones y acciones que ha tomado al encontrarse desescolarizada

"porque sí, porque uno:: cuando uno no ha estudiado, porque como yo nada más estudié hasta segundo de primaria [jajaja] ya nos vinimos al gua desde hace rato, yo estudié hasta segundo de primaria, y en segundo de primaria habían unos tableros, yo a usted le tocó, unos tableros que son así cuadraditos y que acá son como metido y que esos tableros -..salen por aqui los voltea” (Madre, FC, L283).

De otra parte, al ser el arte un foco fundamental para esta investigación se comienza a indagar por el uso del arte en los diferentes procesos de atención y/o terapéuticos, en donde la madre de la familia de Bosa refiere al arte como algo innecesario posiblemente enmarcado esto en su postura rígida de orden cognitivo, "pues no se [jajaja] las vería como innecesarias, como cursis, como no se" (Madre, FB, L368). Lo cual justifica en la creencia de no ser buena en temas artísticos "no me sentiría cómoda con eso, porque si me pusieran a dibujar como algo, no tengo que dibujar" (Madre, FB, L370). Mientras que, la madre de la familia del Centro muestra curiosidad por la mediación del arte incorporando a su pareja desde el saber. "Pues yo de arte no se casi (...) pero mi marido si:: yo creo que sí, ensayando ¿Cierto?” (Madre, FC, L177); “Sí:: ensayar a ver, si uno no sale de la casa, hay que hacerle" (Madre, FC, L188).

\section{Reconfiguración de la experiencia}

De esta manera, y a partir de haber vivenciado acontecimientos producto del CAC las familias de Bosa y del Centro refirieron una serie de situaciones y eventos que les han permitido realizar comprensiones respecto a la forma como han logrado afrontar estas, permitiéndose resignificar o aperturar la resignificación desde otras posibilidades en pro del mejoramiento de su 
calidad de vida.

\section{Dominio paradigmático}

La familia de Bosa expone dificultades en el acceso a necesidades básicas producto del proceso de desplazamiento al llegar al contexto de ciudad, situaciones que le generan una sensación de inconformidad con lo que significa vivir en la ciudad, pero que a su vez se replantea con el ampliar redes de apoyo generando apertura a algunos cambios para sus miembros, en tanto refieren:

“(...) entonces nos vinimos aquí para Bogotá, pero no ha sido fácil este Bogotá, duro, vivir aquí es muy duro, (...) ósea, aquí se queda uno como por costumbre de quedarse pero no es porque uno se adapte a vivir acá, no:: (...) llegamos a una casa de inquilinato en el norte, por allá en San Cristóbal Norte, vivíamos con:: a mí me dieron espacio 5 familias desplazadas vivían ahí en una sola casa, (...) sin conocer prácticamente a nadie I sino a esas familias que habíamos ahí, entonces allá en el norte reciclamos para conseguirnos la comida, (...) y llegábamos a dos o tres empresas y nos hacíamos buena plata, (...), nos hacíamos la comida y por ahí el mercadito que le daba a uno la cruz roja, ahí ese mercadito que le dan a uno de acción social, andando en esas conocí a una, a una familia, a una muchacha muy activa, una muchacha muy activa y ella fue la que me vinculo a Andas" (Padre, FB, L12).

\section{Dominio técnico/interventivo}

De esta forma, se apertura posibilidades de apoyo desde lo que éste padre de la familia de 
Bosa conoce y sabe hacer, resignificando las dificultades en la adaptación al nuevo contexto,

“A Andas a la asociación donde sumerce estuvo allá, (...) entonces yo ah di por trabajar el lunes reciclábamos, y el martes estaba allá en las oficinas, mirando a ver que hacía que nos poníamos a hacer, el miércoles reciclaba y el jueves otra vez estaba allá, entonces de ahí I se dieron así varias cuestiones y ya de ahí de eso comenzamos a hacer un trabajo ya, como dirigente que era, ahí me acogieron bien y me fui abriendo espacios" (Padre, FB, L14).

Permitiéndole ser agente activo en el proceso de reivindicación de sus derechos al encontrarse en condición de desplazamiento,

“(...) ayude a organizar I dos tomas de:: de vivienda aquí en Bogotá, viviendas:: me recuerdo tanto que la primera toma, (...) estaban ellos eran como unos 8 , estaban reunidos, cuando yo llegue a esa reunión que me invitó la amiga, una muchacha que ella es del valle, llama Lorelis, estaba estudiando derecho cuando eso ella, pero es bastante izquierdosa, (...) fue como para un agosto, a tomarse un lote por allá (...) en el norte de aquí de Bogotá, (...) entonces yo me ponía a escucharlo y yo decía hay juepucha y para tomarse uno, en la forma en que llueve aquí en Bogotá, con niños chiquito y todo eso (...) en un lote así a cielo abierto es muy duro" (Padre, FB, L16).

Posibilitando esto que la familia de Bosa se adaptará a su nuevo contexto desde el que uno de sus miembros, su padre, encontró nuevamente su sentido de vida, en relación con el apoyo de otros,

“... me tocó organizar todo eso y a la final yo fui el que me hice al frente de todas las familias y entonces comenzábamos como a organizarnos un poquito y en el trabajo, y en esto, y en el arreglo de la casa, bueno en fin, siempre:: siempre me he caracterizado de ayudar a organizar las cosas, no:: yo nunca espero que me organicen y me pongan ha, ha si 
no que siempre me gusta como buscarme mi propio espacio ¿no? y meterme a::” (Padre, $F B, L 141)$.

Sin embargo, en el caso de la familia del Centro algunos de sus miembros quedaron sin una clara red de apoyo generando algunos niveles de malestar;

“Eso, eso, los primos de él, [ja] dizque sobrinos, los primos de él, están aquí, él llegó fue derecho aquí, y yo acá no tengo a nadie, como le digo yo a nando, usted tiene siquiera con quien conversar o alguna cosa, yo acá soy sola:: con:: sin familia ni nada, esta semana ya hace como un mes, se vino un hermano:: ese si se vino eso sí ya es una ayuda pá uno, ya tiene uno con quien conversar o así, pero eso es muy triste” (Madre, FC, L42).

De otra parte, se resaltan a nivel de la familia de Bosa recursos como la comunicación y el diálogo que les han permitido mantener el vínculo a nivel del subsistema conyugal: "Para nada, prácticamente nosotros somos los mismos casi desde que estamos, (...) las mismas relaciones, si nos ofendemos conversamos, y yo creo que es un ejemplo que casi ninguna familia lleva, conversar bastante, ¿no?, lo que ella no le gusta me lo dice, lo que a mí no me gusta se lo digo” (Padre, FB, L95); vinculación conyugal que se mantiene a pesar de las situaciones difíciles vivenciadas por el CAC “ya ahí se hizo como un antes y un después ¿no? porque ya el callo detenido, yo quede sola con ellos dos, (...) y pues de todas formas ahí sí hubo un:: pero pues no de todas formas no:: no cambio la relación, siguió así como:: como igual” (Madre, FB, L102). Lo que además se extrapola a la dinámica relacional con otros miembros del sistema familiar al mencionarse "no era fácil, pero:: que le digo:: pues tampoco nosotros no permitíamos de pronto:: que los maltratara nadie" (Madre, FB, L140). Ratificando que la dinámica familiar se mantiene antes y después del CAC "no, yo digo que todo ha sido como por el mismo margen (Madre, FB, L94), a pesar de los eventos estresantes que vivenciaron y en los que tuvieron que 
separarse por un periodo de tiempo.

De esta misma forma, en el caso de la familia del Centro se encuentra a partir del relato de la madre que no hubo alteraciones en la dinámica del subsistema conyugal ni parento filial debido al proceso de desplazamiento que vivenciaron en tanto refiere mantener las relaciones sin cambios si retornarán a su lugar de origen "no, seríamos los mismos, porque ese señor es muy cariñoso con todo, en eso sí:: no cambia” (Madre, FC, L85).

\section{Dominio ideológico}

Así mismo, la familia de Bosa reconoce las dificultades que el proceso de desplazamiento genera en las familias, lo cual los invita a evidenciar que las dificultades que vivenciaban con las demás familias con las que convivían presentaban su origen en las nuevas condiciones contextuales a las que tenían que enfrentarse “... a veces disgustos, considero yo, porque no deja de haber alguna familia que trata como de:: de crear pero, pues en si son cuestiones que nosotros aprendimos a manejar en ese entonces" (Padre, FB, L143).

Así mismo, la madre quien participa en un proceso de atención identifica y comprende que las dificultades que la familia vivenciaba por el proceso de desplazamiento se relacionaban a su vez con la manera cómo fue su crianza y las pautas transgeneracionales, resignificando estos aprendizajes familiares para así lograr mantener una relación parento filial distinta en especial bajo esta nueva condición de desplazamiento forzado

"Pues:: digamos que me sirvió mucho I mucho porque yo:: o sea en ese momento por todo lo que me había pasado y yo también, o sea, venía como, digamos yo no tuve papá ni mamá, a mí me crió fue una abuela, eh:: fue mucho maltrato y digamos como que en ese momento se junta todo ¿No? entonces como que todo el mundo se confabulo para acabar con migo, y 
pues esa ayuda en ese momento me sirvió muchísimo, al menos aprendí a no pegarles a ellos, a:: a quererlos, a:: bueno todo ese tipo de cosas" (Madre, FB, L341).

\section{Escenario 2. Profesionales}

\section{Familias impactadas por el conflicto Armado en Colombia (CAC)}

$\mathrm{Al}$ indagar sobre el trabajo con actores del conflicto armado en Colombia y los cambios que se han suscitado a partir de las intervenciones tanto en las familias objeto de atención, como en su misma práctica profesional emergieron diferentes constructos explicativos, formas de proceder y mitos o sistemas de creencias que explican los cambios que se deben visualizar en los procesos interventivos encaminados a gestionar la resignificación y transformación tanto en los individuos como en las familias. Por lo que, la categoría de conflicto armado en Colombia se transforma para dar paso a una nueva categoría denominada familias impactadas por el conflicto armado en Colombia.

\section{Dominio paradigmático}

El conflicto armado en Colombia se ha venido abordando desde un orden más individual que colectivo, entendiendo que la formación de los psicólogos es más de corte clínico -patológico- y desconociendo en gran medida lo contextual, en razón a que

"lo que hoy yo concibo frente a lo psicosocial y frente a la salud mental y frente a la intervención en escenarios de conflicto armado y de posconflicto armado y de construcción de paz son reflexiones que he construido en el marco del trabajo que son muy diferentes a las que tenía recién me gradué de la universidad y recién empecé a trabajar con estos 
escenarios, y ee por su puesto en el marco de reflexiones académicas porque uno trabajando pues ve la necesidad de profundizar en ciertas cosas" (PS1. 4).

Por lo anterior, el conflicto armado en Colombia debe fundamentarse y comprenderse desde los fenómenos sociales en su integralidad, y es allí donde el enfoque sistémico se vuelve protagónico, puesto que busca integrar los diferentes hechos victimizantes o no victimizantes que involucran a un sin número de seres humanos y sus familias, sus contextos y sus comunidades, en tanto que "yo soy familia, yo soy ciudadana, yo soy pareja, digamos psicológicamente también tengo un montón de cosas que me determinan pero yo soy de este contexto político, yo soy de un contexto en el orden internacional, yo soy el resultado de todas esas dimensiones, que me involucran" (PS1.8).

De esta forma, el abordaje del conflicto armado podría alcanzar la prestación de procesos más integradores tanto de saberes como de competencias necesarias para comprender las diferentes rupturas que se presentan en las configuraciones familiares, debido en gran parte a las memorias históricas que se mantienen por los diversos actores a lo largo del tiempo. Lo anterior debido a que, los procesos de atención psicosocial buscan reconocer en la familia interrelaciones movilizadoras y obstaculizadoras, sin embargo, es un tema poco estudiado, en tanto se retoma al individuo o a la comunidad en su generalidad, olvidándose reconocer los diferentes tipos de familia que se han configurado actualmente.

\section{Dominio técnico/interventivo}

En relación al trabajo técnico e interventivo éste debe estar enfocado en la detección de los entornos protectores o expulsores en aras de generar procesos de adaptación que resignifiquen la vida de cada uno de esos actores y de los miembros del sistema familiar al cual pertenecen, en 
donde los contextos y sus interrelaciones juegan un papel predominante en el proceso interventivo, por cuanto la comprensión integral de los fenómenos que se pretende abordar propende por la dinamización de los cambios que requiere el sistema familiar para alcanzar procesos de adaptabilidad; debido a que

"para comprender las emergencias de las nuevas, pues la emergencia de estas nuevas familias ahorita, entonces creo... que los fenómenos además familiares siempre van a exacerbar lo que nosotros sabemos. Cada familia que uno acompaña, digamos empieza a cuestionarse muchas cosas porque esas dinámicas familiares se han venido adaptando mucho a las necesidades mismas de la realidad" (PS1. 10).

Por lo que, para lograr este cometido los procesos de intervención no deben enfocarse en el asistencialismo, únicamente con el afán de cumplir con metas propuestas y ampliar la cobertura, pues lo que se logra es el desconocimiento de las realidades y de los propios dilemas humanos en los actores intervenidos, en tanto "eso es una suma de situaciones, la política pública está orientada a resultados" y "nos cuesta mucho darnos cuenta que los resultados de la intervención social... son muy difíciles de cuantificar”. (PS1. 18), además que la institución

“ponía psicólogos al frente, pero realmente el psicólogo, era un trabajo muy reducido, porque era un trabajo muy instrumental, era un trabajo muy de verificar, que las personas hicieran, cumplieran, hicieran unos talleres, entonces era un trabajo a través de talleres de formación sobre temas que salían, no sabían ni de dónde ni para dónde, pero que eran uno temas que estaban en los protocolos" (TS.22) institucionales establecidos en planes y programas de orden estatal.

Por lo que, la prestación de estos procesos interventivos se enfoca principalmente en una atención organizacional que ofrece una agenda variada de servicios, que no han sido previamente 
contextualizados y analizados acorde con las necesidades de cada uno de los actores del conflicto armado; debido a que este sujeto está

"expuesto a una oferta educativa múltiple, a veces avasalladora. Una oferta que a veces es inconsulta con sus necesidades, expectativas y habilidades que se les aparece de todas partes. Entonces el .... les ofrece empleo y le ofrece talleres de cualquier cantidad de cosas. Hay un montón de entidades que llegan a ofrecerles que les manejan la plata que a ellos les pagan y que a ellos les van a montar un proyecto productivo, y que los van a volver empresarios además" (TS. 24).

De otra parte, se debe vincular a la familia como parte de la intervención psicosocial, mediante la incorporación paulatina de la misma a la organización, para que la red social tenga sentido e importancia en el trabajo con familias impactadas, en tanto permite el reconocimiento de sí mismos desde otra dimensión, en la que las relaciones juegan papeles importantes en la deconstrucción y reconstrucción del sí mismo; en donde en las intervenciones se hace necesario poner de presente la autorreferencia, permitirse reconocer la propia emocionalidad para lograr conectarse con un otro de manera genuina, reconociendo ante todo los recursos de las personas y las familias con las cuales se trabaja, y cómo ellos desde su propia experiencia y saber pueden movilizar transformaciones y cambios; mediante el reconocimiento del sufrimiento del otro y de su historia tanto individual, como familiar y contextual.

\section{Dominio ideológico}

En cuanto a las creencias o lo mitos que se viene configurando en torno al trabajo con las familias impactadas por el conflicto armado colombiano se rescata la existencia de profesionales pluralistas quienes toman cualquier teoría y la asocian a la realidad sin tener claridad epistémica 
sobre la misma, por cuanto "en la realidad tú tienes que integrar saberes, no volverte un pluralista que coge sin ningún fundamento epistémico cualquier teoría" (PS1.8).

Ejemplo de lo anterior, es que una gran cantidad de los profesionales de la psicología conciben la idea de que un actor del conflicto armado en proceso de reintegración anhela volver a vincularse con su grupo familiar, y que este sistema lo debe vincular de una forma armoniosa rápida y segura,

“les pongo un ejemplo, uno supondría que después de que una persona ha pasado por un montón de vivencias en este caso en el marco del conflicto armado, llámese víctima victimario, como se le quiera llamar, desmovilizados, ex-secuestrado, como quieran decirle, uno dice, uno supondría que cuando una persona ha vivido, esta experiencia y por ejemplo tuvo que ausentarse de su familia, uno imaginaría desde mi propia experiencia de vida, que lo mejor que le podría pasar a esa persona es que cuando retorne a donde viven sus padres, pareja o sus hijos, pues que esa persona vuelva a estar con ese núcleo familiar y uno supone que a esa persona que llega, debería hacerlo muy feliz volver y a quienes lo reciben debería hacerlos muy feliz encontrarlo, eso es lo que yo supongo" (PS1. 10).

Es así, que se identifica una idea de la psicología poco integrador y lejana a la realidad de las personas, en donde lo individual no se encuentra permeado por lo social, y las intervenciones grupales desde la psicología no son tan productivas, en tanto se desconocen las reales dinámicas, pautas y puntuaciones familiares que están inmersas en el contexto del conflicto armado en Colombia; debido a que los profesionales en psicología

"hacían un trabajo de acompañamiento, de acompañamiento, de conversa, de escucha y de diálogo con algunos de ellos, pero no en un trabajo de psicoterapia y no era un trabajo. La intervención era muy grupal, entre otras cosas me imagino que también por capacidad, 
eran grupos de treinta - cuarenta participantes para un psicólogo, pero ahí está la capacidad de los protocolos, la guía, las cartillas los modelos de reporte y ahí termina más el trámite burocrático en el diligenciamiento del documento que el proceso metodológico mismo" (TS. 22).

Es por ello, que las familias se encuentran colapsadas no solo por la situación en la cual se encuentran, sino también por la cantidad de ofertas que se le ponen a su disposición, sin lograr utilizar de la mejor manera dichos recursos, puesto que pueden llegar a vivir de los subsidios sin ningún inconveniente, en tanto en ocasiones obtienen subsidios desde distintos roles; y éstas familias se sienten "como avasalladas por la condición en la que están, pero ellas pocas veces logran entenderse como familia, y lograr con familias depurar todas esas ofertas que les están brindando"; terminan convirtiéndose en

"objeto de ellas.... No actores de ellas sino objeto de ellas, entonces en esa medida compiten por esos subsidios, compiten por esas ofertas, hay unos que vician esas familias, hay otros que, que potencian, hay otros que despotencian. Entonces los recursos que llegan por el estado... hay familias que reciben el dinero del desmovilizado pero la esposa también hace parte del proyecto guardabosques, entonces reciben dos o tres subsidios por familia" (TS. 43).

\section{Reconfiguración de la experiencia}

Durante el desarrollo de los escenarios reconocimos como la concepción de salud mental, por parte de los equipos de atención psicosocial, juega un papel primordial a la hora de movilizar la reconfiguración de la experiencia de las personas, familias y comunidades. 


\section{Dominio paradigmático}

Se evidencian falencias en la manera como se concibe y se entiende las circunstancias personales y sociales por la que las personas y grupos atraviesan, por ejemplo

"el desmovilizado puede ser entendido como con un padecimiento de una patología, sin reconocer la historia y condiciones que lo llevaron a pertenecer a un grupo al margen de la ley es así que se cree que el comportamiento delictivo está asociado a situaciones de orden psicológicos, entonces se cree que detrás de este ser humano hay un ser enfermo o con algunas características, eee psicópata. Psicópata, la psicopatía entonces ahí es necesario un psicólogo que lo maneje”. (TS.22)

Existe un cuestionamiento por las rotulaciones víctimas-victimarios, donde se genera una dicotomía. Sin embargo, durante los procesos de atención psicosocial se continúa trabajando dicha distinción, por cuanto

"miren si hay un lugar en donde yo tuve confuso el tema de víctima y de victimario, fue conociendo estos muchachos, ¿quién es la víctima y quienes son los victimarios? uno dice ¿estos son los victimarios?, cuando uno ve a esos muchachos, conversa con ellos y comparte con ellos, uno no ve hay un victimario, uno ve una víctima, otra víctima a otro nivel. Hay dos víctimas, el que ellos masacran, los que matan o que despedazan, y la víctima que era el encargado de cargar el fusil y hacer ese trabajo, ellos otra víctima. porque la condición de ellos es una condición sin sentido" (TS. 24)

Es entonces que se evidencia la necesidad de comprender la salud mental desde otra mirada en la que se el individuo sea comprendido desde una postura eco-eto-antropológica

“...la psicopatología, la perspectiva frente a la salud mental es absolutamente diferente en Colombia concebimos la salud mental, la seguimos concibiendo como enfermedad mental. 
La salud mental va mucho más allá, la salud mental es medio y fin, la salud mental implica la relación el mundo, la relación contexto individuo, eeem lo psicosocial, eee psicopatología, fenomenológica, como empezar a pensar los fenómenos de manera integral eee y sobre todo lo que nos convoca a nosotros son términos como esos, salud mental, convivencia, como entiendo y acompañó eso, impacto del trabajo con el individuo y el colectivo..." (PS1.6)

Por lo que, el trabajo en la salud mental debe ser entendido más como una forma de generar un bienestar general en el ser humano, y no como la ausencia de la enfermedad mental; en tanto es necesario que Colombia se rete a interpretarla como afecta la interacción de las personas con su medio; en tanto“...desde lo conceptual, que es la concepción de salud mental, Colombia tiene un reto enorme, la ley 1616, salió en el 2013, hay se cambia la perspectiva de salud mental, pero nosotros seguimos creyendo que salud mental es la ausencia de la enfermedad mental..."(PS1.22).

\section{Dominio técnico/interventivo}

Los profesionales buscan maneras de promover un trabajo en donde las personas se comprendan como parte de un territorio, de una organización de la cual se encuentran inmersos. Buscan dar un sentido al trabajo en las familias y personas, desde diferentes dimensiones: individual, familiar, territorial; tal como el trabajador social lo expone

“el trabajo que yo hacía, yo hacía un trabajo metodológico en el que lograba que los seres humanos que hacían parte de las organizaciones pensaran su vida, su proyecto de vida, ellos como seres humanos. ¿Cierto? ellos comenzaran a pensar su dimensión como seres humanos, entonces yo les hablaba de su ser, su familia, su territorio, su proyecto de vida, o 
sea les hablaba de dimensión humana, después les hablaba de la dimensión familiar, ósea usted como está en función de su familia y después de la dimensión comunitaria y territorial, este lugar que habito...". (TS. 20)

Pero además reconocen que la intervención debe desarrollarse en un entorno facilitador de la interacción entre terapeuta-consultante y en entornos enriquecidos de estrategias movilizadoras del cambio que faciliten estos procesos adaptativos, en tanto es

“indispensable darle el lugar al otro como experto de su propia vida y como movilizador de sus propios cambios. No soy yo la que sabe cómo mejorar tus relaciones, eres tú en el marco de tus posibilidades y de tu historia el que sabe cómo hacerlo" (PS1. 14), así como "esto se vuelve un elemento para su vida, para reconfigurar la forma de usted vivir y ser un habitante de un contexto diferente" (TS. 12). Es decir que, "Nosotros estamos con la persona, pero cada persona lo que tiene es que despertar, digamos que, su capacidad de recuperación (...) Todo eso, la gente lo va aprendiendo, y ellos se vuelven sanadores y sanadoras" (PS2. 27).

Comprendiendo que los síntomas que emergen durante estas dificultades sociopolíticas son la demostración de dificultades de interacción de la persona con su medio, con su familia o con su comunidad, por ejemplo, la situación de una mujer desvinculada con dificultades para acompañar y orientar a sus hijos;

“...porque esta mujer tiene tan malas pautas de crianza con su hijo, pues porque nunca ha estado con él, entonces miren que eso empieza a encadenar un montón de eventos, no hay buenas pautas de crianza, pero es porque esta mujer ni siquiera tiene la tolerancia que desarrolla una madre o un padre cuando tiene un bebe desde chiquito, ahí se desarrollan unas habilidades. Yo soy tía y yo no tengo las mismas habilidades que mi hermana, ¿por 
qué? pues porque ella lo ha aguantado desde chiquitito y ha desarrollado y se ha adaptado a lo que le exige ser madre. Cuando yo no he hecho eso, por muy madre biológica que sea pues llego y eso me desconfigura a mí, y esa relación difícil, y es difícil para el niño, la niña, es difícil para mí, es difícil para la abuela, y eso desconfigura, en lugar de fortalecer los núcleos familiares o los vínculos familiares los rompe" (PS1.10).

La intervención en salud mental en Colombia se encamina a buscar la ausencia de enfermedades mentales y desconoce la influencia que generan los diferentes contextos en la misma salud de la persona. El proceso interventivo se enfoca en lo individual desconociendo el impacto del medio en el que se desenvuelve esta persona, por lo que “...entonces muy difícil comprender que lo que nosotros hacemos tiene impacto en la salud mental, en la salud mental entendida como bienestar general, y entonces eso nos hace salirnos de nuestro espectro..." (PS1.22).

Es así, que comprendiendo que esta interacción de las familias no solo se da en una sola vía sino por el contrario en una doble vía en donde lo autorreferencial juega un papel importante, en ese proceso de movilización de la reconfiguración de la experiencia de estas familias impactadas. El interventor psicosocial vivencia una serie de cuestionamientos que le permiten comprender al otro de una manera distinta y desde allí intervenir en una co-construcción del bienestar, ya que "Cada familia que uno acompaña, digamos empieza a cuestionarse muchas cosas porque esas dinámicas familiares se han venido adaptando mucho a las necesidades mismas de la realidad" (PS1.10). Se reconoce así la importancia del saber del otro, ya que “... el otro es el que sabe, [y] eres tú el que logra movilizar, poner al lugar al otro de sus cambios y de su propia vida, eso es vital" (PS1.13).

El proceso interventivo debe estar impregnado de la necesidad de dar el lugar que le 
corresponde al otro, para hacerlos parte del cambio, y generadores de sus propias posibilidades de vida; la "gente que ha sido vulnerada y cuyos derechos no han sido reconocidos en muchos años termina aparte de todo haciéndole un favor a los profesionales que los están acompañando. Por un lado, hay perspectivas de... muchos asistencialismos, de mucho, entonces también es yo hago y hago cosas... y de una gran directividad..." (PS1.17).

Aunque se han logrado llevar a cabo intervenciones interesantes con las personas, se evidencian grandes dificultades de estos procesos de atención psicosocial en donde las personas no terminan reconfigurando sus experiencias, al existir tantos niveles de improvisación y de bajo conocimiento de cómo promover una adecuada salud mental a estas personas afectadas, en tanto “...Yo creo que sí, que se han logrado cosas muy chéveres, pero yo creo que no es la generalidad, porque lo que yo hoy he aprendido, ha sido sin duda consecuencia seguramente de muchos errores que yo he cometido, y eso no puede pasar..." (PS1.39).

Por ejemplo, los profesionales no se encuentran preparados para la intervención, y no cuentan con el bagaje suficiente para la misma, la identificación y promoción de los óptimos recursos de las personas, familias y comunidades en pro a la reconfiguración de sus experiencias "Miren ahora hay una cosa muy delicada, es por ejemplo el asunto con las víctimas y es uno de los grandes retos del país es no revictimizar, y cuando yo hago una mala intervención, yo estoy re victimizando, porque le estoy preguntando, porque estoy generando acción con daños, es decir, si yo no estoy preparada para acompañarte, pues no debería sentarme a hablar contigo, y ahora contratan a cualquiera, si, como, usted es psicólogo, venga pa acá, y haga lo que tiene que hacer..." (PS1.39).

Siendo así necesario el realizar un proceso interventivo responsable que permite a la persona/familia impactada por el CAC prepararse para comprender los recuerdos que su 
memoria guarda y cómo traerlos al aquí y al ahora sin generar procesos traumáticos posteriores, en pro a la resignificación de la experiencia vivida, ya que "la memoria es terapéutica, y desde allí lo desarrollamos, pero la memoria también tiene que ser acompañada, porque hemos tenido situaciones muy complejas. Actos de memoria donde llevan a las víctimas y donde las víctimas entran en crisis, pero no en crisis sencillas, sino unas cosas que sorprenden” (PS2. 41).

\section{Dominio ideológico}

Se privilegia la necesidad de aproximar la psicología clínica a lo social, en aras de intervenir desde lo colectivo, para entender cómo el contexto histórico social, político, familiar, cultural, etc., afectan la salud mental y cómo se pueden posibilitar cambios, afirmándose así que "Yo no puedo comprender al sujeto solito, entonces sí me encanta la clínica yo quiero hacer clínica con él solito con el pero yo tengo que entender que ese sujeto es lo que su contexto histórico, político, económico, cultural social ha determinado. Yo no puedo leer un síntoma aislado del contexto..." (PS1.6).

Las dificultades que han surgido referentes a cómo concebir la salud mental han sido un producto no solo de las pocas investigaciones respecto a cómo afecta el conflicto a las personas, familias y comunidades, sino también del déficit de la formación de los profesionales que intervienen en los procesos de atención psicosocial, comprendiendo que “...la salud mental emerge como consecuencia de cuando la gente está bien en sus contextos, en su territorio, y ahí si hay un tema de formación, de que nos enseñaron que era el tema de salud mental, de que nos enseñaron cuál era el objeto de la psicología...” (PS1.22).

La manera de referirse a las personas, tratarlas y de denominarlas se convierte en una dificultad en la reconfiguración de la experiencia, en tanto “... nosotros creemos que sabemos 
nombrar muchas veces el dolor o el sufrimiento y no es tal, por ejemplo, nos encanta colocar, cadenas rótulos, nos encanta poner rótulos, entonces trastorno de estrés postraumático, así era, depresión, y eso en estos contextos es absolutamente nocivo..." (PS1.41). Por ello se evidencia la necesidad de concebir nuevas maneras de comprender los dilemas humanos y las dificultades que surgen de las diferentes interacciones que emergen durante el conflicto y comenzar a “...crear indicadores, de, de eso de bienestar, como están en las familias, bienestar...” (PS1.48).

\section{Proceso de atención psicosocial e interdisciplinar}

Al preguntarle a los entrevistados sobre el uso de actividades artísticas en las intervenciones realizadas por ellos, identificamos que alrededor de esto emergieron diferentes constructos explicativos, formas de proceder y mitos o sistemas de creencias relacionados con los procesos de atención psicosocial y la interdisciplinariedad que explican el uso de esta estrategia de intervención para lograr los procesos de cambio y transformación tanto en los individuos, las familias y el contexto. Por lo que, emerge una nueva categoría desde la que se analizará este escenario y se denomina proceso de atención psicosocial e interdisciplinar, en el cual se abordará además del arte como un proceso de cambio, el rol del interventor psicosocial y la misma interdisciplinariedad.

\section{Dominio paradigmático}

Durante el análisis de los resultados encontramos en común en los profesionales entrevistados que al momento de trabajar o de realizar una intervención con población impactada por el CAC, establecen que todo lo referente a los psicosocial es adjudicado y es reclamado por 
la Psicología, pues ambas palabras tienen la misma raíz, pero no tenemos una definición clara sobre eso que significa o que es, aunque los entrevistados mencionan que los científicos sociales (psicología, antropología, trabajo social, etc.) han ayudado a comprender este concepto desde una perspectiva más amplia, pues “los antropólogos nos han enseñado muchísimo a los psicólogos sobre salud mental eeem y en especial sobre salud mental en escenarios de guerras, conflictos sociales, conflictos armados" (PS. 6).

Es por ello, que se hace necesario que el fenómeno del conflicto armado en Colombia sea abordado desde una postura interdisciplinar enfocada a un carácter más holístico, desde donde otras disciplinas principalmente las que se ocupan del ser humano en tanto social como comunitario, jueguen un papel predominante en la deconstrucción y construcción de este flagelo. Por lo que, profesionales como

“los antropólogos nos han enseñado muchísimo a los psicólogos sobre salud mental eeem y en especial sobre salud mental en escenarios de guerras, conflictos sociales, conflictos armados , lo ... yo... a mí ni me prepararon para trabajar en mi contexto, es decir, a mí me prepararon como si fuera a trabajar en otro contexto, a mí no me dieron suficientes clases de historia del conflicto, de historia de Colombia, ni en el colegio ni en la universidad, y mucho menos me enseñaron a comprender la historia desde la psicología, que es una vertiente que se llama psicohistoria" (PS1. 6).

Dentro de esta percepción, las demás disciplinas plantean que "si se diera un trabajo interdisciplinario e interinstitucional, porque en un trabajo de estos se requiere un trabajo interdisciplinario e interinstitucional, y un trabajo mediado por la política," se daría una intervención impactante positivamente, pero en la realidad se encuentra que "es que esta gente [los psicólogos] de la noche a la mañana terminaron en un modelo de reinserción, sin que la 
ACR tuviera claro el modelo de reinserción. Sin que los cuadros directivos, o militares tuvieran claro el modelo y los participantes mismos (TS. 24).

Siendo así pertinente el que el profesional comprenda como la descontextualización respecto a la realidad del país, implica retos a nivel práctico para atender y desarrollar un adecuado trabajo de atención psicosocial, en tanto

“hay totalmente una descontextualización del país que habitamos entonces creo que ese es el primer cambio eee como enfrentarse a nuevos retos en relación a la atención psicosocial con víctimas de violencia, lo segundo es que en la institución donde trabajo el abordaje no es exclusivamente desde la psicología, ha sido desde la medicina, la sociología, desde el trabajo social, desde la pedagogía y ha sido también una construcción interdisciplinaria donde hemos construido un enfoque común...” (PS2. 06).

Y es así, que la adjudicación de lo psicosocial a la psicología no ha sido el único de los problemas encontrados, sino también el proceso de formación profesional en psicología de las universidades pues

"nuestra formación, como seguramente termina pasando en otras disciplinas, es muy escondidas, entonces o somos muy clínicos o somos muy sociales o somos muy políticos o somos organizacionales, y en ese orden, pues, mmm digamos maduramos conceptualmente dependiendo de lo que nos llama la atención o nos interesa, la realidad no es eso, la realidad nos invita a pensar que no podemos estar tan separados los sociales de los clínicos, [...] que he aprendido, que hay que abrir el panorama, que la psicología necesita otras disciplinas que es absolutamente crítica o necesaria fundamentar la interdisciplinariedad, trabajar con antropólogos" (PS1. 6).

De igual forma, las narrativas de los entrevistados estuvieron orientadas a formular 
constructos explicativos enfocados a cómo los procesos de atención psicosocial usan el arte y las ventajas de utilizarlo en un contexto interventivo, emergiendo la interdisciplinariedad con un papel relevante en este proceso.

Por el ejemplo, el trabajador social menciona que sus procesos interventivos están orientados bajo una técnica de investigación acción participativa desde un ejercicio pedagógico, por cuanto

"Creo que la lúdica es la mejor manera de enseñar [...] desde la lúdica, y fue muy productivo, y muy generador de cosas. Vincule torneos de futbol, ehh, vincule procesos de escriturales, vincule ehhh, mmm, de pintura. Cosas de esas, porque eran cosas en la cuales ellos tenía ocupación, pero a través de su ocupación podían compartir, tener un espacio lúdico, y a partir de ahí ya podía generarse esos escenarios para dialogar lo humano, y para poner en palabras cosas que se sentian y se transformaban” (TS. 46).

Mientras que los psicólogos, mencionan que durante sus procesos de intervención psicosocial con el arte

"todas las cosas simbólicas, terminan siendo herramientas o medios muy eficaces para trabajar con los sentimientos de los otros, ¿por qué?, porque sobre todo en contextos de violencia, porque hay cosas, sobre todo, hay en Colombia nosotros no logramos imaginar las cosas tan horribles que pasan en nuestro país, hay cosas tan difíciles que ni siquiera podemos nombrar, si, no logramos poner en palabras, o si las, o si se pueden nombrar no somos capaces de nombrarlas” (PS1.42).

Refiriéndose así la pertinencia del uso de técnicas artísticas en los procesos interventivos como posibilitadoras de la externalización del problema acorde a la participación de las personas en eventos traumáticos, así como de la misma resignificación de estas vivencias: 
"La música, el teatro, la pintura, la danza, todo eso posibilita... digamos momentos catárticos que no se dan en un espacio terapéutico individual (...) por ejemplo, el canto desbloquea, digamos que desbloquea el cuerpo energéticamente hablando y también te desbloquea emocionalmente o sea lo que no has podido decir lo haces a través del canto y lo permites hacer desde allí eee digamos demuestra un resultado terapéutico mayor, igual con las personas que han decidido usar el teatro como mecanismo de denuncia pero también como forma de reelaboración de las experiencias traumáticas, ellos también han posibilitado... es más ellos también dicen que lo que más les ha servido terapéuticamente es estar en las tablas cuando la gente va los escucha, cuando ellos tienen posibilidades de contar su historia de vida desde de otra manera pero la están contando, pues creo que eso..." (PS2.10).

En los relatos ambos profesionales mencionan, desde la diferencia de su profesión, la utilización de actividades artísticas durante los procesos de intervención psicosocial, como estrategias que permiten una mejor comunicación con y entre los actores del CAC, pues estas les brindan a los intervenidos la posibilidad de expresar las emociones o sentimientos que no se les facilitan mediante el lenguaje verbal.

\section{Dominio técnico/interventivo}

En relación con los procesos técnicos e interventivos de atención psicosocial dirigido a los actores del conflicto armado en Colombia se obtiene que la formación profesional de las ciencias sociales y humanas no suministra suficientes estrategias de intervención psicosocial, que le permitan, por ejemplo, a los psicólogos egresados intervenir en los contextos con este tipo de 
atención. Dado que

“a los psicólogos aún hoy y los profesionales en general, pero pues lo que nos compete sobre todo a los de ciencias sociales no se enseña mucho sobre lo psicosocial" y "entonces, lo que hoy yo concibo frente a lo psicosocial y frente a la salud mental y frente a la intervención en escenarios de conflicto armado y de posconflicto armado y de construcción de paz son reflexiones que he construido en el marco del trabajo que son muy diferentes a las que tenía recién me gradué de la universidad y recién empecé a trabajar con estos escenarios" (PS1. 4).

De otra parte, se ha venido abordando el fenómeno del conflicto armado en Colombia desde una "postura psicoanalítica se trabaja de manera individual con el ser, y sus procesos intrapsíquicos, y lo que descubre la profesional es la importancia de entender a la persona en su contexto, como un ser bio-psico-poli-eco-antropológico. En donde el clínico también desde su quehacer trabaja el contexto de la persona, reconoce sus interacciones y relaciones" (PS1. 6), en razón a la inclinación de un ejercicio profesional impregnado de un enfoque con el que se identifica el profesional desconociendo "que la clínica que hoy Colombia necesita es una clínica muy social entonces a los que les gusta la clínica les gusta atender individualmente y es necesario que a los que nos gusta la clínica trabajemos con colectivos ¿sí?” (PS1. 6). Lo que también lleva a que otras disciplinas perciban al psicólogo como

"al frente [de los procesos de atención psicosocial], pero realmente el psicólogo, era un trabajo muy reducido, porque era un trabajo muy instrumental, era un trabajo muy de verificar, que las personas hicieran, cumplieran, hicieran unos talleres, entonces era un trabajo a través de talleres de formación sobre temas que salían, no sabían ni de dónde ni para dónde, pero que eran uno temas que estaban en los protocolos de la ACR” (TS. 22). 
En relación con lo anterior, se empieza a observar la necesidad de involucrar a los miembros de la familia y los contextos en los cuales el consultante participa como una forma de intervenir: "Bueno, acá nosotros tenemos una posibilidad y es que cuando llega la persona nosotros no atendemos individualmente a la persona, eso es algo que no había dicho antes, pero una vez. llega acá la primera consulta que nosotros tenemos, claro con el consentimiento de la persona es una consulta mixta. Esa consulta mixta es médico y psicólogo y dirá aproximadamente dos horas, ¿porque la hacemos así? Para que haya un solo relato y a partir de ese relato definir una ruta terapéutica que no ... donde la persona no tenga que volver a contar qué es lo que pasa cuando se referencia, va al médico lo referencia a un psicólogo, posiblemente al trabajador social y luego al psiquiatra si lo necesitara, entonces acá intentamos evitar eso, posterior a esa consulta inicia una ruta que no solo es para la persona sino que empezamos abrirla a todo su núcleo familiar entonces posiblemente hay terapia de pareja, terapia de familia y si ella pertenece a un grupo social específico lo vinculamos a ese grupo social también a un espacio acompañado (...) (PS2. 10).

Es por ello, además, que no solo la falta de una formación pertinente influye en los procesos técnicos e interventivos de atención psicosocial, sino que la carencia de conocimiento y contextualización de los profesionales en relación con la historia del conflicto armado en Colombia obstruye las posibilidades de focalizar y direccionar estos procesos de intervención de forma adecuada.

Es por ello por lo que, existe la necesidad de realizar intervenciones integrales que generen mayores diálogos entre saberes para obtener un proceso más enriquecido, en donde de manera holística se articulen las diferentes dimensiones que componen a un ser humano; en razón a que "lo que había eran equipos muy compartimentados, eso me tocó a mí, donde se suponía que 
cada uno, tenía a un saber. Hay uno diferencia entre los transdisciplinario y lo interdisciplinario. Era más transdisciplinario lo que hacíamos, porque lo inter era más como desde la psicología se usan herramientas de la antropología, la sociología, y como los sociólogos usan herramientas de la psicología y así, como utilizamos las herramientas metodológicas de otras disciplinas" (PS1. 34).

Y aunque la estrategia del arte acompaña el proceso de intervención psicosocial como tal, no podemos pasar por alto la necesidad de evaluar el impacto de las mismas en la intervención, vista esta evaluación desde una connotación cualitativa y no cuantitativa meramente de cumplimiento de objetivos. Por lo que, se debe proponer una forma de evaluación desde indicadores cualitativos sobre el uso y el impacto de estas estrategias en la resignificación de las vivencias de las familias impactadas por el CAC y sus miembros, tal como lo menciona la psicóloga con relación a que

"los profesionales en ciencias sociales, muchas veces no quedamos no pues deje que eso fluya, eso fluya, y a la hora de hacer políticas públicas, pues hay que mostrar efectividad y eficiencia en los procesos, que, pero hay que crear formas para medir, si porque las que hay son muy numéricas, y nosotros nos quejamos mucho de eso, ah pero yo no puedo cuantificar el bienestar, subjetivo en la gente. Está bien si no puedes ponerle un número dinos una forma de medirlo, que hacemos, pero no nos hemos puesto a esa tarea, preferimos quedarnos criticando los números. Si hay que crear indicadores, de, de eso de bienestar, como están en las familias, bienestar" (PS1. 47).

\section{Dominio ideológico}

Con relación a las creencias que se pueden tener durante la ejecución de los procesos de 
intervención psicosocial sobre el uso de actividades artísticas, encontramos que para los profesionales les es muy gratificante un proceso que impacte, en vez de la aplicación de protocolos que no generan transformación y cambio, en este sentido el trabajador social recuerda que

"yo me acuerdo de dos experiencias que me han marcado a mí la vida. [...] llegó un pelao y me abrazo. ¿Que más ---!. Y yo, yo no lo conocía. Hay gracias a usted estoy vivo. Y yo. Claro yo era de los mondoñedos de los lecheros del bajo Urabá, gracias a la oportunidad, a la forma como ustedes nos brindaron, ustedes trabajaron con nosotros, yo hoy estoy vivo; mi hermano está muerto, mi primo está muerto que eran de la banda, yo estoy vivo, porque cambie mi vida. Yo iba pa la banda y hoy estoy al frente de la corporación cultural, que le llaman XXX, y nos pusimos a hablar y todo el cuento, y le digo valió la pena haber posibilitado una relación diferente, entonces como que ahí uno le encuentra sentido a lo que uno es como ser humano y a lo que es como profesional. Todos los millones por una vida, aunque hayan sido muchas las que se perdió, pero hay valió la pena, porque hubo una configuración de un sentido de vida. Y hubo otra oportunidad en la que a veces trabajando con lo organizacional y con estas instituciones se mete en muchos escenarios, y en esos programas a veces a uno le piden que genere resultados de cuántas empresas tiene, la empresa cuanto está debiendo, una lógica muy instrumentales, y hay una corporación que yo, yo ayude a montar varias asociaciones en el bajo cauca, y una asociación, fue una asociación que yo nunca le vi que fuera a ser muy productiva caucheramente, ni la gran empresa, pero que si tenía organización que tenía una potencia política y social muy grande; y volví como a los 3 años después de haber estado en ese proyecto, encontré la asociación tal, con su supermercado, empresa, a veces muy alejada de la gente, pera era 
una empresa que mejor dicho que no se había quebrado” (TS. 50).

Así mismo, durante la elaboración del análisis de la categoría del arte como una estrategia de transformación, planteada en el estado del arte documental, encontramos que el arte es una estrategia que ha sido bastante utilizada durante procesos de atención dirigidos a la intervención de cualquier tipo de conflicto, en tanto los entrevistados refieren que no siempre le es sencillo o fácil al actor del CAC atribuir un nombre o expresar verbalmente sus sentimientos, emociones y pensamientos ante las situaciones vividas.

Además, encontramos que los profesionales en psicología, tanto los/las entrevistados(as) como las entrevistadoras "no nos estamos preparando para lo que la realidad requiere de nuestro contexto..." (PS1. 4). Pues como ha sido mencionado, la formación ha estado encaminada a conocer y comprender el surgimiento de la psicología, sus avances, teorías, etc. con base a contextos norteamericanos y europeos, pero se nos está olvidando la comprensión de la profesión desde Latinoamérica, como mínimo, y Colombia. Además, de continuar con la división opositora y excluyente entre los campos de acción de la misma, pues si somos clínicos no podemos ser sociales, pero la realidad contextual hace que se necesite un trabajo conjunto entre ambos campos (como fue expuesto anteriormente desde la voz de la psicóloga).

El profesional debe buscar ampliar sus comprensiones respecto al mundo, permitiéndose capacitaciones en las que se amplíe procesos medicinales y artísticos, al ser pertinente la mediación de un conocimiento más local que posibilite mayor conexión y apropiación de las personas con los procesos terapéuticos propuestos, en tanto que se deja de imponer una visión más occidentalizada, al provenir la población de un contexto más rural (campesinos, comunidades indígenas, etc.), por lo que

“...con medicina alternativa desde... lo digamos desde lo fisico y eso implica un abordaje 
que en el campo nuestro por ejemplo... eee hemos tenido capacitaciones en esencias florales (...) pero también nos hemos capacitado en masaje, masaje terapéutico, eee moxibustión eee en digito puntura, en plantas, entonces todo eso ha sido un proceso formativo que se utiliza con la gente, porque además la proximidad es mayor porque son comunidades indígenas, campesinas, casi todas de origen rural y cuando les ofrecemos todo esto como que hay mayor... bueno un proceso de empatía mayor, por eso hemos utilizado como estas técnicas" (PS2.08).

Así mismo, se está presentando el uso incorrecto de las herramientas técnicas, pues se cae con frecuencia a errores epistemológicos bajo la justificación de la interdisciplinariedad, como lo menciona la psicóloga "ama tu autor favorito maravilloso, pero en la realidad tú tienes que integrar saberes, no volverte un pluralista que coge sin ningún fundamento epistémico cualquier teoría ¡no! pero fundamenta y comprende los fenómenos sociales en su integralidad” (PS1. 8).

Complementando esta claridad epistemológica, el psicólogo explica que hacer uso de la interdisciplinariedad tiene como fin la comprensión y determinación de la intervención y las técnicas para cada caso en particular, es decir que “...si nosotros trabajamos lo emocional pero hay molestias físicas es imposible, pero lo físico es un espejo de lo emocional y cac también encontramos que ha sido eee muy característico que la persona que ha sido impactada por la violencia” (PS2. 12).

Esta categoría emergente nos deja una gran reflexión como investigadoras e interventoras, pues nos hace tener en cuenta el contexto o la realidad de con quienes estemos trabajando en todo momento, sin importar el campo de acción en el que trabajemos ni la corriente formativa que viene del pregrado y/o posgrados, en coherencia con la forma como pensamos, hablamos y trabajamos. 


\section{Conclusiones}

En el desarrollo del estado del arte documental nuestras categorías de análisis eran la paz Conflicto Armado en Colombia (CAC) - posconflicto, salud mental y el arte como proceso de cambio. Sin embargo, luego del desarrollo de los escenarios testimoniales y su respectivo análisis encontramos que estas categorías se transformaron en las categorías de familias impactadas por el Conflicto Armado en Colombia (CAC), proceso de atención psicosocial e interdisciplinariedad y la reconfiguración de la experiencia.

Cada familia desde su particularidad se enfrenta a situaciones adversas propias del proceso del desplazamiento forzado que deben ser tomadas en cuenta por los profesionales en tanto promueven a su vez cambios en la dinámica familiar, que se ven influenciados por el propio ciclo vital de la familia y de sus miembros y sus particularidades mentales y físicas, así como por la situación misma del proceso de desplazamiento y del contexto al cual migran.

Es decir que los equipos de intervención deberían reconocer tanto los entornos expulsores o protectores, así como intervenciones integrales que posibiliten procesos de adaptabilidad, y que realmente se encuentren a su alcance, desde el reconocer el funcionamiento familiar y no solo enfocarse en el miembro que presenta un malestar. Ya que se pierde todo el contexto e historia personal, familiar y social, en donde se entretejen los diferentes puntos que deberían ser trabajados.

En este sentido, se empiezan a realizar comprensiones complejas sobre esta descripción a partir de las explicaciones de las familias y de los conocimientos o hipótesis con las cuales cuentan las interventoras durante el escenario conversacional, se comprende que no solo es el haber enfrentado hechos violentos durante el proceso de gestación de sus hijos, que son definidos 
como problema, sino que existen otros factores propios del contexto y del proceso de desplazamiento que potencian la emergencia de estas situaciones tensionantes.

Se hace evidente, que los procesos de atención que brinda el estado para las familias que han vivenciado el CAC, se encuentra en su mayoría ligado a una recompensa o apoyo económico, situación que ha algunas familias les genera malestar y desinterés al sentir que no son indemnizados, sino que a su vez son re victimizados no solo por el proceso de atención que vivencian sino también por las constantes discriminaciones de la misma población a la que migran.

Sin embargo, cada familia desde sus propias capacidades ha logrado adaptarse al nuevo contexto a partir del uso de los aprendizajes construidos en su experiencia vivida, en donde a partir de los recursos individuales, especialmente de los miembros del subsistema parental, se han aperturado resignificaciones sobre la forma como se relacionan a nivel del subsistema conyugal y parento filial; y aunque se comprenden alteraciones en la dinámica familiar éstas han sido afrontadas de diversas formas para construir y mantener su propias pautas de relación.

Así mismo, estas familias se han permitido ampliar sus redes de apoyo representadas en la comunidad, educación y trabajo a partir del uso de sus propios recursos individuales aperturando nuevas formas de comprender y relacionarse en el nuevo contexto al que llegan luego de vivenciar acontecimientos del CAC; sin embargo, la presencialidad de la red de apoyo familia extensa es escasa y es mencionada para relacionarla con las vivencias del CAC o convocar pautas transgeneracionales aprehendidas y usadas en la dinámica relacional del sistema familiar teniendo en cuenta el contexto particular de cada familia.

Es por ello, que comprender el contexto en el que trabajamos sin importar la corriente epistemológica de formación o el campo de acción es vital para ser coherentes con la forma 
cómo pensamos, hablamos y trabajamos como psicólogos, reconociendo a las personas como seres eco-eto-antropológicos.

En consecuencia con lo anterior y gracias a la formación que brinda la maestría pudimos entender que nuestro fenómeno de estudio, el conflicto armado en Colombia, no solamente se aborda y se puede comprender por las corrientes tradicionales de estudio, quienes lo hacen (victimarios) y quienes lo sufren (víctimas), sino que existen otros sistemas que complementan estos estudios y permiten traer las voces de los demás sistemas que viven el conflicto, como los profesionales que trabajan en pro de la población impactada por el mismo, las familias, las comunidades, las instituciones estatales y privadas, etc.

Así mismo, se reconoce como las dificultades frente a la comprensión de salud mental han generado graves impactos en las intervenciones, al terminarse rotulando, y por ende patologizando a las personas, familias y comunidades que han sido impactadas por el conflicto. Identificándose la necesidad de entender los dilemas humanos y las dificultades de las familias que han vivenciado estos hechos, desde las interacciones entre sus miembros y con el contexto en el cual se encuentran inmersos, constituyendo para Colombia el reto de entender la salud mental como el medio y el fin en el bienestar del ser humano.

De otra parte, se hace necesario vincular a la familia como parte de la intervención psicosocial, mediante la incorporación paulatina de la misma a la organización, para que la red social tenga sentido e importancia en el trabajo con familias impactadas, en tanto permite el reconocimiento de sí mismos desde otra dimensión, en la que las relaciones juegan papeles importantes en la deconstrucción y reconstrucción del sí mismo.

De esta forma, en las intervenciones se hace necesario poner de presente la autorreferencia, permitirse reconocer la propia emocionalidad para lograr conectarse con un otro de manera 
genuina, reconociendo ante todo los recursos de las personas y las familias con las cuales se trabaja, y cómo ellos desde su propia experiencia y saber pueden movilizar transformaciones y cambios; mediante el reconocimiento del sufrimiento del otro y de su historia tanto individual, como familiar y contextual.

A partir de la transformación de las categorías o focos de trabajo, encontramos según lo conversado con los profesionales y las familias que es pertinente hacer uso del arte como estrategia de cambio para conocer la reconfiguración de la experiencia narrada de las familias que vivenciaron acontecimientos del CAC, en razón a que esta estrategia hace parte del proceso interventivo y de diálogo con otras disciplinas; es decir que posibilita la externalización de emociones y sentimientos, como un instrumento que permite desbloquear a la persona y sus familias, desde su capacidad creadora, en la que los saberes locales permiten la transformación de la experiencia; en tanto se hace entrega de los sentimientos vividos, y se permite contagiar a los demás de estos y que así los puedan resignificar.

\section{Discusión Estado del Arte}

El objetivo del siguiente apartado es evidenciar los cambios, reflexiones, intereses y/o transformaciones que ha tenido nuestro tema e interés de investigación desde el comienzo de la elaboración de los estados del arte hasta la escritura de los mismos, teniendo en cuenta las categorías finalmente abordadas en estos, así:

\section{Familias que han vivenciado el CAC.}

En el estado del arte testimonial y documental se confirmó que la intervención con familias 
se ha venido fortaleciendo en tanto cada una, desde su particularidad, se enfrenta a situaciones adversas propias del proceso del desplazamiento forzado generando cambios en el funcionamiento familiar, el cual se ve influenciado por el ciclo vital de la familia y de sus miembros y sus particularidades mentales y físicas, así como por el contexto al cual migran, tal como sucede con las familias entrevistadas en el estado del arte testimonial quienes exponen por ejemplo los dilemas frente al desear volver al campo o continuar en la ciudad

“... ya estoy aburrida como del tema de la ciudad y todo, pero entonces ahora hay un eslabón que son lo hijos que no I que no se quieren ir, como nunca han salido de acá de Bogotá, prácticamente aquí se criaron y todo como que ya ellos no quieren saber qué es eso, que es un pueblo...” (Madre, FB, L73). "Pues estaría ya más contenta, sin un peligro para ella aquí...porque tiene que estar tras de ella, quien llegó a la casa y quien no llegó, porque usted sabe que por ahí la gente :: la niña ya tiene su edad, en cambio allá en la finca estaba ella, ya más relajada por la edad que tiene, está en otro aire, en cambio el aire de aquí de Bogotá no es bueno I no::" (Madre, FC, L75), llevando esto a que se comience a reconocer en las investigaciones, el papel de este núcleo primario en el bienestar tanto del individuo como en la manera que se relacionan, constituyendo los cambios en las relaciones intrafamiliares de acuerdo al evento vivido, la separación o fallecimiento de miembros, la estructuración de los roles familiares y las relaciones y manifestaciones afectivas en el nuevo contexto (Lozano y Gómez, 2004); un punto importante para trabajar en pro a ahondar en las problemáticas que vivencian las personas y familias que se enfrentan a procesos de desplazamiento forzado.

Teniendo en cuenta lo conversado en el testimonial con las familias, se reconoce como estas familias al asentarse en un nuevo contexto debido a la situación de conflicto en la que se 
encuentran inmersas, si bien buscan ampliar sus redes de apoyo representadas en la comunidad, educación y trabajo para así potenciar sus recursos individuales y comenzar a adaptarse a este nuevo espacio en el que se encuentran alejados de sus familias extensas, estas últimas aún están presentes en las pautas transgeneracionales que comienzan a identificar y a tomar fuerza bajo dichos estresores psicosociales frente a lo que una de las familias expone

"Pues:: digamos que me sirvió mucho I mucho porque yo:: o sea en ese momento por todo lo que me había pasado y yo también, o sea, venía como, digamos yo no tuve papá ni mamá, a mí me crió fue una abuela, eh:: fue mucho maltrato y digamos como que en ese momento se junta todo ¿No? entonces como que todo el mundo se confabulo para acabar con migo, y pues esa ayuda en ese momento me sirvió muchísimo, al menos aprendí a no pegarles a ellos, a:: a quererlos, a:: bueno todo ese tipo de cosas” (Madre, FB, L341). Aunque se muestran reservados a compartir su historia “(...), y contábamos así muy someramente lo que:: desplazados, de donde veníamos, sí:: pero no contábamos en sí a fondo" (Padre, FB, L378); “sí, (...), por aquí uno casi ni conoce los vecinos, saben ellos de que uno llegó como familia desplazada pero no:: uno nunca se sienta a contar como, cuando, que le paso, nada, nada, nada de eso, porque uno eso lo tiene como conservado,(...), pero así muy pasajero, recién llegamos, de resto no" (Padre, FB, L382),

en tanto bajó su situación de desplazamiento se presentan procesos de inseguridad, debido a la vulneración y condición de pobreza constante a la cual se enfrentan (Palacio y Madariaga, 2006; citado por Amar-Amar y Otros 2011), evidenciándose así para algunas una mayor confianza en la familia y desconfianza hacia lo comunitario (Dallas, 2005; citado por AmarAmar y Otros 2011) refiriendo "usted tiene siquiera con quien conversar o alguna cosa, yo acá soy sola:: con:: sin familia ni nada, esta semana ya hace como un mes, se vino un hermano:: ese 
si se vino eso sí ya es una ayuda pá uno, ya tiene uno con quien conversar o así, pero eso es muy triste” (Madre, FC, L42).

Lo que es identificado en las investigaciones (del documental) y los profesionales que participaron en el estado del arte testimonial al proponer que se presenta un reto en donde los equipos de intervención deberían reconocer tanto los entornos expulsores y/o protectores, puesto que por ejemplo una de ellas expone que la "postura psicoanalítica se trabaja de manera individual con el ser, y sus procesos intrapsíquicos, y lo que descubre la profesional es la importancia de entender a la persona en su contexto, como un ser bio-psico-poli-ecoantropológico. En donde el clínico también desde su quehacer trabaja el contexto de la persona, reconoce sus interacciones y relaciones" (PS1. 6), así como intervenciones integrales que posibiliten procesos de adaptabilidad y el perfeccionar las estrategias de evaluación y diagnóstico psicosocial (Sinisterra y otros, 2010), en razón a la inclinación de un ejercicio profesional impregnado de un enfoque con el que se identifica "que la clínica que hoy Colombia necesita es una clínica muy social entonces a los que les gusta la clínica les gusta atender individualmente y es necesario que a los que nos gusta la clínica trabajemos con colectivos ¿sí?” (PS1. 6).

Siendo así necesario reconocer las personas como seres eco-eto-antropológicos y así comenzar a generar procesos que permitan a los individuos y las familias obtener recursos que les faciliten afrontar su situación de una manera más adecuada desde una estabilidad emocional, ya que estos actores enfrentan afectaciones en su calidad de vida (Amar-Amar, Abello-Llanos y Otros, 2011; Andrade, Parra y Torres, 2011 y Llanos y Otros, 2009).

Por lo que la familia se convierte en un eje fundamental puesto que es considerado un sistema que se encuentra en relación con otros sistemas, bajo el que se puede desde el enfoque sistémico enfatizar sobre sus relaciones internas y con otros (Andolfi, 1984; Feixas, et al, 2012, 
citados por López, 2014), puesto que desde un trabajo pedagógico en pro a la reconciliación (Guerra y Sánchez, 2015), (Guerra y Plata, 2015), y el desarrollar procesos de emancipación del propio sufrimiento (López y Rodríguez, 2012), se puede obstaculizar la perpetuación de las dinámicas de violencia.

Al identificarse las dificultades estatales por intervenir la relaciones del sistema familiar debido a las pocas investigaciones que indaguen respecto a la realidad de las familias inmersas en estos contextos (Plata y Guerra, 2005) y en especial las que se encuentran en condición de desplazamiento, este trabajo de investigación desde una perspectiva sistémica, facilitará una lectura más compleja y relacional del fenómeno del CAC, y sin duda abrirá varias posibilidades para intervenir estas familias impactadas por el mismo, a través de las narrativas y los mismos patrones de interacción exaltar un abordaje terapéutico que pueda ser útil para la práctica clínica y para los mismos procesos de intervención a esta población.

\section{Salud mental y reconfiguración de la experiencia.}

De otra parte, el segundo de los cambios se presentó en el área de la salud mental, en donde se evidenció que legalmente las personas que han sido impactadas por el CAC deben recibir "el conjunto de actividades, procedimientos e intervenciones interdisciplinarias diseñadas por el Ministerio de Salud y Protección Social para la atención integral en salud y atención psicosocial. Podrán desarrollarse a nivel individual o colectivo y en todo caso orientadas a superar las afectaciones en salud y psicosociales relacionadas con el hecho victimizante (tomado de https://www.minsalud.gov.co/proteccionsocial/Paginas/Victimas_PAPSIVI.aspx; Decreto 4800 de 2011, Artículo 164), puesto que se evidencia que el fenómeno del desplazamiento forzado se encuentra a su vez atravesado por una situación psicosocial y jurídica (Campo-Arias, Oviedo y Herazo, 2014). 
Es así, que, con relación a la salud mental tanto en las investigaciones como en lo planteado por los profesionales del estado de arte testimonial, se identifica la importancia de abordar los conflictos que viven las familias, desde un ámbito social, psicológico y cultural. En tanto desde la postura sistémica, según López (2014), el problema psicológico y compartido en un contexto social no debe ser visto como una situación individual. Además, desde una postura más compleja, el contexto interaccional termina jugando un papel importante en la comprensión de lo psicopatológico. En tanto los profesionales entrevistados afirman "Yo no puedo comprender al sujeto solito, entonces sí me encanta la clínica yo quiero hacer clínica con él solito con él, pero yo tengo que entender que ese sujeto es lo que su contexto histórico, político, económico, cultural, social ha determinado. Yo no puedo leer un síntoma aislado del contexto..." (PS.6).

Así mismo, según los profesionales que han trabajado en procesos psicosociales, identifican las falencias de la concepción colombiana respecto a la salud mental, en donde continúa siendo vista esta como la ausencia de la salud mental. La conciben entonces como un medio y fin hacia el bienestar, en donde influye el contexto (Chaves, 2011). Por lo que, en este punto según Chaves (2011) se hace pertinente reflexionar acerca del conflicto respecto a la manera como reconfiguran e incorporan la violencia en su cuerpo y vidas las personas que se encuentran impactadas o cercanas a esta,

"Pues porque yo quede mejor dicho, con la vida llevada, llevada en ese momento, que quede sin casa, con él detenido, que sin trabajo” (Madre, FB, L147), “(...) entonces nos vinimos aquí para Bogotá, pero no ha sido fácil este Bogotá (...) o sea, aquí se queda uno como por costumbre de quedarse pero no es porque uno se adapte a vivir acá, (...) llegamos a una casa de inquilinato en el norte, por allá en San Cristóbal Norte, vivíamos con:: a mí me dieron espacio 5 familias desplazadas vivían ahí en una sola casa, (...) sin conocer 
prácticamente a nadie (...), entonces allá en el norte reciclamos para conseguirnos la comida (...)" (Padre, FB, L12).

Evidenciando la manera como las personas construyen cambios éticos, morales, e identitarios, naturalizando la violencia, y cómo se construye a partir de una interacción con otros y con el mundo. En tanto esto se comprende con las familias, que no solo es el haber enfrentado hechos violentos durante el proceso de crecimiento de sus hijos, que son definidos como problema, sino que existen otros factores propios del contexto y del proceso de desplazamiento que potencian la emergencia de estas situaciones tensionantes, tal como lo exponen una de las familias quien su segundo hijo presenta dificultades a nivel escolar en su lecto escritura lo cual es relacionado por su familia a lo vivenciado en su infancia en el proceso de desplazamiento; “Cuando llegamos acá no estuvo si no como un mes o dos meses ya antes de:: digamos de salir para:: pal colegio, entonces no tuvo como ese proceso de jardín mientras que él sí y él sí, entonces pues o sea, no sé qué pasó ahi’” (Madre, FB, L188); así como en la otra familia, en el desarrollo gestacional de su segunda hija evidenció todo el proceso de violencia, además de que la infante presentara una meningitis: "Sí, porque uno era:: y a mí siempre yo toda la vida eh sido muy nerviosa, entonces ahí fue donde Paola pudo haber cogido todo eso, que uno le daba miedo y yo miraba, será que viene por uno, o que pasaría, pero no ellos no, pasaban todo:: todas las noches mantenían por ahí en una finca” (Madre, FC, L57).

Lo que hace pertinente el generar comprensiones complejas de la situación que las familias en esta condición de desplazamiento vivencian, proponiendo así Villa (2014) que el foco de la intervención se traslade de una propuesta de estereotipos al reconocimiento de lo que la otra vivencia, que les permita a las personas mediante una memoria colectiva potenciar sus capacidades de afrontamiento y resiliencia. Siendo esta propuesta coherente con la idea de los 
profesionales de "darle el lugar al otro como experto de su propia vida y como movilizador de sus propios cambios. No soy yo la que sabe cómo mejorar tus relaciones, eres tú en el marco de tus posibilidades y de tu historia el que sabe cómo hacerlo" (PS. 14).

Mientras Rodríguez (2015) plantea que las acciones psicosociales y de salud mental deben estar integradas a la atención primaria en salud bajo el modelo basado en la comunidad. Lo que implica una adecuada capacitación y distribución del recurso humano, así como la apertura a nuevos saberes tales como el arte, el trabajo corporal y los recursos sanadores de las mismas personas, quienes son los únicos expertos de lo vivenciado. En este caso "el otro es el que sabe, [y] eres tú el que logra movilizar, poner al lugar al otro de sus cambios y de su propia vida, eso es vital" (PS.13).

Para los profesionales entrevistados reconocen que la manera como los interventores se refieren a las personas, las tratan y las denominan, se convierte en una dificultad en la reconfiguración de la experiencia, en tanto “... nosotros creemos que sabemos nombrar muchas veces el dolor o el sufrimiento y no es tal, por ejemplo nos encanta colocar, cadenas rótulos, nos encanta poner rótulos, entonces trastorno de estrés postraumático, así era, depresión, y eso en estos contextos es absolutamente nocivo..."(PS.41). Por ello se evidencia la necesidad de concebir nuevas maneras de comprender los dilemas humanos y las dificultades que surgen de las diferentes interacciones que emergen durante el conflicto y comenzar a “...crear indicadores, de, de eso de bienestar, como están en las familias, bienestar..." (PS.48).

Es por esto que si bien en las investigaciones se hace evidente que dependiendo de la intensidad y severidad de los eventos vivenciados se generan repercusiones en los estados de ánimo, procesos adaptativos y el trastorno de estrés post traumático (Andrade, Parra y Torres, 2011; Rodríguez y otros, 2011; Castro y Mina, 2008; Rodríguez y otros, 2005; Alejo, 2005; 
Lozano y Gómez, 2004) es decir se presentan síntomas emocionales que se encuentran relacionados a los estresores psicosociales (Campo-Arias, Oviedo y Herazo, 2014), se recalca la necesidad de hacer hincapié en los cambios emocionales, y así en el buscar la reconfiguración de los dilemas humanos que vivencian las personas durante su proceso de desplazamiento forzado en pro a mayores niveles de bienestar.

Por lo que, teniendo en cuenta los planteamientos de Marín (2013) el arte se convierte en un promotor de un proceso de resignificación de los procesos de cambio en el área de salud mental, de manera individual, social e histórica el sufrimiento humano, tal como se evidenció en varias de las investigaciones rastreadas en el estado del arte documental (Alyami, 2015; Farokhi, 2011; Blanco, 2009). Ya que una intervención busca la resignificación de las experiencias vividas durante la guerra mediante el uso del arte, permitiendo a las personas expresar sus más dolorosas vivencias, para así convertirlas en motores que les permiten salir adelante (Marín, 2013); y tal como lo exponen los profesionales al afirmar que

"todas las cosas simbólicas, terminan siendo herramientas o medios muy eficaces para trabajar con los sentimientos de los otros, ¿por qué?, porque sobre todo en contextos de violencia, porque hay cosas, sobre todo, hay en Colombia nosotros no logramos imaginar las cosas tan horribles que pasan en nuestro país, hay cosas tan difíciles que ni siquiera podemos nombrar, si, no logramos poner en palabras, o si las, o si se pueden nombrar no somos capaces de nombrarlas" (PS. 42).

Así mismo, es pertinente aclarar que los actores del CAC, independientemente del lugar o el momento de desplazamiento, expresan que tuvieron y siguen teniendo un sentido de vida; que siempre ha estado presente y se ha transformado a partir del contexto, las experiencias vividas y el significado que le atribuyen a éstas. De esta manera, se puede decir que el sentido de vida se 
construye de una manera dinámica que permite que las personas resignifiquen las experiencias de vida, y por ende le den otro curso a sus proyectos y acciones, llenándolas de sentido (Cardona, Hazbun y Ortiz, 2015; D’Angelo, 2002); en tanto las familias refieren

“... me tocó organizar todo eso y a la final yo fui el que me hice al frente de todas las familias y entonces comenzábamos como a organizarnos un poquito y en el trabajo, (...)” (Padre, FB, L141); y “(...) entonces yo ah di por trabajar el lunes reciclábamos, y el martes estaba allá en las oficinas, mirando a ver que hacía que nos poníamos a hacer, el miércoles reciclaba y el jueves otra vez estaba allá, (...) comenzamos a hacer un trabajo ya, como dirigente que era, ahí me acogieron bien y me fui abriendo espacios” (Padre, FB, L14).

\section{Arte e Interdisciplinaridad.}

Al reconocer la importancia de intervenir las afectaciones del proceso de desplazamiento forzado Estrada, Ripoll \& Rodríguez (2010) y los profesionales entrevistados recalcan que las nuevas investigaciones deben generar un diálogo entre las diferentes disciplinas y actores del conflicto trascendiendo el lenguaje técnico,

"hay totalmente una descontextualización del país que habitamos entonces creo que ese es el primer cambio (...) enfrentarse a nuevos retos en relación a la atención psicosocial con víctimas de violencia, lo segundo es que (...) el abordaje no es exclusivamente desde la psicología, ha sido desde la medicina, la sociología, desde el trabajo social, desde la pedagogía y ha sido también una construcción interdisciplinaria donde hemos construido un enfoque común...” (PS2. 06).

Por ejemplo, por su parte la antropología propone la pertinencia de comprender cómo se desarrollan en el cuerpo los cambios a nivel político, cultural, social y económico (Chávez, 
2011), mientras desde el trabajo social se propone un trabajo con las comunidades respecto a la potenciación de sus capacidades enfocadas a la construcción de paz (Katz, 2011), desde la sociología se comprende el apoyo económico del estado por unos como un proceso de estigmatización para obtener la ayuda o de auto exclusión teniendo en cuenta la importancia del ser proveedor y del estatus que esto brinda en nuestra cultura (Jiménez, 2009) y la medicina propone la necesidad de atender la salud mental como factor primario, ya que este abandono por parte del estado potencia el estigma y silencio ante esta condición de la sociedad (Rodríguez, 2015; Nieto y Hernán, 2012; Campo-Arias; Oviedo y Herazo, 2014). por ejemplo, una de las familias indica

“(...) yo no sé, por allá me mandaron pa 'un hospital, [tos] 8 días me dejaron con ella allá, con $P$, ardida en fiebre, bueno, a mí se me olvido esa carta, viendo a $P$ tan mal, me fui por indigente, [jajaja] y la metí al hospital, donde me dijeron L espere, yo cuando miro una vez, me pongo a rebuscar lo papeles, yo este es que, carta de desplazado, yo oigan pues, y me fui y volví y la metí donde el médico, y desde eso yo, que a rogarle a ese gobierno, no, [tos] mi dios como pueda nos saca adelante, (...)” (Madre, FC, L326).

Es así que comprendiendo la importancia de una atención integral se reconoce como la integración de estas disciplinas permitiría generar procesos de atención integrales, posibilitando el desarrollo de herramientas que permitan promover el bienestar por medio de un apoyo emocional en el que se incluye la familia, la comunidad y redes cercanas (Jiménez, 2009). En tanto se presentan pocas investigaciones referentes a la salud mental en las que se relacionan la violencia sociopolítica y el fenómeno del desplazamiento forzado interno, sino que por el contrario se evidencia una alta tendencia a psicologizar y medicalizar las dificultades propias del conflicto armado colombiano (Campo-Arias, Oviedo y Herazo, 2014). Proponiendo así 
Sinisterra y otros (2010) la necesidad de perfeccionar las estrategias de evaluación y diagnóstico psicosocial y la pertinencia de desarrollar intervenciones integrales con las personas en condición de desplazamiento, ya que algunas investigaciones reconocen dificultades en los trabajos terapéuticos con las personas afectadas por el conflicto bélico (Rodríguez, 2015; Sinisterra \& otros, 2012; Jiménez, 2009; Castro \& Mina, 2008; Puertas y otros, 2006).

De esta manera, las investigaciones mencionan la importancia de intervenir desde estrategias encaminadas a permitirle a los miembros de las familias la construcción de significados recreativos de su propia realidad a partir de su imaginación e idealización para manifestar su sentir y pensar, compartir con otras personas y aperturar otros espacios de bienestar (Fontecha y Moreno, 2010), en tanto se comprende la dificultad para expresar los acontecimientos vivenciados producto del desplazamiento forzado al implicar la narración de la experiencia vivida dolor que obstaculiza los procesos de externalización durante la atención prestada por profesionales de la salud (Nieto y Ravelo, 2012). Así como los profesionales mencionan

"La música, el teatro, la pintura, la danza, todo eso posibilita... digamos momentos catárticos que no se dan en un espacio terapéutico individual (...) por ejemplo, el canto desbloquea, digamos que desbloquea el cuerpo energéticamente hablando y también te desbloquea emocionalmente (..), igual con las personas que han decidido usar el teatro como mecanismo de denuncia pero también como forma de reelaboración de las experiencias traumáticas, (...)” (PS2.10); y “Creo que la lúdica es la mejor manera de enseñar [...] (...) muy generador de cosas. (...) vincule procesos de escriturales, vincule (...) pintura. (...) porque eran cosas en la cuales ellos tenía ocupación, (...) podían compartir, tener un espacio lúdico, y a partir de ahí ya podía generarse esos escenarios para dialogar lo humano, y para poner en palabras cosas que se sentian y se transformaban” (TS. 46). 
Es así como se reconoce la importancia de transformar en los procesos de atención las escalas de trastornos psicológicos o síntomas e instrumentos en los que se enfaticen los datos sociodemográficos exclusivamente por instrumentos en los que se reconozcan los niveles de escolarización y ciclos vitales de las personas que han sido desplazados de manera forzada (Andrade, Parra y Torres, 2011). En este sentido, se comienza a identificar cierto inconveniente por parte una de las familias del estado del arte testimonial, con un nivel de escolaridad bajo, en el reconocer la dificultad que genera el poder externalizar las emociones y pensamientos que se relacionan con los acontecimientos del CAC, "yo siempre soy muy olvidada [jajaja] es lo único que les digo, yo:: como que estoy sufriendo algo:: porque yo las oigo hablar, por eso le decía yo, pero como espere, me gusto lo que ella hablo (mira y señala a T1), lo que:: pero se me olvido” (Madre, FC, L224).

De otro lado, respecto a la metodología de esta investigación se desarrolló un estudio de caso, en tanto se reconoció en los artículos rastreados que estos predominan en un 40\%, ya que permiten comprender los contextos particulares en relación a las formas de interacción que se presentan a nivel de persona o grupo (Eisenhardt, 1989, Martínez, 2006, citados por Fontecha y Moreno, 2010), con la pretensión de comenzar a ahondar en la relación entre los estresores psicosociales por los que la familia atraviesa y su situación de desplazamiento forzado.

Proponiendo desde el enfoque sistémico la utilización del equipo reflexivo como un aporte para el análisis del caso y de ajuste de la misma intervención, puesto que es promotor así de la reflexión en el equipo interventor y para los integrantes de las familias en pro de la apertura al cambio y resignificación del problema (Fontecha \& Moreno, 2010). Así mismo, con la actividad del equipo reflexivo realizado durante la entrevista a familias, la madre logra distanciarse un poco del malestar que vivenciaba en silencio, "como le digo yo a usted, como cuando está el 
señor o ángeles, que lo:: lo:: le van quitando como todo ese estrés:: yo no sé:: mejor dicho, yo me siento como relajada, como que este cuerpito no fuera el mío [jajaja]" (Madre, FC, L273). Esto en tanto se reconoce que, en situaciones de dolor, las palabras no logran ser expresadas, "no se preocupe, importante es que usted nos:: como comprender cómo usted se siente, y lo que nos ha explicado claro, a veces uno no logra entender exactamente con palabras que fue, pero usted::" (Interventoras, FC, 280). Por lo que, Baruch, Bush y Folberg (1996), citados por Estupiñán y González (2006), proponen que desde un enfoque de resiliencia se abarque el conflicto de una forma que genere afrontamiento, revalorización, negociación; reafirmando la apuesta de Villa (2013 - 2014) desde el potenciar las capacidades de afrontamiento y de resiliencia.

Y según Montero, 2003; Madariaga, Abello y Sierra, 2003 y Sluski, 1996; citados por Amar-Amar y Otros 2011, cobra una especial importancia el trabajo en redes como una forma de facilitar el afrontamiento de adversidades debido a las condiciones vulnerables producto del desplazamiento, en pro de generar una mejor calidad de vida desde el apoyo emocional y afectivo que se brindan entre los actores involucrados en estas redes; tanto las redes externas como internas en la familia, en donde el apoyo familiar constituye un elemento indispensable para la superación de las dificultades, siendo un sustento para el desarrollo individual y la calidad de vida (Cox, 2005; citado por Amar-Amar y Otros 2011). Siendo este el enfoque de varios de los artículos rastreados quienes reconocen la necesidad de buscar espacios para compartir el sufrimiento y potenciar una memoria colectiva (Villa, 2014; Villa, 2013), sin embargo, en el testimonial se genera contradicción ya que para las familias quienes al encontrarse predispuestos ante las dificultades que han vivenciado de vulnerabilidad psicosocial reconocen más esta ampliación de red como un apoyo para sobrevivir a nivel social, político y 
económico que a nivel de su emocionalidad.

Teniendo en cuenta que estas familias llegan al nuevo contexto citadino desde diversos lugares de Colombia se hace evidente la importancia de tener en cuenta la multi, pluri e interculturalidad en tanto el tener en cuenta la violencia más como una reconfiguración de la violencia en el cuerpo permite la construcción de cambios éticos, morales y a su vez identitarios (Chaves, 2011), puesto que se evidencia que en los estudios rastreados este criterio de diferenciación de población no es reconocido.

En este sentido, se logra identificar que después de realizar el estado del arte, el interés por el arte dentro del proceso interventivo se mantiene, pero no como una herramienta y/o técnica interventiva sino como una estrategia que posibilita el cambio, es decir alcanzar el bienestar deseado, transformar o resignificar una narrativa que permita convivir con los otros en el nuevo contexto.

Por lo que, se hace necesario y pertinente retomar las definiciones que el diccionario de la Real Academia Española (2018) propone, para técnica, herramienta o estrategia y así dejar explícito el porqué de este interés de este trabajo de grado. Entonces, la técnica es definida como la "habilidad para ejecutar cualquier cosa, o para conseguir algo", la herramienta como un “instrumento, por lo común de hierro o acero, con que trabajan los artesanos” y la estrategia como "un conjunto de reglas que aseguran una decisión óptima en cada momento".

Con base a estos planteamientos, las investigaciones consultadas para el escrito documental y las conversaciones realizadas para el documento testimonial, se logra identificar que el arte ha sido comprendido como un técnica o herramienta que complementa los diferentes procesos interventivos que han sido desarrollados con la población que ha vivenciado el CAC y son expuestos superficialmente dentro de los resultados pero que no permiten comprender la 
evolución de la intervención. Situación que conduce el interés por trabajar con unos pasos o reglas que no son estáticas, definidas, parametrizadas o rígidas sino que se convierten en una guía o ayuda que orientan la intervención, pero que al conocer el por qué o el sentido de la creación, esta adquiere un significado que permita la emergencia de la de nuevas narrativas, la transformación del significado construido en torno al evento traumático y la adaptación al nuevo contexto, es decir el poder alcanzar el bienestar deseado y les permita afrontar la vicisitudes cotidianas.

De esta forma, estos cambios presentados llevaron a que el objetivo que se presentó previamente relacionado con identificar la reconfiguración de las familias vinculadas a instituciones que abordan el conflicto armado en Colombia y la emergencia del arte como movilizador de los procesos de cambio y transformación, se transformará a comprender los cambios de una familia que ha vivenciado acontecimientos del CAC como parte de su proceso de adaptación vital, mediando la experiencia vivida y la experiencia narrada a través del arte. Bajo la orientación o guía de las preguntas de investigación - intervención ¿Cómo se construye el cambio a partir de estrategias artístico-terapéuticas sistémicas, en el funcionamiento de una familia que ha vivenciado acontecimientos del Conflicto Armado Colombiano y que han realizado una demanda de ayuda psicológica? y ¿Cómo posibilitar las estrategias artístico terapéuticas con enfoque sistémico, que sean promotoras del proceso de cambio en el funcionamiento de una familia que haya vivenciado acontecimientos del Conflicto Armado Colombiano y que han realizado una demanda de ayuda psicológica? 


\section{SISTEMA TEÓRICO}

Dentro de la propuesta planteada por la maestría en psicología clínica y de la familia, este sistema teórico busca brindar comprensiones acerca de las nociones y conceptos tanto epistemológicos como teóricos que permitan entender nuestra visión del problema y la forma en cómo se llevará a cabo la investigación. El texto se encuentra dividido en dos grandes partes, en la primera se describen los principios epistemológicos y en la segunda, se encuentran los conceptos teóricos que ayudan a comprender el desarrollo de la misma.

En relación a los principios epistemológicos encontramos las nociones de complejidad, constructivismo, construccionismo y la teoría de los sistemas con base al modelo ecológico de Bronfenbrenner; y como ejes teóricos se retoma, el funcionamiento familiar -desde la estructura, la dinámica y la evolución-, los vínculos, la salud mental, la memoria y narrativa conversacional, el continuo entre vulnerabilidad y generatividad -desde los contextos psicopatológicos y las capacidades de las familias-; así como la construcción del arte como estrategia de cambio partiendo de la definición de este último -desde los enfoques sistémico, ecológico y complejo-, para comprender las transformaciones que surgen durante un proceso terapéutico en una familia que ha vivenciado acontecimientos del CAC siendo el arte un mediador entre la experiencia vivida y la narrada. 


\section{Principios epistemológicos}

Para comprender las dificultades que se gestan en la interacción familiar enmarcada desde lo colectivo y contextos amplios, se hace pertinente abordar, el fenómeno de las familias que vivencian el CAC y presentan una demanda de ayuda frente a un malestar en su salud mental, desde la complejidad, puesto que esta nos brinda la oportunidad de crear mundos posibles que nos permiten adaptarnos y enfrentar el contexto del cual hacemos parte.

No existe una clara definición de la complejidad, puesto que uno de sus principios fundamentales es que estas ciencias no brindan una única respuesta sino que aportan una pluralidad de respuestas (Maldonado \& Gómez, 2011), lo que nos conduce a encontrar como la familia en particular a vivenciado dicho CAC, así como lo ha afrontado y los cambios que esto le ha implicado en términos de su funcionamiento familiar, en tanto para Maldonado \& Gómez (2011) las ciencias de la complejidad se definen como los "ámbitos en donde suceden imprecisiones, vacíos, incertidumbres, no-linealidades, sorpresas, fluctuaciones y cascadas de fallas" (Maldonado \& Gómez, 2011, p. 14).

Comprendiendo que la situación de estas familias no se entiende como catastrófica ni tampoco como complicada (Rosnay, 1995), sino como un compendio de relaciones y conexiones propias de las situaciones familiares y del contexto del cual provienen y al que migran, en tanto no puede ser entendida simple y solamente por la explicación de sus partes ni la relación entre las mismas; sino por la cantidad de elementos que lo componen y la "naturaleza de la interacciones entre esos elementos, el número y la variedad de las conexiones que unen estos elementos entre sí" (Rosnay, 1995, p. 36).

El impacto que deja el Conflicto Armado Colombiano en los miembros, como en las familias, que lo vivencian (tanto directa como indirectamente) es diverso y doloroso, que pueden 
afectar las diferentes áreas del ser humano, haciendo necesario identificar las posibles combinaciones que existen entre los elementos que hacen parte de dicho fenómeno junto a sus relaciones con otros organismos, el contexto sociocultural del cual provienen y al cual deben enfrentarse (Rodríguez \& Serna, 2015).

En este proceso de enfrentarse a nuevos espacios, la incertidumbre se convierte en ese principio de-constructor del contexto que lo mantiene, en tanto el sistema es la construcción de una realidad social por actores sociales, que se dinamiza en las conversaciones de sus participantes y es plasmado no solo en sus relatos sino también en las definiciones y narrativas en relación a los dilemas humanos (Estupiñán, 2003). Es entonces que en dicha construcción social de la realidad se concibe a estas personas y familias como sujetos activos que a su vez son capaces de transformar, deconstruir y construir explicaciones posibles sobre sí, acerca del mundo y de las experiencias por las cuales se han visto forzados a atravesar (Alpízar \& Bernal, 2003).

En el entendido que las familias y sus miembros, que han vivenciado acontecimientos del CAC, son sujetos activos, se entiende desde el constructivismo que estas presentan un desarrollo cognitivo de sus representaciones de sus construcciones del mundo dando espacio así al pensamiento individual, personal y libre del individuo. Por lo que, desde la individualidad de estos sujetos lo particular se encuentra ligado a sus percepciones, experiencias y estructuras mentales (Agudelo \& Estrada, 2012).

Las personas bajo el proceso de adaptarse al nuevo contexto en el cual se encuentran, sus experiencias vividas y conocimientos previos generan una participación activa en las comprensiones del mundo en el cual se encuentran inmersos, como lo menciona Mahoney (1988; citado por Feixas \& Villegas, 2000) desde su primer principio, la experiencia humana, los procesos de adaptación y el conocimiento se caracterizan por una participación activa de la 
persona o de la colectividad en el proceso de construcción de su mundo.

Otro principio, es el desarrollo auto-organizativo o autopoiético, en donde los sistemas humanos se organizan a sí mismos, auto protegiéndose y preservando su integridad. Adquiriendo las personas y las familias impactadas por el CAC esa capacidad para reorganizarse en los nuevos espacios en los cuales se encuentran inmersos. Por medio de procesos adaptativos en los que se permiten adaptarse a las nuevas circunstancias y construir mecanismos de defensa y protección. Logrando modificar su funcionamiento para adaptarse al contexto al cual migran, posibilitando un mayor nivel de complejidad que potencian la posibilidad de sobrevivir (Dabas 1993, Dabas y Perrone, 2006). Por lo que, el terapeuta tiene como tarea identificar las estructuras y procesos mediante los cuales las personas construyen su existencia cotidiana, para que desde sus representaciones del mundo logren identificar sus capacidades para continuar encontrando bifurcaciones a pesar de las adversidades (Mahoney 1988; Feixas \& Villegas, 2000).

La familia y sus miembros entendidos como estructuras morfogenéticas, es decir sistemas abiertos, se relacionan con un nuevo contexto, el cual proporciona los parámetros de relación e interacción entre y con los otros en el entendido que el último principio de Mahoney (1988; citado por Feixas \& Villegas, 2000) manifiesta que estos se deben organizar alrededor de procesos centrales, que son los que dictan y rigen las formas en que se manifiestan a nivel periférico.

Es decir que la familia y sus miembros se encuentran en relación a un nuevo contexto que legitima sus reglas de interacción y hace hincapié en las redes de significado que circulan socialmente en el lenguaje, por lo que desde el construccionismo se considera primordial un pensamiento cooperativo de los grupos sociales, es decir como el actual contexto al que llega la persona que han vivenciado de alguna manera el CAC se encuentra inmerso en la construcción 
de nuevos significados, pudiendo enfatizar en las metáforas que se localizan especialmente en la lingüística, como la narración y la hermenéutica, como posibilitadores de nuevas oportunidades o mundos posibles. Es decir, que se concibe la realidad como el proceso de intercambio entre sujetos que se encuentran inmersos en un mismo contexto cultural (Agudelo \& Estrada, 2012).

En estos nuevos contextos en los que estas personas se encuentran inmersos se puede evidenciar como este propio sistema de construcción coarta la posibilidad de reflejar sus propios valores en un conjunto relativamente restringido de alternativas (Procter \& Parry, 1978, citados por Feixas \& Villegas, 2000), es decir que la construcción de la realidad al generarse en un contexto más citadino, limita la validación o refutación de las construcciones individuales de las personas que migran con valores distintos ya construidos.

Teniendo en cuenta lo anterior, Gergen (1985; citado por Feixas \& Villegas, 2000) identifica 4 supuestos básicos. El primero refiere que la experiencia del mundo no dicta por sí misma los términos en los que será concebido el mundo en sí, es decir que lo vivenciado por las familias no es un determinante para la significación de una vida llena de malestar o sufrimiento sino por el contrario se encuentran un una nueva situación en donde desde las nuevas relaciones que se construyen en ese nuevo contexto identifican posibilidades, encontrándose el segundo principio relacionado a la manera como se concibe el mundo, desde artefactos sociales, producto de intercambios entre personas, que se encuentran históricamente localizados.

Este intercambio de significados dependiendo de la vigencia que le dé el contexto posibilita que nuevas comprensiones familiares y de los miembros se sostengan por medio de nuevas maneras de comunicarse y negociar, puesto que el tercero principio menciona que una comprensión prevalece o se sostiene a través del tiempo dependiendo de la legitimidad empírica de la perspectiva y de las variaciones de los procesos sociales, y el último principio, describe que 
las maneras de comprensión negociadas poseen una significación crítica en la vida social, al encontrarse conectadas integralmente con otras actividades en las que las personas se encuentran implicadas (Gergen, 1985; citado por Feixas \& Villegas, 2000).

Es así que, por sí solo la experiencia de vivir acontecimientos propios de la violencia no determina la concepción que estas personas construyen del mundo, es también importante tener en cuenta sus experiencias previas en distintas áreas de sus vidas. Desde esta postura epistemológica se concibe que la verdad se encuentra en crisis, presentándose un mayor acercamiento a los procesos sociales tales como negociación y resolución de conflictos, los cuales hacen referencia a los consensos sociales (Feixas \& Villegas, 2000), y sobre los cuales actualmente se presta especial atención en pro a una dinámica social más incluyente y coresponsable, en la que se generen espacios de diálogo y de restitución de derechos.

Para llegar a esos consensos sociales el pensamiento sistémico, desde la teoría de los sistemas, expresa que los sistemas constituyen complejos factores que se encuentran en constante interacción, planteando Bateson que estos se comprenden cómo patterns, es decir pautas (Maldonado \& Gómez, 2011). Se habla de esta manera de una totalidad constituida por sus partes. Sin embargo, el problema de esta tradición consistió en la pertinencia de concebir a la totalidad no solo como una unidad y como totalidad de las partes, sino más bien cómo la simple suma de las partes (Luhmann, 1998), situación que se puede evidenciar en las dificultades que se presentan en el comprender el fenómeno del conflicto armado, el cual bien puede percibirse de manera fragmentada o puede reconocerse como un conjunto de circunstancias y de factores sociales, culturales, políticos y jurídicos en relación a un conflicto interno en el país, que impactan a las personas y familias bajo este contexto.

Estas corrientes epistemológicas, anteriormente descritas, permiten afirmar que los procesos 
psicológicos, mentales y espirituales promueven una relación indisoluble entre lo psíquico, lo mental y lo espiritual, ya que entendiendo que el CAC es más que una sumatoria de factores sociales, culturales, políticos y jurídicos que intervienen en la construcción de la realidad a través del lenguaje y de nuestras percepciones individuales, como terapeutas/investigadoras, debemos tener en cuenta en las intervenciones con las familias (incluyendo el trabajo con individuos) que también hacemos parte de esa relación de construcción de significados en donde se deje de lado las distinciones entre lo normal/anormal, lo psicopatológico, la salud/enfermedad, las cuales son necesarias ser vistas de manera circular, desde una mirada sistémica compleja constructivista y socio construccionista.

\section{Principios teóricos}

Al ser la familia -que ha vivenciado acontecimientos del CAC- la unidad de análisis de nuestra investigación, comprendemos que esta posee recursos y posibilidades autoorganizadoras, se asume que el interventor (terapeuta e/o investigador) y sus recursos autorreferenciales aportan al escenario de la ayuda, los procesos reflexivos que representan un valor estratégico para la construcción del cambio, desde una teoría de los sistemas se habla de co-aprendizaje, co-evolución, co-construcción que derivan del cambio y una visión de redes conversacionales posibilita una visión ecológica de lo clínico y de la salud mental (Estupiñán, 2003), desarrollando una reconfiguración de la percepción del papel del investigador interventor dentro del proceso de la comprensión de los procesos de transformación, que las familias y sus miembros, han atravesado luego de encontrarse inmersos en una serie de situaciones y circunstancias propias de una guerra y del contexto político y social colombiano.

Con base en lo anterior, el comprender cómo los sistemas familiares construyen su realidad 
a partir de la interacción con el contexto, dentro los ambientes ecológicos (microsistemas, mesosistemas, ecosistemas, macrosistemas), se genera una nueva forma de comprender los cambios que expresan o manifiestan las familias que han vivenciado el CAC. Los cuales se pretenden describir no solamente en términos de pérdida sino también en relación a lo "ganado", sin entrar hacer valoraciones de bueno o malo, entendiéndose que la familia y sus miembros se constituyen como sujetos activos, que se encuentran mediados por el ambiente y las interacciones; buscando romper con la rutina de victimización o de victimario, para así poder atribuir un nuevo significado a dicha experiencia traumática desde el uso del lenguaje en la interacción con los otros y el contexto.

Para conocer la relación entre la familia y su contexto, anteriormente fueron nombrados los ambientes ecológicos, los cuales -según el modelo ecológico de Bronfenbrenner (Monzón, 2004) se pueden comprender como las interconexiones que se pueden dar entre la persona y el contexto familiar, social, laboral, etc. en donde se estudia al sujeto en desarrollo, el ambiente y su interacción. Es decir, que este solo puede ser comprendido desde las características individuales y las del ambiente en las cuales se desarrolla. Y es así que, desde una postura construccionista y constructivista, es pertinente conocer cómo la realidad objetiva de las familias que han vivenciado acontecimiento del CAC se relaciona en la manera en cómo la persona y la familia se percibe y se describe a través del lenguaje, de la interacción con el otro y del ambiente.

Bajo el principio de la reciprocidad, se comprende que una transformación en alguna de las partes del diseño ecológico puede afectar el desarrollo de lo demás y generar nuevos cambios, tanto a la parte como al sistema; es decir que los cambios propios a nivel familiar como de contexto (económico, político, cultural, etc.) se pueden interrelacionar para producir cambios en estas familias que han vivenciado acontecimientos del CAC. Teniendo en cuenta el ciclo vital de 
estas familias, se comprende que no todas las conductas que fueron adecuadas o posibles en un momento específico de su desarrollo pueden ser útiles o pertinente para la situación actual en la que se encuentran (Monzón, 2004), en tanto pueden surgir adversidades que interfieran no solo en el cauce del desarrollo de las personas, sino también de sus familias y sus dinámicas relacionales, tal como se evidencia en la posibilidad de encontrarse inmerso en medio del conflicto armado.

Por ello, se concibe un ambiente ecológico constituido por un conjunto de estructuras concéntricas que se encuentran incluidas dentro de sí: el microsistema, el primer nivel, engloba los contextos inmediatos en los que la familia (que ha vivenciado el CAC) y sus miembros se desenvuelve: familia, trabajo, escuela, etc. El cual se encuentra conformado por 3 elementos: la actividad, que hace referencia a los procesos que tienen una meta; las relaciones interpersonales, las cuales se originan bajo una estructura diádica básica; y la reciprocidad, es decir el equilibrio de poderes y relaciones afectivas. Sin embargo, se debe tener en cuenta la influencia de terceros lo cual da lugar a los sistemas amplios (efecto de segundo orden), generando posiblemente un efecto inhibidor y/o facilitador sobre el desarrollo, la conducta y el rol, como un conjunto de comportamientos, expectativas y relaciones que se asocian a una posición en la sociedad (Monzón, 2004). Encontrándose de esta manera, por un lado, las expectativas que las personas y familias que han vivenciado el CAC tienen de sí mismos, lo que pueden o no llevar a cabo, las actividades que pueden o no realizar, y de otra parte la manera como estos o esta espera se relacionen con ellos, dentro de estos nuevos contextos a los que han visto obligados a migrar.

El mesosistema, el segundo nivel, está compuesto por microsistemas. Se pueden establecer conexiones entre los entornos en los que se encuentra inmersa la familia que ha vivenciado los acontecimientos del CAC, dándose una participación directa de individuos con las que se 
mantiene alguna relación, conocimiento y comunicación entre contextos. Por lo que es de esperarse que el desarrollo del anterior nivel macro sistémico incremente de acuerdo a los intercambios bidireccionales del entorno, apoyando y promoviendo la confianza y el consenso de metas, manifestando entonces el equilibrio de poderes que favorece el desarrollo de los miembros y su familia -que ha vivenciado el CAC- (Monzón, 2004).

El exosistema, tercer nivel, comprende las estructuras informales y formales de la sociedad, e influye de una manera indirecta a las personas, es decir el contexto político, el conflicto interno del país. Siguiendo una cadena causal en dos pasos: primero, la relación del desarrollo de los microsistemas y del entorno externo y, segundo, la conexión entre los desarrollos de los microsistemas y el comportamiento (Monzón, 2004).

Y, por último, en el macrosistema los sistemas mencionados siguen unos patrones de esquemas determinados; el ideológico y la estructuración de las instituciones sociales similares a una cultura o subcultura, es decir las creencias y costumbres propias del lugar de origen de las personas y familias que migran por su condición, y la relación con las costumbres y creencias de los contextos a los nuevos lugares de asentamiento. Aunque muchas culturas y subculturas difieren entre sí, mantienen unas características fundamentales: los tipos de entornos que contienen, las clases de entornos a los que las personas entran en las etapas de la vida, el contenido y la organización de las actividades morales, los roles y las relaciones que se encuentran en cada tipo de entorno. El alcance y la naturaleza de las conexiones que existen entre los entornos en los que entra la persona y en los que afecta su vida (Monzón, 2004).

Lo que implica crear meta sistemas que permitan comprender los órdenes pragmáticos y significativos de las paradojas de los modos y dominios emocionales, valorativos y narrativos de las problemáticas humanas, en este caso los cambios de las familias que han vivenciado 
acontecimientos del CAC, en donde puedan ser usados los principios auto y hetero-referenciales, la coevolución y la emergencia (Estupiñán, 2003) en un proceso psicoterapéutico con dichas familias.

Este modelo ecológico nos brinda la posibilidad de resaltar, cómo la familia al ser comprendida como un sistema nos permite destacar las formas en las que están relacionadas las partes identificándose un componente predictivo; es decir que cada parte de un sistema afecta a las demás, esos efectos se repiten, haciendo que el estudio de los sistemas sea interesante y posibilite las predicciones. Aun cuando cada sistema es distinto y particular, existe algo que los caracteriza a todos y son las pautas repetitivas (Minuchin, 2000), pautas que surgen en las dinámicas relacionales en los distintos contextos en los cuales el sujeto y estas familias se encuentran inmersos, desencadenándose posibles problemáticas o posibilidades.

Tal como hemos evidenciado la familia juega un papel importante como contexto inmediato de interacción y microsistema, encontrándose a esta como sistema natural, al estar constituida por una red de interacciones respondiendo a exigencias psicológicas y biológicas propias a la supervivencia humana, con unas características propias, ya que no ha existido hasta el momento ninguna instancia social que pueda sustituirla como partida primaria del gozo de las necesidades psicoafectivas de toda persona. Es decir, que entendiendo esta como sistema, se puede afirmar que la familia es más allá que la adición de las singularidades de sus miembros, en tanto posee mecanismos propios y diferentes que la explican (Hernández, 2009). Por lo que, en este entendido y para comprender en mejor medida como son las transformaciones que experimentan las familias que han vivenciado el CAC, se encuentra necesario ahondar en los conceptos de funcionamiento familiar (estructura, dinámica y evolución) y el continuo de vulnerabilidad/generatividad propuesto por Hernández y Estupiñán (2007). 
Siendo así, el funcionamiento familiar entendido como la integración de vínculos afectivos entre los miembros de la familia (cohesión), en donde puedan ser capaces de cambiar su estructura familiar con el fin de sobrepasar los conflictos evolutivos (Ferrer, Miscán \& Otros, 2013), que puedan presentarse de acuerdo al contexto en el cual la familia se encuentre o en el nuevo contexto en el cual deba generar otras dinámicas y estructuras familiares (adaptabilidad), siendo entonces necesario para esto que los límites de los subsistemas sean claros. Deben definirse con suficiente precisión como para que se les permita a los integrantes de los subsistemas el adecuado desarrollo de sus roles sin algún tipo de obstrucciones, pero también el permitir el contacto entre sus integrantes del subsistema y los demás. Entendiéndose como estos se constituyen entorno de las funciones familiares, lo cual se ha evidenciado no es tan representativo, como sí lo componen la claridad de los límites (Minuchin, 2004).

Fortaleciendo la comprensión del funcionamiento familiar, encontramos que la estructura de una familia es el conjunto de demandas funcionales que organizan la forma en que interactúan sus miembros (Ochoa, 1995), mediada por un sistema sociocultural abierto que se encuentra en proceso constante de transformación, siendo permeada por diversas circunstancias normativas, no normativas y adversidades; por ejemplo el crecimiento de los hijos, por un lado como un proceso natural y los cambios que esto implica en tanto crecen en entornos distintos en los que nacieron, y por el otro, la posibilidad de encontrarse en riesgo la vida de alguno de los miembros por amenazas propias del conflicto armado; circunstancias que pueden afectar el desarrollo del sistema, su composición e interacción; generando el desplazamiento de una serie de etapas que hacen parte del desarrollo familiar, que le exigen al sistema no solo re-estructurarse sino también adaptarse a nuevas circunstancias propias del contexto, de tal manera que si bien mantiene su continuidad, fomenta el crecimiento psicosocial de cada uno de sus miembros (Minuchin, 2004). 
De esta forma, cada familia presenta unos límites/fronteras, jerarquías, roles y composición familiar que se puede transformar a lo largo del desarrollo de su ciclo vital, en relación con el contexto en el cual se encuentran, su cultura y las diferentes condiciones por las que atraviesan en determinados momentos. Es así como cada sistema familiar puede llegar a ser analizado en función de las relaciones de distancia, las cuales pueden generar unas pautas de relación particulares en la familia. En el entendido en que se encuentran límites individuales, generacionales y fronterizos, lo cuales hacen referencia al interjuego entre reglas, jerarquías y roles, buscando proteger y diferenciar al sistema familiar en su interior y exterior con otros sistemas (Sánchez, 2004; Minuchin, 1974). Identificándose así, tres (3) tipos de límites/fronteras claros, difusos y rígidos en lo que se puede reconocer la interferencia/claridad en el desarrollo de la autonomía e individuación de los miembros o del sistema en sí (Minuchin, 1974).

Dentro de los sistemas familiares en condición de desplazamiento se pueden ver afectadas las jerarquías, entendidas estas como el nivel de responsabilidad y poder que tiene cada uno de los miembros al interior de la familia, en relación con las pérdidas que las pueden mantener o potenciar de acuerdo con las circunstancias psicosociales por las que ésta atraviese. Lo cual se encuentra estrechamente relacionado con el conjunto de normas y expectativas que son establecidas por la cultura y su familia influenciando la conducta, posición y función que posee cada miembro, es decir el rol que cumplen (Garibay, 2013).

Las condiciones económicas, políticas y sociales de cada sistema familiar permean tanto el rol de cada miembro, como la jerarquía, los límites / fronteras y la composición familiar, siendo este último, donde se entretejen los diferentes tipos de familia en relación con el número de personas, sus relaciones y parentesco (Louro, 2005). Se pueden encontrar entonces los siguientes tipos: familia nuclear, familia monoparental (primario y secundario o dependiente) (Cortés \& 
Cantón, 2010), familias adoptivas, familias bi y monoparentales (Palacios, 2000), familias reconstituidas (Oliva, Parra \& Antolín, 2010) y familias homoparentales (González, López, Gómez, 2010), las familias recurrentes (Arranz, Olabarrieta \& otros, 2010) y las familias tardías (Hernández, 2012).

Es así que, en relación con esta diversidad en la estructura y composición familiar que se hace importante el abordar la dinámica familiar, ya que la familia es vista como una red de relaciones y vínculos que se encuentra cruzada por el intercambio, la colaboración, el poder y el conflicto que se produce entre los integrantes de la familia, de acuerdo con la repartición de responsabilidades de la familia, la colaboración y la toma de decisiones. En este entendido, en el interior de la familia cada uno de los integrantes se encuentra relacionado a los otros mediante relaciones de parentesco, de vínculos afectivos, comunicación, toma de las decisiones, resolución de conflictos y las responsabilidades estipuladas a sus integrantes (Gallego, 2011; Minuchin, 1986). Transmitiendo entonces, en la dinámica y la estructura familiar el contenido de la comunicación a través de un orden de esas comunicaciones (Minuchin, 2004).

Es pertinente reconocer que en la dinámica familiar entran en juego las pautas de relación sintomáticas, alianza/coaliciones, relación afectiva, comunicación, toma de decisiones y resolución de conflictos. Las pautas de relaciones sintomáticas son acciones repetitivas en un largo periodo de tiempo en las interacciones familiares que generar malestar al oponerse a un posible cambio en el sistema, desde una causalidad circular (Garibay, 2013).

Es así que dentro estos tipos de interacción encontramos las alianzas y coaliciones; entendidas estas como la unión de dos personas con un interés común en función de excluir a una tercera, pero en la segunda la exclusión busca agredir y expulsar al tercero que cuenta con una mayor jerarquía, pudiendo esto desarrollar triangulaciones familiares, convirtiéndose las 
características familiares y el síntoma como el foco de la interacción de estos tres miembros (Garibay, 2013). Pudiendo estas triangulaciones transgredir los límites / fronteras y producir perturbación en la organización familiar que desembocan en posibles disfunciones; cabe aclarar que estas situaciones permiten comprender conflictos y tensiones que se presentan al interior y alrededor de la familia y en algunas situaciones en el contexto (Garibay, 2013).

En segunda instancia, la relación afectiva se refiere al apego -desde la vinculación emocional- en la interacción de los miembros del sistema familiar (Olson \& Otros, 1989). Lo cual se relaciona con los niveles de comunicación a nivel analógico y digital entre los miembros, en este intercambio de ideas y sentimientos que al ser contradictorios o ambiguos y manejar las demandas permiten la emergencia del síntoma y/o malestar (Barnes \& Olson, 1985; Hernández, 1997).

Está manera de comunicarse se encuentra estrechamente relacionada con la toma de decisiones, la cual se puede conectar con la jerarquía al darle poder a la persona que tenga mayor nivel al interior del sistema para decidir qué hacer o no hacer, relacionándose estrechamente con la resolución de conflictos, ya que hace referencia a la manera en que se utilizan las estrategias familiares e individuales para resolver las diferencias y dificultades (Barnes \& Olson, 1985).

Como cada sistema puede ir cambiando en relación a su estructura y dinámica respecto a los acontecimientos en los que se puede ver inmerso el sistema familiar a través del tiempo y a la situación del conflicto armado, se hace necesario retomar la evolución familiar, la cual implica la supervivencia a largo plazo del sistema desde la adaptación a corto plazo a las diferentes problemáticas, gracias a las capacidades que tiene la familia para afrontar lo inesperado que se presenta en la cotidianidad (Hernández, 2009). Comprendiendo como la familia al ser un sistema activo, desde la concepción de ajuste y adaptabilidad, logra adaptarse a las nuevas circunstancias 
luego del contexto de guerra vivenciado, y como resultado de este proceso se genera un ajuste paulatino al interior de la familia y entre ésta y su ambiente (físico, social y cultural), buscando mantener un balance en su funcionamiento a partir del uso de sus capacidades para afrontar las demandas, es decir estresores (normativos y no normativos) y tensiones (internas, externas, ambiguos, definidos, voluntarios, involuntarios, crónicos y agudos) que producen un cambio, en relación a los significados que como grupo le atribuyen a dichas capacidades y demandas (Hernández, 2009).

Es así como en el transcurrir del tiempo y en relación con el contexto, a las condiciones políticas, sociales y económicas, que complejizan una serie de etapas en el transcurrir de la vida familiar, pudiendo por un lado surgir periodos de adaptación y equilibrio en los que el sistema logra un dominio pertinente de aptitudes y tareas propias de la etapa, o por otro lado periodos de desequilibrio relacionados al individuo y/o al contexto. Surgiendo de esta manera el concepto de ciclo vital familiar, en donde transcurren una serie de fases, crisis transicionales inevitables, cambios, crecimientos de los miembros de la familia, entradas y salidas de parientes, que a su vez se interrelaciona con el ciclo vital individual (Garibay, 2013).

Situación que inter juega con las funciones y expectativas que se espera que los miembros del sistema desarrollen según el subsistema al cual pertenecen. La relación entre los padres, conocida como la conyugalidad, hace referencia a la forma en cómo trabajan su afectividad, la jerarquía interna y proyectos (González \& Acuña, 2017). La relación entre padres e hijos, conocida como la parentalidad, corresponde a las funciones normativas y protectoras, de amor complejo y nutrición emocional (Linares, 2012, 1996; González \& Acuña, 2017). Y, por último, la relación entre hermanos corresponde a la fraternalidad, en donde se cumplen las funciones de compartir, competir y negociar (Ceberio, 2004). 
Por lo que, en ese proceso de evolución familiar, es decir de reestructuración de cada sistema familiar, interactúan varios factores propios de su estructura y dinámica particular, así como el proceso adaptativo y contextual por el cual se han encontrado inmersos, lejos de seguir una lógica o un tiempo determinado, sino un tiempo propio y particular de ese proceso de aprendizaje de la vida permeado por los cambios propios del ciclo vital familiar - individual y por las adversidades atribuibles al impacto del conflicto armado colombiano.

En este entendido, es necesario no solo conocer el funcionamiento, la estructura, la dinámica familiar, sino también tener en consideración los vínculos entre los miembros de dicho sistema ya que al estos representar un enlace temporo - espacial entre individuos, conectan o unen a una persona con otros desde procesos de significación que contribuyen a su mantenimiento (Miermont, 1993), posibilitando que dicha estructura y dinámica se desarrolle bajo las narrativas individuales y familiares que potencien su calidad de vida. Sin embargo, al estos contar con un valor de supervivencia, se pueden ver amenazados por la vivencia del conflicto armado, al ser considerado un desastre social, que puede llegar a desequilibrar o fragmentar al sistema (Hernández \& Bravo, 2006), generando nuevas formas de relación que obstaculizan la comunicación e interacción entre los miembros de dicho sistema.

Conforme lo plantea Miermont (1993), la hipótesis hace referencia a las interacciones humanas las cuales se configuran por medio de tres operadores temporo-espaciales: el mito, el ritual y la episteme, estos hacen referencia a las relaciones, las creencias y el conocimiento como participantes en interacción para la construcción de los vínculos; por su parte, estos operadores permiten a la vez el implicarse y él observarse. Cada uno de esos operadores se encuentra en los sistemas fabricados de memorización, de tal manera que los vínculos se visibilizan en el momento en que los diversos sistemas de memoria entran en sonoridad. Es así como la 
naturaleza de los vínculos es solo visible cuando se modifican los símbolos por medio del tiempo. Dichas transformaciones permiten el desarrollo de una historia funcionando, así como figuras lingüísticas, donde las analogías temporales se reconocen como una forma de contacto interpersonal, en donde se generan las regulaciones de las secuelas de la distancia y proximidad (Hernández \& Bravo, 2006).

Estos procesos de vinculación se materializan en la ritualización, la cual hace referencia a la estructuración de las interacciones de los seres humanos que encauzan y generan diferentes comportamientos familiares y sociales, reduciendo así la ambigüedad en la comunicación y toma de decisiones para determinar el curso de la interacción. Para ello se plantean las siguientes funciones de ritualización: desde la comunicación se dinamizan nuevas formas de relación y de comunicación entre los subsistemas, en tanto a partir de la ritualización se canalizan comportamientos que pueden llegar a representar amenaza y confusión desde una comunicación analógica que se digitaliza en reglas metalingüísticas no verbalizadas, desde la autonomización de las unidades sociales se apoya el desarrollo de la autonomía en los subsistemas y el sistema desde el definir y afianzar su identidad, permitiendo desde la performativa la estructuración de hechos y realidades propias del sistema, en donde se encuentran los ritos de paso. En el mantenimiento de la cohesión de los grupos se aíslan los que no son miembros del sistema para así protegerse y sobrevivir, y en el marcador de ciclos de vida y de transmisión de valores intergeneracionales por medio de los rituales de inclusión y de pertenencia se transmiten mitos familiares, colectivos y creencias entre generaciones (Hernández, 2010; Miermont, 1987,2001).

En ese estar en sintonía de los procesos de memoria y de vinculación se identifica la generación de nuevas maneras de simbolización que producen procesos comunicacionales en 
donde los sujetos que se encuentran interactuando, hacen comentarios, preguntas y contribuyen a un relato en progreso; a dichos procesos se les denomina narrativas conversacionales los cuales hacen referencia a distintas situaciones y escenarios sociales comunicacionales. Por otra parte, respecto a la dimensión experiencial de la construcción narrativa del sentido y organización de los acontecimientos y experiencias vividas, los autores hacen hincapié en el hecho de que la narración preserva y transforma a los sujetos y sus relaciones. Como señala Ochs, "lo que pensamos de nosotros mismos y de los demás está influido por el contenido del mensaje de los relatos narrados en conjunto y por la experiencia de trabajar juntos para construir una narración coherente" (Ochs 1997:272, citado por González \& Serna, 2006, p. 105).

Es así, que la memoria "al conservar determinadas informaciones, remite ante todo a un complejo de funciones psíquicas, con el auxilio de las cuales el hombre está en condiciones de actualizar impresiones o informaciones pasadas, que él se imagina como pasadas" (Ricoeur, 1999. P. 130; citado por López \& Plazas; 2012). La memoria, según el autor, guarda una relación directa con la historia, de carácter crítico. Esta relación dialéctica, permitió reelaborar el sentido de los acontecimientos, lo cual sitúo en una perspectiva de cambio y movimiento al ser humano. Aclara la visión de la memoria, la cual tradicionalmente se concibió como retrospectiva, para ser pensada como recreadora, decimos entonces, que no recupera estáticamente el pasado, sino que, es en el movimiento de los tiempos, que se reinventan las versiones que configuran el sentido en un tiempo experiencial (López \& Plazas, 2012)

Por lo que se entiende que la memoria, no solo se encuentra dimensionada como fenómeno colectivo, sino también individual; que contribuye a la condición de fidelidad con respecto al pasado al rescatar los recuerdos que se ven amenazados por el olvido y la relación que tiene esta con la construcción de la realidad (Ricoeur, 1999; citado por López \& Plazas; 2012); en tanto 
permite a los miembros de las familias que han vivenciado el CAC recordar las experiencias vividas y re-narrarlas en el aquí y en el ahora de una forma distinta, debido a las nuevas vivencias que cada uno ha experimentado a partir de su interacción en los nuevos contextos en los que se ven abocados a vivir, es decir que esta facilita todo un proceso de resignificación de la situación vivida que permite superar la crisis normativa o no normativa experimentada.

En tanto, su intención no es recuperar el pasado a través de la memoria en un acto intencional y organizado, sino que ésta aparece "en un breve instante de destello que ilumina el sentido mismo del acontecimiento pasado para hacerlo coincidir en el presente" (Rosas, 1999; citado por López \& Plazas; 2012), permitiéndoles resignificar de una forma distinta esas experiencias vividas y comprenderlas de formas diversas para posibilitar el cambio en el presente.

Es decir, que la memoria desde esta perspectiva narrativa favorece conversaciones e interacciones novedosas referidas como esas probables interpretaciones que son consideradas subdominantes, periféricas, marginales, que incluso son concebidas como débilmente articuladas con el propio relato, el cual ha sido configurado desde los previos conocimientos y las experiencias tanto narradas como vividas; surgiendo así memorias alternas de la historia (Estupiñán, 2006) de los miembros de las familias que han vivenciado el CAC permeando su propio funcionamiento familiar.

A través de los relatos que las familias realizan sobre sí mismos, podemos identificar que los sistemas manifiestan tener problemas en la salud física y mental de sus integrantes, en algunas situaciones se podría asignar por patrones y/o formas de crianza, como paradojas vinculares, contradicciones, etc. y en otros casos, verse afectada por situaciones contextuales -en el caso colombiano- como lo es el conflicto armado. Es por ello, que en este trabajo de investigación no 
será abordada la salud mental como la ausencia de enfermedades psicológicas o diagnósticos psiquiátricos, sino será vista como un aprendizaje para vivir la vida, en este sentido, esta es entendida como un proceso que integra las dimensiones biológica, psicológica y sociocultural, compuesta por la capacidad de los sujetos y de las agrupaciones para relacionarse entre sí y con su medio, una manera de propiciar el bienestar subjetivo, el desarrollo y el uso adecuado de las potencialidades psicológicas, cognitivas, afectivas y relacionales, y la obtención de objetivos individuales y colectivos en afinidad tanto con el bien común como con la justicia (Hernández \& Morales, 2003).

De esta forma, en esa comprensión de la familia como sujetos activos que construyen su realidad a partir del lenguaje en el proceso narrativo y en relación con los contextos y las experiencias en cada uno de estos, dentro del marco del conflicto sociopolítico colombiano, que incluye los contextos económicos y jurídicos. Se comienza un proceso de "desmedicalización" de la vida reconociendo la utilidad de los diferentes recursos individuales, familiares y sociales que permiten superar las distintas situaciones y dificultades dejando de lado el déficit o las limitaciones, y permitiendo ahora el identificar la salud mental como ese proceso de aprendizaje continuo para enfrentar y transformar la propia vida (Hernández \& Morales, 2003).

En relación con la salud mental y a la narrativa conversacional Botella y Meritxell (2002) mencionan que los problemas psicológicos pueden ser entendidos como el resultado, primero, del bloqueo en los procesos discursivos, narrativos y relacionales de construcción del significado de la experiencia y, segundo, como el fracaso de las soluciones intentadas a dicho bloqueo:

“En situaciones de crisis, no somos capaces de narrar nuestra propia historia o lo hacemos en formas que contradicen la experiencia vivida. No nos es posible anticipar nuevos acontecimientos, nos faltan aquellos elementos que legitiman y dan un sentido de 
coherencia y perspectiva a nuestra propia vida. En estos casos lo fundamental no resulta ser los estándares de la evidencia, sino la aproximación a un nuevo juego de lenguaje que nos permita acceder a formas alternativas de reconstruir nuestra narración actual" (Estupiñán, Hernández, \& Otros, 2006, p. 109).

Siendo estas narraciones las que permiten comprender el cambio como un "proceso discontinuo que genera la emergencia de la novedad a partir de la misma interacción de actores en el contexto, trabaja por saltos, los que no se vinculan a los programas o los pasos organizados de antemano" (Estupiñán, Hernández, \& Otros, 2006. p. 182; Boscolo \& Bertrando, 1996). Por ello, el cambio se ubica en el dominio de lo que se conoce como lo fenomenológico; en tanto que se entiende como una experiencia particular presente en cada uno de los individuos, en una forma determinada, y en diversos órdenes más, en donde las comunidades comparten las mismas puntuaciones sobre cuándo y cómo comprender ese cambio, el cual puede ser observado por otro individuo, diferente de quien lo experimenta (Estupiñán, Hernández, \& Otros, 2006).

Por lo que, para complementar, comprender y complejizar el proceso de cambio, tendremos en cuenta las diferentes definiciones propuestas por los enfoques: complejo, sistémico y ecológico. La corriente sistémica comprende el cambio desde la comunicación; la ecológica desde los niveles lógicos, la variedad y la comunicación; y la complejidad desde la deriva y la crisis.

Continuando con esta idea, desde los enfoques complejos, se realiza una aproximación a reconocer los procesos de interacción contextual, evolutivos, la creación de la novedad y la emergencia del acontecer que se evidencia en las familias desplazadas. Entendiéndose, por un lado, que el cambio como deriva se relaciona con el concepto de evolución, siendo entendido como "la operación de deriva natural de ciclos de vida de los organismos que operan por 
acoplamientos en sus diversos niveles de operación biológica” (Rodríguez \& Serna, 2015, p. 70). Es decir que en este proceso se pueden presentar condiciones que permiten amplias posibilidades de variación, en torno a las diferentes situaciones en las que se ven inmersos por el CAC.

Y tales variaciones se presentan en contexto. Un contexto que hace referencia a un escenario posibilitador de la evolución y autoorganización espontánea de quienes en él participan. Se refiere al espacio-tiempo en el que el fenómeno ocurre, emerge, se construye. En sistemas humanos, los contextos emergen en la interacción entre los actores de la escena. Es el interjuego de relaciones en el contexto situado, la experiencia vivida (Niño \& Rodríguez, 2006, p. 182), por las personas que han sido impactadas por el conflicto en tanto que han sido actores fehacientes de las diversas formas de violencia que caracterizan el CAC.

En dicho interjuego, se reconoce la comunicación como una vía de posibilidades, por lo que, comprendiendo el cambio como comunicación (desde el enfoque sistémico) se_evidencia que "los cambios se producen al interior del sistema como grupo integrado por sus miembros y las formas en que es posible combinarlos, reconociendo allí que no todas las combinaciones conducen a la varianza, sino que algunas implican lo contrario: la invariancia” (Rodríguez \& Serna, 2015, p. 66). Es decir, que, aunque al interior del sistema se presentan alteraciones, este puede permanecer igual, lo que llevó a promover el cambio de primer nivel y el cambio de segundo nivel. En el primero el sistema puede permanecer igual, pero en el segundo -cambio del cambioel sistema ya puede presentar transformaciones.

De esta forma, al enfatizar en las fortalezas y en diversas soluciones que posibiliten recursos tanto internos como externos, con los que cuentan los sistemas humanos (individuos, familias, comunidades, organizaciones, entre otras) y estos se tengan en cuenta y se activen ante las adversas situaciones que se presentan en el conflicto armado colombiano y que generan un 
cambio en la vida de las personas y familias que han vivenciado hechos violentos, se crean procesos de co-evolución y se definen posibles estrategias en lo relacionado con las acciones profesionales y socio-culturales de orden familiar que movilizan y promueven el cambio desde los contexto terapéuticos.

Comprendiendo estos cambios como parte del proceso de evolución del sistema, y ubicándonos en el enfoque ecológico, en el cual se concibe el cambio desde niveles lógicos, ya que constituye el movimiento como el desplazamiento a un nuevo espacio. En ese nuevo nivel cada fenómeno es emergente y por tanto nuevo, así que no puede ser explicado desde el anterior; y en ese entendido el conflicto armado colombiano ejerce influencia predominante en la relación de los sistemas familiares con sus entornos, y viceversa, estableciéndose entre las familias y los suprasistemas un proceso de cambio de influencia recíproca continua, que inclusive alcanza a la sociedad en general, por ello, es para pensar el cambio y los modos de cambio que van emergiendo en los procesos, es decir en el espacio y el tiempo, como las variaciones entre lo que se dio a llamar el miembro y la clase (Rodríguez \& Serna, 2015), caracterizados por la jerarquización dada en el contexto social, político, cultural y económico colombiano, que permean las desigualdades al interior de la sociedad, de la familia, y entre individuos perpetuando las diversas violencias y reforzando las dinámicas asociadas al conflicto.

Es por ello, que, al adoptar una concepción ecológica, se admite que en las familias que han sido impactadas por el CAC se mezclan y superponen rasgos de variados contextos culturales, de tal manera que cada una de ellas posee un complejo nicho ecológico, al relacionar campos comunes y fronteras con diversas familias, y a la vez tener diferentes formas de observar y posicionarse en relación con la cultura dominante a la cual pertenecen (Walsh, 2008).

Así mismo, el cambio como variedad, hace referencia a la variedad como a la cantidad de 
configuraciones que un sistema puede convertir para sí. Estos pueden provenir de los entornos, tanto de origen como el nuevo al cual se ven abocados a desplazarse, y se puede entender como las combinaciones a diversos niveles en las que el sistema se organiza para proyectar su permanencia y mantener márgenes de adaptación.

A partir de este marco referencial podemos reconocer los diferentes órdenes de aprendizaje y formas de adaptación; por así decirlo promovemos diferentes órdenes y modos de coevolución, los cuales pueden entenderse desde formas muy poco co-inventivas hasta las más elaboradas formas de cooperación / co-construcción de mundos posibles del vivir la vida familiar. Para nosotros estos órdenes son practicados de manera permanente y buscan conquistar ritmos y regulaciones emocionales (acoplamientos emocionales) entre los diferentes actores de los procesos terapéuticos. Este proceso implica entrar en crisis, complejidades, órdenes y desórdenes en los dominios del aprendizaje y en ese sentido la modelización nos permite resolver las contradicciones con criterio estético. Este ejercicio permanente supone la aplicación de varios principios, entre otros, el principio de la relatividad, lo que-permite respetar la diversidad de saberes y hacerlos creativos; el principio de la incertidumbre que nos viabiliza a la incesante búsqueda y la aceptación permanente de nuestros puntos ciegos (Estupiñán, 2006).

Mientras en el cambio como comunicación, "el cambio se refiere aquí a la pragmática de los comportamientos modelados en procesos de comunicación" [...] "El cambio de las pautas de comunicación no deviene del sentido común y la racionalidad implica un súbito cambio que pone en juego las maneras de operación de las lógicas humanas contradictorias" (Rodríguez \& Serna, 2015, p. 69). Los sistemas humanos en sus interacciones construyen lo social, y la recursión produce lo humano de los individuos al brindarles el lenguaje y la cultura en proceso recursivo. En palabras de Morín (1996), "lo que es producido y generado, se convierte en productor y 
generador de aquello que lo produce o lo genera” (Hernández \& Bravo, 2008, p. 116).

$\mathrm{Y}$ es en el proceso narrativo conversacional en donde y para el cual se crean y relatan los viejos y nuevos relatos. Es aquí en donde estas acciones tienen un particular sentido y son intencionales y funcionales al mismo. Los procesos conversacionales que generan aperturas en los relatos dominantes o favorecen estructurar otros alternos, para todos los sujetos (incluidos aquellos que experimentado el CAC):

“ocurren desde acoples lingüisticos y emocionales entre los dialogantes, que validan experiencias y saberes invisibilizados de los actores sociales, y establecen conexiones significativas y novedosas en el relato, entre los dominios espaciotemporales, cognitivos, emocionales, conductuales o relacionales de la experiencia o praxis vital de las personas" (Estupiñán, Hernández, \& Otros, 2006, p. 100).

Por lo que, variar las relaciones entre historia y memoria está condicionado por las configuraciones relacionales (vinculares, transaccionales, organizacionales) del contexto interpersonal y conversacional de emergencia y sentido de tales relatos. Por lo tanto, éste se constituye en una consideración conceptual y metodológica, para operar la identificación y valoración del sentido relacional de los relatos, así como un indicador potencial del alcance del cambio (González \& Serna, 2006, p. 100-104).

De otro lado, se encuentra el_cambio como crisis, concibiendo la crisis por Le Moigne (1999) (Citado por Rodríguez \& Serna, 2015): “La crisis es double bind (o conjunción) de representaciones (por lo tanto, simbólicas) de las situaciones percibidas y de las acciones concebibles que se forman los actores de un sistema [...] (hay múltiple bind cuando el actor ignora que está en situación de double bind)" (Rodríguez \& Serna, 2015, p. 71). Es decir, que el cambio consiste en transformar las representaciones que el sistema construye sobre las crisis que 
presenta a partir de las diversas vicisitudes por las cuales transcurre su vida, dadas por la inmersión a un nuevo contexto, encontrando este fenómeno como un recurso posibilitador de ese cambio y generador de nuevas transformaciones que permitan movilizar estos sistemas.

Con base a lo anteriormente expuesto, Rodríguez \& Serna (2015) proponen comprender el cambio como la emergencia de un plano de relación entre el comportamiento, la interacción y el lenguaje en un contexto determinado, dentro de las nuevas posibilidades de la migración; En donde, los enfoques sistémicos, ecológicos y complejos introducen el tiempo como una “construcción (no como variable dada), que discurre en circularidades (no en modo lineal), que opera sobre principios de continuidad, discontinuidad e irreversibilidad (no en modo de pasado, presente y futuro), que se debe a diferentes niveles u órdenes lógicos (no a la cronológica) y que, en consecuencia, quiebra la idea del cambio sobre sucesión de etapas, fases, estadios o momentos, para conducirla a los órdenes de la simultaneidad y la concurrencia" (Rodríguez \& Serna, 2015, p. 64).

Teniendo en cuenta las diferentes comprensiones, durante el proceso investigativo el cambio hace referencia a una construcción discontinua que se debe a diferentes niveles en donde los sujetos comparten el modo sobre cuándo y cómo comprenderlo, es decir que emerge como una novedad en el plano de interacción bajos los principios de circularidad, relatividad, discontinuidad e incertidumbre, permitiendo la simultaneidad y confluencia, pero no de forma consecutiva, ni paso a paso o controlada. Esta transformación hace parte de la experiencia particular del sistema humano, la cual puede ser puntuado de manera similar y/o diferenciadora por otros, desde el acoplamiento en el plano de la interacción entre los nuevos contextos, que se interconectan en lo social, político, cultural y económico, en el lenguaje y las interacciones respecto a las pautas de comunicación, la ampliación de las fortalezas y soluciones que el mismo 
sistema encuentra en la relación a sí mismo y otros, posibilitando la emergencia de relatos novedosos a partir de las comprensiones del sistema frente a las diversas vicisitudes del transcurrir de la vida, que permiten a su vez su evolución y autoorganización.

Teniendo en cuenta, que el cambio puede emerger entre la vulnerabilidad, la generatividad y entre ambos, como un proceso continuo de la vida, no los entenderemos como excluyentes o distintivos sino como características que pueden presentarse de manera paralela en los sistemas familiares. Autores como Hernández y Estupiñán (2007), en los Lineamientos Técnicos para la Inclusión y la Atención con las Familias en ICBF proponen la Vulnerabilidad como Contextos psicopatológicos, en el que se encuentra inmersa en una situación "patológica", es decir enmarcada en un síntoma como símbolo de las deficiencias interaccionales del sistema, en donde es pertinente por un lado estudiar las pautas que conectan dicho síntoma y el orden de significado dentro de las historias personales y familiares (Estupiñán,2005). En razón a que el síntoma entonces se evidencia en un paciente que ha sido definido como problema, y se le ha dotado de sentido dentro del sistema, obedeciendo así a la lógica circular respecto al origen y al mantenimiento, en tanto la totalidad de los miembros de la familia terminan obteniendo una pérdida y ganancia (Hernández \& Morales, 2003). Siendo evidente en esta vulnerabilidad la imposibilidad de la familia de encontrar oportunidades de adaptación al nuevo contexto en el cual se han visto inmersos y exigiéndoles una doble reestructuración no sólo desde el ciclo vital, sino también desde el cambio de contexto y las adversidades propias de las violencias por las cuales han tenido que atravesar.

En tanto, en estos lineamientos lo que es la vulnerabilidad es en proporción a las mismas limitaciones que se dan para enfrentarse y recuperarse de los impactos de los eventos que inmiscuyen una amenaza a la misma supervivencia como familias; siendo, que estas amenazas 
pueden ser fuente de alguno de lo que son los parámetros de las vivencias familiares, tanto internos como externos, y están en la misma vía paralela con lo que es amenazante y limitante de un entorno que está permeado por el conflicto armado colombiano que genera condiciones adversas para la vida familiar de forma desproporcionada.

De otro lado, y luego de que las familias vivencian estas situaciones adversas y logran generar procesos adaptativos óptimos y alcanzan un proceso de aprendizaje para la vida, se da cuenta de la Generatividad y por ende la posibilidad de la identificación de las capacidades que la familia como sistema ya posee pero que se le ha dificultado reconocer dentro de los cambios drásticos de contextos y el ambiente hostil en el cual se han encontrado inmersas. Es así como, en las capacidades, se integran tanto los recursos tangibles y los psicológicos, es decir los que las familias poseen para resolver sus problemas, y los mismos comportamientos para afrontarlos, refiriéndose a que la misma familia realiza para superar dichas adversidades. Coincidiendo esto en la mayoría de las oportunidades con los factores protectores y de recuperación con los que la familia cuenta (Gómez \& Kotliarenco, 2010).

De esta forma, el enfoque sistémico facilita el trabajar de una forma pragmática con lo que son los recursos, capacidades y/o fortalezas de los individuos que asisten a terapia de forma interaccional en lo que es el aquí y el ahora con los sistemas familiares de forma directa o indirecta, de una forma simbólica en lo que es el contexto de la terapia individual y/o la terapia familiar (Marañón \& Abeijón, 2012).

Por una parte, la persona y familia se encuentra inmersa y mediada por un contexto comunitarios/red, que si bien se constituyen por redes de personas en su misma condición o de redes propias del nuevo espacio en el cual se encuentran, generan una red de apoyo, que junto a los recursos económicos, sociales, jurídicos, políticos, sanitarios, entre otros, les permiten re- 
configurar las experiencias vividas; incluyéndose al ecosistema, el cual se constituye por una serie de relaciones sociales, en donde puede existir contacto con algunas personas y con otras no, identificándose la gran importancia de la reciprocidad de las relaciones, en pro al equilibrio de salud mental (Simon, Stierlin \& Wynne, 2002).

Se comprende entonces que una red social estable, sensible, confiable y activa se convierte en un protector contra posibles patologías, en tanto actúa como una fuente de ayuda, encontrándose en recursividad con las propias acciones de la persona, ya que la red social protege su salud mental, y está a su vez le permite al sujeto mantener su red social (Sluzki, 2002). Por lo que, cuando las familias migran de manera forzada y/o se reencuentran en nuevos contextos luego de ser impactadas por el CAC, sus redes de apoyo son coartadas, sin embargo, como sistemas activos pueden a su vez reconstruirlas en este nuevo contexto.

Lo que permitirá esta construcción de esta nueva red social brindándole en un nivel existencial, sentido a la vida, permitiendo la edificación de la propia identidad mediante la interacción con los otros; a nivel de práctica social permite monitores y protectores de la propia salud activando la posibilidad de consultar a expertos; a nivel de red social promueve el desarrollo de actividades personales que permitan cuidados propios; y a un nivel atávico de base evolutiva, las reacciones de alarma ante un riesgo se disminuye con la presencia de figuras que son familiares (Sluzki, 2002). En este sentido, la red social permite a estas familias impactadas por el CAC encontrarles un sentido a sus vidas, de deconstruir y reconstruir su identidad mediante nuevas actividades que posibiliten su bienestar, siendo el mismo sistema familiar una de las principales fuentes de apoyo.

Es así, que las capacidades familiares entendidas como ese ajuste o equilibrio de los elementos internos y externos de la familia para adaptarse y superar las diferentes situaciones 
problemáticas (González, 2000), se convierten en otro eje fundamental, en donde la manera como la relación e interacción entre los integrantes de esas familias se comunican, re-organizan y re-estructuran generan una posibilidad distinta en el proceso de comprensión de la situación vivenciada, movilizando nuevas formas de narrarse y de generar relaciones armónicas que preserven la vida, permitiendo así superar las crisis y adaptarse al nuevo contexto. Así mismo, los miembros de los sistemas familiares cuentan con capacidades individuales, que les permitan ser sujetos activos de su realidad, brindándoles la posibilidad de afrontar los cambios dados en el medio social y en el grupo familiar, generando crecimiento y desarrollo individual de acuerdo con la etapa de ciclo vital en la que se encuentren (González, 2000).

De esta forma, las capacidades movilizan a las familias a superar la vulnerabilidad generando resiliencia posibilitadora de un proceso de cambio, comprendiendo que esta hace referencia a una capacidad del ser humano de hacer resistencia al sufrimiento y a los rastros de las heridas psicológicas que son el impulso de reparar psíquicamente las heridas que surgen de dicha resistencia (Cyrulnik, 2001). Entendiéndose que el sistema familiar en dicha resiliencia genera una evolución de alta persistencia dentro del máximo desequilibrio, en donde se evidencian grandes fluctuaciones y baja estabilidad (Hernández, 2009), mediante el uso de los recursos y capacidades que la familia posee. Destacándose, además, en la resiliencia, desde el nivel personal y familiar, el rol de adaptación en donde es un proceso dinámico de adaptaciones positivas dentro de un contexto de significativa adversidad, y en donde la recuperación y continuidad del equilibrio previo tras la crisis generan cambio (Gómez \& Kotliarenco, 2010). Siendo así, la resiliencia definida como: "la capacidad humana para enfrentar, sobreponerse y ser fortalecido o transformado por experiencias de adversidad" (Cyrulnik, 2003).

De esta forma, acogiendo una cosmogonía holística, la resiliencia se entiende como una 
situación que afecta a todos los sistemas incluidos el ser humano: es decir a los individuos, a las familias, los grupos, las comunidades, y las instituciones. Los principios de lo que se conoce como la circularidad y la misma totalidad para comprender a las familias como sistemas complejos integrados por lo que se conoce como subsistemas (ejemplo el conyugal, el parentofilial y el fraternal) están inmersos de esa misma forma en lo que se conoce como suprasistema social, el cual varía cuando una de sus partes es afectada y viceversa, lo que da cuenta de que lo que es la activación de la resiliencia en alguna de estas esferas, comprende no sólo los componentes aisladamente, sino al mismo sistema relacional (Quintero, 2005).

Por lo que, se genera entre el tránsito en que la familia pasa de un estado de vulnerabilidad a generatividad, un proceso de cambio que lleva a la resiliencia familiar e individual, mediante la potenciación de las capacidades familiares, que se han re construido durante la reestructuración de la misma estructura y dinámica familiar; recursos, capacidades que el medio les ha brindado como una manera de apoyo, y los recursos y capacidades con los cuales cada miembro cuenta, desde su individuación, para desde sus comprensiones ampliar sus dinámicas relacionales familiares y con el mundo.

Por ello es necesario tener en cuenta que según los Lineamientos Técnicos para la Inclusión y la Atención con las Familias en los lineamientos del ICBF se puede comprender en el devenir entre vulnerabilidad/generatividad las siguientes categorías: en primera medida se encuentra la red vincular y dinámica relacional, que hace referencia al marco en el que se desarrolla la vida relacional de la familia "constituida por miembros de la familia que conviven en el momento, parientes con los que cuentan, instituciones que dan apoyo, grupos políticos, religiosos, deportivos, sociales, etc., a los que pertenecen" (Instituto Colombiano de Bienestar Familiar, 2007, p. 115). 
En segundo lugar, la filiación como "la naturaleza y a la historia de los vínculos de los miembros de la familia. Las distinciones en los tipos de filiación cumplen por lo tanto una función de contención social para la familia como grupo y para sus miembros individuales" (Instituto Colombiano de Bienestar Familiar, 2007, p. 54). En tercera medida se encuentra lo sociocultural que "se refiere a los condicionantes asociados a la pertenencia a un núcleo sociocultural específico por ser miembro de una familiar en particular. Incluye los condicionantes relativos a raza, región, religión, estrato social, grupo político, etc.” (Instituto Colombiano de Bienestar Familiar, 2007, p. 55). En cuarto lugar, la vulnerabilidad social, que “es la dificultad que presentan en la capacidad de los individuos y las familias de prever, resistir, enfrentar y recuperarse del impacto de eventos que implican una pérdida de activos materiales e inmateriales" (Instituto Colombiano de Bienestar Familiar, 2007, p. 56). Como quinto lugar se ubica lo histórico evolutivo, "incluye: a) La cronología de los eventos significativos en la vida de la familia. b) La organización de esa historia como un relato encarnado. c) El ciclo vital de los individuos y de la familia como referente de su evolución como seres vivos. La historia es un contexto que dota de sentido a los hechos presentes, el relato es el vehículo y el contexto del cambio y las etapas del ciclo vital individual y familiar son la síntesis de la familia en cuanto sistema vivo evolutivo" (Instituto Colombiano de Bienestar Familiar, 2007, p. 56).

En cuarta medida, lo jurídico, que "se refiere a la forma como interactúa la familia en cuanto institución social con el sistema jurídico que regula su conformación, las relaciones, los deberes y los derechos de sus miembros entre sí y con la sociedad" (Instituto Colombiano de Bienestar Familiar, 2007, p. 56). Por último, el dinámico relacional son "las interacciones afectivas e instrumentos entre los miembros de la familia y los significados correlativos que mantienen su organización y su identidad" (Instituto Colombiano de Bienestar Familiar, 2007, p. 56) 
Teniendo en cuenta que este transcurrir entre vulnerabilidad / generatividad y los procesos de cambio de las familias que han vivenciado el CAC, implican altos niveles de malestar para sus miembros y transformaciones en el funcionamiento familiar, los cuales pueden llegar a ser contenedores de su posibilidad creativa en pro de un bienestar, se plantea la posibilidad de comenzar a trabajar con el arte como un proceso mediador del sentir del sistema como promotor de cambios. En donde se busca promover en el consultante o en los miembros de su familia movilización hacia el deseo de la construcción de imágenes, objetos, obras tendientes a la autoexpresión que le faciliten la comprensión del problema que ostenta posibilitando la identificación o construcción de posibles soluciones, siendo así pertinente el utilizar el arte como un medio que permite exteriorizar a personas y familias el malestar que se ha dificultado expresar de manera exclusivamente verbal (Marxen, 2011).

En este sentido, se hace necesario dar uso del arte como posibilitador de la resignificación de la experiencia con el que se permita una manera distinta de exploración y de comprensión frente al empoderamiento de aquellas voces que han sido silenciadas en el transcurrir de las distintas vivencias experimentadas por el CAC; en el entendido que son actores políticos y sociales con el poder de transformar su propia vida, privilegiando memorias locales e históricas (Centro Nacional de Memoria Histórica, 2009).

Por lo que, desde el enfoque sistémico comprendemos el arte como un proceso que posibilita procesos de cambio alejándose de una concepción de solo técnica y de experticia, y por el contrario acercándose más a la comprensión del arte como material didáctico, como un espiral que en la vinculación con éste producto artístico y con otros apertura nuevas posibilidades y reconoce las potencialidades particulares y que se gestan en las relaciones. Proponiéndose así una secuencia de relaciones que posibilitan la construcción, en la que según 
Bruder (2011) generan comprensiones en torno a la recuperación de la autonomía, la autogestión, y la resignificación de las experiencias desde bucles reflexivos que apunten a nuevas prospectivas vitales, los cuales se cimientan a partir de las elaboraciones internas de cada una de las personas que conforman el sistema familiar, puesto que al poner en escena sus comprensiones y relaciones muestran o reconfiguran los vínculos que se establecen en su dinámica familiar (López y Población, 1997).

En tanto el arte puede ser un medio de comunicación analógica, que representa una visión personal dentro de la dinámica de la unidad familiar, posibilitando que las familias representen de otra manera la experiencia vivida en ese adaptarse a las nuevas circunstancias (Dalley, 1987).

Es así como el arte se convierte en una estrategia que posibilita la exteriorización, en donde el foco no se encuentre en el producto final sino en la construcción de la representación simbólica, generándose manifestaciones de la relación entre quien crea la obra y para quien es construida (Dalley, 1987; Pain \& Jarreau, 1994). Desde no solo una forma pictórica sino también desde la producción de imágenes y objetos artísticos las personas y las familias pueden representar aquello que consideran atemorizante y amenazante, convirtiéndose en un proceso expresión de lo que es prohibido y de lo que se podría proyectar, de tal manera que conversan sobre su malestar o sufrimiento de manera indirecta, desde la posibilidad de relacionarse consigo mismo y con el mundo de otra manera (Marxen, 2011; Dalley, 1987).

Lo que invita a pensar que el arte permite que la familia externalice su sentir desde su inteligibilidad intacta y en el desviar su instinto al tratar de aliviar el miedo; creando desde esa falta de unicidad del lenguaje y de método una actitud que desde la cotidianidad recrea inquietudes. Constituyendo el arte el mediador entre la familia y su entorno, bajo una poca 
existencia de completudes que recurren a la estética como explicación y reflexión de eso vivenciado (Hernández \& Niño, 2013).

El trabajo gráfico, pictórico y de modelado según Pain \& Jarreau (1994) posibilitan el pasar de aquello que es invisible a la elaboración de obras en donde las personas toman conciencia de la manera de resolver los problemas plásticos con relación a sus propios dilemas. Constituyendo el trabajo artístico un recurso posibilitador de la comprensión de cómo se han entretejido los cambios en la dinámica familiar luego del impacto de la violencia en su contexto más cercano. Permitiendo así que las familias que han vivenciado el CAC puedan encontrar la existencia de un qué para cuando no encuentra un cómo desde el poder comunicar todas las complejidades que le inquietan (Wagensberg, 1985).

Es así que el arte se puede convertir en un camino alternativo de comunicación, de expresión, facilitador de la creatividad y de la participación de todos los miembros de la familia desde su propio nivel. Así como permite mantener vivas las historias en los productos artísticos de manera tangible, los cuales a su vez son susceptibles a posteriores análisis (Dalley, 1987).

En este sentido se genera una experiencia multidimensional, en el que se desarrolla un fenómeno que incluye sensaciones kinésicas, emocionales, estéticas, cognitivas, y culturales, mediante un proceso creativo en el cual surgen aquellos sentimientos que serían difíciles de tolerar para las familias impactadas por el CAC, pero sobre los que se pueden generar aproximaciones por una vía artística - simbólica de manera estética en donde se camufla la identidad en características distintas de la situación, sus personajes, etc., (Wengrower \& Chaikin, 2005); pudiendo así expresar estas familias emociones de dolor y rabia en una obra tangible, para así ampliar sus narraciones emergentes, en tanto al conversar en torno a la comparación de un antes y después de la obra se desarrolla un proceso de verbalización creativo 
y emocional, un cambio tangible (Klein citada por Marxen, 2011).

En el entendido que algunas personas y familias requieren a su vez de un proceso que incluya el movimiento, facilitando la creación y la movilización en dicho proceso, el arte se convierte en un posibilitador de introspección y de reconocimiento de nuevas formas de ser y de prospectiva vital. Por lo que, al implementarse la exploración de diferentes gamas y combinaciones de movimiento a través de la instrumentalización de los cuerpos de los integrantes del sistema, sonidos y contacto con la intervención de la palabra se puede llegar a generar una integración más cercana al self no solo individual sino también familiar (Wengrower \& Chaikin, 2005). Siendo así clave que el terapeuta posibilite un ambiente de confidencialidad, seguridad, empatía y comprensión que le permita a la familia y sus miembros la expresión de su sentir y la co-construcción de comprensiones y nuevas posibilidades (Winnicott citado por Marxen, 2011).

Permitiendo lo anterior posibilitar la emergencia de diversas narrativas identitarias de las familias y de una experiencia vital que hasta el momento ha sido invisibilizada por los relatos dominantes de lo vivenciado luego de los hechos violentos, el proceso de migración y de asentamiento a nuevos lugares, o que por el contrario no han sido aún estructurados, ni se encuentran disponibles para generar un nuevo sentido a los cambios a nivel familiar y personal en su salud mental. Siendo así pertinente el generar espacios conversacionales que le permitan a las familias convocadas reconfigurar su experiencia mediante la conversación y el uso del arte, en tanto los seres humanos tienden constantemente a buscar narrarse y narrar el mundo que los rodea, para darle sentido a lo vivido (Echeverría (1996, citado por Estupiñán, Gutiérrez \& Serna, 2006). Pudiendo ser el arte un puente y objeto transicional mediante el cual la familia y sus miembros se relacionen de manera distinta al nuevo contexto, ampliando distintas redes de 
apoyo (Marxen, 2011).

Siendo el arte el eje posibilitador de nuevos significados se hace importante reconocer cómo a lo largo de la historia este se ha comprendido de diversas maneras, es decir desde distintas perspectivas históricas (renacimiento, edad media, barroco, etc.), y él como estas comprensiones sobre el arte no han terminado siendo en su totalidad satisfactorias, presentándose algunos valores absolutos e independientes del tiempo que se mantienen (Janson, 1972); entendiéndose el arte como toda creación artística que busca generar emociones estéticas en contraposición al denominado "arte de tendencia" que busca promover más un goce exclusivamente estético antes que persuadir o invitar a llevar a cabo una determinada acción (Runes \& Chrickel, s.f.). Aquellas comprensiones que terminan transformándose son las referentes a las obras artísticas, las cuales se ven mediadas por un marco de tiempo, de circunstancias y de opiniones que cambian a lo largo de la historia, en relación a aspectos técnicos de color, estilo, realismo, luz y perspectiva (Janson, 1972; Runes \& Chrickel, s.f.); y además mediadas por las diferentes situaciones problema o crisis que atraviesan los sistemas familiares que favorecen los procesos cristalizadores o contenedores de pautas sintomáticas presentes en los diversos momentos del ciclo vital; generadores de bloqueos en la visualización de posibles alternativas de soluciones y en donde las soluciones intentadas obstaculizan la comunicación e interacción familiar.

Siendo de gran importancia la creatividad, en tanto la mente es en sí misma creativa, puesto que al activar ese potencial es posible generar cambios profundos en las organizaciones humanas. La creatividad es interaccional. El acto creativo se establece entre el creador y el modulador creativo; por consiguiente, se hace necesario recordar y comprender que hay que "dejar de ver el arte como algo accesorio y vistoso, del que se echa mano en celebraciones y ritos ocasionales, y comenzar a ver la actividad creadora como espacio de conocimiento, expresión, 
comunicación y transformación, esencial en las intervenciones que tratan con lo humano" (Martínez \& López, 2009, p.16).

Por lo que desde esta posición es viable comprender la necesidad de promover las capacidades creativas teniendo en cuenta lo referenciado en las artes, en tanto la creatividad es lo que favorece el cambio, y permite descubrir por parte del terapeuta nuevas estrategias para abordar los problemas que expresan las personas y resignificarlos, e inclusive permite fomentar en la familias la exploración de la creatividad de sus miembros, invitándolos a reconocer sus recursos relacionales y de comunicación (Medina, Laso, \& Hernández, 2014, pp. 172-174).

Es así que dichos procesos creativos son comprendidos como procesos terciarios que se equiparan a los procesos psicoterapéuticos en los que se generan nuevas redes de sentido, en los que coexisten distintas temporalidades, en los que las familias y los investigadores-interventores se encuentran inmersos entre polaridades entre la fragilidad y ambigüedad, en ese contrastar el mundo interno con el externo, el pasado, presente y futuro, el deseo, la prohibición, placer y el goce, el sufrimiento, la fantasía y la realidad. Siendo este proceso un acompañamiento de expresión enmarcado en posibilidades, capacidades, mediados por la incertidumbre en el proceso de co construcción del cambio (Marxen, 2011).

Con base a lo anterior, y por lo planteado por Martínez \& López (2009), es posible utilizar el arte como una estrategia de investigación porque, primero, es accesible al ser una actividad pública que puede ser evaluada por los colegas que la utilizan, transparente al tener claro su estructura, procesos y resultados, y transferible, ya que su utilidad no concierne solamente a este proyecto, sino que puede ser utilizado por otros y en otros contextos.

Cabe resaltar que como terapeutas e investigadoras en formación somos conscientes que cada intervención, cada persona que usa y en quien se usa el arte, las narrativas y las 
vinculaciones son únicas y diferentes, pero que la forma de abordar, las estrategias de investigación, las categorías observables nos ayudan a identificar ciertos modelos que pueden ser compartidos como estrategias globales que permitan mejorar y hacer óptima otras intervenciones-investigaciones "que acompañe[n] al otro vulnerable en su búsqueda de un lugar más seguro, de una cartografía más estable y menos dolorosa” (Martínez \& López, 2009, p. 16).

Por lo anterior, se hace necesario entender-la creatividad como la facultad o la capacidad de efectuar una creación de la nada, crear algo nuevo, en donde los conceptos descubrir e invención juegan un papel fundamental en tanto los dos están estrechamente relacionados puesto que representan la solución a un problema, el primero hace relación al conocimiento científico y el segundo a la aplicación práctica de conocimientos. Comprendiendo que en "la sincronización de la integridad y la confianza en las relaciones [,] completa el ciclo de las generaciones y hace que [el sistema consultante] recupere el sentido de la existencia [en] una comunidad que humana que el trauma había destruido” (sic) (Martínez \& López, 2009, p. 75). Entiéndase aquí, que la integración es la capacidad para darle valor a la vida en comparación a la muerte, tragedia y/o tristeza, de poder perdonar o reconciliarse con aquel pasado doloroso y/o tortuoso, y poder aceptar esa realidad sin llegar a caer en la desesperación, frustración o dolor vivido por ese pasado (Hernán, J. citado por Martínez \& López, 2009).

Siendo la imaginación, la que permite descubrir y realizar invención, en tanto esta proyecta imágenes o representaciones del mundo entero que no están sujetas al aquí y al ahora de la sensación y de la misma percepción del individuo, facilitando realizar la ilación libre de contenidos representativos, el establecimiento de relaciones o asociaciones entre dichos contenidos o de combinar los recuerdos para elaborar nuevas formas de ver los problemas, yendo más allá de lo propiamente observado o experimentado y de los mismos procesos intelectuales 
formales. Las ideas son mediadas por el pensamiento y el lenguaje, lo cual vislumbra un pensamiento es decir una realidad física que se exterioriza. Por lo que, el arte termina encontrándose inmerso en todo lo que nos rodea, y estas producciones, las obras de arte, terminan siendo un misterio en donde encajan tanto la obra como los propios sentimientos del artista (Myers, 1972).

Por lo que, de esta manera, la asociación de estos contenidos representativos o de recuerdos, no es otra cosa que asociación de ideas, vivencias, que suceden unos a otros sin pretenderlo y sin que el mismo lazo intelectual que les hila esté presente en la conciencia, puesto que este proceso puede traer a la mente otros recuerdos o vivencias de manera espontánea y sin mayor esfuerzo para el consultante o miembros de la familia; que finalmente movilizan la emergencia en la producción de algo nuevo, a través de diversos conocimientos que permiten nuevas ideas, nuevas formas prácticas de actuación y hasta nuevas soluciones (Bravo, 1994, Pp. 107 - 124).

Si bien algunos artistas (sistema terapéutico) ignoran sus ansiedades y temores inherentes a la condición humana, otros al plasmar físicamente sus dudas, inseguridades y temores liberan esas cargas de su mente (Myers, 1972), es decir que la promoción de cambios en dichas familias impactadas por el CAC pueden ser mediados por el arte como estrategia de reconstrucción y elaboración creativas de los nuevos eventos vitales, posibilitando así que el sistema consultante asuma un rol activo, en tanto se reconoce como responsable de las movilizaciones, enfrentando la frustración al requerir el arte un proceso creativo en el que se necesita constancia, disposición y apertura frente a la construcción de la obra (Marxen, 2011).

Por medio del lenguaje, tal como: la escritura, pintura, escultura, matemáticas, se transmiten ideas, manipulando el medio desde diferentes estilos que son escogidos por el artista (sistema terapéutico); es así que durante el proceso terapéutico la posibilidad de comenzar a exteriorizar 
las emociones y sentimientos no decibles, terminan potenciando la conjugación de procesos analógicos y digitales que desarrollan un cambio en el sistema consultante o en la sintomatología específica, al generarse espacios reflexivos y comprensivos de las situaciones vivenciadas en el pasado, pero que generan impactos contundentes en la actualidad del sistema consultante, desestabilizando la homeostasis familiar (Myers, 1972).

Dichos procesos son particulares de cada familia, por lo que se requiere reconocer en cada interjuego de contextos la circunstancia de estas, y las influencias individuales - sociales que pueden ser destructivas o generativas en pro a la emergencia de novedades adaptativas respecto a las nuevas vicisitudes a las que deben enfrentarse. Siendo el arte un posibilitador de relaciones terapéuticas, en tanto los consultantes pueden utilizar su propio lenguaje y simbolismos sin necesidad de adaptarse al lenguaje propio del profesional y del nuevo espacio en el que se encuentra inmerso (Marxen, 2010); posibilitando las emergencias, de nuevas formas de organización que se enmarcan en una complejidad creciente a partir de los procesos auto organizativos, entendiendo que las ciencias de la complejidad abarcan los tiempos, los fenómenos, siendo característica de los sistemas sus inestabilidades, fluctuaciones, turbulencias, incertidumbres, autoorganización, emergencias y no linealidades (Hernández \& Niño, 2013).

Lo anterior nos permite comprender que la creación artística va más allá de las barreras culturales a pesar que desde cada manera de comprenderse el mundo se presentan aproximaciones distinta al arte, todas las personas presentan un potencial creativo universal, ya que mediante un distanciamiento estético a nivel analógico les brinda mayores movilizaciones desde el desarrollo humano a las familias impactadas por el CAC, en el que la persona y las familias co descubren nuevos significados logrando mayor autonomía, ya que las imágenes al tener un sentido más universal posibilitan no solo las relaciones entre culturas distintas, sino 
también la contención de las comprensiones que surjan del proceso; que permite así el trabajar varios factores propios de la migración tales como familia, amigos, cultura, estatus social, grupo étnico e integridad física, desde comprensiones de su salud mental más locales y vitales para las familias y sus miembros (Marxen, 2011). Lo que implica la búsqueda de un nuevo lenguaje, que a su vez presenta límites para la comunicabilidad, exponiéndose la necesidad de adelantarse a las complejidades que representaría. Es así que el progreso del arte es el producto de una dialéctica entre la autoorganización es decir la innovación en el sistema, la adaptación a nuevas situaciones, y la interrelación entre el ser humano y su entorno (Wagensberg, 1985).

Por lo que las familias que han vivenciado el CAC interjugan con el arte y el terapeuta en el proceso terapéutico por medio de una transformación y la crítica de la situación, posibilitando la creación de mundos posibles, es decir un cambio en el sistema. Ya que es en ese complejizar la vida, las relaciones entre ser humano y arte, ser humano y vida, que los sistemas deben reconocer las no linealidades, las ambigüedades, las sorpresas, las emergencias y la autoorganización, lejos del equilibrio (Hernández \& Niño, 2013).

En este sentido, a la familia y las investigadoras-interventoras provenir de un lugar geográfico, una cultura y/o un contexto distinto, se hace pertinente ahondar sobre la Interculturalidad; la cual procura la relación y el intercambio entre varias culturas diferentes, generando enriquecimiento mutuo entre ellas, implicando este término una comunicación más comprensiva entre las diferentes culturas que comparten y conviven en el mismo espacio, en donde no solo se enriquecen con sus interacciones, sino que se produce un reconocimiento y valoración (externa e interna) de cada una de ellas en el marco de lo que es considerado igualdad (Hidalgo, 2005).

Por ello, la interculturalidad debe ser comprendida como la facultad de los consultantes y 
sus familias, para adaptarse y generar relaciones eficaces en los diversos contextos a los cuales llegan producto de haber vivenciado acontecimientos del CAC, necesitando para esta facultad apertura, preparación y curiosidad por conocer las costumbres y sus usos en la cultura a la que arriban, para interpretar y comprender las diferentes prácticas, mensajes y el propio lenguaje, siendo críticos constructivos de los aspectos positivos y negativos tanto de su propia cultura como a la que llegan y a otras (Artavia \& Cascante, 2009).

En este sentido, la interculturalidad permitirá la creación y desarrollo de estrategias de arte encaminadas a generar, desde el contexto terapéutico, movilizaciones y resignificaciones a partir del mismo interés por la cultura propia de cada uno de los participantes en los encuentros, por su comprensión de las diferencias con otras culturas, apoyando a los miembros de las familias a apreciar y disfrutar los aportes hechos por la diversidad cultural en sus vidas, permitiéndoles generar rupturas en las barreras culturales a las que son sometidos debido a la situación acaecida en razón a la afectación producto de las vivencias y hechos violentos del CAC, en pro de la resignificación y coevolución de sus propias vidas. 


\section{SISTEMA METODOLÓGICO}

Este capítulo permitirá conocer la explicación de la modelización de la investigación intervención describiendo los principios operadores generales de la maestría en psicología clínica y de la familia como contextualidad y lenguaje, procesos conversacionales, autorreferencia, reflexividad y la recursividad en relación a cómo estos se construyen bajo los conceptos metodológicos en correspondencia al cambio relacionados con el fenómeno desde la comprensión de las variaciones respecto a las pautas de comunicación, ampliación de las fortalezas y soluciones que el mismo sistema encuentra en la relación a sí mismo y otros, la emergencia de relatos novedosos a partir de las comprensiones del sistema frente a las diversas vicisitudes del transcurrir de la vida, y los movimientos del sistema hacia la evolución y autoorganización; así como la operacionalización del problema a partir de los conceptos teóricos, tales como la familia y su funcionamiento, vulnerabilidad y generatividad comprendidas éstas últimas como un continuo de la vida, y el arte como estrategia; así mismo se describirán los contextos (de donde provienen y al cual migran) y los actores participantes; utilizando diseños y neo diseños encaminados al análisis de información y construcción final de los resultados de la investigación.

Para el desarrollo de esta investigación- intervención se pretendía realizar un estudio comparativo - multicaso con tres familias, sin embargo luego de llevar a cabo varios acercamientos con diferentes familias que han vivenciado acontecimientos del CAC e instituciones que brindan apoyo a esta población, se concreta el proceso interventivo con una familia, en tanto algunas de estas buscaban suplir inicialmente necesidades económicas antes que 
identificaran que experimentaban un malestar psicológico, no presentaban dificultades al interior del sistema familiar o se mostraban con poca apertura al haber vivenciado inconvenientes con las intervenciones a nivel psicológico.

Para esto se realizó un proceso terapéutico utilizando el arte como mediador entre la experiencia vivida y la experiencia narrada, en el que desde la posibilidad de aperturarse emocionalmente de la familia y sus miembros se posibilita un plan de intervención en donde se desarrollan actividades de tipo artístico, que permite comprender el sentir y exteriorizarlo de diferentes maneras, posibilitando la comprensión del síntoma y el desarrollo de procesos de adaptación para la vida. Llevando a cabo seis (6) escenarios denominados así: Conociendo la familia y su historia, Soñando nuestra familia, Reconociendo relaciones en la familia, Conociendo pautas transgeneracionales, Ampliando la red de apoyo familiar, y Creando el cuento del proceso, desarrollados en ocho (8) encuentros en donde se implementaron estrategias artístico terapéuticas sistémicas: escultura familiar (pasado, presente y futuro), Álbum familiar, Dibujo (familiograma), Collage (red social), Story board family, con una familia en condición de desplazamiento residente en la localidad de Usme en la ciudad de Bogotá, D.C. Para ello se tuvieron en cuenta los cambios en el funcionamiento familiar (a nivel de su estructura, dinámica, evolución) y vulnerabilidad - generatividad; con el uso de la historia clínica, formatos de comprensión del impacto de la intervención y de las estrategias artístico terapéuticas sistémicas.

\section{Diseño de la Investigación}

De esta forma, mantendremos una postura investigativa/interventiva desde los principios epistemológicos de la complejidad, el construccionismo y constructivismo, teniendo en cuenta la teoría de los sistemas. Orientados en estos principios, esta será realizada desde una metodología 
cualitativa, de estudio de caso único con diseño transversal inclusivo, en tanto se analiza y describe solo un tiempo; inclusiva al utilizar varias unidades de observación, las cuales en este caso son seis (6): la estructura, la dinámica, la evolución a nivel familiar, la vulnerabilidad desde los contextos psicopatológicos y la generatividad desde las capacidades en relación a la red, la familia y el individuo.

Es así que desde una perspectiva investigativa/interventiva y acorde a las líneas de investigación propuestas en el programa de formación se trabajará con base en la de "historias y narrativas familiares en diversidad de contextos", utilizando la narrativa conversacional como enfoque contextual en el que se comprende el fenómeno clínico como un proceso emergente de articulación entre el campo y el acto narrativo, definiendo la narración o relato como la conexión entre la experiencia vivida, la narrada y el contexto (Estupiñán, González, 2015).

Entendemos que el campo narrativo será el espacio en el que se desarrolle la conversación con la familia respecto a los cambios, las situaciones por las que atraviesan después de haber vivenciado acontecimientos del CAC, en donde también se generan los procesos de configuración, ordenamiento y reconfiguración de dicha experiencia vivida. Por ello desde la narrativa conversacional, tendremos los siguientes principios operadores -propuestos por Estupiñán \& otros (2006)- como referentes para comprender y desarrollar la investigación: Contextualidad y lenguaje, procesos conversacionales, autorreferencia, reflexividad y la recursividad.

Los autores definen la contextualidad y lenguaje como el significado que es atribuido a cualquier experiencia por la posición del sujeto ante el contexto a través del lenguaje, pues este es el que permite marcar las distinciones que hacemos del mundo, es decir que por medio del lenguaje es posible atribuirle en el aquí y en el ahora un nuevo significado al CAC desde la 
postura de la familia que ha sido impactada, y que se encuentran en adaptación a nuevas situaciones. Comprendiendo de esta forma que los procesos conversacionales son donde se construyen los relatos que dan sentido a la experiencia propia y del otro; permitiendo en esa nueva construcción de significado generar diálogos reflexivos con la familia que ha vivenciado acontecimientos del CAC posibilitando un camino para transformar la experiencia narrada de malestar y/o sufrimiento en bienestar y aprendizaje para sus vidas.

En estos diálogos reflexivos entran en juego las experiencias de las investigadoras/interventoras y la familia que ha vivenciado acontecimientos del CAC, retomando la autorreferencia y la reflexividad, la cual implica adoptar una postura de reconocimiento del sí mismo, teniendo en cuenta las creencias, prejuicios y emociones que permiten la co-construcción de la realidad, en un contexto interaccional humano de un espacio eco-eto-antropológico (Estupiñán \& Otros, 2006), en donde la recursividad nos lleva conectar continuamente diferentes niveles de información que nos conducen a generar comprensiones complejas y reflexivas del conflicto armado, de las posibles afectaciones en la salud mental de algunos de los miembros de la familia que ha vivenciado acontecimientos del CAC por el evento violento y su influencia en el funcionamiento familiar.

Bajo estos principios operadores, los conceptos específicos de la investigación, descritos en el capítulo anterior, fueron operacionalizados de la siguiente manera; comprendiendo que se presentan recursiones entre los conceptos teóricos y la forma en que se evidencian o reconocen en la co-construcción de conocimientos (Serna, 2015) al momento de la transformación de la narrativa de la experiencia vivida.

Respecto a la estructura familiar encontramos los límites, las jerarquías, los roles y la composición familiar. Los primeros se subdividen en límites individuales, entendido como las 
reglas que determinan quién y cómo participa en una interacción, acorde con los roles respectivos. Estos tienen como función proteger la diferenciación del propio sistema y de cada uno de sus miembros, permitiendo así mismo la adquisición de competencias interpersonales (Minuchin, 1974); límites generacionales, que hacen referencia a los subsistemas que presentan funciones y demandas específicas y que generan interferencias entre ellos, por lo que en el interjuego de la cercanía y la distancia, la claridad de estos límites permiten evaluar el funcionamiento familiar (Minuchin, 1974) y las fronteras consideradas como los límites exteriores que buscan proteger y diferenciar al sistema familiar -nuclear- de la familia extensa y/o otros contextos, como el escolar, laboral, social, cultural, etc. (Sánchez, 2004; Minuchin, 1974).

Estos límites y fronteras se pueden clasificar en: claros, es decir aquellos en los que los miembros del sistema familiar presentan reglas claras en sus dinámicas de relación, el desarrollo de las funciones, posibilitando contacto entre subsistemas, sin ninguna interferencia entre estos (Minuchin, 1974); difusos, que son aquellos en donde no se define con exactitud qué miembro del sistema, cómo y cuándo debe participar, posibilitando aglutinamiento en los miembros al presentarse baja autonomía en estos, generando invasión entre subsistemas, pudiéndose sobrecargar y carecer de los recursos necesarios para adaptarse a nuevas situaciones (Minuchin, 1974); y rígidos, en donde la comunicación entre los miembros de la familia es difícil, cada miembro es tan autónomo hasta el punto de ser muy independiente, afectando las funciones protectoras de la familia (Minuchin, 1974).

Además, las jerarquías que son los niveles de responsabilidad y de poder que posee cada miembro del sistema familiar en la toma de decisiones, así como de la posición frente al ofrecimiento de ayuda, protección y cuidado en relación con los otros (Garibay, 2013). Los roles, 
que hacen referencia al conjunto de normas y expectativas de un grupo sobre la conducta y posición de uno de los miembros del grupo, en relación con el lugar que ocupa o de su función en dicho sistema (Garibay, 2013); y la composición familiar que es la estructura del núcleo familiar, que hace referencia a la cantidad de personas que conviven, niveles de relación y parentesco (Louro, 2005).

La familia así se puede tipificar por: familia nuclear, que se encuentra compuesta por el padre, la madre y los hijos, viviendo en el mismo hogar (Valdés, 2007); familia monoparental, en donde sólo está presente un progenitor, el cual es el único que convive y es responsable de sus hijos menores (Cortés \& Cantón, 2010), familia monoparental secundario o dependiente, en la que está presente un progenitor y los abuelos de los niños (Cortés \& Cantón, 2010); familias adoptivas siendo las que adoptan a uno o varios niños sin guardar algún tipo de relación biológica. Incluyen familias bi y monoparentales, parejas hetero y homosexuales, con hijos biológicos previos y sin ellos, que sean pequeños o adolescentes, con o sin especial problemas o serias dificultades (Palacios, 2000); familias reconstituidas, las que resultan de una segunda o tercera unión por parte de al menos uno de los cónyuges. Teniendo como característica el estar compuestas por padres y madres biológicos y no biológicos (padrastro y madrastra), hermanastros, medio hermanos y hermanas con vínculos consanguíneos, pueden vivir en más de un domicilio, los roles, responsabilidades, derechos y obligaciones de los padres no biológicos suelen ser difusos a comparación del de los biológicos y las relaciones evolutivas padres e hijo deben ser desarrolladas al mismo tiempo que la conyugal (Oliva, Parra \& Antolín, 2010); familias homoparentales, pareja constituida por personas del mismo sexo e hijos y/o hijas (González, López, Gómez, 2010); familias recurrentes a la reproducción asistida, que son familias en las que se lleva cabo la función productora fuera de la misma y no existe un vínculo 
directo entre padres, madres e hijos. Situación que puede presentarse en la familia de estructura tradicional, homoparental, monoparental, adoptivas y reconstituidas (Arranz, Olabarrieta \& otros, 2010) y familias tardías en las que se presenta una maternidad o paternidad tardía respecto a las concepciones de parentesco occidental y el principio de generación. En estas familias se pueden encontrar nucleares, monoparentales, homoparentales e incluso de reproducción asistida (Hernández, 2012).

Respecto al segundo concepto, dinámica familiar, encontramos las pautas de relación sintomáticas, alianzas - coaliciones, relación afectiva, comunicación, toma de decisiones y resolución de conflictos. Las primeras son entendidas como el encadenamiento de comportamientos, es decir las relaciones familiares son repetitivas, pautadas y recíprocas, que se articulan con el síntoma y se regulan por una causalidad circular (Garibay, 2013); las alianzas se dan cuando dos o más miembros de la familia al compartir un mismo interés se unen o alían excluyendo a un tercero (Garibay, 2013); manteniendo la idea de las alianzas, las coaliciones emergen cuando dos personas se unen contra un tercero, que en la escala de jerarquía representaría un grado alto de poder, para atacar y excluirlo, transgrediendo las fronteras transgeneracionales de manera implícita o explícita (Garibay, 2013). Estas pueden desembocar en triángulos; en los que se posibilitan dinámicas de interacción bajo el intento de solucionar los conflictos interpersonales entre dos miembros de la familia, a partir de inclusión de un tercero, convirtiéndose sus características y síntomas en el foco de la interacción de estos 3 miembros (Garibay, 2013). Caracterizándose por: "1. Dos personas del mismo nivel jerárquico, y una persona de nivel distinto (dos miembros de una misma generación y otro de otra generación). 2. Se establece una coalición de dos miembros que se encuentran en distintos niveles contra el que queda restante. 3. La coalición contra la tercera persona se mantiene oculta. (Garibay, 2013. P. 
40).

La relación afectiva está relacionada con el apego en cuanto a la vinculación emocional que se produce constantemente en la interacción entre los miembros del sistema familiar (Olson \& Otros, 1989); la comunicación que hace referencia al grado de comodidad del intercambio (compartir y recibir) de ideas y sentimientos entre los subsistemas, sus miembros, tanto en lo instrumental como en lo afectivo, y grado de congruencia entre los mensajes verbales (digital) y no-verbales (analógico). La comunicación es la coordinación de esfuerzos para manejar las demandas y reducir las ambigüedades, conduciendo un cambio menos estresante (Barnes \& Olson, 1985; Hernández, 1997); la toma de decisiones que se puede conectar con el poder, puesto que este tiene la "capacidad de definir la naturaleza de la relación", haciendo que la jerarquía se entienda como "la función relacional que soporta la toma de decisiones en el seno de un sistema. Y es una función que cambia de forma adaptativa con las peripecias del ciclo vital y de forma no adaptativa en determinadas circunstancias [...]" (Linares, 2012, p. 104); y la resolución de conflictos que se trata de los sentimientos, actitudes y creencias frente a la manera de reconocer y resolver las diferencias, las estrategias y comportamientos para solucionar las discusiones (Barnes \& Olson, 1985).

Respecto a la unidad de observación evolución familiar encontramos las funciones de cada miembro, indicadores de ajuste y adaptabilidad y ciclo vital. Dentro de las funciones de cada miembro encontramos la conyugalidad, parentalidad y fraternalidad.

La conyugalidad (diferente e independiente al estado civil de la pareja) puede ser definida "como la manera en que se afrontan los conflictos inherentes al ejercicio compartido de la gestión de los hijos, pudiendo representarse como un continuum inscrito entre dos polos ideales de armonía y disarmonía” (Linares, 2012, p. 69). Sus funciones hacen referencia a lo afectivo, es 
decir a la manera como aprendieron, perciben y demuestran su afectividad; a la jerarquía interna, la cual hace referencia a los juegos de poder y como la pareja se organiza para dominar los espacios en los que se encuentran inmersos, en donde se encuentran de acuerdo de manera implícita o explícita, pudiéndose apreciar las relaciones simétricas o complementarias de la teoría de la comunicación; los proyectos básicos, en los que se visibilizan de manera conjunta proyectos a futuro posibilitando se mantenga, se afiance y se fortalezca la relación; organización interna, en donde se co-relacionan la jerarquía interna, cohesión es decir cercanía emocional y afectiva entre los cónyuges y con sus familias de origen, lo cual promueve una díada de aglutinamiento o desligada, la adaptabilidad y la convergencia de las identidades de la pareja; la mitología de la pareja que se relaciona con las narraciones individuales y las negociaciones que se generan sobre las mismas posibilitando rituales, mitos, elementos pragmáticos y cognitivos en la relación de pareja (González \& Acuña, 2017); la parentalidad a la que corresponden a las funciones normativas y protectoras en donde se les enseña a los hijos e hijas a protegerse y tratar a los otros. Otra de las funciones es la emocional la cual por medio de la circularidad se conjugan el intercambio, el reconocimiento, lo interaccional, la valoración y el amor (Linares, 1996; González \& Acuña, 2017). Es así que, es “una ecuación que recoge el ejercicio de las funciones parentales (amor complejo, nutrición relacional) por parte de los padres o de las figuras delegadas responsables de ellas. Se inscribe en un continuum entre dos polos ideales de conservación primaria y de deterioro primario, en que la condición primaria refleja su independencia de un hipotético impacto de la conyugalidad" (Linares, 2012, p. 69): y la fraternalidad que hace referencia a la manera en que interaccionan los hijos (hermanos) del sistema familiar en donde entran en juego el afecto, la rivalidad, celos, alianzas, coaliciones, etc. (Ceberio, 2004). 
Encontrándose el ajuste y la adaptabilidad separadas por la crisis, entendiéndose la primera como un periodo que es relativamente estable al presentarse cambios menores que son predecibles y aceptables, y la segunda, como el momento en donde el sistema busca a partir de la adquisición de nuevos recursos el recuperar el equilibrio por medio de nuevas conductas de afrontamiento, reduciendo demandas, y transformando su visión de la situación que atraviesan. Como indicadores de adaptabilidad se encuentra la satisfacción y logros, en donde son evidentes los sentimientos de satisfacción, los logros académicos, laborales y personales, y para las crisis se identifican como indicadores problemas en la salud y el comportamiento, es decir sentimiento de malestar, síntomas y tratamientos (Hernández, 2009).

Al momento de enfrentar los procesos de cambio y/o crisis las familias se encuentran bajo estresores (Hernández, 2009); normativos, cambios que son esperables y se asocian con el desarrollo individual y familiar y no normativos, los cambios que se presentan súbitamente y la familia no se encuentran preparadas para ellos. De igual forma otros criterios de clasificación de los eventos estresantes, encontramos estresores (Hernández, 2009): los internos, que inician en un miembro de la familia, los externos, que inician fuera del sistema familiar; los ambiguos que se presenta de forma confusa e impredecible; los definidos, que se saben qué y cómo sucede y por cuánto tiempo; los voluntarios, que son deseados o buscados por la familia; los involuntarios, que se presentan sin ser deseados o buscados; los crónicos, que se refieren a situaciones de larga duración, y los agudos, eventos difíciles pero de corta duración.

Las familias se encuentran atravesadas por ciclos vitales, lo cuales se componen por una serie de fases, crisis transicionales inevitables, cambios, crecimientos de los miembros de la familia, entradas y salidas de parientes, que a su vez se interrelacionan con el ciclo vital individual (Garibay, 2013). La primera etapa se denomina conformación de la pareja (sin hijos); 
caracterizada por procesos emocionales de transición bajo el principio clave del compromiso con el nuevo sistema, que presenta cambios de segundo orden requeridos para el progreso del desarrollo como son la formación del sistema marital y los ajustes en las relaciones con la familia extensa y los amigos para incluir el cónyuge (Hernández, 2009). La segunda etapa o familias con hijos pequeños (hijo mayor de 0 a 5 años), es asociada al principio clave de aceptación de los nuevos miembros dentro del sistema y asociada a cambios descritos como ajuste marital para abrir espacio a los hijos, asunción de los roles parentales y ajuste en las relaciones con la familia extensa para incluir los roles de padres y abuelos (Hernández, 2009).

La tercera etapa o familias con escolares (hijo mayor de 6 a 12 años) con el principio clave de la consolidación de la relación con los sistemas escolar y social más amplio, asociada a cambios como el ajuste de normas internas de diferenciación de la familia y el fortalecimiento de la identidad familiar (Hernández, 2009); la cuarta etapa o familias con adolescentes (hijo mayor de 13 y 18 años), tiene como principio clave incrementar la flexibilidad de la familia para integrar la autonomía de los hijos, reflejando cambios en la relación parental para permitir la movilidad del adolescente dentro y fuera del sistema, re-enfocar la vida marital y la vida personal de los padres y cambios ocasionados por dificultades de la generación de los abuelos (Hernández, 2009); la quinta etapa o salida de los hijos del hogar (hijo mayor de 19 y 30 años), está bajo el principio clave de la aceptación, de los múltiples ingresos y salidas de miembros, en donde se observa cambios como la renegociación del sistema marital como diada, el desarrollo de la relación adulto-adulto entre padres e hijos y ajustes para incluir a la familia política (Hernández, 2009).

Respecto a la unidad de observación vulnerabilidad (contextos psicopatológicos) y generatividad (capacidades-red, familia, individuo) encontramos red vincular - dinámica 
relacional, filiación, socio culturalidad, vulnerabilidad social, histórico y evolutivo y jurídico.

En la red vincular, se encuentra "constituida por miembros de la familia que conviven en el momento, parientes con los que cuentan, instituciones que dan apoyo, grupos políticos, religiosos, deportivos, sociales, etc., a los que pertenecen" (Instituto Colombiano de Bienestar Familiar, 2007, p. 115), la dinámica relacional se “abarcan las interacciones afectivas e instrumentos entre los miembros de la familia y los significados correlativos que mantienen su organización y su identidad” (Instituto Colombiano de Bienestar Familiar, 2007, p. 56); filiación hace referencia a "la naturaleza y a la historia de los vínculos de los miembros de la familia. Las distinciones en los tipos de filiación cumplen por lo tanto una función de contención social para la familia como grupo y para sus miembros individuales" (Instituto Colombiano de Bienestar Familiar, 2007, p. 54); sociocultural "se refiere a los condicionantes asociados a la pertenencia a un núcleo sociocultural específico por ser miembro de una familia en particular. Incluye los condicionantes relativos a raza, región, religión, estrato social, grupo político, etc.” (Instituto Colombiano de Bienestar Familiar, 2007, p. 55); vulnerabilidad social es la dificultad que presentan en la capacidad de los individuos y las familias de prever, resistir, enfrentar y recuperarse del impacto de eventos que implican una pérdida de activos materiales e inmateriales. (Instituto Colombiano de Bienestar Familiar, 2007, p. 56); histórico evolutivo "este parámetro incluye: a) La cronología de los eventos significativos en la vida de la familia. b) La organización de esa historia como un relato encarnado. c) El ciclo vital de los individuos y de la familia como referente de su evolución como seres vivos. La historia es un contexto que dota de sentido a los hechos presentes, el relato es el vehículo y el contexto del cambio y la etapas del ciclo vital individual y familiar son la síntesis de la familia en cuanto sistema vivo evolutivo" (Instituto Colombiano de Bienestar Familiar, 2007, p. 56); y el jurídico "se refiere a la forma 
como interactúa la familia en cuanto institución social con el sistema jurídico que regula su conformación, las relaciones, los deberes y los derechos de sus miembros entre sí y con la sociedad” (Instituto Colombiano de Bienestar Familiar, 2007, p. 56).

De igual forma, según la comprensión presentada del cambio en el sistema teórico "como comprendemos", se describe la operacionalización del mismo para reconocer el resultado del uso de las estrategias artístico-terapéuticas sistémicas desde los siguientes conceptos metodológicos sobre los que se rige la investigación-intervención:

Variaciones respecto a las pautas de comunicación, se comprenden en la narrativa relatos asociados a cambios en el lenguaje digital y analógico entre los miembros de los diversos subsistemas que componen el sistema familiar, y los observados en el desarrollo de las sesiones presenciales en la forma como se comunican, quién dice que, cómo lo dicen, presentándose cambios en la gestión de quien es el narrador de la historia, en la compresión de la pertinencia del contenido mismo de lo que se narra, dando paso a decidir las interpretaciones que surgen de la narración, así como los cambios en las posiciones y actitudes frente a la historia narrada por los protagonistas.

A partir de ello, se busca promover diferentes maneras de relacionarse entre los integrantes; es decir, la emergencia de nuevas pautas relacionales que posibilitan la evolución del sistema re estructurando la dinámica establecida por la familia por medio de procesos de transición emocionales en los que los miembros de la familia experimentan de otra manera sus vivencias y narran de forma distinta los hechos vividos.

Así como, los cambios en las puntuaciones de los hechos en tanto se presentan dobles descripciones de los mismos y la identificación de la transformación de flexibilidad en las pautas complementaria-simétricas de la relación conyugal. 
Ampliación de las fortalezas y soluciones que el mismo sistema encuentra en la relación a sí mismo y otros, referidos en los relatos que dan cuenta del auto y hetero reconocimiento de los aprendizajes, de las formas como se perciben y se comprenden entre ellos, y las nuevas maneras de negociar y tomar decisiones que movilizan la reconfiguración del vínculo en pro al bienestar deseado.

Emergencia de relatos novedosos a partir de las comprensiones del sistema frente a las diversas vicisitudes del transcurrir de la vida, en tanto logran realizar distinciones en torno a la experiencia vivida y a la experiencia narrada, reconociendo en esas distinciones relatos que dan cuenta de su propio cambio, y de la construcción de nuevas posibilidades de relación entre ellos, con su contexto y con sus redes de apoyo, al enfrentarse a estresores normativos y no normativos.

Movimientos del sistema hacia la evolución y autoorganización, observando la transformación de la identidad del sistema familiar respecto a su originalidad y sentido de pertenencia, así como los movimientos que se generan en la vinculación entre los miembros luego de presentarse crisis que desequilibran el sistema familiar, en donde se posibilita la autonomía, que es la capacidad de producir cambios en las pautas relacionales según las exigencias internas (ciclo vital, historia y cultura) y externas (entorno). Surgiendo así una serie de tareas de mantenimiento a nivel familiar que permite su autorregulación y desarrollo luego de enfrentarse a estresores normativos y no normativos, desde cómo la familia maneja la interrelación entre las demandas, en virtud de la percepción que cada miembro presenta frente a las situaciones-problémicas, sus capacidades para enfrentarlas entendidas como recursos y estrategias de afrontamiento, y los significados atribuidos que se han transado a nivel familiar y social, modificándose continuamente y dando respuesta a las perturbaciones internas y externas 
del sistema.

Teniendo en cuenta las diferentes funciones de ritualización, explicadas en el marco teórico, se puede evidenciar el uso del ritual en el proceso de autoorganización de las relaciones interpersonales desde el cambio para identificar cómo se desarrollan nuevas estructuras de interacción, comunicación y de toma de decisiones, indicando un cambio en el nivel de realidad y de meta realidad en el sistema y subsistemas familiares, en su autonomía, en la reestructuración de hechos y situaciones, en la transmisión intergeneracional de mitos, creencias y de rituales que les brindan protección.

\section{Contextos y Actores}

Con base en lo anterior y a nuestro foco de interés, la unidad de análisis es la familia no clínica como eje interventivo, la cual debe configurar una demanda de ayuda psicológica. Es así, que se toma una muestra intencional para determinar los participantes a partir del uso de la entrevista (ver anexo 4). La familia seleccionada se encuentra caracterizada inicialmente como personas que han vivenciado acontecimientos del Conflicto Armado Colombiano (CAC), que solicita una demanda de ayuda -identificado en el resultado de la entrevista-. Entendiendo que las familias no clínicas son aquellas en las que ninguno de los integrantes haya sido diagnosticado o intervenido debido a alguna dificultad de orden psicológico que pueda generar interferencia en su productividad o en su propio bienestar (Hernández, 1989).

En este entendido, fue seleccionada una (1) familia en condición de desplazamiento forzado y actualmente residente en la ciudad de Bogotá. Proveniente del Guamo, Tolima en condición de desplazamiento forzado; se encuentra en los ciclos vitales de familia "con jóvenes e hijos en 
edad escolar", siendo una familia reconstituida. En el hogar conviven los dos padres, la hija mayor (17 años) de la primera unión de la madre y sus cinco hijos, el mayor de 13 años, el siguiente de 12 años y tres niñas de 8 años, 3 años y una bebe de 5 meses.

\section{Descripción de los prediseños, diseños y neodiseños de investigación-intervención}

Para dar inicio al desarrollo de la investigación, esta se dividió en tres fases. La primera denominada "lectura del contexto", en donde se realizó el tamizaje para la selección de la familia participante; la segunda relacionada con la construcción de la información, en la cual se encuentran los escenarios correspondientes al proceso terapéutico en los que se utilizaron estrategias artístico terapéuticas - sistémicas como estrategia de cambio, implementando escenarios conversacionales reflexivos y escenarios conversacionales; y la tercera y última, en la que se desarrolló la sistematización y análisis de la información.

En la primer fase -lectura del contexto- se aplicó entrevista como una práctica de diferentes variables de estructuración bajo guiones o cuestionarios, la cual permitió conocer el comportamiento de los grupos y sus intereses, lo que posibilitó tomar decisiones frente a los mismos (Serna, 2015). Una de las áreas de aplicación de esta técnica es la salud, en donde se identifica su uso en estudios de conocimientos, conductas y actitudes de la población objeto referente a dicha temática (Galindo, 1998). Es así que esta desde un propósito selectivo facilitó identificar aquellas personas que presentan afectaciones en su salud mental y reportaron una demanda clínica, seleccionando y convocando a una (1) familia para desarrollar el proceso terapéutico.

Con esta fase se pretende observar los eventos que ocurren en los espacios en los que las familias que han vivenciado acontecimientos propios del CAC interactúan en un nuevo espacio, 
para de esta manera realizar una comprensión holística de dichos contextos hasta llegar a las vivencias e historias particulares de la familia participante. Esto permitió establecer vínculos entre las investigadoras/interventoras y la familia, para comprender los puntos de vista internos de estas respecto al fenómeno, en relación con la perspectiva de las observadoras, para así ampliar la comprensión de este y su impacto en el funcionamiento familiar; identificando así cómo se entretejen las relaciones, las expresiones e historias de los participantes. De igual manera, se detectó cómo el contexto social, económico y político influye en la manera como la familia se percibe y es leída por la sociedad, y el contexto en el que se encuentra inmersa (Sampieri \& otros, 2010).

En la segunda fase -construcción de la información- se reconoció que todo proceso de construcción de contextos, procedimientos, y escenarios de investigación/intervención son espacios de conversaciones generativos que se entrelazan en bucles recursivos entre los distintos actores: familia, equipos de profesionales, redes sociales, representantes de la comunidad y de las organizaciones, así como los contextos de investigación-intervención. En dichos espacios se evocaron historias significativas de la familia que vivencio acontecimientos del CAC, desde el comprender junto a esta sus relatos, a medida que se buscaba generar una interacción conversacional en la que se posibilitaba la emergencia de nuevos significados tanto de las experiencias vividas, como proyectadas, al promover así posibles formas de relación y de acción. De igual manera, es de resaltar que dentro de los escenarios se comprendían e identificaban los procesos relacionales-conversacionales, es decir lingüísticos, cognitivos, pragmáticos, emocionales, y contextuales que permitían un cambio narrativo (Estupiñán, Gutiérrez \& Serna, 2006).

En tanto, Watzlawick (1985) propone dos axiomas de la comunicación, primero es 
imposible no comunicar, y en segunda medida el ser humano se comunica de manera analógica y digital; la primera representa una poderosa sintaxis lógica que carece de un nivel semántico y la segunda posee una gran semántica que carece de la sintaxis pertinente para reconocer las combinaciones necesarias en pro a la comprensión de las relaciones humanas. Es así que el posibilitar este lenguaje analógico mediante el uso del arte, amplió la posibilidad de las familias de expresar de manera digital aquellas reconfiguraciones de su experiencia vivida luego de ser partícipes de un proceso terapéutico.

Por lo que se buscó poner en juego los dos tipos de lenguaje -digital y analógico- por medio de un guion conversacional y estrategias artístico - terapéuticas sistémicas como posibilitadoras de cambio, en tanto se evidenció la dificultad de las personas de poner en palabras el sufrimiento o malestar por el que atraviesan, y de esta manera se posibilitó un espacio de reflexión para la reconfiguración de la experiencia vivida y la identificación de los cambios acaecidos en la salud mental de la familia que vivencio acontecimientos del CAC y de sus miembros, en tanto las estrategias que hacen parte del área de la expresión artística permitieron la canalización de sentimientos y la proyección de la experiencia interna (Bustos, 2013).

Es así que esta fase, se dividió en seis (6) escenarios con ocho (8) encuentros en las que se utilizaron diferentes estrategias artísticas - terapéuticas - sistémicas- (escultura familiar, fotografía, dibujo, storyboard, collage y álbum familiar) las cuales fueron enmarcados bajo escenarios conversacionales reflexivos, en donde se posibilitó la emergencia de nuevos relatos posibilitadores como nuevos significados tanto de la experiencia vivida, como de nuevas maneras de accionar y relacionarse, a medida que se comprendió junto a la familia como el CAC ha impactado su vida y como los cambios generados han entrelazado nuevos efectos en sus relaciones familiares y con el mundo que los rodea (Estupiñán, Gutiérrez \& Serna, 2006). 
En este sentido se desarrollaron en cada escenario procesos conversacionales referentes al objetivo acordado con la familia para el proceso terapéutico, el cual se orientaba a potenciar las capacidades familiares que le permitieran a la familia adaptarse a los cambios normativos de los procesos de individuación y autonomía de los hijos menores, bajo el cambio no normativo de su actual condición de desplazamiento forzado. Entrelazados con las comprensiones del funcionamiento familiar antes y después de haber vivenciado acontecimientos del CAC en pro a movilizaciones, así como los cambios que se han gestado en el funcionamiento familiar utilizándose estrategias artístico terapéuticas sistémicas como una estrategia de intervención, bajo la luz de los principios operadores explicados previamente (Estupiñán, Gutiérrez \& Serna, 2006).

Cada una de las escenas se desarrolló bajo un proceso conversacional-reflexivo entre la investigadora-interventora (No 1) y la familia mediante el uso de una de las estrategias artístico terapéuticas sistémicas, posteriormente el equipo reflexivo-observador compuesto por las otras dos investigadoras-interventoras (No. 2, 3) conversaron frente a la familia y la interventora investigadora (No 1) respecto a sus comprensiones sobre lo trabajado y las narraciones que fueron evocadas durante la interacción del sistema terapéutico, para que posteriormente la investigadora-interventora (No 1) y la familia externalizara las reflexiones que les suscitaron luego de escuchar al equipo reflexivo.

Para esto se construyeron los pre-diseños basados en las estrategias artístico terapéuticas sistémicas, comenzando con la escultura (pasado-presente-futuro) ya que esta permite reconocer cómo era el funcionamiento familiar y los cambios gestados en éste luego de haber vivenciado acontecimiento del CAC, además posibilita identificar la necesidad de conocer las relaciones familiares que generen reflexiones respecto a su manera de interactuar, lo cual lleva a hacer 
evidente unas fuertes pautas intergeneracionales que se identifican como primordiales para el proceso de cambio, las cuales se logran visualizar por medio del dibujo del familiograma. Al comprenderse estas formas de relacionarse, se reconoce la necesidad de fortalecer la red social familiar, construyendo a través de un collage la red social de la familia, promoviendo los procesos reflexivos en donde se posibilitan nuevas formas de relación que promuevan nuevas interacciones a nivel familiar. Estas sesiones se desarrollaron desde los procesos conversacionales con las tres terapeutas que posibilitan comprensiones de segundo orden, desde procesos auto y heterorreferenciales que movilizaron el hilo conductor mencionado respecto a temas y estrategias artístico terapéuticas sistémicas. Finalmente, y con el objeto de construir procesos reflexivos se elabora el story board family lo que permite a la familia generar comprensiones y visualizarse desde distintas formas, así como proyectarse a futuro y co crear posibles futuros.

Para la ejecución de los escenarios se tuvo en cuenta el siguiente mapa:

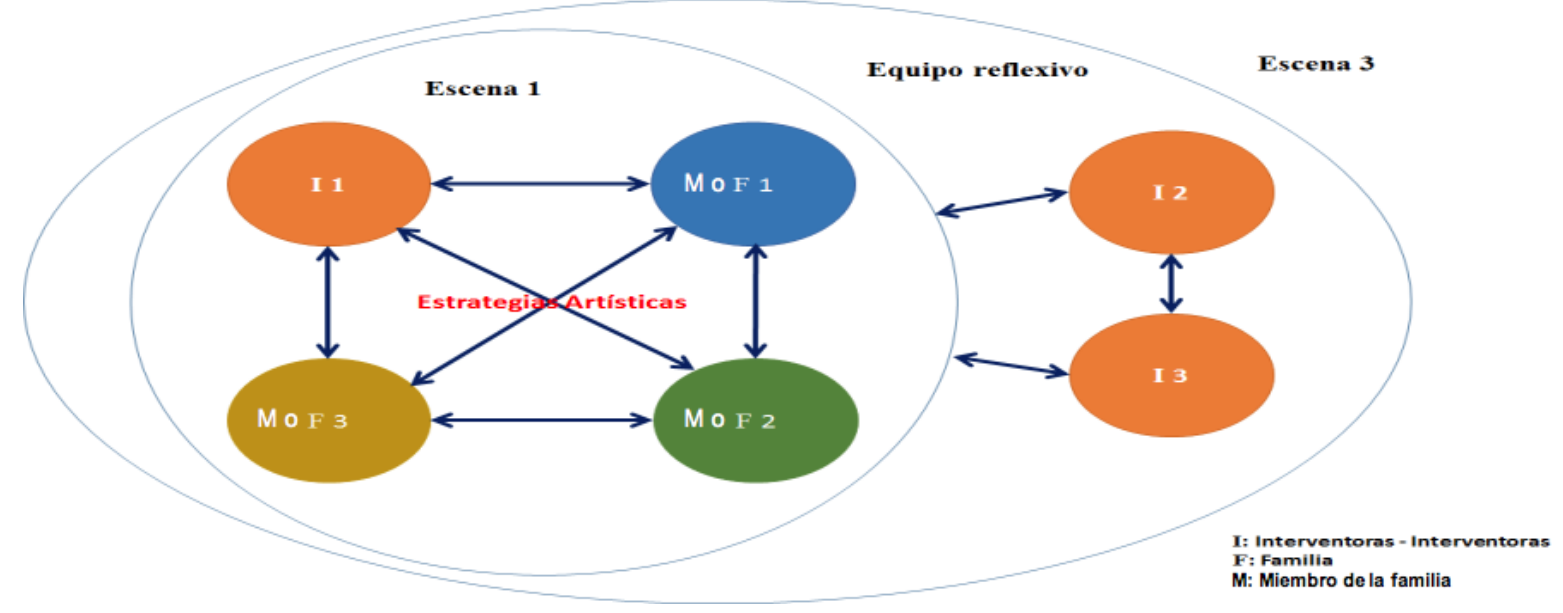

Figura No. 01. Autoras

Inicialmente se propone la siguiente estructura para llevar a cabo los escenarios:

Tabla 1. Prediseño escenarios Escenario 1 al 6. 


\section{Segunda fase}

\begin{tabular}{llllll}
\hline Escenario & Objetivos & Focos & Participantes & Pregunta & Estrategia \\
& & & Orientadora
\end{tabular}

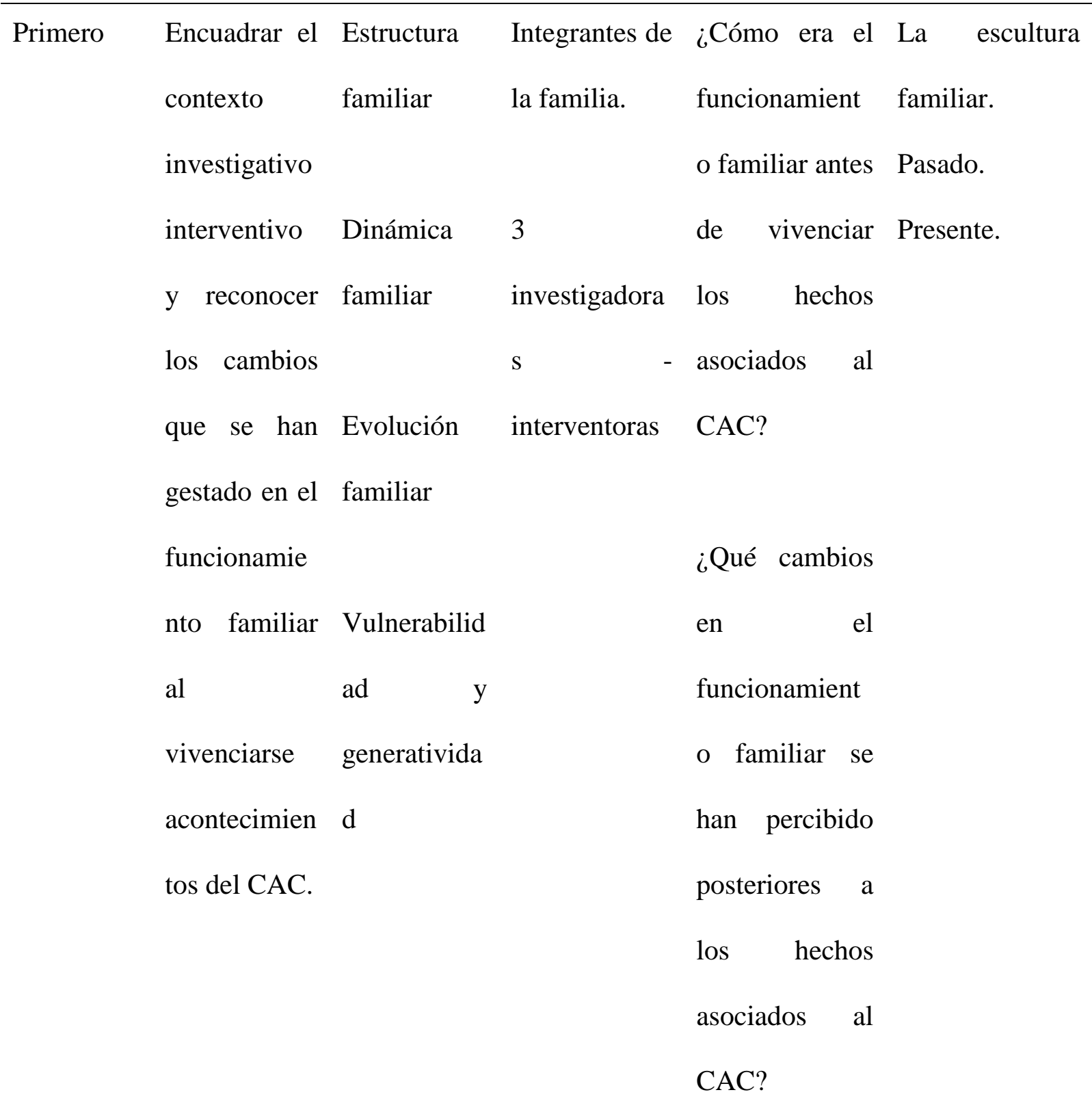

Segundo Comprender Estructura Integrantes de ¿Cuál es la La escultura




\begin{tabular}{|c|c|c|c|c|c|}
\hline & las & familiar & la familia. & prospectiva & familiar: \\
\hline & expectativas & & & vital del & Deseada. \\
\hline & familiares $y$ & Dinámica & 3 & sistema & \\
\hline & generar & familiar. & investigadora & familiar? & \\
\hline & reflexiones & & $\mathrm{s}$ & & \\
\hline & en torno a & Evolución & interventoras & ¿Cómo & \\
\hline & los cambios & familiar & & familia puede & \\
\hline & que & & & ser un actor & \\
\hline & consideren & & & activo de su & \\
\hline & pertinentes & & & propia & \\
\hline & para & & & movilización? & \\
\hline & movilizar la & & & & \\
\hline & dinámica & & & & \\
\hline & familiar. & & & & \\
\hline Tercero & Redefinir & Dinámica & integrantes de & ¿Cuáles son las & Dibujo \\
\hline & objetivo & familiar & la familia. & reflexiones a & familiograma. \\
\hline & terapéutico. & & & nivel familiar e & \\
\hline & Posibilitar & Evolución & 3 & individual que & \\
\hline & reflexiones & familiar & investigadora & son necesarias & \\
\hline & en torno a & & $\mathrm{S}$ & co construir en & \\
\hline & los cambios & Vulnerabilid & interventoras & pro & \\
\hline & que & $\mathrm{ad}$ & & cambio? & \\
\hline
\end{tabular}




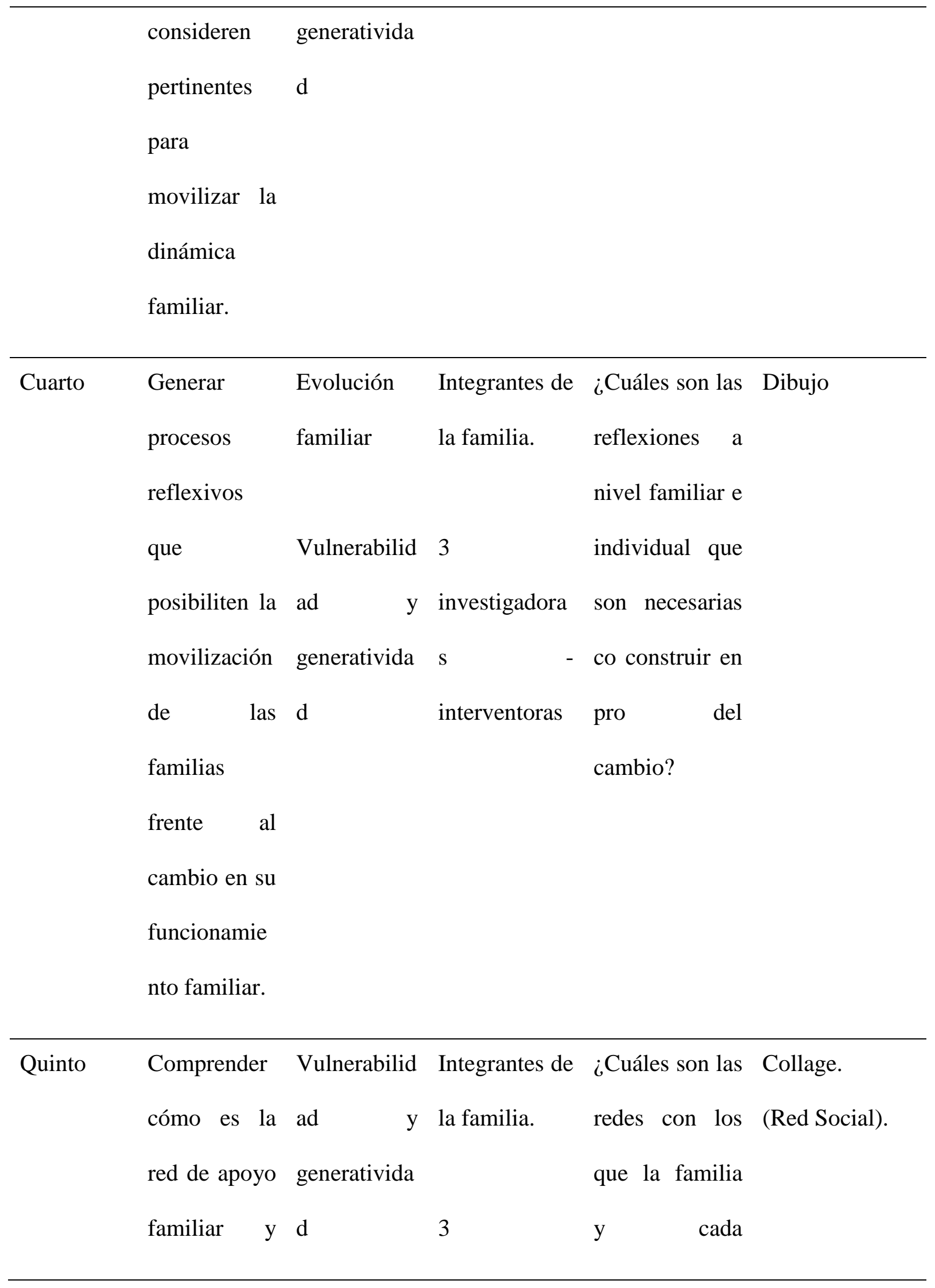




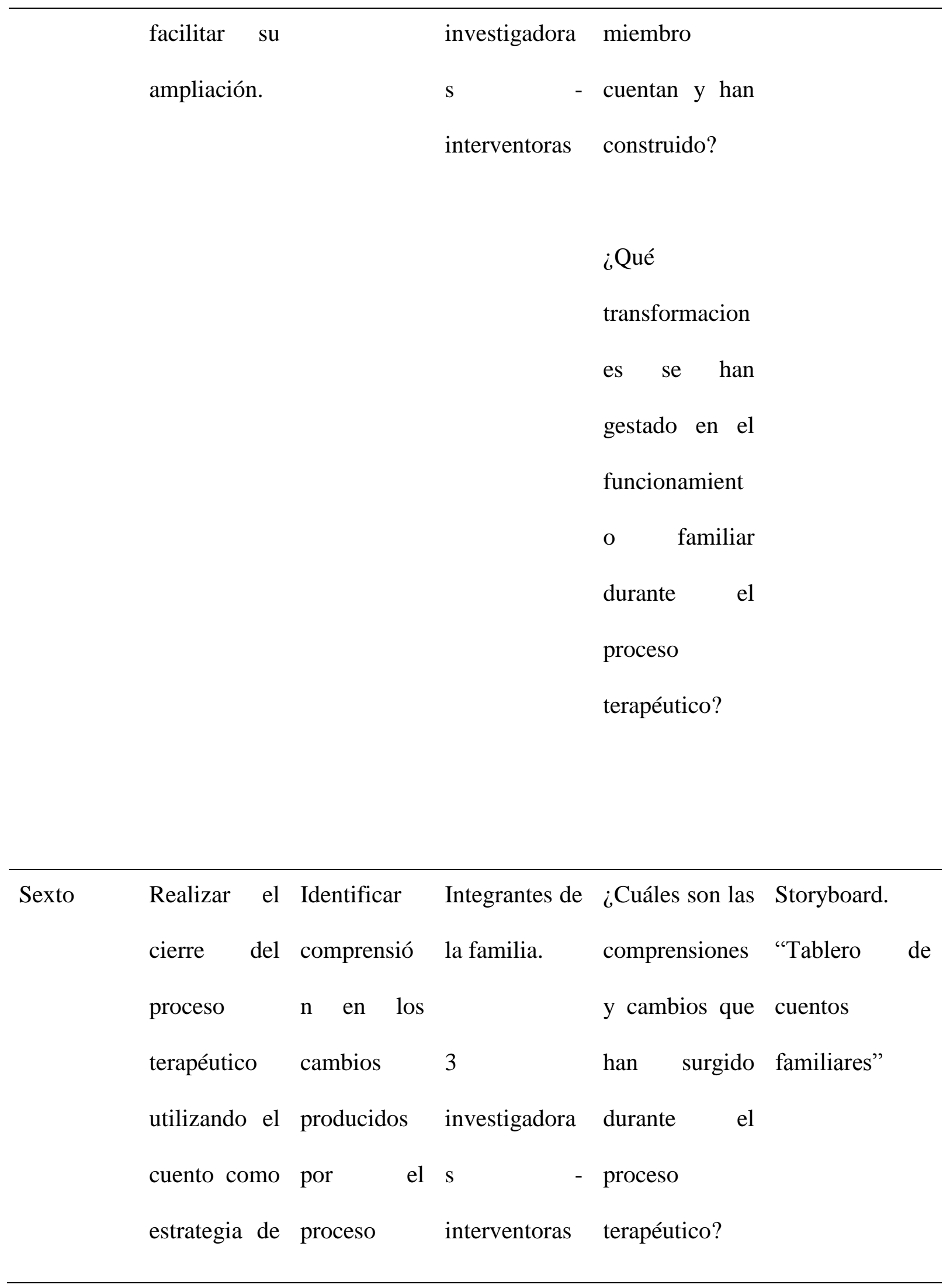


reflexión. investigativ

o-

interventivo.
¿Cómo se
gestan las
comprensiones

de las familias

a partir de

estrategias

artístico

terapéuticas

con enfoque

sistémico?

¿Cómo las

estrategias

artísticas-

terapéuticas

implementadas

posibilitan

nuevas

comprensiones

y cambios en

el

funcionamient

o familiar? 
Sin embargo, durante el proceso terapéutico si bien se pretendió mantener dicha estructura se realizaron ajustes a cada escenario de acuerdo con lo vivenciado en los escenarios anteriores y a la pertinencia de los cambios que eran necesarios generar en pro a los objetivos coconstruidos con la familia para el proceso psicoterapéutico, lo cual a su vez generó variaciones en el número final de encuentros con el sistema consultante. Cabe resaltar que, esta investigación al ser un proceso interventivo (principalmente) inicialmente se construyó el primer escenario, para el cual se planteó un guion conversacional con base a los inventarios sobre la familia de Olson.

Por lo que para el desarrollo del proceso terapéutico se construye el siguiente abanico de estrategias artístico terapéuticas sistémicas para movilizar el cambio en la familia participante y obtener una amplia variedad de estrategias que de acuerdo con la situación particular de la familia se pudieran implementar, siendo así posible solo utilizar algunas de estas o ajustar su plan de implementación:

Los documentos terapéuticos que son cartas, certificaciones, declaraciones, escritos creativos, que pueden también incluir elementos visuales dependiendo de la edad y la situación particular de las personas; que integran nuevos cambios, perspectivas, conocimientos de esa nueva visión que la persona incorpora en su experiencia. Estos pueden no solo ayudar a la persona a evitar la imposición de ideas, sino que también posibilita nuevas expresiones, recordatorios del progreso y nuevos descubrimientos. El objetivo de esta estrategia es fortalecer el relato de sí mismos que se ha comenzado a registrar en nuevos logros e ideas. Durante el desarrollo de esta estrategia se invita al consultante a desarrollar un documento escrito en el que plasme sus pensamientos respecto a un tema en concreto, o se le lleva un documento que el mismo terapeuta ha construido en relación al relato del consultante plasmando las mismas 
palabras que este emplea; posteriormente se conversa dicho documento en sesión invitando a este a reconocer lo que significó el escucharlo o escribirlo, la manera en la que se cambiaron sus pensamientos, sentimientos y cómo contribuyeron para facilitar dichos cambios. Para el desarrollo de esta estrategia se utilizarán materiales que la persona necesite para desarrollar un escrito distinto (vinilos, papel, lápices, colores, esferos, etc.) (Payne, M. 2002).

De otra parte, la elaboración de álbumes familiares se convierte en un documento creativo en el cual las familias plasman sus reflexiones de lo trabajado, presentan algunas nuevas ideas y despejan dudas en pro a dicho proceso desarrollado; es decir, permiten una reorganización metafórica familiar. Lo anterior tiene por objetivo potenciar las reflexiones, ideas, dudas que el proceso va generando en la familia y en sus integrantes, posibilitando el que cada miembro externalice de manera metafórica a los demás miembros otras ideas y pensamientos que considera son pertinentes para comprender a nivel familiar (ICBF Regional Putumayo y Fundación Afecto Modalidad Familias con Bienestar, 2016.

Para desarrollar esta estrategia artística se invita a las familias a construir un álbum en el que se plasman las reflexiones, ideas e interrogantes que les surgen como familia en su hogar luego de los encuentros que se desarrollan, así como se irá exteriorizando el trabajo desarrollado en cada sesión; se realiza recopilación del trabajo desarrollado en la sesión anterior y sus comprensiones serán compartidas al inicio de cada nueva sesión, para así conversar frente a las reflexiones y cambios que se han generado a lo largo del proceso; al final del proceso se utiliza el álbum como una herramienta que permita recopilar y re-narrar el desarrollo del proceso, plasmándose un cierre con un continuará, en el que se señalan los recursos con los cuales cuenta la familia en pro a su prospectiva vital, denotando la posibilidad de continuar escribiendo una historia distinta de familia. Los materiales que se requieren son cartulina, colores, cintas, 
fotografías, stickers, láminas, tarjetas, dibujos y diferentes tipos de papeles.

Así mismo, se utilizará la fotografía como acto narrativo, en donde las fotos actúan como símbolos posibilitadores y metafóricos transicionales que permiten una manera de encuentro con el sí mismo, mediante la exploración a nivel emocional a partir de lo visual, promoviendo así el diálogo terapéutico. La fotografía entonces permite reconocer los relatos en la construcción de experiencias individuales, posibilitando la externalización de discursos interiorizados distanciando a la persona de sus relatos dominantes, para que así surjan relatos emergentes. Por lo que, existen los siguientes tipos: Documental o testimonial, el cual permite documentar las acciones o momentos históricos importantes de la persona o de la colectividad teniendo en cuenta el modo de relación a nivel simbólico, epistémico y estético; la Fototerapia es un proceso llevado por la misma persona para generar un autodescubrimiento o con un propósito artístico, por lo que son activamente tomadas, posadas, escuchadas, habladas, revisadas, reconstruidas en el proceso de generar nuevas narrativas (fotos del consultante tomadas por otros, fotos tomadas por el consultante, autorretratos, fotos familiares autobiográficas, fotos - proyectivas). Esta es una estrategia que tiene por objetivo promover la exploración y comunicación de sentimientos y recuerdos respecto a temas de interés en el proceso terapéutico. Durante el desarrollo de dicho proceso se utilizará la imagen fotográfica de múltiples maneras para dinamizar el encuentro, utilizándose distintas unidades y formas de análisis espaciotemporal ordenándolas como por ejemplo en un álbum familiar, en el que el consultante puede escoger distintos personajes escenarios y temáticas, capturando sus propias imágenes fotografías, o seleccionando aquellas que le llaman la atención, dándoles un sentido con el tópico a trabajar en el proceso; para posteriormente a través del diálogo comenzar a dilucidar la representación simbólica de la movilidad emocional y trascendental durante la 
narración de estas. Lo recursos serán cámara fotográfica y fotografías (Izquierdo, 2014).

De igual forma, se usará el cuento (Story Board Family) como una posibilidad de que las familias escriban cuentos en forma de storyboard favoreciendo las narrativas alternativas a las asignadas por el síntoma. Siendo el objetivo generar una forma de reconexión entre los miembros de la familia a través de un cuento de viñetas, sin palabras. El procedimiento que se realizará durante el proceso terapéutico es solicitar a los consultantes lo siguiente: El cuento debe estar formado por entre 12 y 16 viñetas, cada viñeta debe dibujarse en un folio en blanco, pueden participar todos los miembros de la familia que participan en el proceso, debe tener un principio y un final, el principio debe ser un momento de ciclo vital de la familia (el que ellos deseen), no tienen por qué representar a personas concretas, puede ser una metáfora de la familia, y la distribución puede asignarse, de manera que indique quien realiza la primera viñeta y asignar al miembro que dibuja la última. Siempre recordando que no puede haber texto escrito. Se construye un puzle desordenado salvo en los límites de contexto. Un puzle que después, al traerlo cada miembro, expresa una viñeta que tiene resonancias respecto del resto de las viñetas. Todos los miembros deben conocer el inicio, es decir, pueden ver la viñeta inicial, pero no pueden ver el final. Para terminar, se realizan conexiones narrativas que pueden resolverse, o bien a través de un texto imaginado por los terapeutas en cada viñeta hilando las mismas en solución de coherencia. Los materiales por utilizar son viñetas (dibujos elaborados por cada miembro de la familia) y tablero para organizar el puzle (Medina, Laso \& Hernández, 2014).

Así mismo, se usará el collage como una posibilidad de explorar nuevas formas de comunicarse vinculadas a la capacidad de generar nuevos encuentros emocionales, movilizando al sistema frente al problema o síntoma y su función homeostática en la vinculación familiar. Se 
trata de una elaboración creativa conjunta entre los miembros del sistema familiar; para ello se propondrá a los miembros de la familia que elaboren conjuntamente un collage sobre lo que sienten cada uno que es su forma de vincularse. Podrán hacerlo sobre lo que recuerdan del pasado, sus propias experiencias del presente o lo que esperan del futuro. Podrán expresar todo lo que quieran sin necesidad de dar explicación verbal a los otros, ni pedir o dar explicación de la construcción que se está elaborando. Se deberá disponer cartulinas de colores para que la familia escoja el color que más le parezca para hacer el collage, este color debe ser consensuado. La cartulina será ubicada en un lugar consensuado por los miembros de la familia e iniciarán la construcción del collage. Todos los miembros deben elaborar el collage en la misma cartulina, la cartulina no deberá dividirse. No podrán cuestionar, ocultar ni dirigir el trabajo del otro. Al final deberán consensuar el título que le colocarán. Finalmente se expone la construcción en el contexto terapéutico, momento en el cual se conversa sobre cada detalle, sobre el significado para cada uno de esa construcción, para finalmente construir un compromiso entre los miembros de la familia que apunte a la solución del problema o disminución del síntoma. Analizar la posibilidad de escribir un cuento a partir del collage para hacer devolución a la familia, escribiendo este las terapeutas (Medina, Laso \& Hernández, 2014).

En este sentido con $\underline{\text { el cuento }}$ se pretende que la persona y la familia tomen conciencia del sí mismo y su unidad, permitiéndose el explorar su self, en pro al cambio necesario. Ya que se proporciona mediante este un instante creativo, en el que se presentan 3 funciones; la primera corresponde a los anhelos "rey", quien tiene como función la inteligencia, la autoridad y la decisión, brindando señales de alarma y formulando preguntas de cambio. De otro lado, se ubican los obstáculos, "héroe", representando la función de coraje y valor, mientras se 
encuentra la inspiración en las "hadas" sometiendo el poder del héroe para conducirlo a su meta, a la vez que es cuestionado por el rey (Brasey \& Debailleul, 1999).

A dichas preguntas ubicarse en las limitaciones, y sus respuestas en el velo imaginario, entre la ausencia y las posibilidades se invitará a la familia a construir un cuento de su propia historia familiar, para conversar respecto a los personajes principales y cómo estos se correlacionan con "el rey", "el héroe" y "el hada", encontrándose junto a la familia dichos mundos posibles en el vació de las posibilidades referentes a lo sucedido; del experimentarlo, de llevar a cabo acciones de cambio entre los contrarios, la confrontación de los obstáculos y la inspiración (Brasey \& Debailleul, 1999). Utilizando como recursos hojas y esferos de colores.

En relación con lo anterior, la pintura comprendida también como dibujo puede ser concebida como "un intento de reconciliarse con la vida" (George Tooker, citado por Arias \& Vargas, 2003, p. 145), puesto que esta nos sirve para dar sentido aquello que no está presente, abriendo una puerta a la interioridad -reflexión- y a los sentimientos. "La curación por medio de la arte terapia utiliza la pintura como medio de expresión, para explorar las necesidades psicológicas de los pacientes" (Arias \& Vargas, 2003, p. 146), esto es posible ya que se trabaja el caos emocional para dejarlo fluir sin restricciones en la pintura y su resultado permite ver el "simbolismo de cada uno, y con ello, la manera en que siente y percibe de tal forma que es posible ahondar en los conflictos y la pena" (Arias \& Vargas, 2003, p. 147). Al ser un proceso tan personal permite un trabajo individual y colectivo puesto que el color y la intensidad, la textura, la libertad de expresión en los trazos se pueden plasmar en el papel haciendo emerger y transformar sentimientos - emociones, ya que se podría considerar a la pintura como un autorretrato de nosotros, el cual nos permite captar nuestro sí mismo (la rabia, la culpa, el dolor, pero también la felicidad, satisfacción y reconocimiento) a través de los trazos. 
Hay quienes consideran que la pintura se puede asemejar al cuerpo humano, es decir "el flujo de la pintura con la circulación de la sangre" (Arias \& Vargas, 2003, p. 150) lo que da la oportunidad de que al momento del pintar se renueven los órganos, es decir que se dé un estímulo para él sí mismo lo que permite una renovación del mismo. Al momento de pintar una obra se realizan dos actividades; la primera es expresiva, es decir "una forma de sacar a flote lo más profundo de nosotros mismo", y la segunda es la observación, "pues es necesario dejar que las imágenes nos hablen, ya que la creación pictórica es un espejo de su autor” (Arias \& Vargas, 2003, p. 149).

Por lo que, se desarrollará en tres fases principalmente. En la primera se invita a (los) consultante(s) a realizar un ejercicio de relajación, que le permitirá concentrarse en la actividad. Acto seguido se dará paso a la fase dos, en donde se darán las indicaciones para realizar la actividad. Se le expondrá a la(s) personas(s) que pueden tomar cualquiera de las hojas, colores, pinceles (o su propio cuerpo) y deberán dibujar lo que les plazca. Dependiendo de las situaciones se puede ayudar a la expresión de sentimientos mediante diferentes preguntas (por ejemplo, acerca de sus relaciones familiares y sociales) y en otros casos se puede llegar a utilizar la música como fuente de inspiración. Para finalizar la sesión, es decir la tercera fase, se procederá a realizar preguntas reflexivas que permitan la emergencia de conversaciones que ayuden a resignificar aquel malestar a partir de poder nombrar aquello innombrable. Haciendo uso de recursos tales como; papel (acuarela, cartulina, hojas blancas y/o de colores, etc.), pintura (acuarela, acrílica, témpera, etc.) y pinceles de diferentes tamaños.

De otra parte, la danza es la expresión corporal de la emoción que produce la música y su valor terapéutico reside en la posibilidad de que el consultante y su familia se expresen y sientan. Su propósito es expresar emotivamente las vivencias, los recuerdos y los deseos, liberar 
tensiones, crear y recrear emociones y simplemente dejarse ir. Su objetivo es la estimulación y descarga o liberación de sentimientos a través de los movimientos y gestos corporales, la comunicación y el contacto a través de actividades no verbales, la reducción de ansiedad gracias a la actitud no crítica de las sesiones terapéuticas y a través del olvido de uno mismo que se experimenta en la danza, la experimentación del goce físico y emocional debido al impacto producido y el estímulo auditivo (ritmo), junto con la libertad de movimientos, el uso de la respuesta humana al ritmo, innata, en orden a producir movimiento individual y participación conjunta con otros.

En el entendido que se presenta una relación mente-cuerpo en donde desde lo creativo se trabaja con las emociones, pensamientos y los movimientos que le acompañan, para promover un proceso de integración emocional, cognitivo y físico, en pro a un proceso de integración y crecimiento personal (Bernstein citado por Panhofer, 2005). En donde según Chace citado por Panhofer (2005) a partir de un proceso de comunicación la persona se relaciona consigo misma y con el mundo en el momento en que siente bajo la poca capacidad de utilizar nuevas maneras de comunicarse.

Siendo importante tener en cuenta durante el movimiento; la conciencia kinésica, entendida como la habilidad de conectar emoción y movimiento; la polaridad, en la que surgen de manera simultánea los opuestos; la imaginación activa, como la libre asociación que posibilita el fluir, y finalmente el movimiento auténtico, como el espontáneo y auténtico en el espacio en el que las personas expresan sus polaridades para así tomar decisiones personales (Panhofer, 2005).

El procedimiento se desarrolla en sesiones individuales o en grupo. Los grupos no deben sobrepasar los 10 consultantes. La duración de las sesiones será de 45 minutos. Para desarrollar la sesión de danza se realizará lo siguiente: Se elegirán piezas musicales con un marcado tinte 
emotivo (alegría, tristeza, nostalgia), música instrumental o clásica (instrumentos, como piano, guitarra, sinfonías, entre otras), para esta elección es importante tener en cuenta la idiosincrasia propia de cada familia y gustos particulares de cada uno. Se iniciará el proceso haciendo conscientes a los integrantes de las familias de su propio cuerpo, parte por parte. Se realizarán ejercicios de respiración simultáneos a los movimientos. Se les solicitará hacer movimientos lentos con todo su cuerpo, movimientos hacia el infinito, generando proyección, los cuales estarán ajustados a cada caso particular (Poch, 1998).

Solicitando así en un primer espacio el que los miembros del grupo expresen cómo se siente, exteriorizando como llegan a nivel físico, emocional y cognitivo, para llevarse una primera impresión de este. En la segunda parte se desarrolla el calentamiento que mediante ejercicios físicos y la danza acompañados de la ampliación del vocabulario del movimiento permiten la conciencia corporal, pudiéndose allí intercambiar el liderazgo como posibilitador de empatía entre los miembros de la familia. En la tercera fase, se desarrollan actividades que permitan junto con la música, la utilización de metáforas y símbolos que posibiliten las relaciones de los miembros de la familia según su pertinencia, y finalmente se cierra de manera no verbal y verbal, en la que se retoma la palabra, desde una contención física y emocional (Chace citado por Panhofer, 2005). Utilizando como recursos distintas pistas de música y parlantes.

Así mismo, la música se convierte en un proceso dirigido a ayudar a los consultantes a acrecentar, mantener o restaurar un estado de bienestar utilizando experiencias musicales y las relaciones que se desarrollan a través de ellas como fuerzas dinámicas de cambio. Se trata de usar piezas musicales actuales o del pasado capaces de generar emoción, ya que si es capaz de generar emoción puede tener valor terapéutico para aquella persona concreta que lo percibe con 
tal sentido. En tanto la música tiene la capacidad de producir cambios en el ser humano, a todos los niveles: biológico, fisiológico, psicológico, intelectual, social y espiritual, puesto que, al actuar sobre el sistema nervioso central, provoca o puede provocar en el ser humano efectos estimulantes, sedantes y enervantes, desde el punto de vista dinámico.

Para esto, es importante que la música sea del agrado de quien la escucha, y que la escuche en una situación personal y ambiental adecuada, para despertar, evocar, provocar, fortalecer y desarrollar cualquier emoción o sentimiento en el consultante o su familia. Para ello las siguientes condiciones son importantes: 1 . Capacidades personales para sentirse afectado por la música. 2. La predisposición a escuchar el tipo determinado de música que puede emocionar. 3. Las condiciones personales del momento concreto versus música precisa. 4. Los recuerdos vinculados a una música determinada se incrustan de tal modo en ella que a veces perduran toda la vida y modifican el clima emocional de una composición musical determinada. 5. Las condiciones ambientales en que se escuche la música. No son recomendados los ambientes ruidosos, malas condiciones acústicas, excesiva luminosidad, puesto que no contribuyen a la concentración mental ni a crear el clima adecuado a los estados nerviosos. 6. Somos especialmente sensibles a la música de nuestra cultura respectivamente. 7. Efectos de habituación. Duración de la música y garantía de no interrupción. 8. La actitud crítica frente a una determinada música por parte de uno mismo o proveniente del entorno grupal o social (medios de comunicación), que bloquee cualquier tipo de reacción emotiva si el sujeto no es suficientemente fuerte para hacerle frente en el último caso (Poch, 1998). Por lo que se pretende invitar al consultante a mencionar la música que más le hace conectar con la situación que es considerada como generadora de malestar, así como a identificar aquella que es posibilitadora de tranquilidad y crecimiento familiar, y luego se genera un proceso de comprensión reflexión 
en torno a dichas pistas escogidas, los pensamientos y contrariedades que le suscita. Siendo necesarios como recursos distintas piezas de música, acceso a internet, parlantes.

De otra parte, el psicodrama será usado como una estrategia para explorar problemas psicológicos y sociales animando a los participantes para que actúen en los eventos relevantes de sus vidas, en lugar de simplemente narrarlos, permitiendo una mayor reflexión. Tiene como objetivo el colaborar en el cumplimiento de una meta extraordinaria: la transformación consciente, intencional, de la conciencia misma. El procedimiento estará caracterizado por un inicio, desarrollo, final, y se realizarán técnicas como: - Dramatización: Se trata de la puesta en juego de una situación del protagonista. Se trata de escenificar una situación de la vida de la familia, en donde serán actores y autores de su obra existencial. La situación puede hacer relación al pasado, presente o futuro, siendo conscientes de que todo hace parte del presente (López \& Población, 1997). - Dinámica de roles: Esta forma fomenta un tipo activo y por ende mucho más creativo del pensamiento imaginativo. Contribuirá a que las personas obtengan insights sobre la presencia y naturaleza de diversos complejos o partes de sí misma que es probable hayan permanecido fuera de su conciencia inmediata hallando vías más eficaces para vivir más conscientemente y madura. En esta técnica del psicodrama se puede incluir el descubrimiento, la identificación de las actitudes clave, el esclarecimiento y negociación de las impresiones que se observan en las actitudes, una nueva toma de decisiones y el compromiso en la práctica de nuevas actitudes. Los roles son anotados en una pizarra o papel como parte del proceso de diagramación, para ellos se asignará un nombre a cada rol, lo asignará la familia. Durante el psicodrama pueden surgir cambios en los roles. Puede usarse diagramación (diagramación de red social), objetos o el genograma para representar las relaciones que surgen de los roles y las variantes de los roles que se van mostrando en el psicodrama. - Doble: Estas 
técnica busca que el yo auxiliar se convierta en el otro fundido con el propio sujeto. Oyendo, viendo y sintiendo al yo auxiliar que se fusiona con su mente y con su cuerpo, el paciente se ve a sí mismo, se percibe expresado fuera, pero como él mismo, reconociéndose en esa identidad con la que convive. Sea de un modo u otro el yo auxiliar que hace de doble procura meterse en la piel del doblado, adoptar la postura corporal, sus tensiones musculares, su expresión facial, todo ello como vía para aproximarse a ser el otro. Luego, a su lado o poniéndole las manos en los hombros expresa lo que percibe que no manifiesta el sujeto, pero que forma parte de él. Espejo: Corresponde a la fase de reconocimiento del yo. Permite al sujeto verse representado en su actuación a través del desempeño por parte del yo auxiliar de su rol. - Cambio de roles: Corresponde a la fase del reconocimiento del tú. Permite a cada uno de los sujetos implicados tomar contacto con el otro tal como es y poder tomar conciencia de lo que dé propio se le estaba depositando. Se debe ser cuidadoso de no caricaturizar o agredir al otro en el desarrollo de la técnica. Es preciso explicar claramente lo que se precisa con la solicitud de cambio de roles. Cuando ya esté claro lo que se requiere, se les invita a tomar la posición espacial del otro, terminado se les solicita volver al anterior espacio. - Soliloquio: Se usa para pedir en un momento determinado que el consultante exprese en voz alta lo que se le ocurra en ese instante, puede ser sobre sí mismo o sobre lo que sucede en su entorno. Es una forma de expresión de sentimientos y pensamientos por parte de un individuo sobre la percepción que tiene en ese momento de sí mismo o del sistema al que pertenece. La finalidad es plasmar, evidenciar en el aquí y el ahora, un momento del desarrollo del drama (López \& Población, 1997). Caldeamiento: Técnicas o actividades de dinámica de grupos para estimular la cohesión y espontaneidad grupales. Acción: Aplicación de las técnicas psico dramáticas. - Sharing: Finalizada la dramatización los miembros del grupo comparten con el protagonista y con los 
demás los aspectos de su vida que la dramatización le hizo recordar. En donde los miembros de la familia interpretan diversos roles en el entendido de que éstos no representan la posición real de ejecutante. (Sí más tarde los intérpretes deciden reconocer que ciertos elementos de los roles que desempeñan coinciden con su propia vida, será decisión exclusivamente suya.) Los recursos para usarse son los cuerpos de los miembros de la familia (Yo auxiliares, audiencia), audiencia (otros integrantes de la familia y terapeutas), terapeuta (director), escenario.

Además, se usará la escultura familiar como una expresión plástica simbólica de la estructura vincular de un sistema, mediante la instrumentalización de los cuerpos de los elementos de dicho sistema. La cual tiene por objetivo movilizar a la familia en una posición determinada por parte de uno de los miembros, que puede ser el PI o el miembro más periférico del sistema, permite sacar al grupo de su atrincheramiento dialéctico expresado desde sus posiciones de fuerza. Se sugiere usar los cuerpos de aquellos individuos que forman el sistema familiar, moldeando sus posturas, gestos, posiciones relativas, distancias y contactos, para conformar un grupo escultórico, habitualmente estático, que muestra ya a primera vista el esquema de las interrelaciones de aquel grupo humano. La escultura expresa un contenido del interior del escultor, y por tanto sólo él mismo puede modelar y moldear los cuerpos que son su material en cada una de sus posiciones generales y pequeños detalles. Son sus manos las que deben fabricar la escultura. Es preciso transmitir al sujeto que durante la construcción de la escultura deseche indicaciones y/o expresiones como "colócate como tú quieras, tú sabes lo que quiero expresar, coloca las manos sobre el hombro de, expresa tu alegría,” pues debe ser él mismo el que coloque con sus manos cada posición, cada miembro. (López \& Población, 1997). El procedimiento se ajustará acorde con lo que se pretenda observa y movilizar en el contexto terapéutico en donde se colocará en juego el pasado, presente y futuro de momentos de las 
relaciones familiares con la participación de todos los miembros de la familia asistentes a la terapia. Se realizará registro fotográfico y videográfico de las esculturas elaboradas por cada miembro de la familia para posterior análisis con ésta. Los recursos que se requerirán son sala de terapia, cuerpos de los miembros de la familia, cámara de fotografía y videograbadora.

Teniendo en cuenta las estrategias artístico terapéuticas sistémicas descritas anteriormente se posibilitó en el proceso terapéutico de esta familia cambios individuales y familiares desde el desarrollo de los escenarios por medio de la escultura familiar, la fotografía como acto narrativo, el dibujo, el collage y el story board family. Sin embargo, a estas se les realizan los siguientes ajustes con el fin de movilizar cambios según los escenarios propuestos en relación con los objetivos co construidos con la familia:

Se utiliza la fotografía como acto narrativo, con el fin de potenciar las compresiones a nivel individual y familiar frente a su funcionamiento a partir de la estrategia de la escultura familiar, actuando estas fotos como símbolos posibilitadores y metafóricos transicionales que permitieron una manera de encuentro con el sí mismo de los integrantes de la familia, mediante la exploración a nivel emocional a partir de lo visual, promoviendo así el diálogo terapéutico, la externalización de discursos interiorizados distanciando a la persona de sus relatos dominantes y promoviendo una apertura al cambio.

Con relación a la pintura comprendida también como dibujo fue concebida como un medio de expresión en donde se pudiera dar fuerza a la voz de los hijos en edad escolar de la familia en tanto pudieron externalizar su sentir y se abriera una puerta a su interioridad desde la reflexión. Esta estrategia tenía planteado originalmente tres fases las cuales se transformaron dependiendo del objetivo desarrollado en el escenario, descripción que se encontrará en cada uno de estos. 
Así mismo, con el collage se exploraron nuevas formas de comunicarse vinculadas a la capacidad de generar nuevos encuentros emocionales, movilizando al sistema frente al problema o síntoma y su función homeostática en la vinculación familiar, por lo que desde la comunicación verbal y no verbal de manera interaccional se recuerda el pasado, las experiencias del presente o lo que esperan del futuro durante la construcción de éste.

Respecto al cuento (Story Board Family), utilizando el álbum familiar como las viñetas de la historia, el equipo terapéutico construyó conexiones narrativas, desde la utilización de metáforas propuestas por la propia familia, que permitieron resaltar el cambio y bienestar deseado alcanzado por ésta durante este proceso terapéutico.

\section{Diseños de los escenarios}

\begin{tabular}{|c|c|c|c|c|}
\hline \multicolumn{5}{|c|}{ Diseño - Escenario 1 - Familia 2: Conociendo a la familia y su historia } \\
\hline \multicolumn{5}{|c|}{$\begin{array}{l}\text { Objetivo General: Encuadrar el contexto investigativo interventivo y reconocer los cambios que se han gestado en el funcionamiento } \\
\text { familiar al vivenciarse acontecimientos del CAC. }\end{array}$} \\
\hline \multicolumn{5}{|c|}{ Actores: Integrantes de la familia y tres (3) Investigadoras- interventoras. } \\
\hline \multicolumn{5}{|c|}{$\begin{array}{l}\text { Recursos: Tecnológicos: Videocámara, grabadora de voz, trípode. Plásticos: Cartulina, lana, colores, cintas, fotografias, stickers, láminas, } \\
\text { tarjetas, dibujos, diferentes tipos de papeles. Humanos: Miembros de la familia. }\end{array}$} \\
\hline Escena & $\begin{array}{c}\text { Objetivos } \\
\text { Específicos de } \\
\text { Intervención }\end{array}$ & Focos & $\begin{array}{c}\text { Preguntas } \\
\text { Orientadoras de } \\
\text { Intervención }\end{array}$ & Guión Interventivo / Estrategia Artística \\
\hline Escena 1 & $\begin{array}{l}\text { Realizar } \text { el } \\
\text { encuadre de la } \\
\text { sesión y del } \\
\text { inicio } \quad \text { del } \\
\text { proceso } \\
\text { terapéutico. }\end{array}$ & $\begin{array}{l}\text { Socializar el } \\
\text { consentimiento } \\
\text { informado. } \\
\text { Socializar el marco de } \\
\text { la investigación } \\
\text { intervención. } \\
\text { Establecer acuerdos } \\
\text { para el desarrollo del } \\
\text { proceso investigativo- } \\
\text { interventivo. }\end{array}$ & $\begin{array}{lr}\text { ¿Cómo construir un } \\
\text { contexto } & \text { de } \\
\text { investigación } & - \\
\text { intervención } & \text { con } \\
\text { familias que } & \text { han } \\
\text { vivenciado } & \\
\text { acontecimientos } & \text { del } \\
\text { CAC? } & \end{array}$ & $\begin{array}{l}\text { Proceso conversacional. } \\
\text { Se dará explicación del desarrollo de la sesión. } \\
\text { ¿Tienen alguna duda frente a las actividades que se } \\
\text { desarrollaran? } \\
\text { ¿Cuál es su opinión acerca de la metodología con la que } \\
\text { daremos inicio? }\end{array}$ \\
\hline Escena 2 & $\begin{array}{l}\text { Comprender } \\
\text { los cambios } \\
\text { que se han } \\
\text { generado en el } \\
\text { funcionamiento }\end{array}$ & $\begin{array}{l}\text { Estructura familiar } \\
\text { Dinámica familiar } \\
\text { Evolución familiar }\end{array}$ & $\begin{array}{l}\text { ¿Cómo era el } \\
\text { funcionamiento } \\
\text { familiar antes de } \\
\text { vivenciar los hechos } \\
\text { asociados al CAC? }\end{array}$ & $\begin{array}{l}\text { Estrategia Artística: } \\
\text { La escultura familiar (Pasado - Presente): } \\
\text { - Cada miembro de la familia realizará una escultura } \\
\text { que evidencie cómo es su relación con cada uno de } \\
\text { los otros integrantes y luego se incluirá él mismo en }\end{array}$ \\
\hline
\end{tabular}




\begin{tabular}{|c|c|c|c|c|}
\hline $\begin{array}{l}\text { familiar } \\
\text { después de ser } \\
\text { impactada por } \\
\text { el CAC. }\end{array}$ & $\begin{array}{l}\text { Vulnerabilidad } \\
\text { generatividad }\end{array}$ & $y$ & $\begin{array}{l}\text { ¿Qué cambios en el } \\
\text { funcionamiento } \\
\text { familiar se han } \\
\text { percibido posteriores } \\
\text { a los hechos } \\
\text { asociados al CAC? }\end{array}$ & $\begin{array}{l}\text { - Rescultura. } \\
\text { postesentando inicialmentente el presente. } \\
\text { - Para el caso del pasado se solicitará a la familia que } \\
\text { elaboren una escultura de hace aproximadamente seis } \\
\text { (6) años (el tiempo dependerá de la información } \\
\text { obtenida en el tamizaje) que refleje un momento } \\
\text { significativo asociado a las vivencias con los hechos } \\
\text { del CAC. } \\
\text { - Se les solicita que en silencio esculpan la escultura } \\
\text { utilizando la postura, distancia, gesto y la relación tal } \\
\text { y como la ven en este momento, en donde el escultor } \\
\text { ubicará el cuerpo de los otros integrantes de la familia } \\
\text { como desee hacerlo. } \\
\text { - Se inicia realizando la escogencia de la escena que se } \\
\text { desea representar. } \\
\text { - Se orientará a los miembros para que voluntariamente } \\
\text { inicie quien desee hacerlo. } \\
\text { - Se solicitará a los participantes que expresen lo que } \\
\text { sienten en la postura y situación en la que se } \\
\text { encuentren. } \\
\text { - Acorde con las observaciones y comprensiones de } \\
\text { requerirse se aplicaría otra de las téenicas del } \\
\text { psicodrama como son: Cambios de roles, doble, } \\
\text { espejo, representación directa o simbólica, expresión } \\
\text { de un objeto o una parte del cuerpo, silla vacía, } \\
\text { sustitutos, ego múltiple, corte de la acción, } \\
\text { - Se revisará la relación actual, se observará la } \\
\text { interacción y cuál es la problemática que presenta la } \\
\text { familia. } \\
\text { - Se observará la ubicación de los participantes, la } \\
\text { proximidad entre los miembros, quien está más cerca } \\
\text { a x, o entre, el tono de voz, }\end{array}$ \\
\hline
\end{tabular}

\begin{tabular}{|c|c|c|c|c|}
\hline & & & & $\begin{array}{l}\text { - Se revisará la historia y se observará la emoción } \\
\text { activada con la escultura. } \\
\text { - Se observarán los acontecimientos o situaciones } \\
\text { relevantes que han contribuido al dilema o al síntoma. } \\
\text { - Se conversara con los participantes sobre lo } \\
\text { observado y sentido. } \\
\text { - Se realizará registro fotográfico y grabación de las } \\
\text { esculturas elaboradas, para realizar posterior análisis } \\
\text { con la familia. } \\
\text { Guión Interventivo: Se anexan preguntas guía para tener en } \\
\text { cuenta cada una de las unidades de observación y sus } \\
\text { subcategorías. }\end{array}$ \\
\hline Escena 3 & $\begin{array}{l}\text { Construir con } \\
\text { la familia la re } \\
\text { definición del } \\
\text { problema }\end{array}$ & $\begin{array}{l}\begin{array}{l}\text { Redefinición del } \\
\text { problema. }\end{array} \\
\begin{array}{l}\text { Concertar objetivos } \\
\text { terapéuticos. }\end{array}\end{array}$ & $\begin{array}{l}\text { ¿Qué comprensiones } \\
\text { se han co construido } \\
\text { en relación a los } \\
\text { cambios en el } \\
\text { funcionamiento } \\
\text { familiar? }\end{array}$ & $\begin{array}{l}\text { - Las dos (2) interventoras investigadoras del equipo } \\
\text { reflexivo conversan frente a la familia y la interventora } \\
\text { investigadora frente a sus comprensiones del } \\
\text { funcionamiento familiar. } \\
\text { - Se genera un diálogo conversacional: (1) Investigador - } \\
\text { interventor con la familia sobre lo escuchado de las } \\
\text { investigadoras. } \\
\text { ¿Cuáles son las comprensiones de lo observado durante el } \\
\text { desarrollo de la escultura familiar del pasado-presente? } \\
\text { ¿Qué ideas les surgen luego de escuchar el equipo } \\
\text { reflexivo? }\end{array}$ \\
\hline Escena 4 & $\begin{array}{l}\text { Realizar cierre } \\
\text { del escenario. }\end{array}$ & $\begin{array}{l}\text { Reconocer cambios y } \\
\text { significaciones sobre } \\
\text { lo desarrollado en la } \\
\text { sesión. }\end{array}$ & $\begin{array}{l}\text { ¿Qué } \\
\text { resignificaciones se } \\
\text { han construido sobre } \\
\text { el dilema en torno al } \\
\text { desarrollo del } \\
\text { encuentro? }\end{array}$ & $\begin{array}{l}\text {-Se genera un diálogo conversacional: (1) Investigador - } \\
\text { interventor con la familia sobre las expectativas del espacio } \\
\text { terapéutico. } \\
\text { ¿Qué esperan de este espacio? } \\
\text { ¿Con qué ideas se van del espacio terapéutico? }\end{array}$ \\
\hline
\end{tabular}

Tabla 1. Diseño escenario 1. Conociendo a la familia y su historia. 
Diseño - Escenario 2: Soñando nuestra familia

Objetivo General: Comprender las expectativas familiares y generar reflexiones en torno a los cambios que consideren pertinentes para movilizar la dinámica familiar.

Actores: Integrantes de la familia y tres (3) Investigadoras- interventoras.

Recursos: Tecnológicos: Videocámara, grabadora de voz, trípode. Humanos: Participantes.

\begin{tabular}{|c|c|c|c|c|}
\hline Escena & $\begin{array}{c}\text { Objetivos } \\
\text { Específicos de } \\
\text { Intervención }\end{array}$ & Focos & $\begin{array}{c}\text { Preguntas Orientadoras de } \\
\text { Intervención }\end{array}$ & Guión Interventivo / Estrategia Artístico \\
\hline Escena 1 & $\begin{array}{lll}\begin{array}{l}\text { Realizar } \\
\text { encuadre }\end{array} \text { de } & \text { el } \\
\text { sesión. } & & \end{array}$ & $\begin{array}{l}\text { Establecer acuerdos } \\
\text { para el desarrollo del } \\
\text { proceso investigativo- } \\
\text { interventivo y de los } \\
\text { encuentros. }\end{array}$ & $\begin{array}{l}\text { ¿Cómo construir un contexto } \\
\text { de investigación - } \\
\text { intervención con familias que } \\
\text { han vivenciado } \\
\text { acontecimientos del CAC? }\end{array}$ & $\begin{array}{l}\text { Proceso conversacional a través del cual se dará explicación } \\
\text { del desarrollo de la sesión. Y se formularán las siguientes } \\
\text { preguntas: } \\
\text { ¿Tienen alguna duda frente a las actividades que se } \\
\text { desarrollaran? } \\
\text { ¿Cuál es su opinión acerca de la metodología con la que } \\
\text { daremos inicio? }\end{array}$ \\
\hline Escena 2 & $\begin{array}{l}\text { Reconocer las } \\
\text { comprensiones y } \\
\text { los cambios que } \\
\text { realiza la familia } \\
\text { desde la anterior } \\
\text { sesión hasta el } \\
\text { actual encuentro. }\end{array}$ & $\begin{array}{l}\text { Identificar } \\
\text { comprensiones cambios } \\
\text { producidos por el } \\
\text { proceso } \\
\text { investigativo-interventiv } \\
\text { o. }\end{array}$ & $\begin{array}{l}\text { ¿Cuáles son } \\
\text { comprensiones y cambios } \\
\text { que han surgido durante la } \\
\text { semana anterior al actual } \\
\text { encuentro? } \\
\begin{array}{llll}\text { ¿Cómo se gestan } & \text { las } \\
\text { comprensiones } & \text { de } & \text { las } \\
\text { familias a partir } & \text { de } \\
\text { estratégias artístico } & \text { - } \\
\text { terapéuticas con enfoque }\end{array}\end{array}$ & $\begin{array}{l}\text { Proceso conversacional a través de preguntas de indagación, } \\
\text { reflexivas y circulares usando la estrategia del Album } \\
\text { Familiar, actividad que traerá la familia, en tanto } \\
\text { corresponde a la prescripción del encuentro anterior: } \\
\text { ¿Cómo se sintieron haciendo este álbum? } \\
\text { Explíquenos lo que elaboraron en su álbum. } \\
\text { ¿Cuales diferencias/similitudes encontraron al momento de } \\
\text { realizarlo? }\end{array}$ \\
\hline
\end{tabular}

\begin{tabular}{|c|c|c|c|c|}
\hline & & & $\begin{array}{l}\text { sistémico? } \\
\text { ¿Cómo las estrategias } \\
\text { artísticas-terapéuticas } \\
\text { implementadas posibilitan } \\
\text { nuevas comprensiones y } \\
\text { cambios en } \\
\text { funcionamiento familiar? }\end{array}$ & \\
\hline Escena 3 & $\begin{array}{lr}\text { Identificar } & \text { la } \\
\text { prospectiva } & \text { vital } \\
\text { del } & \text { sistema } \\
\text { familiar. } & \end{array}$ & $\begin{array}{l}\text { Estructura familiar } \\
\text { Dinámica familiar. } \\
\text { Evolución familiar. }\end{array}$ & $\begin{array}{l}\text { ¿Cuál es la prospectiva vital } \\
\text { del sistema familiar? } \\
\text { ¿Cómo se proyecta la familia } \\
\text { en su estructura, dinámica y } \\
\text { evolución? }\end{array}$ & $\begin{array}{l}\text { Estrategia Artística: } \\
\text { La escultura familiar (presente - futuro): } \\
\text { - Cada miembro de la familia realizará una escultura que } \\
\text { evidencie cómo espera que sea su relación con cada uno } \\
\text { de los otros integrantes y luego se incluirá él mismo en la } \\
\text { escultura. } \\
\text { - Representando el futuro deseado. } \\
\text { - Se les solicita que en silencio esculpan la escultura } \\
\text { utilizando la postura, distancia, gesto y la relación tal y } \\
\text { como la verian en ese momento deseado, en donde el } \\
\text { escultor ubicará el cuerpo de los otros integrantes de la } \\
\text { familia como desee hacerlo. } \\
\text { - Se orientará a los miembros para que voluntariamente } \\
\text { inicie quien desee hacerlo. } \\
\text { - Se solicitará a los participantes que expresen lo que } \\
\text { sienten en la postura y situación en la que se encuentren. } \\
\text { - Acorde con las observaciones y comprensiones de } \\
\text { requerirse se aplicaría otra de las técnicas del psicodrama } \\
\text { como son: Cambios de roles, doble, espejo, } \\
\text { representación directa o simbólica, expresión de un } \\
\text { objeto o una parte del cuerpo, silla vacía, sustitutos, ego } \\
\text { múltiple, corte de la acción. } \\
\text { - Se revisará la relación actual, se observará la interacción. } \\
\text { - Se observará la ubicación de los participantes, la }\end{array}$ \\
\hline
\end{tabular}




\begin{tabular}{|c|c|c|c|c|}
\hline & & & & $\begin{array}{l}\text { proximidad entre los miembros, quien está más cerca a x, } \\
\text { o entre, el tono de voz. } \\
\text { - Se revisará la narrativa y se observará la emoción } \\
\text { activada con la escultura. } \\
\text { - Se observarán los acontecimientos o situaciones } \\
\text { relevantes que han contribuido a la construcción de esa } \\
\text { familia deseada. } \\
\text { - Se conversara con los participantes sobre lo observado y } \\
\text { sentido. } \\
\text { - Se realizará registro fotográfico y grabación de las } \\
\text { esculturas elaboradas, para realizar posterior análisis con } \\
\text { la familia. } \\
\text { Guión Interventivo: Se anexan preguntas guía para tener en } \\
\text { cuenta cada una de las unidades de observación y sus } \\
\text { subcategorías. }\end{array}$ \\
\hline Escena 4 & $\begin{array}{l}\text { Generar reflexiones } \\
\text { que permitan a la } \\
\text { familia reconocerse } \\
\text { como agentes } \\
\text { activos de su } \\
\text { proceso de cambio. }\end{array}$ & $\begin{array}{l}\text { Comprender cambios y } \\
\text { transformaciones que } \\
\text { puedan desde la } \\
\text { prospectiva vital de la } \\
\text { familia. }\end{array}$ & $\begin{array}{l}\text { ¿Cómo la familia puede ser } \\
\text { un actor activo de su propia } \\
\text { movilización? }\end{array}$ & $\begin{array}{l}\text { - Las dos (2) interventoras investigadoras del equipo } \\
\text { reflexivo conversan frente a la familia y la interventora } \\
\text { investigadora frente a sus comprensiones del } \\
\text { funcionamiento familiar. } \\
\text { - Se genera un diálogo conversacional: (1) Investigador - } \\
\text { interventor con la familia sobre lo escuchado de las } \\
\text { investigadoras. }\end{array}$ \\
\hline Escena 5 & $\begin{array}{l}\text { Realizar cierre del } \\
\text { escenario. }\end{array}$ & $\begin{array}{l}\text { Reconocer cambios y } \\
\text { significaciones sobre lo } \\
\text { desarrollado en la } \\
\text { sesión. }\end{array}$ & $\begin{array}{l}\text { ¿Qué resignificaciones } \\
\text { han construido sobre } \\
\text { dilema en torno al desarrollo } \\
\text { del encuentro? }\end{array}$ & $\begin{array}{l}\text { - Se genera un diálogo conversacional: (1) Investigador - } \\
\text { interventor con la familia } \\
\text { ¿Cuáles son las reflexiones a nivel familiar e individual } \\
\text { que son necesarias para co construir en pro del cambio? }\end{array}$ \\
\hline
\end{tabular}

Tabla 2. Diseño escenario 2. Soñando nuestra familia.

\begin{tabular}{|c|c|c|c|c|}
\hline \multicolumn{5}{|c|}{ Diseño - Escenario 3: Reconociendo relaciones en la familia } \\
\hline \multicolumn{5}{|c|}{$\begin{array}{l}\text { Objetivo General: } \\
\text { Redefinir objetivo terapéutico. } \\
\text { Posibilitar reflexiones en sub-sistema parental en torno a los cambios que consideren pertinentes para movilizar la dinámica familiar. }\end{array}$} \\
\hline \multicolumn{5}{|c|}{ Actores: Subsistema parental y tres (3) Investigadoras- interventoras. } \\
\hline \multicolumn{5}{|c|}{ Recursos: Tecnológicos: Videocámara, grabadora de voz, trípode. Humanos: Participantes. Plásticos: Papel kraft, marcadores de colores, cinta. } \\
\hline Escena & $\begin{array}{c}\text { Objetivos } \\
\text { Específicos de } \\
\text { Intervención }\end{array}$ & Focos & $\begin{array}{l}\text { Preguntas Orientadoras de } \\
\text { Intervención }\end{array}$ & Guión Interventivo / Estrategia Artístico- terapéutica \\
\hline Escena 1 & $\begin{array}{lr}\text { Realizar r el } \\
\text { encuadre de la } \\
\text { sesión. }\end{array}$ & $\begin{array}{l}\text { Redefinición del } \\
\text { objetivo del } \\
\text { proceso } \\
\text { interventivo. }\end{array}$ & $\begin{array}{l}\text { ¿Cómo co - construir un } \\
\text { proceso en el que desde la } \\
\text { parentalidad se posibiliten } \\
\text { comprensiones que } \\
\text { movilicen el cambio en el } \\
\text { funcionamiento familiar? }\end{array}$ & $\begin{array}{l}\text { Proceso conversacional a través del cual se redefina el objetivo del } \\
\text { proceso interventivo. } \\
\text { Se dará explicación del desarrollo de la sesión. Y se formularán las } \\
\text { siguientes preguntas: } \\
\text { ¿Tienen alguna duda frente a las actividades que se desarrollaran? } \\
\text { ¿Cuál es su opinión acerca de la metodología con la que daremos inicio? }\end{array}$ \\
\hline Escena 2 & $\begin{array}{l}\text { Reconocer las } \\
\text { comprensiones } \\
\text { y los cambios } \\
\text { que realiza la } \\
\text { familia desde } \\
\text { la anterior } \\
\text { sesión hasta el } \\
\text { actual } \\
\text { encuentro. }\end{array}$ & $\begin{array}{l}\text { Identificar } \\
\text { comprensiones } \\
\text { cambios } \\
\text { producidos por } \\
\text { el proceso } \\
\text { investigativo-int } \\
\text { erventivo. }\end{array}$ & $\begin{array}{l}\text { ¿Cuáles son } r \text { las } \\
\text { comprensiones y cambios } \\
\text { que han surgido durante la } \\
\text { semana anterior al actual } \\
\text { encuentro? } \\
\begin{array}{lllr}\text { ¿Cómo se gestan } & \text { las } \\
\text { comprensiones } & \text { de } & \text { las } \\
\text { familias a partir } & \text { de } \\
\text { estratégias artístico } & - \\
\text { terapéuticas con enfoque }\end{array}\end{array}$ & $\begin{array}{l}\text { Proceso conversacional a través de preguntas de indagación, reflexivas y } \\
\text { circulares usando la estrategia del Álbum Familiar, actividad que traerá } \\
\text { la familia, en tanto corresponde a la prescripción del encuentro anterior: } \\
\text { ¿Cómo se sintieron haciendo este álbum? } \\
\text { Explíquenos lo que elaboraron en su álbum. } \\
\text { Si se continúa evidenciando que la familia no desarrolla el albúm, se } \\
\text { indaga sobre el sentido que comprenden este tiene para el proceso, asi } \\
\text { como se utiliza para cuestionar los espacios familiares que se permiten } \\
\text { tener. } \\
\text { ¿Cuales diferencias/similitudes encontraron al momento de realizarlo? }\end{array}$ \\
\hline
\end{tabular}




\begin{tabular}{|c|c|c|c|c|}
\hline & & & $\begin{array}{l}\text { sistémico? } \\
\text { ¿Cómo las estrategias } \\
\text { artísticas-terapéuticas } \\
\text { implementadas posibilitan } \\
\text { nuevas comprensiones y } \\
\text { cambios en el } \\
\text { funcionamiento familiar? }\end{array}$ & $\begin{array}{l}\text { ¿Cómo se sintieron realizando la escultura familiar del pasado, presente } \\
\text { y futuro?, ¿Qué comprendieron cuando la estaban realizando? } \\
\text { ¿Qué reflexionaron respecto a lo que observaron en las fotos de las } \\
\text { diferentes esculturas? } \\
\text { ¿Qué reflexiones surgieron en relación sobre lo conversado en el cierre } \\
\text { de la sesión anterior, respecto a qué sucedería si los demás miembros no } \\
\text { cumplen las expectativas que tienen de los otros, y que es necesario que } \\
\text { cada padre lleve a cabo en pro al cambio? }\end{array}$ \\
\hline Escena 3 & $\begin{array}{l}\text { Reflexionar } \\
\text { cómo se } \\
\text { entretejen las } \\
\text { pautas } \\
\text { intergeneracion } \\
\text { ales en el } \\
\text { funcionamient } \\
\text { o del sistema } \\
\text { familiar. }\end{array}$ & 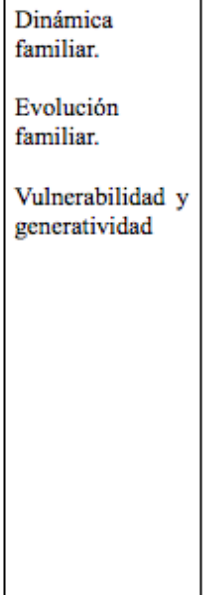 & $\begin{array}{l}\text { ¿Cómo se construyen las } \\
\text { relaciones familiares? } \\
\text { ¿Cómo las pautas } \\
\text { intergeneracionales permean } \\
\text { la dinámica familiar? }\end{array}$ & $\begin{array}{l}\text { Se tocarán algunos temas durante el desarrollo de la estrategia artísticas } \\
\text { que con el equipo terapéutico se identifica son necesarios desglosar, en } \\
\text { pro a los objetivos acordados para el proceso. } \\
\text { Estrategias Artísticas: } \\
\text { - Dibujo (familiograma): } \\
\text { Se explicará la elaboración del familiograma a partir de la muestra de la } \\
\text { familia nuclear de la pareja: } \\
\text { - Se solicitará a la pareja que dibuje en papel craft a los integrantes } \\
\text { de su familia nuclear y de origen, indicando nombre, edades y } \\
\text { oficios. } \\
\text { - Luego que dibujen la forma como se relacionan entre sus } \\
\text { miembros. } \\
\text { - Se preguntará qué diferencias y similitudes encuentran entre las } \\
\text { generaciones. } \\
\text { - Se usará preguntas circulares que permitan comprender pautas } \\
\text { intergeneracionales. } \\
\text { - Se irán incluyendo las temáticas que se tiene planeadas conversar } \\
\text { en el plan temático desarrollado para la intervención. } \\
\text { Guión Interventivo: Se anexan preguntas guía para tener en cuenta cada } \\
\text { una de las unidades de observación y sus subcategorias. }\end{array}$ \\
\hline Escena 4 & Generar & Comprensión de & ¿Cómo la familia puede ser & - Las dos (2) interventoras investigadoras del equipo reflexivo \\
\hline
\end{tabular}

\begin{tabular}{|c|c|c|c|c|}
\hline & $\begin{array}{l}\text { reflexiones que } \\
\text { permitan a la } \\
\text { familia } \\
\text { reconocerse } \\
\text { como agentes } \\
\text { activos de su } \\
\text { proceso de } \\
\text { cambio }\end{array}$ & $\begin{array}{l}\text { la influencia de } \\
\text { las pautas } \\
\text { intergeneraciona } \\
\text { les de la familia } \\
\text { en } \\
\text { configuración } \\
\text { del } \\
\text { funcionamiento } \\
\text { familiar actual. }\end{array}$ & $\begin{array}{l}\text { un actor activo de su propia } \\
\text { movilización? }\end{array}$ & $\begin{array}{l}\text { conversan frente a la familia y la interventora investigadora frente a } \\
\text { sus comprensiones del funcionamiento familiar. } \\
\text { - Se genera un diálogo conversacional: (1) Investigador - interventor } \\
\text { con la familia sobre lo escuchado de las investigadoras. }\end{array}$ \\
\hline Escena 5 & $\begin{array}{l}\text { Realizar cierre } \\
\text { del escenario. }\end{array}$ & \begin{tabular}{ll|} 
Reconocer & \\
cambios & y \\
significaciones & \\
sobre & lo \\
desarrollado & en \\
la sesión.
\end{tabular} & $\begin{array}{l}\text { ¿Qué resignificaciones se } \\
\text { han construido sobre el } \\
\text { dilema en torno al desarrollo } \\
\text { del encuentro? }\end{array}$ & $\begin{array}{l}\text { - Se genera un diálogo conversacional: (1) Investigador - interventor } \\
\text { con la familia } \\
\text { ¿Cuáles son las reflexiones a nivel familiar e individual que son } \\
\text { necesarias para co construir en pro del cambio? } \\
\text { - Se recordará a la familia reunirse para plasmar sus comprensiones y } \\
\text { reflexiones en el álbum familiar durante la semana siguiente, y llevar } \\
\text { lo elaborado al próximo encuentro. }\end{array}$ \\
\hline
\end{tabular}

Tabla 3. Diseño escenario 3. Reconociendo relaciones en la familia. 
Diseño - Escenario 4: Reconociendo pautas transgeneracionales

Objetivo General: Posibilitar reflexiones en subsistema parental y fraternal en torno a los cambios que consideren pertinentes para movilizar la dinámica familiar.

Actores: Madre, Hijo (JP) y tres (3) Investigadoras- interventoras.

Recursos: Teenológicos: Videocámara, grabadora de voz, tripode. Humanos: Participantes. Plásticos: Papel kraft, marcadores de colores, revistas, tijeras, cinta, pegante.

\begin{tabular}{|c|c|c|c|c|}
\hline Escena & $\begin{array}{c}\text { Objetivos } \\
\text { Específicos de } \\
\text { Intervención }\end{array}$ & Focos & $\begin{array}{l}\text { Preguntas Orientadoras } \\
\text { de Intervención }\end{array}$ & Guión Interventivo / Estrategia Artístico- terapéutica \\
\hline Escena 1 & $\begin{array}{llll}\text { Realizar } & & \text { el } \\
\text { encuadre } & \text { de } & \text { la } \\
\text { sesión. } & & \end{array}$ & $\begin{array}{l}\text { Acuerdos para } \\
\text { el desarrollo } \\
\text { de la sesión. }\end{array}$ & $\begin{array}{l}\text { ¿Cómo co - construir un } \\
\text { proceso en el que desde la } \\
\text { parentalidad se posibiliten } \\
\text { comprensiones que } \\
\text { movilicen el cambio en el } \\
\text { funcionamiento familiar? }\end{array}$ & $\begin{array}{l}\text { Se dará explicación del desarrollo de la sesión. Y se formularán las } \\
\text { siguientes preguntas: } \\
\text { ¿Tienen alguna duda frente a las actividades que se desarrollaran? } \\
\text { ¿Cuál es su opinión acerca de la metodología con la que daremos inicio? }\end{array}$ \\
\hline Escena 2 & $\begin{array}{l}\text { Reconocer las } \\
\text { comprensiones y } \\
\text { los cambios que } \\
\text { realiza la familia } \\
\text { desde la anterior } \\
\text { sesión hasta el } \\
\text { actual encuentro. }\end{array}$ & $\begin{array}{l}\text { Identificar } \\
\text { comprensione } \\
\text { s cambios } \\
\text { producidos } \\
\text { por el proceso } \\
\text { investigativo-i } \\
\text { nterventivo. }\end{array}$ & $\begin{array}{l}\text { ¿Cuáles son las } \\
\text { comprensiones y cambios } \\
\text { que han surgido durante la } \\
\text { semana anterior al actual } \\
\text { encuentro? } \\
\text { ¿Cómo se gestan las } \\
\text { comprensiones de las } \\
\text { familias a partir de } \\
\begin{array}{l}\text { estratégias artistico }- \\
\text { terapéuticas con enfoque }\end{array}\end{array}$ & $\begin{array}{l}\text { Proceso conversacional a través de preguntas de indagación, reflexivas y } \\
\text { circulares usando la estrategia del Álbum Familiar, actividad que traerá } \\
\text { la familia, en tanto corresponde a la prescripción del encuentro anterior: } \\
\text { ¿Cómo se sintió explicando lo trabajado en el encuentro anterior a su } \\
\text { familia y plasmandolo con ellos en el álbum? } \\
\text { ¿Cómo se sintieron todos haciendo este álbum? } \\
\text { Explíquenos lo que elaboraron en su álbum. } \\
\text { ¿Cuáles diferencias/similitudes encontraron al momento de realizarlo? }\end{array}$ \\
\hline
\end{tabular}

\begin{tabular}{|c|c|c|c|c|}
\hline & & & $\begin{array}{l}\text { sistémico? } \\
\text { ¿Cómo las estrategias } \\
\text { artísticas-terapéuticas } \\
\text { implementadas posibilitan } \\
\text { nuevas comprensiones y } \\
\text { cambios en el } \\
\text { funcionamiento familiar? }\end{array}$ & \\
\hline Escena 3 & $\begin{array}{l}\text { Reflexionar cómo } \\
\text { se entretejen las } \\
\text { pautas } \\
\text { intergeneracionales } \\
\text { en r el } \\
\text { funcionamiento del } \\
\text { sistema familiar. }\end{array}$ & $\begin{array}{l}\begin{array}{l}\text { Dinámica } \\
\text { familiar. }\end{array} \\
\text { Evolución } \\
\text { familiar. } \\
\text { Vulnerabilidad } \\
\text { y } \\
\text { generatividad }\end{array}$ & $\begin{array}{l}\text { ¿Cómo se construyen las } \\
\text { relaciones familiares? } \\
\text { ¿Cómo las pautas } \\
\text { intergeneracionales } \\
\text { permean la dinámica } \\
\text { familiar? }\end{array}$ & $\begin{array}{l}\text { Se tocarán algunos temas durante el desarrollo de la estrategia artísticas } \\
\text { que con el equipo terapéutico se identifica son necesarios desglosar, en } \\
\text { pro a los objetivos acordados para el proceso. } \\
\text { Estrategias Artísticas: } \\
\text { - Dibujo (familiograma): } \\
\text { Se explicará la elaboración del familiograma a partir de la muestra de la } \\
\text { familia nuclear de la pareja: } \\
\text { - Se solicitará a JP y a la madre a que a partir de recortes de } \\
\text { revistas representen los miembros de la familia de origen, los } \\
\text { cuales irán pegados sobre el papel craft indicando nombre, } \\
\text { edades y oficios. } \\
\text { - Luego de explicarles los tipos de relaciones y sus simbolismos se } \\
\text { les solicita dibujar la forma como se relacionan entre los } \\
\text { miembros. } \\
\text { Intersección de equipo terapéutico para identificar qué movimiento es } \\
\text { necesario llevar a cabo para potenciar las reflexiones, y se solicita a JP } \\
\text { retirarse del espacio terapéutico. } \\
\text { - Se solicitará a la madre que continúe con la elaboración del } \\
\text { genograma para dibujar a la tercera generación. } \\
\text { - Se le preguntará sobre qué diferencias y similitudes encuentran } \\
\text { entre las generaciones. } \\
\text { - Se usará preguntas circulares que permitan comprender pautas } \\
\text { intergeneracionales. } \\
\text { - Se irán incluyendo las temáticas que se tiene planeadas conversar }\end{array}$ \\
\hline
\end{tabular}




\begin{tabular}{|c|c|c|c|c|}
\hline & & & & $\begin{array}{l}\text { en el plan temático desarrollado para la intervención anterior. } \\
\text { Guión Interventivo: Se anexan preguntas guía para tener en } \\
\text { cuenta cada una de las unidades de observación y sus } \\
\text { subcategorías. }\end{array}$ \\
\hline Escena 4 & $\begin{array}{llr}\text { Generar } & \\
\text { reflexiones } & \text { que } \\
\text { permitan } & \text { a } & \text { la } \\
\text { familia reconocerse } \\
\text { como ragentes } \\
\text { activos } & \text { de } & \text { su } \\
\text { proceso de cambio }\end{array}$ & $\begin{array}{l}\text { Comprensión } \\
\text { de la } \\
\text { influencia de } \\
\text { las pautas } \\
\text { intergeneracio } \\
\text { nales de la } \\
\text { familia en la } \\
\text { configuración } \\
\text { del } \\
\text { funcionamient } \\
\text { o familiar } \\
\text { actual. }\end{array}$ & $\begin{array}{l}\text { ¿Cómo la familia puede } \\
\text { ser un actor activo de su } \\
\text { propia movilización? }\end{array}$ & $\begin{array}{l}\text { - Las dos (2) interventoras investigadoras del equipo reflexivo } \\
\text { conversan frente a la familia y la interventora investigadora frente a } \\
\text { sus comprensiones del funcionamiento familiar. } \\
\text { - Se genera un diálogo conversacional: (1) Investigador - interventor } \\
\text { con la familia sobre lo escuchado de las investigadoras. }\end{array}$ \\
\hline Escena 5 & $\begin{array}{l}\text { Realizar cierre del } \\
\text { escenario. }\end{array}$ & $\begin{array}{l}\text { Reconocer } \\
\text { cambios y } \\
\text { significacione } \\
\text { s sobre lo } \\
\text { desarrollado } \\
\text { en la sesión. }\end{array}$ & $\begin{array}{l}\text { ¿Qué resignificaciones se } \\
\text { han construido sobre el } \\
\text { dilema en torno al } \\
\text { desarrollo del encuentro? }\end{array}$ & $\begin{array}{l}\text { - Se genera un diálogo conversacional: (1) Investigador - interventor } \\
\text { con la familia } \\
\text { ¿Cuáles son las reflexiones a nivel familiar e individual que son } \\
\text { necesarias para co construir en pro del cambio? } \\
\text { - Se recordará a la familia reunirse para plasmar sus comprensiones y } \\
\text { reflexiones en el álbum familiar durante la semana siguiente, y llevar } \\
\text { lo elaborado al próximo encuentro. }\end{array}$ \\
\hline
\end{tabular}

Tabla 4. Diseño escenario 4. Reconociendo pautas transgeneracionales.

\begin{tabular}{|c|c|c|c|c|}
\hline \multicolumn{5}{|c|}{ Diseño - Escenario 5: Ampliando la red de apoyo familiar. } \\
\hline \multicolumn{5}{|c|}{ Objetivo General: Comprender cómo es la red de apoyo familiar y facilitar su ampliación. } \\
\hline \multicolumn{5}{|c|}{ Actores: Sistema familiar y tres (3) Investigadoras- interventoras. } \\
\hline \multicolumn{5}{|c|}{$\begin{array}{l}\text { Recursos: Tecnológicos: Videocámara, grabadora de voz, trípode. Humanos: Participantes. Plásticos: Cartulina, marcadores de colores, revistas, } \\
\text { tijeras, cinta, pegante. }\end{array}$} \\
\hline Escena & $\begin{array}{c}\text { Objetivos } \\
\text { Específicos de } \\
\text { Intervención }\end{array}$ & Focos & $\begin{array}{l}\text { Preguntas Orientadoras } \\
\text { de Intervención }\end{array}$ & Guión Interventivo / Estrategia Artístico- terapéutica \\
\hline Escena 1 & $\begin{array}{lll}\text { Realizar } & & \text { el } \\
\text { encuadre } & \text { de } & \text { la } \\
\text { sesión. } & & \end{array}$ & $\begin{array}{l}\text { Acuerdos para } \\
\text { el desarrollo de } \\
\text { la sesión. }\end{array}$ & $\begin{array}{l}\text { ¿Cómo visibilizar las } \\
\text { diferentes redes de apoyo } \\
\text { con las cuales la familia } \\
\text { cuenta en pro a movilizar } \\
\text { el cambio en el } \\
\text { funcionamiento familiar? }\end{array}$ & $\begin{array}{l}\text { Se dará explicación del desarrollo de la sesión. Y se formularán las } \\
\text { siguientes preguntas: } \\
\text { ¿Tienen alguna duda frente a las actividades que se desarrollaran? } \\
\text { ¿Cuál es su opinión acerca de la metodología con la que daremos inicio? }\end{array}$ \\
\hline Escena 2 & $\begin{array}{l}\text { Reconocer las } \\
\text { comprensiones y } \\
\text { los cambios que } \\
\text { realiza la familia } \\
\text { desde la anterior } \\
\text { sesión hasta el } \\
\text { actual encuentro. }\end{array}$ & $\begin{array}{l}\text { Identificar } \\
\text { comprensiones } \\
\text { cambios } \\
\text { producidos por } \\
\text { el proceso } \\
\text { investigativo-in } \\
\text { terventivo. }\end{array}$ & $\begin{array}{l}\text { ¿Cuáles son las } \\
\text { comprensiones y cambios } \\
\text { que han surgido durante la } \\
\text { semana anterior al actual } \\
\text { encuentro? } \\
\text { ¿Cómo se gestan las } \\
\text { comprensiones de las } \\
\text { familias a partir de } \\
\text { estratégias artístico - } \\
\text { terapéuticas con enfoque } \\
\text { sistémico? }\end{array}$ & $\begin{array}{l}\text { Proceso conversacional a través de preguntas de indagación, reflexivas y } \\
\text { circulares usando la estrategia del Álbum Familiar, actividad que traerá } \\
\text { la familia, en tanto corresponde a la prescripción del encuentro anterior: } \\
\text { ¿Cómo se sintió explicando lo trabajado en el encuentro anterior a su } \\
\text { familia y plasmandolo con ellos en el álbum? } \\
\text { ¿Qué le permitió comprender el dibujo del familiograma? } \\
\text { ¿Cómo se sintieron todos haciendo este álbum? } \\
\text { Explíquenos lo que elaboraron en su álbum. } \\
\text { ¿Cuáles diferencias/similitudes encontraron al momento de realizarlo? }\end{array}$ \\
\hline
\end{tabular}




\begin{tabular}{|c|c|c|c|c|}
\hline & & & $\begin{array}{l}\text { ¿Cómo las estrategias } \\
\text { artísticas-terapéuticas } \\
\text { implementadas posibilitan } \\
\text { nuevas comprensiones y } \\
\text { cambios en el } \\
\text { funcionamiento familiar? }\end{array}$ & \\
\hline Escena 3 & $\begin{array}{l}\text { Potenciar la red } \\
\text { de apoyo familiar } \\
\text { visibilizando los } \\
\text { diferentes } \\
\text { contextos, } \\
\text { instituciones, y } \\
\text { sujetos de apoyo, } \\
\text { en pro de su } \\
\text { ampliación. }\end{array}$ & $\begin{array}{l}\text { Evolución } \\
\text { familiar. } \\
\text { Vulnerabilidad } \\
\text { y generatividad }\end{array}$ & $\begin{array}{l}\text { ¿Cuáles son las amistades, } \\
\text { familiares, relaciones } \\
\text { comunitarias y laborales } \\
\text { /escolares que representan } \\
\text { un apoyo para la familia? } \\
\text { ¿Cómo reconocer estos } \\
\text { contextos, instituciones, y } \\
\text { sujetos de apoyo en pro del } \\
\text { cambio del funcionamiento } \\
\text { familiar? }\end{array}$ & $\begin{array}{l}\text { Estrategias Artísticas: } \\
\text { - Dibujo/collage (Red social - Sluzki): } \\
\text { Se explicará el croquis de la red social de Sluzki, para luego precisar } \\
\text { cómo se elaborará en relación al dibujo/collage: } \\
\text { - Se solicitará que conversen respecto a que plasmarán en cada una } \\
\text { de las dimensiones de la red familiar. } \\
\text { - Luego deberán seleccionar y recortar las imágenes alusivas a los } \\
\text { contextos, instituciones y sujetos de apoyo de la familia, } \\
\text { ubicándolos desde los más cercanos a los más lejanos en cada } \\
\text { dimensión. } \\
\text { Inter-sesión de equipo terapéutico para identificar qué movimiento es } \\
\text { necesario llevar a cabo para potenciar las reflexiones. } \\
\text { - Se solicitará a los hijos salir del espacio, para conversar con I } \\
\text { respecto a las comprensiones que la estratégia le suscita. } \\
\text { - Guión Interventivo: Se anexan preguntas guía para tener en } \\
\text { cuenta cada las unidades de observación de evolución familiar y } \\
\text { de vulnerabilidad - generatividad y sus subcategorias. }\end{array}$ \\
\hline Escena 4 & $\begin{array}{l}\text { Generar } \\
\text { reflexiones } r \text { que } \\
\text { permitan a la } \\
\text { familia } \\
\text { reconocerse como } \\
\text { agentes activos de } \\
\text { su proceso de } \\
\text { cambio }\end{array}$ & $\begin{array}{l}\text { Comprensión y } \\
\text { ampliación de } \\
\text { la red social } \\
\text { familiar en pro } \\
\text { de renerar } \\
\text { movilizaciones } \\
\text { en r el } \\
\text { funcionamiento }\end{array}$ & $\begin{array}{l}\text { ¿Cómo la familia puede } \\
\text { ser un actor activo de su } \\
\text { propia movilización? } \\
\text { ¿Cómo pueden emerger } \\
\text { reflexiones a nivel del } \\
\text { funcionamiento familiar a } \\
\text { partir del visibilizar los }\end{array}$ & $\begin{array}{l}\text { - Las dos (2) interventoras investigadoras del equipo reflexivo } \\
\text { conversan frente a la familia y la interventora investigadora frente a } \\
\text { sus comprensiones del funcionamiento familiar. } \\
\text { - Se genera un diálogo conversacional: (1) Investigador - interventor } \\
\text { con la familia sobre lo escuchado de las investigadoras. }\end{array}$ \\
\hline
\end{tabular}

\begin{tabular}{|c|c|c|c|c|}
\hline & & familiar. & $\begin{array}{l}\text { distintos } \\
\text { instituciones y } \\
\text { apoyo? }\end{array}$ & \\
\hline Escena 5 & $\begin{array}{l}\text { Realizar cierre del } \\
\text { escenario. }\end{array}$ & $\begin{array}{l}\text { Reconocer } \\
\text { cambios y } \\
\text { significaciones } \\
\text { sobre lo } \\
\text { desarrollado en } \\
\text { la sesión. }\end{array}$ & $\begin{array}{l}\text { ¿Qué resignificaciones se } \\
\text { han construido sobre el } \\
\text { dilema en torno al } \\
\text { desarrollo del encuentro? }\end{array}$ & $\begin{array}{l}\text { - Se genera un diálogo conversacional: (1) Investigador - interventor } \\
\text { con la familia } \\
\text { ¿Cuáles son las reflexiones a nivel familiar e individual que son } \\
\text { necesarias para co construir en pro del cambio? } \\
\text { - Se recordará a la familia reunirse para plasmar sus comprensiones y } \\
\text { reflexiones en el álbum familiar durante la semana siguiente, y llevar } \\
\text { lo elaborado al próximo encuentro. }\end{array}$ \\
\hline
\end{tabular}

Tabla 5. Diseño escenario 5. Ampliando la red de apoyo familiar. 


\begin{tabular}{|c|c|c|c|c|}
\hline \multicolumn{5}{|c|}{ Diseño - Escenario 6: Creando el cuento del proceso } \\
\hline \multicolumn{5}{|c|}{ Objetivo General: Realizar el cierre del proceso terapéutico utilizando el cuento como estrategia de reflexión } \\
\hline \multicolumn{5}{|c|}{ Actores: Sistema familiar y tres (3) Investigadoras- interventoras. } \\
\hline \multicolumn{5}{|c|}{$\begin{array}{l}\text { Recursos: Tecnológicos: Videocámara, grabadora de voz, trípode. Humanos: Participantes. Plásticos: Cartulina, hojas de colores, marcadores do } \\
\text { colores, tijeras, cinta. }\end{array}$} \\
\hline Escena & $\begin{array}{c}\text { Objetivos } \\
\text { Específicos de } \\
\text { Intervención }\end{array}$ & Focos & $\begin{array}{l}\text { Preguntas Orientadoras de } \\
\text { Intervención }\end{array}$ & Guión Interventivo / Estrategia Artístico- terapéutica \\
\hline Escena 1 & $\begin{array}{lll}\begin{array}{l}\text { Realizar } \\
\text { encuadre }\end{array} & \text { de } & \text { la } \\
\text { sesión. } & & \end{array}$ & $\begin{array}{l}\text { Acuerdos para } \\
\text { el desarrollo de } \\
\text { la sesión. }\end{array}$ & $\begin{array}{l}\text { ¿Cómo posibilitar un espacio de } \\
\text { reflexión frente a lo vivenciado } \\
\text { durante el proceso terapéutico? }\end{array}$ & $\begin{array}{l}\text { Se dará explicación del desarrollo de la sesión. Y se } \\
\text { formularán las siguientes preguntas: } \\
\text { ¿Tienen alguna duda frente a las actividades que se } \\
\text { desarrollaran? } \\
\text { ¿Cuál es su opinión acerca de la metodología con la que } \\
\text { daremos inicio? }\end{array}$ \\
\hline Escena 2 & $\begin{array}{l}\text { Reconocer las } \\
\text { comprensiones y } \\
\text { los cambios que } \\
\text { realiza la familia } \\
\text { desde la anterior } \\
\text { sesión hasta el } \\
\text { actual encuentro. }\end{array}$ & $\begin{array}{l}\text { Identificar } \\
\text { comprensiones } \\
\text { y cambios } \\
\text { producidos por } \\
\text { el proceso } \\
\text { investigativo-in } \\
\text { terventivo. }\end{array}$ & $\begin{array}{l}\text { ¿Cuáles son las comprensiones y } \\
\text { cambios que han surgido durante la } \\
\text { semana anterior al actual encuentro? } \\
\text { ¿Cómo se gestan las comprensiones } \\
\text { de las familias a partir de estratégias } \\
\text { artístico - terapéuticas con enfoque } \\
\text { sistémico? las estrategias } \\
\text { ¿Cómo las } \\
\text { artísticas-terapéuticas implementadas } \\
\text { posibilitan nuevas comprensiones y } \\
\text { cambios en el funcionamiento } \\
\text { familiar? }\end{array}$ & $\begin{array}{l}\text { Proceso conversacional a través de preguntas de indagación, } \\
\text { reflexivas y circulares usando la estrategia del Álbum } \\
\text { Familiar, actividad que traerá la familia, en tanto corresponde } \\
\text { a la prescripción del encuentro anterior: } \\
\text { ¿Cómo se sintió explicando lo trabajado en el encuentro } \\
\text { anterior a su familia y plasmandolo con ellos en el álbum? } \\
\text { ¿Qué le permitió comprender el dibujo de la red de slusky? } \\
\text { ¿Cómo se sintieron todos haciendo este álbum? } \\
\text { Explíquenos lo que elaboraron en su álbum. } \\
\text { ¿Cuáles diferencias/similitudes encontraron al momento de } \\
\text { realizarlo? }\end{array}$ \\
\hline
\end{tabular}

\begin{tabular}{|c|c|c|c|c|}
\hline Escena 3 & $\begin{array}{l}\text { Realizar la lectura } \\
\text { del story board } \\
\text { family realizado } \\
\text { por el equipo } \\
\text { terapéutico. }\end{array}$ & $\begin{array}{l}\text { Cierre } \\
\text { proceso }\end{array}$ & $\begin{array}{l}\text { ¿Cómo posibilitar que la familia } \\
\text { identifique su cambio y evolución } \\
\text { durante el proceso terapéutico? }\end{array}$ & $\begin{array}{l}\text { Estrategia artística: story board family } \\
\text {-El story board será realizado por el equipo terapéutico, } \\
\text { previo a la sesión, con base al álbum realizado por la familia. } \\
\text {-Se leerá el story board por el equipo terapéutico. } \\
\text {-Se le solicitará a la familia que realicen los cambios que } \\
\text { consideren pertinentes. } \\
\text {-Posteriormente deberán construir } 3 \text { finales para finalizar el } \\
\text { story board. } \\
\text {-Se volverá a leer el story board con los cambios realizados } \\
\text { por la familia. }\end{array}$ \\
\hline Escena 4 & $\begin{array}{l}\text { Reconocer las } \\
\text { comprensiones } \\
\text { que realiza la } \\
\text { familia a partir del } \\
\text { story board } \\
\text { family. }\end{array}$ & $\begin{array}{l}\text { Identificar } \\
\text { comprensiones } \\
\text { cambios } \\
\text { producidos por } \\
\text { el proceso } \\
\text { investigativo-in } \\
\text { terventivo. }\end{array}$ & $\begin{array}{l}\text { ¿Cómo se gestan las comprensiones } \\
\text { de las familias a partir de estratégias } \\
\text { artístico - terapéuticas con enfoque } \\
\text { sistémico? las restrategias } \\
\text { ¿Cómo las réricas-terapéuticas implementadas } \\
\text { artísticas } \\
\text { posibilitan nuevas comprensiones y } \\
\text { cambios en el funcionamiento } \\
\text { familiar? }\end{array}$ & $\begin{array}{l}\text { Proceso conversacional a través de preguntas de indagación, } \\
\text { reflexivas y circulares usando la estrategia del story board } \\
\text { family. } \\
\text { ¿Cómo se sintieron escuchando el story board? } \\
\text { ¿Qué comprensiones les genera este? } \\
\text { ¿Qué cambios identifican se han gestado durante el proceso } \\
\text { terapéutico? } \\
\text { ¿Cómo las estrategias artístico - terapéuticas les han ayudado } \\
\text { a hacer comprensiones? }\end{array}$ \\
\hline Escena 5 & $\begin{array}{l}\text { Realizar cierre del } \\
\text { proceso } \\
\text { terapéutico. }\end{array}$ & $\begin{array}{l}\text { Reconocer } \\
\text { cambios y } \\
\text { significaciones } \\
\text { sobre lo } \\
\text { desarrollado } \\
\text { durante todo el } \\
\text { proceso. }\end{array}$ & $\begin{array}{l}\text { ¿Qué resignificaciones se han } \\
\text { construido sobre el dilema en torno al } \\
\text { proceso? }\end{array}$ & $\begin{array}{l}\text { - Identificar percepciones actuales de la familia frente al } \\
\text { dilema con el cual llegan al proceso. } \\
\text { - Se recordará a la familia realizar el seguimiento del } \\
\text { proceso aproximadamente en un mes. } \\
\text { - Se realiza el cierre del proceso por parte del equipo } \\
\text { terapéutico y la familia }\end{array}$ \\
\hline
\end{tabular}

Tabla 6. Diseño escenario 6. Cerrando el proceso. 


\section{Neo - diseños de los escenarios}

Al ser un proceso interventivo, este trabajo de investigación, algunos de los escenarios se transformaron por los cambios y vicisitudes propias del contexto, de la familia y del proceso. Se re plantea el desarrollo del primer y segundo escenario realizando estos el mismo día por lo que para el álbum familiar se entregan las indicaciones al final del segundo escenario; por esto, no se realizó la segunda escena de este escenario dándose inicio a este directamente con la realización de la escultura del futuro y no con el seguimiento del cambio presentado desde la sesión anterior; así mismo en relación a la estrategia artística se realiza ajuste para usar el dibujo como una forma de representar la familia a futuro, en tanto los miembros de la familia se encontraban cansados debido a la prolongación de las sesiones, así como por encontrarse una proporción mayor de miembros en edad escolar que de adultos, por lo que no se logran realizar todas las esculturas del futuro. En esta sesión debido al cansancio del sistema familiar, no se realiza la intervención del equipo reflexivo, pero se realiza intercesión y se envía mensaje. Finalmente se hace seguimiento al cambio en el siguiente encuentro.

Este tercer encuentro, denominado 2B es una continuación del segundo, incluye al padre y la hija mayor del sistema familiar, los cuales no asistieron al encuentro anterior realizándose las esculturas de futuro exclusivamente con los dos miembros del subsistema parental y la hija en etapa de joven. 
Diseño - Escenario 2B: Soñando nuestra familia

Objetivo General: Comprender las expectativas familiares y generar reflexiones en torno a los cambios que consideren pertinentes para movilizar la dinámica familiar.

Actores: Integrantes de la familia y tres (3) Investigadoras- interventoras.

Recursos: Tecnológicos: Videocámara, grabadora de voz, trípode. Humanos: Participantes.

\begin{tabular}{|c|c|c|c|c|}
\hline Escena & $\begin{array}{l}\text { Objetivos } \\
\text { Específicos de } \\
\text { Intervención }\end{array}$ & Focos & $\begin{array}{l}\text { Preguntas Orientadoras de } \\
\text { Intervención }\end{array}$ & Guión Interventivo / Estrategia Artístico- terapéutica \\
\hline Escena 1 & $\begin{array}{lll}\begin{array}{l}\text { Realizar } \\
\text { encuadre de }\end{array} & \text { la } \\
\text { sesión. } & & \end{array}$ & $\begin{array}{l}\text { Establecer acuerdos } \\
\text { para el desarrollo del } \\
\text { proceso } \\
\text { investigativo- } \\
\text { interventivo. } \\
\text { Contextualizar a los } \\
\text { nuevos asistentes al } \\
\text { proceso. }\end{array}$ & $\begin{array}{l}\text { ¿Cómo construir un contexto de } \\
\text { investigación - intervención con } \\
\text { familias que han vivenciado } \\
\text { acontecimientos del CAC? }\end{array}$ & $\begin{array}{l}\text { Proceso conversacional a través del cual se dará explicación } \\
\text { del desarrollo de la sesión. Y se formularán las siguientes } \\
\text { preguntas: } \\
\text { ¿Tienen alguna duda frente a las actividades que se } \\
\text { desarrollaran? } \\
\text { ¿Cuál es su opinión acerca de la metodología con la que } \\
\text { daremos inicio? }\end{array}$ \\
\hline Escena 2 & $\begin{array}{l}\text { Reconocer las } \\
\text { comprensiones y } \\
\text { los cambios que } \\
\text { realiza la familia } \\
\text { desde la anterior } \\
\text { sesión hasta el } \\
\text { actual encuentro. }\end{array}$ & $\begin{array}{l}\text { Identificar } \\
\text { comprensiones } \\
\text { cambios producidos } \\
\text { por el proceso } \\
\text { investigativo-interve } \\
\text { ntivo. }\end{array}$ & $\begin{array}{l}\text { ¿Cuáles son las comprensiones } \\
\text { y cambios que han surgido } \\
\text { durante la semana anterior al } \\
\text { actual encuentro? } \\
\text { ¿Cómo se gestan las } \\
\text { comprensiones de las familias a } \\
\text { partir de estratégias artístico - } \\
\text { terapéuticas con enfoque }\end{array}$ & $\begin{array}{l}\text { Proceso conversacional a través de preguntas de indagación, } \\
\text { reflexivas y circulares usando la estrategia del Álbum } \\
\text { Familiar, actividad que traerá la familia, en tanto } \\
\text { corresponde a la prescripción del encuentro anterior: } \\
\text { ¿Cómo se sintieron haciendo este álbum? } \\
\text { Explíquenos lo que elaboraron en su álbum. } \\
\text { ¿Cuales diferencias/similitudes encontraron al momento de } \\
\text { realizarlo? }\end{array}$ \\
\hline
\end{tabular}

\begin{tabular}{|c|c|c|c|c|}
\hline & & & $\begin{array}{l}\text { sistémico? } \\
\text { ¿Cómo las estrategias } \\
\text { artísticas-terapéuticas } \\
\text { implementadas posibilitan } \\
\text { nuevas comprensiones y } \\
\text { cambios en el funcionamiento } \\
\text { familiar? }\end{array}$ & \\
\hline Escena 3 & $\begin{array}{lr}\text { Identificar } & \text { la } \\
\text { prospectiva } & \text { vital } \\
\text { del } & \text { sistema } \\
\text { familiar. } & \end{array}$ & $\begin{array}{l}\text { Estructura familiar } \\
\text { Dinámica familiar. } \\
\text { Evolución familiar. }\end{array}$ & $\begin{array}{l}\text { ¿Cuál es la prospectiva vital del } \\
\text { sistema familiar? } \\
\text { ¿Cómo se proyecta la familia en } \\
\text { su estructura, dinámica y } \\
\text { evolución? }\end{array}$ & $\begin{array}{l}\text { Estrategias Artísticas: } \\
\text { - Fotografia de las esculturas del pasado y presente: } \\
\text { Se genera conversación con los miembros que asistieron al } \\
\text { anterior encuentro para contextualizar al padre y la hija } \\
\text { mayor frente a las esculturas familiares del pasado y } \\
\text { presente realizadas en el encuentro anterior mediante la } \\
\text { presentación de las fotografias tomadas de cada escultura: } \\
\text { - ¿Qué recuerdan de estas esculturas del pasado } \\
\text { realizadas? (Se muestran fotografias). } \\
\text { - ¿Qué recuerdan de estas esculturas del presente } \\
\text { realizadas? (Se muestran fotografias). } \\
\text { - La escultura familiar (presente - futuro): } \\
\text { Los miembros adultos de la familia realizarán una escultura } \\
\text { con cadencie cómo son y cómo esperan que sea su relación } \\
\text { mismo en la escultura. } \\
\text { Se gibujos de las esculturas del futuro: } \\
\text { anterior encuentro para contextualizar al padre y la hija } \\
\text { mayor frente a los dibujos realizados de la familia deseada } \\
\text { en el encuentro anterior mediante la presentación de la } \\
\text { cartelera: }\end{array}$ \\
\hline
\end{tabular}




\begin{tabular}{|c|c|c|c|c|}
\hline & & & & $\begin{array}{l}\text { - ¿Qué recuerdan de los dibujos del futuro realizados? } \\
\text { (Se muestra cartelera con dibujos). } \\
\text { Guión Interventivo: Se anexan preguntas guía para tener en } \\
\text { cuenta cada una de las unidades de observación y sus } \\
\text { subcategorías. }\end{array}$ \\
\hline Escena 4 & $\begin{array}{l}\text { Generar reflexiones } \\
\text { que permitan a la } \\
\text { familia reconocerse } \\
\text { como agentes } \\
\text { activos de su } \\
\text { proceso de cambio }\end{array}$ & $\begin{array}{l}\text { Comprender cambios } \\
\text { y transformaciones } \\
\text { que puedan desde la } \\
\text { prospectiva vital de } \\
\text { la familia. }\end{array}$ & $\begin{array}{l}\text { ¿Cómo la familia puede ser un } \\
\text { actor activo de su propia } \\
\text { movilización? }\end{array}$ & $\begin{array}{l}\text { - Las dos (2) interventoras investigadoras del equipo } \\
\text { reflexivo conversan frente a la familia y la interventora } \\
\text { investigadora frente a sus comprensiones del } \\
\text { funcionamiento familiar. } \\
\text { - Se genera un diálogo conversacional: (1) Investigador - } \\
\text { interventor con la familia sobre lo escuchado de las } \\
\text { investigadoras. }\end{array}$ \\
\hline Escena 5 & $\begin{array}{l}\text { Realizar cierre del } \\
\text { escenario. }\end{array}$ & $\begin{array}{l}\text { Reconocer cambios y } \\
\text { significaciones sobre } \\
\text { lo desarrollado en la } \\
\text { sesión. }\end{array}$ & $\begin{array}{l}\text { ¿Qué resignificaciones se han } \\
\text { construido sobre el dilema en } \\
\text { torno al desarrollo del } \\
\text { encuentro? }\end{array}$ & $\begin{array}{l}\text { - Se genera un diálogo conversacional: (1) Investigador - } \\
\text { interventor con la familia } \\
\text { ¿Cuáles son las reflexiones a nivel familiar e individual } \\
\text { que son necesarias para co construir en pro del cambio? }\end{array}$ \\
\hline
\end{tabular}

Tabla 7. Diseño escenario 2B. Soñando nuestra familia.

En cuanto al cuarto encuentro denominado escenario 3 se realizó la redefinición del espacio terapéutico en tanto el padre debido a su situación laboral no podía asistir al proceso, posteriormente se lleva a cabo la discusión del seguimiento al cambio mediante conversación reflexiva guiada por el álbum familiar construido por el sistema familiar y a las fotografías de las esculturas realizadas durante los anteriores encuentros retomando algunos temas propuestos en el plan temático previsto para dicho escenario.

En cuanto al quinto encuentro, es decir el escenario 4, se lleva a cabo el familiograma planteado para el anterior escenario dándole fuerza a la visibilización de las pautas transgeneracionales en aras de potenciar cambios en la dinámica familiar del sistema. Respecto al sexto encuentro, escenario 5, debido a dificultades con el contexto terapéutico se debe dividir en dos escenarios, desarrollándose las primeras escenas restantes en un encuentro posterior, el cual se encuentra a continuación, así mismo no se lleva a cabo equipo reflexivo pero si intercesión debido a la prolongación del escenario durante el desarrollo de la estrategia artística y al no contarse con un espacio amplio, ya que se desarrolla en la casa del mismo sistema familiar debido a las condiciones climáticas y de salud de las hijas menores. 
Diseño - Escenario 5B: Ampliando la red de apoyo familiar.

Objetivo General: Comprender cómo es la red de apoyo familiar y facilitar su ampliación.

Actores: Sistema familiar y tres (3) Investigadoras- interventoras.

Recursos: Tecnológicos: Videocámara, grabadora de voz, trípode. Humanos: Participantes. Plásticos: Cartulina, marcadores de colores, revistas, tijeras, cinta, pegante.

\begin{tabular}{|c|c|c|c|c|}
\hline Escena & $\begin{array}{l}\text { Objetivos } \\
\text { Específicos de } \\
\text { Intervención }\end{array}$ & Focos & $\begin{array}{l}\text { Preguntas Orientadoras } \\
\text { de Intervención }\end{array}$ & Guión Interventivo / Estrategia Artístico- terapéutica \\
\hline Escena 1 & $\begin{array}{lll}\text { Realizar } & & \text { el } \\
\text { encuadre de } & \text { la } \\
\text { sesión. } & & \end{array}$ & $\begin{array}{l}\text { Acuerdos para } \\
\text { el desarrollo de } \\
\text { la sesión. }\end{array}$ & $\begin{array}{l}\text { ¿Cómo visibilizar las } \\
\text { diferentes redes de apoyo } \\
\text { con las cuales la familia } \\
\text { cuenta en pro a movilizar } \\
\text { el cambio en el } \\
\text { funcionamiento familiar? }\end{array}$ & $\begin{array}{l}\text { Se dará explicación del desarrollo de la sesión. Y se formularán las } \\
\text { siguientes preguntas: } \\
\text { ¿Tienen alguna duda frente a las actividades que se desarrollaran? } \\
\text { ¿Cuál es su opinión acerca de la metodología con la que daremos inicio? }\end{array}$ \\
\hline Escena 2 & $\begin{array}{l}\text { Potenciar la red } \\
\text { de apoyo familiar } \\
\text { visibilizando los } \\
\text { diferentes } \\
\text { contextos, } \\
\text { instituciones, y } \\
\text { sujetos de apoyo, } \\
\text { en pro de su } \\
\text { ampliación. }\end{array}$ & \begin{tabular}{|l|} 
Evolución \\
familiar. \\
Vulnerabilidad \\
y generatividad
\end{tabular} & $\begin{array}{l}\text { ¿Cuáles son los contextos, } \\
\text { instituciones, y sujetos de } \\
\text { apoyo con los que se } \\
\text { relaciona la familia? } \\
\text { ¿Cómo reconocer estos } \\
\text { contextos, instituciones, y } \\
\text { sujetos de apoyo en pro del } \\
\text { cambio del funcionamiento } \\
\text { familiar? }\end{array}$ & $\begin{array}{l}\text { Estrategias Artísticas: } \\
\text { - Dibujo/collage (Red social - Sluzki): } \\
\text { Se explicará el croquis de la red social de Sluzki, para luego precisar } \\
\text { cómo se elaborará en relación al dibujo/collage: } \\
\text { - Se solicitará que conversen respecto a que plasmarán en cada una } \\
\text { de las dimensiones de la red familiar. } \\
\text { - Luego deberán seleccionar y recortar las imágenes alusivas a los } \\
\text { contextos, instituciones y sujetos de apoyo de la familia, } \\
\text { ubicándolos desde los más cercanos a los más lejanos en cada } \\
\text { dimensión. } \\
\text { Inter-sesión de equipo terapéutico para identificar qué movimiento es } \\
\text { necesario llevar a cabo para potenciar las reflexiones. }\end{array}$ \\
\hline
\end{tabular}

\begin{tabular}{|c|c|c|c|c|}
\hline & & & & $\begin{array}{l}\text { - Se solicitará a los hijos salir del espacio, para conversar con I } \\
\text { respecto a las comprensiones que la estratégia le suscita. } \\
\text { - Guión Interventivo: Se anexan preguntas guía para tener en } \\
\text { cuenta cada una de las unidades de observación de evolución } \\
\text { familiar y de vulnerabilidad - generatividad y sus subcategorías. }\end{array}$ \\
\hline Escena 3 & $\begin{array}{l}\text { Generar } \\
\text { reflexiones que } \\
\text { permitan a la } \\
\text { familia } \\
\text { reconocerse como } \\
\text { agentes activos de } \\
\text { su proceso de } \\
\text { cambio }\end{array}$ & $\begin{array}{l}\text { Comprensión y } \\
\text { ampliación de } \\
\text { la red social } \\
\text { familiar en pro } \\
\text { de generar } \\
\text { movilizaciones } \\
\text { en el } \\
\text { funcionamient } \\
\text { o familiar. }\end{array}$ & $\begin{array}{l}\text { ¿Cómo la familia puede ser } \\
\text { un actor activo de su } \\
\text { propia movilización? } \\
\text { ¿Cómo pueden emerger } \\
\text { reflexiones a nivel del } \\
\text { funcionamiento familiar a } \\
\text { partir del visibilizar los } \\
\text { distintos contextos, } \\
\text { instituciones y sujetos de } \\
\text { apoyo? }\end{array}$ & $\begin{array}{l}\text { - Se reúne con el equipo terapéutico para construir el mensaje que será } \\
\text { entregado a la familia, por medio de la interventora, frente a las } \\
\text { comprensiones de la red realizada por la familia. } \\
\text { - Se genera un diálogo conversacional: (1) Investigador - interventor } \\
\text { con la familia sobre lo escuchado de las investigadoras. }\end{array}$ \\
\hline Escena 4 & $\begin{array}{l}\text { Realizar cierre del } \\
\text { escenario. }\end{array}$ & $\begin{array}{lr}\text { Reconocer } & \\
\text { cambios r y } & \\
\text { significaciones } \\
\text { sobre re lo } \\
\text { desarrollado en } \\
\text { la sesión. }\end{array}$ & $\begin{array}{l}\text { ¿Qué resignificaciones se } \\
\text { han construido sobre el } \\
\text { dilema en torno al } \\
\text { desarrollo del encuentro? }\end{array}$ & $\begin{array}{l}\text { - Se genera un diálogo conversacional: (1) Investigador - interventor } \\
\text { con la familia } \\
\text { ¿Cuáles son las reflexiones a nivel familiar e individual que son } \\
\text { necesarias para co construir en pro del cambio? } \\
\text { - Se recordará a la familia reunirse para plasmar sus comprensiones y } \\
\text { reflexiones en el álbum familiar durante la semana siguiente, y llevar } \\
\text { lo elaborado al próximo encuentro. }\end{array}$ \\
\hline
\end{tabular}

Tabla 8. Diseño escenario 5B. Ampliando la red de apoyo familiar. 


\section{Procedimiento para la construcción de resultados}

En relación a la construcción de los resultados, según la metodología planteada, durante el proceso se utilizaron como instrumentos de observación y registro grabaciones de audio-video, historias clínicas según el protocolo de registro de la IPS de la Universidad Santo Tomás contenidos en los Lineamientos para las prácticas clínicas supervisadas de la Maestría en Psicología Clínica y de la Familia, registro de análisis de las fotografías de los productos artísticos construidos durante cada escenario, y registro de observación de la intervención (Ver Anexos No. 6, 7, 8, 9 y 10).

A partir de la información construida de las observaciones realizadas durante la ejecución de las estrategias artístico-terapéuticas-sistémicas usadas y luego de transcribir la información de los escenarios conversacionales teniendo en cuenta el lenguaje analógico de los participantes, se utilizó el programa ATLAS TI realizando la codificación abierta de cada uno de los encuentros del proceso terapéutico desarrollado con la familia, en relación a las 4 unidades de observación planteadas (estructura, dinámica, evolución familiar y vulnerabilidad generatividad), a la definición de cambio construida por las interventoras - investigadoras y a las reflexiones emergentes del uso de la estrategias artístico terapéuticas sistémicas.

Posteriormente, se realiza la codificación axial en la que a partir del muestreo inicialmente realizado con las unidades de observación se lleva a cabo una relectura de todos los informes generados de los conceptos que se especificaron para la codificación abierta a través de ATLAS TI, realizando una identificación de códigos que permitieron la profundización en la interpretación y el análisis de la información; a medida que se identificaron relaciones entre conceptos y se realizó profundización en la categoría emergente, desde la teorización y el análisis contextual y relacional de las secuencias interaccionales que correspondían a la misma. Luego, se descargaron nuevamente los informes enriquecidos de la anterior fase y se 
compararon de nuevo entre sí encontrando nuevas relaciones que permitieron el reconocimiento de cuatro (4) unidades temáticas.

En la última fase de esta investigación, dichas comprensiones se leen a la luz de las unidades temáticas identificadas: "No quiero ser como mi madre pero estoy condenada a serlo", "Mis hijos pueden ser lo que quieran pero deben ser profesionales", "No quiero un padre para mis hijos, ni un esposo como mi padrastro, pero le exijo ser como él", y "Yo quiero un padre amoroso pero prefiero al hombre de corbata"; las categorías propuestas en los estados del arte: - Conflicto, desplazamiento y memoria histórica / Paz, reconciliación y reparación desde los aspectos psico-socio-jurídicos / Salud mental y bienestar: identidad, vínculos y estrategias de afrontamiento / Arte como estrategia de cambio; y las construcciones del sistema teórico. 


\section{RESULTADOS}

En el siguiente apartado, se encontrarán los resultados de la investigación dividido en tres grandes partes. La primera contiene los cambios en el funcionamiento familiar al vivenciar acontecimiento del CAC, los cambios en el proceso terapéutico y por último los procesos auto y heterorreferenciales de la misma. A su vez, en la primera parte encuentran dichos cambios desde los conceptos metodológicos propuestos, es decir estructura, dinámica evolución y el continuo entre vulnerabilidad/generatividad. Ya la segunda parte, contiene los cambios desde las categorías emergentes: no quiero ser como mi madre, pero estoy condenada a serlo; yo quiero un padre amoroso, pero prefiero al hombre de corbata; no quiero un padre para mis hijos, ni un esposo como mi padrastro, pero le exijo ser como él y, por último, mis hijos pueden escoger lo que quieran, pero deben ser profesionales. La tercera parte se divide en cada uno de los procesos.

Para ello a continuación describiremos el contexto circunstancial, es decir el tiempo, lugar, hechos y desarrollo en que se presenta el síntoma y la manera como se genera la relación familiar, en que se suscita la situación de desplazamiento vivenciado por los miembros la familia del caso único que hizo parte del proceso investigativo - interventivo.

Bajo este particular se trata de una familia en situación de desplazamiento forzado el cual fue vivenciado hace 6 años debido a que el padre iba a ser obligado a hacer parte de las filas de la guerrilla; esto los lleva a migrar del municipio de El Guamo, en un primer momento, al municipio de San Luís, Tolima, y posteriormente a la ciudad de Bogotá, en donde conviven en un barrio de invasión en la Localidad de Usme; En el momento la presencialidad del padre es 
intermitente al movilizarse entre El Guamo / Tolima y Bogotá. Se encuentran en ciclo vital de familia con jóvenes y con funciones de hijos en edad escolar. Refiriendo en la primera sesión el siguiente motivo de consulta

"En el proceso digamos, más que todo me serviría, o me gustaría con él (señala a su tercer hijo). No sé, él pues el carácter de uno no puede cambiar porque, pero sí digamos en la cuestión del estudio, él no, no sé, yo no le veo que él, quiera estudiar, que él quiera avanzar, entonces ese es mi pensamiento, de pronto mi gran preocupación rebasa lo que él piensa porque ya perder para mí ya 2 cuartos, aun cuando se ve lo mismo, perderlo" (Madre, 40 años, E1, L).

A partir de la demanda de ayuda y de lo evolucionado en la primera sesión se comprende un sistema parental complementario, en el que la madre se encarga del establecimiento de reglas mientras el padre es el proveedor, generando así una sobrecarga de responsabilidades a nivel parental sobre la madre que son identificadas por lo hijos, que se encuentran en coaliciones con los padres, quedando los hijos y en especial el hijo portador del síntoma en dicho juego psicológico, al ser los vínculos maritales contenedores del óptimo desarrollo de los vínculos parento-filiales vitales, creativos y movilizadores que han construido para afrontar las condiciones no normativas en el contexto citadino en el que se encuentran inmersos.

Se presenta una narrativa dominante de la madre, en donde se relaciona las dificultades con el tercer hijo a nivel académico y actitudinal propias de estresores normativos de la edad con los estresores no normativos propios del actual contexto, y de las condiciones de la familia, en donde se evidencia cómo el encontrarse en un nuevo contexto coarta el proceso de individuación y autonomía de sus hijos, lo que se podría relacionar con la comprensión metafórica de las investigadoras interventoras de parecer animalitos enjaulados en tanto la madre se refiere a sus 
hijos como cabritas para describir la libertad de sus hijos en el campo.

Así mismo, se evidencia una cultura patriarcal, que la esposa desearía potenciar desde el entregarle a su pareja la responsabilidad del hogar y la proyección vital referente a un mayor crecimiento económico e intelectual para su familia en relación con el nuevo contexto en el que se encuentra que es la ciudad y las condiciones que su red de apoyo, la iglesia cristiana, potencia. Mensajes dobles vinculares que descalifican al padre frente al sistema fraternal.

A partir de las comprensiones construidas se formula la siguiente hipótesis general del caso único, la cual se fue transformando en el proceso:

"La relación conyugal se ha deteriorado, a tal punto que se ha desarrollado una dinámica familiar rígida, en la que se presentan altas demandas frente a las expectativas de ser profesionales y de no llevar a cabo oficios que impliquen gran esfuerzo físico, en contraposición a la realidad familiar y a las condiciones socio económicas, en donde el padre se interesa más por compartir espacios con sus hijos, siendo clara contradicciones a nivel parental que han afectado a JP (portador del síntoma), en tanto se encuentra inmerso en una juego psicológico, es decir triangulado bajo la lealtad que tiene a cada uno de sus padres, lo cual afecta el recurso comunicativo de la familia, en donde la madre expone su fuerte inconformidad con la posición pasiva del padre en la toma de decisiones a nivel familiar, y su poca participación en la disciplina de los hijos, manteniéndose el padre periférico al manifestar no cuenta con suficiente tiempo para ello debido a sus extenuantes horas de trabajo. Situación que puede ser intervenida desde la comprensión frente a cómo las relaciones parentales, han sido permeadas por el deterioro de la relación conyugal".

Cada uno de los procesos de cambio emergieron, se gestaron y se establecieron por medio de 
las estrategias artístico terapéuticas sistémicas, tal como será señalado mediante la voz de cada uno los participantes a continuación.

\section{Cambios en el funcionamiento familiar al vivenciar acontecimiento del CAC}

\section{Estructura Familiar}

Con relación a la estructura familiar se evidencian en el sistema familiar del caso único, el cual se caracteriza en su composición por ser una familia reconstituida nuclear que se encuentra conformada por subsistema conyugal (I de 40 años de edad y E de 33 años) y subsistema fraternal de 6 hijos menores de edad ( $\mathrm{L}$ de 17 años, $\mathrm{S}$ de 13 años, JP de 12 años, A de 8 años, $\mathrm{S}$ de 3 años y M de 5 meses). Si bien se percibe por la familia cambios en el antes y después del proceso de desplazamiento en un comienzo los relacionan más con el hecho de sentirse más libres cuando se encontraban en el campo, tal como menciona la madre "Pues como las cabritas, a ver que son!libres; (le abre los brazos) como si fuera una avecita, y Pere pienso (se pone las manos en la boca) con la pierna así (sube una pierna, y S copia su posición, voltea a mirar a la terapeuta) cómo libres" (Madre, 40 años, E1, L115).

Haciéndose evidente así que tanto antes como después de vivenciar acontecimientos del CAC, se comienza a identificar como el desplazamiento forzado y la vivencia del CAC afectó la dinámica familiar, surgiendo emociones tales como el miedo, que generaron un cambio en los límites entre madre e hijos, afirmando la madre

“...Todo eso ya fueron cambios que quedaron ahi $F$, y eran cosas que de pronto nunca se hablaron si no que se tuvieron ahí guardadas y eran miedos que -..- $P$ eran demonios iban ahí guardados ahí, nunca se hablaron simplemente como que yo quise tomar, tomar el:: ser la cabeza de ellos y protegerlos a ellos, y a la vez de protegerlos era imponerles, 
no con la intención de quitarles los sueños a ellos si no como una protección, de pronto no lo hacía bien, porque ponerme encima de ellos, mis miedos, mis temores, no les daba la oportunidad a ellos de..." (Madre, 40 años, E6, L 763).

Estos límites rígidos al ser una familia desligada son ejercidos en especial por la hija mayor, donde su madre, el padrastro y sus hermanos justifican su distanciamiento de la familia por el tiempo de dedicación a la lectura y en cumplimiento del mandato familiar, el cual está relacionado con la exigencia académica por parte de la madre

“L: (...), quieren ser profesionales, quiere decir que quieren más allá de lo que han aprendido por ahora. Como tal, me parece bien, sí. Porque se puede ver también que tiene metas, que tiene proyectos. Y eso para una persona es algo muy bueno, si, porque quieren algo por que luchar, por el que día a día dedicarse, y realmente me parece algo muy, muy bueno. T3: ¿Para ustedes es importante el ser profesionales? L: Ee :: aa ::, para mi si (se toca el pecho con la mano derecha), la verdad sí, yo sueño todos los días con ir a la universidad (...) T3: ¿Y ese gusto por ser profesional, em .:, sobre todo, que todos dicen mucho que quieren ser profesionales, viene desde hace mucho tiempo, o eso, o esa idea surgió hace poco, o cómo ha sido ese surgimiento? L: Pues yo creo que es desde hace mucho, mi mamá es una de las personas que nos dice que, "el que estudia no es nadie”, (...) entonces considero que mi mamá, pues ha incentivado ese deseo en nosotros, porque ella nos dice que "lo que hagan, háganlo bien, háganlo que cada día surjan más, (...), entonces yo creo que eso también de mi mamá. Ósea desde muy pequeños y ya" (Interacción: Hija: 317 años, Terapeuta 3: 28 años, E 2B L197:203 / 206:211).

Lo anterior, genera tensión a nivel del subsistema parento filial en tanto al interior de este 
subsistema los límites son difusos al punto de generar obstáculos en el desarrollo de la autonomía y en la propia individuación de cada uno de los hijos. En torno a las fronteras entre subsistemas se comprenden transgresiones en los límites difusos intergeneracionales, en razón a que el padre en su posición periférica al interior del sistema lleva a la madre a empoderar a su hija mayor otorgándole funciones para ejercer un rol parentalizado y suplir al padre en las funciones de cuidado y control sobre sus hermanos menores

“I: (...), y a L(...) frenarlas más, porque yo le he dado como mucha autoridad a ella (...), yo le he dado mucha autoridad a ella a algo que no tiene. (...)" "si (...) la verdad ya me preocupa que está mandando más mi hija que mi esposo [risas] entonces la estoy recargando a ella de cosas que no son de ella" (Madre: 40 años, E4, L1279, L1287).

Así mismo, se comprende trasgresión de las fronteras de este sistema familiar nuclear, respecto a la familia extensa materna, en tanto conflictos con algunos de estos miembros producen el primer desplazamiento ya que la familia extensa materna exacerba la narrativa dominante de la exigencia académica y la desvalorización del padre frente a la madre. Así mismo, está familia nuclear vivencia acontecimientos asociados al CAC a través del desplazamiento forzado rigidizando las fronteras con la familia extensa materna en tanto se desplazan a Bogotá buscando huir de los grupos al margen de la ley y evitar los conflictos con esta familia extensa

"E: ... Porque es que entre la familia de ella (señala a I) y la mía fue un problema ahí. Ya ni, ya porque mi hermana es la esposa de él, entonces pues nosotros nos vinimos para acá también. I: Somos dos hermanos, juntos. E: Sí.| (2 seg) Y entonces por eso fue que nosotros nos vinimos, también para acá, sino que yo acá, por ejemplo... (interrumpe T3). T3: ¿Cómo así? I: Una de las situaciones fue la que nos sucedió, pero la otra también 
nos ayudó, ya habíamos, digamos. Es que mi hermano tiene problemas, del ejército salió con problemas psicológicos, y él deja de tomarse la droga y se pone enfermo, y todo lo malo que le pasa a mi hermano es culpa mía. $E:==$ De los dos, porque ... I: = =Bueno en realidad, es de los dos (se sonríe). La mamá de él me echa la culpa a mí, que por mi hermano maltratan a la hermana de él (señala a E). Mi mamá lo culpa a él, por la familia, bueno si, entonces eso es como un enredo terrible (une y abre las manos tensionándolas, encorvada). T3: Entonces esa... (interrumpe I) I: Esa es una situación. T3: ¿Y la otra? I: Nosotros estábamos por allá, y decidimos alejarnos de ellos, del pueblo de donde somos nosotros. T3: ¿De dónde son? Del Guamo, I: Del Guamo. Y ahí por esa situación decidimos alejarnos de nuestra familia, pero ... (T3 interrumpe) T3: Y de ahí. I: Nos fuimos a San Luis, y pues de ahí, tocó venirnos. T3: Ustedes estaban en San Luis por lo que pasó, de que lo querían enfilar. I:(asiente con la cabeza) Si. E: Si. I: Y ahí, nos tocó tomar la decisión de coger los niños y irnos. T3: Y venirse” (Interacción: Madre (I): 40 años, Padre (E): 33 años, Terapeuta 3 (T3): 28 años, E2B, L858 - 879).

De otra parte, se reconoce como un cambio la acentuación de las fronteras difusas entre el padre y su familia extensa, en tanto al sentirse agobiado por las dificultades económicas que vivencia prefiere volver la mayor parte del tiempo al pueblo en donde este vive, afirmando "O sea es bueno, yo me quedé sin trabajo doctora (sube el tronco y dirige su mirada al techo) yo me estrese mucho (dirige la mirada a T3 y se tapa los ojos, limpiándose las lágrimas) | (2 seg) entonces para mí que, yo me fui para Guamo, para allá | (2 seg) (mientras continúa sollozando y limpiándose las lágrimas) (Padre, 33 años, E2B, L845) ..." "Digamos que con los niños más que todo (ubica su tronco al frente) me coge como nostalgia, que de pronto se me pierde una cosa, y que tiene hambre, más que todo la niña 
(I tiene su mirada y cabeza hacia el piso), pequeñita, por ejemplo pa` el tetero de la niña I y entonces acá me coge un desespero, entonces yo por eso, pues ahorita, yo me quedé sin trabajo, fui a varios lados y todo eso, y no encontré trabajo, y lo otro que también pues yo me puse y hice los cursos, y pues yo fui a varios / lados y todo eso, pues por allá me salió trabajo pero por allá muy lejos, por allá en Suba, doctora (intercala mirada entre el horizonte y hacia T3, mientras continúa frotando el ojo derecho), entonces ella cogió a pelearme (señala a I), que pa 'que hacia esos cursos, que pa 'qué le hacía perder esa plata, pues yo me fui para allá | (2 seg) pues yo allá | (2 seg) trabaje 3 semanas y ...” (Padre, 33 años, E2B, L857).

Situación que desemboca en conflictos entre la pareja en tanto la esposa afirma "Pues de parte mía, yo no creo que estemos bien...él vive en Tolima y él quiere estar al lado de su familia (E mientras mira al horizonte cerca al lugar donde se encuentra I, mиеve las manos), yo soy muy lejos de estar en mi familia, yo pienso un hogar no se estabiliza alrededor de una familia sino lejos de tanto de los padres del uno como de los padres del otro ... Me gusta estar lejos, pienso yo que así funcionamos, como que, bueno el me obedece mejor, como que me lleva una serie de ideas, la demora es que se comunica que se desfocaliza de todo (une las manos hacia la izquierda y saca la derecha) y digo yo el amor que él siente por ellos es muy grande más grande, que su familia, digo yo, y coge y chao (da una palmada y sube la mano derecha), entonces a mí me llega un límite que le digo yo no "Si usted no coge las riendas de su hogar, si usted no me quiere colaborar, pues váyase” (Madre, 40 años, E2B, L846).

Por lo anterior, antes y posterior al desplazamiento la madre asume totalmente el establecimiento de normas y límites debido a la posición periférica del padre, tomando las 
decisiones y empoderándose de una posición privilegiada al interior del sistema familiar; por lo que para legitimar este poder la madre usa el golpe, I: (...) me tocaba armarme con un palo y darle” (Madre, 40 años, E1, L289), como una forma de solucionar las diferencias entre el comportamiento de sus hijos y lo esperado por ella. Esperando esta madre que el padre ejerza su función parental normativa de igual forma; sin embargo, al tener este padre una posición periférica bajo la creencia de proveedor económico ejerce su autoridad cuando está presente, de una forma armoniosa, lo que es considerado por la madre como una forma inadecuada que le genera a esta una sobrecarga en sus funciones de orientación y disciplina al ser la que está a cargo del hogar, “I: (...) siempre he sido como le dije.! Yo soy la autoridad de la casa ¡y él es el juego, la recocha de la casa” (Madre 40 años, E1, L914)

Por lo que, esta madre al estar en esta posición privilegiada estaba encargada de fijar las normas y reglas al subsistema fraterno enviando mensajes dobles vinculares a sus hijos en los que descalificaba el rol del padre en su función normativa y como trabajador,

“ellos son felices con él. Y yo le digo a ellos, me voy a trabajar y ellos !bueno mi mamá se va a trabajar quedamos con mi papá; (subiendo la mano derecha y en tono de alegría) (se ríe la madre y la T3) pero porque saben que pueden hacer lo que quieran con él., mientras $S$, A se sonríen continuando en su juego con las manos y JP sonríe mirando a I)” (Madre, 40 años, E1, L681), así como proveedor del hogar “ (...) pero generalmente mi afán, no sé, mi afán de que todos avancen, que escalafonen, porque en nosotros está (se señala a sí misma y a E) el futuro de nuestros hijos, yo no lo visiono viendo pegando ladrillos que todo el tiempo lo estén mandando, yo le digo a él yo no lo quiero ver cómo un viejito, todo vuelto nada las manos muy feítas, yo le digo a él que ese trabajo no le sirve, por la salud de él no le sirve, porque él tiene un problema en la rodilla, no le llega, 
y si no es por mi hija, porque el papá de mi hija le manda plata, con mi hija, ella me prestó una plata para que hiciéramos el curso y se metiera a trabajar en seguridad porque era lo que veíamos opcionalmente mejor para él (...)" (Madre, 40 años, E2b, L881),

contradiciéndose cuando afirma "(dirigiéndose a JP) Pero tampoco vaya a dibujar a su papá acostado, tampoco es tan perezoso, lo que pasa es que trabaja todo el tiempo" (Madre, 40 años, Escenario 2, L450) y dedicarse más a espacios de juego con sus hijos. Esto, además, está sustentado en una creencia patriarcal de la madre en donde está desearía que su esposo como figura masculina debería cumplir una posición de autoridad y de clara orientación hacia los demás integrantes de la familia.

Así mismo, al ser un sistema familiar reconstituido por una segunda unión de la madre, aparece un distanciamiento entre la hija mayor y el padre no biológico, debido a un desajuste en la conyugalidad y al momento del ciclo vital de la familia, "Ella casi con él no, porque ella en sí es hijastra. Ella mantiene en su mundo con su jcelular! ahora pues tiene el portátil..." (Madre, 40 años, L 531). Evidenciándose un rol difuso del padre con respecto a la hija mayor en tanto es reconocido en ocasiones por ella al compartir desde muy temprana edad, pero al no ser el padre biológico y adicionalmente no cumplir con el mandato de la madre a nivel económico y laboral lo descalifica y desconoce como aquella figura paterna ideal frente a los demás miembros de su familia, tomando distancia de él;

"Digamos el ejemplo que da el papá de ellos (se refiere a sus hijos), dice que ella no quiere un esposo así, que ya si llega a conseguir debe ser alguien que dé a las metas de ella, o si no, no (refiriéndose a lo que piensa su hija de su pareja)" (Madre 40 años, E1, L914), 
mientras que éste padre ejerce una función parental de nutrición relacional primordialmente con sus hijos biológicos, "Nos saca a pasear, nos saca a jugar (lo dice mirando al suelo)" "Pero es que nos saca casi todos los días" (Hijo 12 años, E1, L712/716).

\section{Dinámica Familiar}

En relación con la dinámica familiar se comprende que no se privilegian espacios para el diálogo entre los miembros del sistema familiar antes y después de haber vivenciado acontecimientos del CAC,

"T3: ¿y ustedes eran igual cuando estaba en el campo? I: cuando estábamos allá ellos estaba mиy pequeños, ellos generalmente ellos eran en sus pescados en sus trabajos y cuando llegaba así a jugar. T3: o sea es muy parecido a lo que pasa hoy. I: (...) yo soy muy digamos de sentarnos todos en grupo y que hizo hoy qué le parece no, no geralmente está muy cansado viene se acuesta, come y ya, y si tiene tiempo viene y juega con sus hijos o sino se acuesta a dormir (...), pero ya decir que charlar de como están, no. T3: y tampoco ahí, pero lo hacen con los niños independientemente cada uno o no conversan. I: no con ellos si converso" (Interacción: Madre 40 años (I), Terapeuta 28 años (T3), E2b, L 528:539)

y a nivel del subsistema conyugal el diálogo es exclusivo para el control en el cumplimiento de reglas por parte de los hijos,

"T3: Como que cosas se dicen delante de sus hijos y que cosas se hablan como esposos. I: Digamos, que cosas... que le digo delante de mis hijos, por ejemplo, yo les digo hay usted tiene que pegarles, vea castíguelos, cuando ellos le griten cásqueles. T3: ¿Eso se hablan delante de tus hijos? I: Sí, yo a ellos les digo, hay saque la mano y póngasela 
porque cómo va a ser posible que de que usted va a dejar que ellos le alcen la voz. T3: ¿Y eso sería un tema para hablar delante de tus hijos? I: No, a mi varios me han corregido eso, me han dicho que no haga eso delante de ellos" (Interacción: Madre 40 años (I), Terapeuta 28 años (T3), E4, L1183 - L1188).

Esta falencia en la comunicación permea las funciones parentales obstaculizando la expresión del sentir y pensar entre padres y entre padres e hijos; potenciando el uso del lenguaje digital y analógico descalificador e invalidador para el envío de mensajes doble vinculares que generan tensiones y ambigüedades en la relación de los miembros de este sistema familiar.

A partir de lo anterior, se identifica en este sistema una pauta de relación sintomática en donde la madre impone su poder, los hijos expresan (desde un lenguaje más analógico que digital) su inconformidad, pero la madre exige el deber y los hijos terminan complaciendo la demanda de la madre; esta situación se vuelve repetitiva y se exacerba cuando la madre descalifica al padre a través de mensajes doble vinculares por lo que estos hijos intentan defenderlo potenciando la emergencia de una relación tensionante a nivel del subsistema parento filial, en donde la madre incrementa la descalificación hacia el padre en su rol parental normativo debido a la posición periférica de éste, aunque le exige posicionarse en su rol, hasta que el subsistema fraterno incorpora este relato en su narrativa,

“T3: bueno, pero entonces tú quisieras que tu papá... S: fuera más responsable con todos nosotros. A: sí. T3: que fuera más responsable, que sería que fuera más responsable con todos ustedes. S: que estuviera más pendiente de nosotros, que compartiera más con nosotros. JP: él comparte todos los días con nosotros S: Claro, que fuera más trabajador. I: que es no el flojo (no se entiende). T3: Espera (señala a la madre) ok, que fuera trabajador y ¿S que fuera cómo? S. que fuera más responsable. T3: cómo sería ser 
más responsable. S: mmm. A: Que sea responsable con su ropa. =.. = JP: no que va (no se entiende lo demás). A: ¡Si! mi mama le dice váyase bien y dice otras cosas (Interacción: Madre: 40 años (I), Hija: 8 años (A), Hijos de 12 (JP) y 13 (S) años, Terapeuta 3: 28 años (T3), E2, L472 - L485).

Así mismo, este sistema familiar mantiene una narrativa dominante relacionada con las altas expectativas de la madre para que sus hijos sean profesionales en carreras elegidas por ella misma, que fortalecen el área académica de esto hijos, pero no facilita el desarrollo de otras áreas personales, en tanto esta madre no se permite escuchar el sentir y pensar de sus hijos desconociendo además la etapa de su ciclo vital individual activando y reforzando esto la pauta descrita al comienzo; en tanto se configura a través de sus sueños la identidad y los planes a futuro de los hijos, entorpeciendo el desarrollo de la autonomía e individuación de estos niños, niñas y jóvenes lo que configura el motivo de consulta en tanto los deseos de ella entran en disonancia con los deseos de sus hijos, siendo esto característico antes de vivenciar acontecimientos del CAC aunque se exacerba posterior al desplazamiento

“T3: ¿Y ustedes tres, y eso desde muy pequeñitos, ósea desde que estaban en San Luis? I: No. Ya eso es acá. (...), en San Luis ellos estaban muy pequeños, no les hablaba de eso. L: Si. Ella siempre me decía, digamos. T3: Pero también en San Luis / F. L: En el Guamo [] L: Sí porque nosotros estudiamos allí, entonces ella me decía "usted tiene que ser la mejor en el salón, que sí, ee ::, hace sus tareas, hace siempre sus cosas, en esa área, entonces yo creo que sí. Pues a mis hermanos no les gusta, porque ellos hasta ahorita están en -...- T3: Bien. ¿Y señora I usted pensaba, cuando estaba en el Guamo, usted pensaba en que sus hijos fueran profesionales también? I: Siempre ha sido mi pensamiento, sí, que ellos salgan adelante. Yo siempre lo quise hacer. (...) y mi meta mía, 
era estudiar y dos de mis hermanos, mis hermanos lo lograron. Yo no. Era, tocaba salir adelante a toda costa, estudiar, trabajar. Entonces qué hicimos, el uno, escalo y empujo al otro y así sucesivamente, así han seguido, incluso lo han seguido haciendo. Eh, yo trabaje para escalar al otro, pero yo me quede trabajando, y no estudie. Y generalmente" (Interacción: Madre 40 años (I), Hija: 17 años (L), Terapeuta 328 años (T3), E 2B L197:203 / L206:211).

Sin embargo, se comprende una relación afectiva cercana entre padre, segundo, tercero, cuarto y quinto hijo, puntuada como de apego por la madre siendo evidente el disfrute en el encuentro para espacios de juego entre padre e hijos. Así mismo se presenta una fuerte vinculación entre la madre y sus seis hijos al ser fuente de protección. Mientras que en el subsistema conyugal la vinculación emocional se ha debilitado en tanto se presenta una constante descalificación por parte de la esposa al esposo, incorporando éste dicha narrativa dominante, al considerar cuenta con menor experiencia que ella y este esposo fue objeto de una mayor protección y nutrición emocional por parte de su familia de origen

“E: No pues doctora lo que dice ella, pues ella tiene, como le digo yo (...) Ella tiene mejor forma de expresarse que yo, porque ella, ella ha andado más que yo (...). Porque yo, pues toda la vida mía la pasé fue con mis papases, ya trabajando, porque él trabajaba en fincas, fincas (...). En cambio, la vida de ella (...). No. Porque ella me lleva, como más avance, que yo, yo la pasa todo el tiempo en el campo y estudiando y trabajando allá con mis papás, pero en cambio a ella le ha tocado ya muy duro, (señalando a I) ella ya ha recorrido harto, o sea a venido acá en Bogotá, ha trabajado por otros lados (...)” (Padre, 33 años, E2B, L883).

Estas características anteriormente descritas de la dinámica familiar muestran alianzas que 
pueden ser puntuadas en una gran cercanía entre la primera hija y el segundo hijo con la madre en el establecimiento de límites y toma de decisiones al interior del sistema familiar en donde la madre otorga poder a estos hijos en contraposición de la alianza evidenciada entre el tercer hijo y el padre, en tanto esta madre compara constantemente a su segundo y tercer hijo. Sin embargo, este tercer hijo convoca a observar que sus hermanos también se sienten cómodos con el padre, en contraposición a la invalidación de la madre de cómo es ejercido el rol parental normativo por parte del padre.

Siendo esta disyuntiva a nivel parental la que ha permitido que la madre sea la encargada de tomar decisiones hasta el punto de no llegar a acuerdos con los demás integrantes de la familia; sin embargo, los dos hijos mayores en alianza con la madre en ocasiones se permiten en su ausencia también tomar decisiones. Por esto, la madre esperaría que fuera su esposo quien tomará las decisiones en el hogar, “a mi me gustaría que fuera (...), que fuera él quien estuviera en el centro y que él fuera el que estuviera tomando la decisión de toda la familia y sosteniendo un hogar bien, bien, tener una casa bien bonita y él tomando la decisión de todos en general, es lo que yo deseo de él y en un buen empleo” (Madre, 40 años, E2, L334), desde sus creencias patriarcales llevándola a enviar mensajes doble vinculares en donde además descalifica al padre en la toma de decisiones delante de sus hijos y a la vez le exige posicionarse como padre sin darle espacio para ello, lo cual es justificado por éste y por ella nuevamente desde su rol de proveedor.

Finalmente, estos mensajes doble vinculares que la madre emite han generado confusiones a nivel familiar en la comunicación digital y analógica que imposibilitan el solucionar los conflictos al interior y entre los subsistemas

“T3: ¿Tu mamá estaba peleando con tú papá mucho? JP: Porque era desorganizado, 
dejaba los zapatos, por allá tirados. S: Le decía que se arreglara, que se vistiera como un hombre. JP: Como una persona decente. S:! Sij, eso. T3: Ahh. S: No como un indigente, solo le decía eso (la mamá se sonríe como apenada, tocándose la cara con la mano derecha y escucha atentamente)" (Interacción: Terapeuta 28 años (T3), Hijos 12 (JP) y 13 años (S) e Hija 8 años (A), E1, L845:852),

no conversando sobre las dificultades y simplemente evitando las diferencias que se presentan debido a los bajos niveles de diálogo para solucionar las diferencias tanto a nivel conyugal como parento filial, y fraternal "S: Mi papá se ponía bravo y se iba. T3: Mmmm. Y, y ellos, o sea, y ¿ellos después hablaban de eso? ¿lo solucionaban? ¿ ¿simplemente peleaban y ya? S: Lo dejaban y ya” (Interacción: Terapeuta 28 años (T3), Hijo 13 años (JP), E1, L857:860).

\section{Evolución Familiar}

Con relación a la evolución familiar este sistema presentó dos tipos de desplazamiento que generaron en ellos diversas demandas que, aunque fueron tensionantes y estresantes, generaron diferentes estrategias de afrontamiento. Ante el primero, el cual fue decidido por ellos, pudieron afrontar las crisis que se presentaban de una manera que posibilitó el funcionamiento; pero el segundo, forzado como producto del CAC, se configuró como un estresor no normativo, externo, ambiguo, involuntario y agudo lo que hizo que cada miembro de este sistema utilizará sus redes de apoyo para enfrentar lo que hoy en día vivencian como crisis producto de este estresor. Por ejemplo, la madre se refugiaba en la iglesia cristiana invirtiendo todo el tiempo libre para escapar de la situación económica de la que viven actualmente, la hija mayor se concentraba en su estudio para satisfacer ese mandato y no repetir la vida de sus padres bajo las mismas condiciones, los dos hijos siguientes intentan vivir su vida similar a lo que recuerdan (libertad y 
diversión), pero el padre se apoya en su familia de origen cuando no puede afrontar la difícil situación económica por lo que es configurado por la madre como un padre periférico.

Además, en este subsistema conyugal no se desarrollaron canales de comunicación que les permitieran expresar sentimientos, frente a la situación que vive en su actual condición de desplazados y de estar en la capital manteniendo las altas exigencias y expectativas hacia él como padre y esposo. Además, la historia del padre se ha enmarcado dentro la cultura propia del campo y la ruralidad, a diferencia de la madre quien se ha trasladado a la ciudad en varias ocasiones, situación que lleva a que el padre se encuentre frente a una disonancia de costumbres, mientras la madre fortalezca sus mandatos y creencias familiares en este nuevo contexto de la ciudad, potenciando la relación complementaria rígida conyugal en donde el padre se ubica más periférico y la madre más autoritaria,

“(...) Me encanta los hombres bien organizados, no sé porque me fije en él la verdad(...) pero él al principio él era muy organizado en su forma de vestir, en su aspecto, en todas sus cosas, y ya él ya se deja, es más desorganizado, entonces es más como una (con los puños cerrados los une y cierra) que atropella, y que se cansa, eh no sé, yo digo que me falta autoridad no en la situación de pegarles (...), sino centrarle, porque siempre la autoridad del hombre es más que la mujer, es decir usted se hace esto, y se hace (...), yo le digo, se tiene que hacer esto y él no me dice no" (Madre 40 años, E2B, L486).

Así mismo y en relación al ciclo vital se comprende que la familia se encuentra en el ciclo de hijos jóvenes con funciones de hijos en edad escolar e hijos pequeños, en donde se hace necesario enfrentarse a un proceso de transición emocional en la que deben permitir que sus hijos adquieran mayor autonomía e individuación, facilitar el desarrollo del sentido de responsabilidad y de consideración hacia los otros, promover el cuestionamiento, el razonamiento frente a las 
diversas maneras de percibirse la realidad, y posibilitar el espacio de realizar actividades a manera de los padres y de los hijos favoreciendo la expresión e identificación de los sentimientos entre sus miembros (Hernández, 1997). Además, se comprende una disonancia en el reconocimiento por parte de la madre del ciclo de vital de sus hijos antes y después de vivenciar acontecimientos del CAC en el contexto del campo y ciudad, dificultándose para ella desarrollar a cabalidad las funciones antes mencionadas, en tanto surgen altos mandatos de exigencia familiar relacionados con el cuidado de los hijos menores por parte de los mayores, generando sobrecargas y roles parentalizados e identitarios distintos al ciclo vital individual de estos últimos hijos "a ella estudiando juiciosa, la pongo seria porque ella todo el tiempo es riéndose ¿entonces qué es? la pongo seria para que ya como ya está enfocando ee como ya está saliendo del colegio ya visionando se a una profesional" (Madre 40 años, E2B, L736); y con altas exigencias académicas que ponen a prueba las reglas familiares y los roles, obstaculizando el desarrollo de la autonomía e individuación, el sentido de responsabilidad, pensamiento y actuar crítico de todos los hijos.

Es por esto, que se comprende en el subsistema fraternal el desarrollo de funciones de compartir, competir y negociar evidenciadas en el afecto, la rivalidad, celos, alianzas, coaliciones entre los hermanos. A nivel del subsistema conyugal se observa una complementariedad rígida y una sobrecarga de funciones ejercidas por la madre, en tanto la periferia del padre, es justificada por éste, al ser el encargado del sustento económico (proveedor), y la madre constantemente le exige al padre que haga parte de las decisiones, cuidado y sostenimiento del hogar pero al parentalizar a la hija mayor, este subsistema no logra llegar a consensos en lo que respecta a la conyugalidad, parentalidad y los conflictos que se presenten al interior y exterior de la familia.

Esta confusión en las funciones parentales es legitimada por la madre al momento de 
invalidar constantemente el rol del padre y al entregar poder (cuidado, apoyo, control, fijación de normas y reglas) a los hijos mayores. El primer mensaje refiere que el padre

“él le gusta andar si él está sucio le da igual, si él está sucio le da igual [Risas] si está limpio le da igual, todo le da igual” (Madre 40 años, E2 L600), “Ellos son felices con él. Y yo le digo a ellos, ime voy a trabajar y ellos! bueno mi mamá se va a trabajar quedamos con mi papá ;(subiendo la mano derecha y en tono de alegría) (se ríe la madre y al T3) pero porque saben que pueden hacer lo que quieran con él., mientras $S$, A se sonrien continuando en su juego con las manos y JP sonríe mirando a I)" (Madre 40 años, E1, L711);

$\mathrm{y}$, el segundo refiere a que

“son muy apegados, pero, él (señala a JP) con el papá pelea mucho. Son muy apegados, él comparte mucho más con él (señalando a S), pelear, ¡no! él no discute con él, trabaja, o algo así, pero con él (señalando a JP) si discute harto, pero él es muy apegado a él (con su mano derecha empuja hacia adelante). T3: O sea ustedes 3 con su papá. JP: Con Sa (señalando a Sa), los 4" (Interacción: Madre 40 años (I), Terapeuta 28 años (T3) e Hijo 12 años (JP), E1, L707:709).

Además, se evidencia que la relación de la madre con el subsistema fraterno suele estar orientada en la funciones normativas y protectoras, dejando de lado la función emocional, en contraposición a la relación con el padre que suele estar orientada más hacia la función emocional.

\section{Vulnerabilidad y Generatividad}

A nivel histórico evolutivo, se reconoce como el CAC obstaculiza la estabilidad de la 
familia, en tanto los expulsa de un contexto del campo que les permitía convivir cerca a sus familias de origen, pero al mismo tiempo ponerles límites, al tener que desplazarse de manera forzada hacia la ciudad de Bogotá al no desear que el padre se vincule a las filas de la guerrilla, por lo que inicialmente se desplazan voluntariamente del Guamo, Tolima a San Luis, Tolima y finalmente de manera forzada a Bogotá. Sin embargo, al encontrarse en situación de desplazamiento forzado, se evidencia mediana acumulación de eventos estresantes al presentarse dificultades más a nivel económico debido a las exigencias que implican el encontrarse en una ciudad capital y el tener una familia numerosa, 8 miembros.

Siendo concebido el campo como un espacio abierto y generativo en donde la madre se permite reconocer el ciclo vital de sus hijos, mientras significan la ciudad como un espacio hostil en donde al desconocer el ciclo vital de sus hijos limitan su desarrollo individual: "Pues como las cabritas, a ver que son ;libres! (le abre los brazos) como si fuera una avecita, y pere pienso (se pone las manos en la boca) con la pierna así (sube una pierna, y S copia su posición, voltea a mirar a la terapeuta) cómo libres" (Madre, 40 años, E1, L115), lo cual posibilita tensiones familiares debido a las altas exigencias en las funciones desde el nivel cognitivo por parte de la madre que han deteriorado la relación conyugal y por ende la parental, y de igual manera se encuentran lejanos a las dificultades que se han presentado con la familia extensa y el CAC de una manera más directa, sin embargo, estos sucesos violentos generan en la madre altos niveles de preocupación que logra expresar al finalizar el proceso terapéutico. Lo cual se organiza alrededor de una historia que la madre ha construido a partir de pautas intergeneracionales que la conmina al cumplimiento de mandatos familiares relacionados con la creencia dominante de estudiar para poder ser alguien en la vida, ser felices y el cuidado de los hijos menores por parte de los mayores, lo que posiciona a algunos de los miembros del sistema familiar en roles y 
jerarquías que exacerban el surgimiento de malestares al interior de la familia.

De acuerdo a lo descrito, a nivel de red vincular se identifica vulnerabilidad frente al desligamiento de la familia extensa al no existir vínculos significativos, en tanto se evidencia baja cercanía al presentarse eventos tales como violencia intrafamiliar, conflictos entre hermanos de la pareja, quienes a su vez actualmente son pareja; potenciando la ruptura de estos vínculos, especialmente entre madre y su familia extensa y con la familia extensa de su pareja, que llevan a la familia a trasladarse al lugar de donde son obligados a desplazarse de manera forzada hacia la ciudad capital. Reconociéndose como a nivel de instituciones en un comienzo tiene el papel privilegiado la iglesia cristiana, quien brinda a la familia la posibilidad de sentirse seguros y cómodos en este nuevo contexto de ciudad luego de vivenciar acontecimientos del CAC y verse desligadas abruptamente sus redes de apoyo, encontrándose esta no visibilizada por la familia, al igual que la red de apoyo de las instituciones educativas de sus hijos.

A nivel de filiación se evidencia claridad en el vínculo parento-filial, aunque se presenten conflictos en la dinámica relacional, mientras el vínculo conyugal es confuso, en tanto no hay claridad en la función de apoyo mutuo y con evolución, situación que al parecer se mantiene desde el contexto del campo y se exacerba en el nuevo contexto al cual migran. Así mismo, al encontrarse en una situación económica difícil, que les obstaculiza desarrollarse en espacios de mayor comodidad, viviendo en una casa de invasión en la que no existen espacios demarcados que posibiliten el desarrollo de su autonomía e individuación. Dichas dificultades que atraviesan luego de vivenciar acontecimientos del CAC promueven el que el padre se encuentre en una posición desfavorable al lado de la hija mayor, quien ha terminado asumiendo responsabilidades en el apoyo económico en pro al bienestar de la familia al contar con el apoyo económico de su padre biológico. 
El desligamiento de la familia nuclear con la familia de origen materna se exacerba con el desplazamiento y con la llegada al nuevo contexto de ciudad, en tanto por una parte el esposo se aleja en mayor medida de la narrativa dominante familiar de sobre exigencias y el que sean profesionales, al vivir en condiciones de vulnerabilidad que se acentúan en la ciudad, y por otra parte la familia extensa paterna, con quienes la madre comienza a vivenciar más conflictos al sentir que interfieren en su relación y su esposo prefiere mantenerse más cerca de ellos, tendiendo a volver a donde estos en varias ocasiones quedándose su esposa e hijos en Bogotá.

A nivel socio cultural la situación de desplazamiento de la cual han sido objeto también promueve confusión en torno a la prospectiva vital del sistema familiar y a la forma como se vinculan, en tanto el padre asume una posición periférica ligada a su trabajo puesto que debe cumplir con su función de proveedor, tal como lo realizaba en el campo, pero que en este nuevo contexto de la ciudad se limita el tiempo y espacios compartidos. Así como se evidencian creencias familiares de sobre exigencias propias de la cultura colombiana en donde se concibe que el estudiar posibilita salir adelante, es decir obtener mayores posibilidades económicas, exacerbándose dichas creencias bajo la situación de vulnerabilidad que la familia comienza a vivenciar luego del desplazamiento forzado:

"Pues yo creo que es desde hace mucho, mi mamá es una de las personas que nos dice que, el que estudia no es nadie”, si, y que digamos al dedicar un tiempo estudiando, es mucho mejor que andar en la calle, o haciendo, o cosas así, entonces considero que mi mamá, pues ha incentivado ese deseo en nosotros, porque ella nos dice que "lo que hagan, háganlo bien, háganlo que cada día surjan más, que no se queden ahí, sino que siempre vayan avanzando”, entonces yo creo que eso también de mi mamá. Ósea desde muy pequeños y $y a "$ (Primera hija, 17 años, E2B, L201). 
A nivel de dinámica relacional se evidencian conflictos a nivel conyugal respecto a las exigencias por parte de la madre frente a las aspiraciones a nivel académico, llevando esta situación a descalificar la figura de hombre y la paterna, llevando esto a que no se logren expresar su sentir y pensar como pareja frente a la actual situación que viven en su condición de desplazados en la capital; por lo que estos estresores de orden no normativo ambiguos e involuntarios (desplazamiento forzado, mandatos y creencias familiares de la esposa) potencian la dificultad de éste para adaptarse al nuevo contexto de ciudad, modificando la dinámica familiar interna y externa en donde éste se encuentra frente a una disonancia de costumbres que exacerban la relación simétrica conyugal que afectan el ejercicio de la función parental, en donde el padre se ubica más periférico y la madre más autoritaria, rigidizando el vínculo con el subsistema fraterno. Significando, además, la esposa la relación cercana de su esposo a su familia origen (ubicada en un municipio), caracterizada por una gran nutrición relacional desde el orden afectivo y emocional, como el generador del conflicto a nivel conyugal, en tanto la madre se muestra distante con su familia de origen debido a pautas de relación mediadas por la violencia. Permeando a su vez estas dificultades la parentalidad en donde cada padre desde sus creencias familiares se complementa en el cuidado y orientación a sus hijos, mientras la madre se basa en la exigencia, el padre en el juego y el brindar cariño. Por lo que el padre potencia la función emocional, y la madre la cognitiva especialmente sobre unos hijos en comparación a otros, de acuerdo con el actual ciclo vital en el cual cada uno de sus hijos se encuentran y sus altas preocupaciones por mejorar su situación actual económica: "No. Ya eso es acá. (sigue dibujando, sin mirar a la T3), en San Luis ellos estaban muy pequeños, no les hablaba de eso. Ya” (Madre, 40 años, E2, L203). 


\section{Cambios en el proceso terapéutico}

Para dar inicio al proceso terapéutico se construyó como hipótesis inicial que la relación conyugal se ha deteriorado, a tal punto que se ha desarrollado una dinámica familiar rígida, en la que se presentan altas demandas frente a las expectativas de ser profesionales y de no llevar a cabo oficios que impliquen gran esfuerzo físico, en contraposición a la realidad familiar y a las condiciones socio económicas, en donde el padre se interesa más por compartir espacios con sus hijos. Siendo claras las contradicciones a nivel parental que han afectado al tercer hijo, en tanto se encuentra inmerso en una juego psicológico, es decir triangulado bajo la lealtad que tiene a cada uno de sus padres, lo cual afecta el recurso comunicativo de la familia, en donde la madre expone su fuerte inconformidad con la posición pasiva del padre en la toma de decisiones a nivel familiar, y su poca participación en la disciplina de los hijos, ya que el padre se mantiene periférico al manifestar no cuenta con suficiente tiempo para ello debido a sus extenuantes horas de trabajo. Situación que puede ser intervenida desde la comprensión frente a cómo las relaciones parentales, han sido permeadas por el deterioro de la relación conyugal.

Es así como se desarrolla el proceso teniendo en cuenta los postulados de Hernández (1997) quien afirma que las condiciones evolutivas y de crianza del niño de 7 a 12 años, se caracterizan por la separación de la fantasía de la realidad, el desarrollar pensamiento concreto y abstracto, iniciar proceso de desarrollo de los propios valores, y creencias, así como poner a prueba las reglas familiares. Siendo un punto de disonancia en esta familia el que las dificultades que se presentan a nivel de funciones de los padres se encuentran obstaculizando el desarrollo del sentido de la responsabilidad, del razonar, discutir y cuestionar distintas realidades, desde el permitir que el niño explore su contexto a su manera y según las orientaciones paternas. Siendo evidente las dificultades respecto a la cohesión, que han posibilitado la conformación de un triángulo con el tercer hijo por parte de los padres, en donde como portador del síntoma se 
encuentra en mediado de lealtades y confusiones, a los padres buscar de manera natural satisfacción afectiva en sus hijos, lo cual ha deteriorado en la familia la capacidad de proporcionar condiciones óptimas para el desarrollo de la autonomía del niño (Hernández, 1997).

En relación con el recurso de la adaptabilidad se evidencia una dificultad para solucionar problemas y llegar a acuerdos de convivencia, interfiriendo esto de manera directa en el desarrollo de los niños en especial del tercer hijo, puesto que las reglas familiares y disciplina inconsistentes se potencian bajo una mutua desautorización entre los padres. Por lo que, a su vez, el recurso de la comunicación se ha visto afectado al dificultarse la clara expresión de instrucciones y de orientaciones a los hijos, así como la expresión del afecto, en especial por parte de la madre. Lo cual ha desembocado bajos niveles de escucha, en donde predomina de manera particular en el rol materno, al asumir el rol de cuidadora, un patrón comunicativo caracterizado por la repetición de quejas e inconformidades como mujer y la ausencia y pasividad de su pareja. Conllevando esta situación a que se presenten ruidos en la comunicación y de esta manera barreras comunicativas entre las partes al subir tono de la voz, interrumpirse, etc.; en donde las vías de interacción excluyen la participación y colaboración entre la pareja, pretendiendo solucionar las dificultades sólo a nivel verbal (Hernández, 1997).

Dichos recursos familiares se han visto deteriorados por las dificultades que ha vivenciado la familia respecto a enfrentarse a un nuevo contexto, así como a dificultades económicas debido a una situación inicialmente normativa de desplazamiento voluntario y a su vez una no normativa referente al proceso de desplazamiento forzado que deja un desligamiento a su vez en las redes de apoyo familiares y sociales. Por lo que, mediante el uso de las estrategias artístico terapéuticas sistémicas para narrar, re-narrar, significar y resignificar los acontecimientos vividos en el CAC, también se posibilitan nuevos procesos de adaptación, autonomía e individuación que se acoplen 
al contexto al que llegan y a las tradiciones culturales de las que provienen, desde la transformación en la comprensión y significación de la experiencia vivida a partir de la experiencia narrada.

Lo que nos permite a continuación describir de manera gráfica la construcción del problema, las interacciones que se presentan respecto al síntoma y su desarrollo:

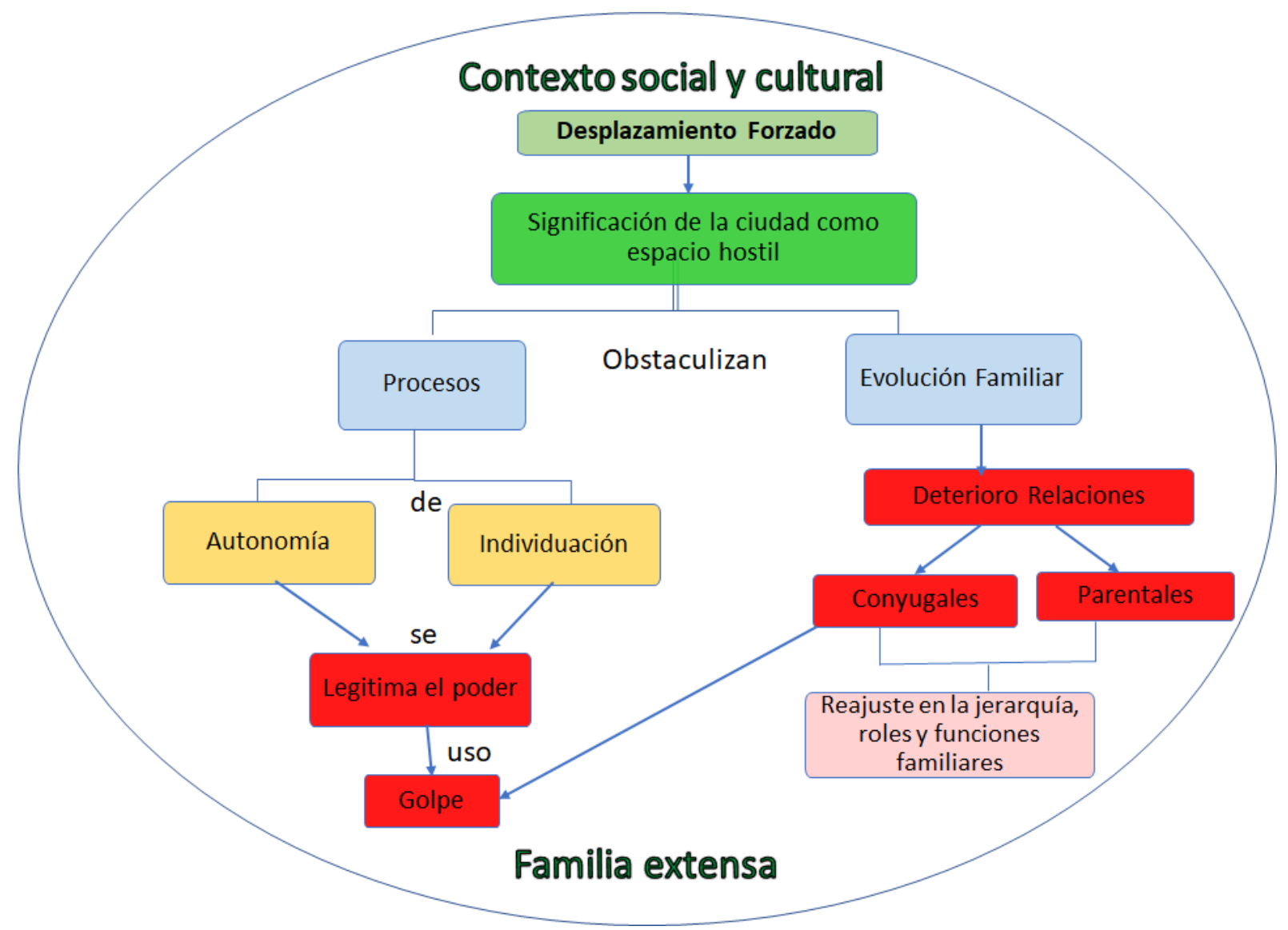

Fuente: Autoras

No quiero ser como mi madre, pero estoy condenada a serlo.

En el escenario uno se propone desarrollar la estrategia artística de la escultura familiar puesto que se pretendía conocer de una forma más didáctica la historia de la familia en términos 
de pasado presente y futuro, para comprender los posibles cambios que se desarrollan a nivel de funcionamiento familiar durante el proceso del desplazamiento forzado, así como posibilitar desde el lenguaje no verbal procesos reflexivos y comprensivos de la historia actuada y así comenzar a potencializar los recursos comunicativos que se han visto obstaculizados debido a la falta de escucha activa entre los miembros de la familia y la constante descalificación entre los padres.

Es así como se evidencia que, desde la sobrecarga en las funciones cognitivas de la madre, quien al ser la encargada de tomar decisiones en el hogar termina utilizando medidas de control físico. Es decir, se legitima su poder a través del uso del golpe como una forma de resolución de conflictos y las diferencias entre el comportamiento de los hijos y lo esperado por ella. Lo cual permite reconocer un relato dominante familiar materno en donde es necesario acudir a la violencia física para lograr disciplinar a los hijos al mencionar la madre durante el desarrollo de la escultura familiar "porque ellos muchas veces se ponían, (S se mueve de la silla, mira a I y se ríe) y se me subían a los palos, y tocaba bajarlos, y eso me tocaba a mí. Me tocaba, a veces pegarles, no hacían caso" (Madre, 40 años, E 1, L 294).

Teniendo en cuenta que la composición familiar es propia de una familia reconstituida por una segunda unión de la madre, se hace evidente cuando la madre menciona durante el desarrollo de la escultura familiar:

"Pues no pelean, pero, pero ella es como muy apartada de los juegos con él, no nada, es como muy separada de él y ya (señala como una restricción con la mano derecha). Y ahorita que esta grande pues ¡hola! Él la llama y ella le contesta sí señor, no señor porque pues que no () ni nada..." (Madre, 40 años, E1, L 539).

Lo cual invita a reconocer un rol difuso del padre con respecto a la hija mayor en tanto es 
reconocido en ocasiones por ella como él mismo, al compartir con ella desde muy temprana edad, pero al no ser el padre biológico mantiene un distanciamiento que se evidencia durante la escultura familiar "Ella casi con él no, porque ella en sí es hijastra. Ella mantiene en su mundo con ¡su celular! ahora pues tiene el portátil..." (Madre, 40 años, L 531), así mismo la madre usa su propia metáfora de la pared en la construcción de relaciones familiares, al igual que en la manera como se relaciona su hija con su esposo, reafirmando la pauta y relato dominante transgeneracional referente a la dureza como fortaleza, para enfrentar las diferentes vicisitudes de la vida "es muy seria, pone como una pared (señala como una restricción con la mano derecha hacia el frente)" (Madre, 40 años, E1, 539), en donde como hijas mayores, la madre y la primera hija aprenden a relacionarse de una manera más distante con los demás miembros de su familia al mencionar metafóricamente crear una pared para defenderse:

“Claro es como una pared que puse para mi vida de que digamos esa pared yo hago que mi propia, digamos yo a mis hijos los quiero mucho, a todos los quiero mucho pero yo los trato de mantener lejos, porque por ejemplo (no se entiende) él es tremendo, pero por ejemplo Ángelo él me dice a mí, porque pues él tiene una vida muy organizadita, muy bonita, yo no puedo decir que no, pero él me dice a mí que él me ayuda pero que tengo que dejarlo a él, yo le digo a él que no” (Madre, 40 años, E4, L1059),

para exponer la forma como se relaciona con sus hermanos y familia nuclear, mostrando la fortaleza que les permita cumplir con el mandato familiar de sobre exigencia y de salir adelante impuesto por la abuela materna, en donde se da gran importancia a la posición económica y laboral, quedando así el esposo de la madre en una posición de descalificación, dificultando dicha cercanía entre primera hija y padre.

Este mandato toma sentido durante el escenario cuatro en el desarrollo del dibujo del 
familiograma ya que en este se identifica que la narrativa dominante es también realimentada por los tíos maternos que en la voz de la madre descalifican permanentemente a su pareja, siendo justificados por ella, permitiéndoles una trasgresión a las fronteras de la familia nuclear, bajo las narrativas dominantes de la familia materna que validan la narrativa de alta exigencia a nivel académico, al mencionar observando el dibujo del familiograma:

"De pronto porque ellos lo ven muy poca cosa, por lo que nunca estudio, de pronto porque no lo ven con una moto, con una profesión, con una ... con un grado de nada, simplemente es trabajador de lo que le toque, como le toque, entonces lo ven como muy poquita cosa para, para que este conmigo, porque puede que ellos estén enseñados a que yo tenía muchachos de muy buena comodidad y muy buena casa, porque llegue a tener un cuerpo muy bonito, no, mejor dicho a mí me seguían, yo digo que a mí me seguían por mi cuerpo no por nada, entonces ellos se enseñaron a verme con personas con mejores escalafones y pues ya bajar de donde estaba a E, para ellos fue impactante” (Madre, 40 años, E4, L 1061).

Situación que afecta la dinámica familiar, en tanto se comprende que el poder ejercido por la madre es tan rígido al interior del sistema familiar que no permite una comunicación fluida entre sus miembros, obstaculizando la participación activa de sus hijos para la expresión de su sentir y pensar, lo cual es más evidente en la interacción con el tercer hijo quien se encuentra en una posición más cercana al padre, en tanto cuando la terapeuta busca indagar respecto a si el segundo, tercer y cuarto hijo pueden expresar su sentir, este hijo de 12 años con su silencio y su postura corporal mirando al suelo reafirma la poca posibilidad con la que cuenta para expresarse, promoviéndose algunos niveles de malestar en el mismo y en la dinámica familiar, mientras los mayores, quienes de alguna manera cumplen con sus expectativas tienen mayores aperturas para expresar su sentir al manifestar el segundo hijo "Yo lo digo y ya" (Segundo hijo, 13 años, E4, L 
596).

Re afirmándose a su vez el relato dominante materno de altas sobre exigencias que permite por un lado que los mayores que se encuentran como sus aliados asuman una postura de baja capacidad para llegar a acuerdos a nivel familiar también, al manifestar el segundo hijo "Y no vamos | Nos quedamos con mi papá. Nos iquedábamos! con mi papá” (Segundo hijo, 13 años, L196).

Para el escenario cuatro se reconoce como la madre si bien se permite el comenzar a entender a nivel cognitivo la importancia de generar transformaciones a nivel de sus funciones parentales respecto a la nutrición emocional, se encuentra en un proceso de aceptación de su realidad que requiere el generar una estrategia que le permita pueda llevar dicha comprensión a un nivel pragmático y emocional, en tanto cuando comentó lo conversado con su familia respecto al encuentro 3 y se conversó respecto al álbum familiar:

“...ahí hablamos de otras, de la situación de como de ciertas cosas podemos reunirnos en otra parte que no sea, que no sea la iglesia Le (mueve los brazos sobre la cabeza y los vuelve a ubicar detrás de esta) como el sitio clave de reunirnos, si no buscar otros sitios para estar juntos ... es buscar otros sitios, compartir, salir a pasear a otras partes, sí pero estar todos, toca mirar a ver que hacemos, / incluso el domingo no salimos a ningún lado, bueno él salió si, con ustedes ¿cierto? (JP asiente en señal de afirmación) y con el perro [se ríe] pero yo no salí, no salí con las niñas porque L se puso, estaba haciendo trabajos y pues estaba haciendo mucho frío y (no se entiende) PP entonces él se fue con los niños, con los dos niños al parque Le (mueve las manos y las bajo cubriéndose las manos con las mangas del frío)” (Madre, 40 años, E4, L33),

lo que permite evidenciar la apertura a un relato emergente en donde se comienza a gestar la 
importancia de buscar espacios de encuentro distintos a los de la iglesia a nivel familiar en donde se involucre también al padre.

Sin embargo, a la madre continuar dándole mayor importancia a buscar cumplir sus funciones parentales a nivel normativo, alejándose de la función más emocional, desconoce los pedidos de su tercer hijo quien mientras conversa respecto al álbum familiar correspondiente a dicho día, el cual fue prescrito para que la familia plasmara creativamente las reflexiones de lo abordado en la sesión anteriormente desarrollada, en pro a la externalización y construcción reflexiva sobre la pregunta realizada por la terapeuta frente a cómo se sentiría si su madre juega más con él, menciona:

"Me pondría feliz Le PP (con los brazos sobre los muslos, la cabeza inclinada a la derecha y manteniendo contacto visual con T3)" (Tercer hijo, 12 años, E4, L113). Lo que invita a hacer evidente cómo el relato dominante de sobre exigencia de la madre obstaculiza que esta se pueda ubicar desde una postura de escucha distinta frente a su hijo, en tanto le implica re estructurar su propio self, teniendo que trabajar en su pared, para acercarse más a su hijo desde espacios más de esparcimiento y diversión que desde espacios académicos y de disciplina, al afirmar durante la conversación del álbum familiar "l 4 seg (T3 entrega el dibujo a I, mientras esta muestra un gesto de preocupación y duda) (no se entiende) PP yo hago lo posible porque para poder tratar, lo que pasa es que yo no soy persona de juegos, yo nunca, soy como muy seca en ese sentido, $=\ldots=($ cuando JP interrumpe se miran y se ríen, luego dirigen nuevamente la mirada a T3) yo tengo que estar como de buenas pulgas para ponerme a jugar con ellos, de resto yo siempre me concentro en las cosas de la casa, lavando, haciendo oficio, en el corre corre de, del día de llevar a uno a estudiar así pero más bien sí últimamente me sirvió esta tarea pero veo de pronto que las tareas que tenga 
que ver con estudio, pero en lo que pueda ayudarle, yo le hago, pero ya de resto que me ponga a jugar no, no me queda tiempo (JP baja su cabeza hacia adelante y dirige su mirada al suelo mientras escucha a su madre)” (Madre, 40 años, E4, L 115).

En este punto se reafirma la pauta intergeneracional que contribuye a la configuración identitaria de la madre y que dificulta nuevas formas de relación y del ejercicio de sus funciones parentales al afirmar observando el dibujo del familiograma:

"De pronto sí, yo digo que sí hay veces que hay cosas que de pronto, de pronto si esa exigencia que de pronto tenía ella conmigo de pronto es (no se entiende)" (Madre, 40 años, E4, L1097), predominando una función normativa por sobre la emocional, al ser esta pauta alimentada por la posición periférica del padre a quien la madre afirmar ver como "Yo digo que él es otro niño igual” (Madre, 40 años, E4, L1099)

y su posición familiar de dar un mayor predominio a lo emocional sobre lo normativo; dificultando así, la manera en cómo la familia llega a acuerdos y soluciona sus conflictos. Sin embargo, la madre en este mismo escenario se permite comprender cómo se mantiene de manera transgeneracional las exigencias de la abuela, que, si bien permiten mayor fortaleza para apoyar a su familia respectivamente como por ejemplo respecto a lo vivenciado por el CAC, afirmando: "por ejemplo esa dureza que ella me puso a mí, me ayudó también a que no nos hicieran daño también allá, porque cuando esos tipos le estaban haciendo daño a él, créame que yo no sé dónde saqué tanta fuerza para que no nos maltrataran, porque a mí me dio mucho, pues de pronto se me vino en la mente todo lo que vivía con mi familia y de ahí fue que me levante con tanta fuerza, con tanta cosa a defender, porque debía ser al contrario [risas] no que yo a él si que lo defendi”" (Madre, 40 años, E4, L1107)

y al mismo tiempo obstaculiza su manera de relacionarse con los otros al afirmar observando 
el dibujo del familiograma: “...yo digo que mi dureza me ha ayudado a sobrevivir, pero también me ha como impedido ser ciertas cosas, como por ejemplo ser más cariñosa con ellos, como más comprensiva, a entender lo que ellos quieren ser, hacer otras cosas, y no las que, no lo que yo quiero si no lo que ellos quieren” (Madre, 40 años, E4, L1105).

A nivel de filiación se comprende que existe confusión, conflicto y distanciamiento en los vínculos del subsistema parento filial en la familia extensa materna, en donde la esposa refiere una relación distante y conflictiva tanto con la madre como con su padrastro; sin embargo, actualmente se ha transformado a una relación cercana conflictiva con su madre y distante con el padrastro al afirmar la madre observando el dibujo del familiograma:

"Sí, porque es que yo con ella siempre he mantenido una relación, no sé, ella siempre, yo siempre he sentido que ella me ha culpado por todo. Nunca he podido empatar con ella. Si ella está contenta con mi papá peleaba conmigo, si estaba brava peleaba conmigo, sí, todo, siempre lo que pasara lo malo lo bueno, todo era culpa mía, no sé, no sé qué pudo haber sucedido...” (Madre, 40 años, 953) “...pues yo lo tengo como papá porque generalmente él ha sido la figura paterna que he tenido siempre, pero ahi ya, lo respeto, pues ahora a lo último he cambiado mucho, he pensado mucho el pensamiento mío hacia él, porque pues él sí me ha ayudado en muchas cosas, a sacar cosas con él, porque incluso mi pensamiento cada vez que yo lo veía o lo miraba era que se muriera, que le pasara algo, porque yo le llegue a tener mucho odio, pero ahorita ya no, ya no, ahorita yo lo veo enfermo, lo veo achacado, de todas maneras son las consecuencias de todo el daño que ha hecho, ya no lo miro con tanta rabia como la de antes, ya ahorita es mi papá...” (Madre, 40 años, L1031).

Así mismo, la madre reconoce durante el desarrollo del dibujo del familiograma una trasgresión de fronteras entre subsistemas que posibilitan su hija mayor asuma un rol 
parentalizado y el padre un rol de hijo periférico asignado por esta cuestionándola al afirmar observando el dibujo del familiograma:

"La verdad yo no quisiera que en un futuro $L$ se alejara así, como me tocó a mí bruscamente PP (no se entiende) Que en la cuestión de hablarse tocaba mirar como en el lugar de hijo no de esposo, como que me refugio mucho en ella mas no lo que debo ser, como que le di más lugar a mi hija que a la persona que tengo a mi lado, la persona que yo misma elegí, (no se entiende, la bebé hace ruidos bastante fuerte) entonces sería darle el lugar que se merece para que él =...= dándole el lugar que él tiene de pronto él muestra lo que él quiere hacer con sus hijos, y a L ponerla... más, frenarlas más, porque yo le he dado como mucha autoridad a ella (con la mano derecha da una indicación como de libertad), yo le he dado mucha autoridad a ella a algo que no tiene, y pues a mi forma de ponerlos a ellos como de muñequitos, pues ahí me toca dejar de acomodar los muñequitos (con la mano derecha da una indicación como de pequeño), y dejar que esos muñequitos se acomoden, porque no son muñequitos, son niños y seres humanos, y que aunque a mí me afané la situación de ellos deseen, es lo que ellos deseen, las metas que ellos tengan, como ellos lo quieren realizar, dejarlos que ellos saquen eso, y no ser yo la que lo saque si no ellos" (Madre, 40 años, E4, L1279),

posibilitando dichas reflexiones que la madre re signifique la manera de relacionarse con sus hijos siendo consciente de la necesidad de reposicionar a su hija mayor al interior del sistema familiar para equilibrar en la relación conyugal a su esposo combinando las funciones parentales normativas y emocionales para dinamizar la relación padre e hijos de una forma más armoniosa, en donde los hijos no sientan malestar por la descalificación hacia su padre, potenciándose así la ampliación de las fortalezas que el mismo sistema encuentra en la relación de sí mismo y otros. 
Encontrándose esto unido a un relato dominante de la madre con relación a la forma como se relaciona el padre y ella con sus hijos, en donde se muestran pautas de relación que dan cuenta de un padre amoroso y afectuoso que proviene de una familia que provee nutricional relacional afectiva y emocional a sus hijos, situación que su vez es descalificada por la madre al mencionar: "Porque ella [madre de E] también le dice que él es muy alcahueta [padre de E]" (Madre 40 años, E4, L1043), y a su vez admirada al mencionar "sí, que él es como parecido a E, le gusta jugar mucho con lo hijos, no los regaña, es asemejado así parecido a E. Él le gusta, él es de los que les gusta jugar con sus hijos. Él, aunque están grandes, están viejos, y ellos lo alzan [risas] lo abrazan, él es muy, le gusta jugar mucho con ellos incluso con los nietos es igual” (Madre, 40 años, E4, L1045),

y a una madre predominantemente normativa que proviene de una familia en la que se privilegiaba el "maltrato" por parte del subsistema parental hacia sus hijos al mencionar observando el dibujo del familiograma:

“Esta cadena como de maltrato, claro, en mi casa yo decía desde muy pequeña que los veía a ellos que se peleaban tanto, que yo a mi papá no lo quería, y mucho menos viendo un papá maltratando, mi papá le pegaba mucho a Oscar de una manera terrible, él se desquitaba mucho con él, entonces yo decía que yo no quería eso, que yo no quería eso" (Madre, 40 años, E4, L1060),

lo cual la lleva a resignificar las razones por las que busca a un hombre como su esposo al mencionar observando el dibujo del familiograma, "a mí me gusta mucho en sí, a veces me saca la rabia, que es que no los regaña, pero en si él los trata bonito, pero el trata como de meterse ser un niño igual como ellos, sino que hay si ellos abusan de la confianza” (Madre, 40 años, E4, L1061), demostrando que le molesta es como su esposo no se impone con mayor autoridad 
situación que sin embargo admira en tanto la familia paterna extensa se caracteriza por las funciones parentales de nutrición relacional, y del vínculo a nivel del subsistema conyugal que es de orden cercano y armonioso, que es un ejemplo para su esposo quien la madre afirma observando el dibujo del familiograma, “...ese respeto que tiene el, el me respeta mucho, eh digamos que él me llegue o me diga malas palabras no, él no los dice conmigo, él lo que pasa es que dice muchos madrazos al aire” (Madre, 40 años, E3, L1051), posibilitando una ruptura en la pauta intergeneracional de maltrato por parte de la figura paterna puntuada por la esposa.

Sin embargo, dicha contradicción lleva a comprender una configuración de pareja fundamentada según la esposa en el priorizar las funciones de nutrición relacional y amor complejo sobre sus expectativas individuales orientadas al crecimiento profesional, en donde esta esposa configura esta relación de pareja con un hombre a través del cual puede mantener el mandato familiar, ya que siente que no puede cambiar, ella necesita buscar a un hombre que le permita mantener su poder pero que sea diferente a la figura paterna en su familia extensa.

Para el escenario quinto se reconoce como mediante la estrategia del álbum artístico terapéutico la madre se comienza a movilizar al presentar acercamientos a espacios más lúdicos con sus hijos y como durante el proceso conversacional de la página del álbum desarrollada emerge un relato que reconfigura la posición de la madre en torno al compartir con sus hijos de una manera diferente generando cercanía entre ella y estos, en donde se apertura distintas formas de relacionarse y de generar espacios distintos para estar juntos al mencionar en el escenario quinto durante la conversación del álbum familiar

“La conclusión fue pues pensado en cómo, en la idea central de la que expuso JP, que era estar juntos compartir, no solamente en el parque, no sé, o tener plata para ser felices -..podemos ser felices en la cama, jugar un rato, l ehh contar unos chistes, $l$ ehh decirnos 
digamos mmm no a mí me preocupa esto, ah sí escucharnos todos en un solo sitio. (en esto último abre sus ojos, mira la T3, mueve sus manos para ratificar lo dicho y sonríe)” (Madre, E5, L38),

encontrándose así en el proceso de transformar estas pautas transgeneracionales de sobre exigencia que, si bien le han posibilitado proteger a su familia, en especial cuando se enfrentaron a los acontecimientos del CAC, dificultan el reconocer como significativas funciones parentales emocionales que el padre sobre desarrollo.

Así como se evidencia el relato emergente que da cuenta de cómo la madre ha comenzado a flexibilizar el vínculo con su tercer hijo desarrollándose una transformación en la función parental emocional ejercida por ésta, en donde se reconoce y se valora al tercer hijo permeando las relaciones fraternales en pro a relaciones más generativas desde el diálogo, al mencionar:

“... Por ejemplo que día l, no sé si fue A, uno de ellos le dijo que era un bobo, entonces es le dijo a mí no me vuelvan a decir así que yo no soy un bobo ac, entonces yo les dije que él no era ningún bobo, que eran hermanos, que dejaran de tratarse así, si usted quiere decir algo, pues dígalo sin rabia, pero no lo trate así porque él se siente mal, a usted le gustaría... fue A P ...No, yo siempre AAA cállese la boca y ya, pero esta vez sí, como que les explico..."(Madre, 40 años, E5, L147).

Es así como se comienza a gestar la apertura de la madre hacia el cambio de la dinámica relacional en donde se privilegian espacios físicos, en común para los diferentes miembros de la familia, que generen acercamiento entre ellos. Y se comprenden variaciones respecto a las pautas de comunicación en tanto la madre se permite usar un lenguaje más apreciativo para realizar orientación a sus hijos, generando apertura al cambio de la dinámica relacional entre ellos.

Por lo que durante el escenario 6 se evidencia como mediante la construcción del 
familiograma, por medio del dibujo como estrategia artístico terapéutico, se permitió la posibilidad de que la madre escuche a su tercer hijo y a su vez este pueda expresar su sentir de una forma más clara a nivel digital, facilitando que esta pueda resignificar los mensajes digitales y analógicos que sus hijos les transmiten, potenciando sus funciones parentales a nivel emocional:

“De la parte del genograma II pues ahí nos dimos cuenta que:: quien estaba más cerca de quien, como que le disgustaba del uno, que porque le molestaba al otro, de pronto había alguno de que se agredían de pronto de palabras y eso de pronto digamos le molestaba a él, que de pronto le dijeran a veces digamos sin querer le dice uno hay usted es un tonto $F$, o usted es bobo, usted no sabe [jajaja] como tratar de no, darle la oportunidad de demostrar de que si sabe que si puede, entonces nos ayudó a nosotros como a nivelar los caracteres" (Madre, 40 años, E6, L783).

Estos cambios a nivel de comunicación y función parental se identifican también durante la estrategia artística del collage de la red de Sluzki, en donde la madre muestra cercanía con sus hijos a través de una interacción caracterizada por la escucha y trabajo conjunto, al mencionar la madre:

"Organice el circulo allá (JP con ayuda de A corta la lana y la coloca sobre la cartulina) eso, eso (Entre todos dan forma de círculo a la lana) esta como cuadradito ahí (I señala una parte de la lana) trátelo de poner como redondo, mire (JP realiza las correcciones que I le indica) eso papi” (Madre, 40 años, E5B, L44).

En donde la madre se moviliza a escuchar la opinión de sus hijos posibilitando una participación más activa de estos y acompañándolos para que establezcan acuerdos entre ellos. Se observan cambios en los miembros del sistema familiar evidenciándose en el lenguaje digital 
y analógico entre ellos, especialmente en la madre. Además, la madre realiza distinciones en torno a la forma como ejercía su rol parental normativo y como activar estar redes de apoyo del contexto religioso le han permitido comprender otras formas de ejercer este rol al mencionar observando el collage de la red de Sluzki:

“...si yo necesitara un consejo acudiría a mis pastores, aparte de ser mis pastores son muy buenos amigos cercanos para mí, porque generalmente ellos me han ayudado mucho, en muchas etapas (I sonríe) en muchas cosas que digamos yo a ellos les pegaba muy duro, (I sonríe) muy duro y peleaba los gritaba demasiado, entonces ya con mucha, sin meterse mucho en mi vida ni nada, sino como con esa forma toda bonita, me decía no pues así no, si usted los grita ellos no le van a mover, mire hágalo de esta manera decía” (Madre, 40 años, E5B, L 1319),

posibilitando así otra comprensión respecto a que la madre no tenga que acudir necesariamente a los golpes para ejercer su autoridad.

Surgen variaciones respecto a las pautas de comunicación con el subsistema fraterno, en donde se posibilitan espacios de conversación apreciativos y asertivos, al mencionar:

"Entonces pues eso ha ayudado también a que ellos también se suelten ellos también muestren lo que ellos quieren tomar, por ejemplo, tener en cuenta lo que ellos opinan, por ejemplo, hay la loza que hay que lavar, sería bueno lavar la loza los dos, entonces sí, colaborarles, porque por ejemplo hoy, hay venga, venga ayuden a arreglar [jajaja] el uno arreglaba el otro miraba y ahí ayudábamos, entre todos lo hacíamos" (Madre, 40 años, E5B, L1430),

lo que genera una gran apertura a confiar en sus hijos y al diálogo apreciativo.

Se comienzan a reconocer relatos emergentes que dan cuenta de los cambios en la relación 
parento filial, especialmente donde la madre ha generado transformaciones en la forma como impone las reglas y las hace cumplir, y en donde el padre es narrado por los hijos desde una posición más presente sin dejar de lado su función de nutrición relacional ya que mencionan:

“Que el día que mi mamá se fue, mi papá ese día llegó temprano, cogió y dijo ay vamos al parque y fuimos $P$ ” (Tercer hijo, 13 años, E6, L739), haciéndose evidente como el tercer hijo se permite expresarse en mayor medida. Por lo que los hijos reconocen cambios a nivel familiar "El de compartir PP” (Tercer hijo, 12 años, E6, L725), “porque mi mamá nos ha dado más confianza, y nosotros hemos aprovechado esa confianza que mi mama ha dado ac y hemos dejado la idea de:: estar peleando, ya no estar así peleando entre nosotros $P$ Le ya nos hemos estado comportando mejor, y::”(Segundo hijo, 13 años, E6, L743),

invitando a reconocer como la madre permite mayor espacio a la función de nutrición emocional.

Es decir que a partir de la comprensión que realiza la madre sobre la construcción de una nueva forma de relación entre ella y el subsistema fraterno basados en la confianza, se identifica el cambio que permite el desarrollo de la autonomía de los hijos, en tanto se comienza a evidenciar que, desde la transformación de la narrativa dominante y la emergencia de nuevos relatos, el sistema familiar reconoce que su interacción se ha transformado:

"Como la confianza, yo creo que ellos les faltaba que yo les diera esa confianza, esa oportunidad de demostrar que si pueden, de pronto (I mira hacia el techo y el horizonte derecho, ) yo no les daba esa oportunidad de comportarse, digamos como que de la autoridad sobrepasaba por ellos y era lo que yo dijera, entonces no les estaba dando como ese campo para que ellos demostraran que si podían, pueden entregar -..- (JP se retira la cobija de las piernas y abriga a M)" (Madre, 40 años, E6, L38)

Los cambios presentados en la posición jerárquica al interior del sistema familiar se hacen 
evidentes en una nueva pauta de interacción que parte desde la confianza, posibilitando la emergencia de relatos que podrían terminar configurándose como dominantes al facilitar la expresión verbal y emocional de los miembros de este sistema. Igualmente, al presentarse una transformación al interior de la estructura familiar, en donde la hija deja de tener un rol parentalizado y asume su rol y función como hermana mayor que apoya a sus padres en el cuidado de sus hermanos no desde la responsabilidad y el poder sino desde el ejemplo:

“y L, yo digo que L porque generalmente ella va más adelantada (I y T3 se miran) lleva más terreno y pues ese es el ejemplo de que ella les ha mostrado de qué es una niña que estudia, que no ha cogido malos ejemplos (JP y S juegan con $M$ en el piso detrás de T3) malas compañías, porque es el ejemplo que ella les ha dado)” (Madre, 40 años, E6, L671), mientras que el padre es reposicionando por su esposa a su mismo nivel y asumen la responsabilidad del hogar de manera conjunta, quedando el subsistema conyugal en una posición superior a la del subsistema fraternal, como responsables del cuidado, protección y apoyo de sus hijos:

"No, no, seriamos como los, nosotros somos como los hombros (I mira a T3 y se toca los hombros) que van teniendo a esas:: a ellos, sería como nosotros como le daría la ayuda de ellos para la fortaleza de ellos para que -..- P Sea como ellos quieran ubicarse:: pero nosotros ser el apoyo de ellos” (Madre, 40 años, E6, L668),

lo que permite que la identidad de cada uno de sus miembros sea vista desde el rol esperado y no del que se había asumido, posibilitando la significación de las experiencias desde este nuevo rol.

Lo cual se potencia con el hecho que el sistema familiar reconozca una red de apoyo amplia en el nuevo contexto en el cual se encuentran luego de haberse enfrentado a estresores no normativos externos y ambiguos, surgiendo un relato alterno que transforma su relato de 
protección del estar solos al identificar que existen amigos, familiares y grupos con las que cuentan para enfrentar las diferentes vicisitudes en su presente y a futuro:

“Pues la red, imagine yo decía que estaba sola, que nosotros estábamos solos aquí en esta ciudad, llegamos solos, si fue verdad, llegamos solos (M grita) ay no más (I le dice a M) llegamos solos pero al darnos cuenta, al ir construyendo esa red, nos fuimos dando cuenta de que a pesar de que tenemos problemas en nuestra familia, hay una familia que está allí, al pendiente de una ayuda para nosotros, a pesar de que hay cosas en ellos, en la familia de mi esposo y en la mía, pero así sea por parte mía ellos nos ayudan, así sea por parte de él están ahí, para apoyarnos, que en el camino, teníamos amigos atrás que también estaban ahí, si nosotros acudimos a ellos también estaban dispuestos a escucharnos, ayudarnos, que en el camino que fuimos conociendo personas que también aportaron para nuestra para salir adelante, para ayudar tanto para ellos como para nosotros" (Madre, 40 años, E6, L785).

Además de poder identificar cambios en la experiencia vivida a partir de las transformación de la experiencia narrada, permite la emergencia de nuevos relatos que dan la posibilidad a esta madre de transformar su interacción al momento de "soltar" o resignificar aquello que le genera malestar y entorpecía el desarrollo de sus interacciones y vínculos significativos y poder acercarse a estas personas desde el amor, cuidado, apoyo y orientación, escuchando las voces, sentimientos y pensamientos de cada uno de ellos. Emergen nuevos relatos que resignifican como se ha gestado la relación parento filial en tanto se hace evidente cómo los eventos no normativos de violencia tanto a nivel familiar como social generaron malestar en la salud mental de la madre llevándola a generar relaciones rígidas de sobreprotección con sus hijos que obstaculizan su desarrollo: 
“Todo eso ya fueron cambios que quedaron ahi $F$, y eran cosas que de pronto nunca se hablaron si no que se tuvieron ahí guardadas y eran miedos que -..- P eran demonios iban ahí guardados ahí, nunca se hablaron simplemente como que yo quise tomar, tomar el:: ser la cabeza de ellos y protegerlos a ellos, y a la vez de protegerlos era imponerles, no con la intención de quitarles los sueños a ellos si no como una protección, de pronto no lo hacía bien, porque ponerme encima de ellos, mis miedos, mis temores, no les daba la oportunidad a ellos de" (Madre, 40 años, E6, L763).

Es decir que al ser consciente de esta relación se permite expresar su experiencia vivida desde una narrativa más posibilitadora y se apertura a la expresión de sus emociones y sentimientos de mayor satisfacción en relación con su nuevo entorno.

Es decir que las estrategias artístico-terapéuticas le permitieron a la madre visualizar la manera como su familia se estaba relacionando y desde allí el escuchar de una manera más apreciativa a su familia para así acercarse más a ella posibilitando mayor acercamiento entre sus miembros "me permitía saber a mí que era lo que ellos querían, como, como se querían ubicar, como pensaban, entonces ahí ellos como que, con todas las maneras ellos hablaban lo que ellos deseaban, (T3 asiente con la cabeza)” (Madre, 40 años, E6, L804), así como le posibilitaron el reconocer las voces de sus hijos en relación con las propias:

“Y al terminar por ejemplo el cambio de los cuentos decía JP que pusiera una ternerita, dos cabritas, y una ternerita, entonces decían ellos como que No, en ese tiempo éramos los dos, A era una bebe, no la metían ahí porque como que era muy chiquita (T3 señala a M) si como ella, entonces los que brincaban de palo en palo eran ellos, entonces ellos dijeron inmediatamente estos somos nosotros, pero A no puede estar ahí, porque ella no estaba así como para compartíamos nosotros, dieron como a saber cómo lo que eran ellos, y ya pues 
le cambiaron la una a la otra la ternerita la chiquitica (I sonríe) no hacía mayor cosa si no ahí, lo mismo que hace M ahorita, entonces ahí como que plasmaron sus ideas cada uno, y plasmamos, porque generalmente yo también plasme mi idea" (Madre, 40 años, E6, L805).

\section{Yo quiero un padre amoroso, pero prefiero al hombre de corbata}

Durante el desarrollo del primer encuentro, se identifica la dificultad para establecer acuerdos y así solucionar conflictos a nivel del subsistema conyugal en tanto no se dialoga frente a las diferencias que se presentan entre los miembros de este subsistema, encontrándose latente un relato dominante familiar en donde el "ser organizado" representa gran importancia para la madre descalificando así al padre, delante de sus otros hijos, quien tiende a vestirse y organizarse de una manera distinta a la esperada por la madre, mencionando los hijos menores "porque era desorganizado, dejaba los zapatos, por allá tirados" (Tercer hijo, 12 años, E1, L846) "No como un indigente, solo le decía eso (la mamá se sonríe como apenada, tocándose la cara con la mano derecha y escucha atentamente)" (Segundo hijo, 13 años, E1, L851).

Así mismo se evidencia como este mismo relato dominante genera conflictos en la relación entre la primera hija y el padre y que a su vez los distancia "Que |, que mi hermana mayor, no le gusta que sean desorganizados. Y él es desorganizado, a veces” (Tercer hijo, 12 años, E1, L868).

Durante el segundo encuentro se reconoce una comunicación a nivel familiar permeada por mensajes doble vinculares emitidos por la madre hacia el subsistema fraterno que desdibujan la figura parental del padre, generando una demanda que posibilita tensiones en la relación padre hijos, ya que por un lado se reconoce un relato dominante referente a un padre "perezoso" y poco "responsable" al no cumplir con las expectativas de la madre respecto a ser un hombre 
organizado en su vestir y en su vida personal, así como sentir poco apoyo a nivel de los que haceres del hogar, lo cual es manifestado desde las voces de los hijos "que sea responsable con su ropa” (Cuarta hija, 8 años, E2, L484) "O sea se refieren a las cosas de la casa, JP: y del trabajo" (Tercer hijo, 12 años, E3, L90), y por otro se reconoce esta postura contradictoria con relatos de la madre en donde expone este es una persona "trabajadora" y es debido a su alta carga laboral en construcción que requiere de grandes espacios para el descanso:

"yo siento que el todo el tiempo lo coloca como una persona floja, lo que pasa es que el aquí no se amaña, él es muy trabajador, y ellos siempre lo mencionan que mi papá la pasa durmiendo [Risas] pero pues el si se acuesta a dormir" (Madre, 40 años, E2, L454), "pero es porque está muy cansado, el trabajo de construcción es demasiado agotamiento, entonces por eso ellos dicen que acostado” (Madre, 40 años, E2, L456),

lo que genera especial malestar en el tercer hijo quien se encuentra en alianza con el padre y excluido de la alianza de la madre y los demás hijos: "no que va” (Tercer hijo, 12 años, E2, L485).

De esta forma, la comunicación doble vincular de la madre reafirma la posición periférica del padre sintiendo el tercer hijo ese distanciamiento en contraposición de su deseo de estar cerca al padre, quedando excluido del sistema, y reafirmando una alianza entre la madre y el segundo hijo. Es decir, que los relatos alternos son expuestos por el tercer hijo, pero como su voz es acallada por el sistema “(JP hace aclaraciones pero no logran entenderse)" (Tercer hijo, 12 años, E2, L488), y es durante el proceso conversacional que se permite expresar que el que su padre cuente con un alto nivel de carga laboral no permite que cuente con espacios para compartir con ellos y por ello busque descansar en gran medida "llegaba a las 12, tenía que salir hasta las 3 de la mañana, llegaba a la 1 de, dos de la mañana...” (Tercer hijo, 12 años, E2, 
L496) y no porque sea una persona "perezosa o poco responsable". A su vez, estos mensajes doble vinculares cobran mayor sentido en el sentimiento de la madre, quien especialmente reclama la ausencia del padre, al este quererse desplazarse para donde su familia extensa, dejando de ser realmente un apoyo económico para la familia "yo digo que ellos es como más, no... lo visiono más yo, que ser responsable es como digamos que él se aparte porque él es muy... todo es la mamá, si la mamá le dice”" (Madre, 40 años, E2, L508).

En tanto en la historia familiar al parecer se han presentado varios acontecimientos en los que el padre decide volver a donde su familia extensa luego de conversar especialmente con su madre, situaciones que desequilibran a su esposa especialmente y así a sus hijos, en tanto desde el relato dominante familiar referente a que el padre prefiere a su familia extensa que a la familia que construyó con su esposa, se descalifica nuevamente su posición y el sobre involucramiento del padre con miembros de su familia extensa (mamá) interfiere en el desarrollo de sus funciones parentales y conyugales:

"si la mamá le dice muévase el deja toda a su familia votada y corre para donde su mamá, incluso eso fue lo que hizo y ya va (no se entiende) la mamá le dice véngase ya y él coge su ropa y se va, entonces lo que él quiere, lo que yo digo que él quiere es que se aparte un poco más de su familia y se acerque más a nosotros y nos veamos más (M empieza a llorar, JP se acerca intentando calmarla, el llanto atraviesa el siguiente fragmento dificultando la escucha y transcripción de las voces)" (Madre, 40 años, E2, L511),

mostrándose más una demanda de la madre por la ausencia del padre para generar cercanía con éste y de éste con sus hijos. Además de reconocerse el relato dominante familiar relacionado al que no cumpla con las expectativas a nivel económico que la madre tiene para poder vivir de mejor manera con sus hijos: 
"con todos, realmente él a veces se conforma con mandarles para que sobrevivan, porque pues yo le digo a él, cien mil pesos es para sobrevivir no para vivir ni para mantenernos bien, entonces él les manda para que sobrevivan y ya cuando llama solo dice cómo está, cómo está, cómo están, cómo estas no les dice qué quieren, me extrañan, les hago falta ustedes, a ustedes les gustaría que yo estuviera con ustedes, voy a (no se entiende) y ya voy por ustedes o ustedes me hacen falta, solo es cómo está, cómo está, cómo está ... entonces yo le digo a el que se aparte de lo que tiene allá y que se posicione en el hogar" (Madre, 40 años, E2, L513).

La madre en alianza con los hijos ven al padre con traje de paño, denotando un relato dominante en el que se espera ver al padre y esposo en traje de paño a pesar de que este no se sienta identificado con dicha imagen, en tanto se relaciona con el hecho de poder cumplir con las expectativas de tener un hombre en casa organizado, con mayor posición social y que así pueda contar con un mayor tiempo para la familia:

"porque yo lo, bueno yo a mí siempre me gustaría dibujarlo con traje de paño porque yo lo ubico ubicaría en un buen empleo, yo te decía" (Madre, 40 años, E2, L591), "En traje de paño bien organizado, por ejemplo como un celador sacarlo de la parte de construcción porque no digo que sea malo, sino que es algo es un trabajo muy duro, un trabajo muy agotador y quita mucho tiempo, en cambio allí pues yo lo visiono con más tiempo para nosotros y al lado de nosotros, bien organizado" (Madre, 40 años, E2, L596),

sin ser la voz del padre escuchada y solo interpretada por el tercer hijo, quien es el que expone cómo en realidad a su padre le gustaría verse, en contraposición al relato dominante de sobre exigencia, pues vestido normal" (Tercer hijo, 12 años, E2, L589). Por lo que se comprende que la baja comunicación en el subsistema conyugal permea la del subsistema parentofilial en donde 
algunos de los hijos terminan solicitando las mismas sobre exigencias de su madre hacia su padre.

Durante el desarrollo del álbum familiar y en el proceso conversacional de las páginas que la familia construye de las reflexiones del encuentro $2 \mathrm{~B}$ se apertura cambios en torno a variaciones respecto a las pautas de comunicación y en la interacción, desde espacios de mayor comunicación en el subsistema parento filial, que posibilitan a los hijos y el padre tener un mayor nivel de intercambio de ideas, en donde cada miembro de la familia se permitió preguntar a los demás cómo se visualizan a futuro, facilitando reflexiones en torno a la importancia de ser conscientes de las expectativas de los otros para co-construir la prospectiva vital familiar, generando además cambios en la posición y actitudes de los miembros, en donde los miembros se permiten una mayor escucha entre sí:

“Donde dejaste [], igual que S. ¡Listo!, pero ven una pregunta |, ¿ustedes tres le preguntaron a su mamá y a su papá que querían? (Terapeuta, 27 años, E2B, L172), Sí. (Tercer hijo, 12 años, E2B, L173), Si. (Segundo hijo, 13 años, E2B, L174), [] (afirma con la cabeza) (Cuarta hija, 8 años, E2B, L175), ¡Ah! y ¿tú le preguntaste a tu papá que quería él? (se dirige a S y luego a JP), ustedes también., (Terapeuta, 27 años, E2B, L176), Sí también. Primero respondió una cosa y luego respondió otra cosa” (Tercer hijo 13 años, E2B, L177). Sin embargo, durante la construcción de la escultura familiar del futuro se hace evidente a nivel conyugal la posición jerárquica de la madre y la posición periférica del padre, aunque en ese momento no se generan movilizaciones en estas posiciones dominantes, al auto descalificarse el padre frente a su poca experiencia y el contar con una familia con una alta nutrición emocional a diferencia de su esposa:

"No pues doctora lo que dice ella, pues ella tiene, como le digo yo (dirige mirada a T3 y 
luego a la ventana y luego a T3) Ella tiene mejor forma de expresarse que yo, porque ella, ella ha andado más que yo (empuña la mano derecha y la golpea a la palma izquierda). Porque yo, pues toda la vida mía la pasé fue con mis papases, ya trabajando, porque él trabajaba en fincas, fincas (I asiente con la cabeza). En cambio, la vida de ella (señala a I, quien asiente con la cabeza). No. Porque ella me lleva, como más avance, que yo, yo la pasa todo el tiempo en el campo y estudiando y trabajando allá con mis papás, pero en cambio a ella le ha tocado ya muy duro, (señalando a I) ella ya ha recorrido harto, o sea a venido acá en Bogotá, ha trabajado por otros lados y todo eso | (3 seg)" (Padre, 33 años, E2B, L883).

Mostrándose a su vez la disonancia entre las expectativas de la diada conyugal y la manera como la hija mayor percibe dicha relación. Reconociéndose así una relación complementaria en donde la esposa es quien tiene el poder y el esposo se ajusta a las expectativas y proyecciones de ella "no pues (| -3 seg -murmurando no se entiende) pues ese es el sueño de ella que de pronto más adelante me vea que de pronto yo avance digamos de pronto ser un arquitecto o un que un maestro avanzado" (Padre, 33 años, E2B, L724), para así cumplir el mandato familiar de las altas expectativas a nivel laboral, siendo difícil para él esposo el expresar verbalmente lo que realmente desea a su familia, buscando por ello escapar e irse a donde su familia de origen en algunas ocasiones al presentarse dicha situación. Comprendiendo aspectos de vulnerabilidad como la falta de trabajo, la ubicación y las condiciones de la vivienda actuales.

Se hace evidente nuevamente la alianza entre el tercer hijo y el padre en el momento en que este hijo menciona: "ella siempre lo desconoce" (Tercer hijo, 12 años, E2B, L777), lo cual invita reconocer como las disonancias a nivel conyugal permean las funciones parentales, ya que los hijos quedan en medio de no solo esta contradicción, sino también de las diferencias entre los proyectos a futuro de la diada conyugal, lo cual potencia un desligamiento a nivel conyugal 
desde una baja cercanía afectiva y emocional, quedando los hijos en medio de la confusión entre observar un padre trabajador y una madre que lo descalifica por ello al no cumplir las altas exigencias a nivel laboral y académico de su familia de origen "lo que ella quiere es que yo o sea consiga avance en un empleo mejor, si me entiende" (Padre, 33 años, E2B, L766).

Situación que ha sido leída por el tercer hijo, quien se ha convertido en el síntoma como manera de hablar del malestar que la familia vivencia. Sin embargo, al presentarse una baja comunicación a nivel conyugal el padre comprende que las exigencias de la madre se refieren exclusivamente a un nivel económico que al de la configuración identitaria del ser hombre, "pues ahí si toca... trabajaríamos más entre los dos" (Padre, 33 años, E2B, L772) "no pues por el momento estoy yo, estaba desempleado, pero ya gracias a dios ya entré a trabajar (llanto de la bebé, no deja entender)" (Padre, 33 años, E2B, L773).

De otra parte, se comprende además que las dificultades que se presentan en las funciones parentales influyen en el desarrollo de una conyugalidad armoniosa, en tanto no hay claridad en los límites de la función conyugal y parental, al parecer se sobreponen sus funciones de ser padres a las de ser pareja incrementando las actuales tensiones que vivencian a nivel conyugal:

"Pues eso les digo a mis hijos, si, pues porque ustedes no están acá porque simplemente fue porque llegaron, no, yo generalmente, yo sí deseé, toda una vida un hogar. Me gustan muchas actitudes de él, muchas, que muchas personas no la !tienen;, que incluso no las encontré en el papá de mi hija, pero en él las encontré porque él tiene cosas muy bonitas, y hoy en día un padre, que se ponga a jugar con un niño, a la mismo nivel de un niño, no los hay, uno no los encuentra"(Madre, 44 años, E2B, L8889) "Pues, pues porque, pues por mis hijos doctora, yo si por hijos, yo mejor dicho, sino lo que pasa es que..." (Padre, 33 años, E2B, L899). 
Así mismo, se presentan acontecimientos, situaciones en donde se presenta una baja demanda laboral, sumadas al relato dominante de sobre exigencias maternas que llevan al padre a alejarse del hogar y ser leída por la madre como un abandono a su familia:

"No, con mi esposa doctora. (T2 interrumpe para manifestar ya van a ser la hora de cerrar el lugar) | (3 seg) Si, sino que pues el inconveniente ahorita es porque yo me quedé sin trabajo doctora y pues yo me desesperé mucho acá, yo busqué, fui a hartos lados y todo y no consegui trabajo así digamos, pues conseguía uno o dos días, y eso así no me sirve” (Padre, 33 años, E2B, L905).

Para el cuarto encuentro, escenario tres, se identifica un proceso de cambio en la ampliación de las fortalezas y soluciones que el mismo sistema encuentra en la relación a sí mismo y otros, ya que se da la apertura a disminuir las tensiones al interior del subsistema conyugal visibilizándose proyectos a futuro que comienzan a posibilitar el afianzamiento y fortalecimiento de la relación, en tanto a nivel de comunicación se apertura espacios para intercambiar ideas y sentimientos, posibilitándose un equilibrio en la jerarquía interna, que a su vez permite que se lleguen a acuerdos para solucionar los conflictos y tomar decisiones, lo cual se posibilita desde el momento en que la esposa logra movilizarse y permite así la reconfiguración del vínculo conyugal en pro de una relación conyugal más armónica, desde relatos emergentes:

"Si, incluso le dije yo que me gustaba la idea de que pusiera él... el horno, yo le dije mire usted puede poner el horno, compra usted la olla grande yo sé hacer los tamales, usted lo sabe hacer, pues ponemos una venta de, el mismo muchacho los, yo los promociono aquí porque en el Tolima uno los hace muy bien, y ponemos una ventica y de ahí arrancamos le dije yo usted por un lado, yo por el otro, ambos en el mismo empleo, yo creo que pues usted sabe que lo duro ya es conseguir el sitio donde ponerlo más abajo, más en el centro le..." 
(Madre, 40 años, E3, L52), “Si, si, si exacto. Entonces yo le digo tanto ponemos la mía y la suya y ahí hacemos algo entre los dos, cuando usted se quede sin ese empleo ya tenemos la otra y ya no nos quedamos tanto, como que bregando para los muchachos, [balbuceo bebé] le dije de todas maneras tenemos que pensar que L ahorita entra una la universidad eso no va a ser barato, cualquier pesito vale... (va moviendo la mano izquierda)" (Madre, 40 años, E3, L54).

Así mismo se apertura mayores espacios de escucha que posibilitan el llegar a acuerdos para tomar las decisiones en el subsistema conyugal, flexibilizándose la jerarquía interna, al surgir un relato alterno en el que la madre comprende como el mandato familiar materno de sobre exigencia genera tensión en sus hijos y en especial en su esposo:

"Pues yo comprendí que, que tenía que dejar de poner más que todo mi autoridad, que siempre ha sido mi autoridad por encima de todos, a pesar, L ha sido una niña muy obediente en todo sentido, pero siempre se ha hecho mi autoridad por encima de ella, y lo mismo ha sido con todos los niños, con todos siempre he sido siempre mi autoridad, con E que es uno de los que más, más le he exigido, [risas] (sube la mano derecha con la palma hacia afuera cierra el puño y lo tensiona hacia abajo) porque es como más, pero que me ha pasado, que poniéndole la autoridad mía a él, (sube la mano derecha con el puño y lo tensiona hacia abajo) lo que he hecho es que lo he neutralizado (deja quieto el puño), y que se queda que no coge ni para allá ni para acá, (mueve la mano derecha hacia el lado y hacia el frente, moviendo su cabeza hacia los lados y subiendo los hombros) como que sale huyendo porque se ve como muy... como agobiado lo veo yo, (mueve la mano derecha hacia atrás tensionándola, con expresión de estar desubicada) esta vez al ver que yo ya no le exigí, si no que le pedí la opinión, entonces ya como que lo que me dijo lo dijo con más 
agrado que.." (Madre, 40 años, E3, L130), "Bajar más la autoridad” (Madre, 40 años, E3, L132).

Se comienza a gestar una dinámica familiar más afectiva a nivel del subsistema conyugal “Él pues, por ejemplo, ayer, ayer fue sorpresa, nunca me traía nada y ayer me traía galletas [jajaja]” (Madre, 40 años, E5B, L1420) “y más cariñoso" (Madre, 40 años, E5B, L1422), en donde la esposa desde una relación de confianza le permite no sólo a este sino al subsistema fraternal mayores espacios de autonomía e individuación, surgiendo nuevos acontecimientos que permiten que los padres tomen espacios para comunicarse sin estar en presencia de sus hijos, posibilitando un mayor acercamiento a nivel conyugal en sus funciones afectivas y emocionales:

"En la relación con él, si, si ha cambiado, por ejemplo, pues ya hay unos temas que hablamos, no se comentan a gritos como se hacían antes, no ya si hay cosas que son con él, porque no lo hizo, porque tal cosa, ya más íntimos, más intimidad, ya en ese sentido, ya si yo tengo algo que reclamarle en lo que, en la parte de nosotros ya lo hago con nosotros solos" (Madre, 40 años, E5B, L1418).

Finalmente en el escenario seis, encuentro ocho, se identifica que desde el proceso conversacional generado a partir de la estrategia de la escultura familiar del futuro desarrollada en el escenario dos b como una estrategia artístico terapéutica brindó la apertura para que desde la expresión de los intereses y opiniones de los miembros del subsistema conyugal en donde se ampliaron canales de comunicación, la esposa se reposicionará desde una mayor escucha al lenguaje digital y analógico de su esposo, a su vez que este logró expresar en estos mismos niveles su sentir, comprendiendo así la madre que éste experimenta ideas y sentimientos que guardan similitud con los suyo:

"Digamos me pareció la actividad digamos de cuando estuvo mi esposo, él se mostró lo que 
él quería, como que no conocía, yo no le había dado la oportunidad de demostrar lo que él quería, lo que él pensaba, entonces allí nos pudimos como que nosotros mostrarlo porque cada uno pensaba, y eso nos ayudó para que cada uno (JP se pasa por el frente con el balón en la mano) dijera no ey yo no quiero esto yo quiero esto, eso es, no es como usted lo quiere pensar si no como yo también pienso, yo también opino, yo también deseo, y los miedos no son solamente suyos, también son los míos, entonces nos ayudó mucho (I asiente con la cabeza sonriendo) mucho a tener en cuenta muchas cosas que nosotros no tenía” (Madre, 40 años, E6, L779),

disminuyéndose estos mensajes doble vinculares emitidos a sus hijos en donde le da la posición al padre amoroso del que se enamoró, y el hombre trabajador que busca brindar desde sus posibilidades y propios deseos un futuro para su familia; promoviendo un proceso de co construcción de una comunicación más apreciativa en donde se presenta un mayor nivel de comodidad en el intercambio de ideas y sentimientos.

\section{No quiero un padre para mis hijos, ni un esposo como mi padrastro, pero le exijo ser como}

él

Iniciando el proceso terapéutico, y a partir del desarrollo de la escultura familiar se pudo identificar que en este sistema familiar las reglas y las normas tienden a estar determinadas y controladas por la madre, exponiendo ésta que ella no cuenta con el apoyo del padre para imponerlas y además que él tiende a solucionar las responsabilidades de los hijos, cuando estos no le hacen caso:

"Eh, no. Nunca, es que generalmente él nunca. Porque a veces yo me voy a trabajar y lo dejo para que ordene y este pendiente y, la casa se vuelve un ocho (se ríe). Ellos no le hacen 
caso a él, él los manda y él es el que termina haciendo el aseo, el que termina haciéndoles de comer" [...] "Él es el que termina lavando. Porque ellos no le obedecen, yo estoy en la casa yo les digo, usted se me va, se me va a hacer el aseo del cuarto, usted se me va a hacer el aseo de la cocina, usted él de tal cosa, usted señorita se me va a lavar (mientras mueve la mano derecha). Y yo los mando a cada uno a hacer su oficio, a mi si me obedecen (se ríe) pero a él si no” (Madre, 40 años, E1, L541).

Cabe resaltar que, aunque el padre no suele ser quien imponga el orden y/o las normas en la casa, los hijos, y principalmente el tercero, tienden a reconocer una mayor cercanía con él, aunque la madre descalifica la relación al momento en que invalida la opinión de este hijo resaltando que ellos (padre e hijo) viven en constante discusión:

“Son muy apegados, pero, él (señala a JP) con el papá pelea mucho. Son muy apegados, él comparte mucho más con él (señalando a S), pelear, ¡no! él no discute con él, trabaja, o algo así, pero con él (señalando a JP) si discute harto, pero él es muy apegado a él (con su mano derecha empuja hacia adelante)” (Madre, 40 años, E1, L677).

Para luego, describir porqué es el cariño y el interés que los hijos tienen sobre el padre de forma que lo descalifica en el relato ya que este no les impone normas; a lo que el hijo aclara que con el padre tiene otro tipo de rutinas porque permiten sentirse más allegados a este:

“Ellos son felices con él. Y yo le digo a ellos, me voy a trabajar y ellos jbueno mi mamá se va a trabajar quedamos con mi papá! (subiendo la mano derecha y en tono de alegría) (se ríe la madre y la T3) pero porque saben que pueden hacer lo que quieran con él., mientras S, A se sonríen continuando en su juego con las manos y JP sonríe mirando a I)" (Madre, 40 años, E1, L681). "Nos saca a pasear, nos saca a jugar (lo dice mirando al suelo)" (Tercer hijo, 11 años, E1, L682). 
Para el segundo escenario, se empieza a configurar la narrativa dominante del padre como periférico, en el relato de la madre, resaltando que es ella quien determina e impone las normas y decisiones y acude a él para informar las últimas " [...] ; Generalmente todas las decisiones que yo tomo se las comento a él, él me dice siempre pues ay! (el ruido no deja entender con claridad) como que él me recarga a mí, yo le doy a conocer esto y eso, y me dice pues bien” (Madre, 40 años, E2, L329).

Aunque hay que reconocer que, la madre quisiera y espera que el padre asuma el rol como debe ser, es decir correspondiendo a la cultura patriarcal en la que el hombre debe "ser el centro, y el que mande en la casa" y tomar las decisiones para "toda la familia", aunque se invite a una complementariedad en el hogar, ella plantea que desearía que la simetría se invirtiera y estuviera a cargo de él:

“a mí me gustaría que fuera digamos (se acerca al dibujo), que fuera él quien estuviera en el centro y que él fuera el que estuviera tomando la decisión de toda la familia y sosteniendo un hogar bien, bien, tener una casa bien bonita y él tomando la decisión de todos en general, es lo que yo deseo de él y en un buen empleo” (Madre, 40 años, E2, L335). “En conjunto, pero digamos que fuera él que mandara en la casa, que él fuera el que dijera vamos hacer esto y bueno esto se hace así, con los, de igual manera pero que él fuera la cabeza de la casa (I mira a la terapeuta y recibe aprobación -con la cabeza-por parte de esta)” (Madre, 40 años, E2, L339).

Reconociendo que quisiera que él empezara a reordenar sus prioridades familiares, dejando claridad que "prefiere" a su familia nuclear, delimitando así las fronteras familiares de su familia nuclear "Claro es algo que yo también deseo que él se olvide que cada vez que la mamá le diga se tiene que venir él se olvide de todo, sino que él diga no yo tengo mi vida acá donde están mis 
hijos y mi esposa. Y yo no puedo pretender” (Madre, 40 años, E2, L513).

Es así como la madre convoca al padre para estar más presente en el desarrollo de su rol parental normativo, dejando de presente una creencia patriarcal relacionada con la posición privilegiada que debe tener el hombre al interior de la familia en la imposición de reglas, en tomar las decisiones para la familia, lo cual es connotado por la madre como el deber ser, visto por ella desde "el centro" y el que "mande en la casa". Lo anterior, debido a que la madre se siente recargada al tener que ejercer la función parental normativa sola ante la posición periférica del padre. Expresando la madre su inconformidad con la intervención de miembros de la familia extensa paterna, puesto que esta convoca al padre con bastante frecuencia, haciendo que se mantenga su posición periférica, según la percepción de esta.

Para el encuentro (escenario 2B) se pudo ya contar con la participación del padre y de la hija mayor, en donde se evidencia la falta de espacios en donde se puedan generar comunicaciones al interior de este sistema familiar, situación que es reconocida por estas dos personas al referir que la forma de relacionarse entre los miembros de este sistema, tanto antes como después del evento de desplazamiento, para conocer las vivencias cotidianas, su sentir y pensar se realiza de una forma diferente:

"no, yo creo que es como muy por partes ¿sí? yo digamos soy una persona que confió mucho ee en mi mamá ¿sí? yo a ella le cuento todo lo que me pasa y bueno ella... pero digamos que yo llegar y decirle de pronto a ellos (señala a E y los niños) venga tal cosa no, o sea no... y digamos como mi mamá tal vez es el núcleo que nos conecta si a todos, porque ee cuando los otros niños mami que tal cosa o pues que ellos hablan como pareja pero como tal de comunicarnos no, por mi parte noo” (Hija mayor, 17 años, E 2B, L530)

“cuando estábamos allá ellos estaba muy pequeños, ellos generalmente ellos eran en sus 
pescados en sus trabajo y cuando llegaba así a jugar” (Madre, 40 años, E2B, L536).

"pero pues generalmente como que siempre pues yo soy muy digamos de sentarnos todos en grupo y que hizo hoy qué le parece no, no generalmente está muy cansado viene se acuesta, come y ya, y si tiene tiempo viene y juega con sus hijos o si no se acuesta a dormir y yo termino muy agotada de lo del día con ellos y pues me acuesto a dormir y acuéstense y ya, pero ya decir que charlar de como están, no” (Madre, 40 años, E2B, L538).

Así como se evidencia un relato dominante en donde la madre descalifica al padre al manifestar que solo juega con sus hijos en ocasiones, manteniendo la idea de que se encuentra cansado siempre por el trabajo, tanto en el campo como en la ciudad, relato que se convierte en una justificación de la madre desde sus creencias patriarcales

"no con ellos si converso, ellos mamá llegan del colegio y les digo como le fue en el colegio, me dicen mamá tal cosa o no mami la profesora me dijo esto, ay mama sucedió esto ellos me cuentan en general así individual si” (Madre, 40 años, E2B, L540).

"Ellos le cuenta a la mamá porque yo como le cuento me la paso trabajando doctora como le digo yo salgo por la madrugada y llegó por ahí en la noche, entonces los días que me quedan así más o menos” (Padre, 33 años, E2B, L541).

"Más que todo es ella es la que maneja doctora porque yo casi ni les pego ni los regaño casi por eso porque yo la paso casi es trabajando y bueno pero los regaño y los casco ay veces los domingos cuando no estoy trabajando" (Padre, 33 años, E2B, L548).

Paralelo a ello, se identifica que tanto la madre como la hija privilegian el rol parental normativo de la primera, en tanto las decisiones tomadas en el sistema familiar terminan siendo decididas por ella cuando no se logren llegar acuerdos, a pesar de que en algunas situaciones haya involucrado al padre en la toma de decisiones al interior del grupo familiar, pero 
rápidamente lo descalifica indicando que éste no logra imponer y hacer cumplir las reglas en el sistema familiar, posición que es ratificada por el padre en tanto se auto descalifica él mismo y se justifica desde la creencia patriarcal familiar del rol de padre proveedor.

"Y si no hay acuerdos? pues yo no digo que siempre podemos estar todos pensando igual, pero... (Terapeuta 27 años, E2B, L568)

"Se hace mi voluntad” (Madre, 40 años, E2B, L569).

"Es lo que ella diga [risas]" (Hija mayor, 17 años, E2B, L570)

$$
[\ldots]
$$

"Yo he intente darle las reglas a él, de darle la ... sí como que él buscara (no se entiende) a sus hijos tomar decisiones porque incluso es agotador solamente una sola persona tomando decisiones para todo como le dije uno siendo papá y mamá es muy difícil entonces yo intente pero aquí él (señala a JP) perdió un año, aquí él (señala $S$ ) niño se metió en cosas que no debía y ...” (Madre, 40 años, E2B, L582) [...]

"Ahí me tocó volver a coger todo (con las manos señala como si estuviera cerrando un paquete)" (Madre, 40 años, E2B, L584).

“Qué opina de lo que dice la señora I" (Terapeuta 27 años, E2B, L585).

“Yo no sé doctora” (Padre, 33 años, E2B, L586).

"Pues lo que digo es que a mí me falta como digamos como autoridad con ellos ponerles orden (La señora I mira a su hija mayor L y empieza a realizar movimientos afirmativos sobre lo que está diciendo el señor E) (E2B, L588).

“También estar más pendientes de ellos porque paso en todo momento es trabajando y trabajando (Padre, 33 años, E2B, L590).

Ante esta invalidación constante de la madre hacia el padre, fue pertinente indagar sobre la 
situación actual de la pareja, pudiendo conocer, un relato privilegiado de la madre en el cual relaciona la estadía del padre en el pueblo de origen como una forma de privilegiar la cercanía con su familia de origen, alejándose de su familia nuclear. En donde ella espera que su pareja esté al lado de ella y de sus hijos, para mantener su posición dominante en tanto refiere que estando su esposo cerca de ella "me obedece más". En esto se refleja como la madre viene dándole una posición de hijo al padre:

"Pues de parte mía, yo no creo que estemos bien, eh yo como le comentaba a sumerce (E se mira las manos), él vive en Tolima y él quiere estar al lado de su familia (E mientras mira al horizonte cerca al lugar donde se encuentra I, mueve las manos), yo soy muy lejos de estar en mi familia, yo pienso un hogar no se estabiliza alrededor de una familia sino lejos de tanto de los padres del uno como de los padres del otro (mueve las manos subiendo primero la mano derecha y luego la izquierda, E corre su tronco hacia atrás). Porque dan a influenciar mucho la (), y un hogar así ¿cómo funciona? | (2 seg.) Eh no me gusta estar cerca ni de la mía (se señala) ni la de él (señala a E). Me gusta estar lejos, pienso yo que así funcionamos, como que, bueno el me obedece mejor, como que me lleva una serie de ideas, la demora es que se comunica que se desfocaliza de todo (une las manos hacia la izquierda y saca la derecha) y digo yo el amor que él siente por ellos es muy grande más grande, que su familia, digo yo, y coge y chao (da una palmada y sube la mano derecha), entonces a mí me llega un límite que le digo yo no "Si usted no coge las riendas de su hogar, si usted no me quiere colaborar, pues váyase", yo no lo puedo detener, yo le digo a él y le hago la semejanza de un perro que tenemos allá que es una fiera, yo no lo puedo a usted coger como el perro (pone sus manos sobre cuello, con expresión de molestia) y amarrarlo aquí al lado mío y de mis hijos (empuña las manos fuertemente y las intenta bajar como clavando algo 
allí en donde se encuentra), yo no puedo hacerlo, sino él quiere es estar allá y no acá, y yo no puedo amarrarme y obligarlo a que esté al lado mío y al lado de sus hijos cuando él lo desea (E se acomoda en la silla dirige la mirada al lado contrario donde está I, se sonríe, ubica su tronco hacia adelante y baja la cabeza, tosiendo). Esa es mi opinión, y yo siempre eh notado pues esa situación en él, de pronto sí, yo soy, muy demasiado autoritaria, en lo que, en qué sentido, si a él, en el aseo, en el orden, yo soy muy cansona en ese sentido, me gusta, que antes de cualquier cosa es que ande bien organizado, y no dependiendo del trabajo que tenga, pero que, el aseo, estando bien organizado, yo creo que porque tenga una esposa no es para que ande así, incluso un día le dije que se consiguiera otra para ver si yo lo veía bien arreglado (Se sonríe y E sonríe con su mirada dirigida al horizonte). Me encanta los hombres bien organizados, no sé porque me fije en él la verdad (se ríe señalando a E, quien se pone serio) pero él al principio él era muy organizado en su forma de vestir, en su aspecto, en todas sus cosas, y ya él ya se deja, es más desorganizado, entonces es más como una (con los puños cerrados los une y cierra) que atropella, y que se cansa, eh no sé, yo digo que me falta autoridad no en la situación de pegarles (cierra los puños y los envía hacia abajo), sino centrarle, porque siempre la autoridad del hombre es más que la mujer, es decir usted se hace esto, y se hace (mientras cierra los puños y los baja con contundencia), yo le digo, se tiene que hacer esto y él no me dice no (E baja la cabeza y se mira las manos), y no sé lo que usted quiera, lo que usted piense, y yo no quisiera que solamente se hiciera como yo pienso (E sube la mirada), yo también quiero que haga lo que él quiere (señalando a E), incluso yo les solté las riendas, y eso se volvió un caos, mucho (se riée). Entonces eso es. No sé, la verdad no sé (señalando a E)” (Madre, 40 años, E2B, L846). Sin embargo, en el proceso conversacional gestado a partir del desarrollo de la escultura 
familiar surge un relato alterno en donde el padre expone no se va para el Guamo a buscar a su familia, sino por la presión que siente debido a la situación socioeconómica que viven, estando su familia nuclear siempre de presente, el cual no es escuchado al encontrarse tan arraigado a la familia el relato dominante de sobre exigencia materno:

“(Se sonríe y voltea la cabeza en dirección a T3, mientras I baja la cabeza). Bueno doctora, lo que pasó fue que, pues, yo me fui, porque digamos acá, nosotros los dos acá, (dirige la mirada hacia la ventana y luego a T3) pues acá en Bogotá de todos modos estamos solos, nosotros acá no tenemos !familia;, pues a nosotros nos ha apoyado mucho la iglesia (rascándose la cabeza), pa que voy a decir que no, sino que por ejemplo, (señalando a I) la manera de ella es muy diferente a la mí (se señala a sí mismo), porque digamos la manera de ella (señala a I), los papases de ella los criaron diferente a los míos (se señala a sí mismo) ¿Sí?” (Padre, 33 años, E2B, L848).

"Entonces digamos que (dirige la mirada a la ventana como pensando), ac yo soy muy apegado a mis papás, y entonces (dirige su mirada al horizonte y se le entrecorta la voz) | (2 seg) (ubica sus manos sobre sus ojos, mientras se le escurren lágrimas) <> 44 seg (mientras I dirige su mirada hacia la ventana con expresión de desaprobación y vuelve ubicarla en el piso con el tronco hacia adelante).(E quita sus manos del rostro y se dirige a T3) hay no sé qué me pasa (vuelve a ubicar sus manos sobre los ojos, mientras y levanta el tronco sonriéndose y juega con la silla del lado izquierdo escondiendo su rostro) | (4 seg)" (Padre, 33 años, E2B, L850).

“(E toca su ojo, y ubica el tronco hacia adelante).O sea es bueno, yo me quedé sin trabajo doctora (sube el tronco y dirige su mirada al techo) yo me estrese mucho (dirige la mirada a T3 y se tapa los ojos, limpiándose las lágrimas) | (2 seg) entonces para mí que, yo me fui 
para Guamo, para allá| (2 seg) (mientras continúa sollozando y limpiándose las lágrimas) (Padre, 33 años, E2B, L854).

"Digamos que con los niños más que todo (ubica su tronco al frente) me coge como nostalgia, que de pronto se me pierde una cosa, y que tiene hambre, más que todo la niña (I tiene su mirada y cabeza hacia el piso), pequeñita, por ejemplo pa`el tetero de la niña | y entonces acá me coge un desespero, entonces yo por eso, pues ahorita, yo me quedé sin trabajo, fui a varios lados y todo eso, y no encontré trabajo, y lo otro que también pues yo me puse y hice los cursos, y pues yo fui a varios / lados y todo eso, pues por allá me salió trabajo pero por allá muy lejos, por allá en Suba, doctora (intercala mirada entre el horizonte y hacia T3, mientras continúa frotando el ojo derecho), entonces ella cogió a pelearme (señala a I), que pa 'que hacia esos cursos, que pa 'qué le hacía perder esa plata, pues yo me fui para allá| (2 seg) pues yo allá| (2 seg) trabaje 3 semanas y [...] (Padre, 33 años, E2B, L856).

“Si | (2 seg) O sea por acá, por ejemplo, acá doctora uno pa moverse para algún lado, tiene uno que tener para el transporte y si uno no tiene para un transporte pues lógico que uno no puede ir a trabajar, y al principio igual acá al principio nos fue bien, pues no todas las veces me ha salido trabajo bueno | (2 seg) [...] (Padre, 33 años, E2B, L858).

Durante el desarrollo de la escultura familiar y posterior a esta, el padre logra expresar lo que siente y piensa, reconfigurar la inconformidad de esta esposa, en donde él expone su angustia para cumplir con su rol de proveedor económico y garantizar las necesidades básicas a sus hijos ante la falta de trabajo llevándole esto a decidir regresar a su lugar de origen, sin que haya sido convocado por su familia extensa.

Así como se comprende que no se privilegian espacios para el diálogo entre los miembros 
del sistema familiar, y el diálogo a nivel del subsistema conyugal se coloca de presente, en algunos momentos, para encauzar el comportamiento de los hijos que no pueden ser controlados por la madre. Esto obstaculiza la posibilidad de que los miembros del sistema familiar puedan expresar lo que sienten y piensan y se generen espacios de cercanía entre ellos. Además, se comprende que la madre en su afán de mantener su posición de autoridad asigna al padre un rol de hijo y parentaliza a su hija mayor, a pesar de expresar constantemente su necesidad de que el padre se haga más presente en el ejercicio del rol parental normativo. Sin embargo, este padre sigue siendo objeto de descalificación por parte de la madre en su rol de padre, narrativa que finalmente es incorporada en el relato identitario del padre, para descalificarse a sí mismo.

Ya hacia el tercer escenario, se empieza a conocer un cambio en la interacción conyugal, que permite conocer la voz del padre desde la madre a través de la realización del álbum familiar, el cual brinda la posibilidad que la madre escuche diferentes voces y se de apertura a la emergencia de nuevos relatos e interacciones familiares:

"Sí, pero se me quedó, (se lleva la mano derecha al rostro en signo de preocupación) los muchachos no me lo echaron, lo hicimos con las niñas, los gordos, entre... bueno E no nos ayudó a hacerlo, él simplemente nos dijo pues que no nos ayudaba porque no tengo tiempo yo llego muy cansado, pero le dije yo, entonces cómo quiere que yo lo ponga, !yo lo puedo dibujar; pero cómo quiere que yo lo ponga, él me dijo pues póngame con un delantal, con un gorrito [risas] y yo le dije de qué color quiere, porque yo lo puedo poner azul, verde, pero si usted no lo quiere así, no pues póngame un color bien bonito, usted sabe que a mí me gustan los colores claros, y yo a bueno, pero yo después lo dibuje, le puse así, me dijo no quedo bonito, y cogió a reírse [se ríe] no quedo bonito, pero en si lo hicimos fue entre los muchachos" (Madre, 40 años, E3, L84). 
Ya para el cuarto escenario, se puede comprender la configuración de las relaciones parentales de este sistema familiar nuclear a través del dibujo familiograma; el cual nos permite conocer las pautas intergeneracionales que se producen y reproducen desde las familias de origen de cada uno de los padres. Con este ejercicio, se comprende una historia que configura el relato dominante de la madre en relación a la forma como se relaciona el padre y ella con sus hijos, en donde se muestran pautas de relación que dan cuenta de un padre amoroso y afectuoso que proviene de una familia de origen que provee una relación nutricional desde lo afectivo y emocional a sus hijos; y por otro lado, a una madre predominantemente normativa que proviene de una familia en la que se privilegiaba el "maltrato" por parte del subsistema parental hacia sus hijos. Es así como durante el proceso conversacional se hace evidente un relato subdominante en el que si bien la madre reconoce le gusta como el padre se comporta como "niño" con sus hijos, a diferencia de su padrastro quien era más violento, se encuentra inmersa en el dilema de la importancia de la sobre exigencia para mantener la autoridad sobre los mismos.

De esta forma se logra identificar una configuración de pareja fundamentada, según la esposa, en el priorizar las funciones de nutrición relacional y amor complejo sobre sus expectativas individuales orientadas al crecimiento profesional, en donde esta esposa configura la relación de pareja con un hombre a través del cual puede mantener el mandato familiar, ya que siente que no puede cambiar, y poder tener una pareja que le permita mantener su poder pero que sea diferente a la figura paterna en su familia extensa:

“Sí, que él [abuelo paterno]es como parecido a E, le gusta jugar mucho con lo hijos, no los regaña, es asemejado así parecido a E. Él le gusta, él es de los que les gusta jugar con sus hijos. Él, aunque están grandes, están viejos, y ellos lo alzan [risas] lo abrazan, él es muy, le gusta jugar mucho con ellos incluso con los nietos es igual” (Madre, 40 años, E4, L1045). 
"Esta cadena como de maltrato, claro, en mi casa yo decía desde muy pequeña que los veía a ellos que se peleaban tanto, que yo a mi papá no lo quería, y mucho menos viendo un papá maltratando, mi papá le pegaba mucho a Oscar de una manera terrible, él se desquitaba mucho con él, entonces yo decía que yo no quería eso, que yo no quería eso" (Madre, 40 años, E4, L1059). "Por eso es que le gusta tanto como su esposo trata a sus hijos, juega y se divierte con sus hijos (Terapeuta 27 años, E4, L1060). “A mí me gusta mucho en sí, a veces me saca la rabia, que es que no los regaña, pero en si él los trata bonito, pero el trata como de meterse ser un niño igual como ellos, sino que hay si ellos abusan de la confianza” (Madre, 40 años, E4, L1061).

Igualmente, en este escenario se empieza a transformar esta narrativa dominante de la descalificación del padre, en tanto la madre comienza a comprender desde el proceso conversacional que la forma como ella descalifica al padre en su rol parental delante de sus hijos tiende a ser uno de los factores que mantiene la relación conflictiva entre ambos padres, puesto que los hijos comienzan a involucrarse haciendo comentarios a la madre para defender a su padre:

“De pronto porque yo a veces le digo, hay usted parece es bobo ahí que si no le dice nada a los niños de pronto no (no se entiende) (Madre, 40 años, E4, L1067) "Y eso se lo dice delante de ellos (señala al genograma) (Terapeuta 27 años, E4, L1068) "Sí, yo le digo delante de ellos, yo no... yo me da malgenio, yo no reparo por lo que les voy a decir a ellos (señala al genograma y asiente con la cabeza) (Madre, 40 años, E4, L1069).

"Pues yo sí creo... | (3 seg-asiente con la cabeza)A qué día me pregunto, estaba yo regañándola, y me dijo "hay yo le voy a decir a mi papi que se consiga otra señora y que se valla conmigo" yo le dije porque usted es muy fastidiosa y usted no respeta a mi papi" 
[risas] yo le dije ay yo no estoy haciendo nada, su papá no hace caso, ¿porque no le pega? "Porque mi papá me quiere mucho" [risas] (Madre, 40 años, E4, L1075).

Así mismo, se identifica que este relato dominante sobre la descalificación y periferia del padre emerge cuando la madre demanda el ejercicio activo del rol normativo por parte de este, mediante el uso del castigo como una forma de hacer cumplir las reglas por parte del subsistema fraterno y como este tema es el eje central de la conversación a nivel del subsistema conyugal, ya que para el padre el castigo físico no es aprendido desde casa y para la madre fue parte de su desarrollo evolutivo. Surgiendo un relato subdominante durante el proceso conversacional en el que la madre comienza a comprender cómo el padre aprende a orientar sin necesidad de utilizar la violencia, y como su postura de sobre exigencia de su función normativa delante de los hijos descalifica al padre.

Comprendiendo esto desde un cambio a nivel de la ampliación de las fortalezas y soluciones que la misma madre encuentra reflexionando sobre su relación con el padre, enunciando relatos expresados por sus hijos que dan cuenta de cómo el lenguaje descalificador que ella usa para referirse al padre afecta la imagen que sus hijos construyen de él y modifica la pauta de interacción entre ellos, aperturandose a repensarse como la perciben sus hijos. Permitiendo así comenzar a gestar cambios respecto a las variaciones en las pautas de comunicación en tanto la madre comprende la diferencia en la forma como ella y el padre imponen y hacen cumplir las reglas al interior del sistema familiar, en tanto provienen de familias de origen con pautas de relación disonantes entre ellas:

"Digamos, que cosas... que le digo delante de mis hijos, por ejemplo, yo les digo hay usted tiene que pegarles, vea castígalos, cuando ellos le griten cásqueles (no se entiende) [risas]" (Madre, 40 años, E4, L1184) Sí, yo a ellos les digo, hay saque la mano y póngasela porque 
como va a ser posible que de que usted va a dejar de que ellos le alcen la voz (Madre, 40 años, E4, L1186) “Sí, porque si el papá [abuelo paterno] le llego a pegar a él dos veces, no creo que le haya pegado tres” (Madre, 40 años, E4, L1192).

Para el quinto escenario (sexto encuentro), a través de proceso conversacional se comprende el cambio evidenciando la emergencia de relatos novedosos en donde la esposa se apresta a dar cuenta de cómo ha superado "esos miedos" y ha logrado aperturarse para igualar la posición de su esposo para ejercer conjuntamente el rol parental de una forma diferente, permitiendo así que sus hijos se sientan más cercanos a ellos y la madre logra comprender, escuchar y respetar sus posiciones, construyendo nuevas posibilidades de relación entre ellos, con su contexto y con sus redes de apoyo, para enfrentarse a estresores normativos y no normativos:

"Sí, incluso como ya se fue la cuñada [] :.: entonces estamos durmiendo aparte con la bebe porque esta pequeñita PP, ya ellos están allá aparte l (1 segundo), y incluso yo le digo, le comento-..-, que A perdió 6 materias, -..- está de descanso valla, entonces él fue donde el profesor y le dijo que no quería hacer nada, y dijo es que usted toda la tarea me la pone a mí l (2 segundos) P, usted también me tiene que colaborar, es su hija" (Madre, 40 años, E5, L140).

Posibilitándose así, que la madre comprenda que este hombre amoroso de quien se enamoró al ser distinto a su padrastro puede cumplir sus funciones normativas no desde la violencia, sino desde sus funciones de nutrición emocional, y aun así desde una mayor flexibilidad en la jerarquía interna en el subsistema conyugal, lo que propicia la comprensión de las ideas y sentimientos de su pareja, representando un hombre que trabaja junto a ella en pro al bienestar de su familia. Lo que, a su vez, ha permitido que la madre pueda reconocer como sus miedos construidos a partir de la vivencia del CAC generaban o influían en gran cantidad sobre las 
disonancias a nivel conyugal, que se presentaban previo al proceso y legitimaban la narrativa dominante que la madre y el sistema familiar había construido sobre el padre:

"Sí, sí señora, se ha avanzado bastante, porque hemos superado como esos miedos que habían, ese miedo en mí, ya se ha, pues no del todo, todo, todo, pero sí ha bajado mucho, he aprendido comprenderlos, a conocerlos, a no imponerles tanto, como que no se les manda siempre, sino que, a ponerme también en el lugar de ellos, a ver sus deseos, sus cosas, a llevarlos y no ser yo por encima de ellos si no todos iguales, pero generalmente, siempre sin perder, el rango de cada uno, yo soy la mamá él es el papá, y cada uno, digamos tiene, como digamos entre los dos llevar la adminis, el hogar” (Madre, 40 años, E5, L248).

\section{Mis hijos pueden escoger lo que quieran ser, pero deben ser profesionales}

Al iniciar el proceso terapéutico, se pudo identificar la configuración de una narrativa dominante referente al estudio, es decir a la necesidad de que cada uno de los miembros fuera o estudiara una carrera profesional a futuro. Esta narrativa estaba orientada principalmente en los dos hermanos mayores (primer y segundo hijo) pero que, hoy en día también se encuentra relacionada con el cuidado de los demás hermanos, esto tiende a evidenciarse en la relación construida madre - primera hija:

“...Ella dice que no, que ahorita el pensamiento de ella no es tener nada de eso, quiere es estudiar y entrar a la universidad, ser profesional, eso le va a servir harto para poder darle estudio a sus hermanitos. Como que ella como que se (señala como si tuviera un costal al hombro y ubica el cuerpo hacia adelante), ella como que se pone mucho esa carga como de, como otra mamá” (Madre, 40 años, E1, L744). “...Siempre hemos sido, desde muy pequeñitos los he enseñado así, que usted ayude a cuidar la niña (señala a JP y a M) que 
usted ayude tal cosa (señala a A), que usted ayude en el colegio, "tenga ojo con la niña”, que esté pendiente que ninguna niña le vaya a !pegar;, que esté pendiente de uno. Bueno ahorita él está solo (señala a JP), me toco cambiarlo de colegio, pero generalmente el uno cuidaba al otro, incluso la grandecita que esta que sale, que está en un colegio en un salón más... (sube la mano)” (Madre, 40 años, E1, L914).

Igualmente, en el tercer encuentro (escenario 2B) se puede reconocer esta relación desde la voz de la hija mayor, en donde este escenario permite resaltar su voz, ya que es el único espacio que se puede contar con la participación de ella y del padre:

“Ee :: a a :., para mi si (se toca el pecho con la mano derecha), la verdad sí, yo sueño todos los días con ir a la universidad y pues por ahora está la carrera de derecho que es lo que más se acopla a mi gusto académico, entonces yo realmente, si en esa área, como tal”-...(Hija mayor, 17 años, E 2B, L199)

Igualmente, se piensa a conocer el porqué de la importancia de esta narrativa para este sistema familiar, principalmente la madre; quien reconoce aunque siempre quiso una familia coloca de ejemplo la situación en la que se encuentran hoy en día, e identifica la importancia de ser profesional para no caer en esa misma vivencia, además de resaltar que su primera hija ya interiorizó dicha narrativa pero que tampoco quisiera construir una familia por las mismas condiciones en las que ella ha crecido:

“... Mi sueño era tener una familia grande, pero no en las condiciones en las que estamos, pero si, los amo mucho, yo les digo a ellos que los amo mucho, quiero que ellos sean alguien, que no se queden digamos, yo tengo mi bachiller, pero no seguí estudiando, entonces quiero que ellos estudien, mi hija pues ya ha entendido todo lo que yo deseo, ella tiene en sus metas, que quiere estudiar, salir adelante. I Un poquito se ha dado como la 
cuestión de muy seria, en la cuestión de la vida personal, por ejemplo, ella dice que familia no, no desea tener hijos, que ella incluso adopta unos de los hermanos (se ríe), qué hijos no, nada que ver, por lo mismo que ella ve como bregamos para una cosa, para otra. Cuestión de esposo, nada que ver, ella dice que no, que en la casa tiene uno, entonces con ese es suficiente con el que tiene en la casa (se rie)" (Madre, 40 años, E1, L912).

Reconociendo a su vez, la superioridad del componente cognitivo sobre el componente pragmático y afectivo al momento de relacionarse madre con sus hijos, identificando que estos suelen ser un factor tensionante en esta relación, ya que para sus hijos - y por su ciclo vital- es muy importante:

“Si, además yo creo $S$, yo digo que S es muy tranquilo, y yo a él le digo, por ejemplo, le digo las cosas, y él las hace, las saca muy rápido, él es muy tranquilo, muy obediente. A veces yo, a veces yo pienso que yo abusó mucho de él, porque a veces yo le digo, vea $S$, ehh ayúdame aquí, S levánteme aquí, porque es como más obediente, en cambio a él (señala a JP) toca decirle muchas veces eh la lora, lora, hasta que haga caso (se ríe). Está prácticamente es con los del juego, ella es el juego, el juego (señala a A), yo a veces le digo mami, no hay que robarle el tiempo al tiempo porque tiene que ubicarse, tiempo para estudiar, un tiempo para que juegue, un tiempo para que haga lo suyo, y verá que no va a tener problemas, si le queda el resto de la tarde, pues para jugar, pues lo hace...” (Madre, 40 años, E1, L967).

Situación que tiende a relacionarse con que sus hijos no puedan expresar su opinión ante una madre autoritaria, que constantemente les ha hecho saber, a través de mensajes enviados por el lenguaje digital y analógico, el interés de ella porque cumplan los sueños de ella y no los propios, ya que no los conoce:

“[...] de pronto, si es verdad de pronto yo les pongo como mucho mi autoridad, y yo les doy 
a tocar, les doy a conocer que es lo que yo quiero, lo que yo deseo, pero pues si muchas veces me paso como de preguntarles qué quieren ustedes, que piensan ustedes, en eso no, digamos siempre he sido como le dije. !Yo soy la autoridad de la casa; y él es el juego, la recocha de la casa, y en entonces en ese sentido sí, es verdad, no, no les pregunto, y pues a veces en esas cosas que estoy discutiendo con ellos, pero dígame, entonces no me responden, yo le digo como que ellos me ven de mal genio, dirán ellos si yo le digo se va a !enojari ..." (Madre, 40 años, E1, L912).

A partir del segundo escenario, y en el desarrollo del dibujo de la escultura familiar se empieza a identificar la rigidez del relato de la madre que, aunque se da la oportunidad para escuchar la opinión de sus hijos, deja claro el interés y deseo que sus hijos salgan adelante cumpliendo el sueño de ella:

"Y pues a mí me toca pues llevarles la idea, porque tengo muy claro que ellos tienen diferencias parecidas y yo no puedo, como le digo como le digo con la hermana, yo no puedo pretender que ustedes sean igual que ella, porque ella tiene su forma de ser y ustedes tienen tienen la suya, pero generalmente me gustaría que entre esos gustos que ellos tienen que entre esos deseos haya algo de lo que yo quiero (Madre 40 años, E2, L413) "Si ahí esta es la visión de cómo yo los deseo a ellos, estudiando y yo trabajando (Madre 40 años, E2, L417) "Pues la verdad no lo puse así porque no puse como ellos se verían yo los puse a mi manera no más, ya después ellos se pusieron a la forma, le agregaron lo que le hacía falta trabajando (Madre 40 años, E2, L419).

Esta narrativa empieza a identificarse como dominante en el sistema familiar, es decir en el discurso y la identidad de los hijos, cuando en el escenario 2B, la segunda hija reconoce la importancia de que sus hermanos tengan las metas definidas tal como ella lo tiene y como su 
madre lo ha expuesto, situación que en algunos momentos pareciera que fuera la madre quien realiza este discurso, pero es la hija mayor quien se está pronunciando:

"Pues no sé, me parece que tienen como tal ya metas trazadas, digamos como lo de S y JP, que ya, que, que, obviamente lo de la batería, y lo que, lo que ellos ahora están tocando. ¿Sí?, porque eso hace mejorar cada día, es de aquí a cinco años, quieren ser profesionales, quiere decir que quieren más allá de lo que han aprendido por ahora. Como tal, me parece bien, sí. Porque se puede ver también que tiene metas, que tiene proyectos. Y eso para una persona es algo muy bueno, sí, porque quieren algo porque luchar, por el que día a día dedicarse, y realmente me parece algo muy, muy bueno” (Hija mayor, 17 años, E 2B, L197). Como fue enunciado la identidad de estos hijos ya se encuentra permeada por este discurso, al punto de llegar a definirse bajo la misma o de considerarla una prioridad, tanto en el contexto actual (Bogotá) como en su lugar de residencia, previo a la vivencia del CAC:

"Pues yo creo que es desde hace mucho, mi mamá es una de las personas que nos dice que, "el que estudia no es nadie”, si, y que digamos al dedicar un tiempo estudiando, es mucho mejor que andar en la calle, o haciendo, o cosas así, entonces considero que mi mamá, pues ha incentivado ese deseo en nosotros, porque ella nos dice que "lo que hagan, háganlo bien, háganlo que cada día surjan más, que no se queden ahí, sino que siempre vayan avanzando”, entonces yo creo que eso también de mi mamá. Ósea desde muy pequeños y ya (Hija mayor, 17 años, E 2B, L201).

Situación que invita a indagar para conocer si esta situación se presentaba solamente en Bogotá, desde la percepción de los hijos, o si se llevaba construyendo tiempo atrás:

"Siempre ha sido mi pensamiento, sí, que ellos salgan adelante. Yo siempre lo quise hacer. Pero desafortunadamente pues también crecí en una familia un poco difícil, 
económicamente, vivencialmente era muy difícil. Donde un papá no respondía por los hijos, tu mamá, maltrataba a su esposa, y mi meta mía, era estudiar y dos de mis hermanos, mis hermanos lo lograron. Yo no. Era, tocaba salir adelante a toda costa, estudiar, trabajar. Entonces qué hicimos, el uno, escalo y empujo al otro y así sucesivamente, así han seguido, incluso lo han seguido haciendo. Eh, yo trabaje para escalar al otro, pero yo me quede trabajando, y no estudie” (Madre, 40 años, E2B, L212).

A través del tercer escenario, se puede identificar una apertura de la madre, para permitir la emergencia de nuevos relatos que permitan transformar esa narrativa dominante del estudio, mediante poder conocer la diferencia entre salir adelante y ser profesional, utilizando la comparación entre la vida que viven sus padres y lo que espera de sus hijos, reconociendo esa diferencia a través de "salir adelante" y la imposición de la profesión que ella desea:

“por ejemplo yo les digo, mira papi, mire hacia el entorno de nosotros, vea a su papá, tiene su bachiller tiene todo, pero mire como sufre bregando para conseguir empleo, bregando para traerles el sustento a la casa le, porque de pronto él se metió mucho con nosotros y dejo la parte de estudiar de salir adelante la dejo atrás, y se dio al dolor que cualquier trabajo le sirve, porque lo importante es traer un sustento a la casa, digo yo no quiero verlos así, no quiero ver que ustedes... ustedes tienen que meterse que tienen una familia, van a tener una familia, más adelante van a tener sus parejas, sus hijos y ustedes tiene que tener como sustentarlos, / yo a veces les pongo de ejemplo mis hermanos, miren nosotros éramos, nos criamos en medio de la necesidad, !incluso de la violencia; [se ríe] fue algo muy tremendo, pero nosotros todos salimos adelante, la única que no salió adelante fui yo en la cuestión de profesión, de estudiar, porque yo no quise estudiar, yo casi el estudio muy poco, pero a los otros les tocaba muchas veces no comer, pasar días, les dio muy duro ese 
colegio donde ellos estaban, y si todo querer uno, desearlo y salir adelante (mueve su mano derecha e intercala la mirada entre T3 y hacia los lados, con expresiones de preocupación cuando se refiere a que no desea pasen sus hijos sus mismas necesidades” (Madre, 40 años, E3 L80).

Así mismo, esta apertura empieza a potenciarse con el uso de la estrategia artística del álbum que les permite crear una nueva dinámica familiar que la posibilita, puesto que la madre comienza a involucrar la voz de otros para elaborar dicho ejercicio y se permite reconocer que:

"Porque yo le dije yo a los muchachos, papi como quiere, no es como yo quiera, (señala adelante y luego se señala a sí misma) es como quiere plasmarse usted, [llanto bebe] (I levanta a Ma de sus piernas y le da la vuelta) entonces se quedó mirándome y me dice mami [se ríe] quien la entiende a usted, y yo no papi, yo no quiero rebozar mis sueños ponérselos a ustedes, porque ya mis sueños fueron mis sueños ahora son los de ustedes, entonces me dijo a bueno, (levantando la mano y los hombros, mientras amamanta a Ma) después cuando S hizo la pared (con la mano izquierda dibuja una pared), y la hizo como con un, como con una, así como arreglando algo así, quedo con ella en la mano, y alrededor le puso las baterías y yo usted si es, sigue con la cosa de querer tocar la batería, y dijo sí mamá, yo quiero ser profesional quiero tocar mejor, y yo a bueno (corre el rostro hacia atrás y con la mano izquierda la mueve señalando adelante) ya eso son sus metas no son las mías, lábrese sus metas (señalando hacia adelante luego de señalarse a sí misma), entonces llegó y hizo así, JP si dibujo no más el bolso, entonces yo pero porque, no quiere, no dice que le gusta la guitarra, entonces me dice si mamá pero déjela ahí, [se ríe] no la vamos a poner esta vez, yo pero porque no si usted le, le, dijo si yo la tengo pero no, no, cómo que no era el punto de él” (Madre, 40 años, E3, L98). 
Así mismo, en este escenario se pudo identificar que la fotografía como estrategia como potencializador de la escultura familiar permitió que la madre realizará procesos de auto y meta observación que facilitó la apertura a anteriormente descrita, a partir de identificar el ciclo vital individual de los hijos, lo que espera que ellos consigan a futuro y que sus hijos no son "muñecos" tal como lo menciona, sino seres que tienen también deseos y expectativas propias, pudiendo así permitirse una nueva forma de interacción que, aunque genera sorpresa tiende a ser bien recibida por su sistema familiar:

"Bueno, (dirige su mirada al suelo buscando recordar) las esculturas, que días mirando las fotos, porque me las cogió SA y yo hay / !no me coja eso ;, entonces llego y me puse yo a mirarlas, entonces yo pues fue, hay una donde yo los puse como eran ellos, (mueve las manos hacia los lados mientras la bebé está cogida de sus manos, sentada en sus piernas) y yo me puse a pensar (cerrando los ojos con expresión de tener un gran deseo) así es como yo los quiero tener quietos, pasmados, (pone las palmas de las manos hacia no puedo abajo y tensionándolas hacia el suelo y abre los ojos) pero entonces decía yo no, yo tener los niños así porque es que no son muñecos, no son marionetas, son niños, y ellos tienen que movilizarse en la manera de ellos, yo no he dejado [...] por ejemplo qué día me puse a jugar con S, me puse a perseguirlo, [risas] salí corriendo con él, me dice ay vea, vea esta señora si se está volviendo loca, yo nunca juego con ellos, entonces ve lo que mi papá está diciendo [risas], y yo no se pongan a molestar y vera que les pego” (Madre, 40 años, E3, L150).

Hay que reconocer que al ser un proceso de apertura todavía se presentan sentimientos de incertidumbre, ante esta nueva forma de relacionarse pero que igual le permite este proceso de transformación:

"Pues sí, tendría que echarle mucha [risas] cabeza a eso la verdad, porque sería dejar 
atrás ciertas reglas ciertos deseos míos (acerca su mano izquierda al pecho) y poner el de ellos (aleja su mano izquierda), como decía usted, dar mi parte para que ellos puedan subir, para que ellos puedan mostrar sin quitarles la autoridad generalmente a ellos y que ellos sigan pp (la bebé balbucea y no se entiende) están en la etapa en que a ellos toca irlos orientando (Madre, 40 años, E3, L219) =... =" [...] "Y ya como aprendiendo, yo digo que es como un aprendizaje diario (mueve ambas manos formando un espiral) con ellos cada día, y yo irme como influyendo en ese aprendizaje para con ellos, ellos me enseñan y yo les enseño de paso (mueve las manos adelante ya atrás para acompañar su oración)” (Madre, 40 años, E3, L221).

Al pasar el tiempo entre este escenario (3) y el escenario 4, se pudo identificar que al realizar el dibujo del familiograma, se pudo concretar aquella transformación en la narrativa dominante de la madre frente al ser profesional, al ella resignificar su posición como orientadora o de apoyo en la construcción de los sueños de sus hijos y potenciar el componente emocional en la relación con los mismos:

“A mi... pues yo, I (4 seg) pude darme cuenta que sí, me toca dejar ser menos autoritaria, tengo que darles más cariño, lo que es darle mucho valor a mis hijos, a dejar que ellos sean, lo que ellos quieran ser, nuevamente tengo que dejarlos que ellos sean no ponerles metas a ellos si no que ellos mismos se las hagan, no yo ser el puente si no que ellos lo construyan” (Madre, 40 años, E4, L1303).

Así como poder identificar la necesidad de disminuir su autoridad con sus hijos mayores para potenciar el desarrollo, autonomía e individuación de estos hijos partiendo de soñar un estudio pero que no sea profesional desde el comienzo, ni el que a ella le gusta (la madre) o determine: 
"Porque yo le decía, yo le había dicho usted tiene que meterse a una carrera, no sé, a cualquier carrera, pero tiene que hacer algo $F$ ac, usted tiene que... si es como imponiendo Le. Mami si usted quiere entrar al SENA entre, No es cuestión de entrar a la universidad, hay muchas personas que han comenzado en SENA y son profesionales, y han avanzado y ahí van avanzando, ahí van escalando Le. (mueve la mano izquierda) (Madre, 40 años, E5, L134).

Éste relato emergente permitió que se presentará transformación en la interacción familiar ya que, al reposicionarse la jerarquía de los miembros de este sistema, se posibilite la delimitación de límites intergeneracionales:

"Ee hubo unos diitas que se me puso como asíl (mueve la dos manos haciendo la señal de garras), y como que le dio mal genio, le cogió como rabia a E, porque ella pensó que yo estaba escogiéndolo a él l, y no a ella, como poniéndolo a él por encima de ella, entonces le dije yo, incluso no lo hicimos hablando, lo hicimos discutiendo porque me hizo dar mucha ira, pero si me dio a conocer -..- que lo respetaba, que no la obligarla a quererlo, porque ella no tenía motivo por el cual quererlo porque no había hecho nada malo, las fallas que él había tenido conmigo, que ella tenía que respetarlo y no meterse en eso, la situación de nuestro hogar es de nuestro hogar, entonces ella como que ya entendió, entonces ahorita hace la comida, ya empaca lo de él, -..- entonces ya está como más ll (6 segundos) (mueve la mano derecha despacio haciendo una señal de despacio) y en lo personal ya eh tratado de no preguntarle nada porque es personal P Le" (Madre, 40 años, E5, L136)

Esta transformación permitió que ambos padres se pudieran posicionar como base o sostén de la casa, para que sus hijos puedan cumplir los sueños de cada uno y en el pasado el autoritarismo de la madre, y la hermana mayor deje de ser otra madre en su casa y se convierta 
en el apoyo de su hogar a partir del ejemplo

“No, no, no, claro, generalmente cada uno lograría su meta (JP pasa por detrás de I jugando con M y el balón, S se sienta en una silla, I se expresa meciendo los brazos y las manos) cada uno su sueño, digamos si el sueño de S:: es ser constructor generalmente sería que el lograra eso \sí el sueño de JP es:: ser médico, pues llevarlo a que él lo logre esa meta sin de pronto ver que hay un impedimento que no puede digamos en el conocimiento ( $S$ se coloca de pie y se va para donde JP está con $M$ ), o que vio que es lo que a él no le gusto, entonces levantarlo y ayudarlo (A llega, y se sienta en la silla que estaba $S$ ) a que él se busque lo que él realmente quiera no lo que nosotros queramos sino que es un ejemplo como que de lucha F (Madre, 40 años, E6, L666).

Ya para el cuarto y quinto escenario, durante el desarrollo del dibujo del familiograma, la madre se permite reflexionar acerca de las pautas intergeneracionales, y aunque ha logrado transformar algunos comportamientos parentales, como la dureza de su madre, ha mantenido un "muro", tal como ella afirma, lleno de exigencias que le han coartado el acercarse más a sus hijos desde la creatividad y el juego, pero que a su vez le han posibilitado el cuidarse y cuidar a su familia. Lo cual posibilita un espacio de comprensión de cómo en las relaciones familiares y las dificultades con el tercer hijo se han gestado desde dichas pautas intergeneracionales, quitando a este la responsabilidad de los conflictos que se presentan en la familia actualmente. Esto produce en la madre altos niveles de reflexión y contradicciones que se manifiestan en un gesto intranquilo, de incomodidad, con ceño fruncido, mirada contrariada. El realizar el familiograma entre el tercer hijo y la madre, y el utilizar materiales plásticos, como revistas y marcadores, les permiten al subsistema madre-hijo el escucharse y comprenderse desde otra perspectiva, pudiendo así este hijo expresar de manera más clara su sentir respecto a su relación con su 
madre, en donde se manifiesta una clara solicitud a la madre por obtener una mayor cercanía, y no sólo encontrarse como figura de exigencia sino también de comprensión, de compartir espacios de diversión, de ocio y de apoyo, así como de protección.

Para dar el cierre del proceso, el sistema familiar identificó que su mayor cambio se encontraba en el apoyo hacia cada miembro para que cada uno cumpla sus sueños y metas en compañía de los seres significativos, posibilitando así el desarrollo de la autonomía e individuación del sistema y de sus miembros:

"El cambio más grande:: el apoyo, el cambio más grande:: eh:: pasar de la autoridad pasar a:: la autoridad suprema, porque era una autoridad suprema allí (I Señala la parte inicial de álbum) ya aquí ya no (I señala la parte final del álbum) la autoridad pero ya no basando a los sueño de cada uno si no teniendo en cuenta metas, entonces ya ha, hay mucho cambio, teniendo en cuenta de que ahí se ahí unos seres que también desean, piensan, sueñan, cada uno su forma de ser, cada uno su estatura a su edad, entonces hay un cambio grandísimo” F (Madre, 40 años, E6, L697).

Lo que al darle espacio a cada uno de explorar, conocer y aprender este sistema reconoce que a su vez puedan identificar sueños individuales y familiares, que les permitirá afrontar las nuevas vicisitudes de la vida:

"Que haya un:: una integración mejor, que haiga que nos entendamos mejor, que entre todos hacemos un futuro, digamos ahorita estamos entre los planes de crear la empresa, pues no será grande pero si vamos a comenzar con algo pequeño, poner la tamalería la lechoneria, conseguir el local, entonces vamos a hacerlo en familia, el uno planta, el otro ya sabe, el otro ya sabe cosas así de mezclar porque -..- cada uno pone su:: su granito de arena para seguir adelante y ayudar a los que vienen atrás” (Madre, 40 años, E6, L699). 


\section{Procesos Auto y Heterorreferenciales}

Desde el comienzo del trabajo nos hemos cuestionado sobre cómo podríamos colocar los procesos de autorreferencia en este trabajo si somos un equipo, puesto que al entrar en conversación nuestras opiniones dejaría de evidenciarse esta autorreferencia individual y empezaríamos a co-construir una heterorreferencia no solamente desde lo teórico sino desde los diversos sentires, cuestionamientos, miedos "asociaciones" que se pudieron ir forjando durante la elaboración de este proyecto de investigación.

Por ello, a partir de estos inconvenientes presentados al momento de construir diálogos conversacionales con la familia, es decir previo y al final de cada encuentro, nosotras como equipo terapéutico conversábamos sobre lo sucedido en el espacio, permitiendo que lo expuesto a continuación sea un proceso autorreferencial desde los diálogos, discusiones y reflexiones que como grupo emergieron durante este proceso de investigación; y lo heterorreferencial lo veremos desde la reflexión que emerge a partir de la teoría propuesta como base de este proyecto.

\section{Procesos autorreferenciales}

Entendiendo que la autorreferencia es parte de los principios operadores de la maestría y de la investigación, comenzamos a co-construir conversaciones reflexivas a nivel de las investigadoras - interventoras, a partir de los diferentes diálogos llevados a cabo con las instituciones, la asesora de investigación, compañeros y otros actores, identificando que al momento de construir esta propuesta estábamos ingresando a un campo amplio y diverso relacionado con el arte, también investigado pero escaso en la divulgación de la información, que da apertura para considerar la realización de este trabajo como la búsqueda de "una aguja en un 
pajar"; puesto que entraban en consideración varios interrogantes que en vez de delimitar el trabajo, en cuestión de practicidad, lo complejizaron volviéndolo atractivo, curioso e interesante para su elaboración.

Es así que surgieron comprensiones diversas a partir de las interacciones en el proceso de identificación de las posibles familias participantes de ésta investigación - intervención, en tanto algunas no se enmarcaron dentro de los parámetros inicialmente establecidos puesto que se encontró, por ejemplo, que las familias identifican la necesidad de conseguir una solución tangible y a corto plazo de sus problemas; la segunda, familias que no identifican una posible relación entre la experiencia vivida por el CAC y sus problemas actuales; y la tercera, lo curioso que puede llegar a ser comprender hechos como el desplazamiento forzado y el llegar a una ciudad capital (como Bogotá) como una situación posibilitadora, pero ¿qué es lo curioso ahí? varias veces solemos escuchar que Bogotá es una ciudad fría, agitada, "fea", "te come viva" en fin es descrita como algo negativa, pero varias de estas familias con las que hemos conversado mencionan que "Bogotá" se ha convertido en un espacio posibilitador, permitiéndoles ver esta ciudad aterradora como un espacio de aprendizaje, cambio, crecimiento y transformación.

Otra de las inquietudes que surgieron durante varios momentos de frustración era preguntarnos ¿qué significado podría tener el no poder realizar un proyecto de intervencióninvestigación como el planteado? primero, nos invitó a cuestionar y reformular la concepción del problema (¿qué es un problema y para quién es el problema?), segundo: la profesión y la manera en que intervenimos, puesto que la forma en como nos han venido educando hace que busquemos enfermedades, y enfermedades mentales, muchas veces donde no las hay y si no las encontramos decimos que hay una resistencias por parte de las personas y de las familias, lo que hace que como profesionales quisiéramos convertirnos en salvadores de ese malestar que 
estamos buscando y se nos olvidará que cada uno es responsable de sí mismo (decisiones, pensamientos, acciones, etc.) por lo que al poder compartir otros espacios, otros diálogos y otras conversaciones, podemos llegar a encontrar o crear y recrear diferentes bifurcaciones en nuestra mente y en nuestro mundo que nos darán la posibilidad de identificar la creación de adyacentes posibles en los cuales nos podemos desenvolver y así alcanzar ese estado de bienestar que tanto buscamos o por lo menos el que necesitamos para vivir y sentirnos bien.

Partiendo de estas inquietudes, co-construimos este apartado a partir de las reflexiones que emergieron en la planeación, elaboración, reedición y análisis de cada escenario, desde las posturas individuales (de la terapeuta y las observadoras) en conversación como equipo para así poderlos exponer a continuación:

Al comienzo del proceso -lo que concierne al primer, segundo y tercer encuentro (escenario 1, 2 y 2B)- pudimos identificar que el sistema familiar no respondía o entendía a las preguntas que nosotras como terapeutas o equipo les realizamos, hasta que la madre repetía la pregunta. En un momento esta situación permitió que en nosotras hayan emergido sentimientos de frustración al no poder conectar narrativamente con la familia, inquietud o temor ante saber si esta continuaba en el proceso ya que no se estaban generando conversaciones sino traducciones, e incertidumbre ante no poder co-construir diálogos, preguntándonos ¿cómo haremos el resto del proceso?

En el primer encuentro se configuró esta inquietud, pero en los dos siguientes escenarios se estaba transformando en una pauta comunicacional puesto que nos hacía cuestionarnos aún más como debíamos preguntar; hasta que pudimos identificar que la pregunta formulada por la terapeuta o el equipo, era reformulada por la madre desde los mismos términos, palabras, oraciones, permitiendo reconocer que -hacia el cuarto encuentro (escenario 3)- esta pauta se 
repite con el padre, conociendo así que este no era solamente un problema de nosotras en la configuración de nuestros discursos en el proceso, sino que también empieza resaltar la pauta de relación establecida al interior del sistema familiar; al evidenciarse que los miembros solo hacen caso a quien tiene el poder, en este caso la madre.

Es así como expondremos nuestras reflexiones ante las categorías emergentes. Hacia nuestra primera categoría, "no quiero ser como mi madre, pero estoy condenada a serlo", encontraremos lo referente a la contradicción en el cual la madre se encontraba inmersa, en donde ella describe que no deseaba ser como su madre, pero lo termina actuando como esta al no encontrar otra manera de relacionarse con su esposo e hijos.

En el primer escenario (primer encuentro) pudimos identificar que la madre nos comentaba sobre cómo era la manera de hacer cumplir las normas cuando se encontraban en el campo, para lo que el segundo hijo nos menciona dónde se subían y la madre debía recurrir "al palo" para poder establecer las normas con sus hijos. Produciendo gracia la forma en como es narrada esta historia, pidiendo a través del lenguaje analógico el continuar con su relato. Esta situación da espacio para que se solape el relato entre la madre e hijo, en donde el segundo nos explica cómo se presentaba el suceso, para lo que la madre nos explica o nos reafirma que hacía uso de la agresión física, es decir "pegarles” cuando sus hijos no le hacían caso.

Así mismo, con relación a este proceso de educación y crianza en su pueblo de origen la madre nos hace la salvedad que su primera no es hija biológica de su esposo, justificando ante nosotras el comportamiento que esta hija tiene con su padrastro, lo que produce en nosotras el interés de conocer a qué edad de esta hija, la madre se une con este esposo. A lo que la madre nos comenta que la hija tenía tres años cuando se da esta unión; generando curiosidad en nosotras si el tiempo de unión es tan extenso, como se ha transformado esta relación; 
reconociendo, y explicando, la madre que ellos no pelean y la hija responde ante los llamados de su esposo de una forma muy respetuosa, pero ella no suele involucrarse en los juegos del padre con sus hermanos haciendo la misma analogía que ella hace para mencionar cómo es respecto a las relaciones interpersonales.

Ante esta falta de interacción y jerarquía de la madre ante la decisión e imposición de normas, como terapeutas buscamos indagar respecto que tanto puede cada miembro en la familia expresar su sentir. A lo que el segundo hijo nos responde de manera segura y afirmativamente, mientras que el tercer hijo en silencio dirige su mirada al suelo pues es quien menos puede expresarse al estar aliado con su padre, mientras la cuarta hija de una manera alegre se expresa sin entenderle bien. Por ello, busco preguntar nuevamente a la cuarta hija si ella puede expresar su sentir en su casa. Dirigiéndose hacia nosotras su respuesta es afirmativa de manera analógica. Acto seguido, le preguntamos directamente al tercer hijo, pero es el segundo hijo quien nuevamente toma la palabra ocupando la voz de su hermano y manifestando el simplemente se expresa sin restricciones. Sin embargo, al reconocer que el tercer hijo no logra expresarse, le vuelvo a preguntar y no recibo respuesta por parte del segundo hijo, aunque éste continúa mirando al suelo, reafirmando así nuestra comprensión inicial respecto a la poca oportunidad que este tiene para poder expresarse con su familia.

Posteriormente, volvemos a retomar la forma en cómo se desarrollan los acuerdos en el subsistema parento filial, especialmente desde la madre. Para ello, el segundo hijo nos responde afirmativamente. Lo que nos da apertura para indagar cómo hacen para llegar a acuerdos, a lo que el segundo hijo expresa con claridad su posición parentalizada al interior de este sistema y a su vez nos expresa abiertamente su sentir, manifestando desde un ejemplo como no llegan a acuerdos, sino que toman de manera particular la decisión. Esto nos permite, aclarar que si bien 
no están de acuerdo terminan accediendo a lo decidido por la madre. Aunque el segundo hijo nos explica que cuando no están de acuerdo, tienden a quedarse en compañía de su padre; situación que nos invita a preguntar si este comportamiento se presenta hoy en día o si también se presentó en el pasado (previo a la vivencia del CAC), a lo que el segundo hijo afirma positivamente.

Hacia el cuarto escenario, pretendíamos indagar sobre la tarea realizada como familia a lo que la madre nos comenta que su familia le pregunta por lo que hizo en el encuentro anterior, exponiéndoles la posibilidad de crear espacios, diferentes a la iglesia, que les permita compartir como familia, aunque hace la excepción en el fin de semana previo al encuentro ya que por el clima ella, la primera y sexta hija no acompañan al resto de sistema al parque. A partir de allí, encontramos que la madre está dispuesta a generar aperturas que le permitan compartir espacios con sus hijos, en especial con el tercero puesto que es él definido como "el hijo problema" y por quien se hace la demanda de ayuda. Ante esta inquietud, el tercer hijo nos expone que son muy pocas las veces que la madre se da la oportunidad, respuesta que viene acompañada de un lenguaje analógico de nervios, desde la risa, por exponer su voz, ante una madre autoritaria. Esta particularidad en la comunicación permite que surja la duda al interior del grupo si para el hijo habría alguna diferencia si su madre se apertura a jugar con él, a lo que el hijo nos responde que sería feliz y estaría contento, reafirmando así la comprensión que nos habíamos planteado de una demanda, por parte del hijo hacia la madre, de acercamiento emocional. Al ser un tema poco llevado por la madre, y desde la mirada del hijo, le preguntó a ella su opinión ante lo expresado por el muchacho, situación que produce un tiempo de reflexión en la madre, reconociendo que ella no es una mujer que le guste jugar y relaciona que esto se puede presentar en acontecimientos especiales, puesto que identifica la necesidad de concentrarse más en los quehaceres del hogar y el rendimiento académico de sus hijos, dejando de lado el tiempo para 
espacios de esparcimiento, justificación que de alguna manera desanima a su tercer hijo, desánimo que expresa cuando dirige nuevamente su mirada al suelo.

Así que, para indagar un poco más, sobre la pauta de interacción familiar, realizamos la construcción del familiograma. Ejercicio que nos permite reconocer una pauta intergeneracional que inicia en la familia de origen de la madre y es replicada hoy en día por esta en su familia, dándonos la oportunidad de exponerle a la madre la comprensión que identificamos al interior de su sistema familiar nuclear, puesto que al manejar los altos niveles de exigencia no se permiten acercarse a ellos de una manera más amorosa sin irse a la posición de su esposo. Reflexión que la madre interrumpe para referirse a su esposo como hijo u otro niño en su hogar. Lo que nos invita a mostrarle cómo se encuentra cada uno a cada extremo del dibujo, lo que es afirmado por la madre y menciona que, aunque ha intentado comportarse un poco más como su esposo no ha podido lograrlo. Esta situación nos permite reafirmar que esos intentos fallidos son debido a las enseñanzas de su madre, pero sin desmeritar que estas enseñanzas han sido de gran aprendizaje para ella, invitándole a reflexionar sobre qué hubiera sido distinto si su madre no hubiera sido tan exigente. A lo que ella manifiesta que, probablemente su vida fuera distinta.

Esta respuesta nos permite comprender que allí se estaba generando una apertura sobre la que era necesario indagar, a lo que la madre nos explica que ella sería menos dura, porque si bien reconoce le ha permitido esa dureza sobre vivir, también ha obstaculizado la posibilidad de escuchar más a sus hijos y así poder ser más cercana desde lo afectivo a ellos. Lo que es reafirmado por nosotras desde un lenguaje analógico y la madre reconoce su dureza como fortaleza al rememorar la situación vivida con el grupo al margen de la ley, en donde lo vivenciado en su infancia con su familia le permite defender a su esposo y no permitir fuera enfilado y maltratado. 
Es así como, a través de esta estrategia podemos reconocer que la relación al interior de la familia de origen del padre es llamativa para la madre, lo que permite ser una apertura para conocer como el padre ha podido ser tan cercano para sus hijos. A lo que la madre nos expone que, para ella, su suegro es más bien permisivo y alcahueta en tanto no les llama la atención como si lo hace su suegra, aunque su suegro le llama la atención a esta por involucrarse en la vida de sus hijos, y a su vez esta lo considera alcahueta. Pudiendo así, relacionar las palabras de la suegra con sus propias palabras, en donde ella nos menciona la comparación que identifica en su suegro y su esposo, ya que ambos se relacionan con sus respectivos hijos, desde una forma cercana a nivel afectivo y emocional. Es por esto por lo que buscamos reflexionar frente a como el padre a partir de la interacción con su suegro se relaciona desde lo emocional. Permitiendo relacionar esta forma de interacción en la familia nuclear del padre, lo que causó gran interés en ella, puesto que termina ampliando su respuesta desde un lenguaje apreciativo hacia su esposo.

En este diálogo emerge un relato de la madre que prefiere estar lejos de su madre, lo que permite cuestionarse el porqué de este mensaje, a lo que ella nos menciona que siempre ha tenido una relación distante y conflictiva con esta, la cual nunca ha logrado comprender, ya que siempre la culpa de todos los sucesos tanto buenos o malos de su vida. Situación que menciona es distinta en su caso al ella no reaccionar de esa manera con sus hijos, separando las dificultades que tiene con su esposo de la relación con estos.

Lo que nos invitan a confirmar si esto que sucedía con su madre lo intenta cambiar para no repetirlo con sus hijos. Lo cual es confirmado desde un lenguaje analógico por parte de la madre y nos explica cómo su madre también siente celos de ella con respecto a su padrastro. Situación que nos induce a indagar sobre esta relación conflictiva y de celos entre la madre-abuela y la hija-madre. A lo que ella nos menciona que, en su infancia el padrastro compartía espacios de 
juego con ella, pero cuando comenzó a formarse más su cuerpo hacia su juventud, este la comenzó a mirar de una manera distinta, más libidinal, como si quisiera que fuera su pareja, algo que para ella es extraño y no comprende muy bien.

Situación que nos genera ruido ante la transformación en la interacción y buscamos aclarar la presencia de un posible abuso por parte del padrastro, ya que menciona que la quería ver como pareja; acontecimiento que la madre aclara mencionando que en un momento el intento abusar de ella y se convirtió en un determinante en la manera como su madre se relaciona con ella. Sin embargo, a pesar de que en su momento sentía mucha rabia hacia él, lo ha resignificado y se ha permitido el continuar verlo como su padre, al encontrarse ya muy enfermo como consecuencia cree ella del daño que ha hecho a su alrededor, y porque a su vez la ha apoyado a ella y a su esposo en varios momentos.

Al momento en que identificamos esta situación de crisis al interior de la familia extensa y el interés de esta madre por romper esta pauta interaccional, se nos da la apertura en el escenario, de poder crear conversaciones reflexivas, en donde la madre espera generar cambios para reposicionar a los miembros de su familia y acercar más al padre e igualarlo con ella en su función parental. Por ello, buscamos desde un lenguaje apreciativo, resaltar los recursos con los que cuenta el padre y llevar a la madre a ver como ella puede también usar esos recursos para generar cambios. A lo que la madre nos describe los cambios que pueda generar en la forma de relacionarse con los demás miembros su familia nuclear.

De esta forma, la invitamos a acercarse a su esposo y generar espacios de conversación que les permitan generar acuerdos en torno a su función parental y a su función conyugal, es decir crear espacios para ellos dos. Retomando y reforzando los aspectos positivos del padre y los esfuerzos que hace para sacar a sus hijos adelante. Situación que permite que la madre desde una 
posición más reflexiva mencione que, desde el uso de la pared como metáfora comenzará a derribarla y a generar cambios en varios sentidos.

Ante la metáfora de la pared, buscamos indagar la emergencia o la construcción de la misma a lo que la madre nos menciona que esta la utiliza como una forma de aislar su relación con su familia extensa evitando que sus hijos tengan contacto con la pauta de relación violenta y de descalificación, dando cuenta de cómo su hermano le condiciona prestarle ayuda a cambio de dejar a su pareja.

Por lo que indago sobre las razones que le llevan a este hermano a hacer dicha solicitud. Situación que nos motiva a indagar sobre esta intromisión familiar, para lo que la madre nos responde argumentado que sus hermanos descalifican a su pareja comparándolo con otras parejas que ella ha tenido y que difieren en gran medida de lo que es la actual.

A partir de ello buscamos reforzar que el padre es respetuoso con su familia nuclear y como ella ha logrado romper la pauta de violencia al interior de su familia de origen en su familia nuclear. Ante lo que la madre nos explica la pauta de maltrato y la relación conflictiva entre los miembros de su familia extensa. Por ello, es que buscamos ratificar la nutrición relacional que el padre provee a sus hijos como algo positivo, siendo resaltado por la madre y nos menciona que esto es algo que le gusta de él, cabe resaltar que en medio de este halago emerge en esta madre su narrativa dominante en torno a la periferia del padre sobre la imposición y control de normas.

Ya para el quinto escenario, como terapeutas buscamos que los miembros de la familia realicen distinciones en torno a la dinámica familiar a partir de la observación del producto artístico. Al respecto la madre nos responde, desde una connotación positiva, que da cuenta de las emociones y la cercanía que se está empezando a presentar entre los miembros de su familia. Esta situación, nos permite retomar las palabras de la madre y los invitamos a reconocer las 
voces de ellos durante el encuentro, por lo que la madre ase apertura a preguntarle a sus hijos y los invita a proponer; describiendo, paralelamente, las nuevas actividades que podrían realizar con sus hijos tanto afuera como en casa, situación que nos permite preguntarle a estos sobre su opinión ante lo expresado por la madre. Ante ello, el tercer hijo nos responde otorgando su aprobación, mientras observamos a los demás hijos jugando, lo que de nuevo nos lleva a indagar si están de acuerdo y si se involucrarían todos en este proceso. Así pues, observamos que la madre toma la idea del tercer hijo y reconoce espacios de interacción y compartir en los diferentes espacios de la casa. Así mismo, indagamos sobre los cambios en la relación parento filial (madre-tercer hijo) a lo que la madre nos responde que ha podido reconocer que ha mejorado el rendimiento escolar de su hijo, permitiendo indagar en profundidad como era antes la relación y la madre menciona situaciones de conflicto que se presentaba entre sus hijos en donde estos usan un lenguaje descalificador hacia su tercer hijo. Permitiendo que la madre reconociera que antes solamente los callaba y hoy en día ya puede retroalimentarlos respecto a porqué están mal sus acciones.

Identificando estos cambios al interior de este sistema familiar, encontramos grandes transformaciones a partir del uso de la estrategia artísticas para el escenario 5B. Por ejemplo, podemos conocer que la madre comienza dando las indicaciones del ejercicio, acto seguido sus hijos realizan preguntas sobre la actividad y la madre se apertura para responderlas desde un lenguaje propositivo, lo que posibilita que sus hijos acaten dichas instrucciones de manera positiva y de la posibilidad de que el tercer hijo realiza preguntas para poder tomar decisiones ante el uso del material en la construcción, permitiéndonos reconocer la transformación más constante de la cercanía entre ellos.

A través de la estrategia buscamos reconocer las personas significativas para la madre y que 
representan un apoyo para ella. A lo que la madre nos responde dando cuenta de personas que están cercanas a ella especialmente de la iglesia y que le han permitido hacer comprensiones diferentes sobre la forma como ejercer su rol parental.

Así mismo, buscamos reconocer los cambios en la relación a nivel del subsistema parento filial, en donde la madre nos explica los movimientos que ella ha venido realizando en la forma como impone las reglas, situación que genera en los hijos un mayor cumplimiento de estas, desarrollándose confianza entre ellos. Permitiéndonos escuchar que, la madre connota los cambios que ha hecho relacionados con la comunicación, confianza, y de establecer unas reglas menos rígidas.

Ya para finalizar el proceso terapéutico, es decir el sexto y último escenario, como terapeutas buscábamos indagar través de la voz de los hijos los cambios vistos por ellos desde el inicio del proceso terapéutico hasta la actualidad. A lo que el segundo hijo nos responde en torno a los cambios que observa en su familia; por ejemplo, sobre cómo su madre se relaciona con ellos y cómo esto genera cambios, también, en cómo entre ellos se relacionan. Para ampliar estas comprensiones, invitamos al tercer hijo al encuentro, a lo que él responde afirmativamente sobre que sí ha visto cambios, y el más significativo es que ellos puedan compartir como familia. Ante esto, él nos menciona que han compartido más con el padre en actividades como ir de pesca al río, comentario que es reafirmado por el tercer hijo.

Así mismo, buscamos conocer la voz de la madre sobre qué cree ella que ha pasado para que se generen estos cambios, a lo que ella reconoce que puede deberse a que ahora les da más confianza, ya no trata de imponerles su autoridad puesto que antes, ella no les daba la oportunidad de comportarse ya que su autoridad iba por encima de ellos, entonces terminaban haciendo lo que ella quería. Dentro de estos cambios, buscamos conocer si en la jerarquía al 
interior de su sistema familiar estaría de forma paralela entre los padres y la hija mayor, a lo que la madre nos responde que no, que ella y su esposo son los hombros que van a tener su casa, ellos le darían apoyo y fortaleza para sus hijos, que ellos verán donde se ubican, pero ellos (los padres) son el apoyo, lo que nos lleva a cuestionarle qué entonces porque dice o nombra a los tres. Ella nos responde que ubica a la hija mayor como ejemplo, ya que ella está más adelante, lleva terreno y ejemplifica que esta hija es una niña que estudia, que no ha cogido malos ejemplos, malas compañía. A lo que les reafirmamos que la ubica ahí como ejemplo, pero no con la responsabilidad del hogar.

Así bien, que para conocer un poco más indago sobre el impacto que había tenido la vivencia del CAC en la madre, por ello ella nos responde que estas vivencias hicieron que creara unos "demonios" que nunca expresó y que los convirtió en imposiciones sobre su familia y no se permitió escuchar a los miembros de esta. Ante esto, indagamos que le generaron en ella estos temores, y ella nos responde desde una postura ambigua, para lo que intentamos indagar un poco más y la madre comienza a hablar sobre su crecimiento, su enfrentamientos en la infancia, aunque empieza a relatar una situación que se presentó, para aclararla y entender mejor este suceso le preguntamos sobre lo que vivieron, a lo que la madre responde que la situación solo la vivieron el esposo y ella, sin ahondar más en esa situación, pues comenta que eso lo guardó en su corazón.

A partir de este momento indago en el sistema familiar sobre el uso de las diferentes estrategias artísticas que utilizamos en el proceso. Comenzamos con el genograma que fue construido por la madre y el tercer hijo; a lo que ella nos responde que con esta ella se pudo dar cuenta quienes estaban más cerca, que le disgustaba al otro, porque molestaba al otro, porque algunos se agredían, nos menciona como ejemplo las cosas que le molestaban a él (tercer hijo), 
puesto que antes le decían tonto, bobo o no sabe y ahora tratar de no hacerlo y poder darle la oportunidad de demostrar que si sabe y puede, mencionando al final que eso ayudó a nivelar el carácter de todos.

Acto seguido, indagamos sobre el ejercicio de la red, a lo que la madre nos comenta que recordaba que siempre consideró que estaba sola, tanto ella como su familia, pero que pudo identificar que hoy en día puede confiar en la familia de su esposo y en la de ella, además de respaldarse en los diferentes amigos que han establecido a través del tiempo.

Continuando con el análisis de nuestras categorías emergentes, identificamos a continuación la referente a "yo quiero un padre amoroso, pero prefiero al hombre de corbata". Categoría que nos expone el dilema en el que la madre se encuentra inmersa, ya que se debate entre el querer ser, es decir lo que su marido le brinda, y el deber ser, es decir lo que espera de él.

En el primer escenario, como terapeutas indagamos sobre la frecuencia que se presentan los conflictos al interior de la pareja, pregunta que es evitada por la familia y el tercer hijo nos presenta las razones por las que se desarrollan dichos conflictos; así mismo el segundo hijo apoya dicha descripción anexa las palabras que la madre utiliza para pedirle al que se arregle de una manera más organizada. Conversación que permite el tercer hijo, apoye nuevamente a su hermano explicando la palabra real que utilizaba la madre de "persona decente", frase que es validada por el segundo hijo. Situación que nos permite solicitarle a los hijos que continúen con esta descripción, por medio de un lenguaje analógico, por lo que el segundo hijo se retracta de lo manifestado anteriormente respecto a cómo la madre describe al padre, afirmando que en realidad dice que la manera de vestirse del padre es como la de "un indigente", siendo evidente en el lenguaje analógico que la madre se siente apenada por los comentarios de sus hijos.

Ante esta descripción de los hijos, buscamos afirmar si la madre utiliza esas palabras para 
descalificar al padre, a lo que el segundo hijo nos explica que el padre se molesta y se retira. Situación que no permite indagar si los padres solucionan esas diferencias o en qué momento lo logran hacer. A lo que el segundo hijo me contesta que no, estas dificultades no se dialogan. Situación que permite que la cuarta hija se involucre en la conversación para mostrar una manera de solucionar el conflicto, relacionada a que el padre busca no permitirle a la madre asistir a la iglesia. Situación en la que el tercer hijo interviene, enunciando que la madre no se permite negociar y busca imponerse ante el padre desconociendo su petición y delegando el cuidado de la hija menor. Hecho que es reafirmado por el segundo hijo. Ante esta forma de solucionar los conflictos al interior de esta familia, buscamos indagar si la hermana mayor presenta dificultades con alguien de la familia. A lo que el tercer hijo nos responde que con el padre. Intentando ampliar esta situación, el tercer hijo a través de su lenguaje analógico, nos da apertura para cuestionar dicho conflicto; a lo que este hijo nos menciona como a la hermana mayor le molesta la desorganización y que su padre sea de dicha manera. Comentario que nos cuestiona si esta es realmente una percepción de la hija o si hace parte del discurso de la madre que ha sido incorporado en la primera hija.

Ya hacia el segundo escenario, podemos resaltar la preocupación de la madre sobre la percepción que sus hijos ha construido sobre el padre, manifestándoles explícitamente al tercer hijo que no lo dibuje acostado, explicándole que el padre trabaja mucho y por ello es su cansancio, pero al mismo tiempo utiliza la palabra "tan" para mencionar que alguna medida considera es perezoso. En medio de esta conversación se escucha que los hijos hablan al mismo tiempo, pero alcanzamos a percibir que el segundo hijo interviene, relacionando lo mencionado por la madre que el padre debería hacer una mayor colaboración en los quehaceres de la casa. Ante esta conversación identificamos que la madre se siente incómoda respecto a cómo el tercer 
hijo dibuja a su esposo, permitiéndonos indagar respecto a cómo es ese sentir y ella nos relaciona como siente que su tercer hijo ubica a al padre como una persona "floja" sin responder a la pregunta de cómo esto la hace sentir a ella. Buscando justificar la posición de su esposo, nos explica, como él no se siente cómodo en Bogotá, describiéndolo al mismo tiempo como un hombre trabajador; sin embargo, de manera contradictoria nos menciona que finalmente es verdad como ellos lo describen, ya que siempre duerme. Conversación que el segundo hijo interrumpe para mencionarnos, de manera descalificante, que su padre duerme varias horas. Al respecto, la madre nos expone un contra argumento, al manifestar que se encuentra muy cansado ya que su trabajo que es de construcción es muy pesado y por ello es por lo que necesita descansar más tiempo, lo cual relacionan sus hijos con el encontrarse acostado la mayor parte del tiempo. Por lo que al ser el tercer hijo quien dibuja a su padre de esa manera, nos permitimos preguntarle, retomando la postura expuesta por la madre, si es distinto para él ahora que puede reconocer que el padre se acuesta más por su cansancio, debido al trabajo que tiene, con el fin de resignificar dicha postura descalificante hacia el padre. Situación que permite un proceso reflexivo en el tercer hijo y posibilita una respuesta más animada de quién es su padre.

Posteriormente, indagamos respecto al significado de responsabilidad al interior de la familia, en tanto se continúa descalificando al padre desde el manifestar que no lo es. Situación que permite que la cuarta hija se involucre en el proceso conversacional, para explicarnos que la responsabilidad se relaciona respecto a cómo lleva su padre la ropa. En contraposición, el tercer hijo muestra su desaprobación, pero al ser su voz opacada por su postura de apoyo hacia el padre se expresa con un volumen de voz muy bajo lo que no me permite escucharlo.

Respondiendo la cuarta hija que su expresión es cierta al buscar traer la voz de la madre, explicándonos que la madre lo que hace es mencionar que se vaya bien organizado. Buscamos 
entonces, reconocer que significa para la familia el ser responsable, pero también hacer evidente que este sentido de responsabilidad que le adjudican al padre proviene de las inconformidades de la madre frente a la desorganización del padre en el hogar, con su ropa y respecto al poco apoyo que ella siente relacionada con los oficios de la casa. Cabe reconocer que, el tercer hijo nos explica que desde el trabajo también. Por lo que nos da apertura para preguntar a qué se refiere con los temas del trabajo ya que esto no había sido antes mencionado. Sin embargo, con esta respuesta el tercer hijo busca exponer su deseo de que su padre no se dedique tanto a trabajar. Lo que nos permite cuestionarles cuál es la relación entre el deseo de hijo de compartir más y la poca responsabilidad del padre, frente a lo que el tercer hijo aclara que se refiere a que al llegar tan cansado no cuenta con tiempo para ellos. En este momento, la cuarta hija interrumpe para re afirmar lo expuesto por su hermano, quien baja el volumen de su voz ya que su postura frente a lo que sucede con el padre es invalidada de manera constante y no puede expresarla de manera abierta, manifestando que a veces su padre llegaba muy tarde en la noche y debía levantarse muy temprano en la mañana. Lo que nos permite comprender que como él llegaba tan cansado de trabajar necesitaba dormir varias horas para recuperarse, siendo la explicación del que durmiera en gran medida y no la de ser flojo, contradicción que entendemos es la que molestaba a este tercer hijo.

Ante eso, la esposa nos explica que, para ella, el que el esposo sea responsable tiene que ver con el hecho de poner límites a su familia de origen, en especial a su madre. Idea que es refirmada por el segundo hijo de manera muy contundente. Continuando la madre su explicación muy molesta, nos describe cómo sucede la situación en donde su suegra logra que su esposo se esté con ella alejándose de la familia que construyeron. Al percibir que reclamo está orientada más hacia el rol de esposo, cuestionamos si sus manifestaciones son solo referentes a ella o esto 
sucede también con sus hijos. Frente a lo que nos contesta que es tanto con ella como con sus hijos, explicándonos adicionalmente que le molesta que su esposo no mande dinero suficiente para suplir las necesidades de todos en el hogar y no se preocupe por comprender cómo se sienten todos respecto a su ausencia a pesar de que pregunte como se encuentran.

Lo que nos lleva a volver a cuestionarnos si es algo que solo la madre espera o que también sus hijos esperan, lo que nos conlleva a pensar hasta qué punto ella les ha preguntado qué opinan y qué sienten respecto al tema, llevando a reafirmarle que es algo que ella también espera, a título personal. Así mismo, el tercer hijo nos comenta que en la familia del futuro todos estarían en la iglesia incluyendo al padre, pero no se encontraría vestido como todos lo han pintado en traje de paño. Lo que nos causa curiosidad e indagamos respecto a cómo se encontraría vestido. Respondiéndonos de manera muy obvia que se encontraría vestido como todos, es decir "normal". Esto nos lleva a preguntarle a la familia las razones que los lleva a ubicarlo siempre de traje de paño y con corbata. En donde la madre nos explica que es ella quien desea verlo así, en tanto esperaría tuviera un trabajo distinto. En ese momento el segundo y tercer hijo interrumpen a la madre obstaculizando que se comprenda lo que la madre se encuentra expresando.

Retomando la conversación, la madre nos explica que quisiera que su esposo estuviera de traje de paño, lo cual relaciona con el estar bien organizado, exponiendo que así puede cambiar de ser constructor a celador, ya que es un trabajo menos pesado en el que podría estar más organizado con su ropa y así mismo contar con mayor tiempo para la familia. Relato que nos invita cuestionar hasta qué punto el padre se siente identificado con lo que la madre expresa, situación que permite un proceso reflexivo en la madre llegando a reconocer que el esposo no se proyecta de dicha manera. Al ver que esta es una idea de la madre, preguntamos cómo se vería realmente el padre con el fin de indagar qué tan claro tiene la esposa los deseos o expectativas de 
su esposo. Algo que no responde la madre, dirigiendo la respuesta a descalificar nuevamente la manera de ser de su esposo al exponer que él se conforma con estar limpio o sucio.

Para el siguiente encuentro, escenario $2 \mathrm{~B}$ contamos con la presencia del padre $\mathrm{y}$, escuchamos lo que cada uno del sistema familiar desarrollo en la página del álbum, cuestionándonos que al parecer todos les preguntaron a sus papás cómo se veían en un futuro. A lo cual el segundo, tercer hijo como la cuarta hija responden de manera afirmativa tanto digital como analógicamente.

Por lo que para indagar cómo fue esto, les preguntamos reafirmado si los tres le preguntaron a su padre que esperaría a futuro, con el fin de que al reafirmar se pueda traer la voz de él. Frente a lo que el tercer hijo nos comenta, afirmando la pregunta y mostrándonos la confusión de su padre, en tanto manifiesta obtiene dos respuestas diferentes. Situación en la que el padre nos manifiesta su respuesta justificando que se le han presentado los dos trabajos, explicando que en este momento tiene una oportunidad de trabajo, pero puede que se le presente en un futuro una distinta. Por lo que le preguntamos si nuestra comprensión respecto a que al ser variable su ámbito laboral decide mantener estas dos opciones de trabajo. Lo que el padre responde de manera afirmativa frente a nuestra comprensión.

Al ver la similitud en los diferentes dibujos continuamos indagando e invitamos a conversar al segundo hijo, puesto que en la anterior sesión contaba con una posición poco conciliadora hacia el padre. Respondiendo que son parecidos, pero no idénticos los ejercicios, lo que nos invita a preguntarle qué quiere decir esa expresión de "casi iguales", a lo que la madre levanta su rostro y se dirige hacia nosotras, afirmando que efectivamente son muy parecidos, pero nos brinda el dato curioso que, lo desarrollaron en momentos y tiempos distintos. Acto seguido, le preguntamos a la esposa sobre qué esperaba mostrar en su página, ante lo que ella nos expone la 
manera como observa a su esposo a nivel laboral, en donde desconoce el empleo en el que actualmente se encuentra, expone su idea de ubicarlo en una posición distinta casi como de arquitecto. Al ver esa disonancia de prospectivas, nos permitimos parar el relato de la esposa para convocar la voz del padre con el fin de reconocer que opina respecto a la idea que esta tiene referente a su futuro laboral.

Frente a lo que el esposo me manifiesta es más el sueño de su esposa en relación con verlo más adelante como "arquitecto o maestro avanzado". Invitándonos a pensar que no son sus expectativas y es necesario la esposa las escuche, desde el cuestionar si este es también su sueño. Exponiéndose en el esposo que, si es su sueño, lo que nos permite ver su dilema, en tanto de alguna manera él también lo desearía al ser sus oficios la construcción y el campo, ya que termina manifestando que de alguna manera también es un sueño suyo. Como nos encontrábamos en la escultura del futuro de su esposa, cuestionamos entonces en donde se sentirá más cómodo en la posición de recibir órdenes en el restaurante familiar o de maestro avanzado como lo ubica su esposa.

Mencionando que se siente más cómodo como maestro. Esta situación nos da la apertura para reafirmar de manera más específica, si se siente mejor como maestro avanzado entonces que como el ayudante del restaurante, lo que él afirma positivamente de manera analógica.

A partir de esta conversación buscamos hacer una devolución a la esposa en donde está exponga cómo se siente frente a la idea que el esposo decide irse debido a la situación económica que viven. Situación en la que la madre explica que no sabe qué responder, justificándose en el hecho que su esposo casi no se expresa, e identifica qué son las altas exigencias las que le generan tensión, justifica así su manera de actuar, desde el preocuparse por la salud de su esposo y el tener que responder por el futuro de sus hijos, a quienes desea también ver profesionales, 
planteando así la necesidad de que el esposo obtenga mejor trabajo; para ello, retoma como el que el padre de la primera hija envíe dinero para esta les ha posibilitado un gran apoyo para suplir el poco ingreso económico del esposo, descalificándolo al explicarnos cómo no ha podido tener una mejor actitud en dicha búsqueda, además de compáralo con ella, describiéndose como más arriesgada puesto que tiene mayor experiencia. Esta interacción nos invita a convocar al esposo para conocer su opinión ante lo mencionado por la esposa, a lo que él nos refiere que ésta tiene razón en su última afirmación en tanto siente que al ser mayor y haber tenido que trabajar en Bogotá y ser más independiente ha adquirido una mejor expresión verbal distinta a la que tiene él, quien ha pasado más tiempo en el campo junto a sus padres, sin mayores preocupaciones. Así mismo, comenta estar en concordancia con ella, en tanto comprende que su esposa espera cada uno trabaje en espacios distintos en pro a darles un mejor futuro a sus hijos.

Sin embargo, al enfocarse en el tema referente a los espacios de trabajo, y el esperar una respuesta más relacionada a la postura de su esposa de encontrarse cansada de sentirlo como un hijo y no como un esposo, un hombre, se intenta indagar sobre dicho tema, pero él evade la pregunta respondiendo de manera afirmativa.

Ante la falta de reflexión por parte del padre para reconocer su sentimientos y opiniones empezamos a expresar sentimientos de frustración, re orientamos la indagación y buscamos conocer qué significado tiene para él ese planteamiento de la esposa, a lo que ella a explicarnos que su esposa espera es crezca a nivel laboral, desconociendo que ella lo está viendo como un hijo. Situación que nos permite afirmar que efectivamente ella espera esto, aunque en realidad busca más es su apoyo. Nuevamente el esposo nos responde es ella la que debe decidir en la relación y su posición continuaría siendo la de apoyarla. Por lo que nos permitimos darle una nueva opción a la jerarquía familiar para traducir las expectativas de la madre, indagando si 
pudieran tomar decisiones como pareja. Frente a lo que nos menciona entonces ya ambos deberían trabajar más en equipo. Esta reflexión podría ser vista como un cambio que deberían realizar a nivel de comunicación, situación que nos confunde e indagamos si sucede ahora o lo deberían empezar hacer. Por lo que el padre nuevamente menciona el ámbito laboral, manifestando que ya cuenta con nuevo empleo, lo cual le ayuda cumplir parte de las expectativas de la madre.

Al evidenciar como equipo terapéutico parece haber una dificultad a nivel conyugal que está permeando la parentalidad, consideramos pertinente preguntarles, en un espacio individual con la pareja, si estos se proyectan como tal. Frente a lo que la esposa nos responde que sí, mostrándose por el contrario unas respuestas dubitativas del padre.

Cabe resaltar que partimos del supuesto de que los hijos pueden ser una razón para que permanezcan juntos por lo que preguntamos si aun independientemente de sus hijos esperan mantenerse unidos. A lo que la esposa y el esposo manifiestan afirmativamente, explicándonos la esposa que ella siempre deseo un hogar y en su esposo ve cualidades que no encontró en otros hombres, comparándolo con el padre de su primera hija, quien fue una figura significativa para ella y representa un ideal de hombre "de corbata" es decir cuenta con recursos económicos; destacando que esas cualidades que le gustan de él se relacionan con la manera como su esposo se relaciona con los niños.

Al evidenciar que reconoce cualidades en este cambiando su postura descalificante, nos permitimos reafirmar si entonces ella quisiera seguir con su esposo. Frente a lo que nos responde de manera afirmativa. Cómo queremos saber la opinión del esposo, nos dirigimos a este para preguntarle si también desea continuar con su esposa, esperando que amplié su respuesta.

Al evidenciar que no la amplia y bajo una sensación de molestia, volvemos a preguntar si él 
quisiera continuar como pareja. Frente a lo que el esposo responde nuevamente que si tanto digital como analógicamente. Al no ampliar su respuesta, nos permitimos preguntarle que le lleva darme esa respuesta. Lo que lleva a retomar su postura anterior y manifestarnos que solo lo haría por sus hijos. Situación que nos conduce a interrumpirlo para recordarle que sus hijos crecerán y se irán del hogar. A lo que nos responde afirmativamente. Bajo esta claridad, nos permitimos preguntarle nuevamente si aun así desea continuar con ella. Frente a lo que nos responde nuevamente de manera afirmativa.

Al continuar con la duda si el esposo quiere continuar con su esposa como pareja e independientemente de si encuentran o no sus hijos, debido a la presencia de ella en el lugar, nos permitimos darle la opción de pensar si se proyecta con otra persona o solo. Por lo que él nos responde, de manera afirmativa y contundente que sí desea continuar con su esposa, justificando que el punto es la dificultad que tuvo a nivel laboral lo que lo llevó a tomar la decisión de irse, ya que encontraba trabajos por días y bajo esa modalidad no le convenía tomar dichas actividades laborales.

Dando un tiempo para que la familia pudiese incorporar dichas aperturas, al siguiente encuentro la esposa nos manifestó su interés por apoyar al padre, a lo que indagamos dichas aperturas respecto al cambio no solo a nivel cognitivo sino también a nivel pragmático en tanto siente en su expresión que no existe una clara postura de apoyo. Cuestionando cómo sería exactamente esa manera de apoyar a su esposo. Al parecer la madre se siente señalada y busca aclararnos su opinión a través de un ejemplo sobre cómo está ayudando a su esposo a nivel económico, y como éste ahora se permitirá hacerlo. Lo cual nos permite aclarar qué tan dispuesta se encuentra de escuchar y apoyar a su esposo, aperturando el hecho a que se busque que como pareja lleguen a acuerdos. Sentimos que la madre comprende que ella se encuentra en un proceso 
de cambio, al identificar que se encuentran llegando a acuerdos desde el reconocer la importancia de escuchar a su pareja en el momento en que llegan a consensos.

Sin embargo, la madre contradice lo expuesto por la interventora, al mencionar que en este momento lo apoya porque está cumpliendo sus expectativas, de que se proyecte en un futuro, demostrando que en realidad no se encuentra dispuesta a escucharlo. Al reconocer que de manera emocional no se ha generado un cambio y a que la madre no está dispuesta a escuchar a su esposo, se formula nuevamente la pregunta con el fin de mostrar la importancia de comenzar a hacerlo. Lo que invita a la madre a volver a ejemplificarnos como se encuentra de alguna manera escuchando a su esposo, en tanto afirma que conversa con su esposo para apoyarlo en la idea de montar un nuevo negocio referente a tamales y lechona, los cuales son diferentes a lo que ella esperaría que él tuviera. Lo que nos lleva a reafirmar la importancia de la escucha a su esposo y a evidenciar que en este ejemplo se retoma el sueño de su esposo, para que esté realmente se sienta apoyado. Por lo que la madre re afirma lo expuesto ya que lo relaciona con una manera de trabajar en equipo para tener una mejor situación económica, estabilidad familiar y a su vez, que les permita apoyar en el momento a su primera hija, quien se encuentra a portas de iniciar la universidad, aspecto que continúa siendo primordial para ella.

Ya que la madre nos menciona el trabajo en equipo, nos permitimos preguntar qué había pensado la esposa respecto a que debía cada uno hacer para que la relación cambiará. Así mismo la madre nos expone que entiende que es necesario bajar su autoridad, es decir identifica que siempre les ha exigido a todos sus hijos y en especial a su esposo, lo cual ha generado en el de alguna manera un bloqueo, que ahora identifica, en tanto logra ya no imponer sino pedirle su opinión, identificando esto le permite actuar con mayor tranquilidad y "agrado". Lo que nos permitió complementarle, explicándole que entendemos que ahora se da cuenta que es necesario 
no solo exponer sus ideas sino también tomarlas en cuenta, permitiéndose mediar con su esposo.

Bajo esta apertura, para el escenario 5B, indagamos respecto a los cambios que se han gestado en la relación conyugal, a lo que la esposa nos comenta que, en la relación con su esposo, ha cambiado en gran medida en tanto ya no se presentan espacios de agresión verbal y logran conversar de manera íntima respecto a las inconformidades que se presentan en la cotidianidad. Como la esposa nos expresa más el cambio de la relación y de ella, nos permitió indagar sobre los cambios que ha evidenciado en su esposo. Contándonos por medio de un ejemplo como ha tenido nuevos detalles con ella. Buscamos comprender cómo vivió la madre el desarrollo de la escultura para conocer que posibilitó el desarrollo de la misma. Frente a lo que la madre nos comenta que especialmente cuando su esposo participa en la escultura les posibilita comprensiones respecto a sus pensamientos, en tanto logra escuchar sus posiciones y miedos, y encontrar puntos en común.

En este transitar de nuestra investigación, podemos identificar en la categoría emergente "no quiero un padre para mis hijos, ni un esposo como mi padrastro, pero le exijo ser como él" en tanto se trata de las comparaciones que la madre realiza entre su familia nuclear y su familia de origen, principalmente en el desempeño o las funciones que espera que su esposo desarrolle o cumpla con la familia construida por ellos dos.

En cuanto al primer escenario, como terapeutas buscamos indagar sobre quienes se encargan de fijar las reglas hacia los hijos, preguntándole a la madre si el padre no lo hace. A lo que la madre nos indica que su esposo "nunca" lo hace, nos describe cómo le asigna tareas a él para que realice mientras ella está fuera de casa y cómo sus hijos no le hacen caso a él. El segundo hijo interviene en la conversación para agregar información sobre lo que la madre nos está diciendo, desde un apoyo hacia ella. La madre continúa describiendo cómo el padre realiza las tareas de 
casa, ante la dificultad para que sus hijos le obedezcan, enunciando como ella asigna las tareas del hogar a sus hijos y estos de forma "obediente" lo hacen, mientras que al padre no. Así mismo, buscamos conocer la cercanía entre los miembros del sistema familiar. Respondiendo la madre de forma exclamativa para expresar la comprensión sobre mi pregunta, optando por una posición reflexiva. El tercer hijo nos indica su cercanía respecto al padre, al ratificar esta respuesta, la amplía incluyendo desde su lenguaje digital y analógico al segundo hijo y luego a la cuarta hija como cercanos también. Al respecto, ratificamos su respuesta y él nos responde incluyendo a la quinta hija. Por lo que se vuelve a reafirmar su respuesta referente a que los 4 hijos son cercanos al padre. Ante esto la madre interviene para explicarme, desde un lenguaje despectivo, porque sus cuatro hijos están cercanos al padre, describiendo las situaciones a través de las cuales ella da cuenta de esta cercanía, sin dejar de descalificar al padre. Por lo que el tercer hijo interviene para explicar tímidamente las actividades que el padre realiza con ellos como una forma que le permite dar cuenta del porque están cercanos a él.

Referente al segundo escenario, como terapeutas buscamos comprender la cercanía entre los miembros del subsistema conyugal para la toma de decisiones, a lo que la esposa nos describe como ella toma las decisiones y luego se las cuenta a su esposo sin recibir la respuesta esperada por ella, sintiéndose recargada con esta responsabilidad. Por lo que buscamos indagar sobre cómo sería esta situación en unos años a futuro, lo que permite que la esposa nos responda considerando que no se presentaría cambio alguno. Es así como, buscamos conocer si ella espera algo diferente en esta situación y recibimos una respuesta afirmativa por parte de ella. Razón por la que buscamos conocer sobre cómo esperaría que fuera esto. Ante esto, la esposa describe como el padre debe colocarse en una posición privilegiada en torno a esta función, desde una posición patriarcal y en mejores condiciones de empleo. Ante esta postura patriarcal buscamos 
llevarla a la reflexión para equilibrar la posición de los dos miembros del subsistema conyugal en torno a la toma de decisiones; sin embargo, ella valida su posición patriarcal, aunque involucrándose sutilmente en esto. La esposa nos relata cómo espera que su esposo se aleja de su madre y sea más "responsable" con su sistema familiar nuclear, a lo que su tercer hijo interviene para validar lo que su madre expresa, la madre continúa explicando cómo su esposo atiende de forma prioritaria la convocatoria que le hace su madre, expresándonos su necesidad de sentir a su esposo más cercano apartándose de su familia extensa. Ante esta situación, nos preguntamos si esto es esperado desde el rol conyugal y/o parental. Por lo que ella desde su rol parental amplía su respuesta para dar cuenta de la poca contribución económica que hace el padre para el sostenimiento de la familia. Así mismo, ella nos explica cómo espera más una nutrición relacional desde lo afectivo y emocional de este padre hacia su familia nuclear.

Ante lo anterior, buscamos ampliar si lo que ella espera es para todos los miembros del sistema familiar o para algunos en particular. Por lo que desde su propia voz considera que lo que piensa también es esperado por sus hijos. Así mismo buscamos que ella se posicione como esposa y lo reconozca desde su rol conyugal; a lo que la madre nos expresa su deseo, pero rápidamente lo relaciona con la necesidad de que el padre se aleje de su familia de origen, colocando en una posición privilegiada su familia nuclear.

En el tercer encuentro con este sistema familiar, denominado escenario $2 \mathrm{~B}$, buscamos indagar si al momento en que el sistema está completo no se pueden generar conversaciones entre ellos como familia, a lo que varios miembros responden a través de un lenguaje digital y analógico que no; siendo la primera hija quien amplía la respuesta, desde su postura, indicando como a nivel de los diferentes subsistemas se pueden dar estas conversaciones; es decir, a nivel del subsistema parento filial (madre - hija / madre - hijos) y subsistema conyugal, pero a nivel 
del subsistema fraterno no. Por lo tanto, convocamos a los otros miembros para que expresen lo que piensan. Ante esto el padre nos responde de forma concreta para manifestar que él tampoco se comunica con los otros miembros de la familia. Por lo que intentamos validar su respuesta buscando que éste amplíe la misma; sin embargo, él usa su lenguaje analógico para enfatizarla. Situación que nos conduce a indagar cómo era antes esta forma de comunicarse entre ellos, convocándolos a relatar el antes en el contexto de campo. Al respecto la madre nos describe someramente cómo era la interacción entre ellos, y cómo se comunicaban. Por ello, buscamos comparar las dos realidades para ampliar la comprensión de esta interacción. Ante mi pregunta, la madre nos relata la comparación entre la forma como ella interactúa con sus hijos y como lo hace el padre, para mostrar la poca comunicación que existe al interior de la familia, contradiciéndose por algunos momentos. Por lo que ante la ambigüedad de la respuesta buscamos realizar una distinción entre sí conversan o no, o si lo hacen cada uno por separado. Es por ello por lo que la madre, nos describe cómo se comunica con sus hijos de forma individual para conversar con los mismos sobre temas escolares especialmente. Conversación que el padre interrumpe para intervenir, en donde nos explica y justifica que los hijos se comunican más con la madre que con él, debido a su trabajo y a los pocos días de descanso que tiene.

Situación que nos permite indagar con el padre si en esos días de la semana que tiene libres se conversa con sus hijos, a lo que el padre responde que no. Por lo que la madre interviene para ampliar que con el padre se comunica cuando no ha logrado que sus hijos cumplan las reglas, convocándolo para que las haga cumplir; sin embargo, finalmente expone que ella es quien lo soluciona. Conversación que nos da apertura para indagar sobre la forma como se fijan las normas y reglas la interior del sistema familiar. Respondiendo el padre que la madre es quien las fijan; emergiendo así, las voces de los hijos que nos ratifican lo dicho por éste, a su vez este 
justifica esta interacción a partir de su condición de proveedor económico; y nos amplía su respuesta configurando las normas y reglas a una forma de castigo o regaño cuando está presente en el hogar en los días que no trabaja; en esta interacción pudimos identificar que mientras se genera la conversación con el padre, mientras que como descalificación la madre y la hija mayor se ríen. El padre continúa su relato, explicando que son los días en que él puede compartir con sus hijos, mientras se suma a la risa el segundo hijo. Ante esta situación se indago si el resto del sistema puede reconocer si se establecen acuerdos entre los padres o si solo los establece la madre, afirmando la hija la respuesta de la madre. Entonces, se busca indagar con el padre si él sigue las reglas que la madre impone o sí él coloca algunas reglas; el padre intenta responder, pero la madre traslapa la conversación para mostrarme que él hace lo que ella diga, lo cual es afirmado por el padre. Al respecto la hija mayor me explica que el padre si tiene unas reglas, lo que asocia con el orden de elementos del padre. A lo que el padre se anima a expresar que es por lo que él pelea en casa, una vez más pensamos que este padre configura las reglas como una forma de pelear o castigar. Ante esto la hija mayor indica que el padre pelea solo cuando se pierden sus cosas, siendo esto ratificado por el padre. Para clarificar el tema de las reglas preguntamos sobre el tema de permisos, es decir a quien los hijos piden autorización. A lo que la madre responde que es a ella, respuesta que es ratificada por su hija mayor y el padre, quien termina justificando su respuesta desde su posición periférica.

Así mismo, como terapeutas buscamos indagar sobre qué sucede cuando no se logran acuerdos a nivel del subsistema conyugal, a lo que la madre me ratifica su posición autoritaria, lo cual es validado por la hija mayor. Ante esto, buscamos ampliar si todos están bajo las órdenes de la madre, para ampliar la comprensión. Por lo que la hija mayor valida esta posición de la madre, situación que nos es explicada por la madre para resaltarnos como ha intentado 
incorporar al padre en la imposición, control de reglas y en la toma de decisiones, descalificando al padre, en tanto el bajo rendimiento académico de su tercer hijo y comportamientos no esperados de parte del segundo hijo, le hacen deducir que el padre no hace bien su labor parental. Es por ello por lo que buscamos ampliar la explicación que da la madre, a lo que ella nos justifica en estas situaciones la necesidad de ella retomar su posición privilegiada de autoridad.

Al respecto, como terapeutas buscamos movilizar reflexiones en el padre en torno al relato de la madre. Sin embargo, él me ofrece una respuesta evitativa, por lo que buscamos llevarlo a responder para que pueda expresar lo que piensa sobre esta situación. Ante esto, el padre me responde reconociendo que le falta autoridad para con sus hijos, y me expresa su necesidad de estar más presente como padre en el sistema familiar. Este conflicto comunicacional nos permite indagar cómo se encuentra hoy en día el subsistema conyugal, situación en el que la madre expone lo que ella espera de la relación con su esposo, describiendo cómo la intervención de la familia extensa de su esposo ella la ve como una intromisión que está generando dificultades en su relación conyugal, realizando además distinciones entre la relación de ella con su familia extensa y de su esposo con la de él. A su vez nos expresa como ella espera que su esposo se mantenga alejado de su familia de origen, como una forma de mantener su posición de poder y continuar colocando a su esposo en un rol de hijo y no de esposo, en tanto lo descalifica en su rol de hombre, de padre y de esposo, colocando de presente su creencia patriarcal de que el hombre es el que debe tomar las riendas de la familia.

Ante esta respuesta buscamos conocer lo que piensa el esposo e indagamos su opinión al respecto, a lo que el esposo nos responde explicando las razones por las que tomó la decisión de irse al pueblo, retomando el bajo apoyo que él tiene en la capital y realizando distinciones en la crianza que han recibido los dos por parte de cada una de sus familias. Ante esta situación, me 
comunico con el padre a través de un lenguaje analógico que le permita reconocer que le estoy entendiendo y él pueda retomar el relato, a lo que nos indica como el estar cerca de su familia es importante para él, expresándome emocionalmente con dificultad lo que siente, limitando su expresión verbal.

Ante esta reacción del esposo, la esposa lo descalifica usando su lenguaje analógico para mostrar su descontento, por lo que buscamos que el esposo externalice lo que siente y piensa llevándolo a retomar el relato preguntándole por su reacción emocional para comprender porque se siente así y mostrándole posibles respuestas, por lo que él retoma explicándome que la falta de oportunidad de trabajo que él siente, le genera "estrés" y es lo que le lleva a tomar la decisión de regresarse al pueblo.

Así mismo, buscamos comprender si el estar en la ciudad lo lleva desesperarse y él nos responde relacionando el estrés con la dificultad que ha tenido para conseguir trabajo, con el bajo apoyo económico que aporta en casa y como observa que sus hijos necesitan alimento y él no puede proveerlo. Esta conversación nos permite generar distinciones en el relato de la madre sobre la cercanía entre el esposo y su familia de origen y el motivo para irse de la ciudad. Situación que posibilita que el padre nos recalque que las condiciones de estar en la capital son diferentes a estar en el pueblo.

Ya para el cuarto escenario, como terapeutas buscamos indagar cómo la esposa comprende la dinámica relacional entre los integrantes de la familia extensa del padre. Ante ello, la madre nos responde que su suegra también cree que su esposo es alcahueta con sus hijos. Esto nos permite aperturar reflexiones a partir de usar las palabras de la suegra con las de ella. Al respecto, la madre nos responde comparando la forma como su esposo y el padre de él se relacionan con sus hijos de forma cercana a nivel afectivo y emocional. Gracias a esta 
interacción del padre con su suegro, buscamos reforzar con la madre como el primero se relaciona desde lo emocional. Por esto buscó reforzar a la madre como el padre a partir de la interacción con su suegro se relaciona desde lo emocional. Ratificándome la madre esto. Situación que buscamos reconocer y exaltar que es la relación con su padre y la madre me valida la respuesta.

Así mismo, buscamos reconocer la forma de relacionarse del padre con lo que le llama la atención a ella de él. Por lo que la madre, nos ratifica su respuesta y la amplia desde un lenguaje apreciativo hacia el padre. De igual manera, buscamos naturalizar la forma como el padre habla y cómo se relaciona con ella; a lo que la madre nos aclara que esto mismo lo hace con sus hijos, describiéndome las palabras que usa para referirse a sus hijos, que, aunque son palabras descalificadoras no son vistas así por ella. Igualmente, buscamos indagar por una de las palabras usadas por el padre, en donde la madre aclara su significado naturalizando nuevamente que no se trata para ella de una mala palabra, colocando un límite para expresar que solo esas palabras son las que usa el padre.

En relación con esta apertura, de reconocerlo y relatarlo positivamente, buscamos reforzar que el padre es respetuoso y como ella ha logrado romper la pauta de violencia al interior de su familia de origen en su familia nuclear. Ante esto la madre me explica la pauta de maltrato y la relación conflictiva entre los miembros de su familia extensa, reconociendo por parte de nosotras la necesidad de ratificar la nutrición relacional que el padre provee a sus hijos como algo positivo. Aunque la madre nos explica que le gusta esto que hace el padre, continúa retomando su narrativa dominante en torno a la periferia del padre sobre la imposición y control de normas.

Esto nos conduce a indagar sobre si la madre le exige al padre que ejerza su rol parental normativo y si lo ha hecho recientemente. Al respecto la madre nos responde indicándonos que 
no y describe nuevas situaciones en las que el padre omite ejercer su rol parental normativo. Ante esta respuesta, buscamos llevarla a reflexionar sobre cómo ella es responsable de que sus hijos lo vean como un padre que no cumple su rol. A lo que la madre nos responde que en efecto ella "a veces" lo descalifica, planteando la necesidad de reconocer si la descalificación la hace delante de sus hijos, a lo que la madre nos responde de forma afirmativa, haciéndose consciente que lo hace sin medir las palabras que usa. Ante esto, buscamos reforzar su responsabilidad ante la descalificación del padre y la imagen de él que construyen sus hijos. Esto permite que la madre reflexione sobre cómo sus mismos hijos le dicen que el padre no le hace caso a ella, planeando la necesidad de comenzar a cambiar su lenguaje descalificador hacia el padre, situación que me permite entender la respuesta de la madre como positiva, aunque no se entienda lo que dice verbalmente. Esto permite hacerle entender que esta situación no solo le afecta a sus hijos y su esposo, sino que también a ella misma. Por lo que la madre nos responde de forma afirmativa y nos coloca un ejemplo de cómo su cuarta hija a usado palabras inadecuadas para dirigirse a ella y defender a su padre argumentando sentirse amada por él.

Como terapeutas buscamos establecer distinciones en las conversaciones que sostiene la pareja como padres y esposos delante de sus hijos. Al respecto la madre indica que su narrativa hacia el padre está relacionada con exigirle castigo para sus hijos, en donde buscamos ratificar la pregunta si esto es lo que se habla delante de sus hijos. La madre nos ratifica su respuesta de pedirle al padre, el castigo para sus hijos para que ellos no le alcen la voz. Situación que nos da la apertura para llevar a la madre a la reflexión preguntándole si esto está bien, respondiéndome que no y describe como terceros le han hecho ver que esto está mal. Le hacemos la devolución haciéndole ver cómo sus palabras y acciones generan distanciamiento con su esposo; reconociendo las diferencias en la crianza de cada uno, respecto a la fijación y control de las 
reglas y normas. Ante este mensaje, la madre nos responde que su esposo no fue maltratado en su familia de origen, ratificando nuestra exposición.

Ya para el último escenario, buscábamos comprender si se ha venido cumpliendo el objetivo terapéutico trazado al inicio del proceso, a lo que la madre nos responde de forma afirmativa y explica ampliamente como ha venido observando cambios en sí misma, en sus hijos y como reflexivamente ha venido igualando la posición de su esposo para los dos tomar decisiones y "administrar, el hogar".

Finalizando el análisis, encontramos la cuarta categoría emergente “mis hijos puede escoger lo que quieran, pero deben ser profesionales", que nos invita a reconocer el principal cambio de la madre ante el interés de que sus hijos estudien lo que a ellos les interese, pero deja de antemano reconocer el mandato familiar de ser profesionales como condición familiar. Lo anterior se reconoce en el primer escenario, cuando se pretendía aclarar y resaltar la cercanía entre la madre y la primera hija, a lo que la madre me responde afirmativamente justificando su cercanía por que su hija "poco sale" resaltando los motivos o lugares que esta hija comparte a parte de su casa. Aclaración que es respaldada por el segundo hijo. La madre me resalta el comportamiento ejemplar de su hija al estar pendiente de sus hermanos menores, mediante el cuidado y apoyo y espera que esta hija pueda ser profesional, para que pueda apoyar a sus hermanos en la realización de estas metas. Ante esto, reconozco entonces que la responsabilidad de su hogar recae en sus manos, por lo que justifica la necesidad de que ellos sean profesionales y cómo ha fortalecido la unión familiar, a partir del cuidado y protección de los hijos mayores hacia lo menores en todos los espacios que ellos pueden compartir, es decir el cuidado en el colegio y en el hogar.

Así mismo, como terapeuta busque hacerle ver que cada hijo es diferente, reconociéndoselo 
a la madre a partir de la frase "no somos iguales"; por lo que la madre nos responde reconociendo las diferencias de cada uno de sus hijos, aunque espera que todos respondan de forma similar, es decir que primero se dediquen al estudio y luego si otros intereses; dentro de estos la madre menciona que no deben salir de la casa porque se pueden presentar accidentes que sean reportados a las instituciones de control, produciendo distanciamiento en la familia.

Bajo esta sintonía, buscamos generar espacios de reflexión a partir de conocer la opinión de la madre ante los cambios que los hijos hicieron al dibujo de ella, para lo que la madre nos responde que sí puede ver los cambios de sus hijos, pero que igual espera que sus deseos sean aceptados por los niños, aunque ella no acepta la posición o deseos de ellos.

Ante esta situación, indagamos sobre la incorporación de la narrativa dominante en este sistema familiar, para lo que la hija mayor me responde que es tan importante que casi se ha convertido "en un sueño" (o meta a corto-mediano plazo). A lo que preguntamos desde cuando ella ha tejido este sueño, y la hija responde que esto viene de tiempo atrás, recordando que su madre les ha repetido constantemente que "el que [no] estudia no es nadie". Ante esto indago este mensaje en los hermanos y la madre me responde que no, que esta presión (hacia lo académico) se ha exacerbado en Bogotá, ya que en su lugar de origen ellos eran muy pequeños. Acto seguido la hija mayor interviene para reconocer que este mandato recae principalmente en ella. Aunque los hijos, eran muy pequeños cuando emerge este relato al interior del sistema familiar, aunque la madre me responde que este pensamiento siempre ha estado en ella porque no quiere que sus hijos tengan una vida como la de ella.

En medio de esta exigencia de antes y ahora, indagamos sobre la posición que tiene la cuarta hija, por lo que la madre nos responde que ella la coloca estudiando y seria, porque siempre se ríe, y la madre considera que esta no es una característica de un profesional. Ante esto 
preguntamos si no es posible que también sonría, y la madre reflexiona, se cuestiona y expresa que si puede sonreír pero que debe "tomar en serio lo que está haciendo, pero también puede sonreír". Esto nos permite cuestionarle si estas dos acciones (ser serio y sonreír) no podrían desarrollarse de forma paralela; a lo que la madre responde reconociendo que sí puesto que "según lo que le guste ella será feliz en lo que está haciendo".

Acto seguido, como terapeutas indagamos con el sistema familiar, principalmente con la madre acerca de cómo podría ayudar a sus hijos sin imponer sus ideas sobre lo que ellos deben hacer en el futuro, por lo que ella responde usando un ejemplo de su familia de origen frente a la importancia de ser profesionales y salir adelante. Durante el proceso le cuestiono que lo que dice "es salir adelante" y no imponer sus deseos, a lo que ella reflexiona que lo importante es que ellos se decidan por algo para que puedan cumplir sus intereses y necesidades.

En este mismo encuentro, también buscábamos conocer como el sistema familiar había realizado el álbum (como acuerdo de la sesión anterior) por lo que la madre responde que no lo tenía en ese momento, y comienza a comentarme como lo realizaron: le preguntaron al padre sobre que quería o como quería que lo colocaran, resaltando que los dibujos y lo demás lo realizó con sus hijos. Acto seguido, pregunta sobre otras partes del dibujo, y la madre me comenta la nueva forma que tendría esa casa, que los dos padres estarían juntos orientados a la misma misión y con el mismo sueño. Además, me explicó que estarían haciendo cada uno de sus hijos desde sus intereses. Así mismo, al realizar la evaluación de la estrategia artística por parte del sistema familiar, principalmente con la madre; podemos conocer en un principio, que las reflexiones que logró se dieron cuando observaba las fotos y pudo recordar cómo había ubicado a los niños, identificando que ellos al no estar conformes iban a expresar su opinión, verbalmente o a través de sus actos. Es así como pretendíamos ayudar a la madre en su proceso de reflexión a 
partir del cuestionamiento de sus sueños individuales y el amor como madre para poder posicionarla como una madre amorosa que acompañe a sus hijos en la elaboración de sus sueños, por lo que la madre me responde que, aunque le cuesta un poco, es una oportunidad de aprendizaje en "espiral" que le permitirá acompañarlos.

Realizando análisis de las estrategias artísticas, con el escenario 4, buscábamos indagar sobre la percepción del familiograma, por lo que la madre responde que "Bonito", puesto que su hijo realizó la mayoría del trabajo, pero no responde sobre que le permitió a ella, por lo que me fue necesario ahondar sobre sus reflexiones. La madre responde reconociendo que con el ejercicio pudo observar que podía ser menos autoritaria, darles más cariño y dejar que ellos tengan sus propios sueños.

Al siguiente encuentro, buscamos indagar si se han presentado cambios en la interacción madre e hija a partir de la conversación armoniosa, en donde la madre me expone que no, porque siempre impuso su relato frente a la universidad, pero hoy en día ya podrían conversar sobre una opción de estudio sobre lo que ella quisiera y no sobre lo impuesto. Lo que da pie para que preguntemos si el colocar un límite intergeneracional permitió otros cambios en dicha interacción, a lo que la madre responde que sí porque la rabia de su hija hacia su esposo era por lo que ella le contaba sobre él ahora al no hablar de eso ya no se dificulta esa relación.

Ya finalizando el proceso, la madre nos menciona que los tres (madre, padre e hija mayor) son el ejemplo de la familia y apoyo para el resto del sistema nuclear, por lo que le preguntamos si esto no se convertiría en lo que ha venido pasando con su hija mayor. A lo que la madre responde mencionando que el apoyo es para todos para que puedan cumplir sus planes y sueños. A partir de esta reflexión, indagamos con el sistema familiar qué cambios habían logrado, según sus propias percepciones. Frente a lo que la madre responde que su cambio más grande es dejar 
la autoridad suprema basada en sus sueños para tener en cuenta los deseos de cada uno de sus hijos. Lo que nos permite preguntarles este cambio qué le ha dado a la familia, respondiendo la madre que identifica que ahora hay una mayor integración y apoyo mutuo, que los invita a trabajar como familia dando "pequeños" pasos.

\section{Procesos heterorreferenciales}

Durante el primer escenario de esta primera categoría emergente, se puede identificar en la conversación que expone la manera como la madre disciplinaba a sus hijos, a partir de "pegarles", puesto que no encontraba otra manera de ejercer su autoridad y que los hijos obedecieran o lo que ella denomina no le "hicieran caso", historias que emergen en el relato del segundo hijo desde una postura de tranquilidad y normalizada. Así mismo, la madre menciona la relación distante que se ha construido entre su esposo y su primera hija, puesto que al estar enfocada más en los medios tecnológicos que en temas de juego, describe a su hija como seria mencionando la misma analogía para referirse a la manera como ella se relaciona con su familia de origen. En el sentido de indagar más sobre la jerarquía familiar y la posibilidad del ser parte de la familia al poder expresar su sentir al interior del sistema nuclear, se hace evidente la posición parentalizada del segundo hijo desde una alianza con la madre ya que este hijo si puede expresar y dar a conocer su opinión, en contra posición al tercer hijo quien tiene una alianza con el padre silenciando su voz al interior de la familia. Así mismo, con relación a esta jerarquía se supondría que esta familia puede realizar acuerdos, pero se evidencia que la madre impone sus decisiones opacando la voz de sus hijos y posible toma de decisiones de los mismos, llegando esta situación a contradecir lo impuesto por la madre y lo deseado por los hijos.

Para el escenario número cuatro (4), se buscaba indagar respecto a las comprensiones de la 
madre sobre el encuentro anterior, en relación con lo que conversa de este con su familia; evidenciándose que si bien a nivel cognitivo comprende es importante encontrar otros espacios de relación como familia distintos a la iglesia; a nivel emocional y pragmático no se identifican movilizaciones, puesto que incumple el acuerdo de salir con sus hijos y esposo durante el fin de semana. Además, se pretende dar a conocer la voz del tercer hijo, quien espera encontrar mayores espacios de juego con su madre, mientras esta por su parte manifiesta se le dificulta encontrarles sentido a estos, ya que considera es más importante dedicar tiempo a los espacios académicos y a los quehaceres del hogar. Este escenario permitió que se construyeran reflexiones en donde la madre se permitiera meta observarse y comprender la necesidad de realizar cambios en la forma como se relaciona con los demás miembros del sistema familiar, en donde se privilegia su voz puesto que desde sus propias comprensiones comienza a darse cuenta de lo que se debe cambiar. De igual forma, se busca ampliar las comprensiones respecto a la pauta transgeneracional por la línea materna, comenzando la madre a reflexionar como esa alta exigencia de su madre hacia ella se ha repetido en la relación con sus hijos obstaculizando el acercamiento más a nivel emocional. Sin embargo, a su vez se evidencia como esta fortaleza le ha permitido sobrellevar algunas situaciones familiares difíciles y proteger a su familia, desviándose la comprensión de que su esposo que es un niño hacía como las diferentes posturas de cada uno como padres se encuentran en los dos extremos: de la extrema exigencia a las extremas muestras de cariño.

En concordancia, se indaga sobre cómo se gesta la relación parento filial del padre y de la madre con sus familias extensas, exponiendo la familia de la madre desde sus altos niveles de sobre exigencia y en donde su suegro es permisivo con su esposo y sus hermanos; en contraposición a su madre, ya que esta mantiene una posición de mucha dureza, descalificándola 
al sentir que su pareja preferiría a su hija sobre ella, llevándola a buscar relacionarse distinto con sus hijos, en el momento en que comienza a tener dificultades con su pareja. En el desarrollo de la conversación, se logra identificar como la madre comprende las relaciones entre los miembros de la familia extensa del padre y en su propia familia de origen. Haciendo reflexiones en torno a cómo el padre usa un lenguaje respetuoso y está más cerca de sus hijos desde la nutrición relacional. Aspectos que son para ella importantes en tanto desea un padre amoroso para sus hijos, que pueda equilibrar su rol parental normativo con el de nutrición relacional y amor complejo. Todo esto lo enmarca en la necesidad de continuar transformando la pauta de relación violenta que ha vivenciado en su familia de origen y de la cual trata de proteger a sus hijos y pareja. Se posiciona desde una postura reflexiva, en la que, aunque es convocada por su hermano para dejar su pareja no se permite dudarlo y por el contrario se apertura a generar cambios para mejorar su relación conyugal.

Para el quinto escenario, a partir de la conversación sobre el producto artístico elaborado por la familia para esta sesión, se buscaba construir reflexiones por parte de los miembros sobre los espacios en los que se pueden dar aperturas para compartir juntos como familia, siendo la madre quien más se moviliza a reconocer en su propia casa espacios en los cuales pueda retomar la idea de su tercer hijo y apertura el diálogo con sus hijos. Así mismo se puede identificar en la narrativa de la madre un lenguaje apreciativo y posibilitador, connotando positivamente los cambios a nivel del rendimiento académico del tercer hijo, reconociendo que ha generado ajustes en la forma como orienta y retroalimenta a sus hijos para no utilizar un lenguaje descalificador entre ellos. Para el séptimo encuentro, es decir escenario 5B, se comprenden los cambios en la interacción parentofilial, desde la madre, en donde esta se muestra más encaminada a la nutricional relacional que normativa, asumiendo una postura de líder que orienta a su equipo de 
trabajo. Paralelamente, la madre reconoce que cuenta con una red de apoyo y que puede activarla en cualquier momento, privilegiando, desde su voz, al contexto religioso en tanto ha sido un contexto significativo y cercano que le ha permitido conocer a personas que le apoyan. Finalizando el proceso terapéutico, se busca que, mediante la conversación, los miembros del subsistema fraternal den cuenta de los cambios que se han suscitado desde el inicio del proceso hasta el momento, como comprenden estos cambios y que sienten y piensan al respecto. Lo que permitió conocer desde la voz de la madre, las contingencias que ella identificaba para que se dieran los cambios en sus hijos. Ejercicio que posibilitó la autoobservación de la madre para identificar la transformación en el amor nutricional que ella brindaba, transformarse de la autoridad totalitaria a la orientación a partir de confiar y escuchar. Situación que permitió una reorganización en la jerarquía familiar, redefiniendo los límites, funciones y roles de cada miembro. Reconociendo que este cambio permite que los padres se funcionen para trabajar en pro de la responsabilidad del hogar y la hija mayor aporte desde su rol mediante el ejemplo.

De igual forma, entendiendo que esta familia presentaba condiciones contextuales específicas, es decir es una familia que se encuentra en condición de desplazamientos por el CAC, se pudo conocer cuando y donde emergieron los "miedos" que la madre había construido, los cuales habían impactado en la forma en la que ella se relacionaba con su sistema familiar. Aunque fueron preguntas dolorosas para la madre, puesto que recordaban un pasado de emociones fuertes y tristes, ella pudo conversar en este espacio de manera abierta y dispuesta permitiéndose resignificar esas consecuencias de esos hechos para cambiar la forma como se relacionaba con ellos. En concordancia con lo anterior y con nuestro interés investigativo, el uso de las estrategias artísticas durante el proceso permitió que, primero, con el uso del genograma el sistema observará la pautas inter e intrageneracionales que se estaban desarrollando, las cuales 
podrían ser causantes o contenedores de los conflictos y así poder dar apertura a cambios que le ayudaran a resolverlos; segundo, con la elaboración de la red social la madre respondiera de manera activa y reflexiva sobre lo que le había permitido a sí misma este ejercicio; y por último, desde el álbum familiar, la familia, principalmente la madre, pudiera resaltar o reconocer las voces de los miembros (sus hijos) para realizar los cambios o ajustes que la actividad necesitaba para que se acomodará a la realidad de ellos y no fuera, nuevamente, una imposición de los "adultos" (la madre o las terapeutas). Este proceso posibilitó un proceso de co-construcción entre el sistema terapéutico a partir de la escucha de las voces de todos los presentes y así resaltar el apoyo nutricional de la madre desde la orientación y no la autoridad totalitaria.

Continuando con este proceso heterorreferencial de la segunda categoría emergente: "Yo quiero un padre amoroso, pero prefiero al hombre de corbata", en el primer escenario se pretendía comprender qué conflictos se generan a nivel del subsistema conyugal a través de la voz de los hijos, quienes se permiten de manera transparente convocar la voz de la madre para enunciar el desarrollo del conflicto, los motivos y sus posibles soluciones. Mientras, el segundo hijo se permite retomar de manera más clara la voz de la madre, el tercer hijo expone sus ideas de una manera más tímida, y la cuarta hija se expresa espontáneamente haciendo aclaraciones más detalladas de los sucesos; tendiendo los tres hijos a ser coherentes en el relato que exponen a la terapeuta de acuerdo con su indagación.

Ya para el segundo escenario se identifican contradicciones en el relato de la madre, puesto que le genera inconformidad la imagen que los hijos han construido como perezosos, ya que ella también tiende a percibirlo y describirlo así. Produciendo que evite las preguntas referentes a su sentir, justificando que de alguna manera no deberían tener esa percepción de este al mencionar es muy trabajador. Si bien tanto el segundo y cuarto hijo se muestran como portadores de la voz 
de la madre cuando esta lo descalifica, el tercer hijo se muestra inconforme con la forma como perciben a su padre, siendo su voz acallada, en tanto el sistema no le permite exponer cómo lo perciben. Así mismo, la madre manifiesta constantemente su molestia con la postura del padre de alejarse de la familia que construyeron por acercarse a la de su familia de origen; es el segundo hijo quien apoya a la madre de manera clara, al parecer también molesto con respecto de la posición de su padre con su abuela paterna. Cuando la madre se expresa se dificulta el poder diferenciar y responder si son exigencias a nivel personal o también que sus hijos le hacen a su padre, al parecer más un reclamo de estos en ocasiones desde su voz, tendiendo a buscar explicaciones que justifiquen su sentir, aunque finalmente logra expresar lo que ella como esposa espera frente a la posición de su pareja, que hace referencia a que esta nueva familia tenga prioridad sobre la extensa. Durante la conversación el tercer hijo se permite ser la voz de su padre para manifestar que, si bien estaría compartiendo mayor tiempo a nivel familiar, no sería como lo han dibujado el resto de la familia con traje de paño. Llevando esta confusión a que la madre explique que es ella quien espera verlo así, en tanto lo relaciona con una oportunidad para verlo más organizado, que es un mandato familiar de su familia extensa y con mayor tiempo para la familia, en tanto es esto lo que le gusta de él como padre.

Para el tercer encuentro, escenario 2B, se hace evidente cómo los hijos comienzan a incluir la voz del padre en la proyección vital de la familia. Durante la explicación del álbum tanto segundo, como tercer y cuarto hijos se muestran participativos y generan opiniones de una manera más abierta, en especial el tercer hijo quien utiliza un tono de voz alto, permitiéndose mayores comprensiones en sus intervenciones, y quien denota las contradicciones que el padre le expone respecto a su ámbito laboral. En este proceso, el padre interrumpe la conversación para justificar cómo espera verse en un futuro de acuerdo con la situación laboral por la que atraviesa 
actualmente desde una postura más realista. En este sentido, la madre se permite exponer sus altas exigencias a nivel laboral respecto a su esposo, las cuales son asumidas en la identidad y narrativa del padre como propias, ya que es en esta posición de mayor independencia que se siente más cómodo a diferencia de la posición de continuar recibiendo órdenes de su esposa tal como la hija mayor lo visualiza.

Siendo así que, durante la conversación, se busca dar fuerza a la voz del padre quien manifiesta se ausenta del hogar debido a la presión que siente por la actual situación socioeconómica que vive la familia, esta situación es identificada y compartida por la madre, pero justifica desde el preocuparse por la salud de este y su afán de sacar a sus hijos como profesionales, descalificando así a su esposo por no buscar estas mismas altas expectativas y el no ser arriesgado como ella. Relato que tiende a ser reafirmado por el esposo desde el buscar continuar justificándose con su esposa, afirmando no ha contado con las mismas dificultades que ella y su misma experiencia para lograr cumplir dichas expectativas, identificando en su narrativa una auto descalificación por la amorosa familia de origen que tuvo. Así mismo, se hace evidente la posición periférica del padre en lo referente a forma en cómo se toman las decisiones en el hogar, en tanto comprende que la dificultad radica en el hecho que no cuente con un trabajo que les brinde estabilidad económica, desconociendo la solicitud de su esposa respecto a tener una mayor participación en la toma de decisiones, en tanto lo percibe más como un hijo que como un hombre. Si bien comprende que como sistema conyugal podrían tomar decisiones en conjunto, su posición es de un apoyo incondicional a su esposa así esto implique ser descalificado. Proceso que permite que el tercer hijo manifieste su opinión para mencionar su madre no reconoce nunca la voz de su padre, lo que torna difícil el que puedan trabajar como equipo.

Bajo estas condiciones en la interacción se pretende generar un espacio de conversación y 
reflexión a nivel conyugal al evidenciarse que estas dificultades se encontraban permeando el ejercicio de las funciones parentales, situación que se reafirma en tanto los padres definen su relación de pareja desde el desear estar con el otro desde la función parental y no desde encontrar cualidades a nivel de pareja. Al parecer la madre destaca el deseo del "hombre corbata", que si bien es una figura que observa en el padre de su hija mayor, destaca a su esposo como el padre amoroso siendo la cualidad por la que se siente atraída por él. Mientras que, el padre se permite reafirmar que las dificultades se centran en no contar con un trabajo fijo, llevándolo esto a huir de la capital, desmintiendo sea porque no quiera compartir con su familia. Cabe resaltar que, durante este encuentro, se evidencia un proceso de isomorfismo por parte de la interventora, al exigirle al padre que responda cuando reconoce que este evade sus preguntas, desconociendo en ese momento la dificultad del padre para generar procesos reflexivos que le permitieran comprender las preguntas y exteriorizar su sentir.

Ya para el escenario tres, se indaga sobre los cambios que la madre identifica al interior del subsistema conyugal, entre ellos se da la apertura para generar espacio de mayor comunicación y apoyo tanto a nivel pragmático, emocional y cognitivo. Como a la madre le cuesta expresar con palabras dichos cambios expone algunos ejemplos que le permiten demostrar cómo se están aperturando esos nuevos espacios de interacción en relación con su esposo, en donde lo apoya en mayor medida, dicho apoyo se relaciona con el hecho que él se encuentra cumpliendo con las expectativas de la esposa de generar acciones concretas que les permitan progresar. Cabe reconocer que es necesario que la madre re ejemplifique ese apoyo, para dar cuenta que son desde los sueños de él y no desde lo deseado por la esposa. Así mismo, se buscaba indagar respecto a las comprensiones de la esposa y los cambios que es necesario llevar a cabo de manera personal e individual en pro a un cambio en la dinámica familiar, mencionando ésta 
desde una posición reflexiva como se ha dado cuenta que ha venido imponiendo su autoridad a todos los miembros de su familia, pero también como ha venido aperturando espacios para que ellos puedan expresarse, lo que ha permitido al subsistema conyugal llegar a nuevos acuerdos.

Para el séptimo encuentro, es decir el escenario 5b, se busca indagar sobre la gestación y el mantenimiento de los cambios mencionados con anterioridad al interior del subsistema conyugal, a lo que la madre refiere que se presenta una relación más cercana, con menores niveles de agresión verbal y en la que conversan sin la presencia de sus hijos sobre sus diferencias. Así como expone cambios de primer orden referentes a nuevas actitudes en donde es más detallista y cariñoso con ella. Aunque continúa ejemplificando los cambios, hay mayor congruencia entre las preguntas de la terapeuta con las respuestas que la madre brinda.

Ya para finalizar el proceso, se pretende indagar el impacto de la estrategia artística escultura familiar, la cual afirma la madre le permitió escucharse con su esposo de otra manera y comprender cómo se conectaban en algunas ideas y emociones, es decir compartir lo que de alguna manera cada uno vivenciaba a su manera.

Estos cambios, permiten ahondar en la tercera categoría emergente: "No quiero un padre para mis hijos, ni un esposo como mi padrastro, pero le exijo ser como él". En el primer escenario, se logra identificar como el poder, en la jerarquía familiar, recae en la madre al ser quien se encuentra a cargo de hacer cumplir las reglas al interior del hogar, mientras que al padre se le dificulta esta labor. Por ello, la madre descalifica permanentemente al padre frente a sus hijos en tanto no logra que este padre imponga las reglas de forma similar a como ella lo hace. Así mismo, esta madre da cuenta del uso de un lenguaje analógico rígido a través del cual asigna las reglas a los hijos, como una forma de lograr el cumplimiento de estas reglas. Así mismo, durante la conversación se puede identificar la cercanía que existe entre el padre y los hijos 
privilegiándose desde la voz del segundo hijo, mientras la madre se esfuerza en describir por qué se da esta cercanía y en qué condiciones, resaltando los conflictos que se presentan entre el tercer hijo y el padre debido al "apego" entre ellos; además esta madre describe desde un lenguaje despectivo como sus hijos están más cercanos a través de la descalificación del rol parental normativo del padre. Mientras que el tercer hijo tímidamente siente la necesidad de expresar su motivación y la de sus hermanos para sentirse más cercanos al padre, dejando clara la disonancia entre su respuesta y la de la madre.

Ya para el segundo escenario, se logra identificar cómo se toman las decisiones al interior del sistema familiar desde el nivel del subsistema conyugal, en donde la esposa expone cómo se encuentra "recargada" en esta labor, en tanto el esposo se mantiene en una posición periférica, aunque refiere esto desde un lenguaje descalificativo hacia el esposo en la toma de decisiones, al denotar el bajo gusto de éste para ejercer esta labor. Así mismo se logra identificar como con esta sobrecarga de funciones en el rol maternal, la madre intenta equiparar esta función de equitativa entre los miembros del subsistema conyugal; sin embargo, se mantiene en una postura patriarcal en donde actualmente ella está sobrecargada, pero esto debe recaer en el hombre para que este sea quien debe "mandar en la casa" y tomar las decisiones al interior del sistema familiar. A partir de la conversación, se logra conocer que las razones por las cuales el padre se mantiene periférico del sistema familiar nuclear, desde la voz de la madre, en tanto ésta se esfuerza en relacionar esa posición del padre con la convocatoria que le hace la familia extensa del padre, mostrando así un bajo compromiso frente al sustento económico y a la relación nutricional que éste debe proveer desde su rol parental y conyugal.

Para el escenario 2B, se identifica como surge la comunicación entre los miembros del sistema familiar, en donde se privilegia la voz de la primera hija, el padre y luego la madre en su 
orden. Así mismo, la primera hija describe como ella privilegia comunicarse especialmente con su madre, mostrando su cercanía hacia la madre y explicitando cómo observa la comunicación entre los miembros a nivel de otros subsistemas. Sin embargo, la esposa se esfuerza en mostrar una comunicación más fluida entre ella y sus hijos justificando al esposo por el agotamiento debido al trabajo, lo cual es retomado por el padre para también justificar su baja participación en estos espacios con sus hijos y su esposa. Además, se puede identificar como el subsistema parental fija las normas y reglas al interior del sistema familiar, en donde se ratifica que la madre tiene una posición privilegiada en esta función normativa la cual es ratificada por el padre y la hija mayor. La madre se esfuerza en mostrar su posición de autoridad, lo que su hija mayor le válida y finalmente el padre termina justificando su posición periférica en su rol de proveedor económico. Esta posición periférica del padre conduce a que la función parental normativa sea definida, impuesta y sostenida en su totalidad por la madre, en tanto no logran realizar acuerdos a nivel del subsistema parental sobre la imposición y control de reglas. Siendo la voz privilegiada la de la madre, quien es apoyada desde el lenguaje digital y analógico por su hija mayor. Siendo predominante el lenguaje descalificador de la madre hacia el rol parental del padre, quien a su vez ha interiorizado en su narrativa identitaria expresiones de auto descalificación.

Este tipo de conversación en el subsistema conyugal invita que sea indagada la relación de pareja, en donde se privilegia la voz de la esposa, quien expresa ampliamente lo que siente y piensa en torno a la posición periférica de su esposo, describiendo cómo la familia extensa coadyuva en la configuración de esta posición del esposo. El esposo se muestra inquieto por las respuestas de la esposa y se apertura a expresar lo que piensa y siente con gran dificultad. Esta esposa usa un lenguaje analógico y digital descalificador hacia el esposo como una forma de movilizarlo a responder. 
Hacia el cuarto escenario, mediante la realización de familiograma, se comprende las relaciones entre los miembros de la familia extensa del padre y en su propia familia de origen. Haciendo reflexiones en torno a cómo el padre usa un lenguaje respetuoso y está más cerca de sus hijos desde la nutrición relacional. Aspectos que son para ella importantes en tanto desea un padre amoroso para sus hijos, que pueda equilibrar su rol parental normativo con el de nutrición relacional y amor complejo. Así mismo, en la conversación se construyen comprensiones en torno a la forma como la madre es responsable de que sus hijos no reconozcan el rol parental normativo del padre en tanto este es objeto de un constante lenguaje descalificador por parte de la madre. Generando esto cambios en la dinámica relacional de los integrantes de la familia, generando cercanía de algunos hijos hacia el padre y de otros hacia la madre. Además, logra identificarse la postura reflexiva la forma como la madre y el padre conversan sobre las normas y las reglas, en donde la madre al buscar mantener unas normas rígidas hacia sus hijos genera un alejamiento del padre puesto que este conoce desde su familia de origen una forma diferente para esto. Para él último escenario, se logra identificar los cambios en la interacción de la madre con su esposo, sus hijos y entre estos, lo que permite el cumplimiento del objetivo y el cierre del proceso terapéutico.

Ya para finalizar este proceso heterorrefencial, cuarta y última categoría emergente "mis hijos puede escoger lo que quieran, pero deben ser profesionales"; se identifica en el primer escenario que este era el encuentro que permitió conocer cómo se gesta la construcción de las relaciones en este sistema familiar, pudiéndose identificar la cercanía entre la madre e hija mayor a partir de la permanencia de esta en el hogar, razón que es respalda por el segundo hijo. De nuevo, la madre exalta un comportamiento ideal que espera que sus demás hijos puedan seguir. Además, se buscaba conocer sobre la construcción de cuidado y amor que la madre ha generado 
hacia sus hijos, en donde empieza a ser más evidente el relato dominante referente hacia el estudio y el ser profesional, influenciando el ideal de familia que los hijos puedan construir. Por ello, se pretende comprender las distinciones que la madre puede reconocer en sus hijos, siendo consciente del ciclo vital que se encuentra viviendo cada uno, atravesado por la esperanza que la madre tiene sobre el comportamiento de cada uno de ellos. Cabe resaltar que, aunque la madre puede reconocer el ciclo vital, espera que sus hijos se comporten igual que la primera y segundo hijo. Para el siguiente escenario, con la conversación se pretendía aperturar espacios de reflexión a partir de conocer la opinión de la madre ante los cambios que los hijos hicieron de su dibujo. Aunque se da la apertura a la reflexión, y la madre me responde que considera que si debe reconocerlos; sin embargo, su lenguaje digital permite identificar que ella sigue decidida en mantener su ideal por encima del querer de sus hijos.

Es así como, para conocer la construcción de este mandato (y a su vez la narrativa dominante) en la madre, se utiliza la escultura como estrategia en el escenario 2B. Por medio de esta indagación, se conoce que esta narrativa dominante ha sido incorporada en los relatos identitarios de los hijos, al punto de establecerlos como meta a corto plazo sin considerar las condiciones contextuales por las que atraviesan, aunque se parezcan a la situación de la madre. Habría que decir también que con esta conversación se pretendía cuestionar a la madre sobre la relación entre el estar juiciosos y sonreír. Este cuestionamiento generó movilizaciones en la madre que le permiten reconocer el ciclo vital de niño y permitir que se sonrían al igual que exigirles que sean juiciosos.

De manera semejante, con el tercer escenario se pretendía conocer como la madre quería o pretendía apoyar el desarrollo de la autonomía e individuación, momento que genera cuestionamiento pero que le permite darse apertura a ese proceso de cambio. Por ello, se indaga 
sobre la construcción del álbum familiar, en donde se puede identificar la invitación, que hace el sistema, al padre para que participe en la construcción de lo que ambos esperaban (padre y madre) para su hogar, así como reconocer las diferencias, intereses y el ciclo vital de cada uno de los hijos, dando apertura a este desarrollo de cada hijo.

En relación con la estrategia artística, se pretende conocer la emoción o el sentimiento que la madre vivencio al momento de realizar el ejercicio de la escultura, por lo que ella explica que el sentimiento emerge cuando revisa las fotografías que le permiten reconocer el ciclo vital de cada uno de sus hijos y lo que puede esperar cuando ella intenta imponerles su opinión o decisión ante los deseos de ellos. Esto moviliza sus sentimientos al punto de dar apertura a nuevas formas de interacción y comunicación con sus hijos; posibilitando que la madre realice aperturas para poder desarrollar cercanía entre la madre y sus hijos, lo que permite identificar una postura participativa y abierta a intentar lograr apoyar los sueños de ellos y no los de ella.

Respecto al escenario 4, se pretendía evaluar el impacto de la elaboración del familiograma, a partir de que la familia reconociera las relaciones que se estaban convirtiendo en conflictivas por la imposición de sus sueños, identificando que ellos son los constructores de su vida y ella es quien los ayudaría brindándoles "el material " para lograrlo. Siendo esto evidente en el escenario 5, en donde se pretendía reconocer los cambios que se estaban gestando en la interacción familiar, principalmente entre madre e hija mayor, ya que era quien tenía más incorporado su relato dominante frente a la academia y la percepción del padre.

Ya finalizando el proceso, se pretendía reconocer los cambios en la jerarquía familiar a partir de conocer los cambios que la familia había percibido, reconociendo principalmente transformaciones en la autoridad "suprema" escucha de otras voces y ampliar la cohesión familiar, pero respetando los límites de cada uno para no caer en un desligamiento o en una sobre 
involucración. 


\section{DISCUSIÓN}

En la investigación-intervención en consonancia con los objetivos, la hipótesis y la pregunta de la investigación frente a los resultados del estudio de caso único de la familia que se encuentra en condición de desplazamiento forzado, se comprenden recursiones entre la vulnerabilidad y generatividad al presentarse cambios en su adaptación vital, como parte fundamental de su evolución familiar particular; puesto que al tener que afrontar conflictos psicosociales, económicos y políticos propios del CAC estos cambios se potencian, al verse esta familia enfrentada a un primer desplazamiento más a nivel voluntario debido a dificultades con la familia extensa materna que se exacerbaron al alterarse la salud mental de uno de los miembros al ingresar al ejército nacional colombiano, y posteriormente a un segundo desplazamiento en ese caso forzado, como estresores no normativos externos en donde la familia debió migrar a la capital huyendo de la posibilidad que el padre de familia fuera enfilado en uno de los grupos al margen de la ley.

Estas recursiones también se relacionaron con relatos dominantes familiares en los que la familia extensa por línea materna se vio inmersa, en donde por ejemplo es necesario estudiar para salir adelante, obstaculizando el adecuado funcionamiento familiar en donde la madre desde las pautas intergeneracionales ejerce una sobre exigencia desde su posición jerárquica al interior del subsistema conyugal y por ende familiar, bajo la continua posición periférica del padre, quien se ve en la necesidad de regresar a su pueblo para suplir la economía de la familia, ya que en este nuevo contexto de ciudad su quehacer representa altas exigencias a nivel físico y son a su vez poco remuneradas, alejando a este de su familia, ya que estas nuevas condiciones no permiten 
que se encuentre con mayor tiempo de compartir con sus hijos, justificando dicha posición periférica, la cual a pesar de ser entendida por la madre termina generando malestar debido a su concepción patriarcal de necesitar un hombre que sea quien tome las decisiones y asuma las riendas del hogar, así necesite posicionarse como su violento padrastro, permitiendo el mantenimiento de una dinámica familiar de maltrato a pesar de escoger a un hombre distinto como su esposo buscando romper dicha cadena.

Lo que invita a reafirmar que los estresores psicosociales posibilitan en la familia el aferrarse a las creencias culturales y religiosas, se aumentan las tensiones en su funcionamiento, se cristalizan pautas intergeneracionales; siendo evidente en el aislamiento del padre y la necesidad de la madre por el control, al ser así una muestra de síntomas emocionales de dichos estresores que se entretejen durante y posterior a vivenciar el conflicto armado colombiano; tal como lo mencionan Campo-Arias, Oviedo, \& Herazo, 2014; Médicos Sin Fronteras, 2013; Andrade, Parra \& Torres, 2011; Castro \& Mina, 2008; Puertas, Ríos \& Valle, 2006; Alejo, 2005; Rodríguez \& Otros, 2005.

Dicho síntomas se exacerbaron en tanto la madre usaba mensajes doble vinculares a través de los cuales invalidaba el rol parental del padre frente a sus hijos y privilegiaba posiciones en sus dos hijos mayores para que asumieran roles parentalizados, posibilitando que se entretejieran pautas sintomáticas que se expresaban en el funcionamiento y la recursión entre la vulnerabilidad - generatividad familiar, al cristalizarse la narrativa de la experiencia vivida, facilitando la emergencia del malestar al interior de la familia y su relación con el entorno, al dejar el CAC residuos en la salud mental de la familia y sus miembros, especialmente en la madre. En tanto tal como lo mencionan Nieto y Ravelo (2012), cuando una persona y familia se encuentra inmerso en un conflicto bélico se presenta una obstaculización respecto a la expresión 
del dolor que bloquea a las personas y familias en relación a reconocer o co-construir recursos personales, familiares y culturales que posibiliten un mayor bienestar.

De acuerdo con las recursividades que se presentan entre la vulnerabilidad y generatividad, y en pro a la mediación del arte entre la experiencia vivida y la experiencia narrada, se reafirma la importancia de intervenir durante el desarrollo de este estudio de caso único, el que se construyeron significados recreativos de la propia realidad (individual y colectiva) por medio de los recursos imaginativos y de idealización que permitieran dejar fluir, manifestar el sentir y el pensar (Fontecha y Moreno, 2010). En este orden de ideas, la escultura familiar como estrategia artístico terapéutica sistémica, es potenciada por la fotografía como acto narrativo ya que al mostrar -a la familia- las fotografías en sesión posterior al desarrollo de las esculturas del pasado, el presente y el futuro, se potencia la recursividad del tiempo y así comprensiones entre el juego de reflexiones de los tres tiempos, en donde los miembros de este sistema además de externalizar sus ideas y sentimientos, logran visibilizar sus voces, escucharse y, en especial en el caso de la madre, ampliar su comprensión en relación a los conflictos que se presentaban a nivel familiar y resignificar así la problemática del tercer hijo, quien se justificaba como el síntoma de dicha crisis en el funcionamiento familiar. Puesto que es en el proceso de la memoria, en donde desde el reconocer de manera retrospectiva lo vivenciado, se recupera el reconocimiento del pasado desde del devenir de los tiempos que posibilitan la reinversión de un tiempo experiencial y re narrar lo vivenciado desde una nueva perspectiva (López \& Plazas, 2012).

En este entendido, esta madre comprende cómo sus altas exigencias se encontraban en disonancia con la etapa del ciclo vital de cada uno de sus hijos, e incluso de las posibilidades de su propio esposo, al ser padre de familia y ejercer el rol de proveedor en el hogar en un contexto distinto al del campo y ruralidad que le exigía gran variedad de capacidades y recursividades 
distintas a las conocidas y ejercidas por él en su contexto de origen. De esta forma, estos cambios se comienzan a fortalecer bajo la estrategia artístico terapéutica sistémica del dibujo mediante la cual se gráfica el familiograma, con el empleo de materiales plásticos, logrando que la madre y el tercer hijo concibieron las necesidades de posibilitar una mayor nutrición emocional, y a su vez al generarse una visualización del dibujo del familiograma el tercer hijo replantea lo que sucede con su manera de relacionarse y la madre construye su comprensión sobre cómo termina ejerciendo un rol parental normativo rígido y mediado por la violencia a pesar de que en su narrativa vislumbra el no querer repetir las pautas intergeneracionales de su familia extensa. Es por esto, que esta estrategia artístico terapéutica sistémica lleva a la madre a movilizarse desde un nivel más emocional, a generar acercamiento con el subsistema fraterno y a flexibilizar el vínculo con su pareja, al establecer la necesidad de desparentalizar a su hija y reposicionar a los miembros del sistema familiar que han acallado sus voces, como el padre y tercer hijo, en el entendido que los procesos conversacionales aperturan conexiones a nivel emocional y lingüístico en pro a relatos novedosos bajo dominios espacios-temporales, emocionales, comportamentales, relacionales y cognitivos, entretejiéndose con la cotidianidad de lo vivenciado por la familia y sus miembros (Estupiñán, Hernández, \& Otros, 2006).

Es así, que la generación de una movilización desde un nivel más emocional y el propiciar acercamientos entre los miembros del sistema familiar llevan al empleo del collage de la red social de Sluzki, para permitir a la familia reconocer las redes de apoyo existentes y propiciar su ampliación, por lo que se reconoce la existencia de personas significativas que les apoyan, nuevas o de relaciones constituidas con anterioridad que aún se mantienen luego de la vivencia de acontecimientos del CAC desde amigos, familia extensa materna y paterna e instituciones; por lo que se convierte ésta estrategia artístico terapéutica sistémica en un puente por medio del cual 
la familia y sus miembros relacionaron de forma distinta el contexto nuevo y el de origen; en tanto al vivenciar una ruptura significativa con las redes de apoyo al desplazarse de manera voluntaria y forzada, se encontraban inmersos en una narrativa dominante de desolación que no les permitía relacionarse de una manera distinta con su entorno, quedando atrapados en una red homogénea, en la que solo se visibilizaba el apoyo de la iglesia, coartando la autonomía e identidad familiar a pesar que éste contexto religioso fuera posibilitador a su vez de cambios en ese funcionamiento familiar. El collage entonces permite que se presenten niveles de comunicación a nivel emocional que permite reflexiones desde la autoobservación y así comenzar a movilizar al sistema respecto a la transformación de la función homeostática del síntoma, desde el posibilitar con esta estrategia gráfica, pictórica y modelada permite por una parte según Pain \& Jarreau (1994), que la familia y sus miembros comprendan los dilemas por los que atraviesan, desde el encontrar el qué a partir de la comprensión del cómo, y así comunicar lo que ha sido difícil de expresar (Wagensberg, 1985).

Por esto, al ser importante continuar afianzando el cambio posibilitador en la dinámica familiar de acercamiento a nivel emocional y el aperturar espacios de conversación entre los miembros del sistema familiar frente a las comprensiones construidas en cada sesión, se recurre a la estrategia artístico terapéutica sistémica del álbum familiar la cual proporcionó a la familia una forma de movilizar inicialmente cambios de primer orden, al posibilitar espacios de interacción que alternaban su dinámica familiar, invitándolos a compartir para plasmar aquellos sentimientos, emociones y aprendizajes de cada encuentro. Mientras que, para las siguientes sesiones permitió visibilizar y potenciar los cambios construidos, identificados y reflexionados por las otras estrategias artístico terapéuticas sistémicas, impactando así su dinámica relacional y los procesos de individuación, autonomía y desarrollo de los diferentes miembros de este sistema 
familiar, lo que puede llegar a permitir una mayor cercanía con el self familiar e individual, en donde se espera se construyen nuevas comprensiones y posibilidades (Winnicott citado por Marxen, 2011; Wengrower \& Chaikin, 2005).

Por lo que, al emerger estos diversos cambios y comprensiones se convoca la construcción del cuento (story board family) a partir de la páginas de los álbumes familiares construidos por los miembros del sistema familiar posteriormente a cada sesión, como una forma de visualizar hacia la familia todos estos cambios y movilizar las capacidades de los miembros reafirmando las transformaciones que éste sistema había vivenciado en torno a su funcionamiento familiar; para ello se reconocieron las capacidades individuales y familiares, desde la comprensión respecto a como lo vivenciado en el CAC es acallado encriptándose en el silencio, fracturando en este caso las relaciones familiares, en donde emergieron sentimientos de soledad, puesto que se vieron enfrentados a un lugar al que no pertenecían y en donde no se permitían contar su historia, y a pesar de encontrarse en una condición de desplazamiento forzado y bajo dificultades económicas las cuales continúan generando mayor preocupación por el sobrevivir logran mantenerse, superar adversidades y evaluar unas nuevas posibilidad de vida. Esto además permite potenciar las voces de cada uno de los miembros del sistema familiar e imaginar mundos posibles sobre cómo podría ser su futuro en el actual contexto en el que se encuentran, desde un acto creador en donde cumplen un papel primordial la expresión, la comunicación, la transformación y el conocimiento (Martínez \& López, 2009), desde el favorecer el cambio fomentando la activa participación de lo miembros y de la identificación de los recursos relacionales y comunicacionales que les permiten ser conversados (Medina, Laso, \& Hernández, 2014). 
De esta forma, la mediación del arte en consonancia con los estados del arte documental y testimonial se comprende como un trabajo gráfico, pictórico y de modelado que posibilitó que los miembros de la familia, en especial la madre, tomaran conciencia en relación a sus propios dilemas de aquello que estaba generando tensiones a nivel familiar, como recurso para comunicar (Wagensberg, 1985) aquellos malestares familiares que no habían sido posibles expresar a los otros miembros, así como las preocupaciones que se potenciaban con las vivencias propias del CAC y las posteriores que se generaron en espacios de la capital también caracterizadas por la vulnerabilidad. Por lo que, el arte se constituyó en el mediador entre la familia y su entorno desde el recurrir a la estética del desarrollo del proceso terapéutico en recursividad con estrategias artístico terapéuticas sistémicas, comprendiendo estas últimas como un diseño determinado en una intervención psicoterapéutica orientado a obtener una de las finalidades que conforman el número de finalidades que el proceso interventivo se ha trazado teniendo en cuenta los objetivos, las técnicas a implementar y la forma como se colocan en juego estas técnicas seleccionadas, que en este estudio de caso único, una de estas finalidades estuvo encaminada a generar adyacentes posibles de explicaciones y reflexiones de eso vivenciado en el CAC. Generándose, como lo menciona Hernández y Niño (2013), una experiencia multidimensional en la que interjuegan tanto las sensaciones kinésicas, emocionales, estéticas, cognitivas y culturales, potenciando el proceso creativo del sistema familiar y sus miembros en ese buscar aliviar aquellos sentimientos de miedo y dolor producto de haber vivenciado acontecimientos del conflicto armado colombiano.

Es por esto por lo que las estrategias artístico terapéuticas sistémicas son un posibilitador de la exteriorización, en donde el foco no es el producto final sino el proceso de construcción de los productos artísticos, en tanto están en consonancia con elementos propios 
del proceso interventivo enmarcado en objetivos, técnicas interventivas y formas de poner en uso estas técnicas interventivas, en aras de movilizar como lo menciona Pain y Jarreau, (1994) y Dalley, (1987) comprensiones de la relación entre el miembro de la familia quien crea el producto artístico y para quien es construido. En tanto éste último autor indica que no solo desde una forma pictórica sino también desde la producción de imágenes y objetos artísticos la familia podía representar aquello atemorizante y amenazante, al expresar lo que era prohibido y lo que podían proyectar, conversando sobre su malestar o sufrimiento de manera indirecta, desde la posibilidad. Por cuanto, producto del desplazamiento y de otras vivencias anteriores, como lo mencionó Andrade, Parra y Torres (2011) el vivenciar procesos de discriminación, que promovieron expresiones poco ajustadas del pasado traumático al buscar adaptarse a las nuevas exigencias del medio citadino y sus demandas, se generó una alta necesidad de protección hacia su esposo e hijos por parte de la madre coartando la posibilidad de pensar y sentir de estos, recargándose a sí misma de la responsabilidad de que dicha familia saliera adelante desde el mandato de exigencia por línea materna, desde la apertura a incluir posibles caminos en el futuro familiar y de sus miembros, potenciando así el cambio en la experiencia narrada del bienestar deseado; aunque como lo menciona Llanos y Otros (2009) estas familias pueden también experimentar un aumento de su propósito de vida, incrementando la satisfacción con esta, lo cual les permite una evaluación positiva de lo que han logrado en pro de la movilización de su prospectiva vital.

Por lo que esta sobreexigencia y sobrecarga de actividades en la madre son reconocidas por ella misma mediante el uso de las estrategias artístico terapéuticas sistémicas al comprender como lo vivenciado durante el CAC potenciaba su desconfianza respecto al nuevo entorno en el cual se encontraba, ampliando sus narraciones emergentes como lo menciona Klein citado por 
Marxen (2011) desde un proceso de verbalización creativo y emocional; reconociendo esta madre que esto vivenciado obstaculizó la evolución familiar y los procesos de autonomía e individuación de los miembros del sistema familiar, en tanto en estos contextos de violencia surgieron sentimientos que fueron evitados por la familia al ser difíciles de tolerar, pero que al representarse a través de los productos artísticos les permitieron como lo explico Wengrower \& Chaikin (2005) generar aproximaciones por una vía artística - simbólica de manera estética a dichos sentimientos, pensamientos en características distintas de la situación, a sus personajes, etc. camuflados en emociones y sentimientos que eran difíciles de expresar en la cotidianidad.

Es por esto, que se comprende que el arte y en este caso las estrategias artístico terapéuticas sistémicas si bien potenciaron en la familia momentos de caos, es allí donde se fortaleció su creatividad para que desde un proceso estético dicho desorden se traslapara con la armonía y la diversidad en pro a la construcción de perspectivas vitales familiares más esperanzadoras y en donde los integrantes del sistema tuvieran la oportunidad de expresarse, que como lo señala Dalley (1987) posibilitando que la familia representará de otra manera la experiencia vivida en ese adaptarse a las nuevas circunstancias.

Estas posibilidades de expresión y resignificación que surgen con la mediación del arte dan cuenta de una propuesta posibilitadora en relación a lo expresado por Medina, Laso, y Hernández (2014) en donde se refieren a la deserción y desvinculación de niños, niñas y jóvenes por el desarrollo de procesos terapéuticos en los que se privilegia el uso de formatos estandarizados e institucionalizados, desconociendo la creatividad como favorecedora del cambio que permite descubrir al terapeuta nuevas estrategias para abordar los problemas que expresan las personas y resignificarlos, e inclusive fomentar en la familias la exploración de la creatividad de sus miembros, invitándolos a reconocer sus recursos relacionales y de comunicación, convirtiéndose 
para la familia de éste estudio de caso único en un camino alterno de comunicación, de expresión y facilitador entre sus miembros desde su propio rol, en tanto no se privilegiaban espacios para el diálogo entre los miembros del sistema familiar antes y después de haber vivenciado acontecimientos del CAC, y a nivel del subsistema conyugal el diálogo era exclusivo para el control en el cumplimiento de reglas por parte de los hijos. Lo que conlleva a comprender lo expuesto por Wagensberg (1985), en cuanto a que los procesos terapéuticos mediados por el arte, en este caso por estrategias artístico terapéuticas sistémicas intervienen entre la autoorganización y la interrelación del ser humano y su entorno, desde la potenciación de la creatividad, es decir dinamizando las capacidades individuales y familiares; que como, lo refiere Rodríguez y Serna (2015), son elementos que interactúan, en relación a otros individuos, comunidades y familias, enfrentándose a un proceso de intercambio entre el contexto sociocultural del que provienen y al que migran.

En este entendido en el que emergen diversos contextos de interacción para estas familias en situación de desplazamiento se hace importante propiciar, como lo refiere Hidalgo (2005), diálogos conversacionales interculturales que posibiliten crear espacios de reconocimiento y valoración de la diferencia de cada uno de los participantes del sistema terapéutico, la familia y el equipo interventivo en concordancia con una línea de conversación en el marco de la igualdad, que coadyuven en la retención de los participantes en el contexto terapéutico. Pues en el estudio de caso único objeto de ésta investigación intervención en consonancia con lo expuesto por Echeverría, (1996) citado por Estupiñán, González y Serna (2006) al generar espacios conversacionales en el desarrollo de las estrategias artístico terapéuticas sistémicas siendo cuidadosos en el reconocimiento del nivel cultural, intelectual y económico de los miembros de la familia, ésta se permitió reconfigurar su experiencia en el entendido que como seres humanos 
se narran y narran el mundo que los rodea, dándole sentido a las circunstancias vivenciadas tanto durante el CAC como posterior a este a partir de lo que conocen y comprenden de él.

Por lo que es en esta construcción social de la realidad, según Alpizar y Bernal (2003), donde se concibe a estas personas y familias como sujetos activos que a su vez son capaces de transformar, de-construir y construir explicaciones posibles sobre sí, acerca del mundo y de las experiencias por las cuales se han visto forzados a atravesar; pues al convocar a Dalley (1987) éste se refiere al arte como un producto artístico que condensa historias de manera tangible, al ser éstas susceptibles de ser observadas y analizadas. Siendo importante aquí mencionar que en ese observar y analizar de historias que las estrategias artístico terapéuticas sistémicas deben seguir siendo potenciadas en los procesos psicoterapéuticos para intervenir problemas o síntomas que puedan ser resignificados a través de la experiencia vivida y la experiencia narrada, teniendo en cuenta componentes esenciales en el planteamiento de estas estrategias artísticas como: primero, el objetivo general del plan o diseño de intervención; segundo, la priorización de objetivos específicos relacionados con el foco de cada sesión de intervención, dándole un orden secuencial a cada finalidad esperada en concordancia con el cambio esperado; tercero, los mecanismos establecidos para alcanzar el objetivo específico definido describiendo el paso a paso de lo que se realizará y las técnicas a emplear, las técnicas que serán apoyo o potencializan a otras técnicas y las que podrán constituir un banco o abanico de técnicas a emplear; y cuarto, la forma como se pondrá en juego este paso a paso y como esto será valorado para la toma de decisiones, ajustes o definir diversas direcciones a tomar en pro del proceso interventivo. 


\section{CONCLUSIONES}

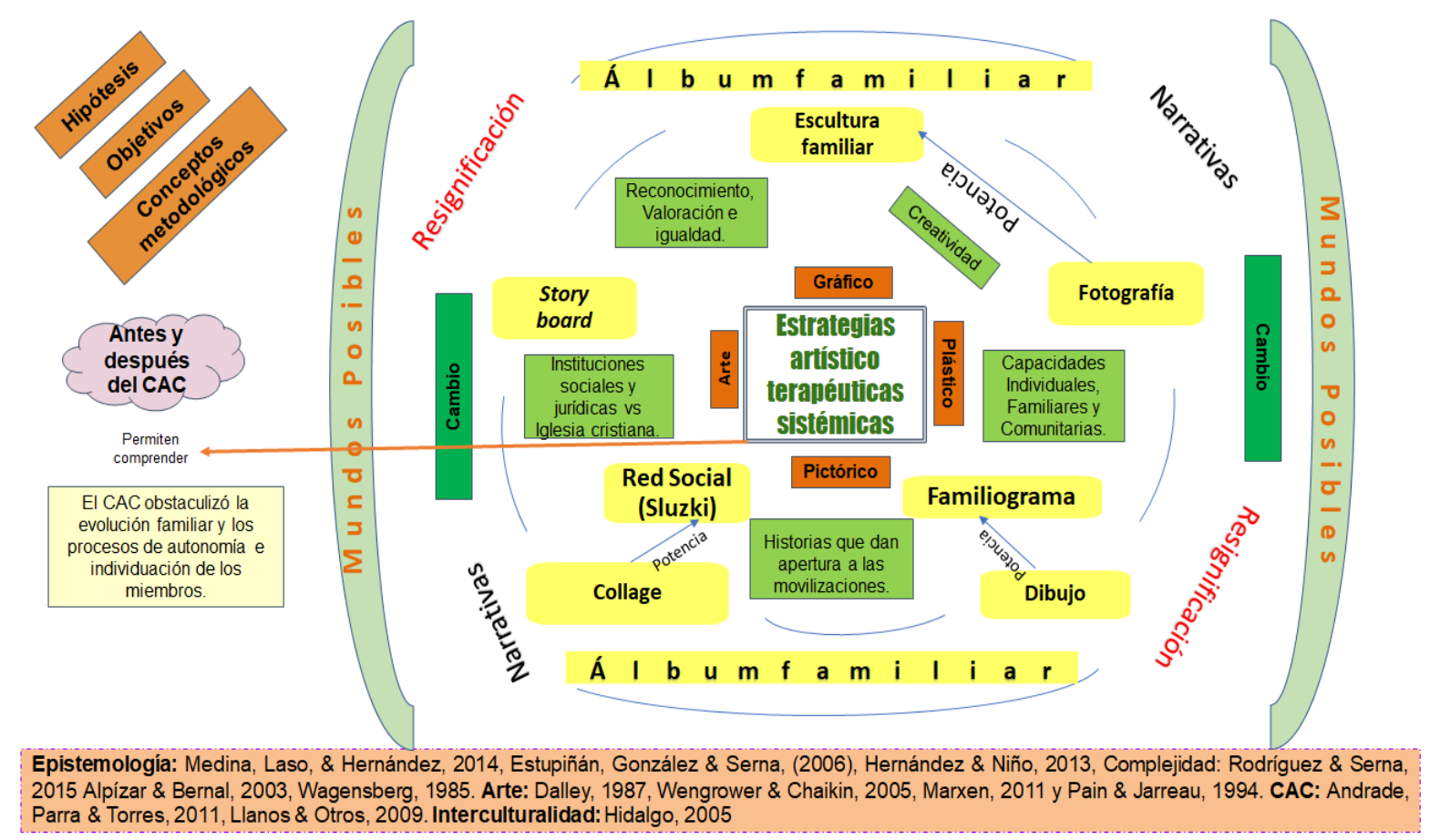

Gráfico 27 - Conclusiones. Fuente Autoras.

Se comprende en el rastreo documental la experiencia vivida en los contextos de guerra como una experiencia aterradora para la que no se facilita su narración; en tanto desde la psicología se ha encontrado que, por ejemplo, uno de los fenómenos de estos contextos violentos es el desplazamiento forzado, como lo menciona Andrade, Parra y Torres (2011), representando un alto riesgo en el desarrollo de desórdenes de la salud mental de las familias y sus miembros, en relación a la intensidad y severidad del evento vivenciado; representandose en un malestar que llega a repercutir en las diferentes dimensiones de la persona y de su familia, como momentos y encriptaciones de silencios, fracturaciones en los sistemas de relaciones, agendas 
ocultas, sentimientos de soledad y en algunos casos llegan a disminuir su autopercepción y hasta logran emerger sentimientos de culpabilidad por la vivencia del hecho (Llanos \& otros, 2009); cabe reconocer que no todos los que han vivenciado estos hechos violentos también logran adaptarse a las exigencias y demandas del medio desconocido llegando a experimentar un aumento de su propósito de vida, incrementando así la satisfacción con esta, lo cual les permite una evaluación positiva de lo que han logrado.

De otra parte, al reconocer la voces de familias que han vivenciado acontecimientos del CAC y de profesionales que han abordado este fenómeno -psicóloga y trabajador social-, se concluye la pertinencia de emplear el arte como estrategia de cambio para conocer la reconfiguración de la experiencia narrativa de dichas familias y sus miembros, en razón a que esta hace parte del proceso interventivo y de diálogo con otras disciplinas; es decir que posibilita la externalización de emociones y sentimientos, como un instrumento que permite desbloquear a la persona y sus familias, desde su capacidad creadora, en la que los saberes locales permiten la transformación de la experiencia; en tanto se hace entrega de los sentimientos vividos, y se permite contagiar a los demás de estos y que así los puedan resignificar . Siendo así vital para ser coherentes con la forma cómo se piensa, se habla y se trabaja como psicólogos, el reconocer a las personas como seres eco-eto-antropológicos.

Para ello el arte se comprende como un medio de comunicación y re-significación de las experiencias de las personas, siendo un instrumento que permite, mediante la conversación sobre el objeto construido, realizar reflexiones e interiorizaciones (Alyami, 2015); así como un posibilitador de la expresión de las emociones, pensamientos, sentimientos -traumáticos, dolorosos o no- siendo a su vez práctico para la diversidad de la población (individuos, parejas, familias y/o grupos). De esta forma, el arte opera en el proceso individual ayudando a conectar 
interculturalmente la vivencia personal y el nuevo contexto al que migra aperturando la resignificación de las experiencias vividas.

En este sentido, al estar el fenómeno del desplazamiento forzado arraigado en el contexto colombiano producto del extenso proceso del conflicto armado, se evidencia durante la lectura de contexto y el acercamiento a dicha población que el funcionamiento de las familias que han vivenciado acontecimientos del CAC presenta cambios en su adaptación vital, los cuales se potencian al verse enfrentados a conflictos psicosociales, económicos y políticos propios de dicho fenómeno, entretejiéndose pautas sintomáticas que se expresan en el funcionamiento y la recursión entre la vulnerabilidad - generatividad familiar, al cristalizarse la narrativa de la experiencia vivida, facilitando la emergencia del malestar al interior de la familia y su relación con el entorno; por lo que, al desarrollar las estrategias artístico terapéuticas sistémicas se dinamizan las capacidades individuales y familiares y se da el cambio en la experiencia narrada del bienestar deseado.

Se entiende así que desde una mirada sistémica, compleja, construccionista y constructivista, el cambio es una construcción discontinua que se debe a diferentes niveles en donde los sujetos comparten el modo sobre cuándo y cómo comprenderlo, es decir que emerge como una novedad en el plano de interacción bajo los principios de circularidad, relatividad, discontinuidad e incertidumbre, permitiendo la simultaneidad y confluencia, pero no de forma consecutiva, ni paso a paso o controlada. Esta transformación hace parte de la experiencia particular del sistema humano, la cual puede ser puntuada de manera similar y/o diferenciadora por otros, desde el acoplamiento en el plano de la interacción entre los nuevos contextos, que se interconectan en lo social, político, cultural y económico, en el lenguaje y las interacciones respecto a las pautas de comunicación, la ampliación de las fortalezas y soluciones que el mismo 
sistema encuentra en la relación a sí mismo y otros, posibilitando la emergencia de relatos novedosos a partir de las comprensiones del sistema frente a las diversas vicisitudes del transcurrir de la vida, que permiten a su vez su evolución y autoorganización.

Además, para esta investigación-intervención se comprendió el arte más como una estrategia y no una técnica en donde se aperturaron procesos terapéuticos sistémicos mediados por los terapeutas con el arte, aún sin tener conocimientos especializados en ello; al comprender las estrategias artístico terapéuticas sistémicas como un diseño determinado en una intervención psicoterapéutica orientado a obtener una de las finalidades que conforman el sinnúmero de propósitos que el proceso interventivo se ha trazado teniendo en cuenta los objetivos, las técnicas a implementar y la forma como se colocan en juego estas técnicas seleccionadas para en este caso reconocer las capacidades potenciadas por una familia que ha vivenciado acontecimientos del CAC y construir adyacentes posibles.

Se posibilitó en el proceso terapéutico de esta familia cambios individuales y familiares desde el desarrollo de los escenarios por medio de la escultura familiar, la fotografía como acto narrativo, el dibujo, el collage y el story board family. De manera transversal se desarrolló la estrategia artística terapéutica sistémica del álbum familiar, la cual generó acercamientos entre los miembros del sistema familiar posteriormente al cierre de cada una de las sesiones interventivas, en donde unidos plasmaron sus reflexiones, ideas e interrogantes del trabajo desarrollado en cada sesión, recopilando y resumiendo el desarrollo del proceso. Por su parte, la escultura familiar posibilitó la movilización familiar como una expresión plástica simbólica de la estructura vincular de la familia, mediante la instrumentalización de los cuerpos de sus miembros, así como permitió que los miembros de la familia visibilizarán como terceros sus propias maneras de relacionarse, dándose la oportunidad de comunicarse de manera distinta. 
Respecto a la estrategia de la fotografía se potenció como acto narrativo, facilitando compresiones a nivel individual y familiar frente a su funcionamiento, actuando estas fotos como símbolos posibilitadores y metafóricos transicionales que permitieron una manera de encuentro con el sí mismo de los integrantes de la familia, mediante la exploración a nivel emocional a partir de lo visual, promoviendo así el diálogo terapéutico, la externalización de discursos interiorizados distanciando a la persona de sus relatos dominantes y promoviendo una apertura al cambio.

Desde el ponerse en práctica la estrategia artística de la pintura comprendida también como dibujo, en relación a la escultura familiar del futuro y el familiograma respectivamente, se concibe como un medio de expresión en donde se da fuerza a la voz de las voces acalladas, en tanto el dibujo se convierte en un proceso de externalización e internalización, así como un potenciador de procesos autorreflexivos y comprensión en ese re observar las escenas presentadas en la escultura y el familiograma.

Por su parte el collage, medio principalmente la construcción de la red de Sluzki, logrando explorar distintas formas de comunicación, vinculadas a la capacidad de generar nuevos encuentros emocionales, movilizando al sistema frente al problema o síntoma y su función homeostática en la vinculación familiar, por lo que desde la comunicación verbal y no verbal de manera interaccional se recordó el pasado, las experiencias del presente o lo que esperaban del futuro durante la construcción de éste.

Finalmente, la construcción del cuento (Story Board Family) -desde la adaptación en su construcción- promovió la recopilación de las viñetas -páginas del el álbum familiar-, que facilitaron al equipo terapéutico la construcción de conexiones narrativas, desde la utilización de metáforas propuestas por la propia familia a través de la creatividad, que permitieron resaltar 
el cambio y bienestar deseado alcanzado por ésta durante este proceso terapéutico. Además, que esta estrategia permite que las investigadoras-interventoras puedan usar su propia creatividad para realizar devoluciones o prescripciones y a su vez facilita a los consultantes la construcción de mundos posibles para ampliar su prospectiva vital.

De igual forma, el dinamizar los procesos psicoterapéuticos con estrategias artísticas facilitó el enganche y permanencia de los miembros del sistema familiar, compuesto por adultos, jóvenes, niños y niñas, posibilitando la expresión en aquellos miembros que por su nivel educativo, contexto social y ciclo vital se les dificulta; aunque se comprendió que estos encuentros mediados por el arte no deben programarse de forma extensa o deben establecerse espacios para que los niños y niñas especialmente puedan contar con momentos de receso para jugar y descansar. Aunque también podría ser interesante programar espacios que acerquen el arte con el juego en el contexto terapéutico como una forma de posibilitar una mayor participación, externalización, reflexión y resignificación de los dilemas o síntomas humanos.

Así mismo una estrategia artística terapéutica sistémica puede ser potenciada con otra estrategia artística, especialmente la escultura familiar con la fotografía como acto narrativo, así como el familiograma con el dibujo y la red de Sluzki con el collage, en tanto al registrar momentos suscitados en el espacio terapéutico y ser observados posteriormente por los miembros de la familia, estos logran narrar la experiencia vivida haciendo recursiones sobre las tensiones o conflictos que se presenten en su funcionamiento familiar y las construcción de distintas posibilidades de ver y comprender estas situaciones.

Por lo que, desde la mediación del arte gráfico, pictórico y plástico se posibilitó que esa experiencia vivida fuese resignificada, en relación a la comprensión de la familia como sistema que desde sus representaciones, de sus construcciones del mundo posibilitan un pensamiento 
individual, personal y libre, respecto a comprender como aquello que fue vivenciado por el CAC ha exacerbado los cambios de la adaptación vital familiar, así como legitima sus reglas de interacción desde las redes de significado que circulan socialmente desde el uso del lenguaje en el nuevo contexto, potenciando así la apertura a diversas posibilidades del presente y futuro familiar, y la comprensión de dicho pasado permeado por la violencia.

Además, aunque la familia reconoce que pueden acudir a instituciones de orden jurídico (como la unidad de víctimas) para restablecer sus derechos debido al acontecimiento de desplazamiento forzado, la potenciación de otros contextos como el religioso disminuye esta prioridad en tanto este contexto surge como fortalecedor de las redes de apoyo de la propia familia. Convirtiéndose esta conexión con su sistema amplio en variables del perfil vulnerabilidad/generatividad, como factores generativos teniendo en cuenta las condiciones socioeconómicas en las que se encuentran en la actualidad. 


\section{POST SCRIPTUM}

Finalizando este trabajo de grado y las reflexiones que emergieron durante la sustentación de éste; encontramos comprensiones referentes a la recursiones entre la experiencia vivida y la experiencia narrada en concordancia al macro proyecto denominado "historias y narrativas de los sistemas humanos en diversidad de contextos", y la identificación y teorización de las categorías emergentes.

En este sentido, se hace necesario reconocer la corporalidad como parte importante de estas recursiones, que al re construir estas narrativas el lenguaje analógico presenta movilizaciones en la danza conversacional que permite, dar apertura y fortalecer lo que el lenguaje digital relata; ya que al presentarse esta danza durante el proceso interventivo, se logra dar la emergencia de estas circularidades posibilitando un cambio, dando un nuevo significado a la emoción y a la interacción.

Con base a lo anterior se logra generar interconexiones en la experiencia vital de los miembros del sistema familiar, desde la comprensión contextual y del momento evolutivo por el cual el sistema atraviesa; puesto que al encontrarse la familia bajo estresores psicosociales se cristalizan comprensiones y experiencias, que al ser re narradas durante el proceso de recordar lo vivenciado de una manera gráfica, pictórica y metafórica, se logra expresar a través de las emociones, sentimientos, sensaciones, los movimientos del cuerpo y la misma experiencia de cada consultante, permitiendo reconocer sus cuerpos para comprender mejor lo que piensan y sienten.

Siendo en este conversar del lenguaje digital y analógico, donde se promueven recursiones desde el orden interventivo, con el diseño de estrategias enfocadas al reconocimiento y registro 
de la postura corporal, para posterior evocación como generadora de nuevas comprensiones y reflexividades en los participantes del contexto terapéutico, al generar conexión entre lo cognitivo y emocional en las interacciones, y es en el proceso de concebir estas posturas donde se generan bucles recursivos en el meta observarse, en tanto el cuerpo en interacción refleja la experiencia vivida y en el proceso de significarse la emoción se construyen experiencias narradas que pueden ser leídas desde el proceso evolutivo por el cual atraviesan tanto el individuo como los miembros del sistema familiar.

Es así que, en los acontecimientos y experiencias se comprenden relatos dominantes en los que se amplían las novedades en la manera en que desde el cuerpo las personas muestran sus relaciones y reconfiguran su identidad al narrarse y re narrarse, por lo que desde el arte se apertura la posibilidad de revivir lo pasado sin borrar, sino recordar de forma diferente al desarrollar nuevas comprensiones en ese proceso conversacional y artístico.

Siendo el cambio una construcción articulada a los procesos conversacionales en los que la memoria narrada comprende su necesidad de compartir las emociones y en ese entretejerse el arte en las comprensiones y maneras de relacionarse las familias, posibilita desde el proceso de aprendizaje un continuo entre la generatividad y vulnerabilidad, en donde el componente evolutivo pauta nuevas maneras de relacionarse, las cuales se reconocen como aprendizajes en situaciones de crisis y de nuevas capacidades que aperturan la visualización de mundos posibles.

En donde las estrategias artístico terapéuticas sistémicas enmarcadas desde la creatividad facilitan al proceso terapéutico el planteamiento, diseño y desarrollo de nuevas formas de intervenir en pro a la particularidad de cada individuo, de la familia, de los diversos contextos y de los mismos interventores, en donde se convoca el arte desde sus diferentes expresiones y especialmente aquello relacionado con el reconocimiento de su cuerpo como una forma de 
comunicar lo incomunicable, de comprender lo que el otro no puede expresar, o de darle un significado nuevo para expresarlo.

Por lo que, la escultura familiar, la fotografía, el collage, el dibujo, el álbum familiar y el storyboard se reconocen como estrategias artístico terapéuticas sistémicas al promover el desarrollo de comprensiones a nivel relacional, concibiendo éstas desde la experiencia y dominios multidimensionales y espacio temporales distintos que interjuegan en la promoción de nuevos niveles de comunicación tanto a nivel individual como familiar respecto a actos creativos.

Con base a lo anterior, se comprenden las categorías emergentes: "no quiero ser como mi madre pero estoy condenada a serlo", "yo quiero un padre amoroso pero prefiero al hombre de corbata", "no quiero un padre para mis hijos, ni un esposo para como mi padrastro, pero le exijo ser como él", y "mis hijos pueden escoger lo que quieran ser, pero deben ser profesionales"; en donde, la primera puede comprenderse como relatos dominantes que se perpetúan como pautas transgeneracionales que validan y definen: las creencias familiares y formas de vinculación e interacción entre los miembros del sistema familiar y a su vez con los miembros de la familia extensa, en donde el familiograma en recursión con el dibujo genera desde lo visual comprensiones frente a estas creencias, vínculos y pautas; y a su vez convoca a la resignificación desde la reflexividad.

La segunda categoría, hace referencia al dilema presente en el ejercicio de las funciones parentales, en donde se contraponen los dominios de las funciones cognitivas (reconocimiento y valorización), las funciones emocionales (la experiencia afectiva) y la función pragmática (socialización y protección) con el imaginario construido como "correcto" para quien debe ser el encargado del sostenimiento del hogar; siendo aquí fundamental la mediación de las estrategias 
artísticas como la escultura familiar, fotografía y dibujo que en recursión con el lenguaje de los cuerpos en su integralidad convocan a los participantes a la narración de lo que piensan y sienten para resignificar sus propias comprensiones y las de los otros participantes. Dilema que entra también a conectarse con la tercera categoría, principalmente con el ejercicio de las funciones parentales, que como ocurre en algunos sistemas familiares la fijación y control de las reglas y las normas son fundamentalmente privilegiadas a uno de los miembros del subsistema conyugal aperturando la configuración de alianzas o coaliciones con los otros integrantes de la familia; siendo aquí fundamental la mediación de estrategias como el álbum familiar, la escultura, la fotografía y el dibujo que promueven actos narrativos metafóricos en pro del encuentro emocional y comunicacional y movilizadores en la función homeostática.

En cuanto a la última categoría, ésta hace referencia -principalmente- al imaginario socialmente construido -y el cual ha sido interiorizado como creencia familiar- en torno a una alta exigencia en la prospectiva vital de los subsistemas de la familia, en donde alguno de los miembros del subsistema conyugal determina las expectativas profesionales y laborales de los participantes del subsistema fraternal. Siendo aquí de gran aporte el uso de estrategias artísticas, como el álbum familiar, el storyboard y el dibujo, al convertirse estas en formas de crear adyacentes posibles frente a la construcción de una prospectiva vital más coherente en relación al ciclo vital familiar e individual en resonancia con la realidad contextual de cada sistema familiar. 


\section{REFERENCIAS}

Agudelo, M. \& Estrada, P. (2012) Constructivismo y construccionismo social: Algunos puntos comunes y algunas divergencias de estas corrientes teóricas. Prospectiva No. 17: Pp. 353-378, noviembre 2012.

Tomado de: http://bibliotecadigital.univalle.edu.co/bitstream/10893/6341/1/14$\% 20$ Constructivismo $\% 20 y \% 20$ construccionismo $\% 20$ social.\%20Algunos $\% 20$ puntos $\% 20$ comu nes $\% 20 \mathrm{y} \% 20$ algunas $\% 20$ divergencias $\% 20 \mathrm{de} \% 20$ estas $\% 20$ corrientes $\% 20$ te $\% \mathrm{C} 3 \% \mathrm{~B} 3$ ricas.pdf

Alejo EG. (2005) Aplicación del modelo de estrés postraumático en el estudio del impacto de la violencia sobre la salud mental en población desplazada. Med UNAB; Vol. 8(1):23-28, recuperado de: http://revistas.unab.edu.co/index.php?journal=medunab\&page=article\&op=view \&path\%5B $\%$ $5 \mathrm{D}=207 \&$ path $\% 5 \mathrm{~B} \% 5 \mathrm{D}=190$

Alpízar, L. Bernal, M. (2003) La construcción social de las juventudes. En: Última década, N. 19. pp. 1-20. Centros de Estudios Sociales: Valparaíso, Chile.

Alyami, A. (2015). The role of art therapy in counterterrorism: The Saudi experience. En: The Arts in Psychotherapy, Vol 44, pp. 1-10. Elsevier: Arabia Saudita.

Amar-Amar, J.; Abello-Llanos, \& Otros R.; Madariaga, C. \& Ávila-Toscan, J., (2011). Relación entre redes personales y calidad de vida en individuos desmovilizados del conflicto armado colombiano. En: Universita Psychologica No 36, pp. 355-369: Bogotá.

Andersen, T. (2009) El equipo reflexivo. Ed. Gedisa.

Andrade, J. Parra, M. \& Torres, L. (2011). Tendencias psicopatológicas en personas desplazadas y 
reasentadas en el departamento del Quindío entre 2005 y 2011. En: AGO.USB. Vol. 11, Núm. 2 Julio - diciembre, pp. 279 - 296: Colombia

Ardón-Centeno, N. \& Cubillos-Novella, A. (2012). La salud mental: Una mirada desde su evolución en la normatividad colombiana. 1996-2012. En: Revista Gerencia y Políticas de Salud, Vol. 11, No. 23, pp. 12-38. Pontificia Universidad Javeriana: Bogotá.

Arévalo, N. L. (agosto de 2010). Atención y reparación psicosocial en contextos de violencia sociopolítica: una mirada reflexiva. Revista de Estudios Sociales, No. 36, pp. 29-39. Obtenido de http://dx.doi.org/10.7440/res36.2010.03: Bogotá.

Arias, D. \& Vargas, C. (2003). La creación artística como terapia. Cómo alcanzar el equilibrio interior a través de nuevas expresiones. Barcelona: RBA libros, S.A.

Arranz, E., Olabarrieta, F. \& otros, (2010). Familias recurrentes a la reproducción asistida y familias múltiples. Desarrollo psicológico de las nuevas estructuras familiares. Madrid: Ed. Pirámide.

Arribas, M. (2004). Diseño y validación de cuestionarios. Matronas profesión. 5(7), 23-29.

Artavia, C; Cascante, L; (2009). Componentes teóricos para la comprensión de la pedagogía intercultural como práctica docente. Revista Electrónica Educare, Vol. XIII. P. 53-70. Recuperado de http://www.redalyc.org/articulo.oa?id=194114416005

Blanco, D. (2009) De melancólicos a rumberos... de los Andes a la costa. La identidad colombiana y la música caribeña. En: Boletín de Antropología Universidad de Antioquia, Vol. 23. No. 40. pp. 102 - 128. Colombia.

Blatner, A. (2005). Bases del psicodrama. México D.F.: Pax México.

Boscolo, L. \& Bertrando, P. (1996) Los tiempos del tiempo. Una nueva perspectiva para la consulta y la terapia sistémicas. Primera edición. Ed. Paidós: España. 
Bottob, A \& Armstrong, J. (2014) El arte como terapia. Editorial Océano: España

Brasey, E. \& Debailleul, J. (1999). Vivir la magia de los cuentos. Como lo maravilloso puede transformar nuestras vidas. Madrid: Ediciones Albin Michel.

Bravo, R. S. (1994). Tesis doctorales y trabajos de investigación científica. Paraninfo.

Bruder, M. (2011) Escritura terapéutica: Enfoque teórico-clínico. Ediciones Hormé S.A.E.: Ciudad autónoma de Buenos Aires.

Bruner, J. (1994) Realidad mental y Mundos posibles. Segunda Edición. Ed. Gedisa, S.A.

Bustos, D. (2013) Arte y familia: Una aproximación por medio de la arte terapia a la resolución de conflictos familiares y grupales. Tesis de grado Universidad de San Buenaventura- Seccional Medellín. Colombia.

Bustos, S. \& Agudelo, A. (2013). Intervención grupal en víctimas de represión política. En: Revista Psiquiatría y Salud Mental, XXX, No 2, pp. 54-59. Sociedad Chilena de Salud Mental: La serena, Chile Santiago.

Campo-Arias, A. Oviedo, H. \& Herazo, E. (2014). Prevalencia de síntomas, posibles casos y trastornos mentales en víctimas del conflicto armado interno en situación de desplazamiento en Colombia: Una revisión sistemática. En: Revista colombiana de psiquiatría, Vol. 43, No 4, pp. 177-185. Elsevier: España.

Campo-Arias, A.; Herazo, E.; (2014). Estigma y salud mental en personas víctimas del conflicto armado interno colombiano en situación de desplazamiento forzado. Revista Colombiana de Psiquiatría, 43() 212-217. Recuperado de http://www.redalyc.org/articulo.oa?id=80635719006

Cardona, J. (2014) Arte, ritual y masacre. Reflexión sobre la reconciliación en el posconflicto colombiano. En: Anuari del conflicte social. Sección IV: procesos de paz. Artículo 22, pp. 576 - 598. Revistes cientifiques de la universitat de Barcelona: España. 
Ceberio, M. (2004). Quién soy y de dónde vengo: el taller del genograma. Argentina: Ed. Tres haches.

Centro Nacional de Memoria Histórica. (2009). Recordar y narrar el conflicto: herramientas para reconstruir memoria histórica. Colombia: Imprenta Nacional de Colombia.

Chaves, J. (2011). Entre la violencia del cuerpo y la violencia incorporada. En: Hacia la promoción de la salud, Vol. 16, No. 12, pp. 162, 172. Redalyc: Caldas.

Cortés, M. \& Cantón, J. (2010). Familias monoparentales. Desarrollo psicológico de las nuevas estructuras familiares. Madrid: Ed. Pirámide.

Cyrulnik, B. (2002). Los Patitos Feos. La resiliencia: Una infancia infeliz no determina la vida. pp. 1 - 75. Barcelona: Gedisa.

Dalley, T. (1987). El arte como terapia. Ed. Herder: Barcelona.

Durston, A. (2009) Cultura, delito y conflicto: Antídotos artísticos para la violencia en Río de Janeiro. En: Urvio, Revista Latinoamericana de Seguridad Ciudadana, No. 6, pp. 99 - 112. Flacso Quito: Ecuador.

Estrada, Ripoll, \& Rodríguez (2010). Intervención psicosocial con fines de reparación con víctimas y sus familias afectadas por el conflicto colombiano interno en Colombia: Equipos psicosociales en contextos jurídicos. En Revista de estudios sociales, No 36, pp. 103-112

Estupiñán, J. González, O. (2015) Narrativa conversacional, relatos de vida y tramas humanos. Universidad Santo Tomás: Bogotá.

Estupiñán, J. \& González, O. (2008) Guion para la elaboración del estado del arte testimonial y sobre fenómenos clínicos en los campos narrativos. Material compartido por la Maestría, Seminario de Investigación Intervención.

Estupiñán, J., Hernández, Á. \&, Bravo, F., (2006) Vínculos, Ecología y Redes. En: Estupiñán \& 
Otros (2006) Dossier de las Líneas/Proyectos de Investigación. Obtenido de Universidad Santo Tomás:

file:///C:/Users/ateho/Downloads/DOSSIER20LINEAS20INVESTIGACIC393N.pdf

Estupiñán, J. González, O. Serna, A. (2006) Historias y narrativas familiares en diversidad de contextos. En: Estupiñán \& Otros (2006) Dossier de las Líneas/Proyectos de Investigación. Obtenido de Universidad Santo Tomás: file:///C:/Users/ateho/Downloads/DOSSIER20LINEAS20INVESTIGACIC393N.pdf

Estupiñán, J. Niño, J. Rodríguez, D. (2006). Modelos contextuales de formación de terapeutas desde un enfoque sistémico y ecológico. En: Estupiñán \& Otros (2006) Dossier de las Líneas/Proyectos de Investigación. Obtenido de Universidad Santo Tomás: file:///C:/Users/ateho/Downloads/DOSSIER20LINEAS20INVESTIGACIC393N.pdf

Estupiñán, J. (2005) Psicoterapia sistémica, psicología y responsabilidad social: La hipótesis de la convergencia entre sabiduría y conocimiento técnico. En: Perspectivas en Psicología. Vol. I / No. 2 / 2005 / pp. $227-237$

Estupiñán (2003). Una narrativa en la construcción de los caminos de la terapia sistémica. En: Construcción en psicología compleja. Aportes y dilemas (Comp.) Ediciones USTA: Bogotá.

Fariña, M. Luzzi, S. (2010) El niño dodecafónico: Contribuciones de la musicoterapia a una clínica de la diversidad. En: II: II Congreso Internacional de Investigación y Práctica Profesional en Psicología XVII Jornadas de Investigación Sexto Encuentro de Investigadores en Psicología del MERCOSUR. Facultad de Psicología - Universidad de Buenos Aires. PP. 113 - 116. Buenos Aires: Argentina.

Farokhi, M. (2011) Art therapy in humanistic psychiatric. En: Procedia - Social and behavioral science, Vol. 30, pp. 2088-2092, Elsevier: Irán. 
Feixas \& Villegas (2000). La epistemología constructivista. En: Constructivismo y psicoterapia. Editorial Desclée de Brouwer: España

Fernández, T. (2005) "Hacia un nuevo camino": programa de investigación-acción sobre autoestima y musicoterapia con mujeres violentadas. En: Enseñanza e Investigación en psicología, Vol. 11, Núm. 1. Enero - junio 2006. Pp. 65 - 79. Consejo Nacional para la Enseñanza en Investigación en Psicología A.C.: Xalapa, México.

Fernández, T. (2011) Musicoterapia en Cuba: aplicación de un programa piloto con mujeres víctimas de violencia doméstica. En: Enseñanza e Investigación en Psicología, vol. 16, núm. 1, enero-junio. pp. 183-205. Consejo Nacional para la Enseñanza en Investigación en Psicología A.C.: Xalapa, México.

Ferrer-Honores, P. Miscán-Reyes, A. \& Otros. (2013) Funcionamiento Familiar según el Modelo Circumplejo de Olson en Familias con un Niño que presenta retardo Mental. En: Rev. enferm Herediana. 2013;6; 6(2):51-58.

Fontecha, P. S., Moreno, P. M., \& Medina, A. A. (noviembre de 2010). Historias co-creadas en la intervención sistémica que promueven la reparación emocional en los niños y niñas víctimas del conflicto armado. Recuperado el 11 de marzo de 2016, de Repositorio institucional facultad de psicología: http://repository.javeriana.edu.co/handle/10554/1251: Bogotá. Pontificia Universidad Javeriana, Facultad de Psicología, Trabajos de Grado Maestría Psicología, Tesis y disertaciones académicas.

Fuks Saúl I. (2009) FSPC: La facilitación sistémica de procesos colectivos. "Artesanía de contextos" focalizada en la promoción de la creatividad y de los procesos participativos en grupos, comunidades y redes. Revista IRICE, 2009, 20, pp. 63-76 (CONICET - UNR). Extraído de https://www.uv.mx/orizaba/cosustenta/files/2014/03/FACILITACION- 


\section{SISTEMICA.pdf}

el 26 de abril de 2017.

Galindo, J. (1998) Técnicas de investigación. En sociedad, cultura y comunicación. Adisson Wesley Longman: México.

Garibay, S. (2013). Enfoque sistémico. Una introducción a la psicoterapia familiar. familiar. Editorial Manual Moderno: México.

Gallego, A. (2011) Recuperación crítica de los conceptos de familia, dinámica familiar y sus características. En: Revista Virtual Universidad Católica del Norte”. No. 35, (febrero-mayo de Dinámica familiar conflictiva, repercusiones en el desarrollo psicológico de los niños del centro de acogida "padre Antonio Amador": proyecto salesiano "chicos de la calle", Guayaquil, año 2012. Recuperado de: http://repositorio.ug.edu.ec/handle/redug/6493

Gómez, E., \& Kotliarenco, M. A. (2010). Resiliencia Familiar: un enfoque de investigación e intervención con familias multiproblemáticas. Revista de Psicología de la Universidad de Chile, Vol. 19 No. 2, pp. 103 - 132.

González, A. \& Acuña, D. (2017). La conyugalidad remanente. Psicología para América Latina. (28) 23-35.

González, I. (2000) Reflexiones acerca de la salud familiar. En: Rev. Cubana Med. Gen Integr v.16 n.5 Ciudad de La Habana sept.-oct. pp. 508- 512.

González, M., López, F. \& Gómez, A. (2010). Familias homoparentales. Desarrollo psicológico de las nuevas estructuras familiares. Madrid: Ed. Pirámide.

Guerra, M. R.; Plata, J. (2005). Estado de la investigación sobre conflicto, posconflicto, reconciliación y papel de la sociedad civil en Colombia. Revista de Estudios Sociales, No. 21. pp. 81-92. Recuperado de http://www.redalyc.org/articulo.oa?id=81502108. 
Guerrero, S. H., \& Sánchez, S. J. (enero - junio de 2015). Una "Pedagogía de los sentimientos": Educación de la autoestima en escenarios de justicia transicional. Investigación \& Desarrollo, Vol. 23, No. $1, \quad$ pp. 58-90. Obtenido de http://rcientificas.uninorte.edu.co/index.php/investigacion/article/view/6240/6867:

Barranquilla.

Gutiérrez, A. V., Venegas, R., \& Caicedo, M. (2017). Indicadores de Ajuste y Adaptabilidad en Familias Víctimas del Conflicto Armado con al Menos un Miembro con Problemas en Salud Mental. Pendiente de Publicación - Universidad Los Libertadores, P. 1-37. Bogotá.

Henao, Á. M. (junio de 2013). Pontificia Universidad Javeriana. Modelo de atención psicosocial de la política de reintegración de grupos armados ilegales una pregunta por la identidad. Obtenido de Repositorio Institucional Facultad de Ciencias Políticas y Relaciones Internacionales: http://hdl.handle.net/10554/15319: Bogotá.

Hernández, Á. (2012) Psicoterapia sistémica breve. La construcción del cambio con individuos, parejas y familias. Ed. El búho: Bogotá.

Hernández, A. (2009) Familia, ciclo vital y psicoterapia sistémica breve. Ed. el Búho

Hernández, A. C. (1989). Familias No Clínicas su funcionamiento según el modelo circumplejo de D. H. Olson. Santafé de Bogotá: Universidad Santo Tomás.

Hernández, A. \& Bravo, (2008). Vínculos, individuación y ecología humana. Hitos para una psicología clínica compleja. Ediciones USTA: Bogotá.

Hernández, A. (2010). Vínculos, individuación y ecología humana. Hacia una psicología clínica compleja. Bogotá: Ediciones USTA.

Hernández, A. \& Estupiñán, J. (2007) Lineamientos técnicos para la inclusión y Atención de Familias. Colombia: Instituto Colombiano de Bienestar Familiar - ICBF- Recuperado de: 
http://www.icbf.gov.co/portal/page/portal/Descargas1/nuevoLineamientosTInclusinAtencionFamilias.pdf

Hernández, A. \& Morales, L. (2003) Salud mental, salud pública e impacto social de la formación clínica sistémico constructivista. En: Construcciones: Construcciones en psicología compleja. Aporte y dilemas. pp. 35 - 46. Ediciones USTA: Bogotá.

Hernández, E. (2012) Familias tardías ¿nuevos retos para la sociedad del bienestar. Modos y maneras de hacer familia. Madrid: Ed. Biblioteca nueva.

I. Hernández, \& R. Niño, (2013), Estética y sistemas abiertos. Procesos de no equilibrio entre el arte, la ciencia y la ciudad (págs. 17-55). Bogotá: Pontificia Universidad Javeriana.

Herazo, E; Oviedo, H C; Campo-Arias, A. (2014). Prevalencia de síntomas, posibles casos y trastornos mentales en víctimas del conflicto armado interno en situación de desplazamiento en Colombia: una revisión sistemática. Revista Colombiana de Psiquiatría, 43() 177-185. Recuperado de http://colpos.redalyc.org/articulo.oa?id=80635719002.

Hidalgo Hernández, V. (2005). Cultura, multiculturalidad, interculturalidad y transculturalidad, evolución de un término. Universitas tarraconensis: Revista de ciències de l'educació, Vol. 1, 75-85.

Ibáñez, (1994); Gergen (1996), citados por González y Serna, 2006. Historias y narrativas en diversidad de contextos. En Dossier proyectos de investigación 2. Historias y narrativas en diversidad de contextos. Universidad Santo Tomás: Bogotá.

Instituto Colombiano de Bienestar Familiar -ICBF- Regional Putumayo y Fundación Afecto Modalidad Familias con Bienestar (2016). Ayllupura en paz. Registro de experiencia.

Izquierdo, N. (2014). La fotografía como acto narrativo y psicoterapéutico. Colombia: Centro Iberoamericano de Publicaciones CIP. 
Janson, H. (1972). Historia del arte. Panorama de las obras plásticas desde la prehistoria hasta nuestros días: Editorial Labor: Barcelona.

Jiménez, W. (2009). Salud mental en el posconflicto colombiano. En: Revista criminalidad, Vol. 51, No. 1, pp. 179-192. Policía Nacional de Colombia: Bogotá.

Katz García, M. (2011). Construcción de paz: una aproximación desde las capacidades locales. pp. 1-50. Universidad Nacional de Colombia: Bogotá. Tomado de: http://www.bivipas.unal.edu.co/handle/10720/588.

Lacárcel, J. (2003) Psicología de la música y emoción musical. En: Rev. Education N. 20-21. diciembre 2003. Pp. 213 - 226. Murcia: España.

Linares, J. (2012) Terapia familiar ultramoderna. La inteligencia terapéutica. España: Ed. Herder.

Llanos, R. \& Otros (2009) Bienestar y trauma en personas adultas desplazadas por la violencia política. En: Univ. Psychol. Vol. 8. No.2. May- Ago. p.p. 455-470: Colombia

López, A. (2014). Transformación de las narrativas y pautas de interacción que surgieron en el transcurso del proceso terapéutico asociadas a las relaciones que establecen las personas en proceso reintegración, con la pareja, con los hijos y con el grupo armado organizado al margen de la ley. Repositorio Institucional - Pontificia Universidad Javeriana, Facultad de Psicología, Trabajos de Grado Maestría Psicología, Tesis y disertaciones académicas.

López, A. G. (25 de noviembre de 2011). El papel social de los sentimientos en la construcción de la identidad social de desmovilizados del conflicto armado colombiano. Universidad de San Buenaventura. $\quad$ pp. 149 Obtenido de: http://bibliotecadigital.usb.edu.co/jspui/handle/10819/310: Medellín.

López, A. G., \& Rodríguez, B. A. (julio-diciembre de 2012). El lugar de los sentimientos, el lugar de los vínculos. Reconfiguración de identidades en el marco del conflicto armado colombiano. 
Revista Colombiana de Ciencias Sociales, Vol. 3, No. 2, pp. 270-289. Obtenido de http://www.funlam.edu.co/revistas/index.php/RCCS/article/view/890/839: Medellín.

López B. E. \& Población K. P. (1997). La Escultura y Otras Técnicas Psico dramáticas Aplicadas en Psicoterapia (Primera ed.). Barcelona: Paidós Ibérica, S.A.

López-López, M d C; Fernández-Herrería, A. (2014). Educar para la paz. Necesidad de un cambio epistemológico. Convergencia. Revista de Ciencias Sociales, Vol. 21, No. 64, pp. 117-142. Recuperado de http://www.redalyc.org/articulo.oa?id=10529071005: Toluca, México.

López Rodríguez, J., \& Plazas Reina, D. (2012). Identidad narrativa y sus posibilidades de reconfiguración en un fenómeno puntuado como psicopatológico, desde procesos abductivos que disponen la emergencia de memorias en escenarios narrativo-conversacionales. Tesis de grado para optar por el título de Magister en psicología clínica y de la familia. USTA: Bogotá.

Louro, I (2005). Modelo de salud del grupo familiar. Rev. Cubana Salud Pública 31(4). pp. 332337.

Lozano \& Gómez. (2004). Aspectos psicológicos, sociales y jurídicos del desplazamiento forzado en Colombia. Acta Colombiana de Psicología, Vol. 4, No. 12, pp. 103-119.

Luhmann, N. (1998) Sistemas sociales. Lineamientos para una teoría general. Anthropos Editorial: Barcelona.

Marañón, D., \& Abeijón, J. A. (2012). El Trabajo Psicoterapéutico con Fortalezas, Capacidades y Recursos. Un Acercamiento Teórico desde el Marco Sistémico Integrador. Obtenido de Escuela Vasco-Navarra de Terapia Familiar: recuperado de http://www.avntfevntf.com/imagenes/biblioteca/Trabajo 203 C2 BA 20BI 2011-12 20- 20Mara C3 B1 C3 B3n, 20D..pdfPdf

Maldonado, C. \& Gómez, N. (2011) El mundo de las ciencias de la complejidad. Editorial 
Universidad del Rosario: Bogotá.

Marín, L. (2013). Encuentros, narrativas y experiencias con jóvenes desvinculados del conflicto armado colombiano. En: Revista de Psiquiatría y salud mental, No 2, pp. 54-59. Universidad de Cartagena: Cartagena.

Martínez, N. \& López, M. (2009) Reinventar la vida. El arte como terapia. Madrid: Editorial Eneida.

Martínez, P. (2006) El método de estudio de caso: Estrategia metodológica de la investigación científica. En: Pensamiento \& gestión, 20. Universidad del Norte, Pp. 165-193.

Marxen, E. (2011). Diálogos entre arte y terapia. Del arte psicótico al desarrollo de la arte terapia y sus aplicaciones. Editorial Gedisa: Barcelona.

Medina, R., Laso, E., \& Hernández, E. (2014). Pensamiento sistémico, nuevas perspectivas y contextos de intervención. Guadalajara, México: Lítteris.

Ministerio de Salud (2013) Ley 1616 de Salud Mental. Recuperado el día 16 de abril de 2016 a las 17:20 hr. $\quad$ Tomado de http://wsp.presidencia.gov.co/Normativa/Leyes/Documents/2013/LEY\%201616\%20DEL\%20 21\%20DE\%20ENERO\%20DE\%202013.pdf

Ministerio de Salud (s.f.) Programas de atención psicosocial y salud integral a víctimas PAPSIVI. Recuperado el día 16 de abril de 2016 a las 17:20 hr. Tomado de: https://www.minsalud.gov.co/proteccionsocial/Paginas/Victimas_PAPSIVI.aspx

Minuchin, S. (1974) Familias y Terapia Familiar. Barcelona, España: Gedisa.

Minuchin, S. \& Fischman, C. (2004) Técnicas de Terapia Familiar. Buenos aires: Paidós.

Monzón (2004). La violencia doméstica desde una perspectiva ecológica. En Maltrato y abuso en el ámbito doméstico. Comp. Paidós: Buenos Aires. 
Montánchez, M. Orellana, C. (2015) Aprendizaje socioemocional en la adolescencia a través de la musicoterapia. En: Iberoamérica Social: revista-red de estudios sociales (IV), pp. 164-174. Asociación Reconocer de Sevilla: España.

Moreno, N. (2007) Arteterapia y adolescente: promoviendo la expresión emocional de los conflictos con la autoridad. En: Tesis especialización en Terapias de Arte, Mención arte terapia. Universidad de Chile: Santiago.

Moreno, J. (2002) Psicología de la música y emoción musical. En: Educativo, No 20-21 • Diciembre. pp. 213 - 226. Universidad de Murcia: España.

Myers, B. (1972). Las bellas artes. Como mirar el arte. Vol. 10. Almicare Bizzi: Milán.

Nieto, L. \& Ravelo, L. (2012). Las familias desplazadas en Colombia ¿Puede que ellas se sientan extranjeras en su propio país? En: Psico gente, Vol. 15, No. 28, pp. 414 -427. Universidad Simón Bolívar: Barranquilla.

Niño, S; Díaz, P; Samudio, M; Rodríguez, M C; Silva, M; (2005). El Desplazamiento como Generador de Crisis: Un Estudio en Adultos y Adolescentes. Terapia Psicológica, 23() 33-43. Recuperado de http://www.redalyc.org/articulo.oa?id=78523204

Ochoa de Alda, I. (1995) Terapia Estructural. En: Ochoa de Alda, I. (1995) Enfoques en Terapia Familiar Sistémica. Pp. 127 - 130. Barcelona, España: Ed. Herder.

Oliva, A., Parra, A. \& Antolín, L. (2010). Familias reconstituidas. Desarrollo psicológico en las nuevas estructuras familiares. Madrid: Ed. Pirámide.

Olson, D. \& Otros. (1989) Inventarios sobre familia. Traducción de Ángela Hernández C. Bogotá: Universidad Santo Tomas.

Palacios, J. (2010). Familias adoptivas. Desarrollo psicológico de las nuevas estructuras familiares. Madrid: Ed. Pirámide. 
Plata, Juan José; \& Guerra, María del Rosario. (2005). Estado de la investigación sobre conflicto, posconflicto, reconciliación y papel de la sociedad civil en Colombia. En: Revista de Estudios Sociales, agosto, No. 21, pp. 81-92.

Pain, S. \& Jarreau, G. (1994). Una psicoterapia por el arte. Teoría y técnica.

Panhofer, H. (2005). El cuerpo en psicoterapia. Teoría y práctica de la Danza Movimiento Terapia. Barcelona: Gedisa.

Payne, M. (2002). Terapia narrativa. Una introducción para profesionales. Barcelona: Editorial Paidós.

Peñas-Felizzola, O. L, Gómez-Galindo, A. M., \& Parra-Esquivel, E. I. (2015). Participación de terapia ocupacional en contextos de conflicto armado y posconflicto. Revista de Salud Pública, Vol. 17, No. 4, pp. 612-625. https://dx.doi.org/10.15446/rsap.v17n4.53047: Bogotá.

Pérez, P. (2014) Terapia Ocupacional y arte en Salud Mental: una perspectiva creativa. En: TOG (A Coruña) Vol. 11. Mono. 6 oct. pp. 160-175. La Asociación Profesional Gallega de Terapeutas Ocupacionales (APGTO): Galicia: España.

Poch B. S. (1998). Compendio de Musicoterapia (Vol. I). Barcelona: Herder, S.A.

Puertas, G., Ríos, C., \& Del Valle, H. (2006) Prevalencia de trastornos mentales comunes en barrios marginales urbanos con población desplazada en Colombia. Rev. Panam Salud Publica. 2006;20; 20(5):324-30.

Quijera, A. (2015) Vivencia de la musicoterapia en pacientes con trastorno de personalidad. En: Nure Investigación número 79. Noviembre - diciembre 2015. España

Quintero Velásquez, Á. M. (2005). Resiliencia: Contexto no clínico para trabajo social. Revista Latinoamericana de Ciencias Sociales, Niñez y Juventud, Capitulo 3 Recuperado de http://projecteuclid.redalyc.org/articulo.oa?id=77330103 
Real Academia Española (RAE) (2018) Diccionario versión Online, Revisado por última vez el día 30 de marzo de 2018. Tomado de: $\underline{\text { http://dle.rae.es }}$

Rico, L. (2012) Arte, terapia y mujeres migrantes. Caso Kauthar. El espejo es la frontera. En: Arteterapia: Papeles de arte terapia y educación artística para la inclusión social, Vol. 7. pp. 141 - 151 Servicio de publicaciones UCM: Madrid.

Riveros, M. \& Garzón, D. (2014) Terapia familiar en problemas de adicción. Narrativas conversacionales y reconfiguración de identidades.

Rodríguez, A. (2015). Atención psicosocial y en salud mental: Claves para el tránsito en Colombia de la confrontación armada a la política. En: Revista Salud Bosque, vol. 5, No 1, pp. 5-8. Universidad del Bosque: Bogotá.

Rodríguez, D. \& Serna, A. (2015) Modelos de aprendizaje y cambio. Ediciones USTA: Bogotá.

Rodríguez, J. de la Torre, A. Miranda, C. (2002) La salud mental en situaciones de conflicto armado. En: Revista Biomédica, Vol. 22 pp. 337-346

Rodríguez, J. (2007) La Reforma de los Servicios de Salud Mental: 15 años después de la Declaración de Caracas. Organización Panamericana de la Salud -OPS/OMS-. Washington. Extraído del 26 de abril de 2017.

Ropers, N. (2008). Transformación sistémica de conflictos: reflexiones acerca del conflicto y del proceso de paz en Sri Lanka. Berghof Research Center for Constructive Conflict Management. http://www.bivipas.unal.edu.co/handle/10720/469.

Rosnay, J. (1996) El hombre simbiótico. Miradas sobre el tercer milenio. Madrid: Ediciones Cátedra, S.A.

Runes, D. \& Schrickel, H. (s.f.). Enciclopedia de las artes. Tomo I. Argos: Barcelona.

Sampieri, R. H., Collado, C. F., \& Lucio, M. B. (2010). Metodología de la Investigación. México 


\section{D.F.: McGraw-Hill / Interamericana Editores, S.A. de C.V.}

Sardi, L. (2010) Musicoterapia y desarrollo personal "Encuentro conmigo misma" En: Monografía de grado. Universidad de Chile: Santiago.

Sarti, C. C. (2015). Guatemala. El reto de construir infraestructura emocional en sociedades posconflicto. Centro de Investigación para la Paz. Recuperado el 11 de marzo de 2016, de Fundación

Propaz: http://www.centropaz.com.ar/publicaciones/paz/Estructura\%20Emocional.pdf

Serna, A. (2015) Disertación elemental. Algunas cuestiones sobre la investigación social. Ediones USTA: Bogotá.

Sinisterra Mosquera, M; Sanguino Leal, J F; Moreno Gutiérrez, V F; Robayo, M F; Figueroa Lozano, F S; (2010). Prevalencia del trastorno de estrés postraumático en población en situación de desplazamiento en la localidad de Ciudad Bolívar Bogotá, Colombia 2007. Psychologica. Avances de la disciplina, 4() 83-97. Recuperado de http://www.redalyc.org/articulo.oa?id=297224090006

Simon, F.B., Stierlin, H., Wynne, L.C. (2002). Vocabulario de terapia familiar. Gedisa: España.

Sluzki, C. (2000). La red social: frontera de la práctica sistémica. Barcelona: Gedisa.

Tenorio, R. \& Mendoza, C. (2005). La atención individualizada en el trabajo social. En: Sánchez, M. (comp.) (2005) Manual de trabajo social. México: Plaza y Valdés, S.A.

Torres Gómez, F. (2013). Intervención profesional desde la consultoría con enfoque resiliente en familias víctima del conflicto armado. Tendencias \& Retos, Vol. 18, No. 1, pp. 33-48. Recuperado dehttp://revistas.lasalle.edu.co/index.php/te/article/view/2486: Bogotá.

Tolosa, R. Á. (pp. 1-40 de 2015). El arte como posible herramienta metodológica para la construcción de paz. Obtenido de Universidad Nacional de Colombia: 
http://www.bivipas.unal.edu.co/bitstream/123456789/727/1/TrabajoFinalAngelaTolosa.pdf

Torres Pachón, A., Jiménez Urrego, Á. M., \& Otros (Wilchez Bolaños, N., Holguín Ocampo, J., Rodríguez Ovalle, D. M., Rojas Velasco, M. A... Cárdenas Posada, D. F. (enero-junio, 2015). Psicología social y posconflicto: ¿reformamos o revolucionamos? Revista Colombiana de Ciencias Sociales, Vol. 6, No. 1, pp. 176-193. Universidad Pontificia Bolivariana: Palmira.

Valdés, A. (2007). Familia y desarrollo. Intervenciones en terapia familiar. México: Ed. Manual Moderno.

Van Lith, T. (2016). Art therapy in mental health: A systematic review of approaches and practices. En: The Arts in Psychotherapy, Vol. 47, pp. 9-22, Elsevier: Florida.

Villa, J. (2013). Consecuencias psicosociales de la participación en escenarios de justicia transicional en un contexto de conflicto, impunidad y no transición. En El Agora USB, Vol. 13, No. 2, pp. 279-539. Bonaventuriana: Medellín.

Villa, J. (2014). Memoria, historias de vida y papel de la escucha en la transformación subjetiva de víctimas/ sobrevivientes del conflicto armado colombiano. En El Agora USB, Vol. 14, No. 1, pp. 37-60. Bonaventuriana: Medellín.

Wagensberg, J. (1985). Ideas sobre la Complejidad del Mundo. Barcelona: Tusquets Editores.

Walsh, F. (1998) "El concepto de resiliencia familiar: crisis y desafío”. En: Sistemas Familiares, Buenos Aires, marzo de 1998, pp.18 - 19.

Watzlawick, P. (1985). Teoría de la comunicación humana interacciones, patologías y paradojas. Editorial Herder: Barcelona.

Wengrower, H. \& Chinklin, S. (2005). La vida es danza. El arte y la ciencia de la Danza movimiento Terapia. Editorial Gedisa: España. 


\section{APÉNDICES}

Se encuentran en el siguiente documento que recibe el mismo nombre que este apartado.

\section{Tabla de contenido Apéndices}

1. Matriz del Estado del Arte Documental. 431

2. Matriz del Estado del Arte Testimonial. 573

- Escenario 1: Transcripción escenario familia 1 que ha vivenciado acontecimientos del CAC 573

- Escenario 1: Transcripción escenario familia 2 que ha vivenciado acontecimientos del CAC 669

- Escenario 2: Transcripción profesional en psicología 1: 740

- Escenario 2: Transcripción profesional en Trabajo Social: 812

- Escenario 2: Transcripción profesional en psicología 1: 850

3. Entrevista de Tamizaje. $\quad 875$

4. Consentimiento Informado. 876

5. Registro de Observación: Escenarios. $\quad 881$

6. Registro de Observación: Estrategias. $\quad 883$

7. Historia Clínica. 884

8. Evoluciones del proceso. 892

10. Cierre del proceso terapéutico. 879

11. Abanico de estrategias artísticas. 893

12. Resumen Analítico 910 